Susanne Eyssen

\title{
Der Aufbruch \\ der Frauen in der SPD
}

Die Entwicklung der

Frauenarbeitsgemeinschaft (ASF)

während der 1970er und 1980er Jahre 


\section{Susanne Eyssen}

Der Aufbruch der Frauen in der SPD 
Susanne Eyssen

\section{Der Aufbruch der Frauen in der SPD}

Die Entwicklung der Frauenarbeitsgemeinschaft (ASF) während der 1970er und 1980er Jahre

Budrich UniPress Ltd.

Opladen • Berlin • Toronto 2019 
Bibliografische Information der Deutschen Nationalbibliothek

Die Deutsche Nationalbibliothek verzeichnet diese Publikation in der Deutschen Nationalbibliografie; detaillierte bibliografische Daten sind im Internet über http://dnb.d-nb.de abrufbar.

Dissertation, Ruhr-Universität Bochum 2017

Die frei zugängliche digitale Publikation wurde ermöglicht mit Mitteln des BMBF Projektes OGeSoMo der Universitätsbibliothek Duisburg-Essen. In diesem Projekt wird Open Access für geistes- und sozialwissenschaftliche Monografien gefördert und untersucht.

Informationen und Ergebnisse finden Sie unter: https://www.uni-due.de/ogesomo

(C) 2019 Dieses Werk ist bei der Verlag Barbara Budrich GmbH erschienen und steht unter der Creative Commons Lizenz Attribution-ShareAlike 4.0 International (CC BY-SA 4.0): https://creativecommons.org/licenses/by-sa/4.0/

Diese Lizenz erlaubt die Verbreitung, Speicherung, Vervielfältigung und Bearbeitung bei Verwendung der gleichen CC-BY-SA 4.0-Lizenz und unter Angabe der UrheberInnen, Rechte, Änderungen und verwendeten Lizenz.

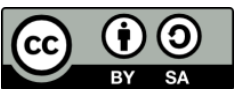

Dieses Buch steht im Open-Access-Bereich der Verlagsseite zum kostenlosen Download bereit (https://doi.org/10.3224/86388794).

Eine kostenpflichtige Druckversion kann über den Verlag bezogen werden. Die Seitenzahlen in der Druck- und Onlineversion sind identisch.

$\begin{array}{ll}\text { ISBN } & 978-3-86388-794-0 \text { (Paperback) } \\ \text { eISBN } & 978-3-86388-365-2 \text { (eBook) } \\ \text { DOI } & 10.3224 / 86388794\end{array}$

Umschlaggestaltung: Bettina Lehfeldt, Kleinmachnow - www.lehfeldtgraphic.de Titelbildnachweis: Foto von Jan Drews - www.drewsjan.de

Satz: Sabine Geicht

Typographisches Lektorat: Anja Borkam, Jena 


\section{Danksagung}

Eine Dissertation nebenberuflich zu schreiben ist ein großes Vorhaben. Es wäre mir nicht gelungen ohne Unterstützung, für die ich mich bedanken möchte.

Mein Dank geht zuerst an Prof. Dr. Ilse Lenz für ihre geduldige Betreuung und ihre vielen Denkanstöße, mit denen sie mir aus manchem Gedankendschungel heraushalf, des Weiteren an Prof. Dr. Britta Rehder für ihr Interesse und ihre Hinweise. Dankbar bin ich für die hilfreichen Diskussionen im Laufe meiner Forschungsarbeit, besonders mit Prof. Dr. Bernd Faulenbach, Prof. Dr. Stefan Goch, Dr. Gisela Notz, Dr. Karin Derichs-Kunstmann, Dr. Barbara Degen und Dr. Sibylle Plogstedt.

Mein Dank gilt den MitarbeiterInnen des Archivs für Soziale Bewegung in Bochum für ihre stets freundliche Hilfsbereitschaft bei der Literaturbeschaffung. Die vielen frauenpolitisch relevanten Parteidokumente hätte ich mir ohne die Unterstützung der MitarbeiterInnen des Politischen Archivs am Willy-Brandt-Haus des SPD Parteivorstands, Berlin, und des Archivs der Sozialen Demokratie der Friedrich-EbertStiftung in Bonn nicht erschließen können. Mein besonderer Dank geht dabei an Petra Giertz, die mir den Zugang zum Bestand mit zusätzlich erstellten Verzeichnissen und Findhilfen erleichterte.

$\mathrm{Zu}$ den aufregendsten Forschungserlebnissen gehören die ZeitzeugInneninterviews. Sie waren mir immer wieder ein Schlüssel zum Verständnis der Parteidokumente sowie der politischen Auseinandersetzungen und parteiinternen Vorgänge im Forschungszeitraum. Deshalb bin ich Ilse Brusis, Herta Däubler-Gmelin, Elfriede Eilers, Birgit Fischer, Angelika Himmert, Antje Huber, Christa Randzio-Plath, Christine Schmarsow, Renate Schmidt, Renate Schmitt-Peters, Dr. Sigrid Skarpelis-Sperk, Inge Stange, Dr. Haidi Streletz, Dr. Hans-Jochen Vogel, Marianne Wallach und Inge Wettig-Danielmeier für die intensiven und offenen Gespräche sehr dankbar.

Mein innigster Dank gehört meinem Lebenspartner Hans-Günther Kondert, der mein Promotionsvorhaben trotz lebensbedrohender Krankheit mit Neugier und Freude begleitete.

Bochum, im August 2017 



\section{Inhalt}

$1 \quad$ Einleitung

2 Parteienwandel, organisationale Geschlechtermacht und Neue Soziale Bewegungen

2.1 Zur Wandlungsfähigkeit von Parteien .27

2.1.1 Parteidefinitionen im wissenschaftlichen Diskurs .......... 28

2.1.2 Die Identifizierung der Wandlungsfähigkeit von Parteien anhand von Parteitypen 30

2.1.3 Parteien im Diskurs soziologischer Organisationstheorien....

2.1.4 Die SPD als demokratische Teilhabeorganisation............39

2.2 Geschlechtermacht und Organisation............................. 50

2.2.1 Die Geschlechtlichkeit von Organisationen ..................... 50

2.2.2 Die Geschlechtlichkeit als Ausschließung........................ 53

2.2.3 Politiken zur Auflösung von Geschlechterhierarchien in Organisationen .............................................................60

2.3 Politische Partizipation und Neue Soziale

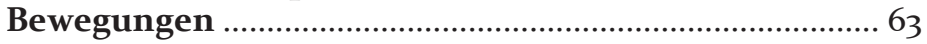

2.3.1 Theoriekonzepte der Neuen Sozialen Bewegungen ......... 65

2.3.2 Die umstrittene Klassifizierung der Neuen Frauenbewegungen als NSB.

2.3.3 Entwicklungsdynamiken der Neuen Sozialen Bewegungen.....

2.4 Die Neuen Frauenbewegungen der 1970er- bis 1990er-Jahre in der BRD

2.4.1 Entwicklungsphasen der Neuen Frauenbewegung und Transformationen .............................................................. 85

2.4.2 Strömungen des Feminismus im Forschungszeitraum ...90

2.4.3 Feministische Diskurse........................................................ 93

3 Die SPD in den 1970er- und 1980er-Jahren Regierungsbeteiligung, innerparteiliche Fragmentierungen und programmatische

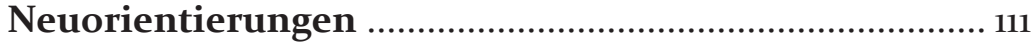

4 Methodische Anlage der Untersuchung...................... 133 4.1 Parteidokumente als historisches Datenmaterial....... 134 
4.2 Die Daten in den ZeitzeugInnen- und

ExpertInneninterviews ................................................... 135

4.3 Die Interviewmethode ....................................................... 139

4.4 Die Auswertung und Verwendung der Interviews .......140

4.5 Beschreibung des Samples................................................ 143

5 Die Arbeitsgemeinschaft Sozialdemokratischer Frauen (ASF) als innerparteiliche Akteurin

5.1 Sozialdemokratische Frauenpolitik und

Frauenarbeit vor der Neugründung der ASF

5.1.1 Sozialdemokratische Traditionen der Frauenpolitik .....150

5.1.2 Die Familie als Keimzelle des Sozialismus ........................ 153

5.1.3 Frau und Familie im Godesberger Programm ................. 155

5.1.4 Zentrale frauenpolitische Themen der 1950er- und 196oer-Jahre .........................................................................156

5.1.5 Die Frauenarbeit der Partei.................................................166

5.2 Der Aufbau der Arbeitsgemeinschaft Sozialdemokratischer Frauen .......................................... 172

5.2.1 Umstrittene Gründung der Frauenarbeitsgemeinschaft ............................................... 173

5.2.2 Die Sozialstruktur der ASF-Mitglieder ...............................181

5.2.3 Repräsentationsdemokratie und

5.2.4 Politische Teilhabe und Karrierechancen in der

5.2.5 Presse- und Informationsarbeit ..........................................191

5.2.6 Politische Bildungsarbeit.....................................................193

5.2.7 Der parteiexterne Netzwerkaufbau ....................................194

5.3 Kollektivbildung, neue Aktionsformen und politische Lager ........................................................... 204

5.3.1 Diskriminierungserfahrungen .........................................206

5.3.2 Formen der Nichtzugehörigkeit zum politischen

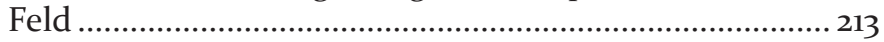

5.3.3 Differente Strömungen und „mühsame Solidarität“ ...... 217

5.3.4 Kulturelle Zwischenwelt und kollektive Selbstermächtigung ......................................................... 220

5.3.5 Neue Formen politischer Kommunikation ...................... 221

5.4 Programmatische Orientierungen und Politiken der ASF 
5.4.1 Der Streit um ein frauenpolitisches Programm ............. 226

5.4.2 Grundlinien des sozialistischen Feminismus.................. 230

5.4.3 Die Logos der ASF ........................................................ 238

5.4.4 Politikfelder der ASF ......................................................... 240

5.4.5 Internationalistische Aktivitäten....................................... 267

5.4.6 Europa der Frauen ........................................................268

5.5 Repräsentation und Partizipation der Frauen in

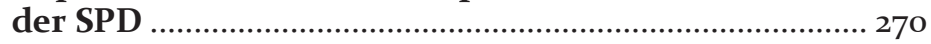

5.5.1 Der Frauenanteil in den Parteifunktionen ..................... 272

5.5.2 Der Zugang zu öffentlichen Ämtern für Frauen ............. 274

5.5.3 Die Auseinandersetzung in der ASF um die Quote....... 276

5.5.4 Die Bewertung der Quote als frauenpolitische Strategie ............................................................................ 280

5.5.5 Ungünstige Wirkungen der Quote auf die Entwicklung der ASF ....

5.5.6 Auswirkungen der höheren Repräsentanz auf parteiinterne Verfahren und

Kommunikationskulturen

5.5.7 Anmerkungen zur ASF als frauenpolitische Akteurin in der Partei heute

\section{Entwicklung und Veränderung der Frauenpolitiken in} der SPD

6.1 Die Demokratisierung und Aktivierung der sozialdemokratischen Frauenstrukturen in der

Partei (1970-1975) .302

6.1.1 Alte Parteikonzepte und neue Ansprüche. 302

6.1.2 Die Formierung einer frauenpolitischen Opposition in den Frauenstrukturen der Partei 304

6.1.3 Initiativen für eine neue sozialdemokratische Frauenpolitik 306

6.1.4 Neue Einmischungen der ASF in die Parteipolitik ........ 307

6.1.5 Streiten um die politische Mitgestaltung ..........................310

6.2 Die innerparteiliche Frauenbewegung im Streit um die Mitwirkung an der Parteipolitik (1975-1979) ........... 314

6.2.1 Wachsender Unmut unter den Frauen gegen die Parteiführung 314

6.2.2 Initiativen zur Neukonzipierung sozialdemokratischer Familienpolitik

6.2.3 Politiken gegen Frauenarbeitslosigkeit und Arbeitsmarktdiskriminierung..... 
6.2.4 Frauen- und familienpolitische Reformen der sozialdemokratischen Regierungspolitik

6.3 Die Institutionalisierung der Gleichstellungspolitik und die neue Attraktivität der Frauenpolitik für das Parteiprofil (1979-1985)

6.3.1 Frauenförderung als Organisationsaufgabe ……........... 328

6.3.2 Ausschließungserfahrungen bei der

KandidatInnenwahl für öffentliche Ämter .

6.3.3 Durchsetzungsprobleme bei der innerparteilichen Gleichstellungsverpflichtung ............................................ 332

6.3.4 Die Einrichtung von Frauenbeauftragten in der öffentlichen Verwaltung....

6.3.5 Regierungskrise und die programmatische Öffnung der Partei.....

6.3.6 Wenig Rückenwind für die Frauen aus Europa ............. 339

6.4 Frauen- und Gleichstellungspolitik der Bundestagsfraktion und erste Quotenreglungen in der Partei (1983-1986)

6.4.1 Verstärkte Bewerbung von Wählerinnen .......................... 341

6.4.2 Die neue Frauenpolitik der Bundestagsfraktion............ 345

6.4.3 Frauenpolitische Institutionalisierungen der SPD auf Länderebene

6.5 Die Geschlechterpolitik im neuen Parteiprogramm und die Einführung der verbindlichen Quote (19861989)

6.5.1 Sozialdemokratische Traditionen der Geschlechterquote

6.5.2 Die Bundestagswahlkampagne $1987 \mathrm{mit}$ frauenpolitischem Profil

6.5.3 Verfahren zur Umsetzung der Quote in der Partei ........360

6.5.4 Quotenbeschluss auf dem Parteitag in Münster 1988....361

6.5.5 „Die Partei ging schwer mit“: die Quote als

Karrierezugang für Frauen 364

6.5 .6 Die Durchsetzung einer neuen Frauenpolitik in der Partei und dem Grundsatzprogramm von 1989 369

7 Eine Bilanz 375

8 Quellen und Literatur. 387

8.1 Archivalien. 387

8.1.1 Archive .387 
8.1.2 Nachlässe und Privatarchive................................................387 8.2 Gedruckte Quellen.........................................................387

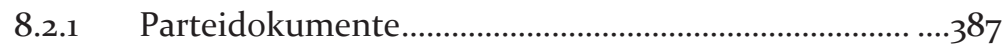

8.2.2 Zeitschriften.....................................................................403

8.2.3 Jahrbücher...........................................................................407

8.2.4 Literatur ...............................................................................408

8.2.5 Onlinedatenbanken und Onlineverzeichnisse................462

8.3 Interviewte ExpertInnen der SPD...................................463 


\section{Darstellungsverzeichnis}

Abb. 1 Bundesvorstand der ASF bei einer

Pressekonferenz, vermutlich Parteitag in Münster 1988........26

Abb. 2 Die Logos der Arbeitsgemeinschaft

Sozialdemokratischer Frauen

Abb. 3 Als Sulfragetten verkleidete Mitglieder der ASF Münster

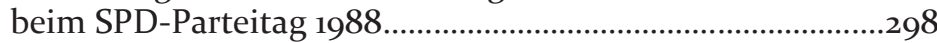

Abb. 4 Entwicklung des Frauen- und Männeranteils in der Mitgliedschaft der SPD .327

Abb. 5 Frauenanteil unter den Abgeordneten des Deutschen Bundestags 368

Tab. 1 Anteil der Berufsgruppen bei den Frauen. SPD-Mitgliedschaft und ASF-Delegierte 1981.... .182

Tab. 2 Frauenanteil in den Landesparlamenten..................................315

Weiterführende Tabellen, auf die im Text verwiesen wird, sind auf der Webseite des Verlags online abrufbar unter:

DOI 10.3224/86388794A 


\section{Abkürzungen}

ASF

AfA

AKE

AWO

AFG

a.o.

BGB

BVerfG

CDU

CSU

DKP

DGB

DF

EKD

FDP

FR

GEW

LV

$\mathrm{MdB}$

MdEP

MdL

NFB

NSB

OR'85

OV

PT

PV

SI

stellv.
Arbeitsgemeinschaft sozialdemokratischer Frauen der SPD

Arbeitsgemeinschaft für Arbeitnehmerfragen der SPD

Arbeitskreis Emanzipation

Arbeiterwohlfahrt

Arbeitsförderungsgesetz

Außerordentlich

Bürgerliches Gesetzbuch

Betriebsverfassungsgesetz

Christlich Demokratische Union Deutschlands

Christlich Soziale Union in Bayern e.V.

Deutsche Kommunistische Partei

Deutscher Gewerkschaftsbund

Deutscher Frauenrat

Evangelische Kirche in Deutschland

Freie Demokratische Partei

Frankfurter Rundschau

Gewerkschaft Erziehung und Wissenschaft

Landesverband

Mitglied des Bundestags

Mitglied des Europäischen Parlaments

Mitglied des Landtags

Neue Frauenbewegungen

Neue Soziale Bewegungen

SPD-Programmtext Orientierungsrahmen 1985

Ortsverein

Parteitag

Parteivorstand

Sozialistische Internationale, internationales Netzwerk sozialdemokratischer und sozialistischer Parteien mit Sitz in London

stellvertretend/e/er 
Socialist International Women, organisiert die Frauenorganisationen der sozialistischen, sozialdemokratischen und Labour Parteien, die der Sozialistischen Internationale angehören oder nahestehen.

SPD Sozialdemokratische Partei

UB Deutschland

WDR

Unterbezirk

WP

Westdeutscher Rundfunk

zit. n.

Wahlperiode

$\mathrm{Zz}$

zitiert nach

ZeitzeugIn 


\section{$1 \quad$ Einleitung}

\section{Das Forschungsthema}

Unter den feministischen BewegungsforscherInnen ist es nach wie vor umstritten, ob die institutionalisierten Frauenbewegungen im Sinne der Neuen Frauenbewegungen als emanzipatorisch gelten können.

Nach Nancy Fraser haben Feministinnen ihre Emanzipationsziele allzu eng auf die Durchsetzung der Geschlechtergerechtigkeit ausgerichtet. Sie nahmen nicht wahr, dass ihre Kritik an Ökonomismus, Androzentrismus und Etatismus vom kapitalistischen Krisenmanagement aufgenommen wurde und sich parallel zum systemkritischen, antikapitalistischen Feminismus ein neoliberales feministisches Double entwickelte. Feministinnen unterstützten damit affirmativ auch solche gesellschaftlichen Umgestaltungen, die dem ursprünglichen Leitbild von sozialer Gerechtigkeit zuwider liefen. Es bildete sich eine „,dangerous liaison' with neoliberalism" (Fraser 2009: 114).

Auch für Tove Soiland hat eine „Entwendung“ feministischer Forderungen im Zuge des globalisierten Kapitalismus stattgefunden. Sie ruft deshalb - wie auch andere feministische Geschlechterforscherinnen - zu einer Reformulierung weiblicher Kollektivität auf, um „das Erbe zurückzugewinnen“ (Haug 2009: 407) und das „Wissen um das beschädigte Leben" (Thürmer-Rohr 2013: 181) für eine herrschaftsfreiere Gesellschaft nutzbar zu machen (vgl. Soiland 2011).

Gerade die institutionelle Gleichstellungspolitik, die in den 1980erJahren als ein Geflecht aus Frauen- und Gleichstellungsbeauftragten in Politik, Wirtschaftsverbänden und Verwaltung entstand und darauf zielte, die Partizipation der Frauen und die Verhinderung von Diskriminierung mithilfe von Vorschriften und Gesetzen zu erreichen, trug nach Birgit Sauer zur Entradikalisierung des Feminismus bei (vgl. Sauer 1994; auch Pinl/Weg 1989). Es entwickelte sich ein „arbeitsteiliges Arrangement" zwischen autonomen Frauenprojekten und Gleichstellungsfeministinnen mit den „fatalen“ Folgen einer „Sozialpolitisierung“ feministischer Ansprüche und einer „Entkoppelung von feministischer Theorie und Praxis", bei der das Ziel, patriarchatstranszendierende Politik zu entwickeln, verloren ging (vgl. Sauer 1994: 14). ${ }^{1}$

1 Die Neuen Frauenbewegungen erlebten eine „Verstaatlichung der Frauenfrage“ (Krautkämer-Wagner 1989). Frauenpolitik wurde mit Gleichstellungspolitik identifi- 
In dieser Geschichtserzählung, nach der der Bewegungsfeminismus der 1970er-Jahre von einem Institutionenfeminismus in den 1980er-Jahren ab- und aufgelöst wurde, erscheint der autonome Flügel der Neuen Frauenbewegungen (NFB) als der des vitalen Feminismus, der institutionelle demgegenüber als gezähmt und von den bürokratischen Strukturen der Organisationen gelähmt. Die vorliegende Forschungsarbeit möchte zu einem differenzierteren Bild von der NFB in der Geschlechter- und Bewegungsforschung beitragen und ist einer institutionellen Frauenbewegung gewidmet.

Dass die Etappenkonstruktion eines Bewegungsgeschehens in den 1970er-Jahren und seines Zerfalls durch die Institutionalisierung in den 1980er-Jahren nicht zutrifft, hat Ilse Lenz 2003 anhand einer Analyse der Presseberichterstattung dokumentiert. Hiernach steigerten sich Mobilisierungsaktivitäten der Frauenbewegungen kontinuierlich und blieben in den Jahren 1990-1995 auf konstant hohem Niveau (vgl. Lenz 2008: 25). In den 1980er-Jahren entwickelte sich nach Lenz zudem ein „magisches Viereck“, in dem sich feministische Wissenschaftlerinnen, Frauenpolitikerinnen, autonome Aktivistinnen und Institutionenfrauen wechselseitig beeinflussten und stärkten (vgl. a.a.O.:360).

Die Kooperationen zwischen den Beteiligten des „magischen Viereck[s]“ gestalteten sich jedoch oft schwierig. Bereits in den Anfängen ihrer Mobilisierung waren die Neuen Frauenbewegungen ${ }^{2}$, die auch in Abgrenzung zu der Frauenbewegung des 19. Jahrhunderts als Zweite Frauenbewegung bezeichnet werden, hoch fragmentiert. Die ersten Gruppen bildeten sich in den studentischen Revolten der 1960er-Jahre und mobilisierten Frauen, die sich in Abgrenzung zu den gesellschaftlichen Organisationen unabhängig formierten. Zugleich aber aktivierte diese Zweite Frauenbewegung auch Frauen in gesellschaftlichen Organisationen und

ziert, so Birgit Sauer. Diese entwickelte sich zu einem „Totem’ bundesdeutscher Frauenpolitik“ (Biester/Holland-Cunz/Maleck-Lewy/Ruf/Sauer 1994: 9). Es entstanden neue Politikfelder wie z.B. die Gleichstellung der Frauen im Erwerbsleben, die institutionelle Verankerung der Gleichstellung in der öffentlichen Verwaltung, der Schutz gegen Gewalt gegen Frauen, die berufliche Förderung von Frauen, die Unterstützung bei Schwangerschaft und Geburt, die gesellschaftliche Integration und Anerkennung gleichgeschlechtlicher Lebensweisen und neue Maßstäbe zur Umsetzung der Gleichberechtigung und Gleichbehandlung der Geschlechter in allen gesellschaftlichen Bereichen. 1994 wurde mit der Änderung des Grundgesetzes der Staat verpflichtet, die Gleichberechtigung von Frauen und Männern aktiv durchzusetzen (Art.3 Abs.2 GG). Die institutionellen Feministinnen verfolgten mit dem sog. Gender Mainstreaming Gleichstellung als Organisationsziel, um auf der Grundlage der „Anerkennung weiblicher und männlicher Identität“ die Verteilung von Verantwortung und Ressourcen auf beide Geschlechter zu gewährleisten (vgl. Sellach/Enders-Dragässer/Baer/Kuhl/Kreß 2003).

2 Ilse Lenz plädiert wegen der Vielfältigkeit der Frauenmobilisierung dafür, die Zweite Frauenbewegung im Plural als „Neue Frauenbewegungen“ zu bezeichnen. 
in Strukturen, die sich bereits im Zuge der Ersten Frauenbewegung gebildet hatten. Die verschiedenen Frauenbewegungen entwickelten ihre je eigenen Diskurse und Arbeitsfelder und Semiöffentlichkeiten (vgl. Lenz 2008). Ihre unterschiedlichen Bedingungen der Selbstorganisierung, Identitätsfindung und Aktionsfähigkeit erschwerten den Austausch und die Verständigung untereinander, obwohl sich ihre spezifische Kollektivitätsbildung auf viele gleiche oder vergleichbare politische Themen bezog. Latent konkurrierten sie um Mitglieder und mediale Aufmerksamkeit.

Die Frauen- und Geschlechterforschung konzentrierte sich auf die autonomen Frauenbewegungen, ihre feministische Gesellschaftskritik, Geschlechterdiskurse und Bewegungsaktivitäten. Die Bewegung der Frauen in den gesellschaftlich etablierten Organisationen wurde dagegen bislang nicht so intensiv erforscht. Bei den neueren Studien bietet die Quellensammlung von Ilse Lenz einen Einblick in dieses Segment der Zweiten Frauenbewegung (vgl. Lenz 2008). Weitere Forschungsarbeiten, die sich mit der Institutionalisierung der Neuen Frauenbewegungen auseinandersetzen, verfolgen die Umsetzung institutioneller Diskurse (vgl. Zwingel 2005) oder die Umsetzung und Verläufe ausgewählter institutioneller Strategien im Ländervergleich (vgl. Ehmsen 2008).

Die vorliegende Studie geht der Formierung einer institutionellen Bewegung nach und analysiert die Beziehungen zwischen autonomem und institutionellem Feminismus am Beispiel der Arbeitsgemeinschaft sozialdemokratischer Frauen (ASF), der parteiinternen Frauenorganisation der Sozialdemokratischen Partei Deutschland (SPD).

Die SPD vollzog in den 1970er- und 1980er-Jahren einen grundlegenden frauenpolitischen Wandel. In dieser Zeit mobilisierten sich die weiblichen Mitglieder der SPD und veränderten nachhaltig die Strukturen, die programmatischen Grundsätze und die Politik der Partei. Aus der parteiinternen Frauenarbeitsgemeinschaft entwickelte sich eine Einfluss nehmende Frauenlobby. Der Historiker Siegfried Heimann bezeichnet sie als die erfolgreichste Arbeitsgemeinschaft der SPD (vgl. Heimann 1993). Mit dieser Mobilisierung entstand innerhalb einer etablierten gesellschaftlichen Organisation mit hierarchischen Strukturen und bürokratischen Prozessabläufen eine parteiinterne Bewegung, die - so das Ergebnis der vorliegenden Studie - den Neuen Frauenbewegungen zugerechnet werden sollte.

Bei der Analyse der historischen Ereignisse in der SPD wird folgenden Fragen nachgegangen:

- Wie entwickelte sich die Arbeitsgemeinschaft sozialdemokratischer Frauen? Wie mobilisierten sich die Frauen in der Partei, 
welche Kollektivbildungen und Formierungen entstanden in der ASF?

- Welche politischen Konzepte und Aktivitäten entwickelte die ASF? Wieweit bildeten ihre Politikentwicklungen Gegenkonzepte zu der Frauenpolitik der Parteimehrheit? Wie kritisierten die Sozialdemokratinnen in ihren Politiken Geschlechtermacht und welche Vorstellung von weiblicher Emanzipation entwickelten sie?

- Welche Strategien verfolgte die ASF, um die Teilhabe der Frauen in Partei und Politik zu erhöhen? Wie wirkte sich die steigende Beteiligung der ASF-Aktivistinnen an der Gremienarbeit der SPD und in politischen Ämtern auf die Arbeitsgemeinschaft selbst aus?

- Wie veränderte sich die Frauenpolitik der SPD im Forschungszeitraum sowohl hinsichtlich ihrer Mitgliederpolitik als auch in Bezug auf ihre politischen Ziele, Aktivitäten und die programmatischen Grundorientierungen? Welche Faktoren und historischen Kontextualisierungen waren für diese Veränderungen bedeutsam?

- Wie ist der frauenpolitische Wandel der SPD aus feministischer Perspektive zu bewerten?

Mit diesen Fragen werden die Ereignisverläufe in der SPD im Zeitraum von 1973 bis 1989 rekonstruiert. Dies sind die Jahre von der Einrichtung der ASF bis zur Deutschen Wiedervereinigung, die eine Zäsur (vgl. Faulenbach 2011: 14) für die Partei und ihre Frauenpolitik bedeutete. Erforscht werden in diesem Zeitabschnitt die Entwicklung der ASF, ihre internen Diskurse und Strömungen, ihre Mitwirkung auf Bundesparteitagen und in der Politik- und Programmentwicklung der Partei, ihre Einflussnahmen auf die Auswahl des politischen Personals sowie ihre Aktivitäten außerhalb der Partei. Der Fokus richtet sich dabei auf die Bundesebene. Des Weiteren wird die frauenpolitische Entwicklung der Partei selbst analysiert, ihre veränderte Mitgliederpolitik und ihre Neuausrichtung der sozialdemokratischen Frauen- und Geschlechterpolitik. Diese Veränderungen wurden nur zum Teil durch die frauenpolitischen AktivistInnen der Partei beeinflusst; für ihre Durchsetzung sind auch innerparteiliche Machtkämpfe in dieser Zeit verantwortlich und die gesellschaftspolitischen Ereignisse im Umfeld der SPD, besonders die Frauenpolitik der konkurrierenden Parteien, des Weiteren die frauenpolitischen Initiativen der Europäischen Union und der UN, die außerparlamentarischen Frauenmobilisierungen und die Frauenaktivitäten in den gesellschaftlich etablierten Organisationen, wie die in den Gewerkschaften, den Kirchen und den traditionellen Frauenverbänden. 
Erforscht werden die Ereignisabfolgen aus einer handlungstheoretischen Perspektive. Das Agieren der frauenpolitischen AkteurInnen, ihre Erwartungen, Handlungskonzepte und -intentionen werden historisch rekonstruiert. Es wird untersucht, welche Reaktionen sie bei den Mitgliedern in der Partei auslösten, welche frauenpolitischen Aktivitäten sich in der Partei entwickelten und wie sich diese Entwicklungen in der Partei auf Identitätskonstruktionen, Selbstermächtigungen und Handlungsorientierungen der ASF-Frauen auswirkten. Dazu wurden Theorieansätze aus der Parteienforschung, der Organisationssoziologie und den Neuen Sozialen Bewegungen sowie feministische Diskurse und Bewegungstheorien zu den Neuen Frauenbewegungen kritisch genutzt. Im Folgenden werden diese Theorieansätze im Kontext der Kapitel vorgestellt und ihre Relevanz für die Forschungsergebnisse erläutert.

Im ersten theoretischen Kapitel 2.1 Die Wandlungsfähigkeit von Parteien werden die institutionellen Bedingungen betrachtet, die die parteiinternen Frauenaktivistinnen förderten oder behinderten. Für das Verständnis der Organisationsinteressen der Parteien und ihre Anpassungsfähigkeit werden Ergebnisse der Parteienforschung ${ }^{3}$ verwendet (vgl. Alemann 1995; Beyme 2000; Biehl 2005; Detterbeck 2002; Gabriel/Niedermayer/Stöss 2001; Decker/Neu 2007; Detterbeck 2002; Raschke/Tils 2007; Poguntke 2000; Schmidt 2007; Wiesendahl 2006). Parteien agieren einerseits als Vermittlerin zwischen BürgerInnen und Staat, andererseits versuchen sie, ihren gesellschaftspolitischen Auftrag der Selektion, Allokation und Integration politischer Interessen und Ziele unter Machterwerbsinteressen zu erfüllen. Die Party-Change-Forschung diskutiert entlang von idealtypischen Modellen, wie sich Parteien dabei an veränderte gesellschaftliche Kontexte und Erwartungen anpassen. Dazu werden verschiedene historische Epochen der parlamentarischen Demokratie mit unterschiedlichen Grundtypen von Parteien verbunden (vgl. Beyme 2000; Jun 2009; Detterbeck 2002; Kirchheimer 1966). Eine andere Perspektive gegenüber den politologisch begründeten Parteimodellen eröffnet sich aus einer organisationssoziologischen Sicht auf den Parteienwandel (vgl. Nachtwey 2009; Roth/Wiesendahl 1985; Wiesendahl 2002). Die Veränderungsfähigkeit einer Partei wird dann in Beziehung zu ihrer Organisationswirklichkeit gesetzt. Volksparteien wie die SPD können nach Elmar Wiesendahl als eine Mischung aus und als Ergebnis von Aushandlungsprozessen zwischen unterschiedlichen AkteurInnen mit je spezifischen Organisationswirklichkeiten interpretiert werden (vgl. 
Wiesendahl 2002). Diesem Parteityp zufolge sind der Wechsel politischer Umorientierungen und die Neuausrichtungen der Partei meist mit Machtverschiebungen verbunden und werden darüber hinaus häufig von organisationspolitischen Umstrukturierungen, sog. Parteireformen, begleitet. Die Studie, die sich an dieser Parteikonstruktion orientiert, untersucht deshalb, wie sich die Durchsetzungserfolge frauenpolitischer Anliegen und Konzepte mit den machtstrategischen Interessen von dominierenden oder aufstrebenden innerparteilichen Interessengruppen verbanden.

Im zweiten theoretischen Kapitel 2.2 Geschlechtermacht und Organisation werden organisationssoziologische Diskurse vorgestellt, die die Beziehung zwischen Handeln und Struktur in Organisationen reflektieren. In der feministischen Organisationssoziologie ist die Kopplung von Geschlechter- und Organisationshierarchien ein zentrales Thema. In diesem Kapitel werden dazu folgende vier Theorieansätze vorgestellt, mit denen die geschlechterpolitischen Konflikte in der Partei erfasst werden:

1. Die These von der Entsexualisierung des Arbeitsvermögens, die Männerherrschaft an biologisch verortete Verfügungskonzepte bindet (vgl. Müller 1993). Wenn auch dieser theoretische Ansatz in den weiteren geschlechterwissenschaftlichen Diskursen nicht weiter verfolgt wurde, hatte er für die damaligen Wahrnehmungen der Geschlechterhierarchien Bedeutung.

2. Das Theoriekonzept der hegemonialen Männlichkeit (vgl. Connell 2006; Meuser 2006). Nach diesem Theorieansatz lassen sich die männlichen Dominanzmuster, die die Organisationskultur, die sozialen Praktiken und die informellen Machtzugänge in der Partei prägen, identifizieren. Die Dokumente belegen, dass die männlichen Parteistrukturen der SPD nicht nur von weiblichen SPD-Mitgliedern scharf kritisiert wurden.

3. Die Tokenismtheorie (vgl. Kanter 1977). Sie definiert Beteiligungsmargen für geschlechtergerechte Partizipation, die auch im damaligen gleichstellungspolitischen Diskurs wichtige Bezugsgrößen darstellten.

4. Mit dem Konzept der sozialen Schließung (vgl. Cyba 1995; Wilz 2004; Steinert 2004) ließen sich in der Studie sowohl die vielschichtigen sozialen Ausgrenzungspraktiken gegen Frauen in den Parteigremien in den Blick nehmen als auch die separatistischen Kollektivbildungen, die von den Genossinnen selbst initiiert und aufrechterhalten wurden. 
Im dritten theoretischen Kapitel 2.3 Politische Partizipation und Neue Soziale Bewegungen werden verschiedene theoretische Konzepte der Bewegungsforschung vorgestellt. Bis zu Beginn der 1990er-Jahre galten in den meisten Bewegungstheorien Bewegungsteilnahme und Parteienengagement als dichotomer Gegensatz. Die theoretischen Ansätze waren geprägt von der Vorstellung einer historischen Etappenentwicklung, einer unausweichlichen Selbstaufhebung sozialer Bewegungen in fest gefügte und sich zum Selbstzweck werdende Organisationen (vgl. Rucht/Blattert/Rink 1997). Solche Konstruktionen lösten sich aber im Laufe der 1990er-Jahre zugunsten einer differenzierten Beschreibung verschiedener institutionalisierter Bewegungsformationen auf. Die sozialdemokratische Frauenorganisation, die als Arbeitsgemeinschaft in der SPD statuarisch streng geregelt und hierarchisch strukturiert war, wies vielerlei bewegungstypische Merkmale auf. Ihre politische Heterogenität, ihre fehlende programmatische Selbstbegründung, ihre flexible Bündnispolitik und ihre separatistischen ${ }^{4}$ Tendenzen trafen bei der damaligen Parteimehrheit deshalb vielfach auf Irritation und Ablehnung.

Der Identifikation solcher Bewegungsmerkmale liegen einzelne Theoriekonzepte der Neuen Sozialen Bewegungen (NSB) ${ }^{5}$ zugrunde: Das Framingkonzept von Robert D. Benford und David A. Snow (vgl. Benford/Snow 200o) untersucht den gemeinsamen und veränderbaren Interpretationsrahmen von Bewegungskollektiven ${ }^{6}$. Das Paradigma der kollektiven Identität diskutiert die Bezugspunkte für Mobilisierung, Kollektivbildungen und Widerstandshandeln (vgl. Roth 1998b; Bergmann/Erb 1998). Die Theorie der Ressourcenmobilisierung reflektiert, unter welchen Voraussetzungen individuelle Unzufriedenheiten zu kollektivem Protest führen (vgl. Klandermans 1998). Im strukturfunktionalistischen Structural-Strains-Ansatz werden Soziale Bewegungen als Reaktionen auf gestörte gesellschaftliche Normalitäten und als potenziell systemintegrative Krisenkorrektive konstruiert (vgl. Brand 1998a). Das Paradigma der Political Opportunity Structures richtet den Fokus auf die

4 Der Separatismus, in den autonomen deutschen Frauengruppen weit verbreitet, wurde von der ASF in den dokumentierten Erklärungen abgelehnt, aber vermutlich in vielen ASF-Gruppen zeitweilig gelebt.

5 Vgl. hierzu insbesondere Rucht 1997; Rucht/Blatter/Rink 1997; Raschke 2003; Roth 1988.

6 In Abgrenzung dazu werden in der Partei Weltsicht, politische Ziele und Handlungsfelder in Grundsatzprogrammen definiert. Sie werden in aufwendigen innerparteilichen Diskussionsprozessen immer wieder den neuen gesellschaftlichen Veränderungen und politischen Erwartungen angepasst. Besonders im Forschungszeitraum galten für alle innerparteiliche Formierungen - und lange Zeit auch für die ASF - programmatische Selbsterklärungen als unabdingbar und als Basis für politische Aktionsfähigkeit (vgl. dazu Kap. 8.4) 
Wechselwirkung zwischen Bewegung und ihren gesellschaftspolitischen Kontexten (vgl. Rucht 1998) ${ }^{7}$. Das Kapitel schließt mit einer kurzen Zusammenfassung der Diskurse zur Institutionalisierung der Bewegungen und den gesellschaftspolitischen Folgen dieser Entwicklung. Demnach galten bereits in den zeitgenössischen Diskursen des SPD-Lagers soziale Bewegungen als historisch neue zivilgesellschaftliche Akteurinnen ${ }^{8}$, die im Regelsystem der repräsentativen Demokratie ein wichtiges Korrektiv für die Regierungsparteien bilden und die neue Formen zivilgesellschaftlicher Partizipation thematisieren.

Das vierte theoretische Kapitel 2.4 Die Neuen Frauenbewegungen der $1970 e r$ bis 1990er-Jahre in der BRD stellt den politisch bedeutsamsten parteiexternen Bezugspunkt der frauenbewegten Sozialdemokratinnen im Untersuchungszeitraum dar. Den ASF-Frauen war bewusst, dass ihre Einflussnahmen auf die Parteientwicklung wesentlich von den frauenpolitischen Aktivitäten im Umfeld der Partei abhängig waren. Viele inhaltliche Impulse erhielten die Parteifrauen aus den feministischen Diskursen außerhalb des Parteienspektrums. Vielerlei Aktionsanstöße der ASF gingen auf Initiativen aus den autonomen Frauengruppen zurück. Manche politischen Aktivitäten oder Projekte entstanden in gemeinsamen Kooperationen zwischen autonomen Frauenkollektiven und ASFFrauen. In diesem Kapitel werden die Transformationen der Neuen Frauenbewegungen und ihre wichtigsten Strömungen im Forschungszeitraum vorgestellt. Aus den feministischen Diskursthemen wurden diejenigen ausgewählt, die für die Auseinandersetzungen der ASF-Frauen mit den Frauenbewegungen und für die Selbstfindungen der ASF-Aktivistinnen besonders wichtig waren. Für die zusammenfassende Darstellung der Neuen Frauenbewegungen und die Analyse ihrer Diskurse wurden vor allem die Forschungsarbeiten von Ilse Lenz verwendet (vgl. Lenz 2002, 2004a, 2008, 2013).

Im Kapitel 3 Die SPD in den 197oer- und 1980er-Jahren - Regierungsbeteiligung, innerparteiliche Fragmentierungen und programmatische Neuorientierungen werden in einer Kurzfassung die politischen Rahmenbedingungen der Partei geschildert, unter denen sich die ASF und die Frauenpolitik im Forschungszeitraum entwickelt haben. Die Darstellung der Mitgliederentwicklung, der innerparteilichen Lagerbildungen und programmatischen Neuausrichtungen, der Regierungsbeteiligung und des -

7 Diese Theorieansätze werden von feministischen Forscherinnen kritisiert (vgl. Dackweiler 2004a; Ferree/McClurg Mueller 2008; Kontos 1988; Lenz/Schneider 2004). Vgl. dazu Kap. 2.3.2

8 Bis in die 1990er-Jahre gingen NSB-ForscherInnen von einer „Veralltäglichung des Protests" aus (vgl. Roth/Rucht 1991). 
verlusts folgen den Darstellungen sozialdemokratischer Geschichtsschreibung (vgl. Boyer/Kössler 2005; Faulenbach 2011; Grebing 1987, 2007; Heimann 1991, 1993; Lehnert 1983; Lösche/Walter 1992; Potthoff/Miller 2002; Osterroth/Schuster 2005; Walter 2002).

In dieser Forschungsliteratur werden die frauenpolitischen Entwicklungen in der Partei ${ }^{9}$ entweder nicht erwähnt oder eher als marginales Phänomen behandelt, wenig bedeutend für die strategische Ausrichtung der Partei. Die vorliegende Kurzfassung der Parteigeschichte verzichtet deshalb auf diese Erwähnungen. Dagegen werden die Entwicklungen und Veränderungen der Frauenpolitiken in der SPD im empirischen Teil der vorliegenden Studie rekonstruiert und analysiert.

Für die Forschungsarbeit wurden unterschiedliche Quellen erschlossen und verwendet. Die Erhebung der unterschiedlichen Daten und ihrer Kombination wird im Kapitel 4. Methodische Anlage der Untersuchung erläutert. Verwendet wurden Parteipublikationen, Sitzungsprotolle und andere zeitgenössische Dokumente, parteinahe Zeitschriften, Erinnerungsliteratur und historische Studien über die Sozialdemokratie im Nachkriegsdeutschland. Die Auswertung der Archivalien orientierte sich an den Ausführungen Reiner Kellers zur Diskursanalyse (vgl. Keller 2007). Mit 16 Parteimitgliedern, die im Forschungszeitraum die Frauenarbeit der Partei mitgestaltet haben, wurden leitfadengestützte Interviews geführt. Alle Interviewten wurden als ExpertInnen und ZeitzeugInnen befragt. Für die Interviewführung wurden die methodischen Hinweise von Christel Hopf (vgl. Hopf 1978, 1996), Fritz Schütze (vgl. Schütze 1983, 1987) und Michael Meuser (vgl. Meuser 1991, 2004, 2005a, $2005 \mathrm{~b})$ verwendet. Die Aufbereitung der Interviewdaten folgt den methodischen Erläuterungen von Aglaja Przyborski und Monika WohlrabSahr (vgl. Przyborski/Wohlrab-Sahr 2008) unter Beachtung der Texte von Gabriele Rosenthal (vgl. Rosenthal 1995; Fischer-Rosenthal 1997) zur Biographieforschung.

Für den theoretischen Teil der Arbeit wurde die bis 2013 erschienene wissenschaftliche Literatur berücksichtigt.

Der empirische Teil behandelt den frauenpolitischen Wandel der Partei von den 1970er-Jahren bis zum Mauerfall 1989 in zwei Kapiteln. Das Kapitel 5 Die Arbeitsgemeinschaft Sozialdemokratischer Frauen (ASF) als innerparteiliche Akteurin stellt die Frauenarbeitsgemeinschaft und ihre 
Entwicklung im Forschungszeitraum vor, Kapitel 6 Entwicklung und Veränderung der Frauenpolitiken in der SPD behandelt den Wandlungsprozess der Frauenpolitik in der Partei.

Das fünfte Kapitel ist in fünf Unterabschnitte gegliedert: Zunächst wird die Frauenpolitik der SPD in den 1950er- und 1960er-Jahren skizziert (vgl. Kap. 5.1). In dieser Zeit organisierte die Partei ihre Frauenarbeit vor allem als Angebote der Begegnung und gegenseitigen Hilfe für ihre weiblichen Parteimitglieder. Sie lag in den Händen von sog. Frauenverantwortlichen im Parteivorstand. Das damit verbundene frauen- und familienpolitische Konzept war geprägt von einem patriarchalen Geschlechterdenken, nach dem Männer für Politik und Partei und Frauen für Familie und Privatheit zuständig waren. Die frauenbewegten Sozialdemokratinnen der 1970er und 1980er-Jahre setzten diesem Modell neue Emanzipationsvisionen und Partizipationsansprüche entgegen.

Im folgenden Unterkapitel (vgl. Kap. 5.2) wird die Entwicklung der Arbeitsgemeinschaft Sozialdemokratischer Frauen von ihren kontroversen Gründungsdiskursen Anfang der 1970er-Jahre bis zur Herausbildung einer in der Partei weit verflochtenen Frauenorganisation mit spezifischen überparteilichen Vernetzungsaktivitäten dargestellt. Die Untersuchung der organisatorischen Strukturen und Verfahrensabläufe der ASF zeigt, welche Partizipationsmöglichkeiten die Arbeitsgemeinschaft weiblichen Parteimitgliedern bieten konnte und wie sich Mitgestaltung und innerparteiliche Karriere verbanden. Zugleich wird auch ein Licht auf die Grenzen der Integration unterschiedlicher frauenpolitischer Erwartungen und Interessen geworfen.

Das dritte Unterkapitel (vgl. Kap. 5.3) analysiert die Herausbildung einer kollektiven Identität innerhalb der ASF. Die verschiedenen Diskriminierungserfahrungen der Frauen in der Partei bildeten dafür eine generationsübergreifende Verständigungsgrundlage und das Fundament. Die weiblichen Parteimitglieder fanden in den ASF-Frauengruppen und der bundesweiten ASF-Organisation einen besonderen Ort der Selbstermächtigung und häufig auch den Einstieg in die politische Karriere. In den Frauenarbeitsgemeinschaften entwickelten die Sozialdemokratinnen neue Formen der politischen Kommunikation und Präsentation.

Im vierten Unterkapitel zur ASF (vgl. Kap. 5.4) werden deren politische Forderungen und programmatische Positionen erläutert. Der frauenpolitische Wandel der Partei wurde von frauenpolitischen Aktivistinnen wesentlich mitgestaltet. Sie brachten feministische Ideen aus den Neuen Frauenbewegungen in die Partei ein und verknüpften sie mit sozialdemokratischen Traditionen. Daraus entstand eine Vielfalt programmatischer Positionen und konkreter politischer Forderungen zu unterschiedlichen sozialen Konfliktlagen weiblicher Lebensverläufe. 
Das letzte Unterkapitel (vgl. Kap. 5.5) behandelt die innerparteilichen Auseinandersetzungen um geschlechterungleiche Partizipation und die Durchsetzung frauenspezifischer Zugänge zu Ämtern und Parteifunktionen. Die Quote, die 1988 auf dem Münsteraner Parteitag beschlossen wurde, war lange Jahre unter den ASF-Frauen in der Partei umstritten. Manche sahen ihre Bedenken und Einwände später bei der Umsetzung der Quote bestätigt. In diesem Kapitel werden die positiven Wirkungen und die schwierigen Folgen der Quote für die ASF und für die Durchsetzungsfähigkeit frauenpolitischer Aktivistinnen in der Partei reflektiert.

Der Wandel der sozialdemokratischen Frauenpolitik findet in der Frauenarbeitsgemeinschaft und in der Partei in parallelen, aber zeitlich versetzten Prozessphasen statt. Das Kapitel 6 Entwicklung und Veränderung der Frauenpolitiken in der SPD analysiert die frauenpolitischen Debatten und Beschlüsse in der Partei. Die frauenpolitischen Policyentwicklungen der Partei erhielten ihre Impulse nicht nur von der ASF. Es gab auch außerhalb der Arbeits- und Kooperationsstrukturen der ASF einflussreiche, frauenpolitisch engagierte Parteifrauen in Parteifunktionen und in öffentlichen Ämtern, die feministische Ideen, Konzepte und politische Initiativen entwickelten und für ihre Durchsetzung in der Partei kämpften.

Die fünf Unterkapitel sind nach Wendemarken im frauenpolitischen Wandlungsprozess der Partei gegliedert. Die Ereignisabfolgen lassen sich in relativ ähnlich großen Abschnitten darstellen, weil parteiinterne Aktivitäten, Regularien und Parteibeschlüsse meist mit Wahlkampfphasen und Parteitagen verbunden sind. In den Unterkapiteln werden die wichtigsten Beschlüsse für die SPD und die ASF erläutert und interpretiert. Die Veränderungen der programmatischen Positionen, die Neuregulierungen der Organisationsstrukturen oder die neuen frauenpolitischen Konzepten der Parteipolitik werden stets als Verhandlungsergebnisse verschiedener AkteurInnen in der Partei dargestellt. Dabei beziehen sich diese Interessengruppen häufig auf unterschiedliche strategische Ziele und finden zu spezifischen historischen Zeitpunkten zu Bündnissen zusammen.

In dem abschließenden Kapitel 7 Bilanz werden die Bedingungen für den Politikwandel der Partei reflektiert und die frauenpolitischen Veränderungen in der SPD bewertet. Weil die Sozialdemokratinnen die Gleichstellungspolitik wesentlich mitentwickelt und getragen haben, die im feministischen Diskurs der 1980er- und 1990er-Jahren eher als Bedrohung des frauenpolitischen Emanzipationsprojekts kritisiert wurde, sind die frauenpolitischen Aktivitäten und die Erfolge dieser institutionellen Frauenbewegung bisher wenig diskutiert und gewürdigt worden. Die 
vorliegende Studie soll diese Lücke schließen und den historischen Beitrag dieser Teilbewegung der Neuen Frauenbewegungen verdeutlichen.

\section{Abb. 1: Bundesvorstand der ASF bei einer Pressekonferenz (vermutlich auf dem Parteitag in Münster 1988) ${ }^{10}$}

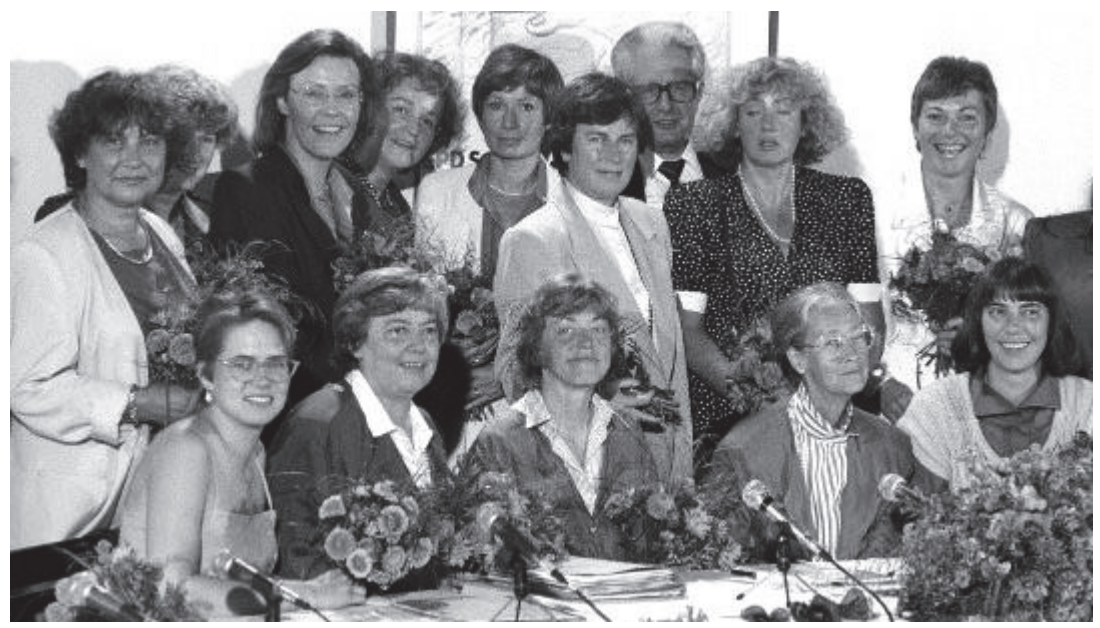

Quelle: Vorwärts, Januar 2014: Nachruf auf Brunhilde Peter, Gründerin des saarländischen ASF-Landesverbands und ASF-Bundesvorstandsmitglied und spätere Saarländische Ministerin. http://www.vorwaerts.de/11'4452/brunhilde_peter_war_eine_tolle_frau_von_elke_fe rner.html [Zugriff: 02.04.2014].

10 Hintere Reihe: Eva Rühmkorf (Kultusministerin Schleswig-Holstein), Anke Brunn (Wissenschaftsministerin NRW), Heidemarie Wieczorek-Zeul (Europapolitische Sprecherin der SPD-Bundestagsfraktion), Hertha Däubler-Gmelin (Präsidiumsmitglied und stellv. Vorsitzende der SPD-Fraktion), Heide Pfarr (MdL, Rechtswissenschaftlerin), Anke Fuchs (Bundesgeschäftsführerin), Renate Schmidt (Stellv.Vorsitzende der SPD-Bundestagsfraktion, Vorsitzende des AK „Gleichstellung von Frau und Mann“), Anke Martiny (Stellv. SPD-Landesvorsitzende Bayern). Vordere Reihe: Susi Möbbeck (Bundesvorsitzende der Jusos), Brunhilde Peter (Saarländische Ministerin für Soziales, Arbeit und Gesundheit), Inge Wettig-Danielmeier (Bundesvorsitzende der ASF), Katharina Focke (MdEP) und Ingrid Matthäus-Meier (Stellv. Vorsitzende der SPD-Bundestagsfraktion). 


\section{Parteienwandel, organisationale Geschlechtermacht und Neue Soziale Bewegungen}

\subsection{Zur Wandlungsfähigkeit von Parteien}

Die Arbeitsgemeinschaft Sozialdemokratischer Frauen der 1970er und 1980er-Jahre wird in der vorliegenden Studie als eine parteiinterne Frauenbewegung erforscht. Zwar war dieser Aufbruch der Frauen in der SPD geprägt von den anti-autoritären und libertären Idealen der StudentInnenbewegung sowie von den Neuen Frauenbewegungen und ihrer Kritik am gesellschaftlichen Ausschluss der Frauen und ihrer Suche nach Emanzipation und Selbstbestimmung, aber die „frauenbewegten“ Sozialdemokratinnen fühlten sich gleichzeitig mit der Partei verbunden und konnte sich eine erfolgreiche gesellschaftspolitische Mitgestaltung nur in den Strukturen der repräsentativen Demokratie, d.h. als aktive Parteimitglieder und durch die Übernahme öffentlicher Ämter, vorstellen. Die antiautoritären Visionen einer Revolte, den Antietatismus und die außerparlamentarische Organisierung als systemsprengende Strategie lehnten sie vehement $\mathrm{ab}$. Nach ihrer Grundüberzeugung war die gesellschaftliche Lage der Frau in Deutschland nur zu verändern, wenn es den Frauen gelang, die Politik der Parteien verändern ${ }^{11}$.

Wodurch und wie sich parteiinterne Formierungen in Großparteien wie der SPD durchsetzen können, auf welche Hindernisse und auf welche Möglichkeiten sie treffen, wird in der Parteienforschung als Wandlungsfähigkeit von Parteien diskutiert. Eine Auseinandersetzung mit diesen Forschungsergebnissen schafft Zugang zu den komplexen Prozessen, mit denen die innerparteiliche Frauenopposition in der SPD konfrontiert war.

11 Die schwindende gesellschaftliche Akzeptanz der Parteien war im Forschungszeitraum noch kein relevantes Thema politischer Strategiediskurse, denn die Beteiligung der Bevölkerung an den Wahlen lag bei den Bundestagswahlen bis zur Wahl 1983 bei $90 \%$ und sank bei der Bundestagswahl 1987 auf 83,1 \% (vgl. dazu Schmid/Zolleis 2005). 


\subsubsection{Parteidefinitionen im wissenschaftlichen Diskurs}

In der Parteienforschung existiert kein einheitlich definierter Begriff von ,Partei', stattdessen werden mithilfe unterschiedlicher Parteikonzepte die Wandlungsbereitschaft und Wandlungsfähigkeit der Parteien untersucht und erklärt ${ }^{12}$. In der vorliegenden Untersuchung werden Parteien als Organisationen mit internen widersprüchlichen „Organisationslogiken“ gefasst oder als eine Komposition von Organisationen verstanden (vgl. Meng 1985; Wiesendahl 1998; Detterbeck 2002). Sie sind vielschichtig strukturiert, sie bestehen meist aus volatilen Mitgliedern und einem Apparat von FunktionärInnen aus angestellten Hauptamtlichen ${ }^{13}$ und den durch Wahl bestimmten Funktions- und AmtsinhaberInnen ${ }^{14}$. In den großen Volksparteien organisieren sich parallel zum Parteiapparat verschiedene zielgruppenspezifische Arbeitsgemeinschaften sowie fachthematische Arbeitskreise und Foren, die oft auch für Nichtmitglieder offen sind. Zur aktiven Partei können auch die parteieigenen Stiftungen gerechnet werden sowie - weniger bedeutend - die mit der Partei historisch verbundenen Verbände und Vereine, die sog. Vorfeldorganisationen ${ }^{15}$.

Die Parteiorganisationen sind durch die Satzung, das gemeinsame Regelwerk aus Verfahrens- und Kompetenzvorschriften, unterschiedlich wirkmächtig in das Repräsentationssystem und damit in das Gesamtgefüge der Partei eingebunden. Die Strukturen der innerparteilichen Demokratie sind mit informellen Verbindungen und Netzwerken verschränkt. Diese bestimmen die Mitwirkungsmöglichkeiten und die Entscheidungsmacht der einzelnen Mitglieder oder Mitgliedergruppen. Die politische Steuerung einer Partei obliegt ihren Führungsgremien, wobei

12 Damit gibt es keine allgemeine Theorie über das Wesen der Partei, ihre Entstehung, Entwicklung und Wandlung (vgl. Wiesendahl 2006, 2010; Gabriel/Niedermayer/Stöss 2001; Decker/Neu 2007; Detterbeck 2002; Schmidt 2007; Schmid/Zolleis 2005; Crouch 2008; Naßmacher 1989; Lösche 1993; Walter 2009; Beyme 2000; Poguntke 1994, 2000, 2006).

13 SekretärInnen und GeschäftsführerInnen ab der Unterbezirksebene sowie die ReferentInnen beim Parteivorstand. Zudem sind die Parteien ArbeitgeberInnen für dienstleistendes Personal.

14 Vorstände und deren Stellvertretungen, KassiererInnen, SchriftführerInnen, die BeisitzerInnen - meist für Spezialaufgaben - sowie die Delegierten für die Interessenvertretungen auf der nächsthöheren Organisationsebene. Nach Josef Boyer und Till Kössler sind auch die KandidatInnen für öffentliche Wahlen hier zuzurechnen, da sie durch innerparteiliche Entscheidungsprozesse platziert wurden (vgl. Boyer/Kössler 2005: 68).

15 Zu den bekanntesten Vorfeldorganisationen der SPD zählen der Sozialverband Arbeiterwohlfahrt e.V., die Umweltschutz- und Tourismusorganisation NaturFreunde e.V. und die Kinder- und Jugendorganisation Die Falken. 
in den regierungsbeteiligten Parteien die Mitglieder mit öffentlichen Ämtern dominieren. Staatsraison bestimmt die Leitungsgremien von Regierungsparteien. Neben den politischen Repräsentationsaufgaben für die Partei besitzen die Führungsmitglieder mit Regierungsverantwortung zugleich die grundgesetzlich geschützte Freiheit des Mandats. Zwischen dem Mitwirkungsrecht der Parteien und dieser Unabhängigkeit der Abgeordneten besteht ein Widerspruch im demokratischen Repräsentationssystem oder zumindest ein Spannungsverhältnis ${ }^{16}$, über das StaatsrechtlerInnen und PolitologInnen seit der Gründung der Bundesrepublik streiten.

Parteien sind im Grundgesetz verankert und geschützt. Seit 1959 wird ihre Mitwirkung bei der parlamentarischen Willensbildung als öffentliche Aufgabe gefördert. Die öffentlichen Gelder bilden für die Parteien eine existentielle finanzielle Basis. Die staatliche Finanzierung ist allerdings an grundgesetzlich verankerte Auflagen gebunden. Sie schreiben eine demokratische Organisationsform, die öffentliche Rechenschaftspflicht über die Parteifinanzen und die Verfassungstreue vor. ${ }^{17}$

Parteien gelten als zentrale AkteurInnen politischer Willensbildung in demokratischen Systemen und sind „als intermediäre Instanzen zur Hervorbringung des Volkswillens unter Bedingungen moderner Gesellschaft im Flächenstaat unerläßlich" (Raschke/Tils 2007: 40). Im Demokratiedreieck „Wähler-Mitglieder-Führung“ (vgl. Raschke/Tils 2007) haben alle politisch interessierten BürgerInnen die Möglichkeit, ihre Ideen und Wünsche in die Diskurse der Parteien einzubringen und nach den parteiinternen Regeln der kollektiven Willensbildung durchzusetzen, wenn sie den programmatischen Werten der Partei zustimmen. Nach Thomas Poguntke wird diese Linkage sowohl direkt - als Kommunikation über Medien und in die WählerInnenschaft - als auch indirekt durch die Ansprache von Organisationsumwelten, Verbänden und Vereinen, die mit der Partei in engen Kooperationen stehen, realisiert. Sie ist häufig gesichert durch personelle Verflechtung und den Austausch zwischen Organisations- und Parteieliten (vgl. Poguntke 2005).

Die politische Integrationsleistung der Parteien gilt als Grundpfeiler der Massendemokratie (vgl. Detterbeck 2002). Nach Elmar Wiesendahl sind Parteien

ideologisch unterscheidbare politische Machterwerbsorganisationen, die ihre Aktivitäten auf die erfolgreiche Teilnahme an Wahlen, die Inbesitznahme von öffentlichen Ämtern und

16 Abgeordnete sind einerseits meist VertreterInnen von Parteien und werden von ihnen mit politischen Erwartungen und Aufträgen aufgestellt, andererseits sind sie in ihrem Amt verpflichtet, als VertreterInnen des „ganzen Volkes“ zu agieren (Art. 38 GG).

17 Art. 21 GG, Kurzdarstellung der Parteienfinanzierung in: Alemann 1995. 
Schaltstellen staatlicher Macht sowie die Entwicklung und Umsetzung kritischer Zielvorstellungen ausrichten. Sie sind Sprungbretter für politische Karrieren und geben freiwillig engagierten Mitgliedern, die sich mit den Prinzipien und der Gesamtkonzeption ihrer Partei identifizieren, Gelegenheit, mitzuarbeiten und für die Verwirklichung der Parteiziele einzutreten. Als politische Willensbildungs- und Entscheidungsinstanzen machen sie die repräsentativ-demokratische Ausübung von politischer Herrschaft unter massendemokratischen Bedingungen möglich. (Wiesendahl 2006: 9)

Damit verfolgen Parteien drei zentrale Ziele: Maximierung von WählerInnenstimmen, Ämtersuche und die Organisation innerparteilicher Demokratie (vgl. Schmid/Zolleis 2005: 286) ${ }^{18}$.

\subsubsection{Die Identifizierung der Wandlungsfähigkeit von Parteien anhand von Parteitypen}

Die Wandlungsfähigkeit der Parteien wird in der Parteienforschung entlang von Parteitypisierungen diskutiert. Gestützt auf empirische Studien werden dazu Organisationsmodelle konstruiert. Spezifische idealtypische Merkmale charakterisieren verschiedene Parteien in unterschiedlichen historischen Epochen und ihr Agieren, in Bezug darauf, wie sie die gesellschaftspolitischen Anforderungen an Partizipation, Identifikation und Integration sowie ihre politische Strategie- und Aktionsfähigkeit realisieren ${ }^{19}$. In der Party-Change-Forschung werden mithilfe dieser idealtypischen Parteimodelle auch Prozesse gesellschaftlichen Wandels widergespiegelt und zeitgeschichtlich verschiedene Epochen des Parlamentarismus beschrieben. Die „Honoratiorenpartei“, auch als Elitepartei oder individuelle Repräsentationspartei bezeichnet, bildet sich aus der Fraktionstätigkeit einer Partei heraus. Ihre AkteurInnen kommen oft ausschließlich zusammen, um die Wahl der RepräsentantInnen zu organisieren. Dieser Parteitypus übernimmt keine Politik gestaltenden Funktionen und bietet seinen Mitgliedern keine organisationsstatuarisch geregelte Partizipation. Die Honoratiorenpartei gehörte in den Grün-

18 Nach Klaus von Beyme bestehen die Aufgaben der Parteien in der Formulierung politischer Ziele, der Artikulation und Aggregation von Interessen, der Mobilisierung und politischen Sozialisierung der BürgerInnen, der Bereitstellung von Führungspersonal und der Fähigkeit, Regierung zu übernehmen (vgl. Beyme nach Wiesendahl 2006: 13ff.).

Die Methodik der Erstellung von Idealtypen geht auf Max Weber zurück. 
dungszeiten des deutschen Parlamentarismus zum dominanten Parteityp. Sie wurde abgelöst durch die „Massenpartei“, die sich bereits zum Ende der Wilhelminischen Ära bildete und sich im Zuge der Neuordnung Deutschlands nach dem Ersten Weltkrieg als dominanter Parteitypus etablierte (vgl. Ebbighausen 1969; Poguntke 2005b; Wiesendahl 2006). Die Massenpartei oder Massenintegrationspartei entspricht eher einer „sozial, kulturell und ideologisch zerklüfteten und zugleich sozial abgeschotteten Konfliktgesellschaft" (Wiesendahl 2002: 78). Diese Gesellschaft ist gekennzeichnet durch sozioökonomische und soziokulturelle Interessensdifferenzen, die sich als Cleavages ${ }^{20}$ gruppieren lassen. Die Konfrontationslinien kennzeichnen politische Lager mit spezifischen soziokulturellen Milieus, denen die Parteien innerhalb des Parteienwettbewerbs Sprachrohre bieten. Darüber hinaus ist die Massenpartei selbst „Teil eines weitläufigen soziokulturellen Milieus, das mit seinen Organisationen, Institutionen und sonstigen Einrichtungen die Lebenswirklichkeit seiner Angehörigen prägt" (Biehl 2005: 67).

Trotz dieser Integrationsfähigkeit wurden die Massenparteien bereits in ihrer Entstehungsphase mit demokratiekritischen Prognosen belegt. Robert Michels stellte in seiner 1911 erschienenen Studie Zur Soziologie des Parteiwesens in der modernen Demokratie die These vom „ehernen Gesetz der Oligarchie“ auf. Danach entwickelt die Massenpartei eine Tendenz zur Bürokratisierung und Oligarchisierung, was zu einer Verselbstständigung des FunktionärInnenapparats und zur Apathie der Mitgliedermassen führt. Robert Michels identifizierte in der Sozialdemokratischen Partei eine Tendenz zur „Verbourgeoisierung“, eine Ablösung der Partei von ihren sozialen Wurzeln in der ArbeiterInnenschaft, um Mehrheiten bei Wahlen durchzusetzen und in Regierungsverantwortung zu kommen ${ }^{21}$ (vgl. Darstellung in Niclauß 2002). Die Grundelemente dieses Massenparteimodells finden sich auch im Parteitypus

20 Die Cleavage-Theorie von Seymour Martin Lipset und Stein Rokkan (1967) basiert auf der Beobachtung, dass politische Parteien relativ soziale homogene Gefolgschaften rekrutieren. Sie erklärt die Verankerung westeuropäischer Parteien aus der spezifischen Konstruktion des politischen Raums heraus, in dem die Parteien als ,agent of conflict and instrument of integration" (Biehl 2005: 67) funktionieren. Die Lagerbildung verläuft im Nationalstaat entlang von vier Cleavages: Konfessionskonflikt, Klassenkonflikt, StadtbürgerInnen vs. LandbesitzerInnen, kulturelle Zentren vs. Hinterland.

21 Robert Michels war ein Gegner der repräsentativen Demokratie und des Parlamentarismus. „,Der Akt der Wahl ist gleichzeitig Ausdruck und Vernichtung der Massendemokratie“ (Michels zit. n. Scheer 1979: 148). Zunächst Mitglied der SPD und Anhänger der „revolutionär-sozialistischen Aktion“, unterstützte er später den italienischen Faschismus (vgl. dazu Scheer 1979). 
„Volkspartei“ ${ }^{\prime 22}$, der auf ein Konzept Otto Kirchheimers aus den 196oerJahren zurückgeht. Otto Kirchheimer beschrieb die Catch-all Party als Ergebnis einer gesellschaftlichen Transformation, die sowohl die „oldstyle bourgeois party of individual representation“ als auch die „mass integration parties“ betrifft, sobald sie Regierungsverantwortung anstreben (Kirchheimer 1966: 187f.). Die Catch-all Party - im Deutschen „Allerweltspartei“ oder „Volkspartei“ - repräsentiert nicht länger vorrangig die Interessen eines sozialen Klientels, das sie programmatisch an sich bindet. Sie öffnet vielmehr ihre Organisation Mitgliedern weiterer sozialer Milieus und ermöglicht damit VertreterInnen marginalisierter Gruppen den Eintritt in die politische Elite. Die Auswahl der politischen Führungsfiguren, insbesondere für die öffentlichen Ämter, ist für den Erfolg der Partei entscheidend (vgl. Kirchheimer 1966: 198ff.). Dieses Parteimodell passte in die politische Kultur der Entideologisierung der deutschen Nachkriegsgesellschaft und zum Gesellschaftskonzept einer „nivellierten Mittelstandgesellschaft", in der nach den Studien Helmut Schelskys soziale Mobilität und staatliche Daseinsfürsorge die Klassengrenzen aufweichen (vgl. Braun 1989). Danach sind die BürgerInnen durch wachsenden Wohlstand und staatliche Wohlfahrt geschützt und erwarten von ihren politischen Führungsfiguren, dass diese kompetent mit den Regierungsgeschäften und den komplexeren Faktoren einer gesellschaftlichen Steuerung umgehen können. Kennzeichen der deutschen Volksparteien sind deshalb der „Niedergang der Ideologie, eine Stärkung der Führung und Schwächung der Mitgliedschaft, die Ausweitung der Zielgruppe auf tendenziell das ganze Volk oder wenigstens einen wachsenden amorphen Mittelstand und die Öffnung der Parteien zu einer größeren Anzahl von Interessensgruppen“ (Beyme 2000: 3of.)23.

22 Zunächst hatte der Begriff der Volkspartei eine negative Konnotation. Nach Klaus von Beyme gilt die NSDAP als Grundtyp der Volkspartei. In ihr werden sozial und kulturell segmentierte Gruppen mobilisiert, tradierte Milieustrukturen unterlaufen und von der Parteiführung gleichgeschaltet (vgl. Beyme 2000). Im Aufsatz Otto Kirchheimers (1965) wurde der Begriff als analytischer Terminus eingeführt. In dieser politisch neutralisierten bzw. positiv besetzten Version wurde er von den westdeutschen Großparteien als Selbstkennzeichnung ihrer Integrations- und Politikfähigkeit übernommen (vgl. Niclauß 2002: 28f.).

23 Die „Entideologisierung der Bevölkerung“ war eher eine euphemistische Umschreibung fehlender Opposition und die verdrängte Auseinandersetzung mit der historischen Mitverantwortung an Kriegszerstörung und Holocaust. Die „Entideologisierung“ war geprägt von aggressivem Antikommunismus, Antisemitismus und einer nach wie vor verbreiteten Orientierung an nationalsozialistischen Werten. Dies waren wesentliche Gründe für die Politisierung und Radikalisierung der deutschen StudentInnenbewegung und die Mobilisierung der „außerparlamentarischen Opposition“ Ende der 196oer-Jahre. 
Die „Volksparteien“ orientieren sich an der Legitimation des bestehenden Systems und sehen ihre Aufgabe in der Aggregation und Schlichtung differierender Interessen, dem Ausgleich zwischen staatlichen und funktionalen Machtgruppen und einer entsprechend moderierten Personalrekrutierung (vgl. Wiesendahl 2006; Mintzel 1984). Um ihre Aufgabe als Vermittlungsinstanz zwischen Bevölkerung und Regierung erfolgreich zu erfüllen und sich in der Regierung behaupten zu können, muss eine Volkspartei veränderte gesellschaftliche Erwartungen erkennen und Missstände und Konflikte frühzeitig aufgreifen. Damit nimmt sie sowohl eine Herrschaft stützende als auch eine Herrschaft korrigierende Aufgabe wahr. Sie bewältigt das ökonomische und soziale Management, in dem sie sich nicht weiter an den traditionellen Cleavages orientiert. Ihre Linkagefähigkeit schwächt aber zugleich ihre demokratischen Funktionen, denn ihre pragmatische Machtausrichtung lässt weniger demokratische Integration und Teilhabe der BürgerInnen zu und durch die Ausrichtung auf die wechselnden politischen Stimmungen der WählerInnen wirkt sie weniger als kritisches Korrektiv der Regierungsarbeit. Die Parteienforschung geht davon aus, dass die Zeit dieses Parteitypus beendet ist, seit in den 1980er-Jahren rückläufige Mitgliederzahlen in den Parteien und der wachsende Anteil von WechselwählerInnen auf eine schwindende Integrationskraft der „Volksparteien“ hinweisen (vgl. Poguntke 2005a; Detterbeck 2002: 297).

Die geringere Beteiligung der Parteimitglieder am Parteigeschehen gilt nun als notwendige Folge eines „,kategorialen Wandels' im Verhältnis von Individuum und Gesellschaft“ (Beck 1986:205). Die „Individualisierung der Lebensformen“ führte zur kompletten Auflösung traditioneller Milieus. Lebensverläufe sind damit entroutinisiert, neue Handlungsoptionen und Entscheidungszwänge pluralisieren die Lebensstile der BürgerInnen. „Ein Riß tut sich auf zwischen den Gesellschaftsbildern, die in Politik und Institutionen vorherrschen, und den Entwürfen, die aus den Lebenslagen der um lebbare Formen ringenden Individuen entstehen." (Beck/Beck-Gernsheim 1994:31).

Entsprechend sind alle folgenden Parteitypen der Party-Change-Forschung gekennzeichnet durch eine schwache Integrationsfunktion und starke staatsmachtbezogene Führungsapparate, Referenzmodell für die Typenkonstruktionen ist das Catch-all-Party-Konzept. Diesen Parteitypus prägen eine geringe programmatische Distanz zu anderen Parteien, eine sozial vielschichtige Mitgliedschaft und ein Netzwerk zu unterschiedlichsten Interessensverbänden. Die Parteiorganisation ist auf Wahlkämpfe ausgerichtet, die mit hohem finanziellen Aufwand betrieben werden (vgl. Kirchheimer 1966). Dazu gehört die „BerufspolitikerPartei" von Klaus von Beyme, die zugleich als eine modernisierte Form der „Honoratiorenpartei“ erscheint (vgl. Beyme 2000, 2004; Niclauß 
2002: 34). Die Ära der BerufspolitikerInnenparteien setzt nach Klaus von Beyme Ende der 1970er-Jahre ein. Mit diesem Parteityp entwickeln sich in der Parteiorganisation ein Verwaltungsapparat und eine „politische Klasse“ aus BerufspolitikerInnen, die parteiübergreifend ein gemeinsames Interesse an Selbsterhaltung hat (vgl. Beyme 2000). Abgeordnete und Regierungsmitglieder bestimmen auch das interne Parteigeschehen. Dabei ist es ihr Bestreben, von der eigenen Parteimitgliedschaft möglichst unabhängig agieren zu können (vgl. Niclauß 2002). Die Partei wird in der Öffentlichkeit vorrangig durch ihre BerufspolitikerInnen repräsentiert. Deren mediale Repräsentation gilt als ausschlaggebend für erfolgreiche Wahlen.

Die Professionalisierung des FunktionärInnenapparats kennzeichnet ebenfalls den Parteitypus „professionalisierten Wählerpartei“ (Angelo Panebianco in: Poguntke 2003: 194). Die strategische Umorientierung der Massenparteien zu WählerInnenparteien fördert die Ablösung der ParteibürokratInnen durch professionals, die als ExpertInnen für Kommunikation und Wahlkampfmanagement auch die politische Ausrichtung der Partei beeinflussen. Zur Mitgliederbasis bestehen nur noch schwache Verbindungen. Das politische Profil einer solchen WählerInnenpartei ist geprägt durch kurzfristige Forderungen und die Präsentation von charismatischen Führungsfiguren. In der Partei selbst übernehmen KarrieristInnen und VerbandslobbyistInnen eine wichtige Rolle.

Diese Merkmale prägt auch die „professionelle Medienkommunikationspartei“ von Uwe Jun ${ }^{24}$. Seit den 1980er-Jahren perfektionieren die Parteien, so Uwe Jun, ihr Kommunikationsmanagement, was zu einer „Medialisierung der Parteien“ führt (vgl. Jun 2009). Der öffentlichen Präsentation der Leitungsmitglieder wird die Mitwirkung der weiteren Mitglieder untergeordnet. „Die Partei als Gesamtorganisation ist gehalten, diese Personen und das strategische Zentrum der Partei nicht zu delegitimieren, um ihre Erfolgschancen im Parteienwettbewerb nicht zu gefährden“" (a.a.O.: 253). Die Wahlkämpfe dieses Parteityps sind fokussiert auf leicht zu identifizierende Markenzeichen, Handelswaren ähnlich, die auf dem Markt konkurrieren. Die Wahlkämpfe sind material- und kapitalintensiv und nur über erhebliche finanzielle Zuschüsse von Interessengruppen und mithilfe der staatlichen Parteienfinanzierung zu realisieren.

Einen anderen Aspekt des Verlusts gesellschaftlicher Verankerung politischer Großparteien beschreiben Richard S. Katz und Peter Mair. Hiernach hat sich in den 1970er-Jahren ein neuer Typus, die „Kartellpartei“, entwickelt. Sinkende Mitgliederzahlen und eine schwindende

24 Otto Kirchheimer hat bereits in den 1950er-Jahren bei den Parteien eine zunehmende Nutzung des Fernsehens und eine „kommunikationstechnologische Hochrüstung“ beschrieben (Darstellung in Wiesendahl 2010). 
StammwählerInnenschaft fangen die Parteien durch eine stärkere Ausrichtung auf das Regierungsgeschäft auf und lassen eine interpenetration of party and state" (vgl. Darstellung in Detterbeck 2002: 37) entstehen. Sie haben den Parteienwettbewerb weitgehend ausgehebelt und etablieren sich als semi-state-agency. Politische Anpassungen an veränderte gesellschaftspolitische Anforderungen folgen einem institutioneneigenen Regelsystem, das Richard S. Katz und Peter Mair als „rationale choice institutionalism" bezeichnen (vgl. a. a. O.: 23). Das Kartell stabilisiert sich durch ausgehandelte Proporzregelungen bei der Besetzung staatlicher Positionen und durch Veränderungen der institutionellen Rahmenbedingungen, z.B. durch neue Wahlkreisaufteilungen. Nach Klaus Detterbeck verschafft das Regierungsamt den Kartellparteien im Wahlkampf einen Popularitätsvorteil (vgl. Detterbeck 2002: 260). Zudem werden sie in ihrer medialen Präsenz bevorteilt, weil sich die Sendezeiten nach den jeweils letzten Wahlergebnissen richten. Die Wahlergebnisse sind außerdem die Berechnungsgrundlage der staatlichen Förderungen ${ }^{25}$. Sie übersteigt bei allen Parteien - außer der SPD - die Einnahmen durch Mitgliedsbeiträge. Während die Volkspartei noch vorrangig elektorale Interessen verfolgte, denen sie im Konfliktfall die Interessen des Staates unterordnete (a.a.O.: 195), wertet Klaus Detterbeck die Kartellpartei als ein neues Stadium der Parteientwicklung, als eine Verstaatlichung der Parteien.

\subsubsection{Parteien im Diskurs soziologischer Organisationstheorien}

Elmar Wiesendahl sieht in diesen Typenkonstruktionen jedoch nur Varianten des Volksparteitypus. Neue Parteitypen bildeten sich nicht durch die Transformation der traditionellen Großparteien, sondern entstünden vielmehr durch Neugründungen wie die Rahmenpartei Bündnis 90/Die Grünen, die Protestparteien der radikalen Linken, die professionelle Medienpartei Forza Italia, die netzwerkstrukturierte Themenpartei Piratenpartei Deutschland. Nach Elmar Wiesendahl heben die verschiedenen Parteimodelle der Party-Change-Forschung spezifische Eigenschaften hervor, in vielen anderen Dimensionen aber sind die Modelle

25 Nach Klaus Detterbeck hat die Nutzung staatlicher Ressourcen in Deutschland durch die Großparteien im Vergleich zu anderen europäischen Ländern früher begonnen und ist ausgeprägter (vgl. Detterbeck 2002). Vgl. dazu auch Stand der Einnahmen der Parteien 2000-2009 in: http://dip21.bundestag.de/dip21 /btd/17/o82/1708200.pdf, S. 38f., Zugriff: 03.10.2016 
vergleichbar: „Jede Partei ist von ihrer Umweltausrichtung und Achsenneigung immer mehr oder weniger Mitglieder-, Eliten-, Wähler- und Staatsapparatepartei." (Wiesendahl 2002: 6)

Mit einer parteisoziologischen Forschungsperspektive werden Parteien im Anschluss an Samuel Eldersvelds Stratarchiemodell eher als offene Sozialgebilde konzipiert ${ }^{26}$ (vgl. Wiesendahl 2006: 106f.). Parteiorganisationen folgen demnach weder gesetzten Anforderungslogiken wie einer Systemangepasstheit und Funktionalität noch ist der Parteienwandel an historische Determinismen gebunden. Sie unterscheiden sich aufgrund ihrer spezifischen Traditionen, Gründungsbedingungen, Linkagemechanismen, Organisationsstrukturen sowie Ressourcen, ein gemeinsames Organisationsmodell für alle demokratischen Parteien zu entwickeln, erscheint hermeneutisch wenig hilfreich (vgl. Poguntke 2000). Stattdessen hat die Konzipierung der Partei als Hybrid ${ }^{27}$, in dem sich verschiedene Organisationswelten, -traditionen und -rationalitäten vereinen, nach Elmar Wiesendahl der Forschung Organisationswirklichkeiten eröffnet, die in der klassischen Parteienforschung „blinde Flecken“ bildeten (vgl. Wiesendahl 1998, 2006). Reinhold Roth und Elmar Wiesendahl bestimmen Parteien als einen „Orientierung-, Erlebens- und Handlungsraum einer abgrenzbaren Anzahl von Menschen, die durch ein Netzwerk sozialer Kontakte und Interaktionen sowie über einen gemeinsamen Orientierungsrahmen des Handelns verfestigte Relationen eingehen." (Roth/Wiesendahl 1985: 19) Parteien gleichen „gastfreundlichen Häusern, wo sich viele Leute nicht entgehen lassen, ein- und auszugehen" (a.a.O.).

Für die Analyse des Parteienwandels werden die internen Strukturen der Partei in den Blick genommen. Ausgelöst „aufgrund einer Existenzkrise, des Wettbewerbsdrucks, der strategischen Modernisierung neuer Parteieliten, des Benchmarkings und der Adaption von Erfolgsmustern, die von Konkurrenten oder aus Nachbarländern übernommen werden“

Samuel J. Eldersveld entwickelte das Stratarchiemodell erklärtermaßen als Gegenmodell zum Bürokratiekonzept der klassischen Parteienforschung, die Formalismus und Effizienz als Basismerkmale unterlegte (vgl. Meng 1985: 23). Robert Michels, Max Weber oder Maurice Duveger sahen Parteien als zweckrational strukturierte, zielorientierte, instrumentell agierende, auf Herrschaftspositionen ausgerichtete Organisationen an. Deshalb bezeichnet Elmar Wiesendahl Parteitypen der Party-Change-Forschung, deren Eigenschaftsmodellen rationalistische Organisationsmuster unterlegt sind, als „neoklassisch“. Sie unterstellen, dass „Parteien einen größtmöglichen Grad der Anpassung und Übereinstimmung mit den sie umgebenden Strukturen und Gegebenheiten aufweisen“ (Wiesendahl 1998: 83), und versperren sich dadurch den Forschungsblick auf die unterschiedlichen Funktionsweisen und Organisationsbeschaffenheiten der Parteien.

27 Peter Lösche analysiert in den Parteien verschiedene Organisationstypen aus unterschiedlichen Epochen nebeneinander (vgl. Lösche 1991). 
(Wiesendahl 2002: 118), brauche jede Veränderung AkteurInnen, Arenen, Ressourcen und die effektive Nutzung von historischen Gelegenheiten sowie Netzwerke zur Machtverschiebung und zur Neuaushandlung der Reviere. Parteiinterne Wandlungsprozesse zeigen sich nicht als eine bloße Anpassung an externe gesellschaftliche, kulturelle, politische Veränderungen. Sie werden durch die verfügbaren Ressourcen an Sachmitteln und Geld, Information und Expertise, BündnispartnerInnen und den Einfluss der Partei in Konkurrenz zu anderen Organisationen und sonstigen BedürfnisträgerInnen geprägt. Die parteispezifischen Wahrnehmungsmuster und Anpassungsaktivitäten folgen dabei vorrangig „Rezepten [...], die sich bereits in der Vergangenheit bewährt haben“ (a.a.O.: 118). Solche Traditionslinien werden in den Party-Change-Modellen, die die Parteien vorrangig auf WählerInnengewinnung hin konzipieren, systematisch unterschätzt, kritisiert Elmar Wiesendahl. Wandel bewirke in Parteien stets Verschiebung in den Kräftekonstellationen zwischen den inneren Flügeln und Fraktionen, meist mit erheblichen Folgen für die programmatische Ausrichtung der Partei, ihre strategischen Konzepte und die personelle Besetzung der Führungspositionen. Die Anpassung der Partei an die Umwelt stellt sich dann als Ergebnis eines konfliktgeladenen Entscheidungshandelns zwischen unterschiedlichen Gruppen und PositionsträgerInnen dar. Ihre kollektive Zugehörigkeit und Integration werden über einen parteispezifischen Referenzrahmen hergestellt, einen vereinheitlichenden Bezugsrahmen des kollektiven Erinnerns und Wahrnehmens, der Bewertung und Orientierung. Er bildet die „kognitive Landkarte“ für alle Parteimitglieder (vgl. Roth/Wiesendahl 1985: 28).

Parteien bewegen sich demnach in einem Spannungsfeld verschiedener und teilweise widersprüchlicher Anforderungen aus Umwelt, Mitgliederinteressen und Traditionen ${ }^{28}$. Typisch dafür sind die organisationspolitische Geschlossenheit und Machtkonzentration herrschender Gruppen, die Strukturschwäche und innerparteiliche Machtdiffusion durch gestreute Machtvorrechte, aber auch die Einflussmöglichkeiten der Mitglieder, denn ihre Unterstützung und ihr Verbleib kann die Parteiführung nicht erzwingen und konfrontiert sie mit einem „unlösbare[n] Freiwilligkeitsdilemma" (Roth/Wiesendahl 1985: 37).

28 Damit setzen sich Reinhold Roth und Elmar Wiesendahl zugleich gegen konsistente Systemmodelle ab, die eine scharfe Grenzziehung zwischen dem Innen und dem $\mathrm{Au}$ ßen der Partei vornehmen. Sie betonen dagegen die Unschärfe zwischen Umwelt und Organisation. Exklusionsmechanismen, wie ungleiche Zugangs- und Teilhabemacht für die Mitglieder oder Mitgliedergruppen, parteiinterne Gatekeeper, die Knotenpunkte und Grenzstellen zwischen Teilbereichen kontrollieren und die Chancenverteilung steuern, sind weniger Gegenstand ihres Forschungsinteresses. 
Parteien weisen in Prozessen des sozialen Wandels unklare Aufgaben- und Verantwortungszuweisungen sowie lückenhafte Kommunikation und Einbindung auf. Das Machtzentrum bilden Elitengruppen, die aber von der Unterstützung der Parteiaktiven abhängig sind. Parteien müssen nach Elmar Wiesendahl als „unterentwickelte, defizitäre und schlecht funktionierende Organisationen" verstanden werden,

... deren Entscheidungsprozesse verschlungene Wege gehen; wo Entscheidungsakteure wechseln, ausgeschlossen und wieder einbezogen werden; wo wechselnde Problemvorstellungen, Interessen, Motive, Entscheidungswünsche, Lösungsideen und Situationsdefinitionen ins Spiel gebracht werden; wo Probleme kommen und gehen und Entscheidungen fallen, die weder Problemen noch Lösungen dienen; Entscheidungen nicht fallen, weil es zu viele Probleme oder Lösungen gibt; Beteiligte Entscheidungen treffen, weil sie nicht wissen, worum es geht, und schließlich Entscheidungen fallen, für deren Umsetzung es keine klare Regeln und erreichbare Lösungen gibt (Wiesendahl 1984 zit. n. Wiesendahl 1998: 243).

Gerade eine traditionelle Programmpartei wie die deutsche Sozialdemokratie wird Elmar Wiesendahl zufolge mit den Eigenschaftstypen der Party-Change-Forschung, die Parteien vorrangig als zweckrationale Machterhaltungsorganisationen konzipieren, nicht beschrieben. Stattdessen definiert er die SPD als „lose verkoppelte, organisierte Anarchie“(a.a.O.: 206) ${ }^{29}$, in der Interessengruppen und Individuen mit unterschiedlichen Interessen agieren und verhandeln. Allerdings weise die SPD alle beschriebenen Merkmale auf: die Orientierung an der GesamtwählerInnenschaft, der Rückgang der aktiven Mitgliedschaft, der dominante Einfluss der BerufspolitikerInnen, die Professionalisierung des Apparates sowie die Tendenz zur Abschottung gegen parteiliche Konkurrenz. Wie die anderen Parteien, so Elmar Wiesendahl, habe sie sich zu einem Dienstleistungsunternehmen für BerufspolitikerInnen entwickelt, die sich vorrangig an den veröffentlichten Bedarfen statt an dem in der Parteiprogrammatik niedergelegten Sinn- und Weltanschauungskonzept orientierten. „Der Strukturwandel hin zur volksparteilichen Wählerpartei ist [...] ohne das Eigeninteresse einer neu entstehenden politischen Klasse an ihrem persönlichen Fortkommen nicht nachvollziehbar." (Wiesendahl 2010: 113).

29 Eine Definition, die Peter Lösche und Franz Walter weitgehend übernehmen. In ihrer Definition der SPD als „lose verkoppelte Anarchie“verzichten sie allerdings auf die von Elmar Wiesendahl aufgeführten oligarchisch-hierarchischen Organisationsmerkmale (vgl. Lösche 1991; Lösche/Walter 1992). 


\subsubsection{Die SPD als demokratische Teilhabeorganisation}

Nach den Studien der jüngeren Parteienforschung haben die Mitgliederparteien als Institutionen demokratischer Partizipation immer mehr an Bedeutung verloren (vgl. Wiesendahl 2006, 2010; Nachtwey 2009; Walter 2007, 2009; Lösche 2009; Gorholt 2009; Jun 2009; Biehl 2005; Alemann 2005; Detterbeck 2002). Dagegen erscheint die SPD der 1970er und 1980er-Jahre in der zeitgenössischen Parteienforschung in einem anderen Licht (vgl. u.a. Steiniger 1984; Krockow/Lösche 1986; Klotzbach 1989; Meng 1985; Steininger 1984; Mintzel 1984; Roth 1985). Hier wird den sozialdemokratischen PolicyaktivistInnen an der Basis, aber auch den FunktionärInnen der Partei und ihren Erwartungen an die Partei als Solidargemeinschaft mehr Aufmerksamkeit gewidmet und es wird ihnen ein höherer Einfluss beigemessen. In diesen beiden Jahrzehnten engagierten sich AktivistInnen in der Sozialdemokratie, um mit ihr und außerhalb der Regierung die Eskalation eines Kriegs zu verhindern und innerhalb der Gesellschaft mehr soziale Gerechtigkeit, mehr Demokratie sowie die Chance auf eine leistungsbezogene Verbesserung der individuellen Lebensverhältnisse durchzusetzen. Sie gestalteten den Wandel der Partei als wichtige AkteurInnen mit. Dennoch ist die Partei in dieser Zeit durch die strukturellen Blockaden im innerparteilichen Willensbildungsprozess gekennzeichnet, die im Folgenden skizziert werden.

\subsubsection{Die Parteimitglieder als BürgerInnenvertretung}

Für einen Parteieintritt gelten unterschiedlichste Motive. Möglich sind die Bindung an familiäre Traditionen, das Festigen freundschaftlicher Beziehungen, der Wunsch nach gemeinschaftlicher Zugehörigkeit oder die Identifikation mit politischen Idealen, aber auch die Absicht der politischen Mitgestaltung oder der Wunsch nach beruflicher Protegierung.

Parteiübergreifend wird die Gruppe der Mitglieder, die mit ihrem Beitritt keinerlei innerparteiliche Aktivitätsziele verbinden, auf $50 \%$ geschätzt (vgl. Klein 2006: 56). Nach einer Studie der Konrad-AdenauerStiftung 1993 nehmen 15-20\% der Parteimitglieder an den Parteiversammlungen teil und übernehmen 5-10 \% Funktionen in der Partei oder Mandate, 25-30\% der Mitglieder gelten als gelegentlich mobilisierbar (vgl. Niclauß 2002: 211) ${ }^{30}$.

Die Bedeutung der gemeinschaftlichen Zugehörigkeit wird unterschiedlich beschrieben. Nach Heiko Biehl wandelt sich die SPD in den

30 Nach Elmar Wiesendahl nehmen 10-25\% der Gesamtmitgliedschaft am Parteileben aktiv teil (vgl. Wiesendahl 1997). Zeitgleiche Studien kommen zu geringeren Zahlen (vgl. dazu Niclauß 2002). 
196oer-Jahren zur Volkspartei und löst sich damit von ihren traditionellen Milieus ab, die sich selbst in Auflösung befinden (vgl. Biehl 2005: 68). Helga Grebing dagegen berichtet - wie auch Stefan Goch -, dass noch in den 1970er- und 1980er-Jahren die Glaub- und Vertrauenswürdigkeit eines Parteimitglieds eng gebunden war an seine Zugehörigkeit zum ArbeiterInnenmilieu oder an eine sozialdemokratische Familientradition; zudem konnte sich die Sozialdemokratie in diesen Zeiten auf eine stabil hohe Wahlunterstützung in den ArbeiterInnenvierteln verlassen (vgl. Goch 2007; Grebing 2007).

Die Partizipationsforschung analysiert, inwieweit die Sozialstruktur der Parteimitglieder die Gesellschaft repräsentiert. Aus ressourcentheoretischer Sicht werden demnach alle Parteien - auch die Sozialdemokratie von BürgerInnen dominiert, die über einen gewissen materiellen Wohlstand und kulturelles Kapital verfügen, oft gebunden an einen höheren Bildungsgrad und die damit verbundenen notwendigen kommunikativen und organisatorischen Fertigkeiten. Darüber hinaus verfügen sie über die für ein politisches Engagement notwendige flexible Zeit. Die Interessen ressourcenschwacher BürgerInnen sind dagegen in den Parteien eher unterpräsentiert. Die Allokationsfunktion der Parteien ist somit recht begrenzt und „die Aktiven bilden in ihrer Zusammensetzung nirgendwo, wo es Parteien gibt, ein Spiegelbild der Gesellschaft." (Wiesendahl 1997: 360) ${ }^{31}$.

\subsubsection{Die Mitgliederorganisation und die Parteiführung}

Die SPD-Partei ist in ihrer territorialen Struktur kaskadenförmig gegliedert und gleicht einer öffentlichen Verwaltung. In ihrer Organisationsstruktur spiegelt sich die föderative Struktur der Bundesrepublik. In den Führungsgremien der mächtigen Bezirke und Landesverbände ${ }^{32}$ sind häufig die MandatsträgerInnen aus den Landtagsfraktionen vertreten.

31 Nach § 1 Absatz 2 des Parteiengesetzes sollen Parteien "für eine ständige lebendige Verbindung zwischen dem Volk und den Staatsorganen sorgen."

32 Die Bezirke besitzen Personalhoheit, sie ernennen auch die GeschäftsführerInnen und Mitarbeitenden der Unterbezirke auf Vorschlag. Anzahl und Bezahlung ihrer Hauptamtlichen richtet sich nach den Mitgliedsbeiträgen, denn die Bezirke sind finanziell autonom. Sie führen lediglich $15 \%$ davon an die Parteizentrale ab. (vgl. www.spiegel.de/spiegel/print/d-41124964.html, Zugriff: 10.09.2011). Initiativen zur Effektivierung der Partei richteten sich häufig gegen die Vormachtstellung der Bezirks- und LandesfunktionärInnen, indem gefordert wird, die Personalverwaltung auf die Parteizentrale zu übertragen oder den Finanzausgleich zwischen den unterschiedlich großen Bezirken zu fördern. 
Der Einfluss dieser Organisationseinheiten in der Partei ist stark abhängig von ihrer regionalen Mitgliederzahl. Ausgehend von diesen Gremien herrscht ein „ausgeprägtes innerparteiliches Einflussgefälle“ (Wiesendahl 2006: 36) bis hinein in die Parteibasis.

Die Parteispitze besteht aus dem vom Bundesparteitag gewählten Parteivorstand, dem Parteirat, dessen Delegierte von Bezirken und Landesverbänden ${ }^{33}$ gewählt werden, und dem Präsidium, das der Parteivorstand als geschäftsführende Parteispitze bestimmt.

Im Parteirat haben VertreterInnen der SPD-Landtagsfraktionen und des Europaparlaments eine beratende Stimme.

Der Parteivorstand ist nach Peter Lösche ein aus verschiedenen regionalen Strukturen, Flügeln und Interessensgruppen zusammengesetztes und in seinem „politischen Gewicht untereinander austariertes“ Leitungsgremium. „Der Vorstand hält die auseinanderstrebenden Kräfte zusammen, er integriert die Partei, führt sie aber nicht" (Lösche 1991: $43)^{34}$.

Die SPD stellt sich in ihren verschiedenen Hierarchieebenen als Verbund aus Teileinheiten mit einem „ausgeprägten Eigenleben“ (Wiesendahl 2006: 36) dar. Sie lässt sich nicht von der Parteispitze entlang der Organisationskaskade kontrollieren, sondern die Parteispitze muss immer wieder für eine Unterstützung ihrer Politik werben und die Mehrheiten innerparteilich dafür sichern. Kennzeichnend für Parteien wie die SPD ist eine "Akteursvielfalt" (Wiesendahl 2002: 195). Mitgliedschaft, Parteiführung, WählerInnenschaft und StaatsakteurInnen bilden unterschiedliche „Erwartungsumwelten“, zwischen denen eine „Zielspannung" herrscht (vgl. a.a.O.; ähnlich bei Raschke/Tils 2007: 40). Für Elmar Wiesendahl existieren zwischen den innerparteilichen AkteurInnengruppen und ihren unterschiedlichen Zielpräferenzen damit nicht lösbare Konflikte. Ein struktureller Widerspruch besteht zwischen den Karriereinteressen der BerufspolitikerInnen und den Wünschen der Mitglieder nach einem deutlich erkennbaren Parteiprofil. Während sich die

33 In den 1980er-Jahren gliederte sich die SPD in 27 Bezirke und Landesverbände (Jahrbuch der SPD [1979-81]: 381f.): LV Schleswig-Holstein, Landesorganisation Hamburg, Landesorganisation Bremen, LV Niedersachsen, Bezirk Nord-Niedersachsen, Bezirk Weser-Ems, Bezirk Hannover, Bezirk Braunschweig, LV Nordrhein-Westfalen, Bezirk Ost-Westfalen-Lippe, Bezirk Westliches Westfalen, Bezirk Niederrhein, Bezirk Mittelrhein, LV Hessen, Bezirk Hessen-Nord, Bezirk Hessen-Süd, LV Baden-Württemberg, LV Bayern, Bezirk Franken, Bezirk Niederbayern-Oberpfalz, Bezirk Südbayern, LV Rheinland-Pfalz, Bezirk Rheinland/Hessen-Nassau, Bezirk Rheinhessen, Bezirk Pfalz, LV Saar, LV Berlin.

34 Nach Peter Lösche war die SPD bis zur Organisationsreform 1958 eine zentralistisch strukturierte Partei: „Die Organisationsentscheidung von 1958 stellte die Weichen für jene Entwicklung, die schließlich in die organisatorische Vielfalt, Heterogenität, Widersprüchlichkeit, Komplexität und Differenzierung mündete, die für die Sozialdemokratie als Volkspartei typisch ist." (Lösche 1993:139) 
Mitglieder mit einer Partei als Gesinnungsgemeinschaft identifizieren, präferiert die Parteiführung eine eher vage strategische Zielbestimmung. Sie lässt den public office holdern maximalen pragmatischen Gestaltungsspielraum (vgl. Wiesendahl 2002: 195f.). Damit befindet sich die Partei bei der Strategiefindung latent in einem Zustand der "Selbstblockade“, bei der sich Führung und Basis gegenseitig behindern (vgl. a.a.O.: 202f.).

\section{Die Parteibasis}

Die Bedeutung der Parteibasisorganisationen für die Allokation gesellschaftlicher Interessen wird in der Parteienforschung kritisch diskutiert (Alemann 1995; Beyme 2000; Biehl 2005; Krockow/Lösche 1986; Gabriel/Niedermayer/Stöss 2001; Niclauß 2002; Poguntke 2005a; Steininger 1984; Wiesendahl 1998,2002). Oft werden sie als besondere Einheiten beschrieben, die gegenüber dem hauptamtlichen politischen Geschäftsbetrieb der Partei eine Welt für sich bilden: „Was sich in dieser introvertierten, ingroup-betonten und vereinspatriotischen Welt alles abspielt, kreist in erster Linie um das emotionale und gesinnungsexpressive Wohlbefinden der Anwesenden." (Wiesendahl 1998: 239)35

Umgekehrt werden Orientierung und Handeln der Parteispitze von der eigenen Mitgliederbasis meist wenig berührt. Was in den unteren Organisationseinheiten an Impulsen und Ideen entwickelt wird, bleibt für die politische Praxis der Partei häufig zunächst folgenlos. Es fehlen „die horizontalen und auch vertikalen Verbindungslinien und Scharniere, um das, was alles an Ideen, Vorstellungen und Meinungen erzeugt und kommuniziert wird, den Parteispitzen übermitteln zu können.“ (a.a.O.) SpitzenpolitikerInnen pflegen ihre Verbindung zur Basisebene entlang persönlicher Kontakte und individueller Netzwerke (vgl. a.a.O.: 241).

Die Arbeit eines Ortsvereins wird in erster Linie durch lokale Themenschwerpunkte bestimmt. Bundespolitische oder weltpolitische Themen werden für interessierte Parteimitglieder in besonderen Bildungsveranstaltungen außerhalb des Politikbetriebs angeboten.

Zugleich ist die Arbeit eines Ortsvereins geprägt von eingespielten Interaktions- und Sitzungsritualen, die parlamentarische Gepflogenheiten und Geschäftsordnungspraktiken kopieren (vgl. Wiesendahl 1997:

„Dieser sozialintegrativ-expressive Organisationsbereich ist, aus der ökonomischen Nutzen- und Verwertungslogik betrachtet, nicht nur weitestgehend unwirtschaftlich und unnütz, sondern lässt sich in seinem Eigensinn und Selbstbezug auch nicht beliebig sozialtechnisch elektoralen Aufgabenzwecken unterordnen“ (Wiesendahl 1998: 239). 
362). Damit schützen die langjährigen Parteimitglieder ihre Deutungsmuster und Problembearbeitungen vor den Erwartungen und Einflussnahmen neu eingetretener Mitglieder.

Innerparteilichen Zusammenkünften beizuwohnen, heißt, in vertraute Situationskontexte mit hochgradig vorstrukturierten Handlungsabläufen und eingespielten kollektiven Handlungsmustern involviert zu werden, die für die Beteiligten über eine hohe Eintritts- und Wiederholungsgewißheit verfügen. (Wiesendahl 1998: 137)

Bereits in den untersten Parteieinheiten sind die Entscheidungsverfahren neben Statuten und Geschäftsordnungen geprägt von den informellen Kommunikationspraktiken der Vorsitzenden, Vorstandsmitglieder und Versammlungsleitenden. Sie können erhebliche Kommunikationsasymmetrien schaffen, um das Erwartungs- und Nutznießungsspektrum aus der Mitgliedschaft zu begrenzen und unerwünschte Begehren abzuweisen (vgl. a.a.O.: 140).

Viele Parteireformen der SPD zielen auf eine Öffnung der Partei, um die Mitarbeit besonders für Neumitglieder attraktiver zu machen, sowie darauf, die Basis durch vermehrte Angebote für eine intensivere Mitarbeit zu aktivieren. In den 1970er-Jahren wurden mit diesem Ziel die sog. Arbeitsgemeinschaften eingerichtet ${ }^{36}$. Diese Organisationsreform traf bei vielen aktiven Mitgliedern auf Abwehr, denn sie fürchteten, dass die Parteiführung mit dieser Maßnahme eigene politisch-strategische Entscheidungen mithilfe des weniger informierten Parteivolks und unter Umgehung der innerparteilichen Meinungsbildung durchsetzen wollte. Meist werden solche Maßnahmen demokratischer Inklusion und Aktivierung deshalb mit exkludierenden Auflagen verbunden, welche die ordentlichen Mitglieder und die innerparteilich-bürokratischen Prozesse privilegieren. Die Arbeitsgemeinschaften der 1970er-Jahre waren deshalb nur beratende Gremien und besaßen in der Partei nicht die Rechte einer Organisationseinheit.

36 Maßnahmen mit dieser Zielsetzung sind auch der Mitgliederentscheid zur Wahl des Parteivorsitzenden, der in den 1990er-Jahren eingeführt wurde, oder die Installation von Internetforen 2007 für die Diskussion des Hamburger Grundsatzprogramms im Vorfeld des Parteitages. 
Das höchste beschlussfassende Gremium ist der Bundesparteitag37. Dessen Delegierte werden über ein mehrstufiges Verfahren aus der Parteibasis gewählt. Einfluss auf den politischen Kurs der Partei nehmen die Mitglieder über Antragstellungen und die Auswahl der Delegierten. Durch dieses Repräsentationssystem wird der demokratische Willensbildungsprozess innerhalb der Partei geregelt, aber auch verzerrt, denn die Delegierten besitzen kein imperatives Mandat. Sie entscheiden ihr Abstimmungsverhalten nach individuellen Abwägungen, möglicherweise nach politischen Opportunitäten und persönlichen Karriereambitionen. Ein einzelnes Parteimitglied kann seine Gestaltungsmacht und seinen Einfluss in der Partei steigern, indem es durch den Ausbau seines persönlichen Netzwerks im Vorfeld von Debatten und Abstimmungen Mehrheiten für seine Anliegen erwirkt oder sichert ${ }^{38}$.

Anträge zu den Parteitagen enthalten Forderungen und Veränderungswünsche. Sie können in allen Organisationseinheiten der Partei verfasst werden, haben aber je nach Hierarchieebene unterschiedliche Bedeutung. Um einen Antrag für einen Bundesparteitag durch mehrere Gremien zu bringen, benötigen die AntragstellerInnen einen hohen Zeitaufwand für Vorbesprechungen, Netzwerkarbeiten und Diskussionen sowie das erhebliche Engagement der aktiven MitunterstützerInnen.

Auf dem Parteitag liegen die Anträge zunächst einer Antragskommission vor, die alle Einreichungen bearbeitet, zu Beschlussvorlagen zusammenfasst und mit Abstimmungsempfehlungen versieht. Diese Bearbeitungen mit dem Ziel der Reduktion der Anträge auf einen abstimmungsfähigen Umfang strukturieren aber auch die Kontroversen und dienen der Stabilisierung des politischen Kurses der Parteiführung (vgl. Steininger 1984).

Die Entscheidungen des Parteitags sind nur dem Grunde nach verbindlich. Faktisch ist ihre Wirksamkeit abhängig von der Durchsetzungsmacht der AntragsstellerInnen nach dem Parteitag. Sie müssen dafür sorgen, dass die Beschlüsse nach der Annahme durch die Parteiführungen oder die Organisationseinheiten in den politischen Konzepten und dem politischen Handeln der Partei umgesetzt werden. Eine Orga-

37 Seit 2012 finden zusätzlich zu den großen Parteitagen mit rund 6oo Delegierten Parteikonvente als sog. kleine Parteitage mit rund 200 Delegierten statt.

38 „Bekannt ist, daß der auf dem repräsentativ-demokratischen Delegationsprinzip fußende und mehrfach abgestufte Prozeß innerparteilicher Willensbildung Kungeleien, Kartellbildungen und oligarchische Verkrustungen fördert." (Wiesendahl 1997: 360) 
nisationseinheit, die einen Parteibeschluss ignoriert, hat auch bei hartnäckigem Boykott nur in Ausnahmefällen Reglementierungen oder gar Sanktionen zu befürchten.

Diese relative Verbindlichkeit betrifft Leitanträge des Parteivorstands ebenso wie Änderungen oder Neuformulierungen des Grundsatzprogramms. Das Grundsatzprogramm gilt als Basis der politischen Identität der Partei. Meist wird es in einem mehrjährigen Prozess von einer von der Parteispitze ausgewählten Programmkommission erarbeitet, begleitet von einem Diskussionsprozess in der Partei und vielen Änderungsanträgen und Neuformulierungen. Es bietet für die Programme der folgenden Wahlkämpfe nur die Textvorlage. Welche Textsegmente in den Wahlprogrammen zum Tragen kommen, wird innerparteilich durch gesonderte Wahlparteitage entschieden ${ }^{39}$.

Die Parteitage werden bestimmt von den Parteivorständen. Diese wählen die Tagungsleitung aus und legen die Inszenierung der Parteitage, die Auftritte der Führungsspitze und GastrednerInnen sowie die Reihenfolge der Debatten fest. Die Parteitage, besonders die Bundesparteitage, bieten vor allem der Parteiprominenz eine mediale Bühne, denn die Parteitage von regierungsbeteiligten Parteien werden von einem hohen Medieninteresse begleitet. Die anwesende Presse übt einen zusätzlichen Konformitätsdruck auf die Delegiertenversammlung aus und diszipliniert die kritischen und unzufriedenen Delegierten (vgl. Wiesendahl 2006).

\section{Der Einfluss der Basis auf den Politikwechsel der Partei}

Die Frage, welchen Einfluss die Parteimitglieder auf den Wandel der Politik ihrer Führung haben, steht im Mittelpunkt der Parteienforschung. Rudolf Steininger sieht die Begrenztheit der Partizipation als ein „Strukturdilemma" der Parteien ${ }^{40}$, in Anlehnung an Robert Michels' These von der „Inkompatibilität von innerorganisatorischer Partizipation und Or-

39 Die zeitlich limitierten Programmparteitage dienen vorrangig der Akklamation des Programmtextes. Elmar Wiesendahl bezeichnet sie deshalb als „Gipfel demoautoritärer Entscheidungsbildung“ (Wiesendahl 2006: 37).

40 Rudolf Steininger sieht Parteien in Anlehnung an Max Weber als rational handelnde Organisationen, die auf den Erwerb von Herrschaftspositionen zielen und ihre Mittel dazu nach Effektivitätskriterien wählen (vgl. Steininger 1984). Sie sind jedoch gekennzeichnet durch einen Widerspruch zwischen den Partizipationsansprüchen der party on the ground und dem Alltagshandeln der party in public and central office. Diese Bezeichnungen unterschiedlicher Organisationswirklichkeiten gehen zurück auf Richard E. Katz und Peter Mair (vgl. Katz/Mair 1993; Wiesendahl 2006). 
ganisationseffizienz" (vgl. Steininger 1984: 122). Eine systematische Willensbildung von unten nach oben wird danach durch die FunktionärInnenschicht aus AnführerInnen von Parteiflügeln, Untergliederungen und internen Fraktionierungen blockiert (vgl. Steininger 1984: 11of.).

Dagegen sieht der Parteienforscher Uwe Jun die gestaltende Macht der Parteibasis weitgehend aufgehoben. Bereits in den 1980er-Jahren entwickelte sich, so Uwe Jun, die „professionelle Medienkommunikationspartei“. In ihr haben die FunktionsträgerInnen ihr Kommunikationsmanagement so weit perfektioniert, dass von einer „Medialisierung der Parteien" gesprochen werden kann. Der öffentlichen Präsentation der leitenden Mitglieder ist die Mitwirkung der anderen Parteieinheiten stets untergeordnet ${ }^{41}$.

Auch in den Großparteien, die am Modell der Mitgliederpartei festhalten, sind die Mitglieder zwar als BeitragszahlerInnen und WahlkampfhelferInnen ${ }^{42}$ willkommen, aber als InformationsvermittlerInnen für gesellschaftspolitische Themen und Meinungen sind sie nach Uwe Jun nicht mehr interessant (vgl. a.a.O.: 249). Dazu beauftragen Parteivorstände Meinungsforschungsinstitute. Diese Medialisierung der Parteien verstärkt die politische Handlungsmacht der Parteiführung. Sie nutzt ihren exklusiven Medienzugang und ihren Informationsvorsprung gegenüber der Parteiorganisation dazu, Darstellung und Interpretation gesellschaftspolitischer Themen, Aktivitäten, Initiativen via medialer Stellungnahme und Inszenierung im Vorfeld der innerparteilichen Willens- und Entscheidungsfindung „ihren Stempel aufzudrücken“ (vgl. a.a.O.: 250) Der Wandel einer Partei wird nach Uwe Jun deshalb eher durch äußere Einflüsse veranlasst.

Dagegen betont Elmar Wiesendahl, dass zwar externe Geschehen als wichtigste Katalysatoren für Parteienwandel gelten können, Veränderungen in der Umwelt der Parteien werden aber nur aufgenommen, wenn sie durch innerparteiliche Gruppierungen in die Partei getragen werden. Dabei kann, so Elmar Wiesendahl, ein Politikwechsel in einzelnen Organisationseinheiten der Partei gelebt werden, während er in anderen abgelehnt und blockiert wird. Einschneidende Politikwechsel wer-

41 „Die Partei als Gesamtorganisation ist gehalten, diese Personen und das strategische Zentrum der Partei nicht zu delegitimieren, um ihre Erfolgschancen im Parteienwettbewerb nicht zu gefährden“ (Jun 2009: 253) Nach Elmar Wiesendahl lockert sich die Bindung der sozialdemokratischen Partei zu ihren Mitgliedern erst ab den 199oer-Jahren immer stärker. Die Mitglieder werden dann von der Parteiführung als retardierend und wandlungshemmend angesehen. Seit ihrem Parteieintritt in den 1970er-Jahren vertreten diese Mitglieder wohlfahrtsstaatliche Politikkonzepte, die aber die Parteiführung als historisch überholt ansehe (vgl. Wiesendahl 2006).

42 Darüber hinaus bilden Mitglieder auch den Pool für die Rekrutierung von KandidatInnen für öffentliche Ämter und stellen häufig die Ressourcen für das politische Personal. 
den für die Gesamtorganisation eher aus den Stabsbereichen der Parteiführungen eingeleitet. Keineswegs seien immer die Parteiführungen das beharrend stabilisierende Element und die Parteibasis das innovative Element. Im Gegenteil:

Es bedarf externer Anstöße und krisenhafter Zuspitzungen der Organisationslage, ehe die Mitgliedschaft solch starker Verunsicherung ausgesetzt ist, daß sie unter Anleitung von ,change agents' und strategischer Akteure als Impulsgeber in der Überwindung hergebrachter Gewißheiten und Anschauungen endet. (Wiesendahl 1998: 130)

\subsubsection{Das Führungspersonal und seine Rekrutierung}

Die politischen Parteien sollen die Verbindung zwischen WählerInnenschaft und staatlichen Institutionen ermöglichen und gewährleisten. Im Zuge der wachsenden Bedeutung der Massenmedien werden die politischen Profile der Parteien zunehmend personifiziert und sind nun eng an ihr jeweiliges Führungspersonal gebunden (Uwe Jun 2009)

Für die unterschiedlichen Parteitypen sind die Rekrutierungsverfahren der politischen RepräsentantInnen ein wichtiger Indikator und ein Verweis auf die innere Verfasstheit einer Partei. Der Gestaltungsspielraum für den innerparteilichen Willensbildungsprozess und die Chancen auf politische Kurskorrekturen sind mit den Führungspersonen verbunden. Satzungsgemäß bestimmt der Bundesparteitag die Parteileitungen. Allerdings gelangen in den Kreis dieser KandidatInnen nur Personen, denen besondere Fähigkeiten zugeschrieben werden. Diese KandidatInnen sind meist langjährige Parteimitglieder mit entsprechenden politischen oder beruflichen Karrieren, besitzen bereits mediale Präsenz oder verfügen über persönliche Beziehungen zu der etablierten Vorstandsprominenz. Häufig finden sich in den Parteiführungen Personen, die bereits Führungspositionen in politisch nahestehenden Verbänden besetzt haben. Gewählt werden sie auf den Parteitagen von Delegierten, von denen viele Ämter oder Parteifunktionen innehaben, also Personen, die durch ihr politisches oder ehrenamtliches Engagement eher konform zur Führungsspitze stehen. Überwiegend teilen sie die politische Pragmatik der Parteiführung und richten ihre Personalentscheidung nach der vermuteten medialen Wirkung der KandidatInnen und deren zukünftig möglichem Wahlerfolg aus.

Die Wiederwahl ist unbegrenzt oft möglich. Amts- und FunktionsträgerInnen sind häufig bemüht, ihre Posten zu halten, und nutzen dafür 
informelle Netzwerke. Die dabei aufgebauten Bindungen und die gewährten oder in Aussicht gestellten Vorteilnahmen ${ }^{43}$ dienen dazu, die eigene Wiederwahl abzusichern. Auf allen Organisationsebenen lassen sich sog. Erbhöfe finden ${ }^{44}$. Diese AltfunktionärInnen, deren Anrecht auf Funktion oder Amt nicht zur Entscheidung gestellt wird, wirken meist als Verharrungselement gegen den Wandel der Partei. Die aufwendigen bürokratischen Verfahren der innerparteilichen Entscheidungsfindung schützen sie vor politisch ambitionierten Neumitgliedern.

Auf den Führungsebenen der Partei hat sich eine Koppelung von AmtsträgerInnen und ParteifunktionärInnen entwickelt. ${ }^{45}$ Klaus Detterbeck sieht darin eine „Föderalisierung“ der Parteien (vgl. Detterbeck 2002). Die Parteispitze, Vorstand und Präsidium, übernimmt die Koordinierung zwischen den BundesparlamentarierInnen, den MinisterpräsidentInnen und den regionalen Parteivorsitzenden. Sie richtet die Partei auf Wahlkämpfe aus, von denen im Jahr bundesweit durchschnittlich 3-4 stattfinden ${ }^{46}$. Die politische Öffentlichkeitsarbeit ist damit zur Sache der Parteizentrale und der ihr zuarbeitenden Werbeagenturen geworden. An ihren Konzepten und Marketingvorstellungen haben sich alle Organisationsgliederungen bis auf die lokale Ebene hin zu orientieren. Die KandidatInnenlisten, insbesondere die Aufstellungen für die attraktiven Landtags- und Bundestagsposten, werden dem Parteivorstand vorgelegt. Die Parteiführung stellt nach Klaus Detterbeck zwar keine GegenkandidatInnen gegen den Widerstand der Parteibasis auf, aber sie nimmt häufig Einfluss auf diese Listenaufstellung, was immer wieder zu - in manchen Fällen öffentlich ausgetragenen - Konflikten führt. Zum einen schlägt die Parteiführung ihre AnwärterInnen nur für die „sicheren" Wahlkreise vor, zum anderen stechen diese KandidatInnen meist die örtlichen BewerberInnen aus, denn die entscheidenden Parteigremien versprechen sich von medial bekannten PolitikerInnen bessere Wahlergebnisse und mehr Resonanz im Wahlkampf sowie - besonders

43 Vorteilsnahmen können unterschiedliche Formen annehmen: die Unterstützung von politischen Anliegen, Empfehlungen bei beruflichen Zugängen, die Weitergabe von Netzwerkkontakten usw.

44 Bereits Willy Brandt schildert dieses Selbstrekrutierungssystem: „Ich habe in der SPD folgendes System geerbt bei der Aufstellung der Kandidaten für den Parteivorstand. Vor einem Parteitag tritt der Vorstand zusammen und der Vorsitzende fragt, ist hier jemand verstorben oder ist sonst etwas Gravierendes gegen ihn vorzubringen. Sofern diese Frage nicht mit Ja beantwortet wird, erscheinen alle wieder auf der Liste“ (Willy Brandt auf der Bundeskonferenz der ASF in Erlangen 1979: SPD PV-9923, D: 17).

45 Bis in die 1950er-Jahre war die Verzahnung von Parteiämtern und politischem Mandat nicht zulässig, um die Unabhängigkeit der Partei zu gewährleisten (vgl. Boyer/Kössler 2005: 68).

46 Vgl. W4. Landtagswahlen 1964-199o. Ergebnisse SPD mit Frauenanteil an den Abgeordneten unter DOI 10.3224/86388794A. 
auch für die Zeiten nach der Wahl - attraktivere Netzwerkverbindungen zur Parteispitze (vgl. Detterbeck 2002: 85).

Die wachsende Einflussnahme der BerufspolitikerInnen in den Parteien führt nach Klaus Detterbeck jedoch nicht zu einer Distanz der MandatsträgerInnen von der Partei, wie es der Oligarchiethese von Robert Michels entspräche; stattdessen sind die Führungsmitglieder eher an einer Anpassung der Interessen und Kooperation der verschiedenen politischen Gruppierungen in der Partei orientiert: „Das parlamentarische Spitzenpersonal nutzt seine Privilegien weniger zur Umgehung denn zur Beherrschung der innerparteilichen Prozesse." (a.a.O.: 119) Das politische Handlungsfeld der SpitzenpoltikerInnen hat sich jedoch von dem Parteileben immer weiter entfernt. Die höheren Anforderungen an fachliche Spezialisierung und Professionalisierung der ParteivertreterInnen haben nicht nur zu einer Ausweitung der MitarbeiterInnenstäbe und einem differenzierteren, an den Ministerien orientierten Ausschusswesen geführt, sondern auch zu einer sukzessiven Erhöhung der Aufwandsentschädigungen, Diäten und Zusatzleistungen, die das Mandat zu einem begehrenswerten Job haben werden lassen. ${ }^{47}$

Nach Elmar Wiesendahl sind die Parteien und deren Zentralen überwiegend staatsfinanziert. Seit der 1967 eingeführten Wahlkampfkostenerstattung nimmt die Subventionierung der Parteien stetig zu. Trotz mehrerer Regulierungen der staatlichen Zuwendungen ist „die Unterhaltszahlung für das ,Party Central Office' in öffentliche Zuständigkeit übergegangen" (Wiesendahl 2006: 51). Die Parteien haben sich tendenziell zu einem professionalisierten Politikbetrieb entwickelt, einem Teil des staatlichen Machtapparates, der von Mitgliederbeiträgen und der Parteibasis unabhängig besteht (vgl. Beyme 2004: 147f.).

Die ASF-Aktivistinnen wurden bei ihrem Kampf für eine Veränderung der sozialdemokratischen Frauenpolitik in der Partei mit verschiedenen Organisationswirklichkeiten konfrontiert. Einerseits boten ihnen die demokratischen Strukturen der Partei Mitwirkungsmöglichkeiten an, die allerdings komplizierte Verfahrensregeln vorschrieben, andererseits trafen sie auf Machtstrukturen, in denen formelle Zuständigkeiten eng mit informellen Netzwerken verbunden waren.

Strukturen und Mechanismen solcher Prozesse der Integration und Abgrenzung sind Forschungsfelder der Organisationssoziologie. Ihre Forschungsergebnisse und Diskurse dazu werden im nächsten Kapitel vorgestellt.

47 Die durchschnittliche Verbleibdauer im Parlament stieg von der 3. Legislaturperiode (1957-1961) von 5,7 Jahren bis zur 11. Legislaturperiode (1987-1990) auf 8,1 Jahre (vgl. Detterbeck 2002: 330). 


\subsection{Geschlechtermacht und Organisation}

Ein Fundament der parteiinternen Frauenopposition war die Kritik an der tief verankerten Geschlechtermacht in den Parteistrukturen und prozessen. Alle Vorgänge der Interessensallokation in den Parteien werden nach festen geschlechterneutralen Regelsystemen gestaltet. Aufnahme und Auswahl der KandidatInnen und damit auch die Zugänge zur Mitgestaltung sind für jedes Mitglied gleichberechtigt definiert. Sie sind in den Statuten der Partei niedergelegt und ebenso verbindlich wie die arbeitsteiligen Zuständigkeiten und die Präsentations- und Partizipationsrechte der einzelnen Organisationseinheiten im hierarchisch strukturierten Gesamtverband. Im Alltag der Partei aber, in der Umsetzung formalisierter Verfahren etwa zu KandidatInnenaufstellungen und bei Abstimmungsprozessen, bestimmen informelle Netzwerke und Organisationskulturen die Entscheidungspraktiken. Die damit verbundenen Machtstrukturen werden in den Interaktionen zwischen den OrganisationsakteurInnen sowie im Austausch der Parteieinheiten mit der externen Umwelt reproduziert und stabilisiert. Wie Geschlechtermacht in Organisationen eingelassen und wirksam ist, wird in der feministischen Organisationsforschung diskutiert. Ihre Ergebnisse lassen sich für die Analyse des patriarchalen Organisationsgeschehen in der Großpartei nutzbar machen.

\subsubsection{Die Geschlechtlichkeit von Organisationen}

Feministische Organisationsforscherinnen untersuchen Organisationen als „zentrale Orte der Herstellung von sozialer Ungleichheit“ (vgl. Wilz 2004b: 443), die sich durch Ausgrenzung und durch Machtzuweisung reproduzieren. Wie veränderungsfähig Organisationen sind und wie ablösbar ihre Strukturen von Geschlechtermacht, wird in der feministischen Organisationsforschung kontrovers diskutiert. Nach strukturtheoretischen Ansätzen ist Geschlecht eine Strukturkategorie von Macht und Rationalisierungssystemen, nach handlungstheoretischen Analysen werden Geschlechterverhältnisse in Aushandlungsprozessen immer wieder reaktualisiert und sind damit prinzipiell veränderbar. Andere Ansätze gehen von einem kontextualisierten Zusammenhang zwischen Geschlecht und Organisation aus (vgl. Wilz 2002; auch Heintz/Nadai 1998).

Verschiedene feministische Studien kombinieren diese Ansätze. Sie decken die strukturbildende Bedeutung geschlechtsspezifischer Arbeits- 
zuweisungen und Machtverhältnisse in Organisationen auf und dekonstruieren die „Normalität“ der männlichen Hegemonie ${ }^{48}$. Nach Joan Acker ist männliche Dominanz u.a. dadurch erkennbar, dass „nur das Maskuline präsent" (Joan Acker zit. n. Müller 1993: 107) ist. Organisationshandeln ist aus dieser Perspektive mit dem geschlechterhierarchischen gesellschaftlichen Umfeld der Organisation verbunden. Damit richtet es sich an Werten, Normen, Wissensbeständen und Leitbildern aus, in denen Geschlechterverhältnisse symbolisch präsent sind. In ihrer Wahrnehmung und Deutung sowie in ihren Handlungen reproduzieren und legitimieren die Organisationsmitglieder die Geschlechterhierarchien.

"Geschlechtsspezifische Subtexte“ (vgl. Wilz 2002) lassen sich nach Ursula Müller in formalen Handlungsanforderungen und in informellen Regeln auffinden, aber auch in der Kommunikation zwischen den Geschlechtern und in der Weise, wie das Geschlechterverhältnis im Organisationsgefüge legitimiert wird (vgl. Müller 1993). Gängige naturalisierende Geschlechterstereotypisierungen begründen die organisationsspezifische soziale Ungleichverteilung sowohl in den Zuweisungsprinzipien als auch bei der faktischen Verteilung von Chancen. Geschlechtsspezifische Zuweisungen sind somit in die Organisationen eingewoben. Sie betreffen Personalentscheidungen, die Verteilung der Arbeit und die Erwartungen an die Verfügbarkeit der Organisationsmitglieder sowie die Diskurse, Regeln und Verfahren ${ }^{49}$ (vgl. Kathy Ferguson dargestellt in Wilz 2004b; Riegraf 1996: 52).

Mit der zunehmenden Institutionalisierung frauenpolitischer Akteurinnen in der zweiten Hälfte der 1980er-Jahre entwickelt sich der organisationssoziologische Diskurs in eine andere Richtung (vgl. Riegraf 1996). Organisationskonzepte, die Geschlechterhierarchie als tragendes Strukturmerkmal werten, kommen durch die zunehmende Präsenz von Frauen im Bildungssystem sowie in Organisationshierarchien und männlichen Berufsfeldern in eine theoretische Defensive. Die Übereinsetzung von vermachteten Organisationsstrukturen und Geschlechterdiskriminierung wird abgelöst von Forschungsperspektiven, die Geschlechterdifferenz und Organisationshierarchie in ihrer Wechselwirkung untersuchen. Beide werden nun als „gleichursprünglich“ (Wetterer 1995: 228) konzipiert und in ihrer konkreten Verflechtung untersucht. Geschlecht verändert sich damit organisationstheoretisch von einer

48 Zusammenfassung vgl. Riegraf 1996: 42-57.

49 Damit sind nach Kathy Ferguson „rationale“ Organisationen grundsätzlich patriarchal geformt. Sie kritisiert damit Kanters Position, nach der die Frauendiskriminierung ein Problem des Minderheitenstatus ist. 
Strukturkategorie, d.h. einem „Platzanweiser“ (Müller 1993: 100), zu einer Prozesskategorie (vgl. Kuhlmann/Kutzner/Müller/riegraf/Wilz 2002: 244f.).

Organisationshierarchien und Geschlecht sind nach Silvia Wilz als „kontingent gekoppelt“ zu analysieren (vgl. Wilz 2002: 275). Geschlechterdifferenz ist demzufolge in Organisationen als ein „latent verfügbares Angebot zur Konstruktion von Hierarchien und ungleichen Chancen" zu untersuchen (vgl. Kuhlmann/Kutzner/Müller/Riegraf/Wilz 2002). Im organisationssoziologischen Diskurs wurde die Kategorie Geschlecht damit tendenziell „dezentriert“ (Wilz 2004: 4). Auch nach Christiane Funken muss „eingeräumt werden, dass Geschlechtsdifferenzen in Organisationen je nach Kontext in den Vordergrund oder in den Hintergrund treten können." (Funken 2004: 25).

Damit bestimmten zwei differente Konzipierungen von Geschlechtermacht den feministischen Organisationsdiskurs: Eine Forschungsperspektive analysierte Organisationshierarchien und männliche Herrschaft als miteinander eng verzahnt ${ }^{50}$, die andere konzipierte Organisationen eher als Arenen, in denen Strukturen als Ergebnisse von Aushandlungsprozessen verstanden werden, auch wenn die Verhandlungspositionen dabei unterschiedlich gestaltungsmächtig sind. (vgl. Wetterer 1995, 2004, 2013; Wilz 2004b, 2013; Riegraf 1996; Müller 1993). In diesem Szenario sind Frauen in Organisationen nicht länger Opfer struktureller Geschlechterhierarchien, sondern werden zu potentiellen Agentinnen eines Organisationswandels (vgl. Müller 1993). Über die Maßgabe Geschlechtergerechtigkeit hinaus können sie via einer Aufwertung weiblich konnotierter Fähigkeiten kulturelle Reformerinnen werden, die die Dominanz der als machistisch kritisierten Konkurrenz- und Hierarchieorientierung auflösen und eine kommunikativere Kultur gegenseitiger Unterstützung und demokratischer Umgangsformen fördern (vgl. Ferguson nach Riegraf 1996: 51ff. $)^{51}$.

50 Dazu zählen Susanne Schunter-Kleemann, Silvia Kontos, Tove Soiland, Nancy Fraser und viele andere Kritikerinnen der Gender-Mainstreaming-Politik.

51 Die Doing-Gender-Politiken der 1990er-Jahre basieren auf diesen Organisationskonzepten. Sie zielen auf die Veränderung kultureller Praktiken, handlungsorientierter Zuweisungen in Organisationen und deren Variabilität $a b$, während die verfestigten Organisationsstrukturen als weniger bedeutend bewertet werden (vgl. Gottschall in Geissler/Maier/Pfau-Effinger 1998). Die institutionelle Frauenpolitik steuerte um auf ein Undoing Gender und entwickelte mithilfe öffentlicher Fördermittel ein florierendes Marktsegment der Organisationsberatung. Eine kritische Analyse des Erfolgs dieser Genderpolitik ist Gegenstand aktueller Diskurse (vgl. Schunter-Kleemann 2001, 2002, 2006; Fraser 2005, 2009; Müller/Riegraf/Wilz 2013). 


\subsubsection{Die Geschlechtlichkeit als Ausschließung}

Spezifikum der Organisation als soziales System ist nach Niklas Luhmann die Geschlossenheit, die Formierung und die Abschließung ihrer Mitglieder in der gesellschaftlichen Gesamtheit (vgl. Darstellung in Martens/Ortmann 2006: 430f.) ${ }^{52}$.

Auch in der handlungstheoretischen feministischen Organisationssoziologie spielt die Schließung eine zentrale Rolle (vgl. Mackert 2004). Vier geschlechtersoziologische Konzepte von Schließungsprozessen und -wirkungen in Organisationen werden im Folgenden vorgestellt. Mit ihnen wurden die ZeitzeugInnenberichte sowie die Beschreibungen der Ausgrenzungserfahrungen von Frauen in der Politik und Partei analysiert.

\subsubsection{Ausgrenzung als strukturfunktionale Ausschließung}

Der Ausschluss der Frauen aus der Erwerbsarbeit ist nach Ursula Müller eng verbunden mit der Entsexualisierung der Arbeit. Unter Rückgriff auf Michel Foucaults Studien zur Sexualität bestimmt sie die kapitalistische Erwerbsarbeit als „desexualisiert“ (vgl. Müller 1993). In Großorganisationen, Armeen und Klöstern wurden die Frauen ausgeschlossen, um die Sexualität aus diesen Bereichen zu verbannen. Die Entsexualisierung des männlichen Arbeitsvermögens schafft das ideale Organisationsmitglied, auf das die Organisation ihre Verfügungsansprüche abgestimmt hat. „Die Normalarbeitskraft (der Homunculus der ,realwirtschaftlichen“ Wertschöpfung) ist die von familiärer Verantwortung befreite, dauerhaft beschäftigt und umfassend eingebundene Arbeitskraft" (Beck-Gernsheim zit. n. Wilz 2002: 50). Mit der Verbannung sexueller Aktivitäten aus der Sphäre der Arbeit ging, so Ursula Müller, der Ausschluss der Frauen einher. Die „Entkörperung der Arbeitskraft“ ist Grundlage und Legitimation für die Ausschließung. Frauen als Gebärende erscheinen nun als sexuelle Wesen, die mit der Neutralität der Organisation nicht kompatibel sind. Die „Sexualisierung der Frauen“ wird zum Mittel der Dominanzsicherung der Männer und findet sich in organisationalen Strukturen und

52 Max Weber unterscheidet zwischen offenen sozialen Beziehungen, an denen alle teilnehmen können, die sich an die Ordnung der Beziehung halten, und geschlossenen sozialen Beziehungen, deren Ziel es ist, Anderen außerhalb der eigenen Gemeinschaft den Zugang zu Ressourcen und Lebenschancen zu verwehren (vgl. Weber 2006: §10). Allerdings hat er den Schließungsbegriff nicht als systematische Kategorie entwickelt, die Schließungsmerkmale sind somit beliebig (vgl. Mackert 2004; Wilz 2004). 
Prozessen wieder ${ }^{53}$. Die Marginalisierung von Frauen erscheint in der Folge als Ergebnis geschlechterneutraler, sachlicher Entscheidungen (vgl. Müller 200o). Im Erwerbsbereich führt dies zu der paradoxen Situation, „daß Frauen immer in der Sphäre der Lohnarbeit anwesend waren, zugleich jedoch von vornherein als nicht am richtigen Platz befindlich wahrgenommen“" (Müller 1993: 104) wurden.

Mittlerweile wird diese starre Genderkonzeptionierung von Organisationen in der feministischen Organisationssoziologie überwiegend abgelehnt (vgl. Wilz 2002, 2004a, 2004d; Müller 2000). In vielen Großunternehmen und Verwaltungen haben Gleichstellungspolitiken erreicht, dass Organisationsprozesse und -verfahren, insbesondere bei der Personalrekrutierung, -auswahl und -förderung, verändert worden sind.

\subsubsection{Ausgrenzung als Folge hegemonialer Männlichkeit}

In Organisationen prägt eine Kultur der Zweigeschlechtlichkeit die Zuschreibungen, das Verhalten und die Wahrnehmung der Mitglieder. Die Unterscheidung zwischen Weiblichkeit und Männlichkeit wird aber nicht als gleichgewichtige Differenzierung, sondern nach dem Muster der Abweichung vorgenommen. Die Schablonen dafür sind Männlichkeitsideale. Der Grad der Integration von Frauen in die Organisationen lässt sich somit am Maß zugelassener weiblicher Abweichungen beschreiben (vgl. Müller 200o).

Die Organisationskultur stellt sich als eine Reproduktion gesellschaftlicher Geschlechterordnung dar. Weibliche Erwerbstätigkeit wird als Zuverdienst konzipiert, für die ein begrenztes berufliches Tätigkeitsfeld mit flexiblen Teilzeitbeschäftigungen und geringeren Verdienstmöglichkeiten angeboten wird. Machtvolle Positionen in Wirtschaft und Politik sind dagegen an ein männliches Erwerbstätigkeitsprofil gebunden. Für sie wird die personelle Verfügbarkeit in einer Kontinuität erwartet, die nur von Personen aufgebracht werden kann, denen die Organisation ihres privaten Lebens, die Haus- und Familienarbeiten, von anderen abgenommen werden. Deshalb sind die Rekrutierungsprozesse auf männliche Positionsanwärter ausgerichtet.

Raewyn Connell erklärt den privilegierten Zugang für Männer zu Machtressourcen in Organisationen mit dem Konzept der „hegemonialen Männlichkeit“. Männliche Dominanz in Organisationen geschieht

53 Beispiele: die Schaffung geschlechtersegregierter Arbeitsplätze, die unterschiedliche Bewertung und Tarifierung der Arbeitsleistungen bei den männlich und weiblich besetzten Berufen, die Bindung von höher positionierten Arbeitsaufgaben an männlich konnotierte Eigenschaften usw. (vgl. dazu Riegraf 1996, 1997; Kuhlmann 2002). 
außerhalb von organisationsspezifischen Rationalitätsparadigmen und funktionalistischen Erklärungsmustern ${ }^{54}$.

Die dominierende masculinity in einer Organisation beruht auf je spezifischen sozialen Konstruktionen von Männlichkeit (vgl. Connell 2006). Macht in Organisationen ist mit konkreten männlichen Dominanzmustern verbunden. Dominante Männlichkeit formt nicht nur die Hierarchien in den Organisationen, sondern bestimmt auch die mit der jeweiligen Organisation verbundenen informellen Netzwerke und Subkulturen. Sie bilden sich als frauenfreie Aushandlungs- und Entscheidungsräume, wie die Männertoilette, der Sporttreff, das sog. ,Bierchentrinken' nach Feierabend. Mit ihnen werden kulturelle Welten geschaffen, in denen Codes und Wettbewerbsregeln gelten, in die Frauen nicht hineinpassen und die sie nicht erfüllen können ${ }^{55}$. Auf diese Weise verfestigen sich männliche Kulturen in den Entwicklungsprozessen von Organisationen, in denen Frauen weder als vertrauenswürdig noch als leistungsfähig gelten (vgl. Meuser 2006; Krell 2004).

Neu entstehende Berufsfelder werden direkt für spezifische Geschlechter entworfen. In einer Studie aus den 1980er-Jahren zur Technologisierung beschreibt Cynthia Cockburn Umstrukturierungsprozesse in verschiedenen Arbeitswelten. Sie zeigt, dass die neuen Tätigkeitsfelder und Qualifikationsanforderungen schon mit ihrer Implementierung so konstruiert werden, dass sie geschlechterhierarchisch besetzt werden können (vgl. Cockburn 1988)56. Silvia Wilz beschreibt die Rekrutierungsverfahren für die Besetzung verantwortungsvollerer und besser bezahlter Positionen. Sie werden so ausgeschrieben, dass für die Auswahl der BewerberInnen männlich konnotierte Eigenschaften als die wichtigsten Qualifikationsmerkmale gelten (vgl. Wilz 2002: 67). Wechseln dagegen in den Berufsfeldern die Geschlechterverhältnisse zugunsten der Frauen, führt dies, so Angelika Wetterer, zu einem Statusverlust und einer Entwertung der Arbeiten (vgl. Wetterer 1995: 132)57

54 Sie betrifft alle Organisationsmitglieder und richtet „die männliche Unterdrückung auch gegen das eigene Geschlecht, gegen die eigene Person wie gegen andere Männer. Handlungen, welche die Macht des männlichen Geschlechts stärken, können für den Einzelnen schädliche bis tödliche Folgen haben." (Meuser 2006: 98)

55 So spielt auch in den organisationalen Alltagskommunikationen das „Verfügen über den sexuellen Diskurs“ eine große Rolle, „was bei einem Mann lustig ist, gilt bei einer Frau schnell als obszön." (Müller 1993: 111)

56 Aus strukturationstheoretischer Perspektive sind diese geschlechtsspezifischen Segregationen allerdings sowohl Voraussetzung als auch Ergebnis asymmetrischer betrieblicher Aushandlungsprozesse (vgl. Wilz 2002: 58).

57 Dieses Phänomen kann nach Margaret Maruani allerdings in neueren Studien nicht mehr beobachtet werden (vgl. Maruani 2010). 
Die in Organisationen institutionalisierten Männlichkeiten sind aber krisenanfällig und veränderbar. Die kulturellen Grundmuster der Männlichkeitskonstruktionen verändern sich oder sie verlieren an Bedeutung wie z.B. die essentialistischen Geschlechterdualismen, in denen männliche Aggressivität, Entschlussfähigkeit und Aktivität denen weiblicher Passivität und Kommunikationsfähigkeit sowie weiblichen Einfühlungsvermögens gegenüber gestellt sind. Gesellschaftliche Konzepte der Geschlechterordnung zerfallen: der Bedeutungsverlust von zwangsheterosexuellen Regeln, die Ablösung des Ein-Ernährer-Familienmodells in den Sozialsystemen, die Aufhebung von geschlechtsspezifischen Berufsverboten (vgl. Heintz/Nadai 1998). Dies führt zu einer Delegitimierung männlicher Dominanz in der Organisation und zur Sanktionierung entsprechender sozialer Praktiken wie z.B. der sexuellen Belästigung am Arbeitsplatz (vgl. Connell 2006: 92ff.)

\subsubsection{Ausgrenzung durch Tokenism}

Eine der ersten Theoretikerinnen struktureller Diskriminierung in Organisationen ist Rosabeth Moss Kanter. Nach ihrer Forschung werden Frauen, die in Organisationen nur eine Minderheit sind - wie auch andere minderheitlich vertretene Gruppen - als token wahrgenommen, „as representatives of their category, as symbols rather than individuals" (Kanter 1977: 996). Personenunabhängig wird jede Einzelne mit stereotypen Weiblichkeitszuschreibungen, sozialer Isolation und Leistungsdruck belegt, mit denen sie sich auseinandersetzen muss. Die mehrheitlich vertretenen Männer aber nehmen sich gegenseitig als Individuen mit ihren je unterschiedlichen Persönlichkeiten und Eigenschaften wahr. Die minderheitlich präsenten Frauen können sich aus diesem Entindividualisierungsprozess einzeln nur schwer herauslösen; zugleich sind sie aufgrund ihrer eher niedrigeren hierarchischen Position als Kooperationspartnerinnen unattraktiv. Damit werden ihre speziellen Anliegen in mehrheitlich männlich besetzten Gremien nicht wahrgenommen und sie können sich nicht erfolgreich in die Aushandlungsprozesse einbringen (vgl. Kanter 1977).

Dem Tokenkonzept liegt ein organisationales Rationalitätsparadigma zugrunde, d.h. Diskriminierung ist hiernach nicht in den Strukturen eingelagert. Für Veränderungen gilt es nämlich auch umgekehrt: Steigt der Anteil der minderheitlich vertretenen Gruppe, verändert sich die Gruppenwahrnehmung und die Position der Minorität. Mit einer erhöhten Repräsentanz können nun Verbündete gewonnen und die Kooperationskultur der Gruppe beeinflusst werden. Für die Klassifizierung des Zusammenhangs von Macht und Repräsentanz hat Rosabeth Moss 
Kanter folgende Zahlenverhältnisse angegeben: Unter $15 \%$ haben Minderheiten einen Tokenstatus, ab etwa $35 \%$ kommt die Minderheit in eine Verhandlungsposition, ab ca. $40 \%$ gelten Gruppen als balanced. Erst im ausbalancierten Zustand werden alle Gruppen- bzw. Organisationsmitglieder entlang ihrer unterschiedlichen Merkmale, Rollen und Fähigkeiten wahrgenommen.

Das Tokenismkonzept wurde durch Organisationsstudien der 1980/9oer-Jahre in Frage gestellt. Nach diesen Forschungen ließ sich Diskriminierung nicht vorrangig in den Repräsentationsverhältnissen verorten, sondern war an komplexere Strukturen wie Statuszuweisungen, männliche Verhaltensnormen und Schließungsmechanismen bei beruflichen Karrieren gebunden ${ }^{58}$. Trotzdem hat die Theorie des Tokenism nachhaltig die Gleichstellungspolitiken geprägt. Maskulinistische Geschlechterhierarchien in Organisationen werden auch in den aktuellen Genderpolitiken primär daran identifiziert, zu welchem Anteil Männer und Frauen in Mitgliedschaft und Entscheidungspositionen vertreten sind. Eine Frauenrepräsentanz von rund 30 \% gilt dabei häufig als Wendemarge ${ }^{59}$, die erreicht werden muss, damit ein kultureller Wandel in Organisationen eingeleitet und der Abbau von Geschlechterasymmetrien in Gang gesetzt werden können.

\subsubsection{Ausgrenzung aus schließungstheoretischer Perspektive}

Schließung in Organisationen betrachtet Eva Cyba als ein Ergebnis von Machtkämpfen und Konkurrenzen (vgl. Cyba 1995). Ungleichheit als eine gesellschaftlich hervorgebrachte, „relativ dauerhafte“ Handlungsbedingung erlaubt nach Eva Cyba „bestimmten Gesellschaftsmitgliedern die Befriedigung allgemein akzeptierter Lebensziele besser als anderen“ (Stefan Hradil zit. n. Cyba 1995: 66). Außerdem ist Schließung „ein Mittel zur Durchsetzung eigener Ziele in Konkurrenzsituationen“" (vgl. Wilz 2004: 216) ${ }^{60}$.

58 Solche Systeme führen Frauen in „berufliche „Sackgassenbereiche“ oder verwehren ihnen berufliche Karrieren(Glass-Cieling) (vgl. dazu: Yoder 1991).

59 In einer Studie der Arbeitsmarkt- und Berufsforschung aus dem Jahr 2009 heißt es: „Betriebe mit einem Frauenanteil zwischen $30 \%$ und $70 \%$ werden als ausgeglichene Betriebe bezeichnet, Betriebe mit einem Frauenanteil von weniger als $30 \%$ als männerdominierte Betriebe und Betriebe mit einem Frauenanteil von mehr als $70 \%$ als frauendominierte Betriebe." (IAB 2009: 14)

6o Diese Konstruktionen gehen auf Max Weber zurück. Nach ihm sind Schließungen eine Reaktion der MarktteilnehmerInnen auf die wachsende Zahl der KonkurrentInnen, wobei die Ausschlusskriterien prinzipiell beliebig sind und je nach kontextspezifischen Opportunitäten entwickelt werden. 
In demokratischen Organisationen - wie den Volksparteien - sind Schließungen jedoch als Ungleichheiten legitimationsbedüftig, wenn sie als stabile Regelsysteme gelten sollen. Genussspezifische Schließungskriterien nehmen deshalb Bezug auf das Wohl der Gesamtheit oder auf sog. natürliche Gegebenheiten. So wurde Frauen der Zugang zu verschiedenen Leistungssportarten aus gesundheitlichen Gründen versperrt, ebenso wurde ihnen der Zugang zu einzelnen Berufen wegen geringerer physischer Kräfte oder wegen einer begrenzteren psychischen Belastbarkeit verweigert. Schließungen sind somit immer verbunden mit Deutungsmacht (vgl. Cyba 1995). Deutungsmacht bezieht sich dabei auf die Legitimationsfolie der Schließungsregularien und auf die Bewertung der vorenthaltenen Ressourcen, deren Zuweisung oder deren Bedeutung (vgl. Wilz 2002: 272).

Im Gegensatz zu Max Weber erscheinen damit Schließungskriterien nicht als beliebig, vielmehr ist die Kategorie Geschlecht kontingent und „eingebettet“ in gesellschaftliche Normen, Deutungen und Wertvorstellungen (vgl. Cyba 2000). Geschlechterasymmetrie formt das alltägliche kollektive und individuelle Organisationshandeln, ebenso ist es in die Abgrenzung der Organisation nach außen eingelagert.

Schließungsprozesse können innerhalb einer Organisation vertikal oder horizontal zwischen Statusgruppen ablaufen. Sie beziehen sich auf hierarchisierte Zugänge zu Ressourcen und Chancen sowie auf Positionen, die den zukünftigen Zugang zu Ressourcen und Chancen sichern. Sie finden innerhalb eines Systems von Regulationen und Strukturen statt, das von allen beteiligten KontrahentInnen als Bezugssystem akzeptiert wird. Schließungsregeln können inklusiv oder exklusiv konzipiert sein.

Auch die Schließungpraktiken, die intensional auf horizontale Inklusionen zielen, bewirken häufig gleichzeitig vertikal Exklusionen, weil sie an gesellschaftliche, überorganisationale, hierarchische Strukturverhältnisse gebunden sind. Sie brauchen die Akzeptanz der Organisationsmitglieder und schaffen zugleich Legitimation, denn jede Ausschließung bewirkt auch ein Stück Identitätsbildung (vgl. Wilz 2004; Cyba 1995). Zustimmung finden besonders genussspezifische Schließungen, wenn sie Geschlechteridentitäten definieren, die einer vorgeblichen Verschiedenheit der Geschlechter Rechnung tragen. Die Ausschließung von Frauen erscheint dann als Folge einer „Vergeschlechtlichung“, die auch im Interesse der Frauen liegt, „,weil sie schließlich deren Präferenzen und Fähigkeiten entspricht" (vgl. Wetterer 1995: 147). Die Schließungsstrukturen und -regulationen formen Wahrnehmung, Deutungen und Handeln der Organisationsmitglieder und sind damit Teil der spezifischen Rationalität von Organisationen. 
Der Vorteil einer schließungstheoretischen Sicht auf vergeschlechtlichte Organisationen ist, dass das Diskriminierungssystem als eine Konstellation von Schließungsregeln konzipierbar ist, auch wenn die Regeln widersprüchlich und disparat sind und sich nicht in ein konsistentes Bezugssystem einfügen ${ }^{61}$. Schließungspraxen sind meist einzeln oder in Kombinationen veränderbar, ohne dass sich der normative Status der Diskriminierung verändert. Auch können sich einzelne Schließungsregeln ändern, ohne dass sich andere, die mit ihnen „logisch“ zusammenhängen, mit verändern.

Nach Eva Cyba sind soziale Praxen als Schließungen zu definieren, die zur Identitätsbildung der ausschließenden Gruppe beitragen und intentional auf die Ausschaltung der Konkurrenz, die Erhaltung der privilegierten Position und die Mobilisierung der Ressourcen und Machtmittel zielen (vgl. Cyba 1995: 54). Die Umsetzung von Regeln erfordert einen entsprechend hohen Organisationsgrad der Gruppe.

Nach Silvia Wilz müssen Schließungstheorien die Verschränktheit von Formalität und Informalität in Organisationen berücksichtigen. Die meisten Schließungsstrategien lassen sich nicht als regulierte Sets von Ausgrenzungshandlungen identifizieren, sondern bilden sich vielmehr als kontrollierte „Kooptationen“, bei denen unterschiedliche Schließungskriterien, darunter das Geschlecht, verwendet werden können (vgl. Wilz 2004c). Sie haben häufig die Form von Zusatzbestimmungen für die benachteiligten Personen oder Gruppen, die mit inferiorem Status und verminderten Rechten verbunden sind, und werden z.B. über den Zwang zur Assimilation durchgesetzt.

Schließungsstrategien gehen jedoch nicht nur von Gruppen mit einem begünstigten Zugang zu Positionen und Chancen aus, sondern sie werden auch als Gegenmaßnahmen der ausgegrenzten Gruppen angewendet $^{62}$ (vgl. Parkin 2004; Murphy 2004). Schließungen wie z.B. die Beanspruchung „männerfreier Räume“ haben das Ziel, Macht zu mobilisieren. Im Zuge kollektiver Identitätsbildung können die ausgeschlossenen Gruppen die Schließungssysteme in Frage stellen bzw. Schließungsregelungen nicht länger akzeptieren.

61 Edith Kirsch-Auwärter beschreibt anhand der organisationalen Abläufe an Hochschulen, wie in uneindeutigen und intransparenten Machtbeziehungen und Dominanzverhältnissen Exklusionsregeln vielfältige unerwünschte Fragmentierungen in hierarchisch untergeordneten Gruppen bewirken und unbeabsichtigte Schließungswirkungen erzeugen können (vgl. Kirsch-Auwärter 2008).

62 Raymond Murphy und Frank Parkin nutzen schließungstheoretische Konstruktionen, um herrschafts- und klassentheoretische Konzepte zu entwickeln. Die Schließungsregeln sind demnach mitgeformt durch die Strategien des widerständigen kollektiven Akteurs. Damit entstehen reziproke Schließungsformen. Sie können sich durch die Kombination unterschiedlicher Schließungsmechanismen für einzelne Gruppen kumulativ verstärken. 


\subsubsection{Politiken zur Auflösung von Geschlechterhierarchien in Organisationen}

Aus strukturationstheoretischer oder systemtheoretischer Perspektive sind Organisationen offene Systeme, Wandel gilt hier als Organisationsphänomen. Organisationen entwickeln sich evolutionär. Anpassungsfähigkeit, Innovationsbereitschaft und die Flexibilität der Organisationsmitglieder sind dabei unterschiedlich hoch (vgl. Miebach 2012). Die einen Wandel bedingenden Veränderungsanforderungen konfligieren meist mit den Interessen von Organisationsmitgliedern oder -kollektiven an einer Verbesserung der Lebenschancen und -lagen, die die Mitglieder mit ihrer Organisationszugehörigkeit verbinden. Veränderungen berühren häufig die bereits ausgehandelten Verteilungen und Verfahren und bedrohen die Zuverlässigkeit von Organisationsstrukturen sowie die Berechenbarkeit organisationaler Praxen. Für eine Analyse der Wandlungsprozesse ist zu klären, welche Strategien entwickelt werden, um Wandlungsprozesse einzuleiten und zu steuern und unter welchen organisationssoziologischen Voraussetzungen „organisationales Lernen" stattfindet.

Dazu entwickelt Joan Acker eine Theorie der Geschlechterhierarchie, die sich von den feministischen Organisationsdiskursen der 1980er-Jahre unterscheidet, welche sich vorrangig am Machtbegriff Foucaults ausrichteten. Sie bestimmt Männerdominanz als Strukturelement, das sich als ein Doing Gender vollzieht:

[...] gendered means that advantage and disadvantage, exploitation and control, action and emotion, meaning and identity, are patterned through and in terms of a distinction between male and female, masculine and feminine. Gender is not an addition to ongoing processes, concieved als gender neutral. (Acker 1990: 146)

Nach Joan Acker reproduziert sich das Doing Gender auf fünf Ebenen sozialen Handelns:

1. in der Differenzierung und getrennten Zuordnung aller Aufgaben und Positionen nach Geschlechtern auf dem Arbeitsmarkt, in der Familie und im Staatswesen mit den dazugehörigen Routinen, Regeln und Verfahren;

2. in der Konstruktion von Symbolen, Bildern und Vorbildern für Erfolg und Macht;

3. in den sozialen Strukturprozessen, die durch Interaktionen zwischen den Geschlechtern hergestellt werden und in denen sich 
Positionsmuster von Dominanz und Unterordnung stetig reproduzieren;

4. in den geschlechtsspezifischen Zuschreibungen bei der individuellen Identitätsbildung und Selbstpräsentation;

5. in der Planung und dem Entwurf sozialer Strukturen (vgl. Acker 1990).

Geschlechterkonstruktionen finden sich als Basiselement in Familienbeziehungen, aber auch in der Entwicklung komplexer Organisationsstrukturen, deren Funktionen oder Positionen vermeintlich geschlechtsneutral geschaffen werden sollen, vor allem aber auch in den Theorien über Organisationen und ihre „exkludierenden“ Reflexionen über Berufswelt und Hierarchien. In deren Logik werden abstrakte Berufsanforderungen und hypothetische Arbeitskräfte konstruiert.

Seit den 1990er-Jahren wird der Wandel von Geschlechterverhältnissen in Organisationen neu diskutiert. Hierarchien innerhalb der Organisationen werden als durch ein „System geteilter Interpretationen, Deutungen und Normen " determiniert analysiert, die aber als ungleiche Verteilungen von Macht, Einfluss, Ressourcen, Prestige zugleich in Verhandlung sind (vgl. Aulenbacher 2005; Heintz 1998, 2001; Wilz 2002, 2004a, 2004b, 2004c, 2004d; Riegraf 1997). Besonders deutlich ist der Wandel der Geschlechterzuschreibungen bei den Berufen. Professionen haben ihren Geschlechterbezug verloren (Gebäudereiniger, Koch, Mathematiker) oder wechselten die Geschlechterdominanz (Programmierer, Ärztin, Juristin, Journalistin). Zum Berufsmarkt erklären feministische Organisationssoziologinnen:,[...] von einer durchgängigen Marginalisierung und Abwertung von Frauen kann so eindeutig nicht mehr gesprochen werden." (Kuhlmann/Kutzner/Müller/Riegraf/Wilz 2002: 224)

Allerdings zeigen die Erfahrungen von GleichstellungspolitikerInnen in Organisationen, dass eine Veränderung der Geschlechterverhältnisse in Organisationen durch AkteurInnen schwieriger und langwieriger Prozesse bedarf. Meist scheinen erst tiefgreifende Organisationskrisen die notwendigen Voraussetzungen dafür zu schaffen, denn ein geschlechterpolitischer Wandel in den Normen- und Deutungssystemen ist nicht nur durch eine Korrektur der Routinen und Regeln herstellbar (vgl. Kuhlmann/Kutzner/Müller/Riegraf/Wilz 2002).

Damit müssen Gleichstellungspolitiken an denjenigen Werten und Normen und vielleicht auch Verhaltensroutinen anschließen können, welche die Identifizierung der Organisationsmitglieder mit der Organisation ermöglichen und an die der Fortbestand der Organisation gebunden wird. Ein Paradigmenwechsel muss mit den „,Grundannahmen ' des Organisationsgedächtnisses“ vereinbar sein und wird geprägt von den 
vorhandenen organisationalen Rahmenbedingungen (vgl. Kuhlmann/Kutzner/Müller/Riegraf/Wilz 2002).

Während die autonomen Frauenbewegungen der 1970er-Jahre die Unterdrückung und Entwertung der Frauen einklagten, setzten die Gleichstellungspolitiken der 1980er- und 1990er-Jahre auf die Delegitimierung der Geschlechterhierarchien. Ziel der GleichstellungsakteurInnen war die „Etablierung von Aufmerksamkeitsstrukturen für die Geschlechterthematik, die Akzeptanz frauenzentrierter Uminterpretationen gängiger Deutungsmuster, die Schaffung wertschätzender Kontexte gegen kulturell vorherrschende Muster der Abwertung" (Müller 2000: 143). Mit der Implementierung von Frauen- und Gleichstellungsbeauftragten waren dafür wichtige Instanzen zur Selbstevaluierung der Organisationen (vgl. Kuhlmann/Kutzner/Müller/Riegraf/Wilz 2002) geschaffen worden. Das mit den Gleichstellungsbeauftragten verbundene Controlling etablierte einen Gleichstellungsdiskurs, der häufig paradoxe Interventionen (vgl. Wetterer 2004) evozierte : Einerseits löste er strukturelle Veränderungen wie die Einführung von Gleichstellungsrichtlinien und -maßnahmen oder eine Korrektur der organisationsspezifischen Leistungskriterien und Auswahlverfahren aus, andererseits war er zumeist mit einer diskursiven Geschlechterdualisierung und Marginalisierung von Frauen verbunden.

Gleichstellungsbeauftragte entwickelten verschiedene Anschlussstrategien, um für ihre Forderungen Akzeptanz zu finden oder bereits getroffene Vereinbarungen erfolgreich umzusetzen oder um sich zunehmend in die Organisationsprozesse und -verfahren integrieren zu können. Für ihren Erfolg brauchten die Akteurinnen eine hohe Kooperationsfähigkeit und Bündnisbereitschaft. Unterstützung fanden die Akteurinnen häufig bei männlichen Organisationsmitgliedern, die die feministische Kritik für eigene Veränderungswünsche an die Organisation nutzten oder sich selbst aus der Kultur der Abwertung befreien wollten (vgl. Müller 2000).

Im Laufe der 1970er- und 1980er-Jahre entwickelten ASF-Aktivistinnen und einzelne männliche parteiinterne Bündnispartner Politiklager übergreifende Strategien der Veränderung, um die Partizipationsansprüche der Frauen durchzusetzen und die Geschlechterpolitik der SPD zu verändern. Die Auseinandersetzungen darüber verliefen in den verschiedenen Parteieinheiten parallel und ungleichzeitig. Auch die ASF selbst war politisch hoch fragmentiert und ihre Mitglieder rangen untereinander um Grundwerte, Strategien und politische Forderungen. Trotzdem konnte sie sich im Laufe der 1970er und 1980er-Jahre zu einer kollektiven Akteurin entwickeln, der im frauenpolitischen Wandel der Partei eine bedeutende Funktion zukam. 
Entstehung und Struktur von Kollektivbildungen wurden in den Theorien zu den Neuen Sozialen Bewegungen erforscht. Ihre wichtigsten Ergebnisse und Diskurse werden im nächsten Kapitel vorgestellt.

\subsection{Politische Partizipation und Neue Soziale Bewegungen}

Von der Gründung der Arbeitsgemeinschaft Sozialdemokratischer Frauen versprach sich der Parteivorstand eine Aktivierung der Frauenarbeit und kam damit den Interessen vieler weiblicher Mitglieder nach, mit arbeits- und beschlussfähigen Strukturen an der Entwicklung frauenund familienpolitischer Parteipolitiken beteiligt zu werden. In der ASF meldeten sich nun an vielen Orten weibliche Mitglieder zu Wort. Allerdings formierte sich zeitgleich in der Reihen der ASF ein innerparteiliches Protestpotenzial, das neue Themen auf die politische Agenda setzte und das kontroverse Positionen zu gesellschaftspolitischen Orientierungen der Partei bezog. Diese Opposition ging zunächst von zahlenmäßig kleinen Gruppen linkssozialistischer, frauenpolitischer Aktivistinnen aus. Viele von ihnen waren in den Studierendenbewegungen der 196oerJahre politisiert worden und unterstützten oder engagierten sich parallel zur Parteiarbeit in Bürgerinitiativen und Protestbewegungen. In der zweiten Hälfte der 1970er-Jahre aber entstand in Kooperation unterschiedlicher politischer Lager und weltanschaulicher Strömungen eine partei- und parteiführungskritische Frauenbewegung, die in den 1980erJahren von einer stetig wachsenden Unterstützung durch die ASF-Mitglieder getragen wurde.

Die ASF ist im Forschungszeitraum sowohl eine Organisation, die durch Wahlprozeduren, hierarchisierte Vertretungsstrukturen und bürokratische Antragsverfahren geprägt ist, als auch eine Struktur, in der dynamische und lebendige Prozesse der politischen Organisierung, Politisierung und der individuellen Emanzipation stattfinden. Beachtenswert sind die heterogenen und veränderlichen politischen Zielsetzungen der ASF, die regionalen Unterschiede ihrer Politiken und die teils unabhängig voneinander agierenden Funktionärinnen sowie die unkonventionellen Aktionsformen der Selbstpräsentation, mit denen sie in der Partei um Aufmerksamkeit kämpfte.

Um das Mobilisierungpotenzial in der ASF zu analysieren, wird auf die Theorien der Bewegungsforschung zurückgegriffen. Hier entwickelte sich in den 1980er-Jahren in Deutschland eine neue Fachdisziplin, die 
Forschung der Neuen Sozialen Bewegungen (NSB) ${ }^{63}$. Sie beschäftigt sich vor allem mit den Protestbewegungen, die sich nach den StudentInnenbewegungen der 196oer-Jahre gebildet hatten. Diese außerparlamentarischen Aktivitäten galten den etablierten Parteien zunächst als jugendliche Mittelschichtsbewegung und nicht als ernstzunehmende neue Formen politischer Partizipation. Entgegen der Prognosen ihrer KritikerInnen aber erhielten diese Bewegungen in den 1970er- und 1980er-Jahren einen hohen Zulauf und verbreiteten sich als Stadtteil-, BürgerInnenund Basisinitiativen, die besonders auf die kommunalen Parlamente einen starken Einfluss ausüben konnten.

Im Laufe der 1980er-Jahre entsteht dazu eine fast unüberschaubare Bewegungsliteratur, inspiriert und beeinflusst von der US-amerika-nischen Bewegungsforschung (vgl. Hellmann/Koopmans 1998). Den neuen gesellschaftlichen AkteurInnen wird nun zielgerichtetes Handeln, Regelhaftigkeit und Durchsetzungsfähigkeit zugeschrieben. Ihre Sozialstrukturen und ihre hohe Fähigkeit zur Ressourcenbeschaffung werden zum sozialwissenschaftlichen Forschungsgegenstand.

Die NSB unterscheiden sich deutlich von Parteien. Parteien weisen eine differenzierte Organisation auf, bestehend aus geregelten Einzelmitgliedschaften, in Statuten festgelegten Binnenstrukturen, definierten Arbeitsteilungen und Zuständigkeiten für spezielle Positionen. Ihr Selbstverständnis ist in Programmen aufgezeichnet und ihre öffentlichen VertreterInnen verstehen sich als RepräsentantInnen gesellschaftlicher Gruppen. Ihr politisches Handeln ist ausgerichtet auf Einflussnahmen in den Regelsystemen der repräsentativen Demokratie, ob als Regierungsbeteiligte oder als Opposition. Ihr Regierungshandeln wird jedoch von einer "Reformen bremsenden Grundstruktur“ bestimmt, bestehend aus Verfassungsgerichtsinterventionen, Einspruchsrechten, Landtagswahlen, Machtgleichgewicht der Großparteien, Föderalismus (vgl. Raschke 2003). Diese Blockaden wirken auf die Politikentwicklung der Parteien lähmend.

In Abgrenzung zu Parteien, Verbänden, Gewerkschaften definiert Joachim Raschke die Neuen Sozialen Bewegungen als

63 Bereits in den 1950er-Jahren gab es in der westdeutschen Gesellschaft ein „Bewegungsgeschehen“ (vgl. Roth/Rucht 2008). Allerdings wurden diese Bewegungen von etablierten politischen AkteurInnen - Gewerkschaften, SPD-Parteimitgliedern und kirchlichen Gruppen - organisiert, sie wandten sich gegen Wiederbewaffnung und Remilitarisierung. 1958 mobilisierte ein Ausschuss Kampf dem Atomtod mehr als 10o.ooo TeilnehmerInnen, dem war 1957 die Göttinger Erklärung vorausgegangen, in der Kernphysiker, u. a. Otto Hahn, Werner Heisenberg und Carl Friedrich von Weizsäcker, vor den Gefahren einer atomaren Bewaffnung warnten und zur Ächtung der Atomwaffen aufriefen. 
mobilisierender kollektiver Akteur, der mit einer gewissen Kontinuität auf der Grundlage hoher symbolischer Integration und geringer Rollenspezifikation mittels variabler Organisationsund Aktionsformen das Ziel verfolgt, grundlegenderen sozialen Wandel herbeizuführen, zu verhindern oder rückgängig zu machen. (Raschke 1987: 77) ${ }^{64}$

Im Gegensatz zu historisch früheren sozialen Bewegungen, wie z.B. den ArbeiterInnenbewegungen, zielen die NSB-AkteurInnen nicht auf die Übernahme von Machtpositionen, sondern entwickeln stattdessen eine Vielzahl gesellschaftspolitischer Kritiken, die die herrschende Ordnung und ihre politische Verwaltung in Frage stellen und einen subversiven Blick auf die Normalität des Alltagslebens und die Fortschrittslogik von Wirtschafts- und Technologieentwicklung werfen. Organisatorisch bilden die Neuen Sozialen Bewegungen ein loses Netzwerk themenspezifischer, dezentral organisierter, basisdemokratischer Formationen (vgl. Brandt 1998b). Die Forschungsergebnisse und Diskurse zu den spezifischen Merkmalen dieser gesellschaftlichen Formierungen werden im Folgenden vorgestellt.

\subsubsection{Theoriekonzepte der Neuen Sozialen Bewegungen}

Kai-Uwe Hellmann und Ruud Knoopmans fassen die wichtigsten Theorieansätze der NSB-Forschung in fünf Paradigmen zusammen: Framing, Collective Identity, Resource Mobilization, Structural Strains und Political Opportunity Structures (vgl. Hellmann/ Koopmanns 1998).

\section{Framing}

Parteiprogramme definieren das gemeinsame Anliegen kollektiven Handelns durch einen Wertekatalog, der eine Einheitlichkeit der Interessen nach innen und die Geschlossenheit der Partei nach außen erzeugen soll (vgl. Stöss 1987). Dagegen finden sich soziale Bewegungen auf der Basis einer gemeinsamen Veränderungszielsetzung zusammen, die unterschiedliche, oft widersprüchliche Konzepte der Intervention zulässt. Die

64 Die Definition Dieter Ruchts erweitert diese Definition und betont die besondere Binnenstruktur der NSB: „Eine soziale Bewegung ist ein auf gewisse Dauer gestelltes und durch kollektive Identität abgestütztes Handlungssystem mobilisierter Netzwerke von Gruppen und Organisationen, welche sozialen Wandel mit Mitteln des Protestes - notfalls bis hin zur Gewaltanwendung - herbeiführen, verhindern oder rückgängig machen wollen. Sozialer Wandel bedeutet in diesem Zusammenhang eine grundlegende Veränderung gesellschaftlicher Ordnung" (Rucht 1994: 77f.). 
Bewegung bietet ein Forum für die Diskussion und eine Plattform für unterschiedliche Aktivitäten. Das Selbstverständnis der BewegungsteilnehmerInnen wird in sog. collective action frames gefasst, sie definieren die historische Chance auf gesellschaftliche Veränderung: „... to proffer a collective action frame is to suggest that an opportunity to affect social change exists, and that people are potential agents of their own history " (Benford/Snow 2000: 631). Angelehnt an Erving Goffmanns schemata of interpretation definieren Robert D. Benford und David A. Snow Frames als ,action-oriented sets of beliefs and meanings that inspire and legitimate the activities and campaigns of a social movement organization" (Benford/Snow 2000: 614). Die Frames haben die Aufgabe, einen Interpretationsrahmen anzubieten "by simplifying and condensing aspects of ,the world out there', but in ways that are intended to mobilize potential adherents and constituents, to garner bystander support, and to demobilize antagonistes"“ (Benford/Snow 1988 zit. in: Benford/Snow 2000: 614). Framings müssen deshalb diagnostisch, prognostisch und motivierend sein. Durch Framing werden nach Klaus Eder die Verantwortlichen für die schlechten Zustände definiert und dem kollektiven Handeln Bedeutung verliehen; zudem ermächtigen sich die kollektive AkteurInnen durch Frames selbst zu AgentInnen des sozialen Wandels (vgl. Eder 1994).

Der Framingforschungsansatz versucht zu erkunden, wie Frames konstruiert sein müssen, damit Protestthemen eine mobilisierende Wirkung entfalten können ${ }^{65}$. Frames werden nach Robert D. Benford und David A. Snow zwischen den BewegungsteilnehmerInnen oder auch zwischen rivalisierenden Gruppen innerhalb der Bewegungsstrukturen in einem diskursiven Prozess ausgehandelt. Beim Framing werden häufig bekannte Ideen zu neuen Kombinationen zusammengefügt, die punktu-

65 Frames werden sehr unterschiedlich definiert. Dies weist auf die analytische Unbestimmtheit des Bewegungsphänomens hin: Tibot Kliment unterscheidet konsensmobilisierende und aktionsmobilisierende Framings (vgl. Kliment 1998); Robert D. Benford und David A. Snow differenzieren Frames nach der Breite der Problemidentifikation; andere systematische Unterscheidungen sind Exklusivität und Rigidität der Framedefinitionen, master frames mit unterschiedlichen Sets von Problem- und Interessensdefinitionen, die Komplexität des Wertehorizont (centrality), die Reichweite der Problemerfassung (range) und die Systematik, Dichtheit und Verflechtung der Argumente (interrelatedness), ein anderes Analyseset besteht aus den Dimensionen empirical credibility, experiential commensurability und narrative fidelity (vgl. Benford/Snow 200o; Darstellung in: Gessenharter 1998). 
elle Forderungen oder Anliegen in einen größeren Zusammenhang stellen, um die Anschlussfähigkeit der Frames zu erhöhen und sie für andere Gruppen attraktiv oder übernehmbar zu machen. ${ }^{66}$

In Deutschland waren die Frames der Neuen Sozialen Bewegungen in den 1970er-Jahren häufig mit Kapitalismuskritik und Emanzipationsvision, später mehr mit einer ökologischen Industrialisierungs- und Modernisierungskritik verbunden. Ab den 1980er-Jahren entwickelten sich sozialkulturelle Ausrichtungen. Die Frames orientierten sich an Veränderungsanforderungen der Lebensweisen und der kulturellen Alltagspraktiken sowie an postmaterialistischen Werten (vgl. Brand 1998; Raschke 1987$)^{67}$.

Anpassungsprozesse von Frames werden ausgelöst durch externe Ereignisse wie Medienresonanz, das Aufgreifen von Forderungen durch die institutionellen Eliten oder durch interne Veränderungen der NSB wie den Zugewinn neuer UnterstützerInnengruppen und neue Aktionserfahrungen der BewegungsteilnehmerInnen, vor allem aber durch die Reaktionen der targeted audiences, mit denen die Bewegungen in einem dynamischen Austausch stehen (vgl. Benford/Snow 2000: 628). Frames sind deshalb in einem fortlaufenden Veränderungsprozess begriffen, in dem die beteiligten Gruppen neue gemeinsame und integrierende Deutungsmuster bestimmen.

Das Frameparadigma erfasst die thematische Heterogenität der NSBTeilbewegungen, aber es erklärt nicht den Zusammenhalt in den Bewegungskollektiven. Im Gegenteil lässt die hohe Variabilität der Frames eher auf eine geringe konstitutionelle Bedeutung für die NSB schließen. Meist bleiben die Frames nach Ruud Koopmans eher vage, um eine gemeinsame Aktionsfähigkeit nicht durch Meinungsdifferenzen zu gefährden, und bieten entsprechend schwache Integrationsleistungen (vgl. Koopmans 1998).

Kollektivbildung in den NSB, Mobilisierung und Zusammengehörigkeit werden in der NSB-Forschung insbesondere unter dem Begriff der „kollektiven Identität“ diskutiert.

66 Für ein solches Reframing werden vier verschiedene Anpassungsstrategien identifiziert: die Identifikation gemeinsamer Problemdefinitionen mit anderen Teilbewegungen (frame bridging), die Erweiterung der Teilbewegungsframes durch Anbindung an gesellschaftliche Werte und Ereignisse (frame amplification), die Erweiterung der Problemdefinition (frame extension) mit dem Ziel, mehr UnterstützerInnen zu mobilisieren, und das Aufgreifen und Umdeuten gängiger öffentlicher Meinungsbilder (frame transformation) (vgl. Gessenharter 1998).

67 Mit der Übernahme der DDR 1989 rückten wieder stärker soziale Themen auf die Agenden der NSB, ausgelöst durch Deindustrialisierung, Massenarbeitslosigkeit, soziale Ausgrenzung und Armut. Ein wichtiges Leitthema der 1990er-Bewegungen war auch die Demokratisierung der Demokratie. Später folgten Kritiken an der Weltvermarktung sowie an der unzulänglichen Steuerung der Kreditmärkte (vgl.dazu: Roth/Rucht 2008). 


\section{Collective Identity}

Das Identitätsparadigma beschäftigt die europäische Bewegungsforschung seit den 1990er-Jahren (vgl. Roth 1998b). Der Forschungsansatz Kollektive Identität will gemeinschaftliches Widerstandshandeln, die Mobilisierungsfähigkeit und ihre Persistenz in den NSB erklären, indem er die Zusammengehörigkeit in den Fremd- und Selbstzuschreibungen und in den Aktionspraxen in den Blick nimmt. Kollektive Identität kann als eine Weiterentwicklung des Framingansatzes angesehen werden, allerdings mit einem anderen Forschungsanliegen: „Es geht um den ,Kitt”, der gemeinsames oppositionelles Handeln ermöglicht und für eine Weile auf Dauer stellt." (Roth 1998b: 52)

Allen theoretischen Ansätzen zur Erklärung kollektiver Identität ist gemeinsam, dass sie als ein veränderbares, flexibles Produkt gemeinschaftlichen Handelns angesehen wird.. Die kollektive Identität interagierender Individuen bestimmt die gemeinsamen Deutungen, die Ausrichtung der Aktivitäten sowie die Begrenzungen, innerhalb derer die Aktivitäten entworfen werden. Die Identitätskategorien bilden somit Strukturmerkmale der Gemeinschaftlichkeit, die Protestpraxis und die Zielsetzungen der jeweiligen Teilbewegung ab.

Dabei wird kollektive Identität in einer strukturell-kulturellen Theorierahmung eher als Eigenschaftsbündel des Kollektivs erforscht, aus sozialpsychologischen Perspektiven eher als ein Phänomen der Bewegungsteilnehmenden. In den kulturorientierten Erklärungsansätzen wird die kollektive Identität vorrangig in den kollektivierenden Alltagspraktiken identifiziert wie z.B. in alternativen Lebensweisen, besonderen Kleidungen, solidarischen Vergemeinschaftungen, abgrenzenden Selbstinszenierungen und Symbolen. Die sozialpsychologischen Erklärungsansätze erforschen Andreas Zick und Ulrich Wagner in einer Untersuchung zur „Ideologisierung von Individuen im Kontext von Gruppen“ (Zick/Wagner 1995: 56). Bewegungen sammeln demnach nicht Mitglieder, die mit ihnen ideologisch übereinstimmen; stattdessen bildet sich die Zusammengehörigkeit im Kollektiv als Prozess einer „Selbst-Kategorisierung" der Mitglieder, in dem die Einzelnen kollektive Frames in ihr Selbstkonzept aufnehmen. „Die erste Frage, die die Gruppenzugehörigkeit betrifft, ist nicht ,Mag ich die anderen Gruppenmitglieder', sondern ,Wer bin ich?'“(a.a.O.: 63). Die Identifizierung mit dem Kollektiv erleben die Gruppenmitglieder als eine Erweiterung ihrer individuellen Identität (a.a.O.: 56). Die Frames des Bewegungskollektivs prägen dann 
die Einstellungen der Mitglieder, ihre Selbstwahrnehmung und ihr Sozialverhalten mit $^{68}$.

Nach Roland Roth sind kollektive Identitäten „Identitäten in Opposition" (Roth 1998b: 54). Die Protesthaltung ist damit ein Kernelement der kollektiven Identität. Sie macht die Neuen Sozialen Bewegungen abhängig von den Reaktionen der Gegner, dem Publikum, dem gesellschaftlichen Umfeld und den historischen Gegebenheiten zum Protestzeitpunkt. Die kollektive Identität muss „auf einem herrschaftlich durchdrungenen, umkämpften Terrain immer erneut errungen werden“ (a.a.O.: 53). Die kulturtheoretische Perspektive verfolgen auch Werner Bergmann und Rainer Erb und erforschen in Anlehnung an Niklas Luhmann das Phänomen der Grenzziehungen als gemeinschaftsstiftenden Faktor. Danach ziehen BewegungsakteurInnen innerhalb des Gesellschaftssystems Abgrenzungen, so als verteidigten sie die Gesellschaft gegen ihre eigenen Institutionen. Sie bauen ein Schema von Inklusion/Exklusion auf, das stets reaktualisiert wird. Mit den Grenzziehungen profilieren sich die kollektiven AkteurInnen nach außen, nach innen begründen sie die Handlungsperspektiven für die Bewegungsteilnehmenden (vgl. Bergmann/Erb 1998; Hellmann 1998a). Nach Werner Bergmann und Rainer Erb ist die kollektive Identität deshalb mit einer „Lagermentalität“ verbunden, ,... wobei der eigenen kollektiven Identität auf der Gegenseite ebenfalls eine homogene Identität zugeschrieben wird" und „kein Versuch unternommen wird, die andere Seite zu verstehen“ (Bergmann/Erb 1998: 149).

In weiteren Theorieansätzen zur kollektiven Identität sind kulturellstrukturelle und sozialpsychologische Perspektiven verknüpft. Kollektive Identität bildet sich z.B. nach Alberto Melucci im Prozess der kognitiven Definition von Zielen, Mitteln, Handlungen sowie aus der Interaktion, dem jeweiligen besonderen Netzwerk aktiver Beziehungen und Kommunikationsformen und den emotionalen Bindungen, welche die Zugehörigkeit zur Bewegung und die Teilnahme an kollektiven Aktionen begleiteten (vgl. Melucci 1996, dargestellt in: Roth 1998b: 54).

Im wissenschaftlichen Diskurs kann keiner dieser Theorieansätze ein tragfähiges und teilbewegungsübergreifendes Erklärungsmodell für die kollektive Identität der NSB zur Verfügung stellen. Deshalb wird der Erkenntniswert der Konstruktion „Kollektive Identität“ infrage gestellt. Beobachtungen ergeben, dass die individuelle Identitätssuche nicht eng

68 Andreas Zick und Ulrich Wagner untersuchten in verschiedenen experimentellen Anordnungen, unter welchen Umständen Gruppenmitglieder in ihrer Wahrnehmung und Beurteilung gesellschaftspolitischer Themen von ihrer Gruppenzugehörigkeit bestimmt werden (vgl. Zick/Wagner 1995). Zu untersuchen wäre, unter welchen Umständen die Spannung zwischen kollektiver und persönlicher Identität zu einer Krise im individuellen Selbstkonzept führt und das Individuum aus dem Gruppenkontext löst. 
mit dem Bewegungsengagement verbunden sein muss, die Einsatzbereitschaft der Einzelnen in der Teilbewegung erheblich variieren kann und sich zudem viele BewegungsteilnehmerInnen in verschiedenen Teilbewegungen engagieren (vgl. Rucht 1995).

Die im Kollektive-Identität-Paradigma vorherrschende Annahme, dass sich in den NSB eine von gesellschaftlichen Entwicklungen bedrohte Mittelschicht mobilisiere, die versuche, mit unkonventionellen Protesten einen neuen gesellschaftlichen Platz für sich zu schaffen, erweist sich nach Roland Roth als empirisch unhaltbar. Zum einen rekrutieren sich auch etablierte politische Eliten aus diesen Schichten ${ }^{69}$, zum anderen mobilisieren die Bewegungen häufig ein breiteres soziales Spektrum (vgl. Roth 1998a).

Die steigende Komplexität der Bewegungen und die Differenzierung und Pluralisierung ihrer Themen lässt schließlich die Bemühungen um eine Definition kollektiver Identität scheitern. Bereits in ihrer Entstehung fehlt der NSB, so Roland Roth, ein „Drang zur Vereinheitlichung“ (Roth 1998: 63). Gerade dieses Phänomen und die breite Differenzierung ideologischer Orientierungen auf der Basis einer gemeinsamen Aktionspraxis unterscheide sie von Parteien.

Auch der Ansatz Dieter Ruchts, kollektive Identität nicht primär in den miteinander geteilten Zielsetzungen zu verorten, sondern in der Identifizierung der BewegungsteilnehmerInnen mit bestimmten Handlungs- und Protestformen zu suchen (Rucht 1995), weist nach Roland Roth zwar auf ein typisches Merkmal der Neuen Sozialen Bewegungen hin, aber eignet sich nicht als heuristisches Instrumentarium für die weitere Forschung. Die Neuen Sozialen Bewegungen seien vielmehr durch eine hohe Heterogenität auch in ihrer Aktionsvielfalt gekennzeichnet, die sich nicht durch besondere gesellschaftspolitische Partizipationsformen beschreiben ließe: „Gerade auf lokaler Ebene haben die neuen sozialen Bewegungen erheblich zu Partei-, Vereins- und Projektbildungen beigetragen - oft auf Kosten einer Politik der Straße“" (Roth 1998b: 66).

\section{Resource Mobilization (RM-Ansatz)}

Im Resource-Mobilization-Theorieansatz werden Neue Soziale Bewegungen als Kollektive bewusst handelnder AkteurInnen interpretiert, denen es gelingt, ihre Mitglieder gemeinsam gegen politische Missstände zu mobilisieren. Dazu braucht es mehr als die Verständigung über gesellschaftliche Problemdefinitionen: „Unzufriedenheit allein ist nicht konfliktfähig“" (Klandermans 1998: 192). Nach der Ressourcenmobilisierungstheorie

69 Roland Roth bezieht sich dabei auf die Milieustudien der Forschungsgruppe um Michael Vester und Heiko Geiling. 
verlaufen Entscheidungen der BewegungsteilnehmerInnen nach den Prinzipien der Rational Choice - im Gegensatz zu sozialstrukturellen Erklärungen, sog. Breakdowntheorien, nach denen soziale Unzufriedenheit kollektives Handeln und Protest mobilisiert. Nach der RM-Theorie wägt jede Person ab, welche Kosten und welcher Nutzen ihr mit der Teilnahme entstehen. Die Entscheidungen fallen dann je nach der individuellen Lebenssituation, den persönlichen Interessen und den Neigungen unterschiedlich aus (Darstellung nach: Klandermans 1998). Der Erfolg von Bewegungen hängt somit von den Anreizsystemen ab, die Bewegungen mobilisieren können, um Gruppen und Personen zu gewinnen. Bewegungen schaffen Anreize über Ressourcenmobilisierung. Unter dem Begriff der Ressourcen werden verschiedene Unterstützungsleistungen gefasst, z.B. materielle Mittel wie Geld, Kontakte, Räumlichkeiten, Sachleistungen oder immaterielle Hilfen wie politische Erfahrungen, kollektive Entscheidungsfähigkeit, Zugehörigkeit. Ressourcenzuwachs entsteht für den einzelnen Bewegungsteilnehmenden auch in den besseren Handlungsmöglichkeiten durch die unterstützenden Organisationen und Netzwerke, die den Bewegungen Infrastrukturen zur Verfügung stellen, sowie „Bewegungsverbündete“, die „Allianzsysteme“ schaffen und Konsens- und Aktionsmobilisierungen außerhalb der Bewegungen ermöglichen (Klandermans 1998: 186).

Das RM-Paradigma bringt gegenüber dem Identitätsparadigma und dem Framingkonzept eine individuelle Ebene in die Betrachtung ein und setzt sich mit der Unterstützung der Bewegung durch ihre einzelnen Teilnehmenden auseinander.

In der deutschen Bewegungsforschung stößt der RM-Ansatz auf weniger Unterstützung als Ablehnung. Mit der Reduzierung des Bewegungshandelns auf strategisches Organisationshandeln, kritisiert KarlWerner Brand, trenne der Theorieansatz die individuellen Handlungsmotive von der sozialen Umgebung und verzichte somit darauf, eine Verbindung zwischen den politischen Verhältnissen, den Entwicklungsprozessen der Bewegung und der Teilnahmebereitschaft der Bewegungsteilnehmenden herzustellen, wie sie sich aber in den unterschiedlichen Semantiken der Bewegungsframes niederschlage (vgl. Brand 1998b). Ebenso wenig lassen sich sozialpsychologische Faktoren und ethisch begründete Handlungsmotive sinnvoll in einem Kosten-Nutzen-Schema abbilden ${ }^{70}$ Nach Ilse Lenz und Brigitte Schneider kann der RM-Ansatz wenig dazu beitragen, die Mobilisierungsbedingungen der Neuen Frauenbewegungen zu klären. Besonders die Frauenbewegungen hätten ihren Teilnehmerinnen wenig attraktive Anreizsysteme bieten können, zudem litten

70 Hartmut Esser lehnt diese Kritik an der Rational-Choice-Theorie allerdings ab. Zu seinen Ausführungen, bounded rationality und Frames zu kombinieren, vgl. Esser 1990. 
die Frauenbewegungen unter chronischem Ressourcenmangel. Auch liefere der RM-Ansatz wenig Erklärungsinstrumentarium für die Analyse der Bewegungsverläufe (vgl. Lenz/Schneider 2004).

Von verschiedenen BewegungsforscherInnen wird der RM-Ansatz kritisch gewürdigt, weil er die Organisationsprozesse, die materielle Infrastruktur der Bewegungskollektive und die Kontexte des Bewegungserfolgs in den Blick nimmt (vgl. Klandermans 1998; Schäfer 2001) ${ }^{71}$. Die Bedeutung der inneren Strukturen der Neuen Sozialen Bewegungen betont auch Klaus von Beyme. Bewegungen sollten nicht mit Graswurzelmodellen beschrieben werden, nach denen wie durch Selbstentzündung ein spontanes Engagement der BürgerInnen entstehe. Vielmehr sorgten Protesteliten in den Bewegungen für die Bereitstellung von programmatischen Erklärungen und Ressourcen, um die Mobilisierungspotenziale zu aktivieren und zu sichern. Diese AkteurInnen handelten als „Bewegungsunternehmer". Sie wären keineswegs ausschließlich in den bewegungszugehörigen Personen und außerhalb des etablierten Systems von Interessensgruppen zu suchen, sondern Führungskräfte aus etablierten Organisationen (Kirchen, Gewerkschaften, Parteien) und außerhalb der alternativen Milieus unterstützen und verstärkten häufig die Handlungsfähigkeit der verschiedenen Bewegungskollektive (vgl. Beyme 2004) ${ }^{72}$. Dem RM-Paradigma entsprechend sind solche Unterstützungen ein wichtiger Faktor für den Erfolg der Teilbewegungen.

\section{Structural Strains (SS-Ansatz)}

Dieser besonders in den politischen Diskursen rezipierte Forschungsansatz der „Analyse gesellschaftlicher Strukturentwicklungen“versucht die Auslöser sozialer Bewegungen zu identifizieren und knüpft dabei an eine marxistische Tradition an (vgl. Hellmann 1998a; Klein 2003a).

Soziale Bewegungen werden hier als Reaktionen auf Störungen und Verwerfungen in den Abläufen gesellschaftlicher Normalität konstruiert. Zugleich gelten die NSB als GestalterInnen dieser Krisenentwicklungen

71 Reinhild Schäfer untersuchte die Schlagkraft der westdeutschen feministischen AntiGewalt-Bewegung. Der Erfolg dieser Bewegung gründete nach ihren Forschungsergebnissen auf der Strategie, die Mobilisierung für die Gesetzesinitiative auf Netzwerke innerhalb und außerhalb des Parlaments aufzubauen und sie als Ressourcen zu nutzen (vgl. Schäfer 2001).

72 Allerdings auch ein riskanter Erfolg, denn externe Patronage kann zu einer Kontrolle des Protests und zur Demobilisierung führen (vgl. Klandermans 1998). Dies erlebten autonome Frauenhaus-Initiativen häufig, wenn sie sich auf eine Kooperation mit Parteien oder Wohlfahrtsverbänden einließen und in Folge bald die Steuerung des Projekts verloren (vgl. Pinl/Weg 1989). 
und als ImpulsgeberInnen für Verschiebungen der bestehenden gesellschaftlichen und politischen Koordinatensysteme. Dabei werden soziale Bewegungen nicht als Ansammlungen von Individuen verstanden, sondern als emergierte „mobilisierte Netzwerke von Netzwerken“ (Neidhardt 1985: 197), d.h. die Mobilisierungsbasis wird durch ProtestteilnehmerInnen gebildet, die bereits vor der Bewegungsaktivierung untereinander in Beziehung stehen. Die Kontaktnetzwerke gründen sich auf familiäre, freundschaftliche Bindungen, Vereinsmitgliedschaften, subkulturelle Zugehörigkeiten oder klassenbezogene Identifizierungen (Hellmann 1998a: 17ff.). Diese Basiskontakte prägen wesentlich die Sozialstruktur der jeweiligen Teilbewegung sowie die Formen und Inhalte ihrer kollektiven Identität.

Im Structural-Strains-Ansatz ist das kollektive Bewegungshandeln mit spezifischen Deutungen verbunden, in denen ,strukturelle Problemlagen, Deprivationserfahrungen und Erwartungsdiskrepanzen" definiert sind sowie eine „Verortung der jeweiligen Bewegung, ihrer Sympathisanten und Gegner im Gefüge gesellschaftlicher Interessenslagen und Machtstrukturen" deutlich wird (Brand 1998a: 34). Die StructuralStrains-Forschung typisiert die Neuen Sozialen Bewegungen der 1980erJahre als gesellschaftliche Formationen mit postmaterialistischen Wertmustern und einer humanistisch-emanzipativen Grundorientierung. Unter den ProtestträgerInnen in dieser Bewegungsperiode sieht man junge, hoch gebildete Personen dominant vertreten. Sie werden als besonders sensibel für die sozialen Folgen gesellschaftlicher Veränderungen angesehen und werden beruflich vorrangig in kulturellen oder sozialen Dienstleistungsbereichen tätig (vgl. Brand 1998a: 37).

Den NSB wird in diesem Theorieansatz ein wichtiges gestalterisches Potential für die repräsentative Demokratie zugeschrieben. Die Bewegungen produzieren Visionen für die Entwicklung eines globalen, zivilgesellschaftlich gestützten, egalitären Gesellschaftsentwurfs. Sie weisen auf zentrale gesellschaftliche Konfliktthemen hin und können als politische AkteurInnen einen kulturellen Gegenpol im Modernisierungsdiskurs bilden.

Nach Dieter Rucht dagegen entstehen soziale Bewegungen ,in unmittelbarem Gefolge von Modernisierungsschüben“ und als Folge „sozialer Verwerfungen“. Soziale Bewegungen sind Kollektive, die sich in „Krisen der Sozialintegration" formieren (Rucht zit. n. Brand 1998a: 43). Sie haben meist minderheitliche Interessen, die sich nicht an die dominanten Diskurse anschließen (vgl. Rucht 1997). Sie eignen sich öffentlichen Raum an, nicht - oder zunächst nicht - um gesellschaftliche Veränderungen einzuleiten oder um staatliche Verwaltungen politisch unter Druck zu setzen, sondern um ihre eigenen Handlungsräume zu erweitern. Dabei fühlen sie sich häufig als „Außenseiter“ marginalisiert, „die 
sich mit ihren Anliegen im politischen Betrieb nicht angemessen repräsentiert und von ,den Herrschenden' nicht hinreichend berücksichtigt finden“" (Neidhardt/Rucht 1999: 130). NSB sind somit eher als „bürgerschaftliche Selbsthilfe“ oder "advokatische Interessensvertretung“ zu definieren, die mit kritischen Gegenöffentlichkeiten auch als „Korrektive etablierter Politik“ wirken können.

Nach Karl-Werner Brand bieten NSB „,reflexive Formen“ der Selbstthematisierung moderner Gesellschaften“" (Brand 1998a: 49) an, weil sie auf die bedrohlichen Wirkungen des technisch-industriellen Fortschritts, die Unzulänglichkeiten des repräsentativen Demokratiemodells und die Gefahren des wirtschaftlichen Wachstums aufmerksam machen. In einer Gesellschaft, die sich in funktionale Teilsysteme differenziert hat, entdecken sie Konfliktthemen, die außerhalb dieser Differenzierung liegen (vgl. Hellmann 1998a). Mit der Perspektive auf „Zivilgesellschaft“ lassen sich NSB als intermediäre AkteurInnen bestimmen, die nicht nur nationalpolitisch zur wechselseitigen Vermittlung von Staat und Gesellschaft beitragen, sondern auch globalisierungspolitisch agieren, „durch weltweite Rezeption kritischer Expertise, durch programmatischen Austausch und die wechselseitige Übernahme von Organisations- und Aktionsmodellen sowie durch die internationale Vernetzung" (Brand 1998a: 49).

\section{Political Opportunity Structures (POS-Ansatz)}

Der Political-Opportunity-Structures-Ansatz nimmt die politischen Rahmenbedingungen für das Entstehen und die Entfaltungschancen Neuer Sozialer Bewegungen in den Blick. Forschungsziel ist es zu identifizieren, welche externen Bedingungen die Mobilisierungen und den Protest begünstigen und welche Umstände, Reaktionen und reflexiven Prozesse in Politik und gesellschaftlicher Öffentlichkeit, ihnen Grenzen setzen (vgl. Rucht 1994, 1998; Koopmans 1998; Brand 1998b; Hellmann 1998a).

Nach Dieter Rucht beziehen sich die Gelegenheitsstrukturen, die als Katalysatoren für die NSB-Entwicklungen wirken, vorrangig - und dem Structural-Strains-Ansatz ähnlich - auf gesellschaftspolitische und strukturelle Entwicklungen. Weniger bedeutsam sind dagegen kulturelle Prozesse. Selten sind die Political Opportunity Structures eindeutig interpretierbar, häufig werden sie von den Bewegungsteilnehmenden unterschiedlich wahrgenommen und erhalten ihre Bedeutung erst im Framing der Bewegung, d.h. durch einen aktiven Prozess der Perzeption und Präsentation (vgl. Benford/Snow 2000: 631).

Empirisch ist nach Dieter Rucht zwar nachweisbar, dass Gelegenheitsstrukturen Mobilisierungsverläufe von NSB begünstigen, wesentlich bedeutsamer als sie aber erscheinen historische Schlüsselereignisse, 
„precipitating incidents“ oder „suddenly imposed grievances“ (Rucht 1998: 123). Er empfiehlt deshalb, zwischen den struktur- und den ereignisbezogenen Erklärungen nur eine „fließende Grenze“ zu ziehen (a. a. O.: 125)..$^{73}$

Außerdem müssen Bewegungsanalysen nach Dieter Rucht auch die internen Bedingungen der Bewegungen als entscheidende Protestfaktoren berücksichtigen, denn Bewegungen können auch selbst politische Gelegenheitsstrukturen gestalten und sich förderliche Bedingungen schaffen, z.B. indem sie durch die Wirkungserweiterung ihrer Konfliktthemen neue Verbündete gewinnen (vgl. Rucht 1998).

In der feministischen Frauenbewegungsforschung hat der POS-Ansatz wenig Beachtung gefunden. Die POS-Konstruktionen lassen sich nach Ilse Lenz und Brigitte Schneider nicht auf die Neuen Frauenbewegungen übertragen. Die NFB wären weder auf Öffnungen des Systems gestoßen noch wären sie durch politische Allianzen gestützt worden, vielmehr wurden sie eher aus dem öffentlichen Diskurs ausgegrenzt (vgl. Lenz/Schneider 2004). Allerdings weisen die beiden Autorinnen darauf hin, dass der POS-Ansatz für die Analyse von Wandlungsprozessen im politischen System und in den Elitenkonstellationen hilfreich sein könnte, um Einflussnahmen der Neuen Frauenbewegungen auf die politische Verwaltung und ihre EntscheidungsträgerInnen zu verfolgen und einen politischen und institutionellen Wandel zu erklären (vgl. Lenz/Schneider 2004).

\subsubsection{Die umstrittene Klassifizierung der Neuen Frauenbewegungen als NSB}

Nach Regina-Maria Dackweiler hatte die NSB-Forschung die Neuen Frauenbewegungen zunächst wenig beachtet. Die Frauenbewegungen entwickelten eine andere Dynamik als die Neuen Sozialen Bewegungen und wurden in der Debatte um „Macht- versus Kulturorientierung“ als

Dazu analysierte Dieter Rucht die Bewegungsdynamik der bundesdeutschen Protestbewegungen mithilfe der von McAdam definierten politischen Gelegenheitsstrukturen. Die statistischen Daten dafür liefert eine Erhebung von Ruud Koopmans und dem Prodat-Projekt des Wissenschaftszentrums Berlin. In der Untersuchung wurde der Mobilisierungsverlauf der Bewegungen durch eine Auswertung der Zeitungsberichterstattungen über Protestereignisse für den Zeitraum Mitte der 1970er-Jahre bis zum Mauerfall erfasst. Durch diese Erhebungsmethode haben allerdings nach Dieter Rucht Friedensbewegung und Anti-Atomkraftproteste sehr hohe statistische Effekte auf die Ergebnisse (vgl. Rucht 1998), während soziale Bewegungen, die wie die Neuen Frauenbewegungen oder die internationalistischen Solidaritätsgruppen weniger öffentlichen Protest und medial wirksame Aktionen als vielmehr Gegenöffentlichkeit, Aufklärung, Selbsthilfe und gegenkulturelle Strukturen organisierten, unterrepräsentiert seien. 
politisch weniger relevant eingeschätzt. Ihr gesellschaftspolitisches Transformationspotenzial wurde von der NSB-Forschung zunächst nicht gesehen, ihre Bewegungsziele wurden dem damals politisch wenig bedeutsamen Reproduktionsbereich zugeordnet.

Feministische Forscherinnen beteiligen sich in den 1980er- und 1990er-Jahren an den wissenschaftlichen Diskursen zur NSB eher distanziert kommentierend, die Differenzen zum männlichen und begrenzten Forscherblick scheinen ihnen unüberwindbar. Eine Zuordnung der Neuen Frauenbewegungen zu den Neuen Sozialen Bewegungen lehnen die meisten ab. Myra Marx Ferree und Carol McClurg Mueller sehen die elementare Emotionalität des Protests in den eher rational strukturierten Frames, wie sie die NSB-Forschung für ihre Analysen verwendet, nicht verstanden. SS- und POS-Ansätze fokussierten zudem nationale Veränderungen und folgen einem verkürzten etatistischen Verständnis von politischem Handeln. Die Transnationalität der NFB, die historischen Traditionen der Frauenbewegung und das breite Zielspektrum ließen sich mit den analytischen Instrumentarien der NSB-Forschung nicht erfassen (vgl. Ferree/McClurg Mueller 2008; auch Kontos 1988). Die NSB-Forschung sehe die sozialen Bewegungen vorrangig als Widersacher gegen das traditionelle Politiksystem und erkenne deshalb, so Barbara Riedmüller, nicht die innovative Kraft der NFB (vgl. Riedmüller 1988). Die NSB-Forschung verstehe nicht das Neue der Frauenbewegung, ihre Grenzverschiebungen zwischen öffentlicher Politik und privatem Bereich, die „Politikrelevanz des Privaten“ (Lenz/Schneider 2004: 136) und ihre neuen politischen Strategien wie die „Politik der Lebensführung“, die Selbstentwurf und Geschlechteridentität zum „Gegenstand multipler Optionen“ mache, um sich von Zwängen und Zuweisungen zu emanzipieren (Giddens zit. n. Kahlert 2005: 152). Stattdessen schreibe die Bewegungsforschung die traditionelle Trennlinie zwischen Privat und Öffentlich fort. Nach Bärbel Clemens sind die Themenstellungen der Neuen Frauenbewegungen universalistischer, sie betreffen keineswegs nur die Normen und Strukturen des Patriarchats, sondern setzen sich mit Strategien zu Dualismus und Egalität auseinander (vgl. Clemens 1989). Die Neuen Frauenbewegungen fordern nach Regina Dackweiler den gleichen StaatsbürgerInnenstatus in allen zivilrechtlichen, sozialen, politischen und kulturellen Dimensionen, aber sie weisen zugleich eine Angleichung der Frauen an die bestehenden patriarchalen Normen und Werte zurück. Nicht eine der „Brüderlichkeit“ entsprechende „Schwesterlichkeit" sei Leitnorm der feministischen Frauenbewegungen, sondern die Anerkennung der „Differenz in der Gleichheit“ (Dackweiler 2004a: 94). 
Die Protestmotive der NFB lassen sich nicht in den Entwicklungskrisen des Kapitalismus finden, sondern liegen in der „doppelten Vergesellschaftung der Frauen" (Becker-Schmidt 1987) begründet, den widersprüchlichen und ungleichzeitigen Entwicklungen zwischen Erwerbsund Familienarbeit und ihren Folgen für die Deklassierung und Diskriminierung von Frauen (vgl. Schäfer 2001; Dackweiler 1995).

Myra Marx Ferree und Carol McClurg Mueller plädieren für einen gegenderten Ressourcenblick auf die Bewegungen. Gerade in Zeiten staatlicher Repression können weibliche Widerstandsgruppen spezifische politische Gelegenheitsstrukturen nutzen und verfügen über besondere Ressourcen aus den domestic-based politics ${ }^{74}$.

Because gender segregation leaves an alternative geography of opportunity open to women more than to men, women's political openings and allies are more to be found in the institutional domains defines as ,apolitical': communities, grass-roots civic organizations, social work, and social services. (Ferree/McClurg Mueller 2008: 590)

Auch die kollektiven Aktionsformen der Neuen deutschen Frauenbewegungen entsprechen den Kritikerinnen zufolge nicht den Bewegungstypisierungen der NSB-Forschung. Die Neuen Frauenbewegungen zielen nicht auf Massenmobilisierungen für öffentliche Proteste, Kundgebungen und Demonstrationen, um ihre Anliegen gesellschaftlich sichtbar zu machen und den herrschenden Diskurs zu verändern; für die Neuen Frauenbewegungen besonders der 1970er-Jahre sind vielmehr Formen kollektiven Handelns typisch, die die Kommunikation zwischen den Akteurinnen fördern. Ilse Lenz und Brigitte Schneider erklären diese Bewegungsformen als eine Empowermentstrategie, denn die Frauen müssen sich aufgrund ihrer politischen Ausgrenzung als Bürgerinnen erst selbst erfinden (vgl. Lenz/Schneider 2004). In Kleingruppen und Frauennetzwerken schaffen sie sich eine eigene Öffentlichkeit, in der sie ihre privaten Erfahrungen von Ausgrenzung, Anpassung und Unterordnung kritisch hinterfragen. Sie gehen auf Distanz zu herrschenden Geschlechterrepräsentationen und Weiblichkeitsnormen, die sie verinnerlicht haben (vgl. a.a.O.: 136). Diese Schutzräume dienen auch der Verweigerung

74 Solche geschlechterspezifischen Widerstandsmöglichkeiten nutzten z.B. die Mütter der Plaza del Mayo in Argentinien, die Bewegung Mujeres Po la Vida unter der chilenischen Militärdiktatur Pinochets und die palästinensisch-israelische Frauenfriedensbewegung Women in Black. 
und haben in den verschiedenen Entwicklungsphasen der NFB eine konstant hohe Bedeutung75.

Nach Myra Marx Ferree und Carol McClurg Mueller umfassen die Neuen Frauenbewegungen nicht nur die Protestbewegungen, sondern das gesamte, breite, strategische Spektrum der Frauenaktivistinnen, d.h. die institutionellen Vertreterinnen mit Expertinnenwissen, die Frauenforscherinnen, die Aktivistinnen der Protestbewegungen, die basisdemokratischen Austauschgruppen und die alternativ lebensweltlichen Projekte (vgl. Ferree/McClurg Mueller 2008). Damit sind für die NFB andere Kollektivbildungen als in den NSB charakteristisch. Die Frauenbewegungen verhandeln nach Ilse Lenz keine pragmatischen Interessenrahmen, sondern gründen sich auf Austausch und Auseinandersetzungen. Diskurse sind ein stetes Strukturelement der Neuen Frauenbewegungen und bringen die differenten Bewegungseinheiten immer wieder neu zusammen ${ }^{76}$ (vgl. Lenz 2001a; Lenz/Schneider 2004; Lenz 2008). Die Neuen Frauenbewegungen zeichnen sich aus durch „nicht angeleitete Prozesse von kulturell-symbolischen Veränderungen und Bewusstseinswandel“" (Lenz 2001b: 195). Sie organisieren sich durch ihre eigenen vielfältigen Dokumentations- und Publikationstätigkeiten und durch separatistisch organisierte Semiöffentlichkeiten (vgl. Schäfer 2001; Lenz 2001a, 2008) 77

75 Selbstbefreiung und Empowerment standen nach Regina Dackweiler auch im Mittelpunkt der politischen Ziele der internationalen Frauenbewegungen (vgl. Dackweiler 2004: 99; Wichterich 2004).

76 Auch konservative Frauengruppen galten den mehrheitlich linken Frauengruppen als bewegungszugehörig, weil sie für Mütter mehr gesellschaftliche Anerkennung und Schutz forderten. Über die Linke-Rechts-Polarisierungen hinweg gelang es verschiedenen Gruppierungen der NFB, gemeinsame Mobilisierungen und Projekte zu organisieren. Dies brachte ihnen immer wieder den Vorwurf des „Unpolitischen“ ein (vgl. Kontos 1986). Der Bündnispragmatismus findet sich auch bei den Frauenpolitikerinnen der Parteien und verschaffte ihnen immer wieder parteiübergreifende Durchsetzungsmehrheiten, für die sie aus den eigenen Reihen vielfach angefeindet wurden. Überregionale Konferenzen erfüllten wichtige organisatorische Funktionen (vgl. Ferree/McClurg Mueller 2008: 594). 


\subsubsection{Entwicklungsdynamiken der Neuen Sozialen Bewegungen}

Robert Michels sieht soziale Bewegungen als Vorstufen von Parteibildungen und ihren Zerfall durch Institutionalisierung als unausweichliche historische Gesetzmäßigkeit der Systemintegration $\mathrm{an}^{78}$. Auch nach Theo Pirker prägt die Bewegungsgeschichte ein „ehernes Gesetz der Kooptation"79 (Pirker, zit. n. Stöss 1987: 285; vgl. Rucht 1987). Diese Vorstellung eines zwangsläufigen Bewegungsverlaufs, „einer mehr oder weniger unausweichlichen Transformation von sozialen Bewegungen in fest gefügte und sich zum Selbstzweck gewordene Organisationen" (Rucht/Blattert/Rink 1997: 38) kritisiert die NSB-Bewegungsforschung. Sie definiert soziale Bewegungen und Parteien als unterschiedliche Formen kollektiven Handelns, für deren Interaktion es keine historisch-logischen Verlaufsmuster gibt. NSB besitzen gegenüber Parteien eine spezifische funktionale Stärke in der Fähigkeit zur öffentlichen Problemartikulation. Ohne taktische Rücksichtnahmen auf BündnispartnerInnen können sie sich ,jenseits der Logik der Koordinierung von Staat und Markt" (Eder 1994: 49) auf Wertfragen, diskursive Intervention und Expertise beziehen (vgl. Roth/Rucht 2008). Diese Gestaltungsoptionen ändern sich allerdings mit einer zunehmenden Verflechtung und Institutionalisierung der NSB. Mit der strategischen Ausrichtung der Bewegungen auf den Wandel staatstragender Organisationen steigt auch der Druck zu Kompromissen. „Institutionalisierung hebt zwar die Bewegung nicht auf, verringert aber ihre Dynamik. Kooperation wird wichtiger als Konflikt." (Raschke 2003: 16; vgl. Rendtorff 1986)

In den Neuen Frauenbewegungen wurden solche Entwicklungen der Kooperation und Institutionalisierung unterschiedlich bewertet. $\mathrm{Zu}-$ nächst wurden sie eher abgelehnt, Silvia Kontos kritisierte sie als eine „unheilige Allianz“, in der die Frauenbewegungen ihre Eigenständigkeit aufs Spiel setzen (vgl. Kontos 1986: 42). Die Übernahme feministischer Forderungen durch die Politik war nach Silvia Kontos unweigerlich verbunden mit einer Zerstörung feministischer Ziele:

Autonome Frauenpolitik wurde zunächst von den Frauen der Bewegung in immer neue gesellschaftliche Bereiche hineingetragen und dann von den traditionellen politischen Institutionen und Organisationen relativ schnell aufgegriffen und in spe-

78 Diskurse und Theorien zu den Institutionalisierungsverläufen: vgl. Rucht/Blatter/Rink 1997: 33-49.

79 Nach Max Weber konnten sich Institutionalisierungen auch wieder verflüssigen (vgl. Rucht/Blattert/Rink 1997). 
zifischer Weise verarbeitet, so daß mittlerweile jede gesellschaftliche Gruppierung, die auf sich hält, eine Frauengruppe, abteilung, -sektion, -stab oder -sekretariat hat und einige bereits von einem konservativen, liberalen, sozialdemokratischen oder Gewerkschaftsfeminismus sprechen. Bei genauerem Hinsehen zeigt sich jedoch, daß autonome Frauenpolitik bei der Rezeption durch die etablierten Parteien und Gruppen einem spezifischen Selektionsprozeß unterworfen wird, in dem alle die politischen Gehalte herausgefiltert werden, die über eine Modernisierung patriarchaler Grundstrukturen hinausführen (Kontos 1990: 62).

Mit der Institutionalisierung der NFB vollzieht sich nach Barbara Rentorff die Auflösung eines gesellschaftlichen Korrektivs ${ }^{80}$ :

Es ist auch nicht verwunderlich, dass die Frauenbewegung das Schicksal aller sozialpolitischen Bewegungen teilte: in demselben Maße, wie die Verbreitung frauenpolitischer Inhalte und Forderungen in den Medien zu einer Verbreitung der Diskussion und ihrer Verlagerung in die Öffentlichkeit geführt hat, hat sie auch den feministischen Inhalten Spitze und Radikalität genommen. (Rendtorff 1986: 176)

In der Bewegungsforschung der 1990er-Jahre wird dagegen das Verhältnis von Bewegung und Institution nicht mehr als komplementärer Gegensatz konstruiert. Institutionalisierungen sind nicht mehr Schlusstransformationen sozialer Bewegungen, vielmehr kann sich eine Bewegung selbst als Institution stabilisieren und bildet dann ein auf Dauer gestelltes Netzwerk, das Beständigkeiten in der Struktur und selbst geschaffene Regelsysteme aufweist (vgl. Rucht/Blattert/Rink 1997: 49ff.).

Auch in den feministischen Bewegungsdiskursen löst sich die Gegenüberstellung von Institution und Bewegung auf (vgl. dazu Pinl/Weg 1989; Lenz 2001, 2008; Brückner 2000; Gerhard 1991, 2006; Nave-Herz 1997; Doderer/Kortendiek 2004). Als Institutionalisierung gilt nicht mehr bloß die Unterstützung autonomer frauenpolitischer AkteurInnen

80 Vgl. dazu Beer/Rode 1986; Greven 1988; Krautkämper-Wagner 1989; Pinl 1989; Gerhard 1994; Henjes 1994; Rudolph 1994; Sauer 1997; Brückner 2000; Lenz 2002b; Dackweiler 2004b; Kramer 2013. „Die schmerzliche Kluft zwischen dem ursprünglichen visionären Projekt einer direktdemokratischen, scharf antipatriarchalen Politik und dem heutigen professionellen Einrichten in repräsentativen Demokratien könnte kaum größer sein.“ (Holland-Cunz 1998: 15) 
durch systemetablierte Organisationen ${ }^{81}$, sondern Institutionalisierungstendenzen werden bereits bewegungsintern identifiziert (vgl. Lenz/Schneider 2004). In den Projekten der autonomen Frauengruppen entwickelte sich mit der Expertise der leitenden Akteurinnen auch ihr Interesse an Professionalisierung, Arbeitsteilung und Formalisierung von Entscheidungsprozessen. Diese wurden gegen die Ansprüche der Bewegungsteilnehmerinnen auf radikale Selbstvertretung der Betroffenen und unbegrenzte partizipatorische Einflussnahmen in mühsamen Auseinandersetzungen erfolgreich durchgesetzt.

Zum anderen ist bereits in den Anfängen der NFB die Grenzziehung zwischen den autonomen Frauengruppierungen und den Frauenstrukturen in etablierten Verbänden umstritten und die konstruierte Abgrenzung von Autonomie und Institution durch vielerlei persönliche Verbindungen faktisch durchbrochen. Bereits in den Anfängen der NFB gibt es „frauenbewegte“ Frauen innerhalb der etablierten Organisationen, die Problemdeutungen und Forderungen der Neuen Frauenbewegungen aufnehmen und eigene Diskurse dazu entwickeln. Ilse Lenz beschreibt die Neuen Frauenbewegungen in ihrer Struktur aus unterschiedlichen Formationen von Frauenaktivistinnen in verschiedenen Gesellschaftssegmenten als ein „samtenes Viereck“, in dem autonome Netzwerke, institutionelle Verbände, Politikerinnen und Wissenschaftlerinnen teils aktiv kooperierten, teils parallel Einfluss nehmend sich gegenseitig verstärkten (vgl. Lenz 2008: 33).

Vielerlei gesellschaftliche Reformen wurden durch die NSB in Gang gesetzt. Die außerparlamentarischen Bewegungen haben Veränderungsprozesse der Parteien angestoßen und erheblich beeinflusst. Sie konfrontieren die etablierten Eliten mit kollektivierten sozialen Anliegen authentisch und themenbezogen und korrigieren auf diese Weise die Selektionsmechanismen der etablierten Systeme der Interessensvertretung. Dabei setzen sie neue Themen, Problemidentifikationen und verdrängte Fragen auf die politischen Agenden (vgl. Rucht 1997; Rucht/Blatter/Rink 1997; Raschke 1987, 2003; Roth 1988) ${ }^{82}$. Die BewegungsakteurInnen werden von den BewegungstheoretikerInnen deshalb als eine

81 Im Zuge der feministischen Projektebewegung entstanden vielerorts Kooperationsbeziehungen zu Personen in der Sozialadministration. Häufig waren mit den neuen Finanzierungen der Frauenprojekte auch Einflussnahmen auf die Zielsetzung und Leistung verbunden (vgl. dazu Schäfer 2001).

82 Roland Roth und Dieter Rucht definieren fünf Dimensionen, in denen Neue Soziale Bewegungen bedeutungsvoll auf das Parteiensystem einwirken: 1. Sie setzen neue Themen auf die Agenda, indem Probleme, die vormals als individuelles Schicksal oder Misslichkeit galten, zu einem gesellschaftlich produzierten und politisch veränderbaren Problem umdefiniert werden; 2. sie verschaffen neuen sozialen Sicherungsleistun- 
„demokratische Produktivkraft“"83 (Rucht 1997: 382) angesehen, der im Vermittlungsprozess zwischen BürgerIn und Staat und neben den etablierten Parteien und Verbänden eine eigenständige und tragende Rolle zukommt (vgl. Rucht 1997; Eder 1994). Allerdings sind die Neuen Sozialen Bewegungen in dieser Machtkonstellation nur Teil eines Vermittlungsprozesses. Sie können ein gesellschaftspolitisches Problem thematisieren, ihm durch Mobilisierungen und öffentlichen Druck Bedeutung verleihen sowie ein Konzept für seine Beseitigung entwickeln, aber für die Realisierung seiner Lösung sind sie auf die Parteien als Verhandlungsermächtigte angewiesen, denn was in Demokratien gesellschaftliche Geltung erhalten soll, wird in politischen Gremien entschieden (vgl. Stöss 1987).

Um die Anerkennung der NSB als politische Mitakteurin in der repräsentativen Demokratie der BRD wurde in den parlamentarisch ausgerichteten Parteien lange Jahre gerungen - auch in der SPD, obwohl sich zahlreiche Mitglieder, insbesondere unter der Jugend und den Frauen, aktiv an den Bewegungen beteiligten. Viele frauenpolitische Aktivistinnen in der SPD fühlten sich den Neuen Frauenbewegungen zugehörig, nahmen deren gesellschaftspolitische Kritiken und Weltsichten in die eigenen Politikkonzepte auf und ließen sich von den neuen Aktionsformen inspirieren. Das nächste Kapitel stellt die Entwicklung der Neuen Frauenbewegungen und diejenigen der feministischen Diskurse vor, die für diese ASF-Strömung wichtig waren und den frauenpolitischen Wandel der SPD beeinflusst haben.

gen (Frauenhaus, Berufsförderungsinitiativen, Notruftelefon für Frauen; Beratungsstellen) Anerkennung gegen das Verwaltungsmonopol etablierter Verbände; 3. sie stoßen die Veränderung von Institutionen (Gleichstellungsbeauftragte, Umweltämter) und prozeduralen Abläufen an, die den BürgerInnen größere Mit- und Einwirkungsrechte verschaffen (vgl. Brokdorf-Urteil des BVG 198582); 4. sie setzten durch ihren kontinuierlichen Protest die Akzeptanz des Protests als akzeptierte Form der Meinungsäußerung durch; 5. sie schaffen durch eine wachsende Beteiligung und soziale Verbreiterung zivilgesellschaftlicher AkteurInnen (ÄrztInnen, PolizistInnen, HochschullehrerInnen) eine Verstetigung der Bewegungsstrukturen, indem sich ein Netzwerk aus Gruppen, Initiativen und Kommunikationszentren herausbildet und „Netzwerkknoten“ Ressourcenmobilisierung übernehmen (vgl. Roth/Rucht 2008: 6ooff.).

83 Die Neuen Sozialen Bewegungen wurden als ein Charakteristikum der Moderne (vgl. Roth/Rucht 2008) definiert, das in „Risikogesellschaften“ (Beck 1986, Buchtitel) Foren der kritischen Beobachtung und steuernden Intervention schafft, in denen „Folgen und ,Selbstgefährdungspotentiale' der technisch-industriellen Entwicklung“ (Brand 1998: 49) thematisiert werden können, jenseits der traditionellen Interessensvermittlung und der bisher gültigen Cleavages (vgl. Eder 1994; Neidhardt/Rucht 1993). Sie bereiten damit den Boden für zivilgesellschaftliche und integrative Gesellschaftsformen einer „reflexiven Modernisierung“ (Beck/Giddens/Lash 1996b: 19ff.) und eröffnen so neue Möglichkeiten für eine deliberative Demokratie (vgl. Jürgen Habermas 1995). 


\subsection{Die Neuen Frauenbewegungen der 1970er- bis 1990er-Jahre in der BRD}

In der Sozialdemokratischen Partei trafen die Impulse der Neuen Frauenbewegungen auf einen schwelenden frauenpolitischen Unmut in der Partei und schlugen vermutlich die Funken für die Mobilisierung der sozialdemokratischen Frauenorganisation. Junge, Ende der 196oer-Jahre eingetretene Parteimitglieder bildeten mit parteierfahrenen Genossinnen frauenbewegte Kreise in der Partei, die unter den weiblichen Mitgliedern eine wachsende Unterstützung erfuhren. Für einzelne Jungmitglieder war die Aktionsfähigkeit der autonomen Frauengruppen oft attraktiver als die Parteiarbeit und sie verlagerten ihr Engagement in die selbstorganisierten Frauengruppen. Für die Mehrheit der ASF-Aktivistinnen allerdings war die Partei der politische Handlungsrahmen und sie beschränkten die Zusammenarbeit mit den autonomen Frauen auf pragmatische Kooperationsaktivitäten, vorrangig um frauenpolitische Selbsthilfeprojekte durch öffentliche Bezuschussung zu realisieren. Obwohl die gestandenen sozialdemokratischen Parteifrauen das politische Selbstverständnis und die gesellschaftlichen Strategien der autonomen Frauengruppen zutiefst ablehnten, wie noch zu zeigen sein wird, griffen sie verschiedene gesellschaftspolitische Thematisierungen der Neuen Frauenbewegungen auf und versuchten zeitweise, basisdemokratische Mobilisierungsformen in ihren eigenen Organisationsstrukturen und Aktionsfeldern zu realisieren.

Im Folgenden werden die Entwicklungen der Neuen Frauenbewegungen, ihre Transformationen und Diskurse, vorrangig im Forschungszeitraum, vorgestellt (vgl. Beauvoir 2005; Becker-Schmidt 1987; BeckGernsheim 1981, 1985; Beer 1984; Bennholdt-Thomsen 1985; BennholdtThomsen/Mies/Werlhof 1983; Bock/Duden 1976; Brückner 200o; Clemens 1996; Dackweiler 1995; Doderer/Kortendiek 2004; Fraser 1989, 2005; Frevert 1986; Gerhard 1991, 1999; Gilligan 1982; Hageman-White 1992; Haug 1996, 2004; Hervé/Doormann 1987; Hoecker 1995; HollandCunz 1998, 2003; Jansen 1986; Janssen-Jurreit 1976, 1979; Kahlert 2004; Kleinau 1985; Knapp 1992, 1997; Kontos 1990, 1994; Kreisky 1995; Lenz 1995, 2000a, 2002a, 2002b, 2004a, 2004b; Libreria delle donna di Milano 1989; Lorber 2004; Maleck-Lewy/Penrose 1995; Meyer 1991, 1997; Mies 1983; Müller 1993; Nickel 2008; Notz 2011; Pinl/Weg 1989; Pateman 1988; Penrose 1996; Riedmüller 1988; Rommelspacher 2006; Sauer 1994a,b, 1999, 2001a,b; Schaeffer-Hegel 1990; Schunter-Kleemann 2011; Schwarzer 1975,1981; Thiessen 2004; Thürmer-Rohr 1997, 2004; Werlhof 1978; Wetterer 1994, 1995; Wichterich 2004; Young 1991). Die Darstellung basiert 
im Wesentlichen auf der umfangreichen Studie von Ilse Lenz und der darin zusammengetragenen Dokumentensammlung (vgl. Lenz 2008).

Die Neuen Frauenbewegungen gehören nach Ilse Lenz zu den erfolgreichsten zivilgesellschaftlichen Protestbewegungen gegen soziale Ausgrenzung und Ungleichheit in der deutschen Nachkriegsgesellschaft. Sie entstanden an verschiedenen sozialen Orten und formierten sich als politische Mobilisierungen gleichzeitig, divers und sich gegenseitig beeinflussend ${ }^{84}$ (vgl. Lenz 2008). Ilse Lenz definiert sie als AkteurInnen und über ihre gemeinsamen Anliegen, Artikulationen und Wirkungen:

Frauenbewegungen sind mobilisierende kollektive AkteurInnen, die sich in verschiedenen sozialhistorischen Milieus entwickeln. In ihnen setzen sich Personen unter maßgeblicher Beteiligung von Frauen für einen grundlegenden Wandel der Geschlechterverhältnisse und damit verbundener gesellschaftlicher Ungleichheiten und Abwertungen ein. Sie kritisieren die herrschenden gesellschaftlichen Leitbilder, Normen und Diskurse und entwerfen Alternativen, die zu neuen Normierungen führen können. Frauenbewegungen artikulieren sich in und zu Modernisierungsprozessen und tragen auf vielfältige Weise $\mathrm{zu}$ ihnen bei, indem sie sie fördern, beeinflussen oder auch hemmen und kanalisieren, (Lenz 2004c: 666, Hervorhebung im Original)

Die Neuen Frauenbewegungen zielen auf persönlichen, politischen und kulturellen Wandel. Ihre Kritik an der herrschenden Geschlechterordnung umfasst sowohl eine Veränderung gesellschaftlicher Strukturen sowie staatlicher Regulationen und Regulative als auch eine Veränderung von Lebensweisen, kulturellen Praktiken und gesellschaftlichen Leitbildern (vgl. Gerhard 2008).

84 Im Folgenden wird die Pluralform „Neue Frauenbewegungen“von Ilse Lenz (vgl. Lenz 2008) übernommen, um die Vielfältigkeit der Mobilisierungen und die Verschiedenartigkeit der Diskurs- und Organisationsformen zu kennzeichnen. 


\subsubsection{Entwicklungsphasen der Neuen Frauenbewegung und Transformationen ${ }^{85}$}

Die westdeutschen Neuen Frauenbewegungen (NFB) mobilisierten sich im Zuge der Jugend- und Studierendenbewegung in den 196oer-Jahren und entwickelten sich in enger Verbindung zu den Neuen Sozialen Bewegungen. Anstöße erhielten die ersten Aktivistinnen durch die Texte und Aktivitäten der französischen und US-amerikanischen Feministinnen. Als structural strains für die massenhafte Mobilisierung der Frauen gilt, dass der Bildungsaufstieg der Frauen ab den 1960er-Jahren zunehmend mit ihren Ausgrenzungen in der Politik und auf dem Arbeitsmarkt in Konflikt geriet. ${ }^{86}$

In den Auseinandersetzungen zur Reform des §218 Anfang der 1970er-Jahre entstanden in vielen Städten Protestbewegungen gegen die Strafbarkeit des Schwangerschaftsabbruchs. Sie wurden mehrheitlich von Frauen getragen und mobilisierten TeilnehmerInnen weit über das Milieu der SchülerInnen und StudentInnen hinaus (vgl. Lenz 2008).

Die erste gemeinsame Konferenz, der Bundesfrauenkongress im März 1972, wird als Beginn der westdeutschen Frauenbewegungen definiert ${ }^{87}$, denn an ihm beteiligten sich - von den Veranstalterinnen unerwartet - über 400 Frauen aus 20 Städten (vgl. Notz 2011: 83).

In den frühen 1970er-Jahren organisierten sich in der NFB in großer Zahl Selbsterfahrungsgruppen. Hier suchten die Frauen nach Wegen der Emanzipation auf der Basis ihrer ,individuellen Subjektpotentiale und Lebenschancen" (Lenz 2008: 22), inspiriert von der US-amerikanischen Consciousness-Raising-Bewegung. In dieser Phase der Selbstfindung und

85 Ilse Lenz teilt den Verlauf der Neuen Frauenbewegungen in vier Phasen auf: 1968 1975: Bewusstwerdung und Artikulation, 1976 - 1980: Pluralisierung und Konsolidierung, 1980 - 1989: Professionalisierung und institutionelle Integration, 1989 - 2005: Globalisierung, deutsche Vereinigung und Postfeminismus. In diesen Phasen weisen die Frauenbewegungen spezifische Konstellationen auf, die sich durch Transformationen der Bewegungen gebildet haben. Die Phasen unterscheiden sich anhand der Dimensionen Trägerschaft, Diskurse, Organisationen und Semiöffentlichkeit (vgl. Lenz 2008: 25). In ihrer Quellensammlung Die neue Frauenbewegung in Deutschland. Abschied vom kleinen Unterschied werden diese Phasen mit umfangreichen Textsammlungen dokumentiert (vgl. Lenz 2008).

86 „Die neue Frauenbewegung hat ihren Ursprung u.a. in dem zunehmenden Spannungsverhältnis zwischen gestiegener Bildung und beruflicher und politischer Ausgrenzung im Wohlfahrtsstaat." (Lenz 2008: 39)

87 In den eher auf das StudentInnenmilieu bezogenen Erzählungen ist ein Tomatenwurf das Fanal des Aufbruchs der Neuen Frauenbewegungen. Danach warf Sigrid Rüger auf der SDS-Delegiertenversammlung am 12.09.1968 Tomaten auf die Konferenzleitung, nachdem der Beitrag von Helke Sander, die im Namen des Aktionsrats zur Befreiung der Frau sprach, von der Tagungsleitung ignoriert worden war. Der Tomatenwurf symbolisierte, dass die Frauen diesen Umgang mit ihnen als Gewalt empfanden und den Dialog aufkündigten (Notz:2006). 
„Selbsterfindung“ (Holland-Cunz 2003: 146) wurden die individuellen Erfahrungen und Wünsche mit Erwartungen und Visionen der neuen Bürgerrechts- und Alternativbewegungen verbunden. Während die Frauenbewegungen der Jahrhundertwende des 19./20. Jahrhunderts vorrangig für Staatsbürgerrechte und gleiche Bildungs- und Lebenschancen kämpften, bestimmten die Neuen Frauenbewegungen Fragen nach einer anderen Lebensweise, einer Alternative zum industriellen Wachstum, nach Selbstbestimmung und Selbstentfaltung (vgl. Gerhard 1999). Mit der Parole „Das Private ist politisch“ wurden Grenzziehungen seitens der Politik in Frage gestellt. Die Ehe wurde als Leibeigenschaft der Frauen kritisiert, sexuelle Unterdrückung wurde als kollektive Erfahrung erlebt, Schutz und Sicherheit vor männlicher Gewalt auch in der Privatsphäre der Familie gefordert. Themen wie Liebe, Sexualität, Beziehungen, Hausarbeit sollten enttabuisiert und verhandelbar werden. Gleichzeitig klagten die sog. frauenbewegten Frauen den Sozialstaat und seine Interventionen als diskriminierend an, seine Regulierungen der Sexualität und Partnerschaft als bevormundend und als Schutz von patriachalen Gewaltverhältnissen (vgl. Meyer 1991).

Die NFB organisierte sich vorrangig in lokalen Kleingruppen, die durch verschiedene Aktivitäten und Konferenzen und durch persönliche und politische Netzwerke miteinander verbunden waren. Wie die antiautoritäre Bewegung traten die frauenbewegten Frauen für eine basisdemokratische Grassroots-Organisierung ein und lehnten die Kooperation mit dem Staat, mit den etablierten, hierarchisch strukturierten Interessensverbänden und mit bürokratischen Massenorganisationen, wie den Gewerkschaften und Parteien, ab. Auf der ersten nationalen Frauenkonferenz 1972 definierten sich die versammelten Frauen als eigenständige gesellschaftliche Bewegung und beschlossen, Männer aus ihren Reihen auszuschließen, ,so lange Frauen in besonderer Weise und mehr unterdrückt sind als Männer" (Protokoll des Abschlussplenums zit. n. Lenz 2008: 87$)^{88}$.

In der zweiten Hälfte der 1970er-Jahren entwickelte sich in den Neuen Frauenbewegungen Projekte, zunächst als Selbsthilfegruppen, später auch als Hilfsangebote für Frauen und Mädchen (vgl. Meyer 1991; Doderer/Kortendiek 2004; Lenz 2008) ${ }^{89}$. Diese Projekte schufen ein soziales Angebot für Betroffene oder Interessierte, lenkten aber auch

88 Der Separatismus war ein besonderes Kennzeichen der deutschen Neuen Frauenbewegungen (vgl. Brüssow 1996).

89 Die ersten Selbsthilfegruppen organisierten Gesundheitsberatung, gynäkologische Selbstuntersuchungen, Selbstverteidigung (vgl. Meyer 1991: 41) oder begleitete Fahrten zu Abtreibungskliniken (,wir fahren nach Holland nicht der Tulpen wegen“, vgl. dazu 
gleichzeitig die öffentliche Aufmerksamkeit auf einen sozialpolitischen Missstand (vgl. Brückner 200o). In vielen Städten entstand eine Infrastruktur „von Frauen für Frauen“ bestehend aus Cafés und Kneipen, Buchhandlungen, Gesundheitszentren, Werkstätten, Musik-, Film- und Theatergruppen. In eher ländlichen Regionen wurden Frauenferienhäuser und -bildungsstätten gegründet. Die Projekte wurden in Selbstverwaltung organisiert ${ }^{\circ}$.

In dieser Zeit der Erweiterung von Aktionsfeldern bildeten sich in und zu den Projekten politische Strömungen und Teilbewegungen in den NFB, die sich als eigenständige Organisationen mit eigenen Diskursen formierten ${ }^{91}$. Manche beteiligten sich in der selbst organisierten „Bewegungsöffentlichkeit" (Lenz 2008: 30) aus Frauenzeitschriften ${ }^{22}$ und Frauenliteratur sowie auf Konferenzen, die von mitgliederstarken Frauengruppen und Netzwerken organisiert wurden und thematisch meist eine Mixtur unterschiedlicher Fragen und Reflexionen anboten ${ }^{93}$, andere suchten keinen Anschluss und die Auseinandersetzung mit anderen Frauengruppen nicht.

Zusammenfassend lässt sich die Entwicklung der Frauenprojektebewegung beschreiben als Profilgewinn - im Sinne einer Professionalisierung der Anliegen von Frauen, aber auch als Identitätsverlust - im Sinne schwindender, gemeinsamer frauenpolitischer Ansätze. (Brückner 2000: 78f.)

Parallel zur Bildung von autonomen Frauengruppen in den 1970er-Jahren hatten auch in den etablierten Verbänden und Organisationen, Kirchen, Wohlfahrtsorganisationen sowie in Parteien und Gewerkschaften Frauen begonnen, eigene Anliegen offensiver zu artikulieren und sich gestärkt durch den sprunghaften Anstieg der weiblichen Mitglieder - in

Pinl/Weg 1989). Später kamen Initiativen in den Bereichen Bildung, Gesundheit/Körper/Sexualität, Gewalt gegen Frauen, Kultur dazu.

90 Im Handbuch Frau konnten bereits 1978110 Adressen von Frauenberatungsstellen und Fraueninitiativen aufgeführt werden (vgl. Notz 2011: 85)

91 Die erste Abgrenzung durch die Formierung einer eigenen Teilbewegung organisierten die Lesben in der Frauenbewegung. Sie bildete eine Folie für die weitere Differenzierung und Pluralisierung der Neuen Frauenbewegungen (vgl. Lenz 2008)

92 Im Juni 1976 erschien die erste Ausgabe der in Berlin gegründeten linksfeministischen Zeitschrift Courage, Anfang 1977 die erste Ausgabe der Emma, die sich auf einen politisch breiten Leserinnenkreis orientierte. deren redaktionelle Arbeit Alice Schwarzer dominierte, der Vertrieb war kommerzialisiert. Die Zeitschrift Emma hatte wenig Einfluss auf die autonome, aber große Bedeutung für die institutionalisierte Frauenbewegung.

93 Erst die 7. Bremer Frauenwoche 1989 bot eine Konferenz an, die diese Form durchbrach und sich ausschließlich mit dem Thema der Reproduktionstechnologien beschäftigte (vgl. Geraedts et. al. 1989). 
eigenen Foren und Netzwerken zu organisieren. Im Laufe der 1970erJahre fanden feministische Ideen und Diskursen in diesem institutionellen Teil der NFB immer größere Resonanz. Ilse Lenz bezeichnet diesen Entwicklungsabschnitt der NFB als „Phase der Pluralisierung und Konsolidierung" (Lenz 2008: 28).

Die frauenpolitischen Akteurinnen in den etablierten gesellschaftlichen Organisationen förderten die Institutionalisierung der Neuen Frauenbewegungen in den 1980er-Jahren (vgl. Lenz 2008: 32f.). In der öffentlichen Verwaltung wurden die sog. Frauenbeauftragten eingerichtet, zunächst auf Bundes- und Länderebene, dann auch in den kommunalen Verwaltungen ${ }^{94}$. Ihre Aufgabe war, durch Information, Beratung und Entscheidungsvorbereitung (vgl. Krautkrämer-Wagner 1989) in der Politik und Verwaltung beizutragen, die Diskrepanzen zwischen rechtlicher Gleichstellung und faktischer Ungleichheit der Geschlechter abzubauen ${ }^{95}$. Allerdings wurden die Frauen- und Gleichstellungsbeauftragten meist mit unzureichenden Befugnissen ausgestattet. In den Kommunen entwickelten sich vielerorts Kooperationen zwischen den institutionellen und den autonomen Frauen. Zum einen wurden die autonomen Frauenprojekte mit Fördermitteln dabei unterstützt, ihre Arbeit zu professionalisieren und ihre Strukturen durch bezahlte Mitarbeiterinnen zu stabilisieren, zum anderen nutzen die kommunalen Gleichstellungs- oder Frauenbeauftragte die Verbindungen zu zivilgesellschaftlichen Fraueninitiativen um ihre Verhandlungsposition in der Verwaltung zu stärken. Die Zusammenarbeit entsprach der erklärten Politik der UN-Frauenkonferenz ${ }^{96}$, differenziertere Interventionskonzepte gegenüber den patriarchalen Institutionen zu entwickeln und „den Staat nicht aus der Verantwortung für sozialen Ausgleich und Wohlfahrt [zu] entlassen“ (Wichterich 2004: 13).

Innerhalb der NSB-Teilbewegungen hatten sich themenspezifische Frauengruppen formiert. Sie entwickelten und repräsentierten dort geschlechtsspezifische Konfliktperspektiven wie die Gruppen der Frauenfriedensbewegung, der Frauenumweltbewegung und der internationalen Frauensolidarität. Sie verstanden sich als Teil der NFB und nahmen teil

94 Bis Ende der 1980er-Jahren hatten bereits mehr als 300 Kommunen solche Stellen geschaffen.

95 Uta Krautkämper-Wagner berichtet, dass in der Ministerialverwaltung des Saarlandes 1950 ein Frauenamt und in Bayern 1971 ein Frauenreferat eingerichtet wurde, beide Instanzen waren jedoch nicht nur für Frauenthemen zuständig.

96 Zur Darstellung der frauenpolitischen Debatten der UN-Konferenzen von 1975, 1980, 1985 vgl. Wichterich 2004. 
an den frauenpolitischen Diskursen, in denen in dieser Zeit differenztheoretische Ansätze ${ }^{97}$ dominierten.

In der zweiten Hälfte der 1980er-Jahre wurden Lehrstühle zur Frauenforschung an den Universitäten eingerichtet. Die Frauenforschung kritisierte den androzentristischen Wissenschaftsbetrieb und hatte nach dem Postulat der „Betroffenheit und Parteilichkeit“ (Maria Mies 1978 zit. n. Thiessen 2004: 36) den Anspruch, als analytischer und kritisch-reflexiver Teil des interventionistischen Frauennetzwerks frauenzentriertes Wissen für gesellschaftliche Veränderungen zur Verfügung zu stellen. In verschiedenen Themenfeldern und öffentlichen Debatten entwickelten sich enge Kooperationen zwischen frauenpolitischen Expertinnen in politischen Institutionen, autonomen frauenpolitischen Aktivistinnen und Genderforscherinnen wie z.B. zur Gewalt gegen Frauen, gegen Zwangsprostitution und internationalen Frauenhandel, zu den geschlechtssegmentierenden Bildungssystemen und Berufsmärkten. Die historische Phase der NFB von den 1980er-Jahren bis zum Mauerfall 1989 bezeichnet Ilse Lenz als „Phase der Professionalisierung und institutionellen Integration" (Lenz 2008: 357).

Die Neuen Frauenbewegungen haben ebenso wie die Neuen Sozialen Bewegungen die demokratische und sozialpolitische Entwicklung der Nachkriegsgesellschaft wesentlich mitgeprägt. In Steuerungskonflikten der Moderne (vgl. Beck 1986, 1996) boten sie neue Orientierungen gegenüber den ,traditionalen Rechtfertigungsgrundlagen politischer Institutionen" (Roth 1988a: 188). Gegen die konservativen Tendenzen zum „Kalten Krieg“, des „Starken Staats“ und der Revitalisierungen patriarchaler Familien- und Berufsstrukturen entwickelten sie neue demokratische Normen.

Dass sie einen hohen Einfluss auf die bundesrepublikanische Gesellschaft ausüben konnten, erreichten sie durch ihre Anschlussfähigkeit. Sie klagten nicht nur Gleichheitsrechte und das Recht auf Differenz ein, sondern setzten sich auch gegen staatliche Bevormundung und Normierung und für die Vielfalt von Lebensstilen und -chancen sowie für individuelle Selbstverwirklichung ein. Hiermit passten sie in eine Modernisierungsdynamik, in der auf der einen Seite dem bzw. der einzelnen BürgerIn höhere Gestaltungsfreiheiten eingeräumt wurden, sich auf der anderen aber unter dem Leitbild der Eigenverantwortung die Ansprüche an eine umfassende Fürsorgeverpflichtung des Staates verringern sollten. Wie in dieser Entwicklung humanistische, egalitäre und demokrati-

97 Die differenztheoretischen Ansätze bezogen sich auf die italienischen Philosophien des affidamento, den Ökofeminismus, feministische Subsistenztheorien und Matriarchatsforschungen (Veronika Bennholdt-Thomsen, Claudia von Werlhof, Maria Mies). 
sche Traditionen der Neuen Frauenbewegungen erhalten bzw. wiederbelebt werden können, bestimmte die frauenpolitischen Strömungen und Diskurse nachhaltig.

\subsubsection{Strömungen des Feminismus im Forschungszeitraum}

Ilse Lenz definiert vier grundlegende Strömungen der NFB entlang der Verschränkung von Geschlechterverhältnis, Herrschaftsanalyse und Handlungsorientierungen ${ }^{98}$.

1. Der „Gleichheitsfeminismus“ bezieht sich auf das dualistisch konstruierte Geschlechterverhältnis von Männerherrschaft und Frauenunterdrückung. Wie Simone de Beauvoir mit dem viel zitierten Satz „Man kommt nicht als Frau auf die Welt, man wird es." (Beauvoir 2005: 334) kritisiert Alice Schwarzer die Geschlechteridentität als eine psychische und gesellschaftliche Deformierung. Radikalfeministinnen sehen in der Unterdrückung der Frau durch den Mann das zentrale gesellschaftliche Herrschaftsverhältnis und fordern alle politisch aktiven Frauen dazu auf, sich vorrangig für eine Aufhebung des klassenübergreifenden Patriarchats einzusetzen (vgl. Schwarzer 1975; Millett 1985). Gleichheitsfeministinnen lehnen alle geschlechterbezogenen Arbeitsteilungen ab und verlangen, Frauen wie Männer in allen

98 Diese Strömungen differenzieren sich im Laufe der 1980er-Jahre durch neue Themen, Akteurinnengruppen und Strategieverschiebungen weiter. Ilse Lenz fasst diese Entwicklung nach zehn verschiedenen Strömungsdefinitionen zusammen (vgl. Lenz 2008: 31).

Barbara Riedmüller definiert 1988 fünf Strömungen entlang der sie prägenden Handlungsfelder: Der Karrierefeminismus kämpft für die Durchsetzung der Gleichheit in Politik und Beruf, der radikale Feminismus setzt auf die Befreiung durch Kritik der patriarchalen Herrschaftsverhältnisse, der liberale Feminismus verfolgt die Idee der Gleichstellung durch eine Veränderung der Institutionen und setzt auf die politische Reform, der linke Feminismus kämpft vorrangig für Reformen in der Berufs- und Arbeitswelt, der kulturelle oder spirituelle Feminismus setzt auf die Wiederentdeckung der weiblichen Geschichte und matriarchaler Spiritualität (vgl. Riedmüller 1988).

Gisela Notz unterscheidet drei Strömungen anhand ihrer Ziele: Die „liberalen Feministinnen“ wollen die Gleichheit im Rahmen der bestehenden Strukturen Beruf, Politik, Familie, die „radikal autonomen Feministinnen“ die Abschaffung des Patriarchats, die „sozialistischen und linken Feministinnen“ die Transformation der patriarchalen und kapitalistischen Gesellschaft (vgl. Notz 2011: 19). Die vorliegende Studie orientiert sich an den Arbeiten von Ilse Lenz. 
gesellschaftlichen Bereichen gleich zu beteiligen. Er ist die dominante Strömung des institutionellen Feminismus und prägt die sozialdemokratische Frauenpolitik bis heute.

2. Der "sozialistische Feminismus“ definiert die Verschränkung von Kapitalismus und Patriarchat als Ursache der Frauenunterdrückung. Für die sozialistischen Feministinnen hat sich der Kapitalismus durch eine patriarchale, geschlechtliche Arbeitsteilung entwickelt. Die sozialistischen Feministinnen verlangten in den eigenen männlich dominierten sozialistischen Organisationen, die Frauenunterdrückung als ein konstitutives Herrschaftsverhältnis anzuerkennen und zu kritisieren, die unbezahlte Versorgungsarbeit der Frauen in die gesellschaftspolitische Kritik der kapitalistischen Arbeit aufzunehmen und in der eigenen Organisation Maßnahmen zu entwickeln, die die internen Geschlechterhierarchien abbauen und antizipatorisch nichthierarchische Kooperationen schaffen. In den NFB setzen sich die sozialistischen Feministinnen dafür ein, feministische Emanzipationsideen mit antikapitalistischen Befreiungsansprüchen $\mathrm{zu}$ verbinden, weil eine Aufhebung der Frauenunterdrückung nur in einer anderen Gesellschaft möglich sei. Aber nach Frigga Haug verlor diese Strömung in den NFB bald an Einfluss. Bereits Anfang der 1980er-Jahre interessierte sich die Mehrheit der Feministinnen nicht mehr für eine Verschränkung zwischen marxistischer und feministischer Kritik (vgl. Haug 2004).

3. Der "Differenzfeminismus“ war in den Neuen Frauenbewegungen der 1980er-Jahre die dominante Strömung. Danach unterscheiden sich Männer und Frauen essentiell in Eigenschaften und Fähigkeiten. Aus dieser unterschiedlichen Natur entwickeln sich auch die unterschiedlichen ethischen Orientierungen der Geschlechter. Für die Humanisierung einer Gesellschaft braucht es die Stimme der Frauen und die Ethik des Weiblichen (vgl. Gilligan 1982), weil Frauen fähiger als Männer sind, Fürsorge und eine humanitäre, friedensorientierte Lebensweise sowie ökologische Verantwortung zu verwirklichen. Frauenbewegungen haben die Aufgabe, weibliche Subjektivität und alternative weibliche Wertmaßstäbe zu entwickeln und damit Gesellschaft zu verändern (vgl. dazu auch Libreria delle donne di Milano 1989). Ein gesellschaftlicher Wandel muss auf die „symbolisch-kulturelle Ebene als zentraler Ebene von Macht“ zielen, die Veränderung der symbolischen Ordnung, der Sprache und Politik (vgl. Kahlert 2004: 94).

4. Eine neue Vision entwickelte der „lesbische separatistische Feminismus“. Heteronormativität und Zwangsheterosexualität 
gelten hier als die maßgeblichen Ursachen für strukturelle Unterdrückung. Der Lesbianismus propagiert separate lesbische Räume, eine eigene lesbische Kultur, gesonderte Theorieentwürfe und eigene Politiken neben den als heterosexuell dominiert und begrenzt kritisierten Frauenbewegungen (vgl. Lenz 2008: 227-266). 99

In diesen vier Strömungen bildeten sich Gruppierungen, die eigene Politiken entlang unterschiedlicher Betroffenheiten und Unterdrückungsdimensionen formulierten. Mit dem Müttermanifest legten Feministinnen aus der Partei Die Grünen ein Konzept eigenständiger Identitätsund Interessenspolitik auf der Grundlage des Differenzfeminismus vor (vgl. Lenz 2008: 623ff.). Migrantinnen und Mitkämpferinnen internationalistischer Befreiungsbewegungen organisierten sich als eigenständige Strömung. Sie kritisierten die Dominanzkultur des weißen Mittelschichtsfeminismus “" ${ }^{100}$. Letzteren warfen sie vor, den Rassismus und die besondere soziale Unterdrückung der Migrantinnen zu ignorieren, und sie forderten, den Kampf gegen das Patriarchat über die Forderungen nach Demokratie und Menschenrechten zu stellen. Die Frauen mit Behinderungen wandten sich gegen eine Frauenbewegung, die ein Nichtbehindertsein als „Normalität“ setzt, und kritisierten das feministische Leitbild der sexuellen Selbstbestimmung.

In den feministischen Entwürfen der 1970er- und der 1980er-Jahre war das Patriarchat die zentrale Kategorie feministischer Kritik. Frauen mussten sich gemeinsam als Unterdrückte gegen eine männerdominierte Gesellschaft und einen Männermacht schützenden Staat wehren. Die feministische Forschung dekonstruierte den Bezugspunkt einer homogenen gemeinsamen weiblichen Erfahrung und trug dazu bei, dass sich der Rahmen kollektiv geteilter Referenzthemen auflöste. Regina Becker-Schmidt entwickelte das sozialistisch-feministische Konzept der doppelten Vergesellschaftung der Frau durch Klassen- und Geschlechterzugehörigkeit. Demnach unterliegen Frauen zwei Herrschaftsformen, die sich mischen und gegenseitig verstärken und sie auf besondere Weise

99 Diese Strömung wird hier nicht weiter ausgeführt. Ihr Einfluss auf die sozialdemokratische Frauenpolitik war weitgehend regional und wird deshalb nicht berücksichtigt.

100 Dazu verweist Ilse Lenz kritisch auf die Verbundenheit der Neuen Frauenbewegungen mit den internationalistischen Gruppierungen der Neuen Linken, auf die internationalen Kongresse und die Rezeption der UN-Dekaden in den Frauenbewegungen sowie auf die Selbsthilfeprojekte, die sich gegen die repressive Migrationsverwaltung richteten, auf die Beratungsstellen für Einwanderungsfamilien, die sich vielerorts bildeten, sowie theoretisch arbeitende und internationalistisch agierende Solidaritätsgruppen. Besondere mediale und politische Resonanz erhielten die Projekte gegen Menschenhandel und Zwangsprostitution (vgl. Lenz 2008: 707ff.) 
diskriminieren, „bei allen sozial Unterdrückten - Kindern, Alten, Arbeitslosen, Unterprivilegierten, Armen und Fremden - verschärfen sich die Diskriminierungserfahrungen, wenn die Betroffenen weiblich sind." (Becker-Schmidt 1987: 18) Frauen haben somit kein kollektiv vereinheitlichbares Diskriminierungsschicksal (vgl. Becker-Schmidt 1987: 18) ${ }^{101}$. Mit historischen Studien über die Rolle der Frauen im Nationalsozialismus (vgl. Thürmer-Rohr 2004) und der Teilhabe der deutschen Frauen an der Kolonialherrschaft (vgl. Mamozai 1982, 1996) wurde die Selbstinszenierung der Frauen als „Opferkollektiv“ (Thürmer-Rohr 1997: 3) in Frage gestellt. Bewertung und Entwertung nimmt nach Christina Thürmer-Rohr nicht jedes Geschlecht für sich vor, sondern Zuschreibungen trage immer auch das andere Geschlecht mit. Frauen seien Mittäterinnen an der „Akzeptanz alltäglichen Gewalthandelns“ (Thürmer-Rohr zit. n. Lenz 2008: 473). Diese Ansätze feministischer Frauenforschung eröffneten ein neues „Denken über Geschlecht“, das die Diskurse der NFB in den 1990er-Jahren bestimmt ${ }^{102}$.

\subsubsection{Feministische Diskurse}

Die nachfolgend dargestellten fünf Themen und Diskurse der Neuen Frauenbewegungen wurden als besonders bedeutend für die politische Kollektivbildung der frauenbewegten und feministischen Frauenaktivistinnen in der SPD ausgewählt. Sie prägten ihre internen Selbstverständnisdiskussionen, die Identitätssuche der ASF-Frauen als feministische

101 Das Konzept wurde Mitte der 1990er-Jahre von Ilse Lenz um die Dimension der Nationalität als dreifache Vergesellschaftung erweitert (vgl. Lenz 1995). In der feministischen Forschung wird diese Diskussion unter dem Titel „Intersektionalität“ weitergeführt (vgl. Knapp 2001; Haug 2009; Soiland 2009).

102 Auf der Basis einer Kritik der „Zweigeschlechtlichkeit“ wurde die Konstruktion und gesellschaftliche Verankerung der Geschlechterkonzepte zum Forschungs- und Politikfeld (vgl. Lenz 2008: 359ff.) In den 1990er-Jahren erreichte Judith Butlers Studie Das Unbehagen der Geschlechter die deutsche Geschlechterforschung und Bewegungsöffentlichkeit. Judith Butler entwickelt darin in Bezugnahme auf den Poststrukturalismus eine wissenschaftstheoretische Kritik gegen essentialistische Feminismen. Sie analysiert die Deutung biologischer Geschlechtsmerkmale als kulturellen Akt und die sozialen Geschlechtseigenschaften als performativen Akt. Darin erscheinen Phallozentrismen ebenso wie weibliche Identitätskonstruktionen als Effekte von Machtformationen. Im Feld der Macht bleibt die Frauenbewegung, die sich auf Weiblichkeit bezieht, einem „Umkehr-Diskurs“ verhaftet, in dem sie reproduziert, was sie bekämpfen will (vgl. Butler 1991). 
Sozialistinnen, ihre innerparteilichen Auseinandersetzungen, ihre Differenzen zu den autonomen Frauengruppen und viele ihrer politischen Forderungen und Initiativen.

\subsubsection{Staat und Autonomie}

In den 1970er- und 1980er-Jahren galt vielen Feministinnen in den autonomen Frauengruppen Macht als falsch und zerstörerisch und der Staat als Herrschaftsinstitution, der die Unterwerfung von Frauen absichert. Die Neuen Frauenbewegungen kritisierten den Staat nicht nur wie die Neue Linke als entmündigendes und unterwerfendes Instrument der Bourgeoisie, sondern als Machtinstitution des herrschenden Patriarchats (vgl. Schaeffer-Hegel 1990; Bennholdt-Thomsen 1985; Clemens 1996) und Männerbund (Kreisky 1995; Meyer 1997) ${ }^{103}$.

Nach Carole Pateman liegt dem bürgerlichen Gesellschaftsvertrag von Beginn an ein „sexueller Kontrakt“ zugrunde, der die Freiheit, Gleichheit und Selbstbestimmung aller Gesellschaftsmitglieder unterlief und diese Rechte geschlechtsspezifisch und ungleich verteilte. Der Vertrag wurde nicht zwischen freien und gleichen Individuen geschlossen, weil Frauen nicht als gleichwertige Bürgerinnen in das Staatswesen integriert wurden. Ehefrauen erhielten nur einen vom Ehemann abgeleiteten Rechtsstatus. Bereiche wie die Hausarbeit wurden für politisch irrelevant erklärt und die privaten Beziehungen wurden nach dem Prinzip „obedience for protection" arrangiert (vgl. Pateman 1988: 31 ). Demnach ist die bürgerliche Gesellschaft deshalb gekennzeichnet von einer über alle Klassen hinweg vorherrschenden geschlechtlichen Arbeitsteilung. Die Erwerbsarbeit des Familienernährers gilt als materielle Existenzsicherung und der Ehemann vertritt die Rechte der Familie. Er repräsentiert damit auch die Interessen seiner Frau in der politisch-öffentlichen Sphäre, im Staat und auf dem Markt, während die Ehefrau in der Sphäre der Privatheit naturbedingt zuständig ist für die Kinderaufzucht, die Pflege bedürftiger Familienmitglieder und die Hausarbeit. Politik und öffentliches Leben sind somit männliche Sphären, Familie und Hausarbeiten weibliche und mit subalternem Status verbunden.

Silvia Kontos zufolge kennzeichnet deshalb staatliches Handeln ein „chronischer Gewissensdefekt gegenüber den Menschenrechten von Frauen" (Kontos 1994: 237).

103 Auch die feministische Forschung war durch ihre enge Verflechtung mit der Frauenbewegung zunächst „staatsblind“ (vgl. Hoecker 1995; Holland-Cunz 1998; Sauer 2001b). Die folgende Darstellung der Diskurse in der NSB ist der wissenschaftlichen Literatur der 1990er-Jahren entnommen, die die Diskussionsentwicklung retrospektiv rekonstruiert. 
Auch der Wohlfahrtsstaat der 1970er- und 1980er-Jahre richtete seine Sozialsysteme an der Erwerbsarbeit aus. Die Sozialleistungen bezogen sich auf eine männliche Normalbiographie, ein lebenslanges, kontinuierliches, den Alltag füllendes Berufsleben, das durch eine eigenständig organisierte Haushaltsführung gestützt und ermöglicht wurde. Personen dagegen, die vorrangig unbezahlte Reproduktionsarbeit leisteten, erwarben nur Rechtsansprüche auf eine existenzsichernde Grundversorgung (vgl. Dackweiler 2004b) ${ }^{104}$. Der Sozialstaat hatte deshalb nach Ansicht der Gewerkschaften und der Sozialdemokratie sicherzustellen, dass die ganze Familie vom Einkommen des Mannes leben und sich die Ehefrau ganz der Fürsorge der Familienangehörigen widmen konnte. Wohlfahrtsstaatliche Politik war somit stets zugleich Geschlechterpolitik,

Die ausgerichtet an Geschlechterleitbildern über die spezifischen Rechte und Pflichten, Aufgaben und Tätigkeiten sowie Zeiten und Orte von Männern und Frauen, ein herrschaftsförmiges Geschlechterverhältnis organisiert(e). (Dackweiler 2004b: 451; Hervorhebung im Original)

Angelehnt an den marxistischen Terminus des „ideellen Gesamtkapitalisten“ wird der Staat in den Neuen Frauenbewegungen der 1970er-Jahre als „ideeller Gesamtpatriarch“ angesehen. In seiner Struktur dominiert ihn ein auf Männer bezogenes Politikmanagement, das Frauen den Zugang zu Entscheidungspositionen weder innerhalb der Verwaltung noch über ein ehrenamtliches Engagement in Parteien ermöglicht (vgl. Meyer 1992; Hoecker 2008). Ihre geringe öffentliche Präsenz wird aber einem „mangelnde Interesse“ von Frauen an der Politik zugeschrieben (vgl. Hoecker 1995). Über das System der Repräsentation setzen Männer ihre Interessen als Allgemeininteressen durch. Frauen werden durch die staatliche Sozialpolitik klientelisiert und entmündigt (vgl. Sauer 2001b). Weibliche Emanzipation kann sich deshalb nur in einem neuen Bezugsrahmen von Politik und nur außerhalb staatlicher Herrschaftsinstitutionen entwickeln, denn aufgrund der unterschiedlichen sozialen Lebenssituationen von Männern und Frauen können nur Frauen selbst Fraueninteressen verstehen und vertreten. Zudem besitzen Frauen als von

104 Im Zuge der 1990er-Jahre wurden Frauen weniger als Opfer patriarchaler Sozialstaatlichkeit definiert, sondern mehr als Gestalterinnen gesellschaftlichen Wandels und Aushändlerinnen von Bürgerinnenrechten und „maternalistischen Politiken“. Das frauenpolitische Forschungsinteresse verschob sich von der „Enttarnung“ des sog. Allgemeinwohls zur Entschlüsselung der Persistenz patriarchaler Leitbilder und korporatistischer Strukturen in einer wohlfahrtsstaatlichen Androkratie (vgl. hierzu die europäischen Geschlechterregimes und die Europäisierung der Standards und Regulierungen in Dackweiler 2004b). 
Macht Ausgeschlossene ein herrschaftskritisches, nicht systemkonformes Subjektivitätspotenzial ${ }^{105}$ :

Die Erkenntnis, daß Staat und Gesellschaft - trotz einiger Zugeständnisse und vieler Lippenbekenntnisse - offenbar nicht willens waren, die Situation von Frauen grundlegend durch Änderung politisch-rechtlicher Rahmenbedingungen zu verbessern, verstärkte die Überzeugung, dass Frauen-Freiräume und eine feministische Gegenkultur nur durch autonome Projekte zu schaffen sei (Pinl/Weg 1989: 37).

Allerdings traf diese gesellschaftspolitische Strategie von Beginn an auf scharfe Kritik der Verbands- und Parteifrauen. Bereits in der zweiten Hälfte der 1970er-Jahre bildeten sich in den Frauenbewegungen Strömungen, die neue Wege der politischen Einflussnahme suchten (vgl. Pinl/Weg 1989). In verschiedenen Parteien meldeten sich kritische meist weibliche - Stimmen, die einen politischen Wandel der Führungseliten forderten. Mit der Institutionalisierung der Gleichstellungspolitik sollten sich dafür neue politische Gestaltungsmöglichkeiten auftun. Viele Aktivistinnen der autonomen Frauengruppen verlagerten ihr Engagement nun in Parteien, Gewerkschaften und etablierte Frauenverbände und stärkten die dort entstandenen Frauenstrukturen oder sie suchten eine engere Kooperation mit den Frauen in den Großorganisationen und politischen Verwaltungen. Birgit Meyer bezeichnet diese Entwicklung der NFB als die Phase der „politischen Einmischung“ (vgl. Meyer 1991). In den feministischen Diskursen wird das Bild vom Staat als monolithischer Block abgelöst von einer differenzierteren Konzeptualisierung des Geschlechterregimes (vgl. Sauer 2001b) und erscheint als ein nichtkohärentes, aus unterschiedlichen Machtblöcken zusammengesetztes, vergeschlechtlichtes Gebilde, dessen Politik in Arenen politisch ausgehandelt und durch Einflussnahmen von Interessensgruppen bestimmt wird (vgl. Holland-Cunz 1999; Knapp 1992; Sauer 1999; Young 1991; Gerhard 1989).

Neben der Entwicklung der feministischen Demokratietheorien bleibt die Kontroverse „Autonomie versus Institution“ in den politischen Diskursen der Neuen Frauenbewegungen lange erhalten. Der autonome Flügel der NFB sah in der Gleichstellungspolitik der 1980er-Jahre keinen

$105 \mathrm{Zu}$ dieser Auseinandersetzung vgl. Schaeffer-Hegel 1984. Feministische Demokratietheoretikerinnen kritisierten diese feministischen Positionen später (vgl. HollandCunz 1994; Sauer 2001; Janssen-Jurreit 1990). Barbara Holland-Cunz mahnt ein „Demokratiedefizit“ in diesen Konstruktionen an. Aus der gemeinschaftlichen Privatheit als Gegenpart zur staatlichen Verfasstheit ließen sich weder eine „Ethik der politischen Verantwortlichkeit" noch feministische Gegenentwürfe für eine demokratisch funktionierende pluralistische Öffentlichkeit entwickeln (vgl. Holland-Cunz 1994). 
Bewegungserfolg, sondern vielmehr den Versuch, Frauen in der Männerwelt zu assimilieren, ohne die geschlechtsdifferenzierte Arbeitsteilung und die patriarchalen Strukturen zu verändern. „Viele autonome Frauen haben grundsätzlich kein Interesse daran, was in den patriarchalischen Apparaten von Politik und Verwaltung abläuft, selbst, wenn es die Überschrift ,Frauenpolitik' trägt“ (Pinl/Weg 1989: 42). Die Trennlinie zwischen autonomen Frauen und Institutionenfrauen verlor sich in der weiteren Pluralisierung der Bewegungen in den 1990er-Jahren (vgl. Sauer 2001).

\subsubsection{Emanzipationsstrategien}

Der Feminismus der Neuen Frauenbewegungen entwickelte sich in Abgrenzung zu den beiden großen politischen Strömungen der bürgerlichen Gesellschaft, dem Liberalismus und der ArbeiterInnenbewegung. Der Liberalismus verband die Ansprüche auf Freiheit, Rechtsgleichheit und Brüderlichkeit mit dem freien Zugang zu Markt und Politik, für deren Verfügbarkeit die BürgerInnen selbst verantwortlich waren. So konzentrierte sich die Frauenbewegung im 19. Jahrhundert auf die Durchsetzung des Wahlrechts und der Bildungschancen. Der ArbeiterInnenbewegung galt die Überwindung der Klassenungleichheit und -spaltung als zentrales Ziel sozialer Gerechtigkeitspolitik, ihre Frauenorganisationen hatten die Aufgabe, dafür die Organisation durch Mitgliedergewinnung und Vereinheitlichung zu stärken.

Die Neuen Frauenbewegungen kämpften um andere Politikmodelle. Durch ihre studentischen Ursprünge waren sie eng verbunden mit den Bewegungsframes einer Demokratisierung der Gesellschaft und einer Solidarisierung mit den Unterdrückten (vgl. Fraser 2009; Notz 2004; Kontos 1990). Sie hatten sich von der StudentInnenbewegung abgesetzt, weil auch dort ihre frauenpolitischen Anliegen und ihre Kritik ignoriert wurden. Für die NFB war Emanzipation zunächst gebunden an die Subjektivität der Unrechtserfahrung und an soziale und persönliche Befreiung $^{106}$. Dazu gehörte auch der eigene Körper. Die Selbstbestimmung der Frauen über den eigenen Körper war ein Emanzipationstopos, der sich über den Widerstand gegen die Neufassung des $\S 218$ verbreitete und in den NFB verankerte. ${ }^{107} \mathrm{Er}$ war Teil der individuellen Emanzipation, die

106 „Es gilt, Privatleben qualitativ zu verändern und diese Veränderung als revolutionären Akt zu verstehen." (Weiberrat zit. n. Notz 2011: 76)

107 Hierzu entwickelten sich eine feministische Körperpolitik und alternative Gesundheitskonzepte als Kritik an der herrschenden Gesundheitsverwaltung und deren Technologien, insbesondere der Gen- und Reproduktionstechnologien. 
für viele frauenbewegte Aktivistinnen der 1980er-Jahre auch eine gesellschaftspolitische Strategie war. So schrieb Silvia Kontos: Es „kann die systematische Selbstreflexion einer kleinen Gruppe von Frauen über ihre Gewalterfahrungen ,politischer' im Sinne von gesellschaftlich folgenreicher sein als eine Großdemonstration im Bonner Hofgarten oder die Installation einer Frauenbeauftragten" (Kontos 1990: 56).

Die feministische Auseinandersetzung über Sexualität und Herrschaft betraf immer auch die privaten Beziehungen. Der Separatismus der Bewegungen, der den NFB als Voraussetzung für frauenpolitische Strategieentwicklung, Empowerment und die Koordination der Interventionen galt, wurde auch als Vorlage für individuelle Lebensmodelle diskutiert. Viele Frauen brachen die persönlichen Kontakte zu Männer ab und bauten in den Bewegungen homosexuelle Beziehungen und Netzwerke auf, deren radikale Flügel sich auch von den heterosexuellen Frauen und Frauengruppen distanzierten (vgl. Lenz 2008: 227-266).

Aufgrund der Differenzierung und Pluralisierung der Neuen Frauenbewegungen existierten unterschiedliche Emanzipationsvisionen nebeneinander. Sie lassen sich den bereits beschriebenen vier Strömungen der NFB zuordnen (Darstellung nach Lenz 2008).

- Der sozialistische Feminismus definiert Emanzipation als die Überwindung von Kapitalismus und Patriarchat, die er als kombiniertes Herrschaftsverhältnis fasst. Emanzipation ist nicht ohne die Veränderung der ökonomischen Verhältnisse möglich. Dafür muss die gesellschaftliche Arbeitsteilung, die Trennung in Produktions- und Reproduktionssektor aufgehoben werden. Dem Marxismus wird vorgeworfen, in einer verkürzten Kapitalismuskritik die Bedeutung der unbezahlten, nicht privatwirtschaftlich verwerteten Subsistenzarbeiten für die Reproduktion des Kapitalismus verkannt und die daran gebundenen gesellschaftlichen Verhältnisse sowie den sozialen Widerstand in diesem wirtschaftlichen Segment entpolitisiert zu haben ${ }^{108}$. In einem marxistischen Revolutionsmodell sind die Unterdrückung der Frau und die Erhaltung der Naturressourcen unbedeutende

108 In Anlehnung an Rosa Luxemburg entstand der gesellschaftliche Reichtum im Kapitalismus nicht nur durch die Aneignung von Werten aus der Lohnarbeit, sondern vorrangig aus der fortwährenden Plünderung der Subsistenzproduktion. Hausfrauen in den Metropolen und Kleinbauern in der trikontinentalen Peripherie waren vergleichbaren Arbeitswirklichkeiten ausgesetzt: ungleicher Tausch, die Aneignung unbezahlter Arbeit und Gewalt- statt Vertragsverhältnisse. Claudia von Werlhof konstruiert gegen das marxistische Zweiklassenmodell deshalb eine dritte internationale Klasse der SubsistenzarbeiterInnen (vgl. Werlhof 1978; Bennholdt-Thomsen/Mies/Werlhof 1983); kritisch dazu: Behrend 1999). 
Nebenwidersprüche. Sozialistische Feministinnen fassen dagegen Geschlechterverhältnisse als Produktionsverhältnisse. Ihre Herrschaftsstrukturen sind nicht nur durch Besitzverhältnisse bestimmt, sondern ebenso durch kulturelle Determinanten wie Recht, Sexualität, Körperkonzepte, Sprache, Moral. Emanzipation braucht deshalb eine vielschichtige soziale Veränderung in den privaten wie in den politischen Verhältnissen, die alle Geschlechter betrifft (vgl. Haug 2004).

Die Emanzipationsdiskurse über den Zusammenhang zwischen Produktionsverhältnissen und Geschlechterhierarchien verloren bereits in den 1980er-Jahren an Bedeutung. Die Neustrukturierung der ArbeiterInnenklasse, die Technologisierung der Arbeit, die Globalisierung der Akkumulation und die Krise der sozialistischen Regime relativierten die politisch-theoretischen Bezugspunkte der marxistischen Kritik und die der feministischen Sozialistinnen.

- Im radikalen Gleichheitsfeminismus wird Emanzipation damit verknüpft, aus einer selbstbeschränkenden Weiblichkeit auszubrechen. Der radikale Gleichheitsfeminismus zielt auf eine Neuorientierung der Geschlechterrollen, in der Frauen sich auch sog. „männliche“ Eigenschaften aneignen müssen, um das Ziel einer vorbehaltlosen gesellschaftlichen Teilhabe der Frauen zu erreichen. Unerlässliche Voraussetzung für jede weibliche Emanzipation ist die Berufstätigkeit der Frau (vgl. Schwarzer 1975: 226). Sie ist die Grundlage für ihre ökonomische Unabhängigkeit von der Versorgerehe und ihre persönliche Emanzipation aus dem häuslichen Patriarchat. Chancengleichheit musste durch einen hürdenfreien Zugang zum Arbeits- und Berufsmarkt, durch die Aufhebung geschlechtsbezogener Berufsverbote sowie die Abschaffung aller Arbeitsschutzbestimmungen außerhalb des Mutterschutzes hergestellt werden. Spezielle Bildungs- und Qualifizierungsmaßnahmen für Frauen sollten die vorenthaltenen Bildungsangebote verfügbar machen, damit Frauen allen gesellschaftlichen Anforderungen gewachsen sind. Konsequent forderte die Zeitschrift EMMA deshalb auch die Öffnung der kämpfenden Einheiten der Bundeswehr für Frauen $^{109}$. Diesem Recht auf Berufstätigkeit stand das in der staatlichen Familienpolitik vertretene Drei-Phasen-Modell ge-

109 Diese Forderung war unter den Gleichheitsfeministinnen heftig umstritten und wurde z.B. von der ASF strikt abgelehnt. 
genüber. Es teilte die weibliche Berufsbiographie ein in Ausbildung und Berufserwerb, unterbrechende Familienphase und anschließende Teilzeitbeschäftigung mit Familienpflichten ${ }^{110}$. Die Gleichheitsfeministinnen kritisieren die in diesem Modell festgeschriebene Doppelbelastung berufstätiger Frauen. Die Familienarbeit, forderte Alice Schwarzer bereits in den 1970er-Jahren, muss von beiden Geschlechtern geleistet werden und ist durch eine fortschreitende Vergesellschaftung der Haus- und Erziehungsarbeiten aufzuheben (vgl. Schwarzer 1975). Marielouise Janssen-Jurreit legte mit einem „Frauenprogramm“ einen umfassenden gleichheitsfeministischen Forderungskatalog vor. Er dokumentiert vielfältige konkrete frauenpolitische Alternativen zu den kritisierten Verhältnissen und sollte beweisen, dass Gleichberechtigung politisch erreichbar war (vgl. Janssen-Jurreit 1979). Für die Durchsetzung der Forderungen strebten die Gleichheitsfeministinnen Bündnisse außerhalb der separatistischen Frauenstrukturen an und forderten eine stärkere Beteiligung in gesellschaftlichen und politischen Machtpositionen.

Die Emanzipationskonzepte der Gleichheitsfeministinnen waren in den Frauenbewegungen der 1980er-Jahre heftig umstritten. Es wurde ihnen vorgeworfen, Frauen als defizitäre Wesen anzusehen und ihre Strategien an vorgegebenen männlichen Strukturen und Karrieren auszurichten. Im Wandel zu einer Geschlechtergerechtigkeit hatten vorrangig Frauen die Veränderungsrisiken zu tragen (vgl. Kontos 1994). Kritisiert wurde auch, dass die Ansprüche der Frauen auf Partizipation mit ihren unterschiedlichen Fähigkeiten und Bedürfnissen begründet wurde, oft „unter Rückgriff auf vorgebliche Kontrasttugenden“ (Knapp 1997: 426). Die Gleichheitsfeministinnen bildeten trotz aller Kritik eine der dominanten Strömungen der Neuen Frauenbewegungen. Ihre Analyse der Geschlechterverhältnisse und der Geschlechterstrukturen in Institutionen bildete sozialpolitische Wirklichkeiten ab und entsprach den Diskriminierungserfahrungen der betroffenen Frauen. Mit den Gleichstellungspolitiken wurden sowohl normative Werte als auch konkrete, umsetzbare Ziele entwickelt. Frauen werden sozialpolitisch nicht aufgefangen. Damit liegt diesem Modell die existenzielle Abhängigkeit der Frauen von einem versorgenden Ehemann zugrunde. 
- Im Zentrum differenzfeministischer Emanzipationskonzepte steht die Fähigkeit der Frauen zum Gebären und die damit verbundenen sozialen Begabungen. In Die andere Stimme, die 1982 in deutscher Sprache erschien, erläutert Carol Gilligan, dass Frauen aufgrund ihrer biologischen Voraussetzungen ${ }^{111}$ entwicklungspsychologisch ein anderes Verhältnis zur Natur und eine andere soziale Verbundenheit erreichen als Männer. Emanzipation ist gebunden an die Entwicklung der persönlichen Reife, die Entwicklung von „Interdependenz und Fürsorglichkeit“ (Gilligan 1982: 210). Dafür müssen Frauen untereinander affidamento aufbauen, Netze vertrauensvoller Beziehungen und Generationen übergreifender Verbindungen zur Wiederentdeckung und -herstellung weiblicher Genealogie, und zwar außerhalb von vorhandenen patriarchalen Machtstrukturen (vgl. Kahlert 2004). Während „Mutterliebe“ von Gleichheitsfeministinnen als Mythos kritisiert wird, der Frauen zu unbezahlter Fürsorge- und Hausarbeit verpflichte (vgl. Elisabeth Badinter zit. n. Galster 2004: 45), ist sie für Differenzfeministinnen eine essentielle Kategorie und ein Schlüssel zur Emanzipation. Italienische Differenzdenkerinnen sehen darin die Substanz für eine noch unbestimmte, unabhängige weibliche Subjektivität und für eine zukünftige eigenständige symbolische Ordnung aus weiblicher Erfahrung ${ }^{112}$. Das politische Emanzipationsziel ist die Anerkennung der Differenz, die sich aus der Verschiedenartigkeit der Geschlechter, aber auch der Vielfältigkeit der Frauen ergibt (vgl. Kahlert 2004: 91). Visionen von Emanzipation werden hier in enger Verbindung von Politischem und Privatem entworfen.

Der Differenzfeminismus fand in den 1980er-Jahren in vielfältiger Weise Eingang in die Protestbewegungen der NSB. Frauengruppen bezogen sich auf differenzfeministische Begründungen bei ihrem Widerstand gegen die Stationierung von Mittelstreckenraketen, bei ihren Forderungen nach nachhaltigem Wirtschaften und ihrer Kritik an den destruktiven Folgen des technischen Fortschritts oder den Gen- und Reproduktionstechnologien. Aus differenzfeministischen Positionen entwickelte

111 Manche differenztheoretischen Strömungen geben der essentialistischen Geschlechterdifferenz keine biologische Begründung, sondern eher eine entwicklungspsychologische oder anthropologische (vgl. dazu Kahlert 2004).

112 Viel gelesen wurde die Schrift des Mailänder Autorinnenkollektivs Libreria delle donne di Milano und der Philosophinnengruppe DIOTIMA an der Universität von Verona. Wie weibliche Freiheit entsteht erschien 1988 in deutscher Sprache. 
sich eine breite ökofeministische Strömung oder auch die „Magiewelle“, in der vielerorts soziale Treffpunkte, Läden und Foren entstanden, die sich auf eine neue Körperlichkeit bezogen und gegen „das entkörperte Subjekt“ (vgl. Thiessen 2004:37) die Entfaltung von Intuition und Spiritualität setzten. In enger Verbindung $\mathrm{zu}$ den ökofeministischen Bewegungen stand das sog. Müttermanifest ${ }^{113}$, das 1986 von weiblichen Mitgliedern der Partei Die Grünen verfasst wurde; am anschließenden Kongress nahmen ca. 5oo Frauen teil. Das Manifest kritisierte den Gleichstellungsfeminismus als Bevormundung und rief zum Aufbau einer eigenen Lobby und einer mütter- und kinderfreundlichen Öffentlichkeit auf, in der nicht mehr „die Logik der Kneipe, des Betriebs oder gar der traditionellen Politik alles Leben durchdringt" (Müttermanifest 1987 zit. n. Lenz 2008: 624).

Die lesbisch-feministischen Frauenbewegungen kritisierten diese feministischen Strömungen als unemanzipatorisch und in den Institutionen der Heteronormativität verfangen ${ }^{114}$. Mit dem Praxiskonzept „Feminismus ist die Theorie, Lesbianismus ist die Praxis“ propagierten sie ein Lebensmodell, in dem die Trennung zwischen privaten Beziehungen und dem öffentlichen feministischen Engagement aufgehoben war. Die Radikalität dieser Orientierung überzeugte viele Frauen, sie schlossen sich diesem Flügel als „Bewegungslesben“ an. Lesbengruppen organisierten die Vierte Berliner Sommeruniversität für Frauen 1979, zu der 7000 Teilnehmerinnen kamen. In den Parteien, besonders der Sozialdemokratie und den Grünen, traten lesbische Frauengruppen offen auf ${ }^{115}$. Ende der 1980er-Jahre entwickelten sich erste postmoderne kulturtheoretische Feminismuskonzepte, die sich nicht mehr auf weibliche Emanzipationsziele ausrichteten (vgl. Becker-Schmidt/Knapp 2003: 113; dazu auch Fraser 2005; Rommelspacher 2006). Gender- statt Frauenpolitik zielt auf eine symbolische Geschlechterordnung ab und rückt den performativen

113 Initiatorinnen waren u.a. Gisela Erler, Monika Jaeckel, Greta Tüllmann. Aus dem Mütteransatz entwickelten sich Mütterzentren, die als Familienselbsthilfen institutionelle Förderungen durchsetzen konnten.

114 Vgl. Darstellung in Brüssow 1996; Holland-Cunz 2003.

115 Hier erstritten sie sich zeitweilig hohen Einfluss. So setzen lesbische Netzwerke 1989 in der rot-grünen Berliner Koalitionsregierung die Wahl der Grünenpolitikerin Anne Klein zur Berliner Senatorin für Frauen, Familie und Jugend durch. Sie war eine Anwältin für Frauen- und Familienrecht, die offen in lesbischer Partnerschaft lebte. 
Akt des Doing Gender in den Fokus der gleichstellungsfeministischen Politik $^{116}$. Nach der 4. Weltfrauenkonferenz in Beijing wurde 1996 Gender Mainstreaming in das Aktionsprogramm der Europäischen Gemeinschaft aufgenommen und gilt seitdem als Leitlinie deutscher Gleichstellungspolitik (vgl. Schunter-Kleemann 2002; Wetterer 2004; Weinbach 2004).

\subsubsection{Körperpolitik und Selbstbestimmung}

Ein zentrales Thema feministischer Gesellschaftskritik war die Befreiung des weiblichen Körpers und die Selbstbestimmung über die eigene Sexualität, das Recht auf Unversehrtheit und der Schutz vor Gewalt. Dazu gehörten ein anderes Körpergefühl mit einer neuen Selbstpräsentation ${ }^{117}$ ebenso wie die Loslösung aus medizinischen Entmündigungen sowie Forderungen nach einem Schutz vor Abwertung in Werbung und Medien oder das Verbot von pornographischer Vorlage für männliche Gewaltphantasien und Begierden. Die feministischen Diskurse über die Körper und Körperpolitik richten sich in den 1980er-Jahren vorrangig an der kulturellen Repräsentation der Zweigeschlechtlichkeit (vgl. Duden 2004) aus.

Die Reform des § 218 und die Strafbarkeit der Abtreibung mobilisierten in den 1970er- und 1980er-Jahren immer wieder große Demonstrationen $^{118}$. Die Parole der autonomen Feministinnen, „Mein Bauch gehört

116 Genderpolitik bot eine neue, attraktive politische Orientierung für institutionelle AkteurInnen und löste bereits in den 1980er-Jahren - bevor entsprechende Konzepte vorlagen - die Politiken frauenspezifischer Förderpläne und Sonderregelungen ab. Statt diesen sollten Frauen gemeinsam mit männlichen Bündnispartnern, die ebenfalls als Betroffene und Beschädigte angesehen wurden, in den Organisationen strukturelle und kulturelle Veränderungen durch neue Normen und Verfahrensregulationen durchsetzen, um eine größere „Gendergerechtigkeit“ zu erwirken (vgl. Lorber 2004; Heintz 1998; Pasero/Prid-dat 2004; Schunter-Kleemann 2001; Truman 2004).

117 Eine andere Kleidung sollte Bequemlichkeit und Bewegungsfreiheit bieten und neue Schönheitskriterien wie Natürlichkeit, gesundes Leben oder körperliche Kraft ausdrücken, die sich gegen die „fremdbestimmten Normen über die ideale Figur“ (Lenz 2004d: 33) richteten.

118 Dazu hatte auch die von Alice Schwarzer organisierte Initiative einer öffentlichen Selbstbezichtigung beigetragen. Im Juni 1971 bekannten sich 374 prominente Frauen öffentlich zur Abtreibung (Wir haben abgetrieben, in: Zeitschrift Stern, 24. Jg., Hft 24, o6.o6. 1971). Auf diese Aktion erfolgten Repressionen, die wiederum eine Solidarisierungswelle auslösten. Als die Zahl der Selbstanzeigen auf 3000 stieg und Bundesjustizminister Gerhard Jahn anderthalb Monate später über 86.ooo Solidaritätsunterschriften ausgehändigt wurden, stellte die Staatsanwaltschaft die weitere Strafverfolgung ein (Darstellung in www.frauenmediaturm.de/themen-portraets/chronik-der-neuenfrauenbewe-gung/1971/ Zugriff: 01.03.2010). 
mir", richtete sich gegen die staatliche Kontrolle der weiblichen Gebärfähigkeit und forderte Frauen auf, ihren Körper in Besitz zu nehmen bzw. zurückzuerobern. Dazu gehörte auch eine Kritik an der medizinischen Entmündigung von Frauen. Der ÄrztInnenschaft wurde vorgeworfen, Frauen medizinisches Wissen über den eigenen Körper vorzuenthalten. Mithilfe von Selbstuntersuchungen erwarben die Frauen gemeinsam medizinische Kenntnisse. Es entstand eine Frauengesundheitsbewegung ${ }^{119}$.

Erotik und sexuelle Praktiken wurden zu öffentlichen Themen erklärt ${ }^{120}$ (vgl. Lenz 2004a). In Selbsterfahrungsgruppen entwickelten Frauen Anfang der 1970er-Jahre den Anspruch auf „selbstbestimmte Lust" und stärkten sich gegenseitig, in ihren heterosexuellen Beziehungen andere sexuelle Praktiken von ihren Partnern durchzusetzen. Gefordert wurden nicht nur das Einverständnis der Partnerin zum Sexualakt, sondern auch das Stimulieren weiblicher Lust und die Verantwortung für den beiderseitigen Orgasmus. Vom Partner wurde erwartet, dass er den hormonellen Zyklus seiner Partnerin kennt und aktiv Verantwortung für Schwangerschaft und Verhütung übernimmt (vgl. Lenz 2004d). Die Lesbenbewegung demonstrierte die Vision von „freier Lust und Lebensformen" offener und provozierender als die heterosexuellen Frauen (vgl. Lenz 2004a: 38). In gemeinsamen Foren der Homosexuellenbewegung artikulierten und organisierten sich im Laufe der 1980er-Jahre auch Bi- und Transsexuelle. In den 1990er-Jahren verloren sich die Grenzen zwischen den verschiedenen Geschlechterformierungen in einer multivarianten Queerbewegung, in der individuelle, sexuell flexibilisierte, gemischte Identitäten gelebt werden konnten.

„Sexuelle Gewalt gegen Frauen“ und „Gewalt in der Familie“ setzten die Frauenbewegungen erfolgreich als ein neues Politikfeld durch. Mit der Einrichtung der Frauenhäuser ${ }^{121}$ und ihrer massenhaften Nutzung machten sie die Ausmaße körperlicher Verletzung und Bedrohung von Frauen öffentlich (vgl. Schäfer 2001). Dazu entstanden in den 1980er-Jahren weitere Selbsthilfeinitiativen, Notrufe und Kurse zur Selbstverteidigung sowie spezielle Beratungsstellen für Frauen mit Behinderungen, die sich in besonderer Weise mit Gewalt konfrontiert sahen. Als „Männergewalt gegen Frauen" fassten die Neuen Frauenbewegungen dabei unterschiedliche Gewaltformen: Vergewaltigung, Frauenhandel, körperli-

119 Sie trug dazu bei, naturheilkundliche Verfahren gegen das Monopol der Schulmedizin in der kassenärztlichen Behandlung durchzusetzen. (zur Kritik der Bewegung und ihrer Anschlussfähigkeit an den Gesundheitsmarkt vgl. Duden 2004).

1201970 erschienen dazu die viel gelesenen Bücher von Shulamith Firestone Frauenbewegung und sexuelle Revolution und von Kate Millett Sexus und Herrschaft.

121 Das erste Frauenhaus wurde 1976 in Berlin gegründet. 
che Übergriffe, Missbrauch von Frauen und Kindern sowie die Entwürdigung von Frauen zu Sexualobjekten in der Werbung und der Pornographie. Sie forderten von der Politik eine Delegitimierung dieser Gewalt und Gesetze zum Schutz der Frauen. Gewalt in der Ehe als Straftatbestand zu werten fand erst 1997 eine parlamentarische Mehrheit, noch 1972 scheiterte die SPD mit einer solchen Gesetzesinitiative. Auf kommunaler Ebene aber wurden ab Mitte der 1970er-Jahre vielerorts die Projekte der Frauenselbsthilfe gegen männliche Gewalt mit öffentlichen Mitteln gefördert. Dazu hatte auch das Internationale Tribunal über Verbrechen gegen Frauen 1976 in Brüssel beigetragen (vgl. Dackweiler 2010). Von der US-amerikanischen Frauenbewegung inspiriert organisierten autonome Frauengruppen in der Walpurgisnacht zu diesem Thema Demonstrationen und prangerten Pornoläden und Bordelle als öffentliche Orte sexueller Gewalt gegen Frauen an.

Die neuen Gen- und Reproduktionstechnologien führten in den Neuen Frauenbewegungen zu erheblichen Kontroversen. Ein dreitägiger Kongress der Grünen im April 1985, Frauen gegen Gentechnik und Reproduktionstechnik, mobilisierte 2.00o Teilnehmende ${ }^{122}$. Radikale Gegnerinnen wie Maria Mies sahen in diesen Technologien eine neue Etappe im patriarchalen Krieg gegen Frauen. Ein neues „Technopatriarchat" versuche, mit Biotechnikern und Medizinern die Gebärfähigkeit zu beherrschen und Frauen zu entmündigen, und zielte auf eine neue „Eugenik im Weltmaßstab“ (Mies zit. n. DIE GRÜNEN u.a. 1986: 44) ${ }^{123}$. Diesem Lager standen kritische Befürworterinnen gegenüber wie Silvia Kontos, die sich auf die Technikvisionen Shulamith Firestones ${ }^{124}$ bezog und für eine feministische Aneignung der neuen Technologien sowie für eine kritische, frauenorientierte Vergesellschaftung des Reproduktionsprozesses plädierte (vgl. DIE GRÜNEN im Bundestag et.al. 1986: 147)

\subsubsection{Arbeitsteilung und Geschlechterordnung}

In den Frauenbewegungen der 1970er-Jahre war die „Politisierung der Reproduktionsfrage“ ein zentrales Anliegen (vgl. Riedmüller 1988: 33). In der Kritik stand die Marx'sche Werttheorie, nach der sich Kapital durch die Aneignung des Mehrwerts bildet, der im Produktionsprozess der

1221988 fand ein zweiter Kongress mit einer gleich hohen Beteiligung statt.

123 In den Reihen der radikalen Gegnerinnen bildeten sich auch militante Zirkel, die mit Anschlägen auf Forschungslabors und Firmen versuchten, dieser Kritik eine Öffentlichkeit zu verschaffen; ihnen schien ein gewaltfreier Widerstand angesichts der staatlich geförderten Forschung und der Macht der Pharmaindustrie ohne Erfolgsaussichten zu sein (vgl. Lenz 2008: 661ff.).

124 Shulamith Firestone sah z.B. in der Retortenzeugung eine Chance zur Befreiung der Frau vom Gebärzwang. 
Waren hergestellt wird, und die den Kern der gesellschaftlichen Herrschaft in einer spezifischen Form der Vergesellschaftung von Arbeit verortet. In dieser Konzeptualisierung gesellschaftlicher Arbeit, kritisieren Feministinnen, bleiben aber wesentliche Arbeits- und Ausbeutungsverhältnisse unberücksichtigt, wie die geschlechterhierarchisierten Arbeitswelten (vgl. Werlhof/Mies/Bennholdt-Thomsen 1983). Diese beschreibt Ursula Beer als einen Prozess gesellschaftlicher Differenzierung, in dem sich die gesellschaftlichen Bereiche von Familie und Erwerb trennen, die in der ständischen frühindustriellen Gesellschaft noch eine Einheit bildeten (vgl. Beer 1990: 166). In der kapitalistisch-industriellen Vergesellschaftung der Arbeit entwickeln sich nach Ursula Beer die bereits existierenden ungleichen Eigentumsverhältnissen zwischen den Geschlechtern zu einer neuen Form geschlechtersegmentierender Nutzung von Arbeitskraft. Dabei bildet sich eine grundlegende gesellschaftliche Arbeitsteilung zwischen Berufs- und Hausarbeit heraus. Die Minderbewertung von Frauenerwerbsarbeit lässt sich nach Ursula Beer bereits in den vorindustriellen Gesellschaften nachweisen, mit der Hausarbeit im Industriekapitalismus aber entwickelt sich Frauenarbeit zu einer „familialvermittelt-unentgeltlichen Arbeitsform" (Beer 1990: 219). Damit entsteht während der Industrialisierung des 19. Jahrhunderts neben der Klasse der Lohnabhängigen eine neue „Dienerklasse“ (Kenneth John Galbraith zit. n. Beer 1990: 220) ${ }^{125}$. Mit der Aufhebung rechtlicher Ehebeschränkungen stehen nach Ursula Beer nun jedem Manne - und nicht nur dem Besitzbürger - via Heirat die persönlichen Dienste einer Frau zur Verfügung, insbesondere wenn sein Einkommen für den Familienunterhalt ausreicht. Im Bereich der unbezahlten Hausarbeit der Frauen verbleiben die gesellschaftlichen Aufgaben der Versorgung der Kinder und der pflegebedürftigen Familienangehörigen.

Mit der Aufteilung öffentlicher und privater Arbeit entsteht die geschützte, intime Familiensphäre, ein Privileg, das bislang nur dem Bürgertum und dem Adel vorbehalten ist und das sich nun als Familienideal auch in den besser situierten Lohnarbeiterschichten verbreitet. Diese gesellschaftliche Arbeitsteilung erschwert in Folge Frauen den Zugang zu eigenständig verfügbarem Geld, einer elementaren Ressource in der Warengesellschaft (vgl. Beer 2004: 56). Da die Konzentration der männlichen Arbeitskraft auf den Erwerbsbereich nur möglich ist, wenn die notwendigen gesellschaftlichen Aufgaben der Reproduktion gesichert übernommen werden, verfestigt sich nach Ursula Beer die Trennung zwischen den Geschlechtern. Zudem wird in einem Arbeitssystem, das nur

125 Ursula Beer spricht von einem industriegesellschaftlichen „Sekundärpatriarchalismus“, weil in ihm Geschlechterhierarchien der Feudalgesellschaft, die sich auf patriarchalen Wirtschafts- und Familienstrukturen gründeten, beibehalten und weiterentwickelt wurden. 
die gewerbliche Arbeit als produktiv und existenzsichernd wertet und alle anderen gesellschaftlichen Arbeiten als nichtproduktiv einstuft und somit nicht entlohnt, weibliche Haus- und Fürsorgearbeit unsichtbar. Die Entwicklung industrieller Arbeit ist somit eng mit patriarchalen Geschlechterverhältnissen verknüpft: „Menschliche Produktivkraft entfaltet sich geschlechtsspezifisch und wird geschlechterdifferent blockiert" (Beer 1990: 227) ${ }^{126}$.

Die Missachtung der gesellschaftlichen Reproduktionsleistungen von Frauen und ihre Einbindung in die Hausarbeit unter männlicher Kontrolle wurde von den feministischen Kritikerinnen nicht als ein Relikt vorindustrieller Gesellschaften gewertet, sondern als eine moderne Herrschaftsstruktur in einem „fordistischen Geschlechterregime“ verurteilt (vgl. Werlhof 1978; Behrend 1999; Nickel 2008). Hierzu wurde Mitte der 1970er-Jahre in den Neuen Frauenbewegungen die Forderung nach einem „Lohn für Hausarbeit" aufgestellt ${ }^{127}$. Mit einer Entlohnung sollte die häusliche Arbeit aus dem ,gesellschaftlichen Schattendasein herausgeholt" (Riedmüller 1988: 31f.) werden ${ }^{128}$. Der Hausfrauenlohn bringe nach Gisela Bock und Barbara Duden materielle Unabhängigkeit für die Ehe- und Familienfrauen und öffne zugleich den Bereich der Hausarbeit für technologische Entwicklungen, damit neue Maschinen die Arbeitsaufwände weiter verringern. Er markiere die Hausarbeit als gesellschaftlich notwendige Arbeit, zerstöre ihren Nimbus als eine wesenseigene, der weiblichen Natur entsprechende Tätigkeit und ließe sich so als Arbeitsverteilung zwischen den Geschlechtern neu verhandeln (vgl. Bock/Duden 1976).

126 Feministische Theorien zur Haus- und Familienarbeit waren zunächst analog zu den marxistischen Arbeitstheorien konstruiert: Mit einem Arbeitslohn kauft das Kapital nach Silvia Kontos und Karin Walser faktisch zwei Arbeitskräfte ein, eine für die Produktion und Reproduktion des Kapitals, eine zweite für die Produktion und Reproduktion der Arbeitskraft (vgl. Kontos/Walser zit. n. Beer 1984: 140f.). Die generative Potenz der Frau ist in das Lohnarbeitsverhältnis einbezogen, ein staatlicher Gebärzwang sorgt für die Aufrechterhaltung dieser Arbeitskräfteökonomie (vgl. ebd.). In den späteren feministischen Theorien werden solche Konzepte der kapitalistischen Supraherrschaft kritisiert, weil sie nur Orte der Unterwerfung definieren, aber keine des Widerstandes für das handelnde Subjekt (vgl. dazu Cyba 2004)

1271972 war eine Kampagne zum Hausfrauenlohn vom International Feminist Collective ins Leben gerufen wurden. 1977 war der Hausfrauenlohn ein zentrales Thema der Berliner Sommeruniversität für Frauen. Die Berliner Sommeruniversität für Frauen hieß eine interdisziplinäre Konferenzreihe zu feministischer Theorie und Strategie, die von 1976 bis 1983 an der TU Berlin stattfand und von wechselnden Veranstalterinnen organisiert wurde.

128 Auch in den Sozialwissenschaften wurde vorrangig nur zur bezahlten Berufsarbeit geforscht, die Hausarbeit blieb dagegen ein wissenschaftlich unbeachtetes Feld (vgl. dazu Brück et al. 1997). 
Die Forderung nach einem Hausfrauenlohn stieß allerdings in den Neuen Frauenbewegungen mehrheitlich auf Ablehnung. Kritisiert wurde, dass er Frauen in ihrer isolierten, depravierenden Hausfrauenund Mütterrolle bestärke. Emanzipation war den Kritikerinnen nach verbunden mit einer Überwindung der „Nur-Hausfrauen-Existenz“ und einer unabhängigen wirtschaftlichen Existenz, die mit hochwertigen Bildungsabschlüssen erreichbar sein sollte. Ihr frauenpolitisches Interesse richtete sich auf die uneingeschränkte Teilhabe am Berufs- und Arbeitsmarkt und die Überwindung der nach Geschlechtern ungleich verteilten Chancen auf diesen Märkten.

In den 1980er-Jahren erschien dazu eine umfangreiche feministische Literatur, die sich mit der Struktur und Persistenz dieser Geschlechtersegmentierung und den Möglichkeiten ihrer Auflösung auseinandersetzte. Elisabeth Beck-Gernsheim stellte dazu eine vieldiskutierte sozialisationstheoretische Position vor (vgl. Beck-Gernsheim 1981) ${ }^{129}$. Danach geraten Frauen in der Erwerbskonkurrenz mit Männern ins Hintertreffen, weil sie durch die tradierte Zuordnung zum „familiären Innenbereich“ ein „weibliches Arbeitsvermögen“ entwickeln. Für ihre Subalternität sind weder biologisch fundierte weibliche Anlagen noch die politökonomisch werttheoretisch begründete Erhaltung einer billigen Arbeitskraftreserve noch die Doppelbelastung durch Berufs- und Familienverpflichtungen ausschlaggebend, sondern die eigenen Arbeitshaltungen wie die „Bereitschaft zur Einfügung und emotionalen Abhängigkeit, Fürsorgeneigungen und Tugenden des Gefühls“ (Beck-Gernheim 1981: 9). Diese Dispositionen prägen Frauenberufe, aber auch die Berufswünsche und Lebensplanungen der Frauen selbst. Es sind solche geschlechterstereotypen und wenig leistungsorientierten Zuschreibungen, die Frauen in ihren beruflichen Entwicklungsmöglichkeiten blockieren. Sie weisen die Frau dem Reproduktionsbereich zu, erklären sie verantwortlich für die Fürsorge und schwächen ihre Position im Erwerbsfeld, weil Frauen wegen der Familienaufgaben auf den Arbeits- und Berufsmärkten nur als Zuverdienerinnen agieren. Eine Berufstätigkeit allein, schlussfolgert Elisabeth Beck-Gernsheim, kann deshalb keine Emanzipation bringen. Selbst eine gleichberechtigte Integration von Frauen in die Arbeitswelt ist auf eine komplexe Veränderung des Berufssystems angewiesen, auf eine Veränderung der Berufsinhalte, des sozioökonomischen Status der einzelnen Berufe und ihrer geschlechtsbezogenen Besetzung.

Für eine Veränderung der Arbeitswelt hatte der Sozialstaat zu sorgen, z.B. für die Öffnung männerdominierter Berufe, die Abschaffung frauenspezifischer und diskriminierender Arbeitsschutzgesetze und das Verbot

129 Elisabeth Beck-Gernsheim legt ihren Untersuchungen und Argumentationen antipodisch konstruierte Persönlichkeitsprägungen von Männern und Frauen zugrunde, die sie aus der Komplementarität der Hausarbeit und Berufsarbeit ableitet. 
frauendiskriminierender Tarifsysteme. Er sollte dafür sorgen, dass das höhere Arbeitslosenrisiko von Frauen aufgefangen wird, die berufliche Integration der Wiedereinsteigerinnen gefördert wird und die Vereinbarkeit von Beruf und Familie durch bessere Infrastrukturmaßnahmen unterstützt wird ${ }^{130}$.

In den 1980er-Jahren versuchten gewerkschaftliche Frauenstrukturen gemeinsam mit „Institutionenfrauen“ ${ }^{131}$ und „Politikfrauen“, dazu parlamentarische Initiativen auf den Weg zu bringen. Als besonders bedrohlich für die weibliche Erwerbsentwicklung erschienen der sog. zweite Arbeitsmarkt, der sich im Zuge der Rationalisierung und Globalisierung industrieller Produktion entwickelte, und die damit verbundene Sockelarbeitslosigkeit, die seit den 1970er-Jahren anwuchs. In diesem Arbeitsmarktsegment wurden überwiegend Arbeitsplätze mit geringen Qualifikationsanforderungen, schlechten Entwicklungsperspektiven, niedriger Bezahlung und wenig Sicherheiten angeboten (vgl. Brück et.al. 1997; Wetterer 1995). Einen Kernbereich bildeten die flexiblen, schlecht bezahlten Teilzeitbeschäftigungen, die es in den 1960er-Jahren als vereinzelte Beschäftigungsformen gab und die sich nun kontinuierlich ausweiteten $^{132}$. Diese Entwicklung schien die These von einer „Hausfrauisierung der Arbeit" zu bestätigen ${ }^{133}$, die die Bielefelder Soziologinnen Claudia von Werlhof, Maria Mies und Veronika Bennholdt-Thomsen entwickelt hatten. Danach waren die westlichen Industriegesellschaften mit einem anwachsenden Arbeitsmarktssegment konfrontiert, in dem sich die Entlohnung der Arbeit nicht mehr am allgemeinen Lebensstandard ausrichtet und auch nicht mehr zu sozialpartnerschaftlich ausgehandelten Vertragsbedingungen angeboten wird. Perspektivisch dehnten sich diese neuen Arbeitsverhältnisse, so die Prognose, auch auf männliche ErwerbsarbeiterInnen aus.

Um Frauen einen besseren Berufszugang zu männlich dominierten Berufsfeldern und qualifizierten, besser bezahlten Tätigkeiten zu ver-

130 In der zweiten Hälfte der 1970er-Jahre war die Frauenerwerbslosigkeit höher und stabiler als die der männlichen Erwerbspersonen. In den Fabriken waren es vorrangig Frauen, die in der Rand- und nicht in der Stammbelegschaft beschäftigt waren und deren Interessen in den korporatistischen Verhandlungssystemen der Tarifpartner wenig Berücksichtigung fanden.

131 Im Laufe der 1990er-Jahre wurden Gleichstellungsbeauftragte auch in privaten Unternehmen etabliert (vgl. dazu Krell 2004).

132 Die Teilzeitquote in Prozent der Erwerbstätigen betrug: 1970: 6,4 \%, 1980: 10,6 \%, 1991 : $18,4 \%$ (vgl. Wanger 2008).

133 Der Begriff wurde von Maria Mies entwickelt, um den präkären Status der indischen Heimarbeiterinnen zu bezeichnen. Sie wurden nicht als Lohnarbeiterinnen behandelt, sondern in einer Art zusätzlicher Beschäftigung als Hausfrauen (vgl. Mies 1983). 
schaffen, bildeten sich bereits in den 1980er-Jahren autonome Frauenberufsverbände. Feministische Technikexpertinnen organisierten sich als Initiative Frauen in Naturwissenschaften und Technik gegen den eher technologiefeindlichen Feminismus ökologisch orientierter Fachkongresse. 1986 gründeten sie den Deutschen Ingenieurinnenbund (dib e.V.). Zeitgleich entstanden in weiteren Berufszweigen Netzwerke wie die Frauen im Ingenieurberuf (fib) des VDI ${ }^{134}$, der Arbeitskreis Elektroingenieurinnen im VDE ${ }^{135}$ und der Journalistinnenbund. Auch traditionelle Frauenberufsverbände erhielten in dieser Zeit neuen Zulauf ${ }^{136}$ und in den etablierten Berufsfachverbänden formierten sich Frauengruppen mit feministischen Ideen ${ }^{137}$. Für eine chancengerechtere Arbeitswelt setzten sich auch die Gleichstellungs- oder Frauenbeauftragten der 1980er-Jahre ein mit dem Ziel, in der öffentlichen Verwaltung gegen die geschlechterbezogenen Berufszuweisungen, das diskriminierende Arbeitsbewertungssystem ${ }^{138}$, die unterschiedlichen Einkommen, Frauen exkludierende Rekrutierungs- und Beförderungssysteme und die Geschlechterdiskriminierung im Arbeitsalltag zu kämpfen ${ }^{139}$.

Diese auf Integration ausgerichteten Aktivistinnen fanden in den autonomen Frauengruppen der 1980er-Jahre wenig Anerkennung. Auch die in diesem Handlungsfeld entwickelten politischen Initiativen, wie z.B. die Entwicklung und Durchsetzung eines Antidiskriminierungsgesetzes oder die Durchsetzung von Quoten in den Beschäftigungssystemen der öffentlichen Verwaltung, fanden wenig Interesse. Politiken der Partizipation und Neuverteilung der Machtpotenziale wurden grundsätzlich von den autonomen Frauenbewegungen mit großer Skepsis verfolgt.

134 VDI: Verein Deutscher Ingenieure e.V., gegründet 1856.

135 VDE: Verband der Elektrotechnik Elektronik Informationstechnik e.V., gegründet 1883.

136 Wie z.B. der Deutsche Akademikerinnenverband, der Deutsche Journalistinnenverband. Die Mitgliedschaft beim Deutschen Juristinnenbund verdoppelte sich in der zweiten Hälfte der 198oer-Jahre (http://www.djb.de/publikationen/ai_sonderausgabe2003/ai_sonderausgabe2003_jahrzehnt4/, Zugriff: 04.07.2013).

137 Verein Deutscher Ingenieure und der Deutsche Journalisten-Verband.

138 Vgl. dazu z.B. Pinl 1979.

139 In den 1990er-Jahren erschienen zahlreiche Studien, die sich der „latenten Sexualisierung scheinbar geschlechtsneutraler Strukturen“ (Müller 1993: 113) widmeten und den Zusammenhang von Männlichkeitskulturen und Hierarchiestrukturen in den betrieblichen Abläufen bezüglich Arbeitsformen, Arbeitsbeziehungen und Konfliktverhalten dokumentierten. 


\section{Die SPD in den 197oer- und 1980er-Jahren - Regierungsbeteiligung, innerparteiliche Fragmentierungen und programmatische Neuorientierungen}

Die Entwicklung der ASF findet in den 1970er- und 1980er-Jahren in einer Partei des Umbruchs statt. In den 1960er-Jahren verändert sich in der Partei die Sozialstruktur ihrer Mitgliedschaft, neue politische Themen werden in die Gremien hereingetragen, traditionelle sozialdemokratische Politikkonzepte werden aufgegeben. Die herkömmlichen RechtsLinks-Lager verlieren durch neue Formierungen und neue innerparteiliche Machtkonstellationen tendenziell an Bedeutung. Alle ringen um Einflussnahme in der Partei und auf die Parteiführungen und suchen dafür BündnispartnerInnen. Dieser Wandel der Partei bestimmt die Handlungsräume der ASF-Frauen und eröffnet ihnen neue Aufmerksamkeiten für ihre frauenpolitischen Konzepte und neue Chancen, ihre Forderungen in den Parteigremien zu vertreten und sich in den Programmdiskussionen einzubringen. Das folgende Kapitel gibt zu diesem historischen Kontext einen kurzen Überblick.

\section{Die Liberalisierung der ArbeiterInnenpartei}

In den ersten Bundestagswahlen der neu gegründeten Bundesrepublik erwartete die SPD, als Gewinnerin des Weltkriegsdesasters hervorzugehen, denn die Partei sah sich als „moralischer Sieger aus der Unterdrückung durch den Nationalsozialismus“" (Boyer 2001: 110). Die Mitgliederzahl wuchs und lag schon 1946 über dem Stand während der Weimarer Republik. Neue Schichten fanden zur klassischen ArbeiterInnenpartei. Manchen GenossInnen bot sie Karriereperspektiven an, anderen Protektion vor einer möglichen Verfolgung wegen ihrer nationalsozialistischen Mitgliedschaft (vgl. Boyer 2001: 11of.). Nach der Währungsreform 1949 und der Teilung Deutschlands, mit der die SPD einen „Gutteil ihres historisch angestammten sozialen und politischen Mutterbodens“ (Mitzel 1984: 27) verlor, änderte sich diese Entwicklung. Drastische Mitgliederverluste $^{140}$ und die Niederlagen bei den Bundestagswahlen 1949, 1953 und

140 Von 1947 mit 875 Tsd. auf 1955 mit 589 Tsd.; vgl. Tab.4: Mitgliederentwicklung der SPD unter DOI 10.3224/86388794A.. 
1957 verstärkten sich wechselseitig. Die Partei schrumpfte auf ihr traditionelles Klientel (vgl. Boyer 2001) zusammen. Mitte der 1950er-Jahre waren zwei von drei neuen Mitgliedern ArbeiterInnen (vgl. Boyer 2001: 111). Die Partei war männerdominiert, ihr Frauenanteil betrug bei den Neumitgliedern ca. $18 \%$. Bei den Neuzutritten unter 25 Jahre lag er sogar unter $15 \%$ (vgl. Boyer/Kössler 2005: 433).

Die programmatische Öffnung der Partei Ende der 1950er-Jahre war eine Initiative der neuen Parteiführung ${ }^{141}$. Diese hatte mit einer organisatorischen Reform auf dem Stuttgarter Parteitag 1958 erreicht, die ehemalige Dominanz der Parteileitung aufzuheben und eine größere politische Eigenständigkeit der Bundestagsfraktion durchzusetzen. Darüber hinaus wurde der Parteiführung ein Präsidium zugeordnet, in dem die Fraktionsmitglieder mit 9:7 dominierten ${ }^{142}$. Parteivorsitz und Fraktionsvorsitz sollten nun von verschiedenen Personen eingenommen werden. Diese Parlamentarisierung der SPD-Parteiführung (vgl. Schuettemeyer 1998) wurde von einem Ausbau der SPD-Fraktion und ihrer Stäbe begleitet. Sie vergrößerten ihre Sekretariatsressourcen, integrierten wissenschaftliche Expertise und entwickelten damit sowohl einen größeren fachpolitischen Sachverstand als auch mehr Möglichkeiten der eigenständigen Politikdarstellung und -vermittlung (vgl. a.a.O.: 10o). Bereits zu den Parteitagen der 196oer-Jahre wurden die meisten Resolutionsentwürfe des Parteivorstandes von der Bundestagsfraktion ausgearbeitet (vgl. ebd.).

An der Erstellung des Godesberger Programms, des ersten Grundsatzprogramms der SPD im Nachkriegsdeutschland, war die Parteibasis nicht beteiligt. Dennoch fand das Programm auf dem Godesberger Parteitag 1959 eine große Mehrheit, obwohl es wie eine "Zäsur“ wirkte (vgl. Grebing 1987). Mit dem Programm trennte sich die Partei von einer marxistischen Herrschaftskritik und sozialistischen Vergesellschaftungszielen. Die Partei wollte ihr Image als „ArbeiterInnenpartei“ ablegen, aber eine Partei der „sozialen Gerechtigkeit“ bleiben, die sich dafür einsetzte, mit staatlichen Regulierungen und „,,sozialverträglichen' Marktkorrekturen" (Schmidt 2007: 91) die gesellschaftlichen Strukturschäden des privatkapitalistischen Wirtschaftsbetriebs aufzufangen Sie blieb dabei der ArbeiterInnenbewegung eng verbunden, für die GenossInnen gehörte

141 Auf dem Stuttgarter Parteitag 1958 wurde der geschäftsführende Parteivorstand abgeschafft und die Unterordnung der Fraktion unter die Parteiführung, bestehend aus Fritz Erler, Carlo Schmidt und Herbert Wehner, aufgehoben (Walter 2002; Potthoff/Miller 2002).

142 Erst Ende der 1970er-Jahre zog in dieses wichtige Gremium die erste Frau, Antje Huber, ein (Faulenbach 2011:603). 
die Mitgliedschaft in einer DGB-Gewerkschaft zum Parteibuch gewissermaßen dazu. ArbeiterInnenfunktionärInnen, BetriebsrätInnen und gewerkschaftliche FunktionsträgerInnen wurden in den Organisationseinheiten und auf den KandidatInnenlisten bevorzugt aufgestellt und zwar in einer Art informeller Quotierung. Auf den Bundeskonferenzen der Arbeitsgemeinschaft für Arbeitnehmer (AfA) war der Auftritt des Parteivorsitzenden ${ }^{143}$ selbstverständlich.

Mit der politischen Neuausrichtung der Partei 1959 war die SPD für konservative Parteien koalitionsfähig. Die erste Chance zur Regierungsbeteiligung bot sich nach dem Rücktritt der FDP-Minister im Oktober 1966. Die Kompromissbereitschaft der Parteiführung, um diese Große Koalition zu bilden, führte allerdings fast zur Zerrüttung der Partei (vgl. Grebing 1987: 10of.). Die „Fronten der Befürworter und Gegner einer stabilitätsorientierten und kapitalismuskonformen Modernisierungspolitik" (Lehnert 1983: 195) verliefen durch die gesamte Partei. Selbst innerhalb der SPD-Fraktion war die Bildung der Großen Koalition umstritten (vgl. Schuettemeyer 1998). In mehreren Großstädten kam es im Dezember 1966 sogar zu Demonstrationen von sozialdemokratischen Mitgliedern, GewerkschafterInnen und StudentInnen gegen die Regierungsbeteiligung der SPD (vgl. Roth/Rucht 2008: 675). Auf dem Nürnberger Parteitag im März 1968 stimmten die Delegierten mit nur $57 \%$ der Regierungsbeteiligung ihrer Partei zu (vgl. Lehnert 1985: 16).

\section{Die Partei als Motor gesellschaftspolitischer Reformen}

Die „Party in Office“ agierte von diesen innerparteilichen Auseinandersetzungen unabhängig. Im Kabinett Kiesinger (1966-1969) übernahm der Parteivorsitzende Willy Brandt das Außenministerium, Herbert Wehner das Bundesministerium für gesamtdeutsche Fragen, Gustav Heinemann das Justizministerium und Karl Schiller das Wirtschaftsministerium, eine Besetzung, die als Bekenntnis der Sozialdemokratie zur Marktwirtschaft gewertet wurde (vgl. Potthoff/Miller 2002).

Während die Parteiführung die Große Koalition als einen historischen Fortschritt ${ }^{144}$ wertete, fanden sich die KritikerInnen des Regierungsblocks innerhalb und außerhalb der SPD zu einer außerparlamen-

143 In den Zeiten der Regierungsbeteiligung der SPD trat auf den Bundeskonferenzen der AfA der Bundeskanzler auf, dies geschah bei der ASF im Forschungszeitraum nur einmal (1979).

144 Willy Brandt hatte darin „die Überbrückung der Kluft zwischen Bürgertum und Arbeiterschaft" (Willy Brandt zit. n. Grebing 2008: 53) gesehen. 
tarischen Opposition zusammen. Zu ihnen gehörte auch der sozialdemokratische Studentenverband SDS. Schon seit den Auseinandersetzungen über die Wiederbewaffnung in den 1950er-Jahren sah sich die Parteiführung mit einer wachsenden innerparteilichen Opposition, insbesondere in den Reihen ihrer intellektuellen Jugend, konfrontiert ${ }^{145}$. Die Partei war politisch tief gespalten, die Anzahl der Mitglieder wuchs ab Mitte der 1950er-Jahre wieder ${ }^{146}$, die Zahl der Neueintritte während der ersten Regierungsperiode war höher als die der $\mathrm{CDU}^{147}$. Die neuen SPD-Mitglieder waren meist jung und stammten aus verschiedenen gesellschaftlichen Schichten jenseits der ArbeiterInnenklasse.

In der Regierungskoalition mit der CDU/CSU stabilisierte sich die SPD. Ein halbes Jahr vor der nächsten Bundestagswahl wurde ihr Kandidat Gustav Heinemann zum Bundespräsidenten gewählt. 1969 stand der Wahlkampf der SPD unter dem Slogan „Wir schaffen das moderne Deutschland“, die Partei versprach den WählerInnen Stabilität und Wachstum für die deutsche Wirtschaft. Der erfolgreiche Wahlausgang verschaffte der Partei die Möglichkeit, in einer kleinen Koalition mit der FDP die 20-jährige CDU/CSU-Regierungsmacht zu beenden. Innerhalb der Partei war zwar auch dieser Schritt umstritten, aber diesmal wurde die Regierungsbildung von einer großen Mehrheit befürwortet (vgl. Grebing 2007). Mancherorts, so Bernd Faulenbach, ließ dieser Regierungswechsel sogar eine Aufbruchsstimmung entstehen (vgl. Faulenbach 2004). Zum ersten Mal in ihrer Geschichte stellte die SPD einen Kanzler.

In seiner Regierungserklärung verkündete der neu gewählte Kanzler Willy Brandt: „Mehr Demokratie wagen “148. Demokratisierung sollte nun alle gesellschaftlichen Bereiche und Institutionen prägen, die Beteiligungen in den Hochschulen wie die Mitbestimmung in den Betrieben ${ }^{149}$ neu strukturieren sowie eine Transparenz der Regierungsarbeit herstellen (vgl. Nachtwey 2009: 154-172; Grebing 2007). Das geplante Reformwerk führte u.a. zum Ausbau der Bildungssysteme, zur Erweiterung von Sozi-

145 Auf dem Bundeskongress des SDS im Dezember 1967 war die Parteileitung offen für ihre Haltung zur Notstandsgesetzgebung kritisiert und die Anerkennung der DDR gefordert worden (vgl. Osterroth/Schuster 2005: 320f.). An den Demonstrationen gegen die Notstandsgesetze im Frühjahr 1968 beteiligten sich SozialdemokratInnen gegen das ausdrückliche Verbot der Parteiführung. Für das Attentat auf Rudi Dutschke im April 1968 machten SozialdemokratInnen nicht nur die Springer-Presse, sondern auch den von der SPD mitverantworteten repressiven Obrigkeitsstaat verantwortlich.

1461955 war die Partei von 714.292 (1947) auf 474.222 Mitglieder geschrumpft.

147 Vgl. Boyer/Kössler 2005.

148 Regierungserklärung Willy Brandts vom 28. Oktober 1969 (vgl. Brandt 1969).

149 Die gesetzliche Ausweitung der Mitbestimmung war zunächst der Koalitionsbildung zum Opfer gefallen (vgl. Lehnert 1983: 201). 
alstaatsleistungen, zur Flexibilisierung der Altersgrenze beim Renteneintritt, der Lohnfortzahlung im Krankheitsfall sowie einer Liberalisierung des Strafrechts, einer Arbeitszeitverkürzung und der Entkriminalisierung der Homosexualität $t^{150}$. Das Reformwerk sollte durch eine Modernisierung des Regierungshandelns und auf der Grundlage der neuen elektronischen Datenerfassung gesteuert werden ${ }^{151}$ (vgl. Faulenbach 2011: 199f.; Franz 2010b). Auf dem Saarbrücker Parteitag 1970 wurde eine Kommission damit beauftragt, dazu praxisnahe Reformschritte, „,quantifizierte' Ziele und Vorhaben“ (Faulenbach 2011: 238) zu bestimmen und ein Steuerungsmanagement dafür zu entwickeln. Mit dem Leitsatz „Wandel durch Annäherung" vertrat die SPD eine neue Ostpolitik ${ }^{152}$. Im Zeichen dieser außenpolitischen Wende wurden 1970 der Moskauer und der Warschauer Vertrag zum Gewaltverzicht unterzeichnet. Das VierMächte-Abkommen vom 03.09.1971, an dessen Verhandlungen sich die sozial-liberale Regierung beteiligte, stabilisierte die politische Verwaltung Berlins und erleichterte den Transitverkehr und die Besuchsmöglichkeiten in die DDR (vgl. Osterroth/Schuster 2005: 421). Für seine politischen Initiativen der Aussöhnung erhielt Willy Brandt 1971 den Friedensnobelpreis. Mitten im Kalten Krieg stand die SPD für eine neue Friedenspolitik und für eine Diplomatie, die nicht länger von Machtpolitik und Militärstäben bestimmt war.

Zwischen 1969 und 1972 erlebte die Partei ihren massivsten Mitgliederzuwachs seit $1945^{153}$. Mit den großen Eintrittswellen änderte sich die Altersstruktur der Mitgliedschaft. Zwei Drittel aller Parteimitglieder waren nun jünger als 35 Jahre (vgl. Walter 2002: 190). Der Frauenanteil bei den Neumitgliedern lag bei ca. 20 \% und damit über dem Frauenanteil in der Gesamtmitgliedschaft von 18 \%. Das schnelle Wachstum der Partei führte zu erheblichen Spannungen zwischen den Erwartungen der Mitglieder an gesellschaftliche Veränderungen und den Rücksichtnahmen der Parteiführung auf den Koalitionspartner, was viele sozialdemokratische Projekte der Wirtschaftsdemokratie und der sozialen Umverteilung verhinderte ${ }^{154}$.

150 Vgl. ausführliche Darstellung in Faulenbach 2011: 181-241.

151 Diese Planungsvisionen umfassten einen Steuerungszeitraum über 10-15 Jahre. Kanzleramtsminister Horst Ehmke hatte dazu einen Planungsverbund gegründet. Das Projekt zerfiel mit der ersten Ölpreiskrise 1973 (Faulenbach 2011:199f.).

152 Dieser Neubeginn der Ostpolitik wurde 1970 unmittelbar vor der Vertragsunterzeichnung durch das Niederknien Willy Brandts vor dem Mahnmal für die polnischen Opfer der NS-Diktatur symbolisiert.

153 Vgl. Tab. 4 Mitgliederentwicklung SPD unter DOI 10.3224/86388794A.

154 Diese Spannungen führten zu verstärkten Lagerbildungen, die aber nach Bernd Faulenbach die Parteibasis nur marginal integrierten. So stritt die Parteilinke bei Fragen der Steuerreform über „Strukturreformen“ und „Systemüberwindung“, während sich die Mehrheit der Partei vorrangig um soziale Gerechtigkeit sorgte (Faulenbach 2011: 223) 
Während die SPD als Partei wuchs, schwanden die Mehrheiten für die sozial-liberale Politik. Nachdem mehrere Abgeordnete von SPD und FDP zur CDU/CSU übergetreten waren, brachte die CDU im April 1972 ein konstruktives Misstrauensvotum gegen Willy Brandt ein, das knapp scheiterte. Als Haushaltsberatungen an den Mehrheitsverhältnissen im Bundestag scheiterten, wurden im November 1972 vorgezogene Neuwahlen eingeleitet.

Für die folgende Bundestagswahl 1972 entwickelte die SPD ein neues Wahlkampfkonzept, das sich an dem US-amerikanischen Campaigning ausrichtete. Die Partei nutzte die zunehmende mediale Personalisierung der Politik und organisierte den Wahlkampf um die Figur Willy Brandts ${ }^{155}$. Mit dieser Neuausrichtung veränderte sie zugleich die Wahlkampforganisation in der Partei. Es fanden keine Regionalkonferenzen mehr mit Bezirks- und Unterbezirksgeschäftsführern statt; stattdessen wurde die gesamte Planung in Kooperation mit einer Werbeagentur, die u.a. bereits 1969 eingesetzt worden war, über eine zentrale Wahlkampfleitung organisiert. Ziel war u.a., Nicht-Parteimitglieder als WahlhelferInnen zu gewinnen. Lokale WählerInneninitiativen konnten ihre eigenen Wahlkampfmaterialien erstellen und wurden logistisch von Berlin aus unterstützt. Zur Seite stand ihnen auch die Sozialdemokratische Wählerinitiative, die eng mit der Parteileitung kooperierte ${ }^{156}$. In 100 der 248 Wahlkreise riefen KünstlerInnen und Prominente für eine Politik der "Sachlichkeit und Verhandlungsbereitschaft" auf und warben für die Wahl der SPD ${ }^{157}$. Organisiert wurde eine Art öffentliches Bekenntnis zum Bundeskanzler mit Aufklebern und Buttons mit der Aufschrift „Bürger für Brandt“. Die Initiative Katholiken wählen SPD warb für Wahlunterstützung in einem der Partei eher verschlossenen Milieu (vgl. Börner 1973; Walter 2002: 192).

155 Dieser Wahlkampf bedeutete für den Kanzler 25 Tage im Wahlkampfeinsatz. Mit Sonderzug, PKW und Flugzeug wurden ca. $900 \mathrm{~km}$ pro Tag bewältigt und insgesamt 120 Wahlkreise besucht, wie der Bundesgeschäftsführer Holger Börner berichtet, „die Regierungsarbeit ist aber dadurch nicht beeinträchtigt worden " (Börner 1973: 44).

156 Die sozialdemokratische Wählerinitiative (SI) war bereits 1965 gegründet worden und schon im Bundestagswahlkampf 1969 aktiv. 17 SchriftstellerInnen, JournalistInnen, ProfessorInnen, Parteimitglieder und Nicht-Parteimitglieder schlossen sich im sog. Wahlkontor zusammen, um Wahlkampfreden und Parolen zu verbessern. In der SI schliffen 17 SchriftstellerInnen an Wahlkampfreden und Parolen, 62 KünstlerInnen und viele Prominente sorgten für eine medial wirksame Präsenz der SPD (u.a. Luise Rinser, Heinrich Böll, Marie Luise Kaschnitz, Marcel Reich-Ranicki, Siegfried Lenz, Günter Grass, Klaus Wagenbach, Günter Gaus, Golo Mann, Dieter Hildebrandt, Inge Meysel, Ernst Bloch).

157 In der Presse erschien ein Wahlaufruf, der von 62 Prominenten unterzeichnet war. 
In der Bundestagswahl 1972, an der sich 90,8 \% aller Wahlberechtigten beteiligten ${ }^{158}$ - mehr als bei einer Wahl davor wie auch danach -, erhielt die SPD mit 48,8 \% der WählerInnenstimmen die größte Zustimmung in ihrer parlamentarischen Geschichte. Zu diesem Ergebnis hatte auch die vorherige Herabsetzung des Wahlalters auf 18 Jahre beigetragen. In der Gruppe der 18- bis 24-jährigen WählerInnen war die Zustimmungsquote mit 55 \% für die SPD am höchsten.

Nach dieser Bundestagswahl 1972 war die SPD zum ersten Mal in ihrer Geschichte stärkste Fraktion im Parlament. Sie hatte mit einer hohen Eigenmobilisierung und den höchsten bisher aufgebrachten Wahlkampfkosten ihre Regierungsteilnahme erfolgreich ausgebaut. Auf die folgende Regierungsbildung hatten die Parteigremien allerdings nicht den erhofften Einfluss, sie wurde in den Führungsgremien mit der Koalitionspartnerin FDP ausgehandelt (vgl. Schuettemeyer 1998: 173).

\section{Innerparteiliche Opposition gegen sozialdemokratisches Krisenmanagement}

Im neuen Bundestag der 7. Wahlperiode gab es eine Vielzahl neuer Abgeordneter im Bundesparlament, darunter viele MandatsträgerInnen aus dem linken Lager, die sich zunehmend gegen den sachpolitischen Diskurs der Bundesregierung wandten (vgl. Schuettemeyer 1998: 102). Ihr Rückhalt in der Partei war aber größer als ihre Macht in der Fraktion, in der die sog. Kanalarbeiter ${ }^{159}$, die sich bereits in den 1950er-Jahren gegründet hatten, die Mehrheiten bestimmten. In der Partei gab es zwar immer wieder Initiativen, die Einflussnahme der Parteimitglieder auf die Regierungspolitik zu verstärken und die Politik der Fraktion an die Parteitagsbeschlüsse zu binden, aber sie fanden keine Mehrheiten und Parteitagsbeschlüsse beinhalteten stets nur unverbindliche Empfehlungen an die Fraktion (vgl. Schuettemeyer 1998).

Die Differenzen zwischen Fraktion und Partei, aber auch innerhalb der Partei selbst, waren durch einen Generationskonflikt geprägt (vgl. Walter 2002: 194-196; Faulenbach 2010). In der SPD des Jahres 1945 waren zwei Drittel der Mitglieder vor 1933 in die Partei eingetreten, noch Mitte der 1950er-Jahre waren nur $25 \%$ der Mitglieder jünger als 40 Jahre alt. 1972 waren dagegen $75 \%$ der Neu-Mitglieder unter 40 Jahre, davon $20 \%$ unter 21 Jahre. 1973 waren zwei Drittel der Mitglieder erst Anfang der

158 Vgl. W2. Bundestagswahlen 1953-1987. Wahlbeteiligung nach Alter und Geschlecht unter DOI 10.3224/86388794A.

159 Aus ihnen entstand später der Seeheimer Kreis der die SPD in den Traditionen des Godesberger Programms weiter entwickeln wollte. (vgl. Ali 2003) Diese Strömung gehörte später zu den Gegnern einer Geschlechterquote in der Partei (FR o.V. 1988). 
196oer-Jahre der Partei beigetreten (vgl. Klotzbach 1989: 117). 1976 war die Mitgliederzahl der SPD auf über 1 Mio. angewachsen. Mit dieser Entwicklung veränderte sich die soziale Zusammensetzung der Parteimitglieder bezüglich Alter und Bildungsstand schneller als die der SPDWählerInnenschaft (vgl. Grebing 1987: 101). In den Ortsvereinen dominierten Gruppen junger AkademikerInnen die Versammlungen, verdrängten die altgedienten GenossInnen und setzten schnell und taktisch erfolgreich neue „Mehrheitsverhältnisse“ in den Parteieinheiten durch (vgl. Lösche/Walter 1992; Walter 2002; Faulenbach 2010). Der Generationenwechsel hatte bald die Führungsgremien bis in den Parteivorstand erreicht, sodass Anfang der 1970er-Jahre und auf Initiative Willy Brandts ein Ältestenrat eingerichtet wurde mit dem Ziel, die historische Kontinuität der Partei zu bewahren und ihre kollektiven politischen Erfahrungen zu sichern (vgl. Brusis/Wettig-Danielmeier 2008: 8).

Die sozialdemokratische Strategie der „sozialen Gerechtigkeit“ und der Abbau gesellschaftlicher Privilegien bestanden vorrangig in der gesteuerten Verteilung der Zuwächse des Bruttosozialprodukts. Mit den absinkenden Wachstumsraten der Wirtschaft, den Preissteigerungen und der ansteigenden Arbeitslosigkeit kam die SPD ab Mitte der 1970erJahre in eine existentielle Krise. Insbesondere die sog. Ölkrise 1973 demonstrierte die Hilflosigkeit und Begrenztheit einer nationalstaatlich ausgerichteten Wirtschaftspolitik. In der Partei wuchsen die Konfrontationen zwischen MarktkonformistInnen und antikapitalistischen StrukturreformerInnen (vgl. Grebing 2001: 181f.; Borchert et.al. 1996). Die Regierungs-SPD geriet in Schwierigkeiten mit ihrer wirtschaftsliberalen Koalitionspartnerin FDP, kam aber auch in Konflikt mit ihren WählerInnen. Sie sah sich konfrontiert mit Gewerkschaften, denen die Kontrolle über den Arbeitsfrieden ${ }^{160}$ zu entgleiten schien, und stieß deshalb auf Kooperationsgrenzen mit ihnen, ihren bis dahin verlässlichsten Verbündeten $^{161}$.

Der Rücktritt Willy Brandts ${ }^{162}$ und die Übernahme der Kanzlerschaft durch Helmut Schmidt - er war von Brandt 1972 als sog. „Superminister“

16o Im August 1973 streikten bei Ford in Köln die ProduktionsarbeiterInnen spontan und außerhalb der gewerkschaftlichen Verhandlungsstrategien gegen Kündigungen, Taktzeiterhöhungen und die geringen Tarifabschlüsse. Im Laufe der nächsten Monate fanden in über zoo Betrieben solche illegalen Streiks statt. Sie waren zumeist getragen von MigrationsarbeiterInnen aus den unteren Tariflohngruppen, für deren Vertretung und Integration sich die DGB-Gewerkschaften wenig engagierten.

1611974 erstritt die Gewerkschaft Öffentlicher Dienst, Transport und Verkehr mit einem bundesweiten Streik eine ungewöhnliche Tariferhöhung von $11 \%$.

162 Medial wurde der Rücktritt als eine Folge der Guillaume-Affäre präsentiert, bei der Günter Guillaume, ein Mitarbeiter aus dem Beraterstab des Kanzlers, als DDR-Spion enttarnt wurde. In den historischen Analysen allerdings wird dieser Schritt Willy 
der zusammengelegten Ministerien Wirtschaft und Arbeit eingesetzt worden und war im Parteirat der einzige Kandidat - bedeutete für die Partei auch das Ende der sozialdemokratischen Reformpolitik. Im Fokus sozialdemokratischer Politik standen nun stärker die Stabilisierung der Währung und die Stärkung der Märkte, insbesondere für die großbetriebliche Industrie. Die SPD-Fraktion erhielt 1975 einen geschäftsführenden Vorstand ${ }^{163}$, der die Meinungsbildungs- und Entscheidungsfindungsprozesse effektivieren sollte, der aber auch als Entmächtigung der Abgeordneten gewertet wurde (vgl. Schuettemeyer 1998).

Während der Regierungszeit der sozialliberalen Koalition verlor die SPD ihre politische Integrationskraft. Sie vermochte keine spezifisch sozialdemokratische Identität zu entwickeln, mit der sie ihre Mitglieder für den Regierungskurs gewinnen und ihre WählerInnen überzeugen konnte (vgl. Grebing 1987: 102).

Mit der anhaltenden Wirtschaftskrise wuchs in den Gewerkschaften die Kritik an der rücksichtslosen Rationalisierung in den Unternehmen. Die Konjunktursonderprogramme ab 1974 aber subventionierten vor allem privatwirtschaftliche Investitionen und nur in geringem Maße Beschäftigungsmaßnahmen. Die wachsende Staatsverschuldung wurde mit Leistungsbeschränkungen der Sozialsysteme aufgefangen. Die Stützung der privaten Wirtschaft war zum sozialdemokratischen Regierungsziel geworden. In den neuen Mittelschichten, die die SPD in den 1970er-Jahren gewonnen hatte, wuchs eine GegnerInnenschaft gegen die ökonomistische Regierungspolitik und den „umweltfeindlichen Wachstumsfetischismus" (Lehnert 1983: 235). GegnerInnen und BefürworterInnen des Regierungskurses begannen, sich in der Partei neu zu organisieren und sich eine politische Stimme zu geben. Dabei gerieten die Lager der ehemaligen Parteirechten und Parteilinken in Bewegung, Abwanderungen gab es aus beiden Lagern und dabei auch in wechselseitiger Richtung (vgl. Meng 1985; Klotzbach 1989; Meyer 1998; Potthoff/Miller 2002; Grebing 2007).

Ab Mitte der 1970er-Jahre war in der Partei die Berufsgruppe der ArbeiterInnen geschrumpft. 1977 betrug ihr Anteil nur noch $22 \% 0^{164}$ (vgl. Becker et al. 1983: 59). Eine Studie im Auftrag des Parteivorstands dokumentierte, dass die SPD sozialstrukturell keine ArbeiterInnenpartei

Brandts als Folge seines innerparteilichen Bedeutungsverlusts gesehen, seines gescheiterten Integrationskurses, seiner politischen Entscheidungsschwächen und einer persönlichen Erschöpfung (vgl. Faulenbach 2011: 399f.).

163 Den Vorstand stellten Willy Brandt, Herbert Wehner und Helmut Schmidt.

164 In den 1950er-Jahren waren über die Hälfte der Neumitglieder ArbeiterInnen, 9o \% der Mitglieder besaßen keine über die Volksschule hinausgehende Bildung (vgl. Lösche 1993). 
mehr war. Die Parteimitglieder waren besser ausgebildet, jünger, beruflich etablierter und der Anteil an Angestellten und BeamtInnen lag höher als in der Gesamtbevölkerung ${ }^{165}$. In dieser "Mittelschichtsspezifik“ glichen sich die deutschen Parteien sowohl in ihrer Mitgliedschaft als auch bei ihren WählerInnenzielgruppen zunehmend an (vgl. Grebing 2007: 183f.).

1976 gewann die sozialliberale Koalition die Bundestagswahlen nur noch mit knapper Mehrheit. In den meisten Landtagswahlen zwischen 1973 bis 1976 hatte die SPD bereits Stimmen verloren (vgl. Faulenbach 2011: 467). Entgegen der Ankündigung Helmut Schmidts, das Kabinett beizubehalten, mussten mehrere MinisterInnenposten neu besetzt werden, weil sich die bisherigen MandatsträgerInnen für eine weitere Wahlperiode nicht mehr zur Verfügung stellten. Die Unzufriedenheit über den Regierungskurs der Koalition wuchs in den Fraktionen beider Regierungsparteien ${ }^{166}$. Auch außerhalb der Parlamente formierte sich der gesellschaftliche Protest gegen das privatwirtschaftliche Krisenmanagement. Die Neuen Sozialen Bewegungen sensibilisierten für die ökologischen und sozialen Folgekosten eines ungezügelten technologischen Fortschritts und Wirtschaftswachstums. Demonstrationen, teils mit gewaltsamen Auseinandersetzungen mit der Polizei, richteten sich gegen Atomkraftwerke und im weiteren Verlauf auch gegen andere Großprojekte wie Autobahn- und Flughafenanlagen. Neben kleinen militanten Gruppen entwickelten sich Arbeitskreise und Verbände mit fachlicher Expertise und juristischem Sachverstand, die gesellschaftliche Alternativen präsentieren und die PolitikgestalterInnen der Parteien unmittelbar herausforderten. Auf dem Parteitag in Berlin ${ }^{167} 1979$ erhielt ein Antrag, aus der friedlichen Nutzung der Kernenergie auszusteigen, solange die Entsorgungsfragen ungeklärt waren, ein starkes Minderheitsvotum von 41 \% (vgl. Osterroth/Schuster 2005 Bd.3: 319). In der Partei stellten Mitglieder die Geschlechterrollen und die sozialdemokratischen Familienideale in Frage, Sozialdemokratinnen forderten in der Partei mehr Selbstbestimmung, Gleichberechtigung und Partizipation.

Bereits in der StudentInnenbewegung hatten sich kleine Gruppierungen gebildet, die sich als Teile einer internationalen Befreiungsbewegung definierten und mit Anschlägen dem kapitalistischen System den Krieg

165 Infas-Report 1977, in Auszügen in: SPD-PV 10409.

166 Mit dem erheblichen Einsatz verteidigten Abgeordnete aus SPD und FDP erfolgreich die im Wahlkampf versprochene Rentenerhöhung und machten ihre Aussetzung rückgängig, nachdem dies in den Koalitionsverhandlungen bereits beschlossen worden war (vgl. Schuettemeyer 1998: 182).

167 Zeitraum des Berliner Parteitags: 03. - 07.12.1979. 
erklärten. Mit der Politik der „Inneren Sicherheit“ richtete sich die Helmut-Schmidt-Regierung aber nicht nur gegen die Mitglieder militanter Gruppen, sondern verfolgte auch deren vermutetes Umfeld. Polizei und Verfassungsschutz gerieten in Konflikt mit der rechtsstaatlich zugesicherten Organisations- und Meinungsfreiheit und standen tendenziell in Gegnerschaft zu allen außerparlamentarischen Neuen Sozialen Bewegungen $^{168}$. Die „Verhärtung des Staates“ (Hirsch 1980: 99) und die wachsende „Durchstaatlichung der Gesellschaft“ mit der „zunehmenden [...] Überwachung und Kontrolle der Individuen“ (a.a.O.: 94) wurden auch in den Reihen der SPD kritisiert. Helmut Schmidt, der auf dem Weltwirtschaftsgipfel in Deutschland 1978 als „Krisenmanager“ geehrt wurde ${ }^{169}$, verlor zunehmend den Rückhalt in der Partei (vgl. Faulenbach 2011).

Im Januar 1979 beschloss ein „Vierergipfel“ aus USA, Großbritannien, Frankreich und BRD, Europa gegen die militärische Macht der Sowjetunion aufzurüsten und in der Bundesrepublik Mittelstreckenraketen zu stationieren ${ }^{170}$. Dagegen mobilisierte sich ein anwachsender Protest an der SPD-Parteibasis, viele SozialdemokratInnen schlossen sich den Aufrufen der Friedensbewegung an und beteiligten sich an den lokalen Friedenskomitees. In der Unterstützung der NATO-Pläne durch die Bundesregierung sahen sie eine Zerstörung der sozialdemokratischen Entspannungspolitik ${ }^{171}$.

Die folgende Bundestagswahl 1980 bestätigte die SPD-FDP-Koalition in der Regierung. Jedoch wurde der Wahlerfolg vorrangig dem „AntiStrauß-Effekt“ zugerechnet. Die CDU/CSU hatte Franz-Josef Strauß als Kanzlerkandidat aufgestellt, einen Politiker, der für polizeistaatliches

168 Als 1977 die „Rote Armee Fraktion“ im April Generalbundesanwalt Siegfried Buback sowie drei Monate später den Sprecher der Deutschen Bank, Jürgen Ponto, tötete und im September Martin Schleyer, den Präsidenten der deutschen Arbeitsgeberverbände BDA und BDI, entführte und tötete, nach dem es ihr nicht gelungen war, ihre Gefangenen mit einer Flugzeugentführung freizupressen, ging die Regierung mit polizeistaatlichen Großeinsätzen und Rasterfahndungen gegen das linke Spektrum der NSB vor, das sie als mutmaßliche UnterstützerInnen der militanten UntergrundkämpferInnen ansah (Darstellung der Ereignisse: vgl. Wolfrum 2007: 335-349).

169 Das Jahr 1978 bezeichnet Edgar Wolfrum als „Glanzjahr der Regierung Schmidt“ (Wolfrum 2007: 348). In diesem Jahr brachte sie die Bundesrepublik in eine initiative Position zur Steuerung der Weltwirtschaft.

170 Im Dezember 1979 verabschiedete der NATO-Rat den NATO-Doppelbeschluss, der eine atomare Bewaffnung der BRD vorsah, falls die UdSSR sich weigern sollte, binnen vier-Jahren ihre SS20-Raketen abzubauen. Die offensive Unterstützung dieser Pläne durch Helmut Schmidt war selbst in der Parteiführung umstritten (vgl. Wolfrum 2007: 382-390).

171 Im Zuge dieser Sicherheitspolitik wurde die anwachsende DissidentInnenbewegung in der DDR nur verhalten unterstützt, die neuen Entwicklungen der europäischen ReformkommunistInnen wurden von der Parteiführung gänzlich ignoriert (vgl. Faulenbach 2011: 538-540). 
Durchgreifen und repressive Konfliktregelungen stand und den viele Medien als korrupt ${ }^{172}$ und machtbesessen präsentierten (vgl. Wolfrum 2007). Der Ausgang der Bundestagswahl stärkte den linken Flügel in der SPD-Fraktion, aber die eigentliche Profiteurin der CDU/CSU-Wahlniederlage war die FDP173.

1981 lief das Zukunftsinvestitionsprogramm der Bundesregierung aus. Mit dem Nachfolgeprogramm, der sog. Operation ' $82^{174}$, einigte sich das Bundeskabinett auf Steuermehrbelastungen und weitere Sparbeschlüsse (vgl. Faulenbach 2011: 727). Diese monetaristische Politik führte für viele BundesbürgerInnen zu Einschränkungen des Lebensstandards. Bereits ab 1980 waren die Reallöhne gesunken. Nun wurden auch Kernstücke sozialdemokratischer Reformpolitik ${ }^{175}$ zurückgenommen (vgl. Freyberg 1989: 525). Der Abbau sozialstaatlicher Leistungen trug kurzfristig zur Haushaltskonsolidierung bei, konnte aber die Arbeitslosigkeit nicht reduzieren. Vor allem die Kürzungen im sozialen Bereich brachten die SPD-Mitglieder in Opposition zu ihrer Parteiführung. Auch die Arbeitsgemeinschaft für Arbeitnehmerfragen, ursprünglich eine zuverlässige Anhängerschaft Helmut Schmidts, entzog der Regierung mehrfach ihre parteiinterne Unterstützung (vgl. Lösche/Walter 1992: 256-268).

Im August 1982 plädierte Hans-Jochen Vogel in einer Präsidiumssitzung dafür, die Koalition zu beenden (vgl. Faulenbach 2011: 747). Die Divergenzen zur Koalitionspartnerin waren in wirtschaftspolitischen, in finanz- und fiskalpolitischen sowie in sozialpolitischen Fragen gewachsen. Sozialdemokratische Programme schienen in der Regierungskoalition gegen den Neoliberalismus der FDP nicht mehr durchsetzbar. In den Ländern verlor die SPD WählerInnen, während sich die Mehrheit der

172 Mit Strauß wurden mehrere Korruptions- und Schmiergeldaffären in Verbindung gebracht. Eine strafrechtliche Verfolgung wurde nie eingeleitet. Gegen Helmut Kohl als Kanzlerkandidaten hätte - nach Einschätzung Edgar Wolfrums - die sozialliberale Regierungskoalition die Bundestagswahl 1980 nicht gewonnen (vgl. Wolfrum 2007: 350).

173 Von der Niederlage der CDU/CSU profitierte vor allem die FDP: CDU/CSU 44,o \%: 4,0 \%; SPD 43,5\%: +o, $4 \%$; FDP 10,6\%: +2,8 \%.

174 Die Operation '82 sah u.a. die Kürzung der von der Bundesanstalt für Arbeit entrichteten Beiträge zur Rentenversicherung vor, die Einführung eines Krankenversicherungsbeitrags für RentnerInnen, die Selbstbeteiligung von Krankenversicherten an bestimmten Krankheitskosten und die Erhöhung der Arbeitslosenversicherungsbeiträge (vgl. Wolfrum 2007: 353).

175 Frauenpolitisch besonders bedeutend: die Kürzung des Kindergeldes, das nach Pressedarstellungen zum Rücktritt von Antje Huber führte; außerdem Kürzungen beim SchülerInnen-BaFöG, Reduzierung der Arbeitslosenunterstützung (vgl. Jahrbuch der SPD 1982-83: 60) sowie Reformrücknahmen beim MieterInnenschutz, bei der Selbstbeteiligung bei Krankheitskosten und eine Lockerung des Arbeitsschutzes (vgl. Faulenbach 2011: 729f.). 
CDU/CSU im Bundesrat festigte. In der Partei mehrten sich Unmut und Parteiaustritte. ${ }^{176}$

Drei Strömungen bestimmten in der SPD die Debatten der Parteitage ${ }^{177}$ :

- die TraditionalistInnen, die wie Richard Löwenthal eine scharfe Abgrenzung zu den sog. AussteigerInnen aus der Industriegesellschaft forderten und sich für die Rückgewinnung der ArbeitnehmerInnen einsetzten ${ }^{178}$;

- die Links-Alternativen um Erhard Eppler, die den postmateriellen und ökologiesensiblen Wertewandel als neue politische Bezugsgrößen für die Partei definierten und sich als „Bindeglied“ zwischen der Alternativbewegung und den Institutionen der repräsentativen Demokratie sahen (vgl. Vorstand der SPD 1982: 38);

- die ModernisiererInnen, wie der Bundesgeschäftsführer Peter Glotz, die den ArbeiterInnen in der Partei mehr Gehör verschaffen wollten, aber zugleich den Kontakt zur Alternativbewegung suchten ${ }^{179}$ und für linke Bündnisse aus sozialen Bewegungen und traditioneller ArbeiterInnenbewegung eintraten (vgl. Glotz 1982), in denen die SPD das organisierende Zentrum stellen sollte (vgl. Grebing 1987: 103).

Im politischen Wandlungsprozess der Partei verloren die TraditionalistInnen an Einfluss. 1982 veröffentlichte der Parteivorstand ein Papier der Grundwertekommission Die Arbeiterbewegung und der Wandel des gesellschaftlichen Bewusstseins und Verhaltens. In ihm wurde die Partei

176 So hatte der Münchner Parteitag der SPD 1982 ein Beschäftigungsprogramm gefordert, dessen Finanzierung durch die Besteuerung höherer Einkommen gesichert werden sollte (vgl. Faulenbach 2011: 730). Der Beschluss wurde von der Fraktion nicht weiter bearbeitet. Johanno Strasser bemerkte dazu: „Noch nie in der Geschichte der SPD sind die Beschlüsse von Parteitagen so zynisch mißachtet worden wie in den letzten Jahren." (Strasser zit. n. Lehnert 1983: 227)

177 Neben diesen Strömungen standen führende SozialdemokratInnen wie z.B. Hans Matthöfer, der in einem sog. Ölpapier von der Partei eine energiepolitische Wende forderte, ohne die Positionen der TechnologiekritikerInnen zu teilen (vgl. Abelshauser 2009: 527-532). Außerdem begann sich in der Partei ein neoliberaler Flügel zu formieren (Lahnstein-Papier), der für eine Neukonzipierung des Sozialstaats mit einer Reprivatisierung sozialer Risiken eintrat (vgl. Faulenbach/Adler 2008: 28).

$178 \mathrm{Zu}$ Richard Löwenthal: vgl. Seitz 2010; Faulenbach 2011: 642f.

179 Vom 27. bis 29.1.1978 fand an der Technischen Universität Berlin der „Tunix-Kongreß“ mit mehreren Tausend TeilnehmerInnen der NSB statt. Ziel war, einen Weg aus der lähmenden und aussichtslosen Konfrontation mit dem Staat heraus zu finden. Viele Alternativprojekte, wie die Tageszeitung taz, die Partei der Grünen, aber auch privatwirtschaftliche Projekte (Biohöfe, Handwerkskollektive) entstanden hier oder wurden hier vorgestellt. An dem Kongress beteiligte sich der damalige Berliner Wissenschaftssenator Peter Glotz. 
aufgefordert, den „Dialog“ zwischen ArbeiterInnen- und Alternativbewegung herzustellen, um ökologische Themen und produktivitätskritische Positionen aufzunehmen und mit den sozialdemokratischen Grundwerten zu verbinden (vgl. Vorstand der SPD 1982).

Im September 1982 gab der Bundesverband der deutschen Industrie (BDI) eine Denkschrift heraus, die eine Wende der Wirtschafts- und Sozialpolitik forderte. Wenige Tage danach und während der Bundeshaushaltsverhandlungen 1983 veröffentlichte Wirtschaftsminister Otto Graf Lambsdorff ein Papier, das diesen Kurs unterstützte und die Kürzung von Sozialleistungen und Löhnen sowie die Beendigung staatlicher Beschäftigungsprogramme forderte (vgl. Meng 1985: 64; Osterroth 2005). Die FDP-BundesministerInnen traten zurück. Gemeinsam brachten CDU/CSU und FDP ein Misstrauensvotum gegen Helmut Schmidt ein, dem der Bundestag am o1. Oktober zustimmte. Mit einer knappen Mehrheit wurde Helmut Kohl zum neuen Bundeskanzler gewählt und Neuwahlen wurden angesetzt. In der folgenden vorgezogenen Bundestagswahl 1983 verlor die SPD 4,7\% der Stimmen und fiel mit 38,9\% nahezu auf den Stand von $1965(39,8 \%)^{180}$, die CDU/CSU dagegen erreichte mit 48,4 \% ihr bestes Wahlergebnis seit den 1950er-Jahren.

\section{Programmatische Neuorientierungen in der Opposition}

Mit dem Verlust der Regierung war zwar ein ,sozialdemokratisches Jahrzehnt“ (vgl. Bernd Faulenbach 2011: 766 f. ) zu Ende gegangen, aber den regierungskritischen Gruppen in der Partei erschien der Wechsel auf die Oppositionsbänke als ein „Aufbruch nach vorne“ (Lehnert 1983: 229; vgl. Walter 2002). Die Veränderung der Parteienlandschaft durch die Partei Die Grünen, die sich 1980 gegründet hatte und bereits 1983 mit 27 Abgeordneten im Deutschen Bundestag und in sechs Landtagen ${ }^{181}$ vertreten war, galt den ErneuerInnen in der SPD als Beweis für die gesellschaftliche Relevanz der neuen politischen Themen wie z.B. Umweltschutz, Energiewende, Gleichstellungspolitik.

Weg von der Regierungsverantwortung und in der Opposition vollzog die SPD einen „radikalen Bruch“: „Binnen weniger Monate distanzierte sich die sozialdemokratische Opposition von allen zentralen Richtungsentscheidungen der sozialdemokratischen Regierungspartei aus den Jahren der Kanzlerschaft Schmidts“ (Walter 2002: 215). Nun fand das

180 Vgl. Tab. 8 Bundestagswahlergebnisse nach Geschlecht und Alter unter DOI 10.3224/ 86388794A.

1811979 in Bremen, 1980 in Baden-Württemberg, 1981 in Berlin, 1982 in Niedersachsen und Hamburg, Hessen. 
Abrüstungsthema, das die Partei entzweit hatte ${ }^{182}$, Unterstützung im Parteivorstand. Bereits auf der ersten großen Friedensdemonstration im Bonner Hofgarten am 10.10. 1981 war das damalige Präsidiumsmitglied Erhard Eppler als Kritiker des NATO-Doppelbeschlusses aufgetreten und damit in Distanz zum eigenen Kanzler gegangen, vier Monate vorher hatte sich schon der Landesparteitag Baden-Württemberg dem Protest gegen die Nachrüstung angeschlossen und weitere Bezirke waren ihm gefolgt. Nun sprach Willy Brandt am 22.10.1983 auf der Friedensdemonstration im Bonner Hofgarten, die über eine Million Menschen mobilisierte. Vielerorts stellte die Parteibasis der pazifistischen Bewegung ihre Büros zur Verfügung. Riskierten die FriedensaktivistInnen noch vor kurzem ein Parteiausschlussverfahren ${ }^{183}$, empfahl nun die Bundestagsfraktion den Parteimitgliedern die Teilnahme an friedenspolitischen Protestaktionen. Der Münchner Parteitag 1983 beschloss einen Sonderparteitag zum NATO-Doppelbeschluss. Auf diesem Parteitag lehnten die Delegierten die Stationierung der Mittelstreckenraketen mehrheitlich $\mathrm{ab}^{184}$. Auf dem folgenden ordentlichen Parteitag in Essen $1984^{185}$ wurde selbst die Mitgliedschaft in der NATO in Frage gestellt.

Nach dem Sturz durch das konstruktive Misstrauensvotum stellte sich Helmut Schmidt für die kommende Wahl nicht mehr zur Verfügung. Stattdessen wurde Hans-Jochen Vogel von der SPD als Kanzlerkandidat aufgestellt, der als „reformatorischer Gegenpol“ zu Helmut Schmidt galt (vgl. Schuettemeyer 1998: 214), aber den politischen Dialog innerhalb der Fraktion, ihre politischen Diskussionen und die konzeptionellen Arbeiten wenig förderte (vgl. Apel 1991; Schuettemeyer 1998). Bei den Bundestagswahlen 1983 erreichte die SPD nur noch 38,2 \% der WählerInnenstimmen ${ }^{186}$. Da nach den eigenen Meinungsumfragen der SPD eine Wahlniederlage von $29 \%$ vorausgesagt worden war, galt das erreichte Wahlergebnis jedoch nicht als desaströs (vgl. Apel 1991: 245).

182 Der Bundestagsabgeordnete Karl-Heinz Hansen war wegen seiner Unterstützung der Friedensbewegung 1981 ausgeschlossen worden. Er gründete mit Manfred Coppik, der austrat, die Partei Demokratische Sozialisten. Sie erreichte weder auf Landes- noch auf Bundesebene Mandate.

183 Eine Zeitzeugin berichtete, dass die Parteiführung den KritikerInnen mit dem Parteiausschluss drohte, aber keine Repressionen einleitete (vgl. Zz 9; dazu auch SPIEGEL 1981b). Führende SozialdemokratInnen wie Annette Schavan verurteilten die außerparlamentarischen Aktivitäten als Angriffe auf den Staat und die repräsentative Demokratie (vgl. Hansen 2013: 533f.).

184 a.o. Parteitag 18./19.11.1983 in Köln.

185 Parteitag 17.-21.5.1984 in Essen.

186 Vgl. W1. Bundestagswahlen 1953-1987. Wahlergebnisse nach Alter und Geschlecht unter DOI 10.3224/86388794A. 
Trotzdem trugen die verlorenen Bundestagswahlen 1983 nach Heinrich Potthoff und Susanne Miller dazu bei, dass sich in der Parteispitze der 1980er-Jahre mehrere Machtzentren unterschiedlicher parteiinterner Lager entwickelten (vgl. Potthoff/Miller 2002: 301-308; Freyberg et al. 1989). Die Parteiführung konnte sich in dieser Zeit nur schwer koordinieren und das Präsidium setzte keine Steuerungsimpulse, beschreibt Hans Apel den Prozess politischer Fragmentierung (vgl. Apel 1991) . In den SPD-regierten Ländern waren nun die Gestaltungsmöglichkeiten für die Partei größer als im Bund. Auf Länderebene erreichte die SPD ab Mitte der 1980er-Jahre bedeutende Wahlerfolge. Im Saarland erreichte der Saarbrücker Oberbürgermeister Oskar Lafontaine 1985 einen Wahlerfolg von 49,2 \% der Stimmen mit einen Zugewinn von 3,8 \% und wurde Ministerpräsident ${ }^{187}$. Johannes Rau gewann die NRW-Landtagswahl 1985 mit 52,1\% der Stimmen. Die erfolgreichen LandespolitikerInnen, besonders die Ministerpräsidenten, bekamen in der Partei mehr Gewicht (vgl. Schuettemeyer 1998; Grebing 2007: 188). Das Prestige der verschiedenen SpitzenkandidatInnen stützte sich auf den Ausgang der jeweiligen Landtagswahlen. Dies spiegelte sich in der Nominierung von Johannes Rau als Kanzlerkandidat für die Bundestagswahl 1987 wider.

Die große Eintrittswelle in die SPD der 196oer-Jahren versiegte bereits Mitte der 1970er-Jahre. Ab 1976 verlor die Partei kontinuierlich Mitglieder, während die anderen im Bundesparlament vertretenen Parteien Mitgliederzuwächse verzeichneten. Mit der wachsenden Regierungskrise und der Neuorientierung der Partei verlangsamte sich aber dieser Mitgliederrückgang. Ende des Jahres 1982 hatte sich die Zahl der Parteieintritte im Vergleich zum Vorjahr fast verdoppelt. Die offenen Diskussionsprozesse und die Suche nach einem neuen sozialdemokratischen Profil boten den Mitgliedern vielerorts Partizipationsmöglichkeiten, Diskussionskreise und Foren. Ihre aktive Mitwirkung wurde von der Parteiführung gefördert ${ }^{188}$. Auf dem Parteitag in München 1982 präsentierte sich die Parteibasis unter dem Motto „lebendiger Ortsverein“ mit ihren Aktivitäten (vgl. Brandt/Lehnert 2013) ${ }^{189}$, hervorragende politische Ideen wurden mit dem Wilhelm-Drösche-Preis ausgezeichnet (vgl. Faulenbach 2011: 739).

In dem Prozess der politischen Erneuerung entwickelten sich die innerparteilichen politischen Lager weiter und formierten sich neu. So war mittlerweile ein starkes Lager von BefürworterInnen marktliberaler Po-

187 Vgl. W3. Ergebnisse der Landtagswahlen aller Parteien unter DOI 10.3224/86388794A. 188 Dies wird in den Erinnerungen von Hans Apel, Der Abstieg, deutlich (vgl. Apel 1991). Auch verschiedene Zeitzeuginnen berichteten von der lebendigen und transparenten innerparteilichen Diskussionsprozessen in dieser Zeit (Zz 5, 6, 8, 9, 11).

189 Diese Ausstellung wurde danach zu einem festen Programmbestandteil der Parteitage. 
litiken entstanden, das keynesianistische Programme staatlicher Wirtschaftssteuerung ablehnte und sie nach den Erfahrungen 14-jähriger Regierungsarbeit als gescheitert ansah (vgl. Lehnert 1983: 236). Ihnen stand eine beachtliche Opposition verschiedener Strömungen gegenüber (vgl. Freyberg 1989: 544f.). Die wirtschaftsdemokratische Linke fühlte sich gestärkt durch internationale Entwicklungen wie die erfolgreiche Durchsetzung der Gewerkschaftsbewegung in Polen und die Ausrufung der Perestroika durch den im Frühjahr 1985 neugewählten Generalsekretär der KPdSU Michail Gorbatschow. Sie forderte eine Verstaatlichung der Banken und ihr Antrag auf Verstaatlichung der Schlüsselindustrien wurde vom Essener Parteitag 1984 nur nach der massiven Intervention des Parteivorstandes und des Parteivorsitzenden abgelehnt. Angewachsen war auch das Lager der von den Neuen Sozialen Bewegungen angeregten PostmaterialistInnen. Mit einem wachstumskritischen Kurs und feministischen Positionen wollten sie die jungen, politisch engagierten BürgerInnen für die Partei zurückgewinnen, die sich seit der Gründung der Grünen von der SPD abgewandt hatten (vgl. Walter 2002: 217). Innerhalb der Parteilinken hatte eine neue Strömung der ModernisiererInnen an Einfluss gewonnen, die die Partei auf eine ökologische Wirtschaftssteuerung und die Förderung erneuerbarer Energien sowie auf die Förderung einer Technologisierung der Arbeitswelt ausrichten woll$\operatorname{ten}^{190}$. Den Wandlungsprozess förderte, dass mittlerweile viele Neumitglieder aus den 1970er-Jahren Parteifunktionen innehatten und einen starken Flügel gegen die marktwirtschaftsorientierten GewerkschaftsfunktionärInnen repräsentierten.

Die Politik der CDU/FDP-Regierung, von der die SPD sich politisch abgrenzte, stärkte den linken Flügel in diesem Findungsprozess. Nach der Reaktorkatastrophe in Tschernobyl ${ }^{191}$ am 26.04.1986 beschloss der Nürnberger Parteitag $1986^{192}$ den Ausstieg aus der staatlich subventionierten Kernenergie, allerdings in einem marktwirtschaftlich orientierten Rahmen von 10 Jahren. 1986 entschied der mitgliederstarke und eher konservative Bezirk Westliches Westfalen, sich dafür einzusetzen, dass die Entwicklung einer Thorium-Hochtemperatur-Technologie für das AKW Hamm-Uentrop eingestellt wird.

Um die verschiedenen Lager und diskrepanten Strömungen in die Partei zu integrieren sowie ein konsistenteres politisches Profil gegen die starke konservative Regierung zu entwickeln, beschloss der Essener Parteitag 1984, eine Kommission mit der Überarbeitung des Godesberger

190 Dazu wurde von Oskar Lafontaine ein Programmpapier Fortschritt '9o vorgelegt (vgl. Miller/Potthoff 2002: 321).

191 Im April 1986 war der sowjetische Kernreaktor in Tschernobyl in Brand geraten und hatte erhebliche Mengen radioaktiver Teilchen gestreut. Die Wolke zog über Europa.

192 Parteitag 25.-29.8.1986 in Nürnberg. 
Programms zu beauftragen. Eine Historische Kommission wurde vom Parteivorstand eingerichtet mit der Aufgabe, politische Erfahrungen zur verfügbar zu machen und die "historischen Dimensionen politischer Entscheidungen“ zu reflektieren (Grebing 2007: 190).

1986 legte die Programmkommission der Partei den ersten Entwurf eines neuen Grundsatzprogramms, den sog. Irseer Entwurf, vor. Das umfangreiche Dokument präsentierte die neuen politischen Orientierungen 193: eine ökologische Ausrichtung des Wirtschaftens und Konsumierens, die gesellschaftssichernde Kontrolle der kapitalistischen Großunternehmen durch Staat und Gewerkschaften, eine neue Kritik der Geschlechterhierarchie, ein verändertes Verständnis gesellschaftlich notwendiger Arbeit, die Berücksichtigung nicht gewerblichen Arbeitens in den Systemen sozialer Sicherung und die Bedeutung Europas als zukünftiger Sozialraum. Auch wenn sich die Parteimitglieder mit vielerlei Debatten und Anträgen an der Erstellung des Programms beteiligten, blieb das neue politische Profil der Partei eher ein Thema von Fachtagungen und internen Versammlungen und ging kaum in die Außendarstellung der Partei ein (vgl. Miller/Potthoff 2002: 320). Im Regierungsprogramm zur Bundestagswahl $1987^{194}$ waren vorrangig die frauenpolitischen Forderungen $\mathrm{zu}$ finden.

In den 1980er-Jahren konnten die Großparteien SPD und CDU auf ihre StammwählerInnen bauen, so die Historikerin Beatrix Bouvier, ihre Wahlkämpfe richteten sie auf eine sog. gesellschaftliche Mitte und deren spezielle Bedürfnisse und Erwartungen aus (vgl. Bouvier 1993). Mit welchen politischen Aussagen die SPD WählerInnenmehrheit zurückgewinnen werden könnte, war unklar, denn alle politischen Strömungen konnten auf Landtagswahlerfolge verweisen. In Hessen war die SPD 1985 durch eine rot-grüne Koalition an die Regierung gekommen ${ }^{195}$. Johannes Rau hatte 1986 mit einem traditionellen Wahlkampf ${ }^{196}$ die absolute Mehrheit in NRW erreicht, in Hamburg ließ sich 1987 eine Koalitionsregierung mit der FDP bilden, in Schleswig-Holstein gewann die SPD 1988

193 Der Text zeigt die Probleme einer programmatischen Integration der unterschiedlichen Strömungen. So werden einerseits größere Steuerungsaufgaben des Staates definiert, andererseits wird ein weniger reglementierender Staat verlangt (vgl. Papcke 1987).

194 Zukunft für alle - arbeiten für soziale Gerechtigkeit und Frieden (vgl. Vorstand der SPD 1987).

195 Sie scheiterte nach 14 Monaten, gilt aber als Vorbereiterin der rot-grünen Bundesregierung, weil im Zuge der Koalitionsverhandlungen insbesondere energiepolitische Differenzen verhandelt und ausgeglichen wurden.

196 Mitbestimmung, Konjunkturprogramme, Sicherung der alten Industriestrukturen, vgl. SPD-Pressemitteilung 277/1985, http://library.fes.de/cgi-bin/digibert.pl?id=0143 79\&dok=34/o14379\&c=36 [Zugriff: 22.01.2010]. 
die absolute Mehrheit mit 54,8 \% der Stimmen, nachdem Björn Engholm, der spätere Ministerpräsident, im Wahlkampf jede Koalition mit den Grünen ausgeschlossen hatte. Andererseits sah sich die SPD mit einer wachsenden politischen Landschaft der zivilgesellschaftlichen Organisationen konfrontiert. Durch Zusammenschlüsse entwickelten sich größere Verbände, die Ansprüche an die Parteien stellten, wie die Organisation Pro Asyl, die sich 1986 als bundesweite Arbeitsgemeinschaft aus Kirchen, Wohlfahrtsverbänden, Gewerkschaften und Flüchtlingsräten bildete ${ }^{197}$, oder der Bundesverband Homosexualität, der sich als BürgerInnenrechts- und Selbsthilfeorganisation im gleichen Jahr in Köln gründete $^{198}$.

Bei der Bundestagswahl 1987 erreichte die SPD mit dem Kanzlerkandidaten Johannes Rau nur 37,0 \% der WählerInnenstimmen. Das Ergebnis lag damit noch um 1,2 \% unter dem Bundestagswahlergebnis 1983 mit Hans-Jochen Vogel als politischer Leitfigur. Besonders hoch waren die Stimmeinbrüche bei jungen WählerInnen, in der Altersgruppe, in der die Grünen stark hinzugewonnen hatten ${ }^{199}$. Im Bundesrat verfügte die CDU bereits seit 1972 über eine knappe Mehrheit; diese konnte sie bis $1989 \mathrm{zu}$ einer stabilen Mehrheit ausbauen und halten. Auch bei den Wahlen zum Europaparlament verlor die SPD von 1979 bis 1986 sowohl gegenüber den Konservativen als auch gegenüber den Grünen.

Zwei Monate nach den Bundestagswahlen 1987 trat Willy Brandt als Parteivorsitzender zurück. Hans-Jochen Vogel wurde als sein Nachfolger gewählt und hatte nun die Aufgabe, in der Doppelfunktion von Parteiund Fraktionsvorsitz die Partei zusammenzuhalten (vgl. Apel 1991: 439). Zeitgleich rückte eine neue Generation von SpitzenpolitikerInnen, die sog. Enkel Brandts ${ }^{200}$, in die Führungsgremien auf, die sich eher dem linken Flügel der Partei zurechneten und damit tendenziell in Opposition zu Hans-Jochen Vogel standen. Im Parteivorstand hatte die Linke bald eine Mehrheit erreicht (vgl. Apel 1991: 417). Sie war von zwei Lagern geprägt: einer postmodernen Linken ${ }^{201}$, die sich in die programmati-

1971986 gelang es der Bundesregierung, die DDR für eine Abriegelung gegen die Zuflüchtenden zu gewinnen. Die Unterverhandlungen dafür übernahm Egon Bahr - nach Hans-Jochen Vogel: „kein Ruhmesblatt für die Bundesrepublik“ (Vogel 1997: 216; dazu auch Potthoff/Miller 2002: 307).

198 Vgl. dazu Dokumentationen der Stiftung Mitarbeit; Boeßenecker/Bühler 1991.

199 Vgl. dazu Tab.9 Bundestagswahlen 1953-1987 Wahlergebnisse nach Alter und Geschlecht unter DOI 10.3224/86388794A

200 Dazu gehörten Rudolf Scharping, Björn Engholm, Herta Däubler-Gmelin, Oskar Lafontaine.

201 Diese Linke bezog sich auf Schriften Jürgen Habermas zur „neuen Unübersichtlichkeit“ und dem Ende arbeitsgesellschaftlicher Utopien (vgl. Habermas 1985). 
schen Diskurse der Partei stark eingebracht hatte, und einer neuen Strömung von ModernisiererInnen, die sich gegen den Fortschrittsskeptizismus der neuen Programmentwürfe wehrten und in der Computerisierung eine Zukunftstechnologie mit neuen beruflichen Entwicklungschancen sahen. Die ModernisiererInnen setzten sich für eine Flexibilisierung von Arbeitszeit und -bedingungen ein und forderten von der Politik, mit ausreichenden Qualifizierungsangeboten die Anpassung leistungsbereiter ArbeitnehmerInnen zu fördern ${ }^{202}$ (vgl. Miller/Potthoff 2002: 321).

1988 verankerte der Münsteraner Parteitag die Geschlechterquote in der Parteisatzung. Sie verpflichtete die Partei, in allen Entscheidungsgremien, bei der Besetzung von Funktionen und Mandaten und allen Wahlvorschlägen, eine 40\%ige Mindestvertretung von Männern und Frauen sicherzustellen. Außerdem verabschiedete der Parteitag ein Sozialpolitisches Programm, das auf einen „Wertewandel in der Industriegesellschaft" setzte (Sozialpolitisches Programm 1988: 7). In den zukünftigen sozialen Bündnissen galten die Gewerkschaften nicht länger als prioritäre Reformkräfte und genuine BündnispartnerInnen der Partei ( a. a. O.: $6)$.

Am 20. Dezember 1989, wenige Wochen nach der Maueröffnung, verabschiedete ein außerordentlicher Programmparteitag, der aufgrund der epochalen Ereignisse von Bremen nach Berlin verlegt worden war, das neue Parteiprogramm, um das fünf Jahre lang in der Partei gerungen und gestritten worden war. Die Endfassung des Grundsatzprogramms wurde mit großer Zustimmung angenommen ${ }^{203}$.

202 Zum ökologisch postmateriellen Lager zählten etwa Erhard Eppler und Peter von Oertzen, zu deren KritikerInnen Rudolf Scharping, Björn Engholm, Gerhard Schröder und Oskar Lafontaine, der mit der Leitung der Programmkommission betraut worden war (vgl. Miller/Potthoff 2002: 321; dazu Vogel 1997: 234f.).

203 Stichworte zum neuen Berliner Programm: Gleichheit zwischen den Geschlechtern bedeutete neben rechtlichen Fragen auch „gleiche Chancen der politischen und sozialen Teilhabe und der sozialen Sicherung“ (Grundsatzprogramm der SPD 1989: 380); eine neue Kultur des Zusammenlebens unter Anerkennung unterschiedlicher Lebenskonzepte und mit einer Gleichbewertung verschiedener Arbeitsformen aus Erwerbs- und Familientätigkeiten, ehrenamtlichen und kulturellen; ein Arbeitsleben, nicht mehr als „Daseinszweck“, sondern als Teil eines gesellschaftlichen Lebens, zu dem auch seine familiengerechtere Gestaltung gehört (Grundsatzprogramm der SPD 1989: 20-22); eine moderne Sozialpolitik, die individualistische Lebensentwürfe20з berücksichtigt und die Selbsthilfefähigkeit der Betroffenen fördert; die Förderung bürgerInnennaher Verwaltungen statt Obrigkeitsstaat; die Förderung plebiszitärer Beteiligungen wie Volksbegehren, Volksentscheide und BürgerInneninitiativen; stärkere staatliche Regulierungen unkontrollierter wirtschaftlicher Macht und Arbeits- und Einkommensverteilung sowie zur ökologischen Ausrichtung kapitalistischen Wirtschaftens; Lösung der Wirtschaftspolitik aus dem nationalstaatlichen Handlungsrahmen und Ausrichtung auf ein vereinigtes Europa. 
Auf die weitere Gestaltung der Parteipolitik hatte das neue Grundsatzprogramm jedoch kaum Einfluss (vgl. Lösche/Walter 1992). Weniger, weil der Text zu akademisch war, zu weit entfernt von den Erfordernissen praktischer Politik (vgl. Miller/Potthoff 2002: 324) oder - wie Peter Glotz kritisierte - weil er voller „Erstrebeformeln“ (Glotz 2005: 253), war; vielmehr hatte ein neues Kapitel bundesdeutscher Geschichte begonnen, das in den Text jedoch keine Berücksichtigung gefunden hatte $^{204}$. Das sog. Berliner Programm bot damit schon bei der Verabschiedung keine zeitgerechte politische Stellungnahme der SPD zur bundesdeutschen Gesellschaft. Von der Presse wurde der Parteitag kaum wahrgenommen. Parallel zum Parteitag hielt Helmut Kohl seine erste öffentliche Rede in Dresden und wurde auf der Straße und in den Medien als Wiedervereiniger einer gespaltenen Republik gefeiert. Die folgende Bundestagswahl im Dezember 1990 gewann die schwarz-gelbe Regierungskoalition mit einem Stimmenzuwachs, während die SPD 3,5\% der Zweitstimmen verlor und auf $33,5 \%$ fiel.

204 Die SPD war auf diese gesellschaftliche Umwälzung nicht vorbereitet. Sie hatte sich mit ihrer Verständigungs- und Friedenspolitik auf die Anerkennung der Systeme und damit auf die Regierung der DDR konzentriert (vgl. Text der Grundwertekommission der SPD 1987). 
132 


\section{Methodische Anlage der Untersuchung}

Die vorliegende Studie analysiert interne Entwicklungen einer Partei im Wandel. Dafür mussten die historischen Ereignisabfolgen einer bestimmten Epoche rekonstruiert werden. Um die Diskurs- und Verhandlungsverläufe nachzuvollziehen und die Bedeutungen von Ereignissen zu verstehen, wurden mehrere Datenquellen verwendet. Die Untersuchung stützt sich auf die Auswertung von Archivalien, ExpertInneninterviews und auf Literatur zur Parteiengeschichte.

Für unveröffentlichte und publizierte Quellen bietet das Archiv für Soziale Demokratie der Friedrich-Ebert-Stiftung in Bonn den umfangreichsten Fundus verzeichneter und nicht verzeichneter Bestände. Sie setzen sich zusammen aus Ablagen des Frauenreferats, des Parteivorstandes und des Sekretariats des Bundesvorstandes der ASF sowie aus Deposita führender sozialdemokratischer FunktionärInnen. Ergänzend stellt auch das Archiv des Parteivorstandes in Berlin Restbestände des Vorstandsarchivs mit frauenpolitischen Materialien und Veröffentlichungen des Bundesvorstandes der ASF zur Verfügung. Verschiedene zeitgenössische Dokumente, historische Studien über die Sozialdemokratie im Nachkriegsdeutschland und Erinnerungsliteratur prominenter SozialdemokratInnen lassen sich auch im Institut für soziale Bewegungen in Bochum auffinden.

Eine wesentliche Datenquelle für die Arbeit bildeten die ExpertInneninterviews mit sechzehn ParteifunktionärInnen aus verschiedenen Führungsebenen der SPD. Mit ihnen wurden im Zeitraum zwischen 2006 und 2008 leitfadengestützte, meist mehrstündige Interviews geführt. Dies lieferte Hinweise für die Klärung der AkteurInnenstrategien und der historischen Zusammenhänge. Alle Interviewten waren in den 197oer und 1980er-Jahren aktiv in der Partei, mehrere waren an der Parteispitze und wurden somit sowohl als ExpertInnen für innerparteiliche Prozesse als auch als ZeitzeugInnen für diese besondere Epoche sozialdemokratischer Frauenpolitik befragt.

In einer Sekundäranalyse wurden Studien zur Sozialdemokratischen Partei, die den Aufbruch der Frauen und die Durchsetzung der Quote in der Partei mehr oder weniger ausführlich beschreiben, ausgewertet (vgl. Heimann 1991, 1993; Faulenbach 2008; Lösche/Walter 1992; Walter 2002, 2009; Potthoff/Miller 2002). Feministische Studien zur sozialdemokratischen Frauenpolitik liegen vor von Ulrike Honnen zur Gleichberechtigungspolitik der SPD (vgl. Honnen 1988) und von Gaby Brüssow, die die Emanzipationskonzepte der Frauen in der Sozialdemokratie und bei der Partei Die Grünen vergleicht (vgl. Brüssow 1996). Zur Entwicklung der 
sozialdemokratischen Frauenorganisationen hat Wolfgang Pausch 1985 eine Dissertation vorgelegt, die die politischen Aktivitäten und innerparteilichen Diskurse der ASF-Frauen bis zum Jahr 1983 darstellt (vgl. Pausch 1985).

Für die Rekonstruktion der historischen Ereignisabfolgen und -auslöser sowie die Analyse innerparteilicher Auseinandersetzungen wurden unterschiedliche Daten verwendet. Wie die verschiedenen Datenquellen bewertet, gegeneinander gewichtet und kombiniert wurden, wird im Folgenden erläutert und diskutiert.

\subsection{Parteidokumente als historisches Datenmaterial}

In den genannten Archiven waren Parteipublikationen, Jahrbücher, Sitzungsprotokolle, interne Diskussionspapiere und Briefe, Flugschriften, Presseerklärungen und parteinahe Zeitschriften verfügbar. Sie wurden in Bezug auf Stellungsnahmen und Beschlüsse zu frauenpolitischen Themen ausgewertet. Diese Dokumente wurden im historischen Kontext ihrer Entstehung analysiert. Außerdem wurden die Interessen ihrer HerausgeberInnen berücksichtigt, z.B. werden Sitzungsprotokolle meist mit Rücksicht auf spätere, kritische Einsichtnahmen verfasst. Selten liegen sie als Wortprotokolle - in paraphrasierter Form - vor. Üblicherweise geben sie summarisch die Gesprächsthemen und Diskussionen wieder, wobei minoritäre Wortbeiträge sowie Vorschläge und Kontroversen meist nicht komplett aufgeführt werden. Politische Kontroversen finden sich in den parteieigenen oder -nahen Zeitungen und Zeitschriftenreihen, wobei hier die Diskussionsbeiträge statushoher Parteimitglieder dominieren. Die Presseberichterstattung spiegelt die Vorstandsmehrheiten und ist ein Mittel zur Meinungssteuerung in der eigenen Organisation. In den Eigendarstellungen soll die Partei als eine geschlossene, entscheidungsstarke Organisation erscheinen, welche die gemeinsame Tradition bewahrt und sich zugleich flexibel neuen Anforderungen stellt. Damit waren manche für die Entwicklung bedeutende historischen Ereignisverläufe und Auseinandersetzungen zwischen den politischen parteiinternen Lagern in den Parteidokumenten nicht zu finden, sie waren aber in den Erinnerungen der ZeitzeugInnen präsent und manchmal auch in den privaten Archiven.

Die Auswertung dieser Dokumente orientiert sich an der wissenschaftssoziologischen Diskursanalyse von Reiner Keller. Er versteht Texte als "Elemente eines überindividuellen sozio-historischen Diskurses“ (Keller 2007: 33). Sie bilden „Sinnordnungen“ und „Bedeutungsverket- 
tungen“, die dem Handeln der DiskursteilnehmerInnen Struktur und Orientierung geben. Diskursanalysen konzentrieren sich auf „gesellschaftliche Praktiken und Prozesse der kommunikativen Konstruktion, Stabilisierung und Transformation symbolischer Ordnungen sowie deren Folgen: Gesetze, Statistiken, Klassifikationen, Techniken, Dinge oder Praktiken“ (Keller 2007: 57; vgl. Jäger 2004) Nach Michel Foucault besitzt jede geltende Wahrheit eine Ordnung, ein „Ensemble der Regeln, nach denen das Wahre vom Falschen geschieden und das Wahre mit spezifischen Machtwirkungen ausgestattet wird“ (Foucault 1978: 53). Eine „Politik der Wahrheit" gestaltet, nach welchen Regeln und durch welche Instanzen falsche von wahren Aussagen unterschieden werden und welchen Status diejenigen haben, die Wahrheiten festlegen und andere sanktionieren können (vgl. Keller 2007).

In der vorliegenden Untersuchung wurde bei verwendeten Parteidokumenten stets der jeweilige historische Kontext der Texte angegeben sowie der Status der AutorInnen, bzw. auf welcher Hierarchieebene die unterzeichnende Parteieinheit stand, um die Bedeutung der Archivalie zu bestimmen oder zu belegen. Eine solchermaßen kontextualisierte Interpretation der Dokumente kann die Fehlerhaftigkeit und Beliebigkeit der Interpretation reduzieren, ganz ausschließen kann sie sie aber nicht.

Bei der Analyse der Texte wurde verfolgt, wie die VerfasserInnen die Bedeutung ihrer Anliegen begründen, z.B. wie sie an den sozialdemokratischen Grundwerten ansetzen und wie sie ihren Beitrag zum politischen Profil der Partei in der Parteienkonkurrenz oder ihren Wert für die WählerInnen- und Mitgliedergewinnung erläutern. Dabei war der Bedeutungswandel verschiedener Begriffe und Argumentationsabfolgen zu berücksichtigen. Welche gesellschaftlichen Themen schließlich als politikfähig gelten und welche Interessen zu legitimen Ansprüchen an die Partei erklärt werden, wird in innerparteilichen Aushandlungsprozessen entschieden. Diese aber waren durch die starken politischen Lagerbildungen in der SPD der 1980er-Jahren geprägt, sodass zu verschiedenen Themen mehrere "Wahrheiten" in der Partei parallel existierten.

\subsection{Die Daten in den ZeitzeugInnen- und ExpertInneninterviews}

Für die Erforschung des sozialen Feldes wurden ExpertInnen befragt. ExpertInnen sind „Spezialisten für bestimmte Konstellationen“ (Gläser/Laudel 2004: 38). Bei der Auswahl der ExpertInnen wurde berücksichtigt, dass sie „Teil des Handlungsfeldes“ (Meuser/Nagel 1991: 443) wa- 
ren und über ein sozial wirkmächtiges Wissen verfügten ${ }^{205}$. Da sie an Entscheidungen beteiligt waren, sowohl an ihrer Vorbereitung als auch an ihrer Durchsetzung, verfügten diese ExpertInnen bezüglich der Organisation über "Betriebswissen“ (Meuser/Nagel 2005b: 264) ${ }^{206}$ und besaßen als langjährige Parteimitglieder eine „spezifische Binnensicht“ (Przyborski/Wohlrab-Sahr 2008: 132), die es ihnen ermöglichte, Parteiwandlungen zu beschreiben und aus eigener Anschauung zu bewerten, Außerdem waren sie im Forschungszeitraum als frauenpolitische AkteurInnen daran beteiligt und konnten durch ihr frauenpolitisches Engagement in den Parteigremien auch "Deutungswissen" präsentieren, d.h. Kenntnisse über Prozesse der "Etablierung und Durchsetzung von Deutungen" (a.a.O.: 133).

In den Interviews wurden die ExpertInnen vorrangig als ZeitzeugInnen befragt. Als ExpertInnen wurden 16 Personen, 15 Frauen und 1 Mann, ausgewählt. Das Sample repräsentiert dabei unterschiedliche Erfahrungen und Sichtweisen durch die verschiedenen Parteifunktionen, die die Einzelnen in dieser Zeit innehatten, sowie durch ihre Zugehörigkeiten zu differenten politischen Strömungen in der Partei oder der ASF.

Für die Verwertung der Interviewergebnisse als Daten wurde berücksichtigt, dass sich über die subjektive Verarbeitung von Ereignissen eine Folie der Erinnerung zieht. Die Datenqualität von Erinnerungszeugnissen ist deshalb wissenschaftlich umstritten. Ihre Verwendung zur Rekonstruktion historischer Ereignisse wird im Folgenden diskutiert.

\section{Historische Fakten in Erinnerungszeugnissen}

Mit Erinnerungszeugnissen lassen sich nach Lutz Niethammer historische Datenquellen auffüllen. Sie können als „Pfadfinder“ zu neuen oder zu wenig berücksichtigten Quellen führen oder dienen bei der Rekonstruktion geschichtlicher Ereignisse als „Stimulator zum Stellen neuer Fragen“ (Niethammer 1980: 19). Nach Alexander von Plato läuft ein Historiker, der sein historisches Quellenmaterial ausschließlich auf Verwaltungsakten stützt, Gefahr, unreflektiert die Perspektive der „herrschenden" Geschichtspolitik zu übernehmen (vgl. Plato 2000).

205 „Der Experte verfügt über technisches, Prozess- und Deutungswissen, das sich auf sein spezifisches professionelles oder berufliches Handlungsfeld bezieht [...][. E]s weist zu großen Teilen den Charakter von Praxis- und Handlungswissen auf, in das verschiedene und durchaus disparate Handlungsmaximen und individuelle Entscheidungsregeln, kollektive Orientierungen und soziale Deutungsmuster einfließen [...][. D]er Experte besitzt die Möglichkeit zur (zumindest partiellen) Durchsetzung seiner Orientierungen" (Bogner/Littig/Menz 2005: 46).

206 Zur kritischen Reflexion über ExpertInnentum vgl. Bogner/Menz 2002, 2005. 
Methodisch umstritten ist, wie mit dem Anteil des individuell Subjektiven am Berichteten, der individuellen Erfahrung und persönlichen Verarbeitung von geschichtlichen Ereignissen, umzugehen ist und was er für die Datenauswertung bedeutet (vgl. Rosenthal 1995; Jureit 1998; Welzer 2000; Plato 2000; Przyborski/Wohlrab-Sahr 2008).

Nach Harald Welzer wirken bei ZeitzeugInneninterviews dieselben psychologischen Mechanismen wie bei der ZeugInnenvernehmung (vgl. Welzer 200o). Hohe emotionale Beteiligungen, z.B. Ängste, verengen die Aufmerksamkeit auf einzelne Situationsmerkmale; hoch traumatisierte Erinnerungen sind deshalb wenig zuverlässig (vgl. Welzer 2000: 56). Erinnerungen lassen keine Rückschlüsse auf Ereignisse zu, denn bei der Vergegenwärtigung des Vergangenen sind nicht nur die Selektion und Bedeutungsmarkierung der Ereignisse zweifelhaft, sondern der Prozess der "Erfahrungsaufschichtung“ macht fraglich, ob das vermeintlich Erlebte überhaupt stattgefunden hat. In der Vergegenwärtigung wird das Vergangene durch Reflexionen immer neu überarbeitet und verschmilzt mit aktuellen Diskursen. So entstehen kryptomnestische Erinnerungen, weil „mediale Produkte und Diskurse Erinnerungen nicht nur überformen, sondern oft überhaupt erst entstehen lassen" können (a.a.O.: 6o). Die eigenen Erinnerungen erscheinen ZeitzeugInnen umso angemessener - und möglicherweise Interviewten wie Interviewenden umso authentischer -, je mehr sie kulturell abgestützten Erzählmustern entsprechen und sich den sozial abgestützten Ereignisüberlieferungen annähern. ZeitzeugInnenaussagen können nach Harald Welzer deshalb nicht mehr liefern als Anschauungsmaterial, an dem sich die „Erinnerungskultur" zu geschichtlichen Ereignissen erforschen lässt, also „wie etwas von heute aus als vergangenes Ereignis wahrgenommen wird.“ (a.a.O.: 61)

Gabriele Rosenthal bezweifelt die geringe Datenqualität des Erinnerns. Für sie ist Erinnern in seiner Rekonstruktionstätigkeit an das Thema gebunden, zu dem es stattfindet. Nach ihren Forschungen können spätere Erinnerungen sogar dem Erlebnis näher sein als die zeitlich davor liegenden. In den Erzählungen der Interviewten entstehe häufig beim Erinnern ein Selbstlauf, weil sich die Befragten im Erinnern neu erlebten. In diesem Prozess tauchen dann Eindrücke und Bilder auf, die absolut inkongruent zur Gegenwartsperspektive erscheinen oder zumindest zu dem thematischen Feld, das sie eigentlich begründen und erläutern sollen (vgl. Rosenthal 1995: 81). Die individuelle Sinnstiftung, die Rückbezüge zu Vor- und Nachgeschichten schaffe und frühere Erlebnisse und spätere Sichtweisen in Beziehung setzt, finde nicht nur im Darstellen, sondern bereits im Wahrnehmen statt, sie seien nach Gabriele Rosenthal immer „Akte des Entwerfens eines Ganzen“ (Rosenthal 1995a: 32). Ohne Bedeutungszuschreibungen seien schließlich erfahrene Ereignisse im Erzählen nicht reproduzier- und erinnerbar (a.a.O.: 73). 
Das „Erzählnetzwerk“ (Plato 200o: 21), das ZeitzeugInnen als ExpertInnen über den Gegenstand präsentieren, ist ein an ihre Person gebundenes Wissen, bei dem die Daten unmittelbar an die Biographie der Interviewten gebunden sind. Beschreibungen und Deutungsmuster der ExpertInnen sind somit von ihren Interessen, ihren Positionen im sozialen Feld und ihren aktuellen Selbstverortungen abhängig. Zudem werden ihre Darstellungen von Ereignissen häufig von Erzählzwängen ${ }^{207}$ gesteuert, die die Schilderungen anlassungebunden formen (vgl. Schütze 1987; Schütze 1983; Lucius-Hoene/Deppermann 2002; Przyborski/WohlrabSahr 2008: 92-96). Im Interview mit ZeitzeugInnen sind dies zentrale Botschaften, die Auswahl, Darstellung und Bedeutungsaufladung der geschilderten Begebenheiten, Handlungen und Einschätzungen bestimmen (vgl. Rosenthal 1995; Fischer-Rosen-thal/Rosenthal 1997). Sie sind auf die interviewführende Person gerichtet und werden in der Gesprächssituation des Interviews konstruiert. Die Erzählungen sind an der Generierung von Plots ausgerichtet und die Ereignisabfolgen und die Verknüpfungen werden auf diese Plots hin konstruiert (vgl. Lucuis-Hoene/Deppermann 2002: 36; Welzer 2000).

Der Reflexion über Konstruktion und Faktizität stellt Alexander von Plato eine andere Perspektive gegenüber. Nach Alexander von Plato geht es der Erinnerungsforschung gerade um die subjektive Verarbeitung und Aneignung von Geschichte, darum, herauszufinden, wie die Menschen als Subjekte mit den Zwängen und Möglichkeiten ihrer Zeit umgehen, wie sie diese einschätzen, wie sie sie erfahren und wie sie diese Erfahrungen verarbeiten und weitergeben. Diese subjektiven Verarbeitungen sind nicht als individuelle Akte zu fassen, sondern als Produkte „kollektiver Mentalitäten" und Erzähltraditionen (Plato 2000: 8f). Erinnerungskonstruktionen sind nur zugänglich, weil sie nicht ausschließlich retrospektiv sind, sondern weil die Gegenwart nur als eine aus der Vergangenheit rekonstruierte zu verstehen ist.

Wir leben in einem Geflecht von alten und neuen Erfahrungen, das unsere heutigen Haltungen und Bewertungen bestimmt. Wir erinnern uns zwar nicht immer genau, sind aber dennoch ohne aufgetürmte und sich überlagernde Erfahrungen nicht nur ohne Vergangenheit, sondern vermutlich auch ohne Orientierung in der Gegenwart, ohne Fähigkeit der Zuordnung, ohne emotionale Empathien und Zuwendungen. (Plato 2000: 8f.)

207 Dazu gehören die Reziprozitätskonstitution, die Sicherung der Wechselseitigkeit, die Einheitskonstitution, die Bildung einer Selbstidentität und der sozialen Interaktionseinheiten, die Handlungsfigurkonstitution und die Ordnung zeitlich kausaler Handlungsabläufe (vgl. Przyborski/Wohlrab-Sahr 2008: 93). 
Die Interviewten präsentieren somit bedeutsame Erfahrungen. Sie wählen aus einer Fülle von Konstruktionen und Erinnerungsmustern diejenigen aus, die ihr Handeln maßgeblich bestimmt oder legitimiert haben. Sie „verweisen damit immer sowohl auf das heutige Leben mit der Vergangenheit wie auch auf das damalige Erleben dieser vergangenen Ereignisse."(Fischer-Rosenthal/Rosenthal 1997: 148) In der Auswertung der Erinnerungszeugnisse ist dieses Relevanzsystem zu erkennen und zu analysieren.

\subsection{Die Interviewmethode}

Nicht nur im narrativen Interview der Biographieforschung, sondern auch im ExpertInneninterview soll es der interviewenden Person gelingen, möglichst authentische, $d$. h. von den Relevanzsystemen der interviewenden Person getrennte und von den vermuteten Erwartungen der interviewten Person unabhängige, „selbstläufige Passagen zu evozieren, also Gesprächsabschnitte, die allein von den interviewten Personen selbst bestritten werden" (Przyborski/Wohlrab-Sahr 2008: 80) Nach Christel Hopf stellt das qualitativen Interview ein „Pseudo-Gespräch“ dar, weil Regeln der Alltagskommunikation wie Reziprozität oder die Unzulässigkeit des einseitigen Ausfragens nicht gelten (vgl. Hopf 1978: 107). Ziel des Interviews ist es, ein wissenschaftlich wenig erschlossenes Feld zu erforschen und deshalb den Befragten einen „breiten Spielraum für Strukturierungen und Äußerungen subjektiver Deutungen“ (a.a.O.: 99) anzubieten, aber auch Forschungsfragen zu klären, die sich nicht unbedingt mit dem „Relevanzsystem“ und den Orientierungen der Befragten deckten. Das Dilemma, die Spannung zwischen Offenheit und Strukturierung des Gesprächs zu bewältigen, erfordert eine Gesprächsführung, die eine Kombination von themenbezogener ExpertInnenbefragung und selbstläufigen Erzählsequenzen der Interviewten zulässt. Gerade in der sog. Stegreiferzählung geben nach Fritz Schütze die Interviewten ihre subjektiven Erfahrungen am authentischsten wieder und lassen die Interviewenden die innere Verarbeitung der Geschehnisse am besten erkennen $^{208}$. Solche Erzählabschnitte können Wissensbestände eröffnen, die das Interview auf neue Daten und unerwartete Perspektiven lenken und möglicherweise den geplanten Interviewverlauf korrigieren, indem Fragen ergänzt und präzisiert oder sogar die Themenfelder im laufenden In-

208 Die „Homologie von Erzählkonstitution und Erfahrungskonstitution“ (Schütze 1987) ist in der qualitativen Forschungstheorie umstritten (vgl. dazu ausführlicher Przyborski/Wohlrab-Sahr 2008: 223). 
terview verändert werden müssen (vgl. Fritz Schütze, dargestellt in Przyborski/Wohlrab-Sahr 2008: 92f.). Für den Interviewleitfaden wurde deshalb eine offene Form gewählt, in der die Gesprächsführung durch neun Leitfragen vorstrukturiert war (vgl. Meuser/Laudel 2005b).

Da alle befragten ExpertInnen noch immer politisch aktiv sind, wurde ihnen vor dem Interview zugesichert, dass Textsequenzen nur ohne Namensnennungen verwendet werden. Rainer Trinczek empfiehlt solche Diskretionsangebote, um eine „folgenentlastete[...] Gesprächssituation“ (Pfadenhauer 2005: 120) zu schaffen.

Die Interviews dauerten zwischen 0:52 und 3:55 Stunden, die durchschnittliche Dauer betrug 2:15 Stunden. Die Interviews fanden im Zeitraum September 2006 bis November 2008 statt. Sie wurden durchgeführt an den Arbeitsorten der ZeitzeugInnen. Bei den aus dem aktiven Erwerbsleben Ausgeschiedenen fanden sie in deren Privatwohnungen, in einem Fall in einer Flughafen-Lounge statt. Die ExpertInneninterviews wurden nummeriert. Im folgenden Text sind die zitierten Passagen aus einem Interview oder Verweise auf ein Interview mit dem Zusatz „Zz“ und der entsprechenden Nummer gekennzeichnet.

\subsection{Die Auswertung und Verwendung der Interviews}

Das Auswerten des ExpertInneninterviews ist ein rekonstruktiver Akt des Fremdverstehens. Um Interviewaussagen bei ihrer Verwendung nicht zu verfälschen, wird zunächst das Relevanzsystem der jeweiligen interviewten Person, das den Textsequenzen Sinn und Bedeutung gibt, analysiert und erfasst. Ziel der qualitativen Forschung ist es, durch hermeneutische Methoden ein "methodisch kontrolliertes Fremdverstehen“ (Przyborski/Monika Wohlrab-Sahr 20o8: 217) zu ermöglichen und den klassischen Gütekriterien Objektivität, Validität und Reliabilität zu genügen (vgl. a.a.O.: 36).

Die Interviews wurden mit einem Voicerekorder aufgezeichnet. Statt einer Paraphrasierung der Interviews, wie es Phillip Mayring empfiehlt (vgl. Mayring 2003), wurden die Audioaufnahmen komplett transkribiert, um die Komplexität und Authentizität der Textpassagen zu bewahren. Für die Transkription wurden die Transkriptionsregeln für eine bessere Lesbarkeit der Texte reduziert ${ }^{209}$. Gekennzeichnet wurden besonders betonte Worte oder Silben durch Großbuchstaben. Lautstärke,

209 Gerade in den emotionalen Passagen reichen selbst die prosodischen Regeln für die Transkription nicht aus, die Phonetik der gesprochenen Texte müsste vielmehr als Partitur geschrieben werden. 
Stimmlage oder Verzögerungen sowie nonverbale Kommentare wie Lachen, Laute oder deutliche emotionale Zustände wie Erregung, Unwille oder Bewunderung wurden in Klammern ergänzt. Nicht transkribiert wurden Interviewabschnitte, die mit den Themenfeldern in keinem erkennbaren Zusammenhang standen, sondern aktuelle oder sehr lokale Ereignisse betrafen. Diese Auslassungen wurden im Text vermerkt und mit Stichworten begründet. Die Transkriptionen wurden als Arbeitsmaterialien angefertigt. Vor dem Zitieren in der Studie wurden stets Auswahl und thematische Zuordnung der Textausschnitte anhand der originalen Audiodokumentation überprüft.

Der Interviewtext wurde in mehreren Stufen erschlossen. Zunächst wurde die Gestalt des Berichteten analysiert (vgl. Rosenthal 1995). Dazu wurde für jedes Interview ein „Fallprofil“ erstellt, dessen Konzept sich an der dokumentarischen Methode von Ralf Bohnsack anlehnte. Das Analyseverfahren der sog. dokumentarischen Methode basiert auf der Wissenssoziologie Karl Mannheims. Danach erhält jede Aussage eines Interviews erst Sinn und Bedeutung in Bezug auf die kollektiven Praxen und den konjunktiven Erfahrungsraum ${ }^{210}$, in dem die Interviewten agieren und in dem sie sich untereinander unmittelbar verständigen können. Mit der „dokumentarischen Interpretation“ soll derjenige Sinngehalt aufgedeckt werden, der zur „Herstellung sozialer Realität“ beiträgt (Bohnsack zit. n. Przyborski/Wohlrab-Sahr 2008: 275). Auf dieser Sinnebene wird analysiert, was sich in den Interviewtexten über die Darstellenden und ihre Orientierungen „dokumentiert“; Geltungsansprüche und Wahrheitsgehalt der Darstellungen werden nicht überprüft (vgl. Bohnsack 2007: 64). Der "dokumentarische“ Sinngehalt bestimmt das atheoretische Wissen der Kommunizierenden und erfasst unabhängig von dem Anlass der Kommunikation das kollektive „Orientierungswissen“, das den Interaktionen zu Grund liegt (vgl. Przyborski/WohlrabSahr 2008: 280). Diesem „dokumentarischen“ Sinngehalt steht der „immanente" gegenüber. Dieser bezieht sich auf das handlungspraktische Wissen der Kommunizierenden, bezogen auf den Kommunikationsanlass lässt er sich unabhängig vom soziokulturellen Entstehenszusammenhang als richtig oder falsch darstellen.

Bei einer Analyse des thematischen Interviewverlaufs wird eine „Rekonstruktion fremden Sinns von dessen Zentren her" (Bohnsack 2007: 86) verfolgt. Dazu werden Interviewpassagen identifiziert, die besonders hohe Intensität, Dichte und emotionale Beteiligung vorweisen, die sog.

210 Damit bezeichnet Karl Mannheim den kollektiven Erlebniszusammenhang, den die Kommunizierenden sozial und kulturell teilen und der ihnen eine besondere Verständigung auf gemeinsam geteilten, aber nicht explizierten Bedeutungen und Sinnbezügen ermöglicht (Karl Mannheim zit. n. Przyborski/Monika Wohlrab-Sahr 2008: 278f.). 
„Fokussierungsmetaphern“(Bohnsack 2007: 86) ${ }^{211}$. In ihnen drücken sich der Orientierungsrahmen und das Relevanzsystem (vgl. Bohnsack 2007) der Befragten aus. Dafür sind besonders die Textpassagen mit Beschreibungen und Erzählungen geeignet (vgl. Przyborski/Monika WohlrabSahr 2008: 284). Sie lassen sich auch in typischen Formen der diskursiven Praktiken erkennen, z.B. in den Homologien, die sich in unterschiedlichen Textsequenzen wiederfinden lassen, in den Metaphern oder Bildern sowie in den inszenierten dynamischen Sprechakten ${ }^{212}$.

In einem weiteren Auswertungsschritt wurden in den Texten Passagen gekennzeichnet, die den thematischen Feldern der Forschungsfragen zugeordnet wurden bzw. die die Forschungsfragen erweiterten. Dazu wurden die Interviewtexte nach einem Kategoriensystem ausgewertet, das bei der ersten Gesamtdurchsicht der Textaufzeichnungen entlang der Forschungsfragen erstellt worden war. Mithilfe von Kodes ${ }^{213}$ wurden die Textstellen danach - mehrfach dimensioniert - einem grob strukturierteren Kategoriensystem zugeordnet mit dem Ziel, Passagen verschiedener ExpertInnen zu ähnlichen Themen und differente Sichtweisen zu gleichen Problemstellungen auffindbar zu machen ${ }^{214}$.

In der Wiedergabe werden die Textpassagen so ausgeschnitten, dass sie als subjektiv verarbeitete Erfahrungen und persönliche Deutungen von historischen Vorgängen und Zusammenhängen erkennbar sind. Sie werden generell nicht als Datenquelle zur Rekonstruktion historischer Ereignisse verwendet, sondern verdeutlichen die Bedeutungszuschreibungen für spezifische historische Ereignisse oder zeigen exemplarisch unterschiedliche Sichtweisen auf Ereignisse und Verhältnisse und unterschiedliche Interpretationen geschichtlicher Verläufe, manchmal ergänzen sie die Archivalien und die Darstellungen aus der Sekundärliteratur oder beleuchteten diese kritisch. Stets sind die Erzählungen eng an die

211 Sie wurden über Fallprofile für die einzelnen Interviewten erschlossen, die nach folgenden Parametern angelegt wurden: zentrale Themen und grundlegende Botschaften, Selbstentwürfe des politischen Subjekts und des eigenen Engagements sowie Widersprüche und Auslassungen.

212 Nach Aglaja Przyborski und Monika Wohlrab-Sahr werden auch nur diese Passagen transkribiert (vgl. Przyborski/Wohlrab-Sahr 2008: 287). Für die vorliegende Rekonstruktion wurden allerdings die Interviews nahezu vollständig transkribiert. Dieses Vorgehen hat sich im Laufe der Studie bewährt, denn die Bedeutsamkeit verschiedener Passagen erschloss sich erst im weiteren Zuge der Ereignisrekonstruktion.

213 Bedeutsame Textpassagen wurden mit mehreren Kodes belegt, darunter häufig mit Begriffen, die induktiv als „In-vivo-Kodes“ am Textoriginal entwickelt worden waren.

214 Dieses zergliedernde Verfahren ist nach Jochen Gläser und Grit Laudel für alle qualitativen Interviews zulässig, bei denen ein sozialer Sachverhalt Forschungsgegenstand ist und nicht der Erzähltext selbst wie im biographischen Interview, in dem Erzählaufbau und Textfolgen für die Analyse im Vordergrund stehen (vgl. Gläser/Laudel 2004: 44). 
individuelle politische Involviertheit der Interviewten gebunden, an ihre damaligen Positionen oder Funktionen, die persönlichen Beziehungen und Mitgestaltungsmöglichkeiten sowie an die jeweiligen individuellen Erfolgs- und Misserfolgserlebnisse ${ }^{215}$.

\subsection{Beschreibung des Samples ${ }^{216}$}

Befragt wurden 16 Parteimitglieder, die während des Untersuchungszeitraums in der Arbeitsgemeinschaft Sozialdemokratischer Frauen Politik gestaltet oder sich auf der Bundesebene der Partei mit Frauen- oder Gleichstellungspolitik auseinandergesetzt haben.

Die Interviews wurden mit einem Mann und ${ }_{15}$ Frauen geführt. Ihr ExpertInnenstatus war belegt durch Hinweise in Parteidokumenten, durch Namensnennungen in der Sekundärliteratur und durch Empfehlungen von Mitgliedern der Parteiführung.

Die Interviewten befanden sich während des Untersuchungszeitraums in unterschiedlichen Positionen im Organisationsgefüge der Partei, sie nahmen daher im Interview verschiedene Perspektiven auf die Gesamtorganisation und die innerparteilichen Auseinandersetzungen ein. Zwölf Expertinnen waren Aktivistinnen der ASF. Neun Frauen waren Mitglieder des Bundesvorstandes der ASF, zwei davon als Vorsitzende. Zwei weitere Zeitzeuginnen waren in dieser Zeit Vorstandsmitglieder eines Landesverbandes, eine Zeitzeugin war in dieser Zeit Mitglied des Ortsvorstands und des Unterbezirks.

\section{Sozialdaten der ExpertInnen}

Acht der 16 ExpertInnen wurden vor dem Zweiten Weltkrieg geboren, fünf im Zweiten Weltkrieg, drei in den 1950er-Jahren in der Bundesrepublik. Sie repräsentieren damit drei Generationen mit jeweils spezifischen kollektiven Erfahrungen.

Zwei der 15 Interviewpartnerinnen sind nicht verheiratet. Sechs Frauen haben keine Kinder, vier Frauen haben drei Kinder, zwei Frauen haben zwei Kinder, drei Frauen haben ein Kind. Kinderlose und sind in allen drei Generationen vertreten, die unverheirateten Frauen gehören zwei verschiedenen Generationen an. Der männliche Interviewte ist verheiratet und Vater von drei Kindern.

215 Die Fallprofile reflektieren die hieraus entstandene Grundgestalt der Erzählungen.

216 Vgl. dazu Tab.1 InterviewpartnerInnen mit Kurzbiographien unter DOI 10.3224/ 86388794A. 
Alle GesprächspartnerInnen haben eine Hochschulausbildung. Sechs Frauen haben ihre akademische Qualifikation als Weiterbildung erworben und hatten zunächst eine schulische oder duale Ausbildung absolviert.

Drei Frauen sind beruflich selbstständig gewesen, drei weitere Frauen haben vor ihrer Arbeit als Berufspolitikerin in der privaten Wirtschaft gearbeitet, alle anderen zehn ZeitzeugInnen - und damit ein überdurchschnittlicher Anteil - sind im öffentlichen Dienst als Lehrerinnen, Sozialarbeiterinnen oder Angestellte der ministeriellen Verwaltung beschäftigt gewesen.

Viele ExpertInnen sind zum Zeitpunkt des Interviews - unabhängig von ihrem teils hohen Alter - ehrenamtlich aktiv. 13 Personen engagieren sich in sozialen Projekten und NGOs, 12 engagieren sich für kulturelle Initiativen. Sieben Expertinnen sind aktiv in der evangelischen Kirche.

Bei der regionalen Verteilung repräsentieren die ExpertInnen die für die damaligen Auseinandersetzungen relevante Bezirke: Neun ExpertInnen leben und lebten in Nordrhein-Westfalen, zwei ExpertInnen in Bayern, zwei ExpertInnen in Hessen/Hessen-Süd, ein/e ExpertIn in Niedersachen, eine weitere in Hamburg und eine in Baden-Württemberg.

\section{Parteimitgliedschaft und politische Karriere}

Zum Zeitpunkt der Interviews waren alle ExpertInnen Mitglied in der Partei, mehr oder weniger aktiv beteiligt am lokalen Parteigeschehen, in Arbeitsgemeinschaften und in Beratungsgremien des Vorstandes. Alle ExpertInnen traten - nach eigenen Angaben - zunächst ohne persönliche Karriereabsichten in die Partei ein. Die BerufspolitikerInnen unter ihnen betonten, dass es ihnen zu jedem Zeitpunkt möglich gewesen wäre, aus der politischen Karriere auszusteigen und in einen Beruf zurückzukehren.

Bei drei ExpertInnen war es Familientradition, Mitglied der SPD zu sein. Alle anderen entschieden sich aus gesellschaftspolitischen Motiven für ihre Mitgliedschaft, sie sahen in der Partei eine Chance, die Republik zu demokratisieren und gerechter zu gestalten oder die Gewerkschaften in der Gesellschaft zu stärken, oder sie hatten friedenspolitische Gründe. Fünf ExpertInnen waren mit der großen Eintrittswelle zwischen 1966 und 1977 Parteimitglied geworden, drei ExpertInnen traten Anfang der 1980er-Jahre ein.

Elf Frauen haben in der Partei Karriere gemacht bzw. wurden dazu motiviert, unterstützt oder gedrängt. Zehn Frauen wurden als Frauenaktivistinnen in die Führungsspitzen der Partei gewählt, acht Frauen in den Bundesvorstand der Partei, zwei Frauen in Vorstände von Landesverbänden. 
Elf Frauen wurden als Kandidatinnen aufgestellt und zogen als Abgeordnete in den Bundes- oder in einen Landtag ein. Fünf Frauen wurden für Kabinettbesetzungen vorgeschlagen, vier als Ministerinnen berufen.

Drei der Expertinnen hatten vor der politischen Karriere bereits leitende Positionen in einer DGB-Gewerkschaft oder der Arbeiterwohlfahrt, acht Frauen dagegen starteten ihre berufliche Karriere erst in der Partei, die meisten im Zuge der gleichstellungspolitischen Aktivitäten der Partei.

Frauenpolitisches Engagement in der Partei ${ }^{217}$

Eine Expertin kam aus der autonomen Frauenbewegung und trat unter anderem aus frauenpolitischen Motiven in die Partei ein, für alle anderen Expertinnen war das Thema „Gleichstellung“ oder „Geschlechtergerechtigkeit“ kein Beitrittsmotiv. Sechs Expertinnen schilderten, dass sie eher von der Partei zur Frauen- und Familienpolitik überredet worden seien und sich weniger aus eigenem Interesse dafür entschieden haben. Ihr anfängliches Zögern begründeten sie mit der Sorge, sich mit diesen Themen in der Partei politisch zu marginalisieren. Zwei Expertinnen wollen ausdrücklich auch heute nicht als Frauenpolitikerinnen bezeichnet werden. Alle Expertinnen gaben an, dass die Themen Familie, Vereinbarkeit von Beruf und Familie und Antidiskriminierung für sie immer schon sozialdemokratische Grundsatzthemen dargestellt hätten.

217 Die Angaben beziehen sich auf die weiblichen ZeitzeugInnen. 


\section{Die Arbeitsgemeinschaft Sozialdemokratischer Frauen (ASF) als innerparteiliche Akteurin}

1973 richtete der Parteivorstand die Arbeitsgemeinschaft Sozialdemokratischer Frauen (ASF) als demokratisch strukturierte Organisation ein. Bestehende sozialdemokratische Frauengruppen sollten sich in die ASF integrieren. Die ASF forderte keine besonderen Mitgliedschaftskonditionen, sondern jedes weibliche Parteimitglied gehörte gleichzeitig der Frauenorganisation an; deshalb waren alle politischen Lager in der SPD auch in der ASF vertreten. Politische Forderungen und Initiativen der frauenbewegten Aktivistinnen mussten immer zunächst in der eigenen Organisation durchgesetzt werden, bevor sie in die Gremien der Partei gebracht werden konnten.

Die folgenden fünf Kapitel analysieren die Entwicklung der ASF im Forschungszeitraum unter verschiedenen Aspekten.

Das erste Unterkapitel gibt einen Rückblick auf die Geschichte und Traditionen der SPD-Frauenarbeit. Die konservativen Frauen- und Familienbilder der SPD, gegen die die frauenbewegten ASF-Aktivistinnen angingen, bildeten bis in den 1970er-Jahren nicht nur in der Partei, sondern auch in den Frauenarbeitsgemeinschaften die Mehrheitsmeinung. Sie spiegelten die existentiellen Erfahrungen der Nachkriegszeit und die Diskurse der Partei aus den 1950er- und 196oer- Jahren wider. In dieser Zeit organisierte die SPD für ihre weiblichen Mitglieder gesellige Zusammenkünfte und Bildungsveranstaltungen, die von Mitgliedern des Parteivorstand betreut wurden; Foren der frauenpolitischen Meinungsbildung und Intervention waren dagegen nicht vorgesehen.

Das zweite Unterkapitel stellt die ASF als politische Organisation vor. Die ASF war als Arbeitsgemeinschaft eine Sonderorganisation der Partei und besaß keine eigenständigen Antrags- und Vertretungsrechte. Ihre Gründung war unter den weiblichen Parteimitgliedern nicht unumstritten. Für die politische Integration ihrer Mitglieder und die Schulung ihrer Funktionärinnen standen der ASF-Führung nur wenige Informationsmedien zur Verfügung. Die politische Sozialisation verlief deshalb eher dezentral durch den Erfahrungstransfer unter den Genossinnen in den lokalen Arbeitsgemeinschaften und durch Schulungsprogramme, die die Partei auf Bezirks- und Bundesebene anbot. Ein zentrales Element der ASF-Strategie war die Netzwerkarbeit, mit der sie die Unterstützung politischer Anliegen durch AkteurInnen außerhalb der Partei mobilisierte. 
Im dritten Unterkapitel wird die Kollektivbildung der ASF-Frauen analysiert. Eine wichtige Grundlage bildeten die Diskriminierungserfahrungen der Sozialdemokratinnen innerhalb der Partei und der Politik. Politische Aktivistinnen sahen sich und ihre politischen Anliegen in mehrfacher Weise marginalisiert. Die Auseinandersetzungen in der ASF waren durch eine starke politische Fragmentierung geprägt, zum einen durch die Links-Rechts-Lagerbildung der Partei, zum anderen durch vielerlei verschiedene politische und weltanschauliche Strömungen. Trotzdem suchten die Frauen bei der Entwicklung politischer Positionen und Strategien und bei der Organisierung gemeinsamer Aktivitäten immer den Dialog, sodass sich die ASF trotz ihrer politischen Heterogenität im Laufe der 1970er- und 1980er-Jahre in der Partei als eine frauenpolitische Opposition entwickelte und sich auch als solche verstand.

Das vierte Unterkapitel stellt die programmatischen Positionen und die wichtigsten politischen Kontroversen in der ASF vor. Zunächst versuchten linkssozialistische ASF-Aktivistinnen, ein politisches Programm für die ASF zu entwickeln, scheiterten aber an einer ASF-Führung, die mehrheitlich daran interessiert war, mit der Arbeitsgemeinschaft praxisnahe politische Konzepte im Dienste der Partei zu entwickeln. In den Sachthemendebatten aber aktualisierten sich die Konfliktlinien und Lagerbildungen immer wieder, die die Kontroversen in der ASF viele Jahre bestimmten. Die Strömung, die in den 1980er-Jahren die ASF am stärksten beeinflusste, bezeichnete sich selbst als „sozialistische Feministinnen". Ihre Grundorientierungen lassen sich in allen politischen Konzepten und Forderungen finden, die die ASF zu verschiedenen gesellschaftspolitischen Themen entwickelte. Als Teil der Zweiten Sozialistischen Internationale pflegte die ASF internationale Kontakte, besuchte internationale Meetings und organisierte internationale Solidaritätsarbeit; ihre politischen Aktivitäten und Diskussionen waren jedoch vorrangig auf Konflikte in der deutschen Gesellschaft und auf nationalstaatliche Themen ausgerichtet.

Das fünfte Unterkapitel setzt sich mit einem Handlungsfeld der ASF auseinander, das im Laufe der 1980er-Jahre immer wichtiger wurde: dem Kampf um die Partizipation der Frauen in Partei und Politik. Bis Anfang der 1970er-Jahre waren die ParteifunktionärInnen der SPD fast ausschließlich männlichen Geschlechts, genau wie die RepräsentantInnen der Partei in den öffentlichen Ämtern. Mit dem Zustrom junger Mitglieder in die Partei meldeten Frauen verstärkt eine Teilhabe an der Macht an. Den Vorschlag der Parteiführung, diese Partizipation über eine Quote sicherzustellen, lehnte die ASF-Mehrheit zunächst ab. Als sich aber in verschiedenen Parteieinheiten Quotenverfahren durchzusetzen begannen, rückte die ASF-Führung von dieser Verweigerung ab. Die quotierte Berücksichtigung von Frauen bei Gremienbesetzungen und 
KandidatInnenaufstellungen hatte für die ASF und ihr politisches Engagement erhebliche Folgen. Recht unterschiedlich beurteilen die Zeitzeuginnen den Erfolg der Quote auf die Partizipation und die Wirkung der erhöhten Frauenpräsenz auf die Politikentwicklung und die Organisationskulturen der SPD.

\subsection{Sozialdemokratische Frauenpolitik und Frauenarbeit vor der Neugründung der ASF}

Nach sozialdemokratischer Überzeugung war die geringere Stellung der Frau in der Gesellschaft ihrer natürlichen Bestimmung als Mutter und der mangelnden gesellschaftlichen Anerkennung dieser Leistung geschuldet $^{218}$. Schuld daran hatten die Frauen selbst, denn sie interessierten sich nicht für Politik, ihre Welt war die Familie. Ihre Wahlbeteiligung lag stets unter der der Männer; gingen sie wählen, wählten sie konservativ $^{219}$. Frauen schienen sich aufgrund ihrer geringen Allgemeinbildung nur für eine begrenzte Weltsicht zu interessierten, nicht aber für die großen gesellschaftspolitischen Themen. Auf einer niedersächsischen Regionalkonferenz erklärt Parteivorstandsmitglied Elfriede Eilers im März 1968: „Frauen halten Politik abstrakt und allgemein zwar für eine wichtige Sache, konkret stehen sie dem politischen Geschehen jedoch fern" (Eilers 1968: 5)

Zwar sah die SPD vielerlei rechtliche Benachteiligungen der Frauen, die aufgehoben werden mussten, aber eine gesellschaftliche Emanzipation der Frau war nach ihren Vorstellungen nur durch eine Veränderung gesellschaftlicher Leitbilder zu erreichen. Für diese Ziele mussten zunächst die Frauen selbst gewonnen werden. Die Frauenpolitik der Partei war deshalb als eine breiten Bildungs- und Aufklärungsarbeit über einen historisch lang andauernden Zeitraum konzipiert. Ein Facharbeitskreis des Parteivorstandes zur Frauenarbeit erklärte 1970:

Die Gründe für die Unterprivilegiertheit der Frau sind in der Tradition, in der Erziehung und in der Ausbildung zu suchen. Das beginnt in der Familie, und darum ist eine Änderung auch

218 Vgl. dazu Godesberger Programm, Kap. Frau-Familie-Jugend: 363; dazu auch: Renate Lepsius, Mitglied des Frauenauschusses beim Parteivorstand, 1963: „Der eigentliche Gegenstand der Emanzipation, der noch heute aktuell ist, liegt in der Anerkennung der Gleichrangigkeit der Rollen der Frau in Familie und Gesellschaft" (Lepsius 1963: 34).

219 Vgl. Tab. 8 Bundestagswahlergebnisse nach Geschlecht und Alter 1953-1987 sowie Tab. 9 Bundestagswahlen 1953-1987. Wahlbeteiligung nach Alter und Geschlecht unter DOI 10.3224/86388794A. 
nur durch die Familie zu erreichen. Hier hat die SPD eine Erziehungsaufgabe, wenn es ihr wirklich ernst ist mit der Gleichberechtigung der Frauen. (Beirat für Frauenpolitik der SPD 1970:2)

Für die frauenbewegten Neumitglieder der 196oer- und des Anfangs der 1970er-Jahre waren dies Vorstellungen eines etablierten Parteipatriarchat. Zudem stand Frauenpolitik im strategischen Konzept der Parteipolitik unten auf der politischen Agenda. Sozialdemokratische Frauenpolitik bezog sich auf wenige Themen, der Fokus lag auf Familienpolitik.

Relevante politische Impulse wurden von weiblichen Parteimitgliedern wurden nicht erwartet, sie galten als eher unpolitisch und vorrangig geselligkeitsinteressiert. Dabei gab es auch in der Sozialdemokratie der 1950er- und 196oer-Jahre bedeutende Politikerinnen ${ }^{220}$. Häufig kamen sie aus ArbeiterInnenfamilien und waren über ihre Mitgliedschaft in der Sozialdemokratie ermutigt worden, Bildungsbarrieren zu überwinden und sich weiter zu qualifizieren. Sie bezogen sich auf die frauenrechtliche Tradition der SPD und sahen in den Frauen stets ein Potenzial für eine humanitärere Politik und eine sozial gerechtere gesellschaftliche Entwicklung (vgl. dazu Marquardt 1999; Lepsius 1987; Meyer-Schoppa 2004; Notz 2003, 2007). In der Partei und in parteinahen Verbänden erreichten sie bemerkenswerte Karrieren und bildeten dadurch später für die SPD-eigene Frauenbewegung wichtige Bezugspunkte und Idole.

\subsubsection{Sozialdemokratische Traditionen der Frauenpolitik}

1879 erschien August Bebels umfangreiches Werk Die Frau und der Sozialismus, das schnell das „meist gelesene Buch innerhalb der Arbeiterbewegung“ wurde (Lösche 1993: 58). Es symbolisiert bis heute die aufklärerische und frauenemanzipatorische Tradition der Sozialdemokratie. August Bebel steht dabei für die Aufgeschlossenheit und das frauenpolitische Engagement männlicher Parteiführer, ungeachtet der frauenpolitischen Kritik an seinen Positionen und seiner Ignoranz bedeutenden Genossinnen wie Pauline Staegemann ${ }^{221}$ oder Luise Otto-Peters gegenüber,

220 Neben der bereits erwähnten Elisabeth Selbert waren das z.B. Marta Schanzenbach, stellvertretende AWO-Bundesvorsitzende und MdB; die Reichstagsabgeordneten und AWO-Leitungsmitglieder Marie Juchacz (ausführlich: vgl. Meyer-Schoppa 2004), Maria Ansorge und Louise Schroeder; die Bundesministerinnen Käte Strobel (vgl. dazu Marquardt 1999) und Marie Schlei; die Bundestagsmitglieder Helga Timm und Hildegard Schimschock (vgl. Lepsius 1987).

221 Sie gründete 1873 mit Berta Hahn und Johanna Schackow die erste sozialdemokratische Frauenorganisation in Berlin, die sich vor allem um die Arbeitsbedingungen der 
die er nicht als Vorgängerinnen sozialdemokratischer Frauenpolitik und Mitautorinnen des Buchs erwähnte.

Die Partei bezog in ihrer Geschichte sehr unterschiedliche Positionen zu Frauenrechten, der weiblichen Berufstätigkeit und der Teilnahme der Frauen am Parteigeschehen (vgl. Niggemann /Baader 1981). Auch das Wahlrecht für Frauen war in der Sozialdemokratie zunächst umstritten. Der Vereinigungskongress des Allgemeinen Deutschen Arbeitervereins und der Sozialdemokratischen Arbeiterpartei 1875 in Gotha lehnte es ab, die Forderung nach dem Frauenwahlrecht im Programm der Partei zu verankern. Erst das Erfurter Programm 1891 enthielt die Forderung nach allgemeinem Wahlrecht mit einem Passus „ohne Unterschied des Geschlechts für alle Wahlen und Abstimmungen“ (Erfurter Programm 1891 zit. n. Dowe/Klotzbach 1990: 188). Im Deutschen Reichstag engagierten sich die sozialdemokratischen Fraktionsmitglieder für das Frauenwahlrecht - gegen den Spott der bürgerlichen Parteien ${ }^{222}$ und der politischen Rechten -, bis am 12. November 1918 der Rat der Volksbeauftragten das allgemeine Wahlrecht für ,alle mindestens zwanzig Jahre alten männlichen und weiblichen Personen “223 verkündete (Reichs-Gesetzesblatt 1918 zit. n. Miller/Potthoff 2002: 467).

Das Erfurter Programm von 1891 hatte erstmals die Forderung nach „Abschaffung aller Gesetze, welche die Frau in öffentlicher und privatrechtlicher Beziehung gegenüber dem Manne benachteiligen“" (Erfurter Programm 1891 zit. n. Dowe/Klotzbach 1990: 188), in den sozialdemokratischen Wertekanon aufgenommen ${ }^{224}$. Im Programmtext des Gothaer Vereinigungskongresses der ADAV und SDAP 1875 gab es keine Kritik der Geschlechterungleichheiten, stattdessen hatten die Anhänger Ferdinand Lassalles, die die Mehrheit stellten, ein „Verbot der Kinderarbeit

Berliner Arbeiterinnen kümmerte. Seit 2004 ehrt die ASF Brandenburg mit dem Pauline-Staegemann-Preis Frauen für besondere Zivilcourage und den Einsatz für Gleichberechtigung und soziale Gerechtigkeit.

222 In diesen Parteien hatten sich die mittlerweile starken Frauenvereine lange nicht durchsetzen können (vgl. Gerhard 1991: 280-288).

223 Die anschließende Wahl zur verfassungsgebenden Nationalversammlung im Januar 1919 verlief allerdings für die SozialdemokratInnen enttäuschend. Zwar hatten Frauen und Männer sich gleich stark an der Wahl beteiligt (ca. 50\%), aber Frauen hatten mehrheitlich für die konservativen Parteien gestimmt (vgl. Miller/Potthoff 2002).

224 Nach dem Erfurter Programm war es die Aufgabe der Sozialdemokratie gegen jede Form der Ausbeutung und Unterdrückung zu kämpfen, „richte sie sich gegen eine Klasse, eine Partei, ein Geschlecht oder eine Rasse“ (Erfurter Programm 1981 zit. n. Dowe/Klotz-bach 1990: 187) Ein explizites „allgemeines Recht der Frauen auf Erwerbsarbeit" allerdings, das nach der Historikerin Antje Dertinger in diesem sozialdemokratischen Programm erstmalig aufgenommen wäre (zit.n. Dertinger 1980:210), lässt sich weder in den Grundsätzen noch in den Forderungen des Erfurter Programms finden (Dowe/Klotzbach 1990: 185-189). 
und aller die Gesundheit und Sittlichkeit schädigenden Frauenarbeit" (Gothaer Programm 1875 zit. n. Dowe/Klotzbach 1990: 179) in das Selbstverständnis der neugegründeten Sozialistischen Arbeiterpartei Deutschlands aufnehmen lassen ${ }^{225}$.

Das Recht auf eigenständige Vertretung in den Parteileitungen hatten die Frauen seit dem Parteitag in Halle 189o. Lange Jahre wählten die Genossinnen ihre Vertreterinnen dafür in eigenen Frauenversammlungen, weil die restriktive Gesetzgebung des preußischen Vereinsgesetzes von 1850 Frauen, SchülerInnen und Lehrlingen die Mitgliedschaft in politischen Vereinen und Verbänden verbot. Als dieses Verbot 1908 aufgehoben wurde, entfiel in den neuen Parteistatuten das eigenständige Wahlrecht der weiblichen Mitglieder, die Frauenvertreterinnen in den Gremien wurde nun von allen gewählt.

Nach der Aufhebung des Sozialistengesetzes 1890 entwickelte sich die sozialdemokratische Frauenarbeit. Die Partei finanzierte dafür eine Frauenwochenzeitschrift namens Die Gleichheit ${ }^{226}$, darüber hinaus Bildungsabende und Versammlungen und ab 1910 jährlich durchgeführte Frauentage $^{227}$ (vgl. Niggemann 1981).

Sozialdemokratische Aktivistinnen wie Luise Zietz, Emma Ihrer, Martha Rohrlack, Marie Greifenberg, Ottilie Baader, Clara Zetkin und Rosa Luxemburg engagierten sich vor allem für die Verbesserung der sozialökonomischen Lage der Arbeiterinnen. Ehe, Familie und Sexualmoral waren für die Sozialdemokratinnen dagegen eher Privatsache. Die Einheit der ArbeiterInnenklasse stand für sie alle als das wichtigste Ziel über den als gruppenspezifisch geltenden Fraueninteressen. Mehrheitlich vertraten Sozialdemokratinnen ein bürgerliches Familienideal. In ihrer Zeitschrift Die Gleichheit wurde von einer „heilige Verpflichtung der Mutterschaft" (Gerhard 1991: 200) geschrieben. In der SPD, resümiert Susanne Miller die Geschichte der sozialdemokratischen Frauenpolitik, habe es „zu keiner Zeit eine Theorie der Frauenemanzipation gegeben“ (Miller 1978: 554).

225 Nach den politischen Ideen der Lassallianer sollte die Frauenarbeit auf Heimarbeit beschränkt werden, um Arbeitskraftkonkurrenz und Lohndrückerei zu vermeiden und der Vernachlässigung der Kinder und Familien entgegen zu wirken (vgl. Brunn 1972).

226 Zunächst erschien die Frauenzeitung unter dem Titel Die Arbeiterin und wurde von Emma Ihrer herausgegeben. 1891 übernahm Clara Zetkin die Leitung, die Zeitung erschien dann mit dem Titel Die Gleichheit.

227 Führende Frauenpolitikerinnen wie Ottilie Baader, auf deren Initiative das Vertretungsrecht der Frauen in der Partei zurückgeht, setzten sich dafür ein, dass zur Gewinnung neuer weiblicher Mitglieder spezielle Veranstaltungen und Schulungen angeboten wurden (vgl. Niggemann 1981; Weis 1995). 


\subsubsection{Die Familie als Keimzelle des Sozialismus}

Wie sich weibliche Emanzipation und gesellschaftliche Veränderungsziele in den Politikentwürfen der Nachkriegs-SPD zusammenfügten, erläutert Heike Meyer-Schoppa in ihrer Dissertation Zwischen ,Nebenwiderspruch' und ,revolutionärem Entwurf ${ }^{\prime}$ und lässt in ihrer Studie die damals führenden Sozialdemokratinnen zu Wort kommen (vgl. MeyerSchoppa 2004). Herta Gotthelf, die von 1947 bis 1958 im Parteivorstand für Frauenfragen zuständig war, konnte sich Frauenbefreiung nur in einem Prozess gesellschaftlicher Emanzipation vorstellen: „Es gibt für die Erkämpfung der Rechte der Frauen kein anderes Forum und keine andere Möglichkeit als den Kampf um die Änderung der Grundlagen unserer Gesellschaftsordnung" (Herta Gotthelf 1948 zit. n. Meyer-Schoppa 2004: 184). In diesen gesellschaftspolitischen Kampf sollten die Frauen ein ganz eigenes Potenzial einbringen, denn die Sozialdemokratinnen waren überzeugt davon, dass der Krieg das Prinzip der männliche Rationalität hatte scheitern lassen und dass in den Frauen die Fähigkeit steckte, neue Formen des gesellschaftlichen Zusammenlebens zu entwickeln. Welche Stärke Frauen dafür besaßen, hatten ihrer Überzeugung nach die unmittelbaren Nachkriegsjahre bewiesen, in denen es vorrangig die Frauen, die Töchter, Witwen und Mütter, waren, die das Überleben ermöglicht und Nahrung, Kleidung, Hausbrand und Wohnung organisiert hatten ${ }^{228}$.

Der Sozialismus ${ }^{229}$, der als gesellschaftliche Alternative gegenüber Kapitalismus, Krieg und Vernichtung aufzubauen war, brauchte eine Generation von Menschen, die nach den Grundsätzen der Gleichberechtigung, der gegenseitigen Hilfe und der Solidarität erzogen werden sollten. Gerade Frauen hatten, so Herta Gotthelf, daran mitzuwirken, „neue menschliche Sitten, Kollektive und sozialistische Sitten auszuarbeiten“ (Herta Gotthelf 1948 zit. n. Meyer-Schoppa 2004: 184. Gesellschaftspolitik bedeutete für die sozialdemokratische Frauenpolitik der Nachkriegszeit, die „Ordnung des kleinen Kreises auf das Ganze [zu] übertragen“ (Meyer-Schoppa 2004: 188). Frauen konnten die Gesellschaft bereits mitgestalten, indem sie als Hausfrauen für den Aufbau einer guten und gerechten Ordnung im Bereich der Familie sorgten. Im Privaten sollte der Sozialismus entwickelt werden und reifen.

228 Vgl. dazu eindrucksvoll die gesammelten Berichte in der Broschüre Vor 5o Jahren: Wie Frauen das Kriegsende erlebten. Zeitzeugen berichten (ASF-Unterbezirk OsnabrückStadt o. J.)

229 Bis zum Godesberger Programm war der Sozialismus das erklärte Gesellschaftsziel der deutschen Sozialdemokratie. Herta Gotthelf sprach deshalb auch von den historischen Aufgaben der „sozialistischen Frauen“ der SPD. 
Nach Heike Meyer-Schoppa war dies auch die Überzeugung der Parteimehrheit. Die Familie sollte die „Keimzelle“ der neuen Gesellschaft bilden, mit gerechten Eltern, die ihre Kinder nach Bedürfnis und Begabung fördern. Das verlangte besonders von den Müttern, Vorbild zu sein, ,in äußerer und innerer Haltung stets ein sauberer und anständiger Mensch" (Meyer-Schoppa 2004: 256). Heirat und Mutterschaft war das Lebensmodell einer sozialdemokratische Frau: „An der Seite des Mannes ist der Platz der Frau“ (Notz 2003:, 479), warb die SPD zur Bundestagswahl 1949.

Mit dieser Familienorientierung fügte sich die Sozialdemokratie in den allgemeinen Familientrend der 1950er-Jahre ein. Im Nachkriegsdeutschland schien die Institution Familie zunächst in der Krise. Ein hoher Frauenüberschuss ${ }^{230}$, nicht eheliche Lebensgemeinschaften von Kriegswitwen mit einem neuen Partner, die sog. Onkelehen, in den Kriegswirren schnell geschlossene und kriselnde Ehen, außerdem schwerst traumatisierte Kriegsrückkehrer und Väter, die von ihren Kindern nicht erkannt oder von ihren Ehefrauen nicht mehr in ihrer traditionellen patriarchalen Position akzeptiert wurden - dies alles hatte die Scheidungsraten ansteigen lassen. In der neugeordneten Republik aber sollte die bürgerliche Kleinfamilie ein gesellschaftliches Grundelement bilden. Sie galt als das „,letzte stabile Gebilde der Gesamtgesellschaft““ und Ort der „sozialen Zuflucht und Sicherheit“ für das „entwurzelte Individuum“ (Helmut Schelsky zit. n. Frevert 1986: 253).

Der linke Flügel der Sozialdemokratinnen kritisierte dieses Familienkonzept jedoch. Genossinnen wie die Bremer Journalistin und ehemalige Kommunistin Irmgard Enderle setzten sich dagegen für kollektive Hauswirtschaftsformen mit Großküchen und gemeinsamen Waschküchen ein, damit „das Mütterliche und diese Begabung für häusliche Dinge in einem genossenschaftlichen Ganzen, in einer größeren Gemeinschaft, sich noch mehr entfalten kann und noch mehr Leuten zugutekommen kann." (Irmgard Enderle auf der Wuppertaler Frauenkonferenz 1948 zit. n. Mayer-Schoppa 2004: 169) Sie fanden allerdings keine Mehrheiten in der Partei. In der Zeitschrift Genossin ${ }^{231}$ dominierten hausfrauliche Themen wie Erziehungsprobleme und die planvolle Gestaltung der Hausarbeit. Die SPD forderte einen bundesweiten „Haushaltstag“232.

230 Das Zahlenverhältnis der Geschlechter in den drei Westzonen 1946: in der Altersgruppe der 20-30 Jährigen: 100 Männer zu 167 Frauen, in der Altersgruppe der 30-40 Jährigen: 100 Männer zu 151 Frauen (vgl. Frevert 1986: 252).

231 Die erste Ausgabe der Zeitschrift erschien im März 1948. Aufgrund von geringen Papierzuteilungen erschien sie zunächst nur in einer Auflage von 5.000 und 12 Seiten stark. 1950 wurde die Zeitschrift umbenannt in Gleichheit. Organ der arbeitenden Frau. 1963 wurde sie eingestellt. Danach gab die SPD keine Frauenzeitung mehr heraus.

232 Ein solcher Tag hatte bereits in einzelnen Bundesländern bestanden (vgl. Notz 2003: 101, 298). 
Für die Dominanz familienpolitischer gegenüber frauenpolitischen Themen in der SPD sorgte auch die christdemokratische Parteienkonkurrenz, denn für Schutz und Wahrung der Familie standen eher die christlich Konservativen als die Sozialdemokratie. Mehrere SPD-Ortsvereine forderten deshalb auf dem Parteitag 1968, ein Zeichen zu setzen und das Referat Frauen beim Parteivorstand in Frauen und Familien umzubenennen (vgl. Parteitag der SPD 1968).

\subsubsection{Frau und Familie im Godesberger Programm}

Auf dem Parteitag in Bad Godesberg 1959 wurde das erste Grundsatzprogramm der Partei nach 1945 verabschiedet. Im Abschnitt Frau-FamilieJugend war ein Bekenntnis zur Gleichberechtigung der Frauen enthalten, das aber zugleich die Rechte einschränkte:

Die Gleichberechtigung der Frau muß rechtlich, sozial und wirtschaftlich verwirklicht werden. Der Frau müssen die gleichen Möglichkeiten für Erziehung und Ausbildung, für Berufswahl, Berufsausübung und Entlohnung geboten werden wie dem Mann. Gleichberechtigung soll die Beachtung der psychologischen und biologischen Eigenarten der Frau nicht aufheben. Hausfrauenarbeit muss als Berufsarbeit anerkannt und entlohnt werden (Grundsatzprogramm der SPD 1959:363).

Die Naturalisierung von Geschlechterunterschieden ${ }^{233}$ begründete für Frauen nicht nur den eingeschränkten Zugang zum Arbeitsmarkt, sondern auch ein spezifisches Hilfsbedürfnis, das den patriarchalen Schutz erforderte: „Hausfrauen und Mütter bedürfen besonderer Hilfe. Mütter von vorschulpflichtigen und schulpflichtigen Kindern dürfen nicht genötigt sein, aus wirtschaftlichen Gründen einem Erwerb nachzugehen." (ebd.)

233 Eine explizite Definition, welche geschlechtsspezifischen „Eigenarten“ ihren Besitzerinnen den Zugang zu gesellschaftlichen Ressourcen und Macht versperren, ließ sich in den Parteidokumenten nicht finden. Sie bildeten Teil eines gemeinsamen Wissens und waren nicht Gegenstand der politischen Debatte. Eine krude Vorstellung natürlicher Geschlechterdifferenz stellt August Bebel in seinem erwähnten Standardwerk vor. Danach haben gemäß der Darwin'schen Entwicklungslehre Frauen aufgrund der Jahrhunderte währenden Erziehung einen geringer entwickelten „Vorderkopf" ausgebildet, in dem der „Verstand“ anzusiedeln ist, und besitzen einen stärker ausgeprägten „Mittelkopf“ als Männer, der das „Gefühl- und Gemütsleben“ steuert (vgl. Bebel 1964: 289). 
Um der Frauenpolitik, dem „Stiefkind der Partei“, einen größeren Stellenwert zu verschaffen, hatte sich Marta Schanzenbach ${ }^{234}$ auf dem Godesberger Parteitag dafür eingesetzt, der Frauenfrage eine breitere gesellschaftliche Rahmung zu geben, indem „all die Fragen, die mit der Gleichberechtigung der Frau, mit der Familie und mit der Jugend zusammenhängen, einander zugeordnet" werden (Parteitag der SPD 1959: 258). Die Stellung der Frau in der Gesellschaft war in der SPD damit unmittelbar durch ihre Mutterschaft geprägt. Ziel sozialdemokratischer Frauenpolitik war es, das Marginalisieren, das gesellschaftlich-politische Ignorieren der Familienfrauen und ihrer Arbeitsleistung aufzuheben ${ }^{235}$. Der „eigentliche Gegenstand der Emanzipation“, schrieb die sozialdemokratische Frauenpolitikerin Renate Lepsius, seit 1962 Mitglied des Frauenausschusses beim Parteivorstand (vgl. Meyer 1997: 117.), „liegt in der Anerkennung der Gleichrangigkeit der Rollen der Frau in Familie und Gesellschaft" (Lepsius 1963:34)

\subsubsection{Zentrale frauenpolitische Themen der 1950er- und 196oer-Jahre}

In der Partei dominierten familienpolitische Anliegen die sozialdemokratische Frauenpolitik, aber es gab auch andere Politikfelder ${ }^{236}$, die der sozialdemokratischen Frauenbewegung der 1970er-/1980er-Jahre wich-

234 Erläuterungen von Marta Schanzenbach auf dem Parteitag in Hannover 1960 (vgl. Parteitag der SPD 1960: 502). Marta Schanzenbach leitete mit Käte Strobel seit 1958 den Frauenausschuss des Parteivorstandes.

235 Dr. Renate Lepsius auf dem Karlsruher Parteitag 1964: „Als Sozialdemokraten werden wir es nicht zulassen, dass zwischen Öffentlichkeit und Privatheit, deren Spannungsverhältnis ein unaufhebbares Merkmal aller industriellen Gesellschaften ist, ein tiefer Graben liegt. Wollen wir Staatsbürger, nicht Untertanen, dann ist die Überbrückung dieser Spannung eine Lebensnotwendigkeit" (Parteitag der SPD 1964: 105). Ein politisches Konzept wurde dafür nicht vorgelegt.

$236 \mathrm{Im}$ Folgenden nicht aufgeführt ist der Verbraucherschutz. Er galt in der Sozialdemokratie bis in die 1970er-Jahre hinein als frauenpolitisches Thema, um das sich Politikerinnen kümmerten. Dies entsprach seiner historischen Entstehung. Verbraucherverbände waren in der Nachkriegszeit von Frauen gegründet worden, um u.a. die teils sehr niedrige Qualität der Lebensmittel zu kontrollieren. 1953 schlossen sich die verschiedenen lokalen Gruppen zu einem Verein zusammen, um Warentests für den VerbraucherInnenschutz in größerer Zahl durchzuführen. 1964 entstand aus dem Verein die Stiftung Warentest (vgl. http://www.vzbv.de/cps/rde/xbcr/vzbv/Chronik-Verbraucherarbeit.pdf [Zugriff: 02.06.2011]). Für die frauenpolitischen Auseinandersetzungen der 1970er- und 1980er-Jahre in der Partei hatte das Thema aber keine Bedeutung. 
tige Anknüpfungspunkte boten. Dieser Anschluss an sozialdemokratische Traditionen und programmatische Kontinuität erhöhte in der Partei das Verständnis, die Akzeptanz und die Bedeutungsbewertung für neue politische Anliegen und Forderungen der Frauenpolitik.

\section{Gleichheit der Geschlechter vor dem Gesetz}

„Männer und Frauen sind gleichberechtigt.“ Dieser Teil des Artikels 3 im Grundgesetz für die Bundesrepublik Deutschland geht auf die Initiative der Sozialdemokratin Dr. Elisabeth Selbert ${ }^{237}$ zurück. Der Antrag Elisabeth Selberts ${ }^{238}$, einen Gleichberechtigungsparagraphen in das Grundgesetz aufzunehmen, wurde zunächst vom Parlamentarischen Rat abgelehnt. Daraufhin rief Elisabeth Selbert Frauenverbände, Gewerkschafterinnen und weibliche Abgeordnete der Landtage zum öffentlichen Protest auf. Auch die konservativen Frauenvereine schlossen sich an und beteiligten sich mit eigenen Schreiben an dem Rat ${ }^{239}$. Dass der Zusatz zum Artikel 3 schließlich auch die Zustimmung der CDU fand, lag an dem juristisch wenig verbindlichen Begriff ,gleichberechtigt“ und daran, dass die Gleichheitsregelungen unkonkret ${ }^{240}$ und interpretierbar blieben. Ungleichbehandlungen waren somit legitim, wenn sie mit den Andersartigkeiten der Geschlechter begründet werden konnten (vgl. Pausch 1985: 104).

Mit einer Übergangsregelung war das Parlament verpflichtet worden, bis Ende März 1953 alle der Gleichberechtigung entgegenstehenden Regelungen im bürgerlichen Recht abzuschaffen. Damit verloren dem

237 Elisabeth Selbert, 1896-1986, promovierte Juristin aus Kassel, Mitglied des Parlamentarischen Rates. Sie hatte 1930 über das Zerrüttungsprinzip bei Ehescheidungen promoviert und erhielt 1934 als eine der letzten Frauen eine Zulassung als Anwältin. Sie verdiente in der Ehe den Lebensunterhalt, denn ihr Mann wurde 1933 als Sozialdemokrat und Beamter entlassen und der Gestapo-Überwachung unterstellt (vgl. Darstellung in Dertinger 1980: 227-241) Ihr frauenpolitisches Engagement war vielleicht ein Grund ihrer mangelnden Unterstützung in der Partei, in der neuen Bundesrepublik blieb ihr ein Bundestagsmandat ebenso verwehrt wie die Position der Bundesverfassungsrichterin (vgl. Notz 2003: 99).

238 Zwar war Elisabeth Selbert Vorstandsmitglied der SPD, aber der Kampf um den Paragraphen war vor allem eine von ihr persönlich getragene Initiative, die in der damaligen Parteiführung kein Interesse fand.

239 Nach den Forschungsergebnissen von Karin Gille-Linne füllten die Protestschreiben und Resolutionen keine Waschkörbe, wie es in vielen historischen Darstellungen berichtet wird, sondern die Reaktionen lagen unter einem Dutzend; allerdings kamen sie aus einem einflussreichen gesellschaftspolitischen Spektrum (vgl. Gille-Linne 2011).

240 Eine grundgesetzlich garantierte Lohngleichheit forderten nur die KommunistInnen. In den anderen Parteien wurde die Forderung diskutiert. Auch Helene Weber (CDU) unterstützte sie, konnte sich aber in der eigenen Partei ebenso wenig durchsetzen wie die Sozialdemokratinnen (vgl. Notz 2003: 65). 
Grund nach ab 1. April 1953 alle dem Gleichberechtigungsprinzip entgegenstehenden Gesetze ihre Rechtsverbindlichkeit. Faktisch kam es aber weder zu einem juristischen Desaster noch wurden die juristischen Lücken frauenpolitisch genutzt; stattdessen, so kritisiert Egon Bahr, tolerierten die bundesdeutschen Regierungen und auch die etablierten Großverbände den „permanenten Verfassungsbruch“ (Egon Bahr zit. n. Dertinger 1980: 241).

Trotz der geringen juristischen Bedeutung bildete der Gleichberechtigungsparagraph einen wichtigen Bezugspunkt für die Neuen Frauenbewegungen. Insbesondere die Frauen in den Parteien bezogen sich bei den Forderungen nach neuen Rechtswirklichkeiten auf die Umsetzung des Artikels 3 GG, z.B. bei der unzulänglichen Verteilungsgerechtigkeit in der Alterssicherung, im Scheidungsfall oder bei der juristischen Bewertung der Geschlechterverhältnisse und -beziehungen in der Ehe, im Arbeitsleben und auf dem Berufsmarkt.

\section{Weibliche Berufstätigkeit und Bildungsbeteiligung}

Die Erwerbstätigkeitsquote der Frauen war bis Anfang 1950 auf 30,2 \% gesunken und lag damit ungefähr halb so hoch wie bei den Männern mit 63,8\%.241 Bald aber führte der Wirtschaftsaufschwung in der Bundesrepublik zu einer verstärkten Nachfrage nach Arbeitskräften. Insbesondere im expandierenden Dienstleistungssektor wurden Frauen angeworben $^{242}$. Gleichzeitig stiegen die Konsumansprüche der Bevölkerung und die männlichen Alleinernährereinkommen reichten meist nicht mehr aus. Die Technisierung der Hausarbeit erleichterte es auch den Frauen mit Familienpflichten, eine eigene Erwerbstätigkeit aufzunehmen. Laut einer Umfrage bei 1.ooo berufstätigen Müttern im Jahre 1956/1957 waren nach Elisabeth Pfeil nur 13 \% der Frauen aus wirtschaftlicher Not berufstätig, 49\% gaben dagegen an, dass ihre Einkünfte zu einem höheren Familieneinkommen und einem höheren Lebensstandard beitragen sollten. Allerdings war die Erwerbstätigkeit bei den Frauen häufig mit dem schlechten Gefühl verbunden, ihren „eigentlichen“weiblichen Aufgaben in der Familie nicht ausreichend nachkommen zu können (vgl. Elisabeth Pfeil zit. n. Frevert 1986: 256).

In der Sozialdemokratie galt die Berufstätigkeit zwar als Recht der Frauen und als Schritt zur weiblichen Emanzipation. Was aber als Beruf

241 Daten nach gesis histat. Vgl. http://www.gesis.org/histat/de/table/details/2BBE45

DA53B2DoB96AD97D3F422A10D6\#tabelle [Zugriff: 20.02.2011].

242 Zahlen dazu vgl. Frevert 1986: $258 f$. 
zu bezeichnen war, war umstritten ${ }^{243}$ und vom Familienthema bestimmt. Im Godesberger Programm 1959 wurde deshalb die Anerkennung der Hausfrauenarbeit als Berufsarbeit gefordert und die Partei setzte sich für einen Hausfrauenlohn ein. Konkrete politische Vorstellungen, wie die geforderte Gleichberechtigung der Geschlechter in Erziehung und Ausbildung, bei der Berufswahl und -ausübung sowie bei der Entlohnung hergestellt werden sollte, waren dagegen im Programmtext nicht zu finden (vgl. Grundsatzprogramm der SPD 1959: 363). Die Doppelverdienerehe wurde bis in die 1950er-Jahre hinein in der Partei mehrheitlich abgelehnt. Wegen der hohen Arbeitslosigkeit sollten Frauen auf eine Erwerbstätigkeit verzichten, wenn ihnen andere Einkommensquellen zur Verfügung standen, das vertraten auch die sozialdemokratischen Frauen. Diesen Einkünften zuzurechnen waren Mieten oder Pacht sowie auch der Verdienst des Ehemannes. Gewerkschaften tolerierten ArbeitgeberInnen, die ihre weiblichen Beschäftigten bei Eheschließung entließen ${ }^{244}$ (vgl. Frevert 1986: 254; Meyer-Schoppa 2004; Notz 2007b: 25).

Allerdings änderten sich die politischen Diskurse mit der weiter anwachsenden weiblichen Erwerbsquote ${ }^{245}$. Die Benachteiligung der Frauen auf dem Arbeitsmarkt kam auf die Agenden sozialdemokratischer Parteitage und führte zu Forderungen nach Ausbau der öffentlichen Kinderbetreuung, nach Abschaffung von Frauen benachteiligenden Arbeits- und Arbeitsschutzregelungen und der weiblichen Berufsverbote. Politische Konzepte und Forderungen zur Geschlechterdiskriminierung auf dem Arbeitsmarkt bezogen sich allerdings stets auf das DreiPhasen-Modell ${ }^{246}$ der weiblichen Berufsbiographie: Danach schloss die moderne Frau ihre berufliche Ausbildung ab, zog sich dann mit der Eheschließung für 15-20 Jahre vom Arbeitsmarkt zurück und suchte nach der

243 Vgl. dazu die Debatte zwischen Monika Plessner und Renate Lepsius in der Zeitschrift Die Neue Gesellschaft (vgl. Lepsius 1963; Plessner 1961, 1965). Dr. Axel Möller, Bundesminister der Finanzen in der sozialliberalen Koalition, war zwar ein Fürsprecher für eine größere Beteiligung von Frauen in der Wirtschaft und Politik, die Geschlechtersegregation des Arbeits- und Berufsmarktes stand dabei außer Frage. Zu den weiblichen Berufsfeldern zählte er 1960: „,insbesondere die haus- und landwirtschaftlichen Tätigkeiten, Erziehung und Unterrichtung, Pflege und Fürsorge und nicht zuletzt die künstlerische und wissenschaftliche Betätigung" (Möller 1960: 4, in: AdSD SPD-PV 10383).

244 Diese Diskriminierung schafften nicht Gewerkschaften oder Politik, sondern die Rechtsprechung ab. Die Kündigung nach Eheschließung wurde durch ein Urteil des Bundesverfassungsgerichts im März 1957 verboten.

245 Auf dem Parteitag 1964 belegte Marta Schanzenbach die veränderte gesellschaftliche Entwicklung mit Zahlen: $20 \%$ der Familien waren „unvollständig“. 90,1 \% der Alleinerziehenden bezogen ein Erwerbseinkommen, ebenso 60,9\% der geschiedenen und 73,7\% der ledigen Frauen (Parteitag der SPD 1964:115).

246 Dieses Lebensmodell entwickelten Alva Myrdal und Viola Klein 1956. 
Versorgungsphase der Kinder wieder eine Erwerbstätigkeit, meist in Teilzeit (vgl. Frevert 1986: 258) Mit diesem Modell war die Marginalisierung der Frauen auf dem Arbeitsmarkt konzeptionell festgelegt, zum einen, weil die Doppelbelastung von Familien- und Erwerbsarbeit ausschließlich den Frauen zugewiesen wurde, und zum anderen, weil weibliche Arbeitsleistung immer nur eingeschränkt verfügbar war, ob durch den betreuungsbedingten Erwerbsausstiegs oder die anschließende Berufsrückkehr in Teilzeit. Darüber hinaus wurde ein geringeres Interesse der Frauen an beruflicher Qualifizierung und Entwicklung unterstellt (vgl. Lepsius 1963).

1963 beantragte die SPD-Fraktion eine Untersuchung zur gesellschaftlichen Situation der Frauen. Sie wollte damit die die Ungerechtigkeiten in der Geschlechterordnung auf die politische Agenda der Bundesregierung setzen. Der Antrag wurde erst nach zweijähriger Ausschussberatung vom Parlament angenommen, 1967 erschien der Bericht der Bundesregierung über die Situation der Frauen in Beruf, Familie und Gesellschaft (vgl. Notz 2007b: 21f.).

Nach Ansicht der SPD lag die Ursache der schlechteren beruflichen Chancen auf dem Arbeitsmarkt im geringeren Schul- und Berufsausbildungsniveau der Frauen: „Nur neun Prozent der berufstätigen Frauen haben einen qualifizierten Arbeitsplatz, 46 Prozent sind kurzfristig angelernt, 45 Prozent umgelernt" (Jahrbuch der SPD \{1964/65\}: 196). 90 \% aller Anlernverträge wurden für junge Frauen abgeschlossen (vgl. Junker-Seelinger 1968: 8). Bereits in den 1950er-Jahren hatten die SozialdemokratInnen das undurchlässige dreigliedrige Schulsystem kritisiert und die spezielle Förderungen sozial benachteiligter SchülerInnen gefordert. Sie drängten auf die Verabschiedung eines Ausbildungsförderungsgesetzes, dessen Bedarf bereits 1959 vom Bundestag beschlossen worden war (vgl. Notz 2007b: 109). Außerdem sollten für Frauen mit Familienpflichten besondere Weiterbildungsmöglichkeiten geschaffen werden ${ }^{247}$.

Zwei Muster bestimmten die sozialdemokratische Frauenpolitik zur beruflichen Chancengleichheit in der Arbeitswelt: 1. Es gab eine naturgegebene geschlechtsspezifische Verteilung gesellschaftlicher Arbeiten mit der Zuständigkeit der Frau für Kinder und Haushalt, 2. eine Verbesserung der wirtschaftlichen Lage und der beruflichen Chancen sowie ein Erwerbseinkommen und damit auch die Sicherung im Alter waren vorrangig durch eine höhere Bildungsbeteiligung zu erreichen. Somit war

247 Der Parteitag 1968 verabschiedete außerdem: Ausbau der Betreuungsangebote für StudentInnenehepaare mit Kindern, damit eine junge Elternschaft nicht den Studienerfolg infrage stellte; sowie die steuerliche Absetzbarkeit aller Weiterbildungskosten beim Familieneinkommen (vgl. Parteitag der SPD 1968: 1088f; Jahrbuch der SPD \{1968/69\}: 421f). 
die Aufhebung der weiblichen Benachteiligung vorrangig vom individuellen Engagement der Frauen abhängig.

\section{Gleichrangigkeit der PartnerInnen in Ehe und Familie}

Das Familienrecht der 1950er-Jahre definierte den Mann als Familienoberhaupt und gab ihm das alleinige Entscheidungsrecht in allen Familienfragen. Ehefrauen hatten nur insoweit ein Anrecht auf Erwerbstätigkeit, wie es sich mit ihren Pflichten in Ehe und Familie vereinbaren ließ (§ 1356 BGB). Darüber entschied der Ehemann. Sein Name war Familienname, er bestimmte den Wohnort der Familie und hatte die Schlüsselgewalt. Er bestimmte die Haushaltsführung, entschied über die Ausbildung der Kinder und konnte den Arbeitsvertrag seiner Ehefrau kündigen, wenn sie seinen Versorgungsansprüchen nicht nachkam. § 1385 BGB sicherte dem Ehemann im Falle einer Scheidung ein Viertel des in der Ehe zugewonnenen Vermögens vorab zu, anschließend hatte dann die Ehegattin einen potenziellen Anspruch auf die Hälfte des verbleibenden Zugewinns. Ehen mussten nach dem Schuldprinzip geschieden werden, dafür war eine Verletzung ehelicher Pflichten vor dem Gericht offen zu legen und zu begründen.

Die SozialdemokratInnen setzten sich - ebenfalls unter maßgeblicher Führung von Elisabeth Selbert - für eine Neuordnung der Rechtsstellung der Ehefrau ein ${ }^{248}$. Sie prangerten die Bevormundung von Hausfrauen an und forderten, das Zerrüttungsprinzip in das Scheidungsrecht einzuführen. Darüber hinaus setzten sie sich dafür ein, die elterliche Gewalt für uneheliche Kinder generell auf die Mutter zu übertragen ${ }^{249}$, eheliche und nichteheliche Kinder ${ }^{25}$ juristisch gleichzustellen und das

248 Auf der ersten Wuppertaler Frauenkonferenz der Frauen 1947 wurden Forderungen zum Prinzip der Gleichstellung in der Ehe verabschiedet (dokumentiert und kommentiert: vgl. Meyer-Schoppa 2004).

249 Bis 1961 entschied das Vormundschaftsgericht im Einzelfall, ob die Vormundschaft vom Jugendamt auf die Mutter übertragen werden konnte. Nach der Reform konnten die Mütter dieses Recht beantragen.

250 Vor der Reform des Nichtehelichen-Gesetzes (NehelG) galten uneheliche Kinder und ihre Väter nicht als verwandt (§ 1589, Abs. 2). Damit hatten nicht eheliche Kinder keine Ansprüche auf Erbschaftsanteile und ihre Väter keine Unterhaltspflichten. Das Gesetz über die rechtliche Stellung der nicht ehelichen Kinder, das nichteheliche mit ehelichen Kindern gleichstellte, wurde im August 1969, zur Zeit der Großen Koalition, verabschiedet. Damit wurde eine alte sozialdemokratische Forderung realisiert, denn diese Gleichstellung der unehelichen mit den ehelich gezeugten Kindern findet sich schon im Heidelberger Programm 1925 (vgl. Dowe/Klotzbach 1990: 216). 
Adoptionsrecht zu reformieren ${ }^{251}$ (Dertinger 1980: 227-241; Janssen-Jurreit 1976: 305-328).

Bereits 1949 brachte die SPD-Fraktion einen Initiativantrag zur Gleichberechtigung der Frau in der Ehe in das Parlament ein. Unterstützung fand sie in den Reihen der JuristInnen, z.B. kritisierte der 38. Deutsche Juristentag im September 1950 in Frankfurt das alleinige Entscheidungsrecht des Mannes in der ehelichen Lebensgemeinschaft ${ }^{252}$. Aber die BefürworterInnen und VerteidigerInnen der patriarchalen Familienordnung fanden sich in allen Parteifraktionen und selbst nach jahrelangem Streit im Bundestag und vielerlei Ausschussdebatten war die Entscheidungsgewalt des Ehemannes bis 1954 nur geringfügig eingeschränkt worden (vgl. Ruhl 1992). Erst eine Verfassungsklage brachte eine Änderung der Gesetzgebung ${ }^{253}$ : 1957 trat das Gesetz über die Gleichberechtigung von Mann und Frau auf dem Gebiet des bürgerlichen Rechts in Kraft, das vor allem die Nachrangigkeit der weiblichen Erwerbstätigkeit vor den Familien- und Haushaltpflichten abschaffte. Mit dem Familienrechtsänderungsgesetz 1961 wurden Frauen im Falle der schuldlosen Scheidung bessergestellt und der Kinderunterhalt um zwei Jahre bis zum 18. Lebensjahr erweitert ${ }^{254}$.

\section{Regulierte Schwangerschaft und sexuelle Emanzipation}

Bereits in den ersten Nachkriegsjahren war die Legalität des Schwangerschaftsabbruchs ein wichtiges gesellschaftspolitisches Thema in der SPD. Im Oktober 1947 beschäftigte sich ein Sachverständigenausschuss der Partei mit dem § 218. Gesetzlich stand der Abbruch zwar unter Strafe $^{255}$, er war aber bei Vergewaltigungen durch Besatzungssoldaten

251 Das Adoptionsrecht war bis dahin an der Versorgung kinderloser Eltern bzw. der Erhaltung von Familienvermögen orientiert. Nun sollte es sich am Kindswohl orientieren und bedürftigen Kindern ein neues Zuhause schaffen. Deshalb wurde ab 1961 das Alter der Adoptiveltern von 50 auf 35 Jahre gesenkt (Gesetz zur Vereinheitlichung und Vereinheitlichung familienrechtlicher Vorschriften, Familienrechtsänderungsgesetz (Fa$\mathrm{mR} \ddot{\mathrm{A}} \mathrm{AG})$ ).

252 Eine Ablehnung der Stichentscheidregelung, die dem Ehemann im Streitfall das Letztentscheidungsrecht über Familienangelegenheiten zusprach, fand auf der Tagung allerdings keine Mehrheit.

253 §§ 1628, 1629 BGB werden für nichtig erklärt.

254 Weitere familienpolitische Streitthemen wurden erst in Gesetzesänderungen ab den 1970er-Jahren verhandelt.

255 Der Paragraph war 1871 in das Strafgesetzbuch eingeführt worden und sah für Abtreibungen eine Strafe von mindestens sechs Monaten bis fünf Jahren Zuchthaus vor. In der Weimarer Zeit hatte sich daran wenig geändert, außer dass die Kerkerstrafe auf Initiative der SPD hin in eine Gefängnisstrafe umgewandelt worden war. Nur die KPD 
geduldete Praxis (vgl. Meyer-Schoppa 2004: 239-244.). SozialdemokratInnen forderten, das Verbot beizubehalten, jedoch die bestehende medizinische Indikation für einen legalen Abbruch um eine soziale Indikation zu erweitern. Hierfür sollten Beratungsstellen eingerichtet werden. Außerdem forderte die SPD, das Verbot von Kontrazeptiva aufzuheben. Auf der ersten SPD-Bundesfrauenkonferenz im Nachkriegsdeutschland 1947 wurden zu dem Thema Abtreibungsverbot jedoch keine Forderungen aufgestellt. Nach Heike Meyer-Schoppa war dies Ausdruck einer gesellschaftlich wachsenden repressiven Haltung zur Sexualität in Reaktion auf die Nachkriegswirren, denn nach dem Ende der Naziherrschaft und in der Nachkriegsnot hatte das sog. Froilein-Wunder die Moralvorstellungen gelockert. Manche alleinstehende Frau hatte sich aus Armut und für eine Verbesserung ihrer Lebenssituation auf eine Prostitutionsbeziehung zu einem Besatzungssoldaten eingelassen. Das hatte die Zahl unehelicher Kinder mehr als verdoppelt und galt außerdem als Ursache für die erhebliche Zunahme der Geschlechtskrankheiten (vgl. MeyerSchoppa 2004: 243-244).

Initiativen zu einer Lockerung der strengen Moralvorstellungen gingen in der Partei eher von SpitzenpolitikerInnen als von frauenpolitischen Gremien aus, zum Beispiel von Käte Strobel. Die frauenpolitisch engagierte Sozialdemokratin ${ }^{25}$ wurde mit dem Eintritt der SPD in die Regierung 1966 zur Bundesgesundheitsministerin ernannt. Sozialdemokratische Familienförderung hieß für sie nicht nur eine Reform des Familienlastenausgleichs und die Zahlung von Kindergeld statt der Gewährung von Steuerfreibeträgen, sondern bedeutete Familienplanung. Dazu

forderte die Streichung des $§ 218$. In der neugegründeten Bundesrepublik wurde dieses Gesetz übernommen. Erst nach dem Regierungswechsel 1972 wurde die Änderung des $\S 218$ im Zuge einer großen Strafrechtsreform von der SPD/FDP-Regierung in Angriff genommen (vgl. http://www.bundestag.de/dokumente/textarchiv/serien/24039384_ debatten serie/25475709 debattenoz/index.jsp [Zugriff: 10.02.2013]; http://www.awoschwanger.de/ Der_218.html [Zugriff: 10.02.2013]; http://www.dhm.de/lemo/html/weimar/alltag/ kollwitz/ index.html [Zugriff: 13.12.2010]).

256 Von Käte Strobel stammt der vielzitierte Ausspruch: „Politik ist eine viel zu ernste Sache, als dass man sie allein den Männern überlassen könnte“ (Strobel 1959 zit. n. und weitere Informationen zur Person Käte Strobels in Notz 2003: 483-501).

Mit ihren Initiativen war Käte Strobel auch in der Partei umstritten. Ihre Forderung nach einer Pille für den Mann sowie ihr Tagesmüttermodell, mit dem die Vereinbarkeitsprobleme von berufstätigen Müttern bewältigt werden sollten, stießen auf heftigen Widerstand in allen Parteien, auch in ihrer eigenen. 
gehörte eine breite gesundheitliche und sexuelle Aufklärung der Bevölkerung. Einen „Sexualkundeatlas“257 für Jugendliche finanzierte das Gesundheitsministerium, um den Aufklärungsunterricht an Schulen unterstützen. Das Buch war aber auch im freien Handel erhältlich. Außerdem ließ Käte Strobel den Aufklärungsfilm Helga produzieren. Er wurde in Kinos gezeigt und bald mit 40 Millionen Zuschauern zum „erfolgreichsten deutschen Nachkriegsfilm" (Notz 2003: 499). Dabei zielte die ministerielle Aufklärung über Schwangerschaft und Verhütung fernab von erotischen Thematisierungen auf eine geordnete Zeugungsplanung und benutzte für die Enttabuisierung des Sexualitätsthemas recht grobe Bilder und nüchterne Fakten. Käte Strobel setzte sich außerdem für Beratungsstellen ein, die bei Schwangerschaft, Schwangerschaftsunterbrechung und Empfängnisverhütung BürgerInnen unterstützen sollten. Aber erst mit der Markteinführung der Pille in den 196oer-Jahren ${ }^{258}$ stand die Einrichtung solcher Beratungsstellen auf der politischen Agenda der SPD.

1969 verabschiedete die Große Koalition die erste Strafrechtsreform. Eingeleitet worden war sie unter dem sozialdemokratischen Justizminister Gustav Heinemann. Mit ihr wurde der Schwangerschaftsabbruch von einem „Verbrechen“ in einen „Vergehenstatbestand“ abgemildert ${ }^{259}$. Sozialdemokratische Abgeordnete forderten im Zuge dieser Reform auch die Aufhebung der Strafbarkeit von Homosexualität zwischen Erwachsenen ( $§ 175$ StGB) und die Abschaffung des Ehebruchparagraphen (§ 172 StGB), gewannen dafür im Parlament jedoch keine Mehrheiten ${ }^{260}$. Auch die von SozialdemokratInnen geforderte Streichung des Kuppeleiparagraphen $^{261}$ (§ 18o StGB) konnte erst 1974 mit einer der späteren Strafrechtsreformen von der Kleinen Koalition durchgesetzt werden.

\section{Frauen und Friedenspolitik}

Frauen galten im sozialdemokratischen Diskurs als besondere Leidtragende des 2. Weltkriegs. Nach dem 2. Weltkrieg waren $40 \%$ der Familien

257 Er wurde in vielen Bundesländern, auch SPD-regierten, nicht für den Unterricht freigegeben (vgl. SPIEGEL 1969). Im Buchhandel allerdings war die erste Auflage schnell vergriffen.

2581966 brachte Schering Eugynon, 1970 Neogynon auf den Markt.

259 Weitere Änderungen der Strafregelungen fanden erst in den 1970er-Jahren statt.

260 Die Streichung des § 175 erfolgte erst 1994 (vgl. ausführlich dazu das Symposium 2011 \$ 175 StGB Rehabilitierung der nach 1945 verurteilten homosexuellen Männer, http//www.berlin.de/imperia/md/content/lb_ads/gglw/veroeffentlichungen/doku2 8__175_bf_final__3_pdf ? start\&ts=1331655131 \&file=doku28__175_bf_final_3_.pdf [Zugriff: o8.o8.2013].

261 Er stellte das Zulassen von vorehelichem sexuellem Verkehr, die sog. Unzucht, unter Strafe. Das konnte z.B. Eltern, LehrerInnen oder VermieterInnen betreffen. 
ohne Väter, also „Mutterfamilien“ (Notz 2007b: 23). Frauen wurden „als Trägerinnen und Hüterinnen des Lebens" beschrieben (Notz 2003: 137), die in und nach den Kriegen die "meiste Überlebensarbeit" (ebd.) aufbrachten. Ihnen wurde ein größerer Friedenswille als Männern zugeschrieben und sie hatten als Mütter die Verantwortung für eine Erziehung der nächsten Generation zum Frieden.

Die Nachkriegs-SPD verstand sich zunächst als eine Antikriegspartei. 1954 hatte sie sich gegen die Einrichtung einer Bundeswehr und gegen die "Westintegration“ der BRD in ein militärisches Bündnis eingesetzt und die Massenproteste gegen die Wiederbewaffnung sowie die Demonstrationen zum „Kampf dem Atomtod“ mitorganisiert (vgl. Potthoff/Miller 2002). Die Großkundgebungen in München, Stuttgart, Frankfurt und Dortmund mobilisierten Hunderttausende TeilnehmerInnen. Ein Bündnis aus GewerkschafterInnen, SozialdemokratInnen und evangelischen ChristInnen setzte sich im Deutschen Manifest gegen die Wiederaufrüstung ein und forderte die Aufnahme von Verhandlungen für eine Aufhebung der deutschen Teilung (vgl. Kraushaar 2005). Der Internationale Rat Sozialdemokratischer Frauen rief 1956 zu einem Internationalen Frauentag für Freiheit, Frieden und soziale Gerechtigkeit auf $^{262}$. Die deutschen Sozialdemokratinnen stellten diesen Tag allerdings in den Dienst des Bundestagswahlkampfes 1957 und organisierten eine Kundgebungsreihe gegen die Rüstungspolitik der CDU. Die erneute und herbe Wahlniederlage, die der CDU/CSU zum ersten Mal die absolute Mehrheit einbrachte, ließ die SPD sich auch zum Thema Wiederbewaffnung neu ausrichten.

Im Godesberger Programm 1959 bekannten sich SozialdemokratInnen nun zur „Landesverteidigung“ (Grundsatzprogramm der SPD 1959: 355f.) und die Partei zog sich aus der Friedensbewegung zurück. Als die Notstandsgesetze 1968 erneut viele SozialdemokratInnen gegen eine Remilitarisierung und für eine Verteidigung der Demokratie mobilisierten, wurde die Teilnahme an den Demonstrationen vom Parteivorstand unter Androhung des Parteiausschlusses verboten. Die Mehrheit der sozialdemokratischen Frauen folgte dem Kurswechsel der Parteiführung. Der innerparteiliche Protest wurde vorrangig von der Arbeitsgemeinschaft der JungsozialistInnen getragen. Bei der Verabschiedung der Notstandsgesetzgebung stimmten 53 der 169 SPD-Abgeordneten dagegen, unter den weiblichen SPD-Abgeordneten lag der Anteil der Nein-Stimmen mit 11 von 22 Parlamentarierinnen wesentlich höher (vgl. Notz 2007b: 39).

262 Jutta Limbach: 100 Jahre Frauentag. Was bleibt zu tun?, Rede auf der SPD-Veranstaltung 10o Jahre Frauentag - Ohne Gleichstellung kein Fortschritt, Berlin, 28. Februar 2011, vgl. http://www.spd.de/scalableImageBlob/10114/data/20110228_frauentag_re-de_jut ta_limbach-data.pdf [Zugriff: 02.02. 2012]. 
Friedenspolitik und Antimilitarismus bildeten für die frauenpolitisch aktiven Sozialdemokratinnen der 1970er- und 1980er-Jahre nahezu unabhängig von ihrer politischen Lagerzugehörigkeit Kernelemente ihrer politischen Identität. Zu diesem Themenbereich fanden regelmäßig national und international politische Austauschtreffen und Frauenfachkonferenzen statt.

\subsubsection{Die Frauenarbeit der Partei}

Frauen stellten in der deutschen Nachkriegsgesellschaft die größte WählerInnengruppe mit ca. 2/3 aller Wahlberechtigten. Bereits 1948 mahnte Kurt Schumacher die Partei, stärker die Frauen anzusprechen: „[...] in ihrer Hand liegt die politische Formung Deutschlands, wenn sie sich dessen bewußt sind und wenn sie ihren Einfluß geltend machen wollen“ (Kurt Schumacher 1948 zit. n. Dertinger 1980: 219). Sein Nachfolger, der Parteivorsitzende Erich Ollenhauer, bezeichnete es als „eine der bedenklichsten Folgen des Dritten Reiches“, „daß in Deutschland die Gleichberechtigung von Mann und Frau erneut ernsthaft in Zweifel gezogen wird“ (Ollenhauer 1947 zit. n. Dertinger 1980: 215). Bedeutende Wahlsiege waren nach seiner Auffassung von der Zustimmung der Frauen abhängig. Der Düsseldorfer Parteitag 1948 beschloss, die volle Gleichberechtigung der Frau als vordringlichste Aufgabe der Gesamtpartei anzusehen. Ein kleiner Parteitag verabschiedete 1949 die sogenannten Herner Beschlüsse. Nun war jeder Ortsverein mit mehr als 10 weiblichen Mitgliedern verpflichtet, eine Frauengruppe anzubieten und eine gesonderte Frauenarbeit zu organisieren. Dies hieß zunächst einmal die Durchführung von regelmäßig stattfindenden Frauenabenden. Außerdem sollten Frauen bei Delegationen und Wahlen berücksichtigt werden (vgl. Dertinger 1980: 214). In den Vorständen finanzierte die Partei ab der Bezirksebene hauptamtliche FrauensekretärInnen. Im Parteivorstand war bereits 1946 ein Frauenbüro eingerichtet worden ${ }^{263}$. In der Bundestagsfraktion traf sich ab der 1. Wahlperiode der Zentrale Frauenausschuss, später

263 Für dessen Leitung setzte der Parteivorstand Marie Juchacz ein. Unter der Leitung von Marie Juchacz wurde 1919 die Arbeiterwohlfahrt gegründet, 1946 war sie bereits 70 Jahre alt. Sie übergab das Frauenbüro nach einem Jahr ihrer ehemaligen Mitarbeiterin Herta Gotthelf,. Herta Gotthelf hatte während ihrer Emigration in London eine „Frauen-Internationale“ gegründet (vgl. Dertinger 1980: 208). 1959 wurde sie von Marta Schanzenbach abgelöst, sie war seit 1949 über die Landesliste Baden MdB, seit 1956 im Vorstand der Bundestagsfraktion und seit 1958 Mitglied des Parteivorstands. In einem Interview 1986 mit Renate Lepsius erklärte sie, dass sie heute als junge Frau vermutlich 
Fachausschuß für Frauenfragen, ab 1966 umbenannt in Bundesfrauenausschuß. Zunächst bestand er aus ca. 30 Mitgliedern der Bundestagsfraktion und verschiedenen ExpertInnen und wurde von der Verantwortlichen für Frauenfragen im Parteivorstand geleitet. 1966 wurde der Ausschuss in ein Parteigremium umgewandelt, dem auch VertreterInnen der Bezirke ${ }^{264}$ angehörten. 1967 richtete der Parteivorstand darüber hinaus einen Beirat für Frauenpolitik mit 15 parteiexternen ExpertInnen unter dem Vorsitz von Elfriede Eilers ein, der den Bundesfrauenausschuss beratend begleitete (vgl. Notz/Wickert 2008). Die Jahrbücher der 1960er-Jahre dokumentieren die regelmäßigen Sitzungen dieser Gremien, die vier- bis sechsmal im Jahr zusammenkamen, sowie frauenpolitische Tagungen und Konferenzen. Sie fanden zu unterschiedlichen, meist staatspolitischen und demokratiepolitischen Themen statt, über Diskurse sozialdemokratischer Frauenpolitik oder frauenpolitische Initiativen ist dagegen in den Jahrbüchern nichts zu erfahren.

\section{Mitgliederwerbung und Partizipation der Frauen}

Die sozialdemokratische Frauenpolitik hatte vorrangig zwei Aufgabenbereiche: die Anwerbung neuer weiblicher Mitglieder und die Schulung der Genossinnen ${ }^{265}$. Weibliche Mitglieder sollten mit besonderen Bildungsangeboten ${ }^{266}$ an die Parteiarbeit herangeführt werden.

Die SPD verstand sich als Massenpartei. Nach ihrem Selbstverständnis war ihr Anspruch auf gesellschaftspolitische Mitsprache eng verbunden mit ihrer großen Mitgliederzahl, den geringen Frauenanteil in der Mitgliedschaft wertete die Partei als eine politische Schwäche. Gleichzeitig aber galten Frauen als schlecht organisierbar. Nicht nur für Parteien, auch für Vereine und Verbände waren sie nur schwer als Mitglieder zu gewinnen.

Dass Frauen in den Gremien und der Politik der Partei so wenig präsent wären, läge, so der Parteivorstand, an diesen Umständen,

nicht in einer möglichen Zurückhaltung einer hauptsächlich von Männern bestimmten Parteiorganisation, sondern in der Tatsache begründet, dass der Anteil der Frauen an der Mitgliedschaft

Feministin wäre (vgl. Notz 2003: 457). Ihre Nachfolgerin ab 1967 war Annemarie Renger.

264 In den Bezirken waren das Verantwortliche für Frauenfragen, SekretärInnen oder GeschäftsführerInnen.

265 Wuppertaler Reichsfrauenkonferenz im September 1948, vgl. Meyer-Schoppa 2004: 149-153.

266 Thema der zentralen Frauenveranstaltung 1960: „die geistige Auseinandersetzung mit dem Kommunismus“ (Marta Schanzenbach, Parteitag 1960: 499). 
der Partei etwa 19\% beträgt. Die Frauen müssen daher erst noch in einem weit größeren Maße als bisher für eine Mitarbeit gewonnen werden. (Jahrbuch 1960/61: 338)

Mit dieser Zuschreibung von politischem Desinteresse sahen sich aber auch die politisch aktiven Genossinnen in der Partei konfrontiert. Bereits 1946 hatte sich Herta Gotthelf über "gewisse Vorbehalte gegen die gleichberechtigte Mitarbeit der Frauen in allen Funktionen der Partei“ (Herta Gotthelf zit. n. Dertinger 1980: 216f.) beklagt, die mangelnde Unterstützung der Funktionärinnen angemahnt, insbesondere bezüglich frauenpolitischer Beiträge in den Parteileitungen und Parteimitteilungen, und dazu aufgerufen, die aktiven Frauen bei Delegationen und Wahlen stärker zu berücksichtigen (vgl. ebd.). Wie in der gesamten Partei sah Herta Gotthelf aber vor allem die Frauen selbst in der Verantwortung, diese Situation zu verändern: „Nur allzu viele versteckten und verstecken sich immer noch hinter der bequemen Ausrede, dass Politik und insbesondere Parteipolitik nicht Sache der Frauen sei“ (Gotthelf 1948: 5). Grundsätzlich nämlich böte die Partei, so Herta Gotthelf, uneingeschränkte Beteiligungsmöglichkeiten. Eine Konfrontation der Geschlechter lehnte sie entschieden ab: „Wir Frauen innerhalb der SPD sind keine Frauenrechtlerinnen. Wir wissen, daß der Kampf um die Gleichberechtigung der Frau nur eine Seite des Kampfes um eine neue Gesellschaftsform ist." (Herta Gotthelf auf dem Hamburger Parteitag 1950 zit. n. Pausch 1985: 122) Schon auf der ersten Bundesfrauenkonferenz 1947 hatte sich Irmgard Enderle, Mitglied der Bremischen Bürgerschaft, von den streitbaren sozialdemokratischen Vorkämpferinnen abgesetzt. Der Kampf der Frauen ihrer Zeit, erklärte sie, sei nicht mehr so frauenrechtlerisch wie in den 1920er-Jahren:

„Immer wieder erleben wir es, wie im allgemeinen und vor allen Dingen von unseren Funktionärinnen alle diese Fragen als Fragen des sozialen Lebens, des Kampfes eben in der gesamten Gesellschaft und zusammen mit den Männern verstanden werden.“ (Irmgard Enderle zit. n. Meyer-Schoppa 2004: 165) ${ }^{267}$.

Dass der Weg einer gesellschaftspolitischen Veränderung mit den Männern gemeinsam entwickelt werden müsste, stand auch für die Mehrheit der sozialdemokratischen Frauenaktivistinnen der 1970er- und 1980erJahre außer Frage. Viele hielten wie Lenelotte von Bothmer, eine scharfe

267 Gegenteilige Erfahrungen wurden besonderen Umständen zugerechnet. Dass z.B. die BetriebsrätInnen und Gewerkschaften die Kontrollratsdirektive „gleicher Lohn für gleiche Arbeit" ignorierten, obwohl der Stundenlohn von Frauen bei durchschnittlich 63,6 \% des Lohns der Männer lag, wurde als Überlastungsproblem bei den ArbeitnehmerInnenvertretungen gedeutet (vgl. Meyer-Schoppa 2004). 
Kritikerin patriarchaler Parteistrukturen, die relative Machtlosigkeit der Frauen in der Partei für mitverschuldet. Frauen, so Lenelotte von Bothmer, hätten eine Neigung zur Haltung der Einzelkämpferin, Männer dagegen suchten stets Mitstreiter im Vorfeld politischer Entscheidungen (vgl. Bothmer 1976: 28).

\section{Politische Organisations- und Bildungsarbeit}

Mit speziellen Veranstaltungsangeboten, „Tonbildvorträgen, Filmveranstaltungen, Besichtigungen, Modeschauen, Ausflügen, Quizabenden, Bus-und Dampferfahrten“ (Jahrbuch der SPD \{1954/55\}: 227f.) bemühte sich die Partei, Frauen die „Scheu“ vor politischer Organisierung zu nehmen. Dafür hielt man das normale, „tägliche Parteileben“ für ungeeignet, denn es „spiegelt in Sitzungen, Versammlungen, Konferenzen und Wahlvorbereitungen nur die nüchterne Arbeitsatmosphäre der ,männlichen Welt' wieder." (Jahrbuch der SPD \{1958/59\}: 296) Für die weiblichen Mitglieder an der Parteibasis wurden gesonderte Veranstaltungen angeboten, auf denen Fachleute zu Themen wie „Die Frau als Staatsbürger" (Notz 2007b: 203), zum Verbraucherschutz, zu Erziehungsthemen oder zu Gesundheitsfragen referierten. Diese Frauenveranstaltungen wurden in der Partei mit „spürbarer Geringschätzung“ (ebd.) betrachtet. Als politisch bedeutend wurden nur die Sitzungen der Organisationseinheiten angesehen. Zwar war auch hier der Geselligkeitswert hoch, üblicherweise fanden sie in verrauchten Gaststätten und mit Alkoholausschank statt, aber die Frauengruppentreffen galten als bloße „Kaffeekränzchen" (Pausch 1985: 149).

Bundesweite Frauenkonferenzen wurden in unregelmäßigen Abständen einberufen. $\mathrm{Zu}$ diesen Treffen schickten die Bezirksvorstände so viele Genossinnen, wie sie für die Reise und Unterbringung finanzieren konnten oder wollten. Aber auch sie dienten vorrangig der Information der weiblichen Parteibasis durch die Parteivorstände.

Um in der Partei mehr Anerkennung zu finden, hatte bereits Kurt Schumacher die Frauen aufgerufen, sich nicht auf die traditionellen Politikfelder der Fürsorge, Frauen- und Erziehungsfragen zurückdrängen lassen, sondern auf dem „Gesamtgebiet der Politik“ Einfluss zu nehmen (Kurt Schumacher 1948 zit. n. Dertinger 1980: 219). Aber von den frauenpolitischen Parteistrukturen gingen in den 1950er- und 196oer-Jahren wenig Initiative aus, ihr gestaltender Einfluss auf die Partei war gering. Die Frauenorganisationen suchten weder die Kooperation mit anderen gesellschaftspolitisch agierenden Gruppierungen noch entwickelten sie 
eigene gesellschaftspolitische Aktivitäten ${ }^{268}$. Elfriede Eilers resümierte auf der Bundesfrauenkonferenz Bonn 1968: „Direkte Aktionen von Frauengruppen oder -arbeitsgemeinschaften, die auf die Lösung eines aktuellen politischen Problems gerichtet sind, kommen selten vor." (Eilers zit. n. Pausch 1985: 147)

Auf den Konferenzen, die die Partei für ihre weiblichen Mitglieder organisierte, wurden die patriarchalen Parteihierarchien nicht kritisiert, sondern eher mitgetragen. Lenelotte von Bothmer ${ }^{269}$ berichtet von einer Bundesfrauenkonferenz, auf der die Versammlungsleitung die Gattinnen hoher Funktionäre herzlich begrüßte, aber die im Plenum anwesenden Politikerinnen nicht einmal erwähnte (vgl. Bothmer 1976: 32f.).

\section{Frauen in sozialdemokratischen Führungspositionen}

Wenn auch die SPD-Fraktion gegenüber den anderen Parteien in den 1950er- und 196oer-Jahren stets die höchste Frauenquote aufwies, so lag doch der Frauenanteil in der Fraktion weit unter dem in der Mitgliedschaft. In politischen Ämtern galten Frauen als Exotinnen. So waren im ersten Bundestag nur 6,8\% aller Abgeordneten weiblich. Auch in den folgenden Wahlperioden blieb ihr Anteil unter 10 \%. Zum Ende der jeweiligen Legislaturperiode stieg der Frauenanteil leicht an, dann kamen die Nachrückkandidatinnen zum Zuge, die bei der Wahlaufstellung auf die hinteren Plätze gesetzt worden waren. Die Presse inszenierte regelrechte „Miss-Wahlen“, wenn eine neue attraktive Abgeordnete ins Parlament nachrückte (vgl. Zeitzeuginnenberichte in Notz 2007b). Auf den niedrigsten Stand von 5,8 \% sackte der Frauenanteil in der 7. Wahlperiode $(1972-1976)^{270}$.

In den ersten Jahren der Amtszeit von Theodor Heuss (1949-1959) wurden die weiblichen Abgeordneten nicht als gleichwertige Mitglieder der Regierung behandelt; ihre Anwesenheit bei großen Empfängen war

268 Nach Gisela Notz wurde selbst das individuelle Engagement der Genossinnen in überparteilichen Frauenverbänden nicht gerne gesehen (vgl. Notz 2003: Tl.1).

269 Nachdem der Vizepräsident des Bundestages Richard Jaeger (CSU) erklärt hatte, dass er keiner Frau erlaube, das Plenum in Hosen zu betreten oder mit einer solchen Bekleidung am Rednerpult zu sprechen, beschaffte sich Lenelotte von Bothmer, 54 Jahre alt und Mutter von sechs Kindern, für ihre Rede eigens einen Hosenanzug. Sie hielt ihre Rede am 15.04.1970 im Plenarsaal ungehindert (http://www.welt.de/die-welt/debatte/ article7404987/Kleiderordnung-Lenelotte-von-Bothmer.html [Zugriff: o8.10.2010]; http://de. wikipedia.org/wiki/Lenelotte_von_Bothmer [Zugriff: o8.10.2010]; WDR 5, Zeitzeichen vom 15.04.1970).

270 Vgl. W5. Frauenanteil bei den Abgeordneten im Deutschen Bundestag 1949-1990 nach Parteien (in Prozent) zu Beginn der Wahlperiode unter DOI 10.3224/86388794A. 
deshalb nicht vorgesehen, sie wurden stattdessen von der Bundespräsidentengattin Elly Heuss-Knapp zum Tee geladen (vgl. Notz/Wickert 2008: 56).

Die Benennungen von Elisabeth Schwarzhaupt zur Gesundheitsministerin 1961 und Annemarie Rengers zur Bundestagspräsidentin 1972 schätze Lenelotte von Bothmer nicht als ein Partizipationsangebot für Frauen ein, sondern in der Besonderheit eher als ein Symbol für den Ausschluss der Frauen in den „Hohen Häusern“. Als Käte Strobel zur Ministerin für Gesundheitswesen berufen wurde, trat sie dieses Amt in Nachfolge von Elisabeth Schwarzhaupt an. Zwei Frauen im Kabinett wären, so Elisabeth Schwarzhaupt, „nicht vermittelbar“ gewesen (Notz 2003: 493). Beim Regierungswechsel 1969 war die SPD mit der Parole „Wir haben die besseren Männer" angetreten und hatte ihre Spitzenpolitikerin Käte Strobel in einer Hausfrauenschürze präsentiert.

Die Historikerin Gisela Notz hat die Lebenswege sozialdemokratischer Parlamentarierinnen im Parlamentarischen Rat (vgl. Notz 2003) und im deutschen Bundestag (vgl. Notz 2007b) rekonstruiert. Anhand der Biographien dieser 38 Politikerinnen werden Muster sozialdemokratischer Karrierewege deutlich. Überwiegend kamen die Frauen aus ArbeiterInnenfamilien, meistens waren die Eltern bereits politisch in der Partei aktiv und die politische Laufbahn begann häufig in den Vorfeldorganisationen der Kinder- und Jugendarbeit der Partei. In die aktive Arbeit der Partei stiegen viele über die Frauenarbeit ein. Überwiegend hatten die Spitzenpolitikerinnen einen Beruf erlernt, meist einen typischen Frauenberuf wie Verkäuferin, Sekretärin oder Schneiderin. Viele Frauen, ca. $25 \%$, fanden im Anschluss eine Anstellung in der Partei, meist als hauptamtliche Funktionärinnen oder in der Redaktion einer der parteieigenen Printmedien. Einige sozialdemokratische Parlamentarierinnen waren auf anderen Wegen zu ihrem politischen Mandat gekommen: Sie hatten berufliche Qualifikationen oder verfügten über attraktive Netzwerke, die sie für die Parteiarbeit interessant machten ${ }^{271}$. Diesen GenossInnen mit Karrieren ohne Ochsentour fehlte jedoch der vertraute „Stallgeruch“. Bei politischen Initiativen waren sie häufig mit einer mangelnden Unterstützung durch die Partei konfrontiert (vgl. Notz 2007b:

271 Beispiele dafür sind etwa folgende: Die Ärztin Dr. Elinor Hubert war vom Parteivorstand zur Kandidatur aufgefordert worden und saß als einzige Akademikerin in der SPD-Fraktion der 1. Wahlperiode. Frau Dr. Ilse Elsner leitete vor ihrem Bundestagsmandat 1961 als promovierte Volkswirtin den Wirtschaftsteil der Tageszeitung Hamburger Echo und schrieb für die Zeitung Die Welt. Hedwig Meermann bekam als Dolmetscherin Kontakt zu führenden FunktionärInnen in Gewerkschaften und Partei, bevor sie 1961 für den Bundestag aufgestellt wurde. Dr. Ursula Krips war als Wirtschaftswissenschaftlerin über die Landesliste 1965 in den Bundestag eingerückt. (vgl. Notz 2007; Bibliographiearchiv des AdsD) 
156ff.). Fast alle Führungsfrauen waren verheiratet und hatten eine Familie gegründet. Bei fast einem Drittel der Sozialdemokratinnen war der Ehemann oder ein enger Verwandter bereits hochpositionierter Parteifunktionär, dessen Renommee und dessen Kontakte vermutlich als wichtige Karrierefaktoren wirkten. $25 \%$ der Politikerinnen hatten bereits Führungspositionen in anderen Organisationen wie den DGB-Gewerkschaften, der Arbeiterwohlfahrt oder anderen Parteien wie der KPD oder dem Zentrum/GVP besetzt ${ }^{272}$.

Mit der Einrichtung der Arbeitsgemeinschaft Sozialdemokratischer Frauen 1973 eröffneten sich parteiintern neue Karrierewege für weibliche Parteimitglieder.

\subsection{Der Aufbau der Arbeitsgemeinschaft Sozialdemokratischer Frauen}

Im folgenden Kapitel wird die ASF als soziale Organisation vorgestellt. Die Organisationsstrukturen der ASF waren hierarchisch, die Abstimmungsverfahren zeitaufwendig. Zwischen den politischen Aktivitäten des Bundesvorstands und denen der Frauenarbeitsgemeinschaften an der Basis gab es relativ wenige Wechselbeziehungen außerhalb von Wahlkampfzeiten.

Ebenso wie die Partei selbst stellte sich die ASF parteisoziologisch als ein Verbund aus relativ eigenständigen Organisationseinheiten mit einem ausgeprägten informellen Kontaktnetzwerk dar, das neben den formalisierten Kommunikationsstrukturen die Personalentscheidungen und die Politikentwicklungen bestimmte. Die Organisationseinheiten agierten relativ unabhängig voneinander; die Politisierungs- und Mobilisierungsprozesse in der bundesweiten Frauenarbeitsgemeinschaft verliefen deshalb ungleichzeitig und parallel, die jeweiligen Mehrheitsverhältnisse waren für die ASF-Führung stets schwer einzuschätzen. In den 1970er- und 1980er-Jahren entwickelte sich in der ASF eine eigene Bewegungsdynamik. Schließungs- und Konfrontationserfahrungen in der Partei wurden gemeinsam erlebt und verarbeitet, Forderungen der Neuen Frauenbewegungen wurden aufgenommen und weiterentwickelt. In dieser Zeit entstand mit der ASF eine innerparteiliche Frauenlobby, in der das Lager der sozialistischen und feministischen Aktivistinnen seinen Einfluss stetig ausbaute. Im Zuge der Mobilisierung der SPD-Frauen ver-

272 Auswertung der Biographien anhand der beiden Studien Gisela Notz' über Sozialdemokratinnen im deutschen Bundestag von 1948/49 bis 1957 sowie 1957 bis 1969 (vgl. Notz 2003, 2007). 
änderte sich die soziale Zusammensetzung der ASF-Gremien. Die Frauenarbeitsgemeinschaft wurde in der Partei stärker durch hoch qualifizierte, berufstätige und redegeschulte Frauen repräsentiert. Die autonome Frauenprojektbewegung und die frauenpolitische Mobilisierung in anderen gesellschaftlichen Großorganisationen wie dem DGB, den Kirchen und den Wohlfahrtsverbänden sowie die Einrichtung von frauen- und gleichstellungspolitischen Strukturen in der öffentlichen Verwaltung bildeten für die ASF ein politisches Umfeld, in dem die ASFFrauen Bündnispartnerinnen fanden und das ihren Einfluss in der Partei vergrößerte.

\subsubsection{Umstrittene Gründung der Frauenarbeitsgemeinschaft}

Auf der Saarbrückener Frauenkonferenz 1968 löste die Benennung der ASF-Leitungsmitglieder durch den Parteivorstand unerwartet vehementen Protest unter den versammelten Frauen aus. Statt dieser bis dahin üblichen Praxis wurde verlangt, der Frauenorganisation das Recht auf eigene Vorstandswahlen zu geben. Die folgende Nürnberger Frauenkonferenz 1970 forderte den Parteivorstand mit großer Mehrheit auf, für die Frauenarbeit der Partei eine Arbeitsgemeinschaft mit demokratischen Strukturen einzurichten. Unter der Leitung Elfriede Eilers, Parteivorstandsmitglied und stellvertretende Frauenbeauftragte, wurde daraufhin eine Arbeitsgruppe einberufen, in der Frauen aus verschiedenen Bezirken Satzung und Richtlinien für eine Arbeitsgemeinschaft erstellten und dem Parteivorstand vorlegten (vgl. Lepsius 1987). Die Aufgaben dieser Arbeitsgemeinschaft sozialdemokratischer Frauen (ASF) entsprachen denen anderer Arbeitsgemeinschaften in der SPD: Mitglieder mit der Politik und den Zielen der Partei vertraut zu machen, zur „Änderung des gesellschaftlichen Bewusstseins beizutragen“, neue Mitglieder zu gewinnen, frauenpolitische Interessen und Forderungen in der Partei „zur Geltung zu bringen" sowie durch Kontakte zu Verbänden und Organisationen den Einfluss und das Wirkungsfeld der Partei zu erweitern (Richtlinien der ASF 1972: 587).

Auf der Ludwigshafener Bundesfrauenkonferenz 1973 kamen zum ersten Mal gewählte Delegierte zusammen und wählten den Bundesvorstand der Arbeitsgemeinschaft. Mit dieser Neugründung der ASF verfügten die weiblichen Parteimitgliedern nun über eine eigenständige Arbeitsstruktur. Ab 1973 waren die bundesweiten Frauenkonferenzen der ASF Entscheidungsgremien, bei denen über Delegierte die Politik der Arbeitsgemeinschaft bestimmt wurde. Die Konferenzen waren ein Grad- 
messer des Basiskonsenses und wurden ausschließlich durch das jeweilige Führungsgremium der ASF selbst ausgerichtet und einberufen ${ }^{273}$. Die Bundeskonferenzen fanden in statuarisch festgelegten Zeitabständen von zwei Jahren statt. Die Partei verpflichtete sich, die Strukturen zu finanzieren und ihnen Ressourcen zur Verfügung zu stellen. Es gab Regularien für demokratisch strukturierte Policyprozesse, für die Wahl der Sprecherinnen und die Einberufung frauenpolitischer Foren, in denen sozialdemokratische Frauenpolitiken entwickelt und verhandelt werden konnten. Die von den ASF-Gremien gewählten Frauen fanden in den Parteigremien mehr Gehör und Aufmerksamkeit und besaßen damit bessere Verhandlungspositionen. Allerdings galten Arbeitsgemeinschaften in der SPD als Sonderorganisationen und waren keine Organisationseinheiten der Partei. Damit besaß die ASF kein selbst verwaltetes Budget, die Frauenarbeitsgemeinschaften mussten ihre gesellschaftspolitischen Aktivitäten und Veröffentlichungen stets mit der jeweiligen Parteileitung abstimmen ${ }^{274}$; außerdem hatten Vertreterinnen der Arbeitsgemeinschaften keine Anhörungs- und Teilnahmerechte für die Gremien der Partei ${ }^{275}$. Im Gegensatz zur Frauenunion in der CDU hatte die ASF bis in die 1990er-Jahre keine Antragsrechte für die Parteitage ${ }^{276}$. Bei der Auswahl der weiblichen Kandidatinnen für Funktionen oder Wahllisten besaß die ASF kein Vorschlagsrecht, die Nominierung blieb den Parteieinheiten vorbehalten. Außerdem durfte die ASF die von ihnen vorgeschlagenen Kandidatinnen nicht an Beschlusslagen binden.

273 Versammlungskonzeption und Tagesordnung mussten allerdings vorher dem Parteivorstand vorgelegt werden.

274 Die formalen Entscheidungsverfahren in der Partei führten dazu, dass die ASF-Frauengruppen auf politische Ereignisse meist nur zeitverzögert reagieren konnten.

275 Die Arbeitsgemeinschaft für Arbeitnehmerfragen (AfA) hatte dagegen - nach Aussagen verschiedener Zeitzeuginnen - ein faktisches Partizipationsrecht in den Parteigremien. Begründet wurden diese privilegierten Rechten damit, dass ArbeiterInnen aufgrund ihrer Schichtzeiten am Organisationsleben nur schwer teilhaben könnten und ihre Integration in die Partei nur so sicherzustellen wäre.

276 Den Bundesfrauenausschuss und die Bundesfrauenkonferenz als Beschlussgremien mit Antragsrechten auszustatten, hatten schon Elfriede Eilers und Annemarie Renger bei der Neugründung der ASF gefordert (vgl. Bundesfrauenausschuss 1970b: 2). Aber erst 1991 im Zuge einer der vielen Organisationsreformen der Partei wurde den Arbeitsgemeinschaften und damit auch der ASF auf Bundesebene ein Antragsrecht zugestanden (vgl. Oertzen/Möbbeck 1991: 176; Detterbeck 2002: 177). 
Kritik der Ausdifferenzierung von Mitgliederinteressen und Parteistrukturen

Über die Einrichtung einer Arbeitsgemeinschaft entschied der jeweilige Parteivorstand. Aber viele Parteimitglieder hatten gegen diese Sonderorganisationen grundsätzliche Bedenken. Sie wünschten sich - auch in Abgrenzung zur CDU - eine geschlossene Mitgliederpartei. Die Basis der Partei sollte ausschließlich der Ortsverein sein. Er bildete auch den Rückhalt für die MandatsträgerInnen, selbst in höchsten ministeriellen Positionen $^{277}$. Arbeitsgemeinschaften, so wurde befürchtet, könnten die Aktivitäten der Parteimitglieder aus dieser Basisorganisation heraus verlagern und die Arbeit der Ortsvereine schwächen.

Also, es war damals die ganz große Sorge: Wir machen die Partei kaputt, wenn wir das hier so diversifizieren, und am Ende sind wir auch nur noch die Holding. (Zz 6)

Gegen die Einrichtung der ASF gab es unter den Sozialdemokratinnen zudem noch andere Bedenken. Eine Frauenpolitik unabhängig von Klasseninteressen konzipieren zu wollen, lehnten vielen linke Sozialdemokratinnen der 1970er-Jahre ab. Für manche Genossinnen waren solche geschlechterspezifisch begründeten Interessen unsozialdemokratisch: „Viele Sozialdemokratinnen hielten es mit Rosa Luxemburg, für die eine spezielle Frauenfrage nicht existierte“" (Dertinger 1980: 203; vgl. dazu auch Kontos 1979 $)^{278}$. Andere sahen in der ASF eine organisationspolitische Realisierung der vielkritisierten biologistischen Passagen des Godesberger Programms von 1959. Weitere fürchteten, mit der ASF würde eine genussspezifische Organisation geschaffen und statuarisch konstituiert, die drohe, alle weiblichen Mitglieder der Partei in einer Sonderstruktur zu separieren. Strittig war unter den Kritikerinnen damit, ob die Arbeitsgemeinschaft die Frauen in der Partei strategisch eher ein- oder eher ausschloss.

Ein entsprechender Antrag für die Auflösung der ASF verfehlte auf der Landesdelegiertenkonferenz in Bremen 1972 nur knapp die Mehrheit. Frauen, so die Begründung im Antragstext, wollten sich nicht in

277 Die Unterstützung der Mitglieder im Ortsverein war für FührungsgenossInnen elementar wichtig - sowohl für die politische Legitimation ihrer Position als auch für den individuellen psychologischen Rückhalt (Zz 1).

278 Auch Clara Zetkin sah in einer solchen Politik eine „Frauenrechtlerei, die durch die bürgerlich-demokratischen Ideen und Schlagworte das Klassenbewusstsein der Proletarierinnen trübte und verwirrte." (Clara Zetkin, zit. n. Kontos 1979: 112; vgl. dazu auch Holland-Cunz 2003) 
eine separate Frauenorganisation abschieben lassen, damit sich die Partei, nun „unter sich“, nicht mehr „ernsthaft“ mit Gleichstellungsfragen auseinandersetzen müsse (vgl. ASF LO Bremen 1991).

Frauenthemen verwandelten sich zu „zielgruppenspezifischen“ Anliegen, um die sich die ASF-Frauen kümmern müssten. Frauenpolitik sollte stattdessen in einflussreichen Parteigremien entwickelt werden. Ein „Naturschutzgarten der Frauen“, warnte die Hamburger SPD-Landesvorsitzende Christa Randzio-Plath, richte Hürden gegenüber der männlichen Parteimehrheit auf (vgl. Randzio-Plath 1980: 78) und erschwere damit Veränderungen in der Partei, denn für sie kämen die notwendigen Mehrheiten doch nur mit männlicher Unterstützung zustande $^{279}$ (vgl. hierzu auch Nolan 1977). Auf der Ludwigshafener Bundesfrauenkonferenz 1973 setzten sich verschiedene Genossinnen, darunter auch die niedersächsische Delegierte Inge Wettig-Danielmeier, für eine Aufnahme emanzipationswilliger Männer in die ASF ein (vgl. Junker 1998). Ika Klar ${ }^{280}$, frauenpolitische Aktivistin und Gründerin der ASF in Berlin, plädierte noch Anfang der 1980er-Jahre für eine gemischtgeschlechtliche Mitgliedschaft in der Arbeitsgemeinschaft. Sie fand, dass Frauen, die Emanzipationshilfen und Selbstbehauptungstrainings suchten, sich an die bestehenden Frauenselbsthilfeinitiativen und nicht an die Partei wenden sollten (vgl. Klar 1981). Frauen seien stark, aber Frauen und Männer stärker, schrieb Anke Fuchs 1972 und warnte vor einem „Abschweifen in den jetzt verbreiteten Feminismus“ (Fuchs 1972: 9). Auch Lenelotte von Bothmer, die die jungen, frauenbewegten ASF-Aktivistinnen unterstützte, warnte vor der neuen Arbeitsgemeinschaft, weil sie in der Partei wenig Anerkennung zu erwarten hätte. Frauengruppen gälten bisher als „schöne Spielwiese“ und nicht als politisch ernstzunehmende Arbeitskreise, ihnen gegenüber pflegten die meisten Parteigremien „eine Art karikatives Verhältnis“" (Bothmer 1976: 31). Die Einrichtung einer Frauenarbeitsgemeinschaft erschien ihr als die Wiedereinführung einer Sonderstruktur für Frauen. Gerade hatte der Godesberger Parteitag 1971 dem Antrag linkssozialistischer Juso-Frauen zugestimmt und die „Schutzklausel“, die die Mindestpräsenz der Frauen in den Leitungsgre-

279 Molly Nolan vertritt die These, dass die Frauenbewegung am Vorabend des Ersten Weltkriegs so stark war, dass sie eine Diskussion in der Gesamtpartei hätte erzwingen können. Ihr Separatismus aber habe verhindert, „dass die ungeheuer wichtige Frage des Verhältnisses von der Emanzipation der Frauen einerseits und Klassenkampf und Sozialismus andererseits nicht gründlich ausdiskutiert wurde." (Nolan 1977: 373f.)

28o Ika Klar, Studiendirektorin des Pestalozzi-Fröbel-Hauses, einer Fachschule für Sozialpädagogik und ErzieherInnen, gründete 1972/73 die ASF Berlin und war zugleich Mitglied des Berliner Frauenbundes 1945 e. V. (vgl. http://berliner-stimme.de/jahrgang2011/ber-liner-stimme-18-2011-vom-24september-2011.pdf [Zugriff: 23.03.2012]). 
mien der Partei sicherte, gestrichen, weil, so die Begründung, Sonderregelungen stets einen diskriminierenden Sonderstatus implizierten ${ }^{281}$. Es gäbe aber keine frauenspezifische Politik, die Männer nichts anginge.

Darüber hinaus fürchtete Lenelotte von Bothmer wie andere linkssozialistische Genossinnen, aber auch die konservativen Mehrheiten bei den sozialdemokratischen Frauen. So konnte die Frauenarbeitsgemeinschaft für eine potentielle Kandidatin im Ortsverein zur zusätzlichen Hürde werden, wenn sie nicht von der ASF unterstützt wurde (vgl. Bothmer 1976: 31). Einen politischen Wandel der Frauengruppen hielt Lenelotte von Bothmer für wenig aussichtsreich: „Alle Bemühungen einzelner Frauen, ihre Arbeitsgemeinschaften zu politisch gewichtigen Gruppen zu machen, haben meist nur vorübergehend oder bei einzelnen Anlässen Erfolg." (dies.: 32)

Trotz der vielfältigen kritischen Stimmen unterstützte allerdings die Mehrheit der Sozialdemokratinnen die Einrichtung einer Frauenarbeitsgemeinschaft und viele sahen in ihr ein kommunikatives und politisches Forum und eine symbolische Anerkennung der Bedeutung frauenpolitischer Themen in der Partei. Als Elfriede Eilers als erste Vorsitzende in der neu gegründeten ASF erklärte, die Frauenarbeitsgemeinschaft sei eine Übergangsorganisation bis zur vollen Integration der Frauen in die Partei und ihr Ziel sei es deshalb, sich überflüssig zu machen, löste sie stürmischen Protest aus. Der Verlauf der innerparteilichen Auseinandersetzung und vermutlich auch der separatistische Einfluss der Neuen Frauenbewegungen ließen die ASF eine eigenständige kollektive Identität entwickeln ${ }^{282}$. Zum 10-jährigen Jubiläum der ASF 1983 erklärte die ASF-Vorsitzende Inge Wettig-Danielmeier:

Die Frauenfrage ist für sie kein Nebenwiderspruch, sie ist ihr brennendstes und vorrangiges Problem. Die sozialdemokratischen Frauen sind nicht mehr bereit, die Interessen der Frauen hintan zu stellen um eines vermeintlich sozialdemokratischen Gesamtinteresses willen. Dieses Selbstverständnis verlangt zwingend eine möglichst eigenständige Frauenorganisation. (Wettig-Danielmeier 1984a: 173)

281 Dazu Lenelotte von Bothmer: „Wir wollen nicht ,berücksichtigt' sein oder als Besonderheiten gelitten, etwas in der Weise, wie man unter vielen weißen Hühnern der Kuriosität halber auch ein paar bunte hält." (Bothmer 1976: 35)

282 Dazu auch Sigrid Metz-Göckel: „Erst über die Trennung vom vermeintlich Gemeinsamen, das hat die Arbeitsgemeinschaft Sozialdemokratischer Frauen gezeigt, bekommen Frauen in der Politik eine kräftige Stimme" (Metz-Göckel 1992: 62). 
Manche frauenpolitischen Arbeitskreise, die sich bereits vor der ASFNeugründung 1973 zusammengefunden hatten, wollten sich der Frauenarbeitsgemeinschaft nicht anschließen. Die ASF war bereits bei ihrer Neugründung eine bürokratisch strukturierte Organisation, von einer Mehrheit parteiführungsloyaler Mitglieder geprägt, aber zugleich auch politisch heterogen. Je nach den bereits bestehenden sozialdemokratischen Frauengruppen formierten sich die ASF-Gruppen in den Städten unterschiedlich. In Münster gründete sich in Abgrenzung zu der lokalen ASF, die von langjährigen Parteimitgliedern und etablierten Lokalpolitikerinnen dominiert wurde, eine Initiative sozialdemokratischer Frauen (ISF). Sie bestand aus 4o Parteimitgliedern und Nichtmitgliedern, die alle - anders als in den Statuten der $\mathrm{ASF}^{283}$ festgelegt - gleiche Rechte besaßen. Sie lehnten die neue Arbeitsgemeinschaft als „Sumpf des Konservatismus" ab und hielten die Neugründung der ASF für eine Bevormundung der ,arrivierten“ Frauen aus dem Parteivorstand ${ }^{284}$. Vermutlich gab es auch andernorts innerparteiliche Frauengruppen, die Vorbehalte hatten, sich in die neugegründete ASF einzugliedern ${ }^{285}$.

An anderen Orten löste die ASF-Neuorganisation Gründungsinitiativen aus, in denen sich eine lebendige politische Basisarbeit spiegelte. Eine Zeitzeugin berichtete, wie sich ihre ASF-Arbeit aus persönlichen Netzwerken entwickelte.

[...] im Unterbezirksvorstand gab's keine Frau, als Delegierte für Bezirkslandesparteitag, Bundesparteitag - nirgendwo eine Frau. Und dann hab ich mich so ein bisschen rumgehört; da gab's überall mal die eine oder andere, dann bekam man die Kontakte, dann hat man so langsam ein Netzwerk gesponnen [...]. (Zz 9).

Eine andere Zeitzeugin berichtete von der ASF-Gründung als politische Aktion:

283 „Antragsrecht, Stimmrecht, aktives und passives Wahlrecht in der ASF steht nur Parteimitgliedern zu." (Richtlinien der Arbeitsgemeinschaft Sozialdemokratischer Frauen (1972): Grundsätze I,3)

284 In einem Gespräch am o1.09. 2008 am Rande der Veranstaltung der ASF zum 20-jährigen Jubiläum der Quote berichtete eine Zeitzeugin aus Münster, dass die ASF nach den damaligen Überzeugungen der Münsteranerinnen von den konservativen FührerInnen der Partei gegründet worden wäre, um den rechten Flügel der SPD gegen die linksdominierten Jusos zu stärken (diese These unterstützend: vgl. Pausch 1985: 172f.; Lösche/Walter 1992).

285 Auch in Bochum existierte die SPD-Frauengruppe zunächst parallel zu den offiziellen ASF-Strukturen. 
[...] das war eine kleine Gruppe von gleichaltrigen Frauen so plus zehn, minus fünf Jahre, damals so um die dreißig rum -, und wir haben gesagt, so, also erstens einmal Ziel Landesvorstand, wir fangen an auf kommunaler Ebene, Verdoppelung der kommunalpolitischen Mandate innerhalb eines Jahres, gell (?), und dann haben wir große Anzeigen in die Zeitung gesetzt und gesagt, wer will bei uns mitmachen, das ist unser Ziel, und dann haben wir ein Jahr lang jedes Wochenende, das Gott gab, auf irgendeiner Heimvolkshochschule, gell (?), ein Treffen mit Frauen gemacht, das immer höchst vergnüglich verlief, gell (?), wo wir uns Freitag abends getroffen haben, eine Einführung gemacht haben, zusammen was getrunken haben, in die Sauna oder ins Schwimmbad gegangen sind und dann bis Sonntagnachmittag gearbeitet haben wie die Knechte, gell (?), und also: Was ist ein Gemeinderat, was ist ein Haushaltsplan, wie macht man das, wo guckt man nach, gell (?), wie rede ich frei. Und das hat immer auch einen Schneeballeffekt gehabt, wir haben mehr als das Doppelte der Mandate bekommen, und das war das, weil wir gesagt haben, wir können das, und da tauchten dann so alte Schlachtrösser, die also völlig entmutigt aufgegeben haben bei uns [...] die kamen dann, und da haben wir uns natürlich ungeheuer gefreut. (Zz 8)

Eine Zeitzeugin berichtete von der großen Resonanz an der Parteibasis. An der "Montagsschulung“ des ASF-Unterbezirks Gelsenkirchen nahmen Anfang der 1970er-Jahre bis zu 120 Frauen teil und wurden am Montagmorgen "politisch geschult, also immer mit brennenden Themen“ ( $\mathrm{Zz}$ 12).

In vielen Ortsvereinen trafen die jungen, frauenbewegten ASF-Aktivistinnen aber auf die traditionelle Frauenarbeit der Partei. Ihre Initiativen, mit „geselligen und informatorischen Veranstaltungen“ die älteren Genossinnen „für die eigentliche politische Arbeit vorzubereiten“, wie es Christine Schmarsow in einem Strategiepapier erläuterte (vgl. Schmarsow 1973), trafen bei den Altmitgliedern oftmals auf wenig Begeisterung. Eine Zeitzeugin berichtete über feste Sitzordnungen und Sonderrechte, durch die langjährige Parteimitglieder die Gruppe der Neumitglieder reglementierten:

[W]enn dann Jüngere kamen, die hat das doch sehr abgeschreckt, dieses Verhalten, ne? Die merkten das ja auch, ne (?), dass du da, wenn du dich einbringen willst und was politisch initiieren willst oder was verändern willst, dass du da nicht unbedingt so willkommen bist. (Zz 16). 
Andernorts formierten sich frauenbewegte SPD-Mitglieder zu Frauenstammtischen und Frauentreffs (vgl. Hempel-Soos 1980) sowie zu „Selbsterfahrungszirkeln“, von denen sich allerdings die linkssozialistischen ASF-Aktivistinnen distanzierten:

Die saßen zusammen und beklagten sich laufend, wie schlimm ihre Männer und die Umgebung sind. [...] [E]in Teil der ASF ist über diese sicherlich wichtige Selbsterfahrung und psychische Stabilisierung nicht hinausgekommen. Und wie gesagt, ich will das nicht gering schätzen, aber wenn sie eine politische Partei treiben und eine Gesellschaft ändern wollen, reicht das nicht aus. (Zz 11)

Im Laufe der 1970er-Jahre wandelte sich die Frauenarbeitsgemeinschaft trotz dieser unterschiedlichen Organisationsinteressen und den oft konfliktreichen Kollektivbildungsprozessen. Viele politisch ambitionierte Frauen fanden in der Arbeitsgemeinschaft Partizipationsmöglichkeiten und Mitkämpferinnen. In den Organisationseinheiten der Partei konnten sich die ASF-Frauen zunehmend erfolgreicher einbringen. Ende der 1970er-Jahre beschrieb die linkssozialistische ASF-Aktivistin Ursula Pausch-Gruber einen Wandel der ASF:

Die Frauenarbeit hat sich völlig verändert. Die Arbeitsgemeinschaft Sozialdemokratischer Frauen (ASF), wie die früheren Frauengruppen heute heißen, sind politisiert. Sie sind in weiten Bereichen die [Hervorhebung S.E.] aktive und kontinuierlich wirkende Gruppierung der Partei geworden. (Pausch-Gruber 1978: 75)

Auch wenn in der ASF noch jahrelang, wie eine Zeitzeugin ihre Erfahrungen in der lokalen Arbeitsgemeinschaft schilderte, um ein „Solidaritätsgefühl mühsam“ gerungen werden musste $(\mathrm{Zz} \mathrm{12})$, schlossen sich im Laufe der 1970er-Jahre alle frauenpolitisch aktiven Lokalgruppen den ASF-Strukturen an. 1981 besaß die ASF ca. 2.300 Frauengruppen bundesweit (vgl. Klar 1981). 1983 berichtete die Vorsitzende der ASF, Inge Wettig-Danielmeier, dass keine Arbeitsgemeinschaft so weit untergliedert sei wie die ASF (vgl. Rechenschaftsbericht 1981-1983). Auch der Parteivorstand würdigte diese Entwicklungen und schrieb den kontinuierlichen Zuwachs an weiblichen Parteimitgliedern den verstärkten Aktivitäten der ASF an der Basis zu (vgl. Jahrbuch der SPD \{1973-75\}: 292). 


\subsubsection{Die Sozialstruktur der ASF-Mitglieder}

Auf Bundesfrauenkonferenz 1981 wurden 215 Delegierte nach Beruf, Ausbildungsstand und ASF-Engagement befragt. Ein Vergleich dieser Daten mit den zeitgleichen Daten zur weiblichen Mitgliedschaft der Partei gibt Hinweise auf das Sozialprofil der Frauen, die als Vertreterinnen der Basis über die Ausrichtung und Politik der ASF in dieser Zeit diskutierten und entschieden.

Unter den ASF-Delegierten lag der Anteil der erwerbstätigen Frauen fast doppelt so hoch wie in der Gesamtpartei. Auch bei den ca. $25 \%$ der Delegierten, die als Hausfrauen arbeiteten, kann davon ausgegangen werden, dass viele davon eine qualifizierende Berufsausbildung hatten, denn $86 \%$ aller Befragten gaben einen beruflichen Abschluss an, etwa $53 \%$ hatten eine Lehre und ca. $33 \%$ ein Studium absolviert. Der berufliche Status der ASF-Delegierten lag damit deutlich über dem der weiblichen Parteimitglieder ${ }^{286}$ :

286 In einer zeitgleichen Studie wurde nachgewiesen, dass in der SPD die VertreterInnen in den Gremien im Vergleich zu den Mitgliedern über einen höheren Bildungsgrad und ein größeres soziales Kapital verfügen (vgl. Becker et al. 1983: 62). 
Tab. 1: Anteil der Berufsgruppen bei den Frauen. SPD-Mitgliedschaft und ASF-Delegierte $1981^{287}$

\begin{tabular}{|l|l|l|}
\hline Berufsstatus der Frauen & $\begin{array}{l}\text { 1982: Partei } \\
(\text { in\%) }\end{array}$ & $\begin{array}{l}\text { 1981: ASF-Delegierte } \\
\text { (in\%) }\end{array}$ \\
\hline ArbeiterInnen & 5,2 & 0,0 \\
\hline Angestellte & 22,6 & 35,6 \\
\hline BeamtInnen & 4,7 & 20,0 \\
\hline Selbstständige & 1,8 & 3,9 \\
\hline RentnerInnen/PensionärInnen & 6,7 & 2,0 \\
\hline Hausfrauen & 49,2 & 25,4 \\
\hline Lehrlinge & 1,2 & - \\
\hline SchülerInnen/StudentInnen & 6,0 & 6,3 \\
\hline Arbeitslos & - & 2,4 \\
\hline ohne Angaben & 2,6 & 4,4 \\
\hline Gesamt & 100 & 100 \\
\hline
\end{tabular}

Quelle: Eigene Darstellung.

$40 \%$ der Delegierten war jünger als 40 Jahre, in der Gesamtpartei waren $35 \%$ der Frauen in dieser Altersgruppe. 52 \% der Delegierten waren Anfang der 1970er-Jahre oder später in die Partei eingetreten.

$40 \%$ hatten zwischen 1971 und 1975 begonnen, sich für die ASF zu engagieren. Nur $25 \%$ waren vor der Neugründung der ASF bereits in der sozialdemokratischen Frauenarbeit aktiv, 75\% der Delegierten waren erst in der SPD für die Frauenpolitik mobilisiert worden.

Alle Delegierten verfügten über ausgewiesene politische Erfahrung. Der überwiegende Anteil hatte eine Funktion in der Partei, meist im Ortsverein oder Unterbezirk. 21 \% der Delegierten besaßen ein Mandat, davon ca. $72 \%$ in der Kommune, die anderen auf Landesebene, eine Person auf Bundesebene. Über 88 \% der Delegierten gaben Mitgliedschaften in Gruppen und Verbänden außerhalb der Partei an, in der AWO und den DGB-Gewerkschaften sowie in Elterninitiativen, Frauengruppen

287 Vgl. Auswertung der Fragebögen der Delegierten der Bundeskonferenz der Arbeitsgemeinschaft Sozialdemokratischer Frauen (ASF) in Bonn-Bad Godesberg 1981 in Akten des PV 9390; Boyer/Kössler 2005: 289 und eigene Berechnungen. 
oder der Humanistischen Union. $65 \%$ der Delegierten waren auch außerhalb der Partei frauenpolitisch aktiv.

Die meisten Delegierten trugen Familienverantwortung. $75 \%$ der Frauen hatten Kinder, 6o \% mehr als ein Kind, $25 \%$ mehr als drei Kinder. Nur $16 \%$ der Delegierten waren nicht verheiratet. Damit befanden sich unter den Delegierten, wie eine Zeitzeugin berichtete, viele Mütter aus unterschiedlichen sozialen Schichten und Milieus, die die Probleme bei der Vereinbarkeit von Berufs- und Familienanforderungen und die Erfahrungen der Benachteiligung auf dem Arbeitsmarkt teilten.

Die Bundeskonferenzen der ASF waren somit zwar von der parteitypischen Akademisierung der Gremien geprägt, aber die Konferenzen wurden weniger von jungen, familiär ungebundenen Erwerbstätigen dominiert, als es der ASF von parteiinternen KritikerInnen vorgehalten wurde ${ }^{288}$.

\subsubsection{Repräsentationsdemokratie und Organisationspolitiken der ASF}

Wie in der Gesamtpartei lehnte sich der Organisationsaufbau der ASF an den staatlichen Verwaltungsstrukturen $\operatorname{an}^{289}$. Die demokratischen Verfahren beruhten auf den Prinzipien der Repräsentation. In dem kaskadisch aufgebauten Delegationssystem wurde auf jeder Ebene nach dem Mehrheitsprinzip entschieden. ${ }^{290}$ Der Satzung entsprechend bestimmten die Führungsgremien Kurs und Profil der ASF entscheidend.

Auf den zweijährlich stattfindenden Bundesfrauenkonferenzen trafen sich - damals ca. 250 - Delegierte, die in einem dreistufigen Auswahlverfahren - Wahl der Delegierten zum Unterbezirk durch die Ortsvereinsmitglieder, Wahl der Delegierten zur Bezirkskonferenz durch die Unterbezirksdelegierten, Wahl der Delegierten zur Bundesfrauenkonfe-

288 Dieses Erzählmuster, nach dem diese Gruppe die Hausfrauen und Mütter aus dem Arbeitermilieu aus den Gremien der Frauenorganisation verdrängten, findet sich auch in vielen sozialdemokratischen Geschichtsschreibungen (vgl. Lösche/Walter 1992; Walter 2002; Faulenbach 2012).

Nur der Bundesvorstand der ASF setzte sich fast ausschließlich aus Akademikerinnen zusammen. Unter ihnen waren Mütter wie Inge Wettig-Danielmeier, die 1981 zur Vorsitzenden gewählt wurde, in der Minderheit.

289 Der Kommune entspricht der Unterbezirk, die Bezirke befinden sich innerhalb von Landesgrenzen.

290 Zum Organisationsaufbau vgl. Abb.2 Organisationsstruktur der ASF unter DOI $10.3224 / 86388794 \mathrm{~A}$. 
renz durch die Bezirksdelegierten - bestimmt wurden. Die Bundesfrauenkonferenz wählte auf zwei Jahre eine Vorsitzende ${ }^{291}$ mit zwei Stellvertreterinnen und den Bundesvorstand. Er tagte etwa einmal im Monat. Im Bundesvorstand arbeiteten im Forschungszeitraum neben den Vorsitzenden rund 13 Vertreterinnen der über 20 Bezirke und Landesverbände ${ }^{292}$ mit. Ab 1975 übernahmen Vorstandsmitglieder sog. Patenschaften für die im Vorstand nicht vertretenen Bezirke ${ }^{293}$, um Austausch und Information in der gesamten ASF zu sichern. Meist funktionierten diese Kontaktwege aber vor allem von oben nach unten, selten wurden die Patinnen aus den Bezirken angesprochen. Der Bundesvorstand bildete aus seinen Reihen zu aktuellen Themen ad hoc Arbeitsgruppen, die auch sachkundige Genossinnen und parteiexterne Expertinnen zu ihren Diskussionen hinzuzogen.

Die gesamte ASF-Arbeit wurde ehrenamtlich geleistet. Führende ASF-Frauen hatten neben dem Beruf und den Familienaufgaben meist auch ein Parteiamt oder sogar ein Mandat - oder strebten dies an. Selten stellten die Parteieinheiten für die Verwaltungsarbeiten der ASF Ressourcen zur Verfügung. In den meisten Bezirken fehlten die satzungsgemäßen hauptamtlichen SekretärInnen für Frauenfragen oder sie nahmen ihre Zuständigkeit nicht wahr. Da die ASF weniger BerufspolitikerInnen und FunktionärInnen in den eigenen Reihen besaß als die anderen Arbeitsgemeinschaften der SPD, konnte sie kaum über externe Ressourcen verfügen. Die unzureichende Ausstattung bewertete der Bundesvorstand als diskriminierend und beschwerte sich darüber wiederholt beim Parteivorstand.

Die Durchsetzung von ASF-Forderungen durch wenige hauptberufliche und ehrenamtliche Funktionsträger gegen die Politik von Männern, denen Mitarbeiterstäbe und alle Informationsquellen zur Verfügung stehen, ist äußerst schwierig (Rechenschaftsbericht 1979: 28).

291 Übersicht der ASF-Vorsitzenden ab 1973 vgl. Tab.3 Bundesvorsitzende der ASF unter DOI $10.3224 / 86388794$ A.

292 Im Jahr 1973 werden 22 Bezirke (Jahrbuch der SPD:\{1973-75\}), im Jahr 198127 Bezirke und Landesverbände aufgeführt (Jahrbuch der SPD \{1979-81\}:381f.).

293 Siehe Rechenschaftsbericht des Bundesvorstandes auf der Bundeskonferenz 1979 in: PV-Akten 9924. 
Bis in die 1980er-Jahre stand der ASF ausschließlich das Frauenbüro des Parteivorstands ${ }^{294}$ mit zunächst nur zwei Mitarbeiterinnen zur Verfügung. Erst in der zweiten Hälfte der 1980er-Jahre wurde der Bundesvorstand der ASF mit weiteren Bürokapazitäten ausgestattet.

Die Politik des Bundesvorstands wurde durch den Bundesfrauenausschuss ${ }^{295}$ begleitet. Dieses Gremium setzte sich aus den Landes- und Bezirksvorständen sowie Vertreterinnen der Parteiführung zusammen und tagte drei- bis viermal im Jahr. Seine Debatten galten der ASF-Leitung als „Stimmen der Basis“296 und hatten einen starken Einfluss auf die Leitungspolitik.

Die Bundesfrauenkonferenzen sind nach der Satzung das höchste beschlussfassende Organ. Zu Beginn jeder Konferenz legte die Vorsitzende Rechenschaft über die Arbeit und Politik der letzten Wahlperiode ab ${ }^{297}$. Neben Vorträgen verschiedener Ehrengäste oder ExpertInnen fanden Abstimmungen über Personen und Anträge zu unterschiedlichsten frauenpolitischen Themen statt, durch die die Richtung der ASF für die nächsten zwei Jahre bestimmt werden sollte. Sie behandelten politische Ausrichtungen der Arbeitsgemeinschaft, Stellungnahmen und Forderungen zu gesellschaftspolitischen Ereignissen. Es wurden Forderungen an den Parteivorstand und Arbeitsaufträge an den ASF-Bundesvorstand formuliert.

Die wachsende Mitgliedschaft und die starke Heterogenität der ASFFrauengruppen führten zu einem parallelen, widersprüchlichen und ungleichzeitigen Prozess politischer Meinungsbildung, sodass es auf den Bundeskonferenzen zu wiederkehrenden, gleichlautenden Anträgen ${ }^{298}$

294 Die Besetzung des Frauenbüros bestimmte der Parteivorstand. In den 1970er-Jahren wurde es von Anni Janssen geführt, die den feministischen ASF-Frauen im Bundesvorstand der Arbeitsgemeinschaft außerordentlich misstrauisch gegenüberstand.

295 Leider ließen sich die Protokolle des Bundesfrauenausschusses in den Archiven nicht vollständig auffinden. Sie wurden nicht gesammelt abgelegt, sondern waren nur vereinzelt in den verschiedenen Sachordnern vorhanden.

296 Eine vollständige Sammlung der Protokolle der Bundesfrauenausschusssitzungen ist bisher in den Archiven der Partei und der Friedrich-Ebert-Stiftung leider nicht verfügbar.

297 Die Vorsitzende Inge Wettig-Danielmeier führte ausführliche Berichte über die Vorstandsarbeit und eine sorgfältige Dokumentation der Aktivitäten der Vorstandsmitglieder in der ASF ein.

298 Dazu trug vermutlich auch bei, dass der personelle Wechsel unter den Delegierten der Bundesfrauenkonferenzen recht hoch war. Nach der Delegiertenbefragung von 1981 nahmen zwei Drittel der Frauen zum ersten oder zweiten Mal an der Versammlung teil, die nach der Neugründung der ASF als fünfte Bundesfrauenkonferenz stattfand. Der Posten einer Delegierten war für viele Frauen nicht sehr attraktiv. Er war mit langen Sitzungen, dem Durcharbeiten von einer meist über 100 Seiten starken Konferenzvorlage und der Investition eines kompletten Wochenendes verbunden. 
kam - trotz Antragskommission und den Informationsbulletins des Bundesvorstands. In der Folge waren die Bundesfrauenkonferenzen bald vom gleichen Antragsbürokratismus geprägt wie die Parteitage. Aufbruchsstimmungen und Initiativen gingen selten von den Bundesfrauenkonferenzen, sondern eher von ASF-Unterstrukturen auf Landes- oder Ortsebene aus.

Um die Fülle der Appelle und Stellungnahmen, die den Konferenzen in nahezu gleichem Wortlaut vorlagen, zu reduzieren, entschied die Bundesfrauenkonferenz 1975, gültige Beschlüsse der ASF in einer Sammelmappe und Broschüre zusammenzustellen. Eine gleichlautende Aufforderung verabschiedete auch die Mannheimer Konferenz 1987. Dieses Informationsmaterial wurde jedoch nicht erstellt. ${ }^{299}$

Meist stellte der Bundesvorstand die jeweilige Bundesfrauenkonferenz unter ein frauenpolitisches Tagungsmotto, an dem sich die RednerInnen orientierten. Für den weiteren Konferenzverlauf, die Anträge und die Abstimmungen zur ASF-Politik hatte der Tagungstitel allerdings wenig Bedeutung ${ }^{300}$.

Um Profil und Anliegen der ASF in der Partei zu schärfen, beschloss die Erlanger Bundesfrauenkonferenz 1979 auf Initiative des Bundesvorstands, das Engagement der ASF „strategisch auszurichten“. Die Arbeit sollte auf Themen konzentriert werden, die „strategische Punkte der Gesellschaftsveränderung" (Antrag E1 Buko 1981 in Dokumente 14/1981) betreffen und die Themen einer breiten politischen Bewegung werden könnten (vgl. Rechenschaftsbericht 1981: 16). Mit dem Titel der Bonner Bundesfrauenkonferenz 1981, „Vereinbarkeit von Beruf und Familie“301, sollte ein solches Thema gefunden sein. Aber diese Initiative entsprach nicht der Heterogenität der Arbeitsgemeinschaft und konnte auch die zunehmende Pluralisierung ihrer frauenpolitischen Themen nicht einfangen. In dieser Themenfülle blieben verschiedene politische Konzepte, die in Arbeitsgruppen, Kommissionen und im Zuge von Fachtagungen mit viel Engagement entwickelt worden waren, politisch folgenlos oder gerieten in Vergessenheit, selbst wenn sie in den Bundesfrauenausschüssen vordiskutiert und in den Bundeskonferenzen mit großer Mehrheit angenommenen worden waren.

Im Zuge der Entwicklung veränderte sich die Bedeutung der Bundesfrauenkonferenzen. Für politische Debatten boten die Delegiertenversammlungen schon wegen der Abstimmungsverfahren und Wahlprozeduren wenig Raum. Darüber hinaus waren die meisten Anträge und Kandidatinnen in den informellen Netzwerken im Vorfeld der Konferenzen

299 Dies bestätigt Zeitzeugin 9; in den Archiven fand sich kein Hinweis auf eine solche Broschüre.

300 Vgl. dazu Tab.2. Bundeskonferenzen 1968-1990 unter DOI 10.3224/86388794A.

301 Bundesfrauenkonferenz vom 15. - 17.06. 1981 in Bonn/Bad-Godesberg. 
vorabgestimmt, um offene Aussprachen und Auseinandersetzungen zu umgehen. Alle Konferenzbeschlüsse wurden mit einfachen Mehrheiten entschieden, häufig wurden wichtige Entscheidungen auch gegen große Minderheiten getroffen. Für viele Delegierte waren die Bundesfrauenkonferenzen deshalb weniger Foren des Austauschs und der Diskussion als ein Gremium des Netzwerkens. Die Konferenzen dienten weniger der politischen Steuerung und Koordinierung der ASF als vielmehr der Kollektivpflege. Durch sie wurden eine für alle spürbare inhaltliche Gemeinsamkeit und Zugehörigkeit inszeniert und sie boten denen eine Bühne, die sich als Aktivistinnen sichtbar machen wollten.

Ende der 1970er-Jahre hatte die ASF sich ein breites Spektrum frauenpolitischer Positionen und Politiken erarbeitet und über die Bundeskonferenzen einen internen Konsens dazu hergestellt. Aus dieser Fülle von Politiken wählten sich die ASF-Organisationseinheiten die gewünschten Beschlüsse nach eigenen, regionalen politischen Interessen aus. Eine Begründung oder Absprache mit dem Bundesvorstand gab es nicht; die Beteiligung der Arbeitsgemeinschaften an den bundesweiten Diskursen war sehr unterschiedlich, wie eine Zeitzeugin als ehemaliges Bundesvorstandsmitglied berichtete:

Es gab Bezirke, die haben sich nicht beteiligt an der Frage oder an einer anderen oder so, das hat man hingenommen, was hätte man anderes tun sollen? [...] dann gab's also Bezirke, die auch Leute vom Bundesvorstand eingeladen haben zu Referaten zu bestimmten Themen, um die auf Bezirksebene voranzutreiben, das gab's halt auch. (Zz 9)

Wie sich die Meinungs- und Mehrheitsverhältnisse in der ASF entwickelten, war somit für die Führungsgremien schwer einzuschätzen. Einerseits bewegte die ASF zu ihrer Meinungs- und Entscheidungsfindung ein aufwändiges hierarchisch-bürokratisches Abstimmungssystem, andererseits waren die ASF-Frauengruppen in ihrer Politikgestaltung von der Bundes-ASF weitgehend unabhängig. Sie definierten ihren Bezug auf Parteipolitik und gesellschaftliche Themen nach ihren eigenen Prioritäten und Rücksichtnahmen auf ihr politisches Umfeld, in dem sie agierten. Auch ihre Aufgabe, durch Kooperation und Netzwerken „das Wirkungsfeld der Partei zu verbreitern“ (Richtlinien 1974: II.) nahmen sie nach eigenen Vorstellungen wahr.

Die Bundesvorsitzende mahnte in verschiedenen Rechenschaftsberichten eine bessere Kooperation zwischen Bundesvorstand und Bezirken an. Dafür unternommen wurde allerdings nichts, denn diese Konstellation hatte, so vermutete eine Zeitzeugin, auch für den Bundesvorstand erhebliche taktische Vorteile. Die Bundeskonferenzen legten auch 
für die ASF-Führung keine politischen Arbeitsschwerpunkte ${ }^{302}$ fest und boten dem Bundesvorstand mit dieser strategischen Unschärfe Aktionsspielräume. Neben wenig bedeutenden Einzelaufträgen durch die Bundeskonferenz konnte der Bundesvorstand innerhalb eines Koordinatensystems frauenpolitischer Positionen relativ ungebunden agieren. ${ }^{303}$

\subsubsection{Politische Teilhabe und Karrierechancen in der Frauenarbeitsgemeinschaft}

Von 1970 bis 1989 stieg die Zahl der weiblichen SPD-Mitglieder von 143.043 auf 248.004 stetig an ${ }^{304}$. Damit war die ASF in dieser Zeit der numerisch größte Frauenverband in der Bundesrepublik. Wie viele weibliche Parteimitglieder sich aktiv in die ASF einbrachten, ist nicht systematisch erfasst worden, die Schätzungen variieren stark. Nach Beate Hoecker fühlte sich ein Drittel der weiblichen Parteimitglieder bei unterschiedlich hohem Engagement zu den ASF-Gruppen hingezogen (vgl. Hoecker 1987a: 19). Nach Elmar Wiesendahl kann der Kreis der aktiv partizipierenden Mitglieder, der „Daueraktiven“, als bei $25 \%$ liegend angenommen werden (vgl. Wiesendahl 2006:39). Nach Isabell Kürschner differiert das Parteiengagement geschlechtsspezifisch und ist auf unterschiedliche Eintrittsmotive zurückzuführen. Nach ihren Studien lag der Einsatz der Frauen unter dem der Männer, denn sie verbinden mit ihrem Parteibeitritt Zugehörigkeit, während Männer mit dem Beitritt ein Beteiligungsinteresse haben (vgl. Kürschner 2009: 16f.). Eine Infas-Studie von 1977 belegt diese geschlechtsspezifischen Unterschiede mit Zahlen:

302 Für Wolfgang Pausch war dies ein zentraler Grund für die eingeschränkte Handlungsfähigkeit der ASF und ihre verpassten Chancen, sich in der Partei durchzusetzen. Allerdings wäre die von ihm geforderte programmatische Konsistenz und Profilierung der ASF nicht möglich gewesen. Außerdem hatten sich die Jusos in politischen Grundsatzdebatten jahrelang gelähmt, während gleichzeitig die pragmatischen Ein-PunktBewegungen der Neuen Sozialen Bewegungen eine hohe Aktionsfähigkeit erreichen konnten.

303 Aus diesem Grund war die Initiative eines ASF-Bezirks, Anträge, die bereits abgestimmt waren und keine neuen Politiken eröffnen konnten, nicht mehr zuzulassen, im Bundesvorstand verworfen worden, erklärte eine Zeitzeugin,:,,Ja, es wäre eine Bereinigung und eine Konzentration auf Strategie gewesen. War nicht gewünscht." (Zz 9)

304 Der einzige Rückgang fand in den Jahren 1981/1982 statt, vgl. Tab. 7 Entwicklung des Frauenanteils an der Mitgliedschaft in allen Parteien unter DOI 10.3224/86388794A. 
Bei den weiblichen Mitgliedern wird der durchschnittliche Beteiligungsgrad mit $5 \%{ }^{305}$, bei den männlichen Mitgliedern mit 10-15\% in der Gesamtpartei angegeben (vgl. Wiesendahl 2006:39). Die meisten engagierten Sozialdemokratinnen waren dabei in der Kommunalpolitik aktiv.

Die Arbeitsgemeinschaften waren als exklusive Struktur organisiert. Nichtparteimitglieder konnten sich nur auf Ortsvereinsebene beteiligen und waren dort lediglich als DiskussionsteilnehmerInnen zugelassen. Entscheidungs- und Delegationsrechte waren an eine Parteimitgliedschaft gebunden.

Nach den Parteistatuten sollte das Engagement in den Arbeitsgemeinschaften der Mitarbeit in den Parteigremien untergeordnet sein, deshalb hatten die Arbeitsgemeinschaften der SPD keinen Zugang zur innerparteilichen Entscheidungsfindung. Sie hatten gegenüber den jeweiligen Organisationseinheiten eine ausschließlich beratende Position. Politische Anliegen in der Partei auf den Weg zu bringen und Kandidatinnen zu platzieren, bedeutete für die ASF-Aktivistinnen deshalb doppeltes Engagement und kontinuierliche Mitarbeit, sowohl in der Partei als auch in der ASF.

Trotz ihrer wachsenden Beteiligung blieben die ASF-Aktivistinnen immer in einer relativen Minderheit in den Gremien und waren von der Aufgeschlossenheit und der Handlungsbereitschaft der jeweiligen Organisationseinheit abhängig. Je höher das Gremium in der Parteihierarchie stand, das die frauenpolitischen Anträge unterstützte, desto mehr politisches Gewicht hatten diese in der Partei. Um frauenpolitisch Einfluss nehmen zu können, mussten die ASF-Aktivistinnen deshalb möglichst hohe Funktionen erreichen.

In der ASF selbst waren die Zugangschancen zu ASF-Funktionen für Neumitglieder je nach Ort sehr unterschiedlich. In mitgliederstarken ASF-Bezirken in den sog. SPD-Hochburgen besetzten häufig Altmitglieder die ASF-Strukturen, dagegen fanden die jungen ASF-Aktivistinnen in neu gegründeten oder kleineren Arbeitsgemeinschaften leichter Zugang zu Funktionen. Zwar wurde vielerorts in der ASF das parteiübliche Ancienitätsprinzip (vgl. Wiesendahl 1998) gelebt, nach dem verdiente Parteimitglieder gegenüber Neumitgliedern bevorzugt vorgeschlagen und gewählt wurden, aber es gelang den meist besser ausgebildeten, frauenbewegten ASF-Aktivistinnen recht erfolgreich, Vertreterinnen-

305 Damit wäre durchschnittlich jedes aktive ASF-Mitglied auch gleichzeitig Funktionärin gewesen, was aber den Dokumenten und Berichten der ZeitzeugInnen nicht entsprach, allerdings zu den Beschreibungen der ASF von Peter Lösche und Franz Walter passen könnte (vgl. Lösche/Walter 1992: 248). 
und Führungspositionen zu erreichen, sodass diese Gruppe in den ASFLeitungsgremien bald stark vertreten war ${ }^{306}$.

Erfolgreiche Karrieren funktionierten durch die Akkumulation von Kontakten und durch die wachsende Distinktion gegenüber dem „einfachen" Parteimitglied. Schon die ersten Vorstandspositionen an der Parteibasis waren mit exklusiven Zugängen zu Netzwerken und privilegierten Informationen verbunden und statteten ihre Inhaberinnen dadurch mit zusätzlichen Durchsetzungschancen aus. Diese Exklusivitäten entschädigten sie für den Aufwand im ehrenamtlichen Engagement, den hohen Einsatz an privater Zeit und die erwartete Verfügbarkeit. Jede höhere Position schaffte einen besseren Zugang zum nächsten Schritt auf der politischen Karriereleiter. Die Wahlchancen einer Bewerberin stiegen zusätzlich, wenn sie von der nächsthöheren Führungsinstanz als Kandidatin vorgeschlagen wurde. Dabei ließen sich Partei und Arbeitsgemeinschaft wechselseitig zur Karriereförderung nutzen ${ }^{307}$.

Ein gutes Netzwerk war für eine aussichtsreiche Anwartschaft auf ein Mandat unabdingbar. Die Mitgliedschaft in der lokalen Führungsstruktur der Partei erleichterte dabei den Aufbau der innerparteilichen Hausmacht und den Weg auf die KandidatInnenliste (vgl. Hoecker 1987b; Hoecker/Scheele 2008). Inwieweit ein Mitglied an der ASF teilnehmen und sich einbringen konnte und ob sein Engagement auch einen politischen Karriereweg eröffnete, hing weitgehend von der Vorsitzenden der jeweiligen Arbeitsgemeinschaften der ASF ab. Sie steuerte den Informationsfluss aus den übergeordneten Gremien und verwaltete die Teilhabe der Frauengruppe an den frauenpolitischen Diskursen in der ASF. Nach Ika Klar nahm noch Ende der 1970er-Jahre die Mehrheit der ASF-Vorsitzenden nicht am frauenpolitischen Aufbruch teil:

Wie erfolgreich im emanzipatorischen Sinn eine ASF arbeitet [...], hängt weitgehend von der Arbeit und Integrationsfähigkeit des jeweiligen Vorstandes ab. Fortschrittliche Vorstände bei den

306 Diese Entwicklung spiegelt sich in der Entwicklung der Altersstruktur bei den Bundeskonferenzdelegierten. Auf der Nürnberger Bundesfrauenkonferenz 1968 waren nur 23 Frauen im Alter von ca. 30 Jahren unter den Teilnehmerinnen gewesen, so die Zeitzeugin 5. Auf der Bundesfrauenkonferenz 1981 lag der Anteil dieser Gruppe bereits bei $9 \%$ der Delegierten. Frauen, die eloquent politische Anliegen vortragen konnten, die „ihr Wort machen“ konnten (Zz 1), hatten stets einen leichteren Zugang zu politischen Karrieren.

307 Eine Zeitzeugin berichtet, dass sie über die Partei als Mitglied des Unterbezirksvorstands zur Vorsitzenden der ASF gewählt wurde, „gewählt worden zwar, aber so draufgesetzt“. In dieser Position hätte sie dann die Frauengruppe „umkrempeln“ können (Zz 12). 
Frauenarbeitsgemeinschaften unserer Partei gibt es im Bundesgebiet. Aber sie sind die Ausnahme. (Klar 1981: 126f.)

\subsubsection{Presse- und Informationsarbeit}

Jahrzehntelang war die sozialdemokratische Frauenarbeit mit der Herausgabe einer Frauenzeitschrift verbunden. 1892 wurde unter der Chefredaktion Clara Zetkins Die Gleichheit herausgegeben. Ab 1948 wurde sie von Herta Gotthelf redigiert. 1965 jedoch wurde diese Zeitschrift eingestellt, weil „das Interesse an politischen Publikationen immer mehr abgenommen" hatte ${ }^{308}$ (die Redaktion zit. n. Martiny 1986: 121). 1970 wurde die Beilage Frau im Staat der bonner depesche ebenfalls eingestellt. Die Neugründung einer sozialdemokratischen Frauenzeitschrift nach dem Vorbild der österreichischen Wochenzeitschrift Die Frau ${ }^{309}$ wurde mehrere Jahre in der ASF diskutiert, aber letztendlich als nicht realisierbar verworfen (vgl. $\mathrm{Zz} 4)$.

Das Frauenbüro des Parteivorstands brachte ab 1974 durchschnittlich 2- bis 3-mal im Jahr den Sozialdemokratischen Informationsdienst. Frau und Gesellschaft heraus. Darin wurden zu wichtigen frauenpolitischen Themen $^{310}$ sozialdemokratische Positionen vorgestellt, es wurde über Parteitage und Fachkonferenzen informiert und politische Positionspapiere und Stellungnahmen aus dem Bundesvorstand wurden hier veröffentlicht. Konferenzdokumentationen erschienen auch in der Reihe Frauenpoliti $k^{31}$. Einzelne Bundeskonferenzen wurden als Broschüren in der Reihe Frau und Gesellschaft ${ }^{32}$ dokumentiert. Im Zuge der Auseinandersetzungen um das Grundsatzprogramm, an dem sich viele ASFFrauen, insbesondere aus dem Bundesvorstand, intensiv beteiligten, erschien unregelmäßig und mit wenigen Ausgaben die Reihe Materialien. Beiträge zur sozialdemokratischen Programmdiskussion. Diese Mitteilungen und weitere Schnellinformationen verteilte der Bundesvorstand über die Organisationsstrukturen der ASF. Es waren Informationen ohne aufwendige journalistische Aufbereitung, eher Arbeitsmaterialien, die

308 Die CDU gab seit 1955 die Zeitschrift Frau und Politik heraus.

309 Die Frau wurde 1987 eingestellt. Nach Angaben der Redaktion hatte sie bis zum Schluss 10o.ooo Leserinnen, war aber finanziell von Zuschüssen der Parteileitung abhängig.

310 Wie z.B. zum Gleichstellungsgesetz, zu sozialer Sicherung, Frauen für Frieden, Biound Reproduktionstechnologie, Arbeitszeitverkürzung u. a., vgl. unter Dokumente in der Literaturliste.

311 Herausgeber: Vorstand der SPD.

312 Ab 1985 Frauen in der SPD, herausgegeben von der ASF. 
sich vorrangig an politisch interessierte Funktionärinnen richteten und weniger an die weibliche Mitgliedschaft an der Parteibasis.

Für Mitglieder in den lokalen ASF-Gruppen kam 1987 ein Handbuch zur Frauenarbeit heraus, in dem die Funktion von Gleichstellungsstellen, der Internationale Frauentag und die Kampagne Ran an die Zukunft313 sowie weitere Initiativen zur Frauen- und Mädchenarbeit in den Bereichen Ausbildung, Arbeitsmarkt, Neue Technologien, Mütterzentren, Gewalt und Friedenspolitik erläutert wurden (vgl. ASF 1987b).

Flyer und Kurztexte entstanden im Zuge verschiedener Aktionen und dabei besonders in Wahlkampfzeiten. Zum 75-jährigen Jubiläum des Internationalen Frauentags gab die ASF 1985 eine kleine Broschüre in hoher Auflage heraus. Darin wurde mit vielerlei Bildmaterial der historische Beitrag der SozialdemokratInnen beim Kampf für Frauenrechte vorgestellt und ein Bogen zwischen diesen Traditionen und den zentralen Forderungen der ASF sowie zu bedeutenden sozialdemokratischen Politikerinnen geschlagen (vgl. ASF 1985b).

Wer die parteieigenen Zeitschriften ${ }^{314}$ verfolgte, konnte dort gelegentlich frauenpolitische Artikel finden. Ab September 1986 übernahm der zwd Frauen und Politik ${ }^{315}$ eine regelmäßige Berichterstattung über Frauenpolitik und frauenpolitische Arbeit in der öffentlichen Verwaltung; an seiner Herausgabe war auch die ASF-Bundesvorsitzende Inge Wettig-Danielmeier beteiligt. Die Zeitschrift richtete sich allerdings vorrangig an Gleichstellungsbeauftragte in Behörden.

Bis in die 198oer-Jahre kämpfte der Bundesvorstand der ASF darum, an den Presseterminen des Parteivorstands mit frauenpolitischen Stellungnahmen mitwirken zu dürfen. Dies war ihnen zugesichert worden, wurde jedoch nicht realisiert. Der Bundesvorstand berichtete auf der Bundesfrauenkonferenz 1981 von einer weitgehenden Aussperrung der ASF aus der Öffentlichkeitsarbeit der Partei:

Die ASF hat keinerlei Zugang zu aktuellen Nachrichten, Pressemitteilungen, Agenturmeldungen, sie ist in kaum einem Presseverteiler. Eine Unterstützung der Pressearbeit der ASF durch den Parteivorstand fand nicht statt. Insgesamt kann man von abenteuerlichen Rahmenbedingungen sprechen. (Rechenschaftsbericht 1981b: 21)

313 Eine Kampagne der ASF und der Jusos zur Verbesserung der Ausbildungschancen für Mädchen.

314 Besonders Die neue Gesellschaft - Frankfurter Hefte, Vorwärts.

315 Das Informationsblatt war eine Nachgründung des Zweiwochendienstes, der als parteiunabhängig finanzierter Informationsdienst für eine Gegenöffentlichkeit gegen die Kohl'sche „geistig-moralische Wende“ in der bildungspolitischen Landschaft sorgen sollte. Der zwd Frauen und Politik erscheint mittlerweile nicht nur als Printausgabe, sondern ist auch im Internet unter www.zwd.info verfügbar. 
In den folgenden Jahren erschienen im Sozialdemokratischen Pressedienst zwar regelmäßig kurze Presseerklärungen der ASF-Vorsitzenden, sie wurden aber von den Printmedien nur selten aufgenommen. Den autonomen Frauengruppen gelang es dagegen, beklagte die ASF-Vorsitzende Inge Wettig-Danielmeier, sehr viel erfolgreicher, von den etablierten Medien wahrgenommen zu werden (vgl. Rechenschaftsbericht 1981: 20). Eine größere mediale Aufmerksamkeit konnte die ASF in der zweiten Hälfte der 1980er-Jahre für sich gewinnen.

\subsubsection{Politische Bildungsarbeit}

Für die angestrebte gleichberechtigte Teilhabe der Frauen in der Partei brauchte es eine ausreichend große Anzahl von Genossinnen, die sich mit politischem Sachverstand, aber auch den nötigen kommunikativen Fähigkeiten und Verfahrenskenntnissen durchsetzen konnten. Dazu bildeten die Arbeitsgemeinschaften wichtige Orte der politischen Bildung und "Sozialisation“.

[...] [W]eil da war ja nichts da, woher sollten Frauen das, insbesondere wenn sie zu Hause waren, lernen? Konnten sie nicht, hatten sie Ängste. Und das haben wir dann also systematisch geübt und Leute ermuntert und so. Außerhalb der Studentinnen und der Akademikerinnen war keiner geübt, frei zu sprechen oder seltenst vor einem Publikum. (Zz 11)

In den Frauenarbeitsgemeinschaften konnten Frauen lernen zu verstehen, wie die Partei in ihren Abläufen funktioniert, wie man sich einmischte, und sie lernten parteistrategisches Denken und Handeln.

[I]n Wirklichkeit habe ich über die Frauen dadurch ganz viel erfahren, was auch auf anderen politischen Ebenen läuft. D. h. diejenigen, die in Funktionen waren - Unterbezirksvorsitzende der ASF oder dann Vertretungen im Bezirksvorstand oder Landesvorstand - die haben sehr stark berichtet und versucht, Frauen auch einzubinden. Und das in einer Situation, die nicht geprägt war von gegenseitiger Konkurrenz, sondern eher von dem Willen, gemeinsam etwas zu tun. Und ich bin mir bis heute ziemlich sicher, dass ich diese Erfahrung ohne die ASF so nicht gemacht hätte, sondern innerhalb normaler, üblicher Parteigremien wäre das sehr viel stärker geprägt gewesen von Konkurrenz, von Politisch-eine-Rolle-spielen-Wollen, von weniger sachorientiert, auch persönlichkeitsmotiviert eine Karriere innerhalb einer Partei machen zu wollen. (Zz 14) 
Die Friedrich-Ebert-Stiftung bot für politische AktivistInnen ein umfangreiches Schulungsprogramm an. Das Themenspektrum umfasste politisches FunktionärInnenwissen, die Vermittlung von Verwaltungskenntnissen für zukünftige Mandatsträgerinnen sowie Trainingsmaßnahmen für freies Sprechen oder Pressearbeit. Diese Seminarangebote wurden durch weitere Bildungsangebote in den Bezirken und auf Ortsvereinsebene ${ }^{316}$ ergänzt. Neben Wissenstransfer boten sie Foren der Auseinandersetzung und Meinungsbildung.

In der Zeit, in der ich aktiv war, haben wir SEHR viel Seminare gemacht. Ich würde fast sagen, ich war an jedem Wochenende weg irgendwo [...] Auf diesen Seminaren hat man auch unkonventionelle Ideen verbreiten können, ne? Es gab da sehr heftige Diskussionen. (Zz 12)

Auch wenn es in der ASF und der Partei unterschiedliche Orte gab, das Empowerment der weiblichen Mitglieder zu erhöhen, war die Frauenarbeitsgemeinschaft immer von einem Mangel an politisch geschultem Personal gekennzeichnet, was ihre Einflussmöglichkeiten in der Partei, aber auch die Meinungsbildung und aktive Beteiligung in den eigenen Strukturen begrenzte. Über die Godesberger ASF-Bundeskonferenz 1983 schrieb die Journalistin Nina Granenberg: „Es gibt nur wenige weibliche Profis, die es gelernt haben, Konflikte in offener Feldschlacht auszutragen. Die meisten trauen sich nicht zu reden, sie gucken nur" (Granenberg 1983).

\subsubsection{Der parteiexterne Netzwerkaufbau}

Auf der Bundesfrauenkonferenz 1981 beschloss die ASF, den „Schwerpunkt unserer Arbeit auf den Dialog mit gesellschaftlichen Gruppen zu richten“ als „eine notwendige Ergänzung" zur innerparteilichen Arbeit (Dokumente 14/1981: 18). Mit einer stärkeren gesellschaftspolitischen parteiexternen Unterstützung wollte sie ihren Einfluss und ihre Handlungsfähigkeit innerhalb der Partei erhöhen.

Über die Kontakte zu den Gewerkschaften hinaus suchte die ASF in den 1980er-Jahren politische BündnispartnerInnen bei den Gleichstellungsbeauftragten in den öffentlichen Verwaltungen durch Kooperationen mit dem Deutschen Frauenrat, den Frauenorganisationen anderer Parteien, den Kirchen und den autonomen Frauenbewegungen. Der

316 Nach Angaben einer Zeitzeugin (Zz 12) trafen sich in Gelsenkirchen in den 1970er-Jahren zur sog. Montagsschulung am Morgen bis zu 120 Frauen. 
Netzwerkaufbau belebte und vervielfältigte die Themen und Handlungsfelder der ASF und erweiterte ihre Ressourcen und Handlungsmöglichkeiten. Zudem lockerten die neuen politischen Diskurse die verfestigten politischen Lager auf. Allerdings präsentierten sich die ASF-Frauen in allen Netzwerk- und Kooperationsaktivitäten stets als Vertreterinnen der SPD und achteten darauf, dass die sozialdemokratische Politik, wichtige sozialdemokratische Führungsfiguren und die politischen Ziele der Partei in den Frauenbündnissen dominant präsent und sichtbar waren.

\section{Kooperationen mit Gewerkschafterinnen}

Die engsten und kontinuierlichsten Kontakte wurden zu Gewerkschafterinnen gepflegt, die den meisten ASF-Führungsfrauen als „natürliche Bündnispartner" (Rechenschaftsbericht 1981: 17) galten ${ }^{317}$, begründet auf den gemeinsamen geschichtlichen Bezügen und Traditionen der ArbeiterInnenbewegung. Außerdem hatten sich in vielen Einzelgewerkschaften und dem DGB parallel zu den Entwicklungen in den Parteien ebenfalls Frauenstrukturen gebildet und aktiviert, die für eine Veränderung der Politik und um mehr Einfluss in den Entscheidungsstrukturen der eigenen Organisationen kämpften ${ }^{318}$. Als die Gewerkschaftsfunktionärin Elfriede Hoffmann als ASF-Vorsitzende ${ }^{319}$ abgewählt wurde, bemühte sich der neue Vorstand darum, die gewerkschaftlichen Netzwerke zu stabilisieren. Unter dem Vorsitz von Inge Wettig-Danielmeier fand jedes Jahr mindestens eine Tagung zu Fragen der weiblichen Berufstätigkeit, der Lohn- und Tarifstruktur und der Vereinbarkeit von Beruf und Familie für und mit Gewerkschafterinnen statt, auf der auch gemeinsame politische Positionen und Forderungen definiert wurden. Mit gegenseitigen Konferenzbesuchen sollte der regelmäßige Austausch zwischen ASF und Gewerkschaftsfrauen gewährleistet werden. Bei allen frauenpolitischen Aktivitäten wie den Veranstaltungen zum § 218, den Demonstrationen gegen die Stationierung der Mittelstreckenraketen oder den Internationalen Frauentagen bemühte sich die ASF darum, eine gemeinsame Mobilisierung mit den Gewerkschafterinnen zu realisieren. Aller-

317 So hatte die ASF 1975 ein eintägiges Seminar mit 5o Betriebsrätinnen organisiert, um für die anstehenden Betriebsratswahlen zu mobilisieren.

318 Als Zeichen für eine erfolgreichere Durchsetzung der Frauen in den DGB-Gewerkschaften galt die Wahl von Monika Wulf-Mathies zur Vorsitzenden der Gewerkschaft Öffentliche Dienste, Transport und Verkehr im September 1982. Sie war die erste Frau im Vorsitz einer deutschen Gewerkschaft, der zweitgrößten des Deutschen Gewerkschaftsbundes.

319 Elfriede Hoffmann hatte den Vorsitz von 1977 bis 1981 inne, vgl. Tab. 3 Bundesvorsitzende der ASF unter DOI 10.3224/86388794A. 
dings entstanden aus dieser Kooperation - zumindest im Untersuchungszeitraum dieser Forschungsarbeit - keine spezifischen frauenpolitischen Aktivitäten. Die Gewerkschafterinnen waren, erläuterte eine Zeitzeugin, vorrangig auf die Politik der eigenen Organisation, die Tarifpolitik und die Verbesserung der Arbeitsbedingungen ausgerichtet und an den politischen Themen der Parteifrauen wenig interessiert (Vgl. dazu Zz 11).

\section{Überfraktionelle, außerparteiliche Kooperationen}

Zur Bundestagswahl 1980 diskutierten die Neuen Frauenbewegungen die Wahlfähigkeit der Parteien. Im Mai 1981 kamen zum Gründungskongress einer Fraueninitiative 6. Oktober (FI) 40o Frauen zusammen, darunter auch aktive Sozialdemokratinnen. Diese Initiative hatten das Ziel, eine „mächtige Frauenlobby“ ${ }^{20}$ zu schaffen, damit sich Frauen in der Politik erfolgreicher durchsetzen konnten, denn trotz Sachverstand und Engagement hatten in den Parteien nur wenige Wahlkandidatinnen aussichtsreiche Listenplätze erreichen können (vgl. Lenz 2008: 515, 590). Die Unterstützung dieser frauenpolitischen Opposition war in der ASF nicht unumstritten: Sie führte zu heftigen Kontroversen im Bundesvorstand, die zeigen, dass die Auseinandersetzungen in den ASF-Führungsgremien keineswegs nur durch gemeinsame Beratung und nach argumentativer Abwägung entschieden wurden. Die Gründungsinitiative war im Vorfeld vom ASF-Bundesvorstandsmitglied Ursula Pausch-Gruber begleitet worden. An ersten Bundeskonferenzen der Fraueninitiative nahmen mehrere ASF-Bundesvorstandsfrauen teil. Sie nutzten die Initiative als ein Forum des Austauschs und der Reflexion und diskutierten unter anderem darüber, ob eine Übernahme feministischer Forderungen durch etablierte Parteien als Vereinnahmung oder als Erfolg zu werten wäre (vgl. Heidi Baumann zit. n. Lenz 2008: 515- 517) und ob eine Quotierung in der Politik ${ }^{321}$ gefordert werden müsste: „[D]ie Hälfte der Ratssitze den Frauen" (Heidi Baumann zit. n. a. a. O.: 516).

Die Mitarbeit in der FI war in der ASF jedoch umstritten, für die Mehrheit im ASF-Bundesvorstand waren in der FI die Vertreterinnen der autonomen Frauenbewegungen zu dominant. Als sich herausstellte, dass an der geplanten Kampagne „Aktion Muttertag“ 1985 die Gewerkschaftsfrauen nicht beteiligt waren, nahm dies der ASF-Bundesvorstand zum

320 „Wir wollen arbeiten wie Rhizome, nämlich als ,Unkraut', dessen Wurzeln sich unter der Erde ausbreiten und immer weiter verzweigen, selbst wenn es an der Oberfläche ständig gerupft wird.“ (Heidi Baumann, Mitbegründerin der Initiative 6. Oktober, zit. n. Lenz 2008: 515)

$321 \mathrm{Zu}$ dieser Zeit wurde die Quotenforderung in der ASF noch mehrheitlich abgelehnt. 
Anlass, sich aus der FI zurückzuziehen (vgl. Rechenschaftsbericht 1987). Die Entscheidung führte zu einer Krise in der ASF-Führung und verdeutlicht die spannungsreichen Verhältnisse zwischen den politischen Strömungen in der ASF. Als Vorstandsmitglied Ursula Pausch-Gruber ihre Mitarbeit in der FI trotz des Bundesvorstandsbeschlusses nicht aufgeben wollte, kritisierte die Bundesvorsitzende Inge Wettig-Danielmeier ihre Stellvertreterin öffentlich im Vorwärts ${ }^{322}$. Nur die zahlreichen Proteststimmen aus den ASF-Gruppen konnten verhindern, dass die Vorsitzende ihre Stellvertreterin vorzeitig aus dem Vorstand drängte. Auf der nächsten Bundesfrauenkonferenz 1985 jedoch wurde Ursula PauschGruber durch die gewerkschaftsnähere Karin Junker ersetzt (vgl. PauschGruber zit. n. Junker 1992).

Zur Frauenunion, der Frauenorganisation der CDU, wurde der Kontakt ab Mitte der 1980er-Jahre institutionalisiert, Vertreterinnen beider Bundesvorstände nahmen nun wechselseitig an den Bundesfrauenkonferenzen teil. Die Parteienkonkurrenz sorgte jedoch weiterhin für eine politische Distanz zwischen diesen Frauenorganisationen.

Eine erfolgreiche Kooperationsinitiative initiierte die ASF-Führungsfrau Karin Hempel-Soos für frauenpolitisch engagierte Parlamentarierinnen. Gemeinsam mit Bonner Journalistinnen gründete sie die Gesprächsrunde Lila Karte in Bonn. Ihr Ziel war es, Frauenthemen stärker in die Medien zu bringen. Auf Initiative dieses Frauennetzwerkes hin verabschiedete der Parteivorstand am 15.12. 1986 den Beschluss, zukünftig für mehr Repräsentanz von Frauen in den Medien, besonders in politischen Sendungen, zu sorgen (vgl. Rechenschaftsbericht 1987: 33 f.).

In vielen Bundesländern vergab die ASF sog. Frauenpreise für herausragende frauenpolitische Arbeit. Der erste Frauenpreis wurde im Sommer 1988 von der niedersächsischen ASF an die parteipolitisch unabhängige Lyrikerin und Musiktheaterakteurin Lilo Zack übergeben, und zwar durch SPD-Parlamentarierinnen aus dem Landesparlament. Die Prämierung parteiexterner Frauen sollte öffentlich zeigen, dass es den Sozialdemokratinnen vorrangig um die Unterstützung frauenpolitischer Ziele und nicht nur um die Unterstützung ihrer Partei ging.

\section{Kooperationen mit etablierten Frauenverbänden}

Nach dem Regierungsverlust der SPD und der zunehmenden Stabilisierung der konservativen Regierung erweiterte der ASF-Bundesvorstand die Netzwerkaktivitäten stärker auf etablierte Organisationen. Auch in ihnen hatten die Neuen Frauenbewegungen Resonanzen erzeugt und

322 Vgl. Vorwärts Nr.42; dazu auch taz vom 07.10.1985. 
frauenbewegte Mitglieder begannen sich zu formieren. Zur evangelischen Kirche, der die meisten religiös orientierten Sozialdemokratinnen angehörten, entwickelten sich die engsten Kooperationen. Im Juni 1985 beteiligte sich der Bundesvorstand der ASF zum ersten Mal mit einem eigenen Informationsstand am Evangelischen Kirchentag unter dem Leitthema „Kinder, Küche, (C)Komputer“, der über die Auswirkungen der Telearbeit informierte, und auch an der Ausrichtung des Kirchentages im Folgejahr. Zum Katholischen Frauenbund wurden ebenfalls intensive Kontakte aufgenommen und gepflegt.

Schwerer tat sich die ASF mit einer aktiven Mitarbeit im Deutschen Frauenrat, zu der sie sich erst in der zweiten Hälfte der 1980er-Jahre entschloss. Noch 1985 schwankte sie zwischen Austritt und Engagement (vgl. Rechenschaftsbericht 1985: 29), denn nicht nur die historische Erblast, die Ausgrenzung deutscher Sozialdemokratinnen in den Anfängen der bürgerlichen Frauenbewegung (vgl. Gerhard 1991: 178-180), sondern auch jüngere Erfahrungen beeinträchtigten die Beziehung. 1976 hatte der Deutsche Frauenrat (DF) Helmut Schmidt für die Aufnahme von zwei Frauen in die Bundesregierung nach der Bundestagswahl und für die Berücksichtigung von DF-Forderungen öffentlich gelobt, die ASF sah darin eine Schwächung ihrer Kritik an der Parteiführung und ihres innerparteilichen Kampfes für eine höhere Teilhabe der Frauen an der Politik. Vor allem aber machte die geringe Aktionsfähigkeit den Deutschen Frauenrat für die ASF unattraktiv. Durch seine große Mitgliederzahl, den Zusammenschluss gegensätzlichster Strömungen und durch seinen „Einstimmigkeitsgrundsatz“ war er kaum zu öffentlichen Stellungnahmen fähig. ${ }^{323}$ Vorrangig stellte er ein Forum für den Informationsaustausch und die Präsentation einzelverbandlicher Interessen dar (vgl. dazu Lenz 2008: 517-522). Allerdings gab es Anzeichen für eine Mobilisierung des DF. 1978 schloss sich er sich einer Beschwerde Alice Schwarzers gegen den Deutschen Presserat an. Die Beschwerde sah vor, der Zeitschrift Stern ${ }^{324}$ eine Rüge wegen sexistischer Titelfotos zu erteilen. Solche Annäherungen von Frauenverbänden und autonomen Frauenbewegungen blieben im DF allerdings Ausnahmen. Mehrheitlich dominierten konservative Frauenverbände den Verband (vgl. Stoehr/Pawlowski 2001: 74). Als sich der DF aber dem Thema „Unterrepräsentanz von Frauen im Parlament" erneut widmete und dazu 1986 Öffentlichkeitsaktivitäten und eine öffentliche Anhörung organisierte,

323 Die Studie des Bundesministeriums für Familie, Senioren, Frauen und Jugend über den Deutschen Frauenbund von 1996 dokumentiert die relative Unzufriedenheit der Mitglieder mit der Verbandsarbeit (vgl. Schreiber 1996).

324 Der Stern hatte im Juni 1971 Alice Schwarzer beim Kampf für straffreie Abtreibung mit einer Dokumentation von Abtreibungsbekennerinnen als Aufmacher unterstützt. 
entschied sich die ASF zu einer dauerhaften Kooperation. Ab 1987 beteiligten sich ASF-Bundesvorstandsmitglieder an der Antragskommission zur Vorbereitung der DF-Konferenzen. Als Mitglied des Deutschen Frauenrates nahmen ASF-Frauen bereits im Juni des gleichen Jahres als Beobachterinnen an der Weltfrauenkonferenz teil.

Kooperation und Vernetzung mit den feministischen Akteurinnen außerhalb der Partei

Für die politische Positions- und Politikentwicklung der Arbeitsgemeinschaft pflegten die ASF-Führungsfrauen den Kontakt zu Wissenschaftlerinnen. Damit nutzten sie die Professionalisierung der Frauen- und Geschlechterforschung an den deutschen Universitäten, an denen ab Mitte der 1980er-Jahre die ersten Lehrstühle für Frauenforschung eingerichtet wurden. ${ }^{25}$ Ein solcher Einbezug parteifremder Expertise war in der SPD nach den Berichten einer Zeitzeugin in dieser Zeit keineswegs üblich (vgl. Zz 5). Juristinnen arbeiteten für die ASF an dem Entwurf für ein Antidiskriminierungsgesetz, feministische Ingenieurwissenschaftlerinnen und Informatikprofessorinnen waren in die Diskurse über Informationstechnologie für Frauen, feministische Medizinerinnen und Naturwissenschaftlerinnen in die zur Bio- und Gentechnologie eingebunden. Alle Expertinnen nahmen an Fachtagungen und an der Erarbeitung von politischen Stellungnahmen teil. Die Ergebnisse wurden in der Reihe Frau und Gesellschaft veröffentlicht.

Dagegen verliefen die Kooperationsbeziehungen zu den autonomen Fraueninitiativen konfliktreicher und meist eher auf kommunaler Ebene. Das velvet triangle aus feministischer Forschung, Politik und außerparlamentarischer Bewegung stieß auf vielerlei Hürden. Die Berufspolitikerinnen, so Barbara Holland-Cunz, wurden der „Bevormundung und illegitimen Stellvertreterinnenpolitik“ (vgl. Holland-Cunz 2003: 166) verdächtigt, weil sie im Namen aller Frauen sprachen. Sie sorgten nach Ansicht der nichtinstitutionellen Frauenpolitikerinnen aber nicht für eine transparente Reflexion und Öffentlichkeit ihrer Politiken, sodass sich die basisdemokratischen Aktivistinnen übergangen oder überredet fühlten. Die Gleichstellungsbeauftragten waren meist in Verwaltungsroutinen involviert und wenig zugänglich für Impulse und neue Idee von außen, die autonomen Projekte fanden bei ihnen häufig schwer Gehör. Sie und die Aktivistinnen der autonomen Frauenprojekte traten sich nach Margrit Brückner vielfach wie Kontrahentinnen gegenüber (vgl. Holland-Cunz 2003: 166; Brückner 2000: 89f.). 
Anfang der 1970er-Jahre trennte eine tiefe Kluft die Parteifrauen und die autonomen Frauengruppen. „Bei Worten wie Patriarchat, Diskriminierung und Unterdrückung von Frauen bekamen die Genossinnen eine Gänsehaut“, so Barbelies Wiegmann (Wiegmann 1991, zit. n. ASF o. J. \{1992\}: 160.). Im Laufe der Politisierung der ASF, der wachsenden Zahl frauenbewegter Neumitglieder und deren persönlicher Involviertheit in die Projektphase der autonomen Frauenbewegungen entwickelten sich trotz der Vorbehalte, Missverständnisse und des Misstrauens pragmatische Kooperationsbeziehungen. Viele autonome Frauenprojekte wie Frauenhäuser, Gesundheits- und Beratungszentren wären ohne sozialdemokratische Ratsfrauen nicht auf den Weg gekommen oder hätten sich nicht erhalten können. Obwohl die Sozialdemokratinnen mehrheitlich nie die Forderung nach ersatzloser Streichung des § 218 unterstützten, war es besonders die Sozialdemokratie nahe AWO, die ab März 1983 mit der Eröffnung von Schwangerschaftskonfliktberatungszentren dafür sorgte, dass schwangere Frauen auch unter der Regierung Kohl Unterstützung erhielten und auf legalem und ärztlich betreutem Weg eine Schwangerschaft beenden konnten.

In den Erinnerungen der Zeitzeuginnen spiegelte sich die Distanz der Sozialdemokratinnen zu den autonomen Frauenaktivistinnen. Auch wenn immer mehr Sozialdemokratinnen die Kritik an den herrschenden Geschlechterverhältnissen - auch in der eigenen Partei - teilten, blieben ihnen die streng separatistische Politikorientierung, die lockeren Organisationsformen und die oft undiplomatischen Formen der Interessensartikulation der autonomen Frauengruppen fremd. Eine Zeitzeugin erzählt von differenten Welten:

[E]s gab auch die eine oder andere gemeinsame Veranstaltung; man besuchte auch Veranstaltungen wechselseitig, das war keine totale Abschottung, aber es gab schon auch wechselseitige Vorbehalte gegenüber denen, die in völliger Ungebundenheit ihre ... also und auch keine Verantwortung übernehmen wollten - so haben wir das gesehen - ihre Forderungen vortrugen, die zu Teilen ja auch identisch waren mit unseren, und die Vorbehalte umgekehrt gegenüber diesen Gremienfrauen, die sich da die Zeit in diesen Gremiensitzungen um die Ohren schlagen, und wir wurden ja total auch verachtet, muss man sagen, von der autonomen Frauenbewegung. Nur das war für uns keine Kategorie, weil, wenn man was durchsetzen will, dann muss man dabei sein und mit am Tisch sitzen. ( $\mathrm{Zz} \mathrm{6)}$

Eine andere Zeitzeugin erinnert sich mit unguten Gefühlen an die Kooperationen zur Realisierung eines Frauenhauses in der Stadt: 
[D]ie autonomen Frauen haben mitgemacht, allerdings hatten die autonomen Frauen aus meiner Sicht ja damals eine ganz merkwürdige Art und Weise. Wenn sie einen Menschen aus irgendeinem Grund nicht leiden konnten, dann haben sie den ja so kaputtgeredet und am Ende noch drauf herumgetrampelt. Also, wir haben schlechte Erfahrungen mit den autonomen Frauen gemacht. (Zz 12)

Ende der 1970er-Jahre planten einige feministische Führungsfrauen aus dem ASF-Bundesvorstand, ihre Position in der ASF zu stärken und den Kontakt zu den autonomen Frauenbewegungen zu intensivieren. Im April 1978 luden sie deshalb 40 Fraueninitiativen aus unterschiedlichen Bereichen wie Beratung, Gastronomie, Buchhandel u. a. zu einem bundesweiten Treffen ein, um über Kooperationsperspektiven zu diskutieren und die politische Auseinandersetzung zu suchen ${ }^{326}$. Auch sollten die Konkurrenzen zwischen Parteifrauen und autonomen Frauengruppen abgebaut werden und engere Kooperationsbeziehungen verhindern, dass die ASF weiterhin Aktivistinnen aus der Parteiarbeit an die praxisorientierten feministischen Projekte verlor. ${ }^{327}$ Aber das Treffen blieb ergebnislos, die beiden Seiten verloren sich im gegenseitigen Unverständnis. Die Parteifrauen kritisierten die feministischen Gruppen als interessenspartikular und zu wenig gesellschaftsbezogen und warfen ihnen mangelnden „Mut zur Macht“ vor (vgl. Pausch-Gruber 1978). Die autonomen Frauen bemängelten bei den Parteifrauen eine zu geringe Kritikbereitschaft und Handlungsfähigkeit. ${ }^{328}$ Eine autonome Lesbenzeitung

326 Dazu Bundesvorstandsmitglied Ursula Pausch-Gruber: „Daß der psychologische Ansatz der Frauenfrage damit verstärkt beachtet wird, ist erfreulich; daß er sich in einigen Gruppierungen dieser Bewegung weitgehend verselbstständigt hat, ist bei der Anziehungskraft dieser Frauengruppen auf jüngere Frauen eine ernstzunehmende Konkurrenz für die sozialdemokratische Frauenbewegung. Auch die Gesamtpartei muß die Gefahr sehen, denn mit dem Verlust des ökonomischen Ansatzes der Frauenfrage wird die Grundlage der Solidarität zwischen der arbeitenden Bevölkerung und den Frauen gefährdet." (Pausch-Gruber 1978: 87)

327 Vgl. dazu Antrag E1 Selbstverständnis der ASF, Bundesfrauenkonferenz 1981. Darin heißt es, dass Frauen vermehrt ihre Aktivitäten in autonome Frauengruppen verlagerten, weil sie in der Partei zu wenig erreichen könnten (vgl. Dokumente 14/1981). Ähnlich erklärte der ASF-Bundesvorstand in seinem Rechenschaftsbericht 1981 das schwindende Engagement „ehemals aktiver Genossinnen“. Sie engagierten sich eher in autonomen Frauengruppen oder zögen sich gänzlich ins Private zurück, weil sie die Erfahrung machten, dass die SPD als Partei oder Fraktion nur auf den Druck von außen reagiere, nicht aber auf die Initiativen der eigenen Frauenorganisation (vgl. Rechenschaftsbericht 1981: 16).

328 „Angst hat sich ins Vertrauen auf Parteimacht geflüchtet“ (Schöfthaler 1978 zit. n. Courage 3/1978: 19). 
bilanzierte: „Auf beiden Seiten herrschte Skepsis“ (E.R. 1978: 29) Im damaligen ASF-Bundesvorstand war diese Initiative aus dem eigenen Kreis mit wenig Sympathie begleitet worden, im mündlichen Rechenschaftsbericht der Bundesvorsitzenden Elfriede Hoffmann auf der folgenden Bundeskonferenz 1979 wurde das Apriltreffen nicht einmal erwähnt (vgl. Rechenschaftsbericht 1979).

Eine ähnliche Initiative kam kein weiteres Mal zustande, aber informell und durch Veranstaltungsbesuche ${ }^{329}$ wurden die Kontakte von einzelnen Bundesvorstandsfrauen weiter gepflegt, wie eine der Zeitzeuginnen erzählte:

Also, die Zeit war damals auch sehr aufgewühlt und also ... ich hab das auch immer zusammen mit den autonomen Frauen und Frauengruppen und ich weiß nicht wem allem gemacht, ich hab also schon immer diese ... versucht, dass dieser Dialog irgendwie weiterging, weil niemand hatte ja eine endgültige Position. (Zz 7)

Der Ausbau einer Kooperation mit den autonomen Frauenbewegungen wurde durch eine Aktion des Frauenbüros im Parteivorstand, das den feministischen Strömungen in der ASF überaus kritisch gegenüberstand $3^{3{ }^{\circ}}$, Anfang 1980 endgültig zerstört. Auf der Frauen-Herbstuniversität in Berlin 1979 war über einen Wahlboykott der Bundestagswahlen 1980 diskutiert worden, um die Parteien zu einer stärkeren Wahrnehmung frauenpolitischer Interessen zu zwingen (vgl. Hempel-Soos 1980; Pausch 1985: 222f.). Im März 1980 erschien eine Sonderausgabe Wahlboykott? der Zeitschrift Emma, deren Leserinnen nach eigener Umfrage die SPD bei den Bundestagswahlen 1976 mit 71,2 \% unterstützt hatten. In dieser Sonderausgabe mahnte Alice Schwarzer das „bankrotte Stellvertreterprinzip“ an und befand, „daß die Frauen in der SPD, verglichen mit Frauen in anderen Parteien, die geducktesten und angepaßtesten sind" (Recher/Schwarzer/Strobl 1980: 50). Eine Podiumsdiskussion zum Thema „Wahlboykott“, die der ASF-Bundesvorstand daraufhin organisierte, wurde von Alice Schwarzer boykottiert. Als Antwort auf die Son-

329 Gesprächsrunden zum Feminismus im April und November 1979, Teilnahme am Tribunal zum § 218 in Frankfurt (vgl. Rechenschaftsbericht 1981: 24).

330 „Teile der ASF stehen der Emma-Ideologie völlig unkritisch gegenüber“, kritisiert Anni Jansen in einem Brief an Egon Bahr vom 02.10.1980 (AdsD SPD PV: 9615). 
derausgabe veröffentlichte SPD-Frauenreferentin Anni Jansen im Vorwärts einen Artikel ${ }^{331}$, der Alice Schwarzer „kommerziellen Feminismus“332 vorwarf, und gab eine Presseerklärung heraus mit dem Schmähtitel „Die Ziege als Gärtnerin“333 sowie eine Wahlinformation mit dem Titel „Das Märchen vom Wahlverhalten der ,progressiven Frauen“" (SPD o. A. $\{1980\}$. Diese war auch von der ASF-Bundesvorsitzenden Elfriede Hoffmann für die ASF unterzeichnet worden334. Die Aktionen des Frauenbüros riefen innerhalb der ASF und in verschiedenen anderen SPDOrganisationseinheiten eine Welle der Empörung hervor. Wütende Protestschreiben 335 gingen beim Parteivorstand ein, manche mit Unterschriftensammlungen, auch verschiedene Bundestagskandidatinnen schlossen sich dem Protest an.

Als die ASF-Bundesvorsitzende Elfriede Hoffmann das beschlossene öffentliche Dementi des ASF-Bundesvorstands verschleppte, wurde von ihr verlangt, zurückzutreten ${ }^{336}$. Im Oktober 1980 setzte der ASF-Bundesvorstand die stellvertretenden Vorsitzenden Ursula Pausch-Gruber und Inge Wettig-Danielmeier zu kommissarischen Leiterinnen ein, die folgende Bundesfrauenkonferenz im Juni 1981 wählte Inge Wettig-Danielmeier zur neuen Vorsitzenden. Eine Gegenkandidatin hatte sich nicht zur Wahl gestellt (vgl. Pausch 1985: 226-228; Rechenschaftsbericht 1981). Möglicherweise trugen diese Turbulenzen zu dem zeitweiligen Rückgang der weiblichen Mitgliederentwicklung bei: 1981 war das einzige Jahr, in dem die Zahl der weiblichen Mitglieder in der Partei vorübergehend schrumpfte ${ }^{337}$.

331 Vorwärts, Nr. 32 vom 31.06.1980: 9.

332 Alice Schwarzer hätte die Wahlboykottdebatte nur aufgegriffen, um neue Leserinnenschichten zu gewinnen, die sie mit dem „Sexkram“ ihrer Zeitschrift bisher nicht hätte erreichen können (SPD o. A. \{1980\}: 7).

333 Auch abgedruckt in parlamentarisch-politischer pressedienst, 31 (105) vom 10.09.1980.

334 In den Texten wurden auch die Aktivitäten Alice Schwarzers kritisiert, die von der ASF unterstützt worden waren, wie u. a. die Selbstanzeigenkampagne zum § 218 der Zeitschrift Stern „Ich habe abgetrieben“ im Jahr 1976 und die Klage gegen den Stern wegen eines Titelfotos aus dem Jahr 1978. Gezeigt wurde ein Foto Helmut Newtons mit der gefesselten und nackten Künstlerin Grace Jones.

335 Aus einem Schreiben eines Parteimitglieds an den Parteivorstand vom 22.09.1980: „Der Gipfel ist es, daß ohne Wissen der ASF in deren Namen Wahlkampfinfos herausgegeben werden, die Frauen auf Frauen hetzen. Das grenzt schon an Faschismus [...] Ich komme auch langsam zu der Überzeugung, daß die SPD eine ,MännerPartei‘ ist, welche die neue Frauenbewegung nicht aufzunehmen versteht. D. h. die SPD wünscht politisch unmündige und beherrschbare Frauen. Daher ist sie gerade von den politischen Frauen nicht mehr wählbar." (AdsD SPD PV: 9615)

336 Elfriede Hoffmann akzeptierte diese Rücktrittsaufforderung, sie war gerade zum Mitglied des geschäftsführenden Hauptvorstandes der HBV ernannt worden.

337 Die Mitgliederverluste bei den Frauen lagen mit 9.313 (1981) fast $20 \%$ über denen von 1980 (7.893) und 1982 (7.394) (vgl. Boyer/Kössler 2005: 140). 
Nach der Übernahme der ASF-Leitung durch ASF-Feministinnen fanden Themen der autonomen Frauenbewegung mehr Resonanz in der ASF. Bundesweite Veranstaltungen, Tagungen, Werkstätten und Podiumsdiskussionen zur sozialen Situation und Lebenswelt von Lesben, zur Rechts- und Lebenssituation von Migrantinnen, zu Sextourismus und Menschenhandel und zu Leben und Sexualität im Alter wurden organisiert. Engere Kooperationen wurden jedoch nicht angestrebt. „Die Forderungen der autonomen Frauengruppen sind unübersichtlich und ohne gemeinsame Durchsetzungsstrategie“, bilanzierte ein Diskussionspapier des Bundesfrauenausschusses Feminismus - Konservatismus im März 1981 (SPD-Parteivorstand 1981: 2). Dem Streit zwischen den verschiedenen Strömungen der Frauenbewegungen stand die ASF-Führung distanziert gegenüber. Als 1987 das Müttermanifest ${ }^{338}$ erschien, das sich gegen die enge Verbindung von Emanzipation und Erwerbstätigkeit wandte und sich für eine neue politische und soziale Anerkennung der Mutterschaft einsetzte, suchte die ASF auch hier den Dialog und erklärte, dass viele Forderungen des Müttermanifests „wortgetreu den von der ASF jahrelang gestellten Forderungen" (Rechenschaftsbericht 1987: 7) entsprächen, obwohl die Manifestlerinnen die sozialdemokratische Gleichstellungspolitik in ihrer Grundsatzerklärung als "Ghetto der Nichtmütter“ und „Aquarium der Karrierefrauen“ (Müttermanifest zit. n. Lenz 2008: 625) diffamiert hatten.

\subsection{Kollektivbildung, neue Aktionsformen und politische Lager339}

Die sozialdemokratischen Aktivistinnen der 1970er- und 1980er-Jahre fühlten sich in der Partei mit männlicher Dominanz konfrontiert und klagten die alltäglichen Ungleichbehandlungen als Folgen einer hierarchischen Geschlechterordnung an. Das Agieren der männlichen Funktionäre und Mitglieder empfanden viele Genossinnen als diskriminierend. Dies bildete ein Grundelement der „Frauensolidarität“, einer kollektiven Identität der ASF-Frauen. Nach den Geschichtsschreibungen der Partei

338 Mitautorin war Gisela Erler, Mitglied der Grünen und Mitbegründerin des Trikont-Verlags und dem daraus ausgegründeten und ältesten Frauenverlag in Deutschland, der Frauenoffensive.

$339 \mathrm{Zu}$ diesem Thema erschienen mehrere Studien zu den Erfahrungen deutscher Politikerinnen: Schöler-Macher 1994; Sauer 1994; Schaeffer-Hegel 1990; Meyer 1988; Dackweiler 2007; Hagemann-White 1987; Holland-Cunz 1994, 1999; Biester/HollandCunz/Sauer 1994; Lang 1997, 1989, 2004; Schenk 1990; Hervé 1987; Penrose 1996; Lepsius 1987; Henninger 2005; Baer/Kletzing 2004; Hoecker 1995, 1998, 2008b; Marquardt 1999; Knapp 1995; Götte 1991; Edinger 2005; Notz 2003; Clemens 1996. 
werden die Entwicklungen der ASF als radikaler Generationenwechsel beschrieben, in dem junge hochqualifizierte Berufstätige die parteiführungstreuen, meist über die Ehemänner an die Partei gebundenen Hausfrauen aus der Frauenorganisation und ihren Gremien verdrängten (vgl. z.B. Lösche/Walter 1992; Faulenbach 2012: 314-321) Mit diesem Erzählmuster wird aber übersehen, dass Ausschließungserfahrungen und Diskriminierungserlebnisse in der Partei eine breite, generationenübergreifende Verständigung schaffen konnten. Zwar blieb die ASF in den 1970er-/8oer-Jahren durch große politische Lager und vielerlei Strömungen hoch fragmentiert, doch trotzdem fand die neue Generation von ASF-Aktivistinnen auch bei den langjährigen Mitgliedern eine wachsende Unterstützung.

Ziel der frauenpolitischen Aktivistinnen war es, veränderungswürdige Missstände zu identifizieren, diese Ungleichheit als Ungerechtigkeit in das Bewusstsein der Partei zu bringen und einen Anspruch auf politische Partizipation durchzusetzen. Dabei wurden geschlechtliche Zuschreibungen nicht generell als Diskriminierung abgelehnt. Manche soziale „weibliche“ Eigenschaften nahmen die ASF-Aktivistinnen in die eigenen Argumentationen auf, z. B. die stärker integrative Diskussionsweise der Frauen gegenüber der auf Konkurrenz und Selbstpräsentation ausgerichteten Kommunikation der Männer oder die besser ausgeprägte Friedensorientierung und Lebensweltausrichtung. Sie wurden als Begründungen für eine angemessene Präsenz der Frauen in den Verhandlungsstrukturen der Politik genutzt.

In den Frauenarbeitsgemeinschaften fanden die frauenpolitischen Aktivistinnen der SPD Selbstvergewisserung und Selbstermächtigung. Solche Orte bezeichnet Dagmar Schultz in Anlehnung an Carol Hagemann-White als kulturelle Zwischenwelten. Sie beschreibt dieses Phänomen in einer Studie über Nachwuchswissenschaftlerinnen an Universitäten. Konfrontiert mit einer Arbeitswelt, die von Geschlechterhierarchien geprägt ist, entwickelten die jungen Akademikerinnen auf ihrem Karriereweg und zur Etablierung in hochqualifizierten Positionen Rückzugs- und Reflexionsorte, sog. kulturelle Zwischenwelten, mit denen sie sich ein Sinn stiftendes, ,zusammenhängendes Konstrukt von Sicht- und Handlungsweisen im Rahmen widersprüchlicher Lebens- und Arbeitsbedingungen" (Schultz 1992: 239) verschafften. Für die Zeitzeuginnen stellte die ASF diese Orte zur Verfügung ${ }^{34^{\circ}}$, in denen die Frauen besondere Weltsichten entwickelten. Diese basierten auf der kollektiven Rahmung individueller, gemeinsamer und kolportierter Sozialerfahrungen.

34011 der 15 Zeitzeuginnen berichten davon, dass sie in den Frauenarbeitsgemeinschaften den Rückhalt und die Selbstsicherheit fanden, gegen die in der Partei herrschenden Ablehnungen und Ausgrenzungen anzugehen. 
Diese Erfahrungen führten die verschiedenen Strömungen und Interessengruppen in der ASF mit ihren je unterschiedlichen Erwartungen an eine sozialdemokratische Frauenpolitik zusammen.

Nachdem zunächst die Parteiloyalität der weiblichen Parteimitglieder unerschütterlich zu sein schien, erklärte der ASF-Bundesvorstand bereits Ende der 1970er-Jahre die Mehrheit der ASF-Frauen zu einer kollektiven Opposition (vgl. Roth 1998a). Im Sozialdemokratischen Pressedienst vom Juli 1981 berichtete die ASF, dass die Probleme zwischen den „Männer-Vorständen“ (Wettig-Danielmeier 1981: 5) der Partei und der Frauenorganisation zunähmen und sich unter den Frauen eine ähnlich kritische Bewegung wie in der Parteijugend entwickelte.

Intern versuchten die ASF-Gruppen, basisdemokratische Arbeitsformen zu entwickeln, und für ihre nach außen gerichteten Aktionen übernahmen die ASF-Aktivistinnen Politikformen der Neuen Sozialen Bewegungen. Mit solchen neuen internen und externen Kommunikationsformen wollten die Frauen die in der Partei üblichen hierarchischen Interaktionsprozesse kritisieren und sich nach außen von den förmlichen Politikpräsentationen der SPD absetzen.

\subsubsection{Diskriminierungserfahrungen}

Alle Zeitzeuginnen berichteten von persönlichen Diskriminierungserlebnissen. Der Geschlechterkonflikt überblendete in den Erinnerungen die besonderen Konfliktanlässe, persönlichen Motivlagen und Umstände. Er bildete ein elementares Erfahrungsmuster in der Wahrnehmung und im politischen Selbstverständnis der Zeitzeuginnen.

In den Zeitzeuginnenberichten lassen sich drei unterschiedliche Ausschließungsformen erkennen: Erstens entstanden manche Ausschlüsse aus den Routinen hegemonialer Männlichkeit. Hier wurden Zugangschancen mit männlichen Geschlechterattributen verknüpft. Exklusionen waren bei diesem Ausschließungshandeln nicht beabsichtigt, sondern in tradierten parteiinternen Verfahren eingelagert, nach denen sich Männer wie Frauen richteten (vgl. Cyba 2000: 93-190). Dagegen können zweitens solche Diskriminierungshandlungen als aktives "doing masculinity“ (vgl. Meuser 1998) gelten, in denen Personen als „Token“341 behandelt und mithilfe von stereotypen Geschlechterbildern oder geschlechtsspezifischen Erwartungen ausgegrenzt wurden. Es wurde drittens von den Zeitzeuginnen aber auch von offensiv-aggressiven Ausschließungshandlungen berichtet, mit denen Frauen als potenzielle Konkurrentinnen demoralisiert oder durch Verspotten und Beleidigen sozial isoliert werden 
sollten. Die unterschiedlichen Erzählungen bezogen sich nicht auf bestimmte Männertypen, Regionen oder politische Lager der SPD. Die Zeitzeuginnen betonten vielmehr die Gängigkeit solcher Strukturen und die Verbreitung ausschließender Handlungen in der gesamten Partei.

In der folgenden Darstellung illustrieren die Interviewtexte die subjektive Verarbeitung solcher Ausschließungserfahrungen. Die Zeitzeuginnen präsentierten dabei in ihren Erzählungen typische Diskriminierungsformen der männlichen Mehrheit gegenüber den Frauen in der SPD der 1970er- und 1980er-Jahre.

Eine Analyse der Diskriminierungsebenen zeigt die Bedeutung dieser Erfahrungen und das Konfliktpotenzial, das diese Erfahrungsmuster beinhalteten.

Individuelle Missachtungserlebnisse wurden von den ASF-Aktivistinnen ursächlich mit der mangelnden Präsenz von Frauen in politischen Funktionen verkoppelt - und mit der Geringschätzung von familien- und frauenpolitischen Themen in der Politik.

\section{5·3.1.1 Geschlechterasymmetrische Zugänge}

Bis in die 1980er-Jahre waren die Wahlen von den in der Partei stark vertretenen Beschäftigten- und Gewerkschaftsgruppen dominiert, die KandidatInnen und Listenplatzverteilungen untereinander aushandelten. Frauen waren in diesen Berufsbereichen und -hierarchien unterrepräsentiert. Da sie in der Partei auch keine alternative Hausmacht besaßen, mussten sie - nach Meinung der meisten Zeitzeuginnen - für ihre Wahlchancen mehr politisches Profil und Engagement aufbieten können als ihre männlichen Konkurrenten (vgl. dazu auch Hoecker 1987b; Bothmer 1976). Eine Zeitzeugin schildert diese Struktur:

Also, wir hatten in den großen Wahlgremien, wenn also dann die Kandidaten gewählt wurden, dann hatten wir die IG Metall und die IG Bergbau und die ,IG Stadtverwaltung' (lacht), die hatten wir; und die hatten untereinander eine Quote, die hatten sich schon abgesprochen; also die ... wer da mitschwamm, der hatte einen sicheren Platz, war also vollkommen klar. Und eine Frau brauchte immer eine Querbeet-Mehrheit; das heißt, sie musste ... außerhalb dieser Ströme musste sie bekannt sein, sie musste gut sein, sie musste ihr Wort machen, dann hatte sie ... wurde sie gewählt - aber nur DANN ( $\mathrm{Zz} 1)$.

Hatten einzelne Frauen die Aufnahme in ein parteiinternes Gremium geschafft, fühlten sich viele auch weiterhin in den Gremien ausgeschlossen, weil männerbündische Gemeinschaftlichkeit, für die die Abwesenheit 
von Frauen konstitutiv ist, die informellen Netzwerke und Kommunikationskanäle prägten ${ }^{342}$. Mit drastischen Schilderungen beschrieb eine Zeitzeugin ihre Wut über die intransparenten Absprachen und Entscheidungswege:

[W]ir Jüngeren hatten ja den Eindruck, wenn wir nur unsere Arbeit gut machten, dann würden wir auch akzeptiert und anerkannt, und die gute Arbeit würde anerkannt. Das ist nicht so. Das kann ich auch rückwirkend sagen, ne? Das ist nicht so. 'Ne Frau ist 'ne Frau, und das Schlimmste ist, dass wir nicht während einer Sitzung mit dem anderen mal eben im Stehen pinkeln gehen können, ne? Da wird ja wer-weiß-was beschlossen. Und wenn Sie die einzige Frau sind, sind Sie immer draußen - immer. (Zz 12)

\subsubsection{Marginalisierende frauenspezifische Zuschreibungen}

Ausschließungshandlungen können auf kulturell legitimierten Mustern der Diskriminierung beruhen; dabei wird die betroffene Person als VertreterIn einer besonderen Gattung (tokenism) behandelt. Mehrere Zeitzeuginnen berichteten von einer gängigen Ungleichbewertung der RednerInnen, wobei die Frauen grundsätzlich als weniger kompetent angesehen und ihre Redebeiträge weniger beachtet wurden als die der Männer:

[W]enn eine Frau was sagt, nehmen Männer das nicht so schrecklich ernst. Es kommt in Gremien immer noch vor, ne? Frau macht eine kluge Bemerkung oder bringt ein wichtiges Argument, keine Reaktion. Eine halbe Stunde später wird das Gleiche von einem Mann gesagt: ,Ja, ja, da haben Sie Recht'. (Zz 10)

Als typisches abwertendes Verhalten gegenüber Rednerinnen beschrieb eine andere Zeitzeugin die ungeduldigen Reaktionen der männlichen Anwesenden. Dieser Umgang schien ihr auch deshalb so gravierend, weil sich nur wenige Frauen trauten, sich zu Wort zu melden:

[I]ch hab ja auch damals, als ich an den ersten Stadtverbandparteitagen teilgenommen habe ... ja, wenn sich da mal eine Frau zu Wort gemeldet hat oder so in den 8oern oder Ende der 8oer, da wurde immer noch gesagt: ,Ach, jetzt muss die auch noch was dazu sagen', oder so (Zz 16). 
Eine andere Form der frauenspezifischen Marginalisierung schilderte Lenelotte von Bothmer bei der Kandidatenauswahl für Funktionen und Ämter. Hierbei wurden Beurteilungskriterien für weibliche Politiker aufgestellt, die für Männer keine Rolle spielten wie z.B. „die ist doch geschieden" (deswegen vermutlich wenig umgänglich und vertrauenswürdig) oder „sieht sie wenigstens gut aus?“ (und ist somit als Parteirepräsentantin attraktiv). Oder die Eignung der Kandidatin wurde an Ressourcen gebunden, die Frauen weniger zur Verfügung standen, wie die Erreichbarkeit während des Tages und ein eigenes Telefon am Arbeitsplatz (Bothmer 1976).

Bei der Besetzung von Führungspositionen kamen nach Ansicht einer Zeitzeugin Frauen vor allem für die subalternen, arbeitsintensiveren Posten in die Wahl:

Also, wenn's um Bundestagsmandate ging, wenn's um Landtagsmandate ging, wenn's um irgendwelche höheren Positionen ging. Also, das klassische Gegenbild ist die Schriftführerin im Ortsverein oder eigentlich auf jeder Ebene. Also als Schriftführerin konnte man wirklich Karriere machen, man musste nur Schriftführerin bleiben, dann war man hochgeliebt und geschätzt, aber sobald man was anderes wollte, wurde es schwierig. (Zz 6)

Die Ausgrenzung von Frauen in Bewerbungsverfahren erklärte eine Zeitzeugin mit dem geschlechterselektierenden Blick, der in männlich dominierten Organisationen vorherrsche:

Das habe ich immer wieder festgestellt. Und Männer sehen Frauen nicht. Wenn es z.B. um die Besetzung einer Stelle geht, insbesondere einer Führungsstelle, sie gucken gar nicht auf die Frauen, die es da gibt, die sehen die gar nicht, die sehen nur die Männer. (Zz 10)

Die ASF der 1970er-Jahre war überzeugt, dass eine enge Verbindung zwischen den Zugangshürden für Frauen zu attraktiven Ämtern und dem Desinteresse der Partei an frauenpolitischen Themen bestand; deshalb erwarteten die Sozialdemokratinnen, dass sich mit einer zunehmenden Würdigung frauen- und familienpolitischer Themen gleichzeitig die politischen Karrierewege für Frauen öffnen würden. Die Zeitzeuginnen berichteten aber, dass der Konkurrenzkampf weiterhin hart war und „in der Regel blieben die Frauen zweite Sieger" (Zz 6).

[D]er Unterschied zwischen Emanzipation im Kopf und praktischer Gleichberechtigung war weit verbreitet. Dieses habe ich in den Gremien der SPD-Bundestagsfraktion und auch des Vorstandes häufig wiedergefunden. (Zz 8) 
Die ungleichen Chancen der Frauen wurden in der Partei, so erklärte eine Zeitzeugin, nicht als Ergebnis von Diskriminierungsakten wahrgenommen, sondern als Folge gesellschaftlicher Verhältnisse:

[D]as war ja auch immer die Krux. Dass die Situation der Frauen immer mit ihrer Rolle begründet wurde und von daher eine Ungleichheit gar nicht als Ungleichheit wahrgenommen wurde von den Frauen schon, aber nicht in der allgemeinen Wahrnehmung -, sondern es wurde mit der Rolle begründet oder entschuldigt. (Zz 14)

\subsubsection{Offensive Ausschließungspraktiken}

Acht Zeitzeuginnen ${ }^{343}$ schilderten Diskriminierungspraktiken, die sie zwar als besonders empörend, aber auch als typisch bewerteten. Diese Erlebnisse stammten aus parteiinternen wie aus öffentlichen Versammlungen und beschrieben aktiv ignorierendes bis aggressives Ausschließungsagieren. Bei ihren Berichten ging es den Zeitzeuginnen nicht nur um die konkrete Beleidigung oder Erniedrigung, sondern um eine Darstellung des Klimas und um die Billigung oder sogar Unterstützung der Ausschließungsakte durch Andere.

Eine Zeitzeugin schilderte die Geste eines Parteiführungsmitglieds auf dem Münsteraner Parteitag 1988, der sich nach ihrer Vermutung über die Quote und den Erfolg der ASF ärgerte, als Beispiel für ein solchermaßen aggressives Agieren:

[A]lso, die Aachener Frauen, es war da in Münster und die Aachener Frauen waren auch gekommen - es waren viele Frauengruppen gekommen, weil das ja nun anstand -, und die Aachener Frauen hatten Aachener Printen mitgebracht und jedem Delegierten so ein kleines Printenpäckchen hingelegt und gesagt: ,Wir bitten um Deine Unterstützung. Die ASF aus Aachen'. [...] Ich geh aufs Podium, also aufs Podium, der Vorstand saß ja immer so 'n bisschen höher. Da kommt mir der [Name ausgelassen,S.E.] entgegen und sagt mir nicht ,Guten Tag' oder irgendwas, schmeißt mir so ein Paket vor die Füße und sagt: ,Ungenießbar wie diese ganze ASF.' Ich sag das nur mal so, so waren die Umgangsformen ( $\mathrm{Zz}$ 5).

Als männlichen Machtmissbrauch werteten Zeitzeuginnen, dass für Männer die Geschlechtszugehörigkeit nur bei ihnen selbst zur schützenswerten Intimsphäre gehörte, bei Frauen jedoch nicht. Sie fühlten 
sich als Frau stets vergeschlechtlicht. Die Aufmerksamkeit richtete sich nicht auf ihre Qualitäten als Genossinnen und Politikerinnen, sondern wurde begleitet oder bestimmt vom männlichen Blick auf vermeintliche geschlechtliche Eigenschaften und Beziehungseignungen, auf ihre erotische Ausstrahlung und ihren Körper. Eine Zeitzeugin erläuterte dies anhand von Bemerkungen, mit denen sie konfrontiert war, wie „Schreckgespenst" oder "mit so einer Frau möchte ich nicht verheiratet sein“ (Zz 5). Eine andere Zeitzeugin erzählte vom ersten Bericht der Frauenbeauftragten im Landtag. Die Reaktionen aus den Reihen der Parlamentarier empfand sie als typisch für das damalige Klima kollektiver Missachtung:

[D] as war wie in so einem Bienenhaufen von halbwüchsigen, halb besoffenen Gymnasiasten mit ihren Zoten und ihren Bemerkungen, es war irre, eine Stimmung ... oder wie im Offizierskasino, ne (?), wo man Zoten reißt, so haben die das Thema auch angegangen, aufgefasst, und ich musste da reden, logischerweise, es war ja mein Bier. Dann, wie ich zurückkam auf meinen Platz, lag da ein Zettel ,Wenn die Frauen verblühen, verduften die Männer', so [...] in diesem Ton ging das - die ganze Zeit [...] quer durch über alle Fraktionen. (Zz 9)

Der respektlose Umgang der Männer mit Frauen in den innerparteilichen und parlamentarischen Gremien wurde von den männlichen KollegInnen nicht als Diskriminierung wahrgenommen, berichtete eine Zeitzeugin:

Zwischenruf [...]: ,Sie sehen auch besser aus, als Sie reden.' Und weil's so lustig war, noch einmal, ja (?), und dann bin ich zu ihm hin [...]: ,Sagen Sie mal, was fällt Ihnen eigentlich bei so was ein?', ja (?) und da hat er gesagt: ,Das war doch ein Kompliment.' Der hat das ernst gemeint, ja (?) (Zz 13).

Unerschüttert in ihren kulturellen Praktiken hegemonialer Männlichkeit hätten viele Männer auch die kritischen Stimmen nicht wahrgenommen, erläuterte eine Zeitzeugin:

[D]a habe ich extra mal eine Veranstaltung als Abgeordnete gemacht sonntags nachmittags mit Kuchen, damit sie ihre Frauen mitbrachten; brachten ihre Frauen auch mit; und einiges war ihnen gar nicht recht, was ich denen da in die Ohren trötete, von Selbstständigkeit und dergleichen - die Männer mein ich jetzt , und Fazit war, dass der Ortsvereinsvorsitzende sagte: [...] [D]a brauchst du dir gar keine Sorgen zu machen, bei uns das läuft schon richtig, wir sagen unseren Frauen schon, was sie wählen sollen.' (Zz 2) 
Frauen mussten auch mit männlichen Belästigungen rechnen, so eine Zeitzeugin, eine Zurückweisung habe man ihnen eigentlich nicht zugestanden:

Andere haben's probiert, bei mir persönlich privat zu landen ist ja eine Frau, gell (?), kann man ja probieren -, und wenn man da abgelehnt hat, hat man einen Feind auf Lebenszeit. Das erleben Männer logischerweise nicht, aber Frauen schon. (Zz 9)

Anhand von zwei Erlebnissen verdeutlichte eine Zeitzeugin, dass Männer selbst bei Akten der Demütigung auf eine breite männliche Komplizenschaft bauen konnten:

[D]ann sahen die Kollegen von der Union, wie sie da vorgeht, war ... Entwicklungspolitik, hat die was gesagt, haben die gesagt: ,Die ist bestimmt auch besser im Bett als in der Politik', ja (?), und das hört die noch, wie sie rausgeht, und ... oder die Lilo Blunk hat 5.00o Unterschriften zur Rettung des Wattenmeers dabei [...]... war am späten Abend, und man soll es auch nicht alles überbewerten, sagt: So, und jetzt, Herr Staatssekretär, möchte ich Ihnen jetzt die 5.0oo Unterschriften, die wir gesammelt haben zur Rettung des Wattenmeers, überreichen', und geht da rüber und das ganze Parlament, das ganze, nicht nur eine Fraktion, brüllt: ,Küsschen, Küsschen', ja (?) (Zz 13).

Eine Zeitzeugin berichtete von der Verhinderung ihrer Kandidatur, um zu illustrieren, mit welchen undemokratischen Abwehrhandlungen Frauen in der Partei konfrontiert werden konnten:

Ich war nominiert für den Bundestag, und es gab Festzusagen vom Bezirksvorstand, da ging es um einen sicheren Listenplatz, und auf dem Nominierungsparteitag kam dann auf diesen Listenplatz ein Mann, der den Wahlkreis in ... hinter Soest, Sassendorf da irgendwo in der Gegend, nicht abgesichert war, und ich rutschte also mehr nach hinten, und ich war wirklich die Kandidatin der Frauen, und die Frauen waren empört und haben versucht, mit dem Unterbezirks- und Bezirksvorstand ein Gespräch $\mathrm{zu}$ führen, und wir wussten, dass eine Sitzung stattfand, und wollten mit den Genossen sprechen, und die Genossen haben uns nicht reingelassen. [...] Das war 1975, '76, und ich war nicht die Einzige, der das passiert ist. ( $\mathrm{Zz} 4)$

Neun der elf Zeitzeuginnen, die selbst eine politische Karriere durchlaufen haben, hielten ein frauenpolitisches Engagement in der Partei in der Regel für karriereschädigend. 
Also, ich denke, dass also viele Frauen, die aktiv in der ASF-Arbeit waren, auch richtig abgestraft worden sind von der Partei in früheren Jahren, dass sie gar keine Chance hatten, ein Mandat zu kriegen, ne (?), dass ihnen gesagt wurde so ungefähr, dass du ASF-Arbeit machst, disqualifiziert dich dafür, ein Amt oder Mandat zu kriegen, ne? ( $\mathrm{Zz} 7$ )

Auch die langjährige ASF-Bundesvorsitzende Inge Wettig-Danielmeier hätte das frauenpolitische Engagement ihre eigene Karriere gekostet ${ }^{344}$, meinte eine Zeitzeugin:

[A]ls der Schröder das erste Mal Ministerpräsident in Niedersachsen wurde, wäre die Inge eigentlich dran gewesen und die (gesetzte) Kultusministerin gewesen. Sie war bildungs- und hochschulpolitische Sprecherin als Landtagsabgeordnete, das wäre ganz ... wie selbstverständlich gewesen, dass sie das wird, hat er natürlich nicht gemacht, weil ihm die Inge auch nicht handzahm genug war. So könnte man das am Beispiel VIELER Frauen durchdiskutieren, dass die am Ende sich dann doch in den unterschiedlichen Positionen durchgesetzt haben, ist eine andere Frage, aber da gibt's, glaube ich, bei allen gibt's solche mehr oder minder gravierenden Erfahrungen. (Zz 6)

\subsubsection{Formen der Nichtzugehörigkeit zum politischen Feld}

An diesen Schilderungen zu den vielfältigen Ausschließungspraktiken verdeutlichten die ZeitzeugInnen, dass ihnen eine Zugehörigkeit zum politischen Feld (vgl. Bourdieu 2001) verweigert wurde. Frauen sahen sich in ihrer Partei auf drei Ebenen diskriminiert, die für sie eng zusammenhingen:

1. Frauen fühlten sich bei den Verhandlungs- und Entscheidungsprozessen der Partei nicht als gleichwertige TeilnehmerInnen wahrgenommen.

Frauen werden bis heute, also man kann es nicht generell sagen, aber in ganz vielen Fällen nicht so richtig wahrgenommen. Man

$344 \mathrm{Ob}$ diese Interpretation zutrifft, ist in diesem Zusammenhang nicht wichtig. Zur Auseinandersetzung in der niedersächsischen SPD vgl. auch das Porträt Inge Wettig-Danielmeiers von Gabriele Andretta in: Clemens 1996: 140-155. 
weiß, es geht nicht mehr ohne Frauen, natürlich müssen Frauen dabei sein, aber ob sie's so richtig können? (Zz 10)

Frauen wurde eine mangelnde Eignung für Politik zugeschrieben, sie waren als Mitglieder in der Partei in der Minderheit, in wirkmächtigen Parteifunktionen selten zu finden und auch an der Parteibasis wenig sichtbar. Der Ortsverein und sein Vorstand trafen sich üblicherweise in den Hinterzimmern der ansässigen Kneipe, dort herrschte eine männliche Stammtischkultur ${ }^{345}$. Die Treffen wurden zu Tageszeiten einberufen, die für Eltern mit Schulkindern zu den Stoßzeiten gehörten.

Auch in der medialen Berichterstattung über Politik waren politische Expertinnen selten zu finden; die Medien trugen nach Beate Hoecker wesentlich dazu bei, die männliche Dominanz im Feld der Politik zu reproduzieren: „[... ] [D]ie fast ausschließlich mit Männern besetzten Diskussionsrunden im Hörfunk wie im Fernsehen, kurz das Fehlen von Frauen auf der öffentlichen Bühne scheint implizit die Auffassung von der weiblichen Politikunfähigkeit nur zu bestätigen." (Hoecker 1987: 127) Bis in die 1970er-Jahre hinein war man in der SPD der Meinung, dass insbesondere Frauen keine Frauen wählen (vgl. Bothmer 1976: 21).

\section{Die von Frauen eingebrachten Themen wurden nicht als politisch bedeutend gewertet und ihre Diskurse galten nicht als politikentwickelnd.}

Parteivorstandsmitglied Susanne Miller fand, dass die politischen Erwartungen der frauenbewegten ASF-Frauen die „Grenzen der Einflußmöglichkeiten des Staates oder einer Partei“ häufig überschritten und stattdessen in den Bereich des Privaten gehörten, ,in dem Menschen ihr Zusammenleben frei regeln müssen“ (Miller 1978: 566). In einer Festschrift zum 7o. Geburtstag Richard Löwenthals 1978 erklärte sie dazu:

Wer die Diskussionen von Frauengruppen, sozialdemokratischen und anderen, in den letzten Jahren verfolgt und miterlebt hat, wird immer wieder feststellen, daß das eigentliche Problem vieler, besonders jüngerer, Frauen ein sehr persönliches ist: Sie leiden unter dem Mangel an Bereitschaft ihres Freundes oder Ehemannes, sie als in jeder Hinsicht gleichwertigen Partner anzuerkennen. (Miller 1978: 565f.)

Als Folge einer solchen Problemwahrnehmung und Deutungshoheit in der Partei wurden nach Ansicht der ASF-Frauen existenzielle Probleme

345 Anke Riedel-Martiny berichtet von einer bayrischen Genossin, die an den Parteiveranstaltungen ihres Mannes nicht teilnahm, weil sonst die Parteifreunde meinen könnten, „sie zähle ihrem Mann das Bier nach." (Riedel-Martiny 1975: 732) 
von Frauen aus der Politik und der Zuständigkeit staatlicher Fürsorge ausgegrenzt. Häufig galten die Frauenthemen in der Konkurrenz zu anderen politischen Themen als eher nebensächlich ohne ausreichende Evidenz für den politischen Diskurs, bestenfalls wurden sie als Spezialthemen für Politikerinnen gewertet.

Frauenpolitische Parteibeschlüsse der SPD sowie innerparteiliche gleichstellungspolitische Regelungen wurden vielerorts in der Partei zunächst selbst dann ignoriert, wenn es sich um Leitanträge des Parteivorstandes handelte ${ }^{346}$. Es brauchte meist stetes frauenpolitisches Engagement, um sie in den jeweiligen Parteieinheiten und in deren öffentlichen Darstellungen durchzusetzen. Als Beispiel dafür berichtete eine Zeitzeugin von den nervenaufreibenden Interventionen der ASF-Vorsitzenden in Parteigremien gegen den Gebrauch des generischen Maskulinums in den Parteidokumenten. Der entsprechende Parteibeschluss wurde auch in Führungsstäben wenig ernst genommen:

[A]ber es war schon so, dass eine Zeitlang bei FAST jedem Beschluss die ASF sich meldete und sagte: ,Aber hier muss stehen Männer und Frauen'. Das ging natürlich einigen fürchterlich auf den Zeiger. Dann fingen die schon an mit den Augen zu rollen, weil sie das alles für dummes Zeug hielten. Rau hat ja bis zum Schluss in seinen Reden gesagt: ,Als guter Sozialdemokrat muss ich ja jetzt sagen ,Sozialdemokratinnen und Sozialdemokraten'. Eingesehen hat er das nicht. Er hat nie begriffen, dass durch einen bestimmten Sprachgebrauch möglicherweise Frauen auch ausgegrenzt werden $[\ldots]$. (Zz 10)

\section{Geschlechtergerechtigkeit und die Emanzipation der Geschlechter gehörten nicht zum sozialdemokratischen Grundwertekanon.}

Nach Ansicht der Zeitzeuginnen bestand eine enge Verbindung zwischen dem bürgerlichen geschlechterhierarchischen Familienideal, das nicht nur in den Arbeitermilieus der Partei gelebt wurde, sondern auch für die Lebensverhältnisse leitender Parteifunktionäre typisch war, und dem politischen Desinteresse an Geschlechtergleichheit in der Partei.

Das liegt auch daran, dass natürlich zum ... insbesondere zum damaligen Zeitpunkt eigentlich die Partnerin oder Ehefrau eines Abgeordneten im Regelfall nicht erwerbstätig war, insbesondere dann nicht, wenn Kinder da waren, weil das also mit einem solchen Job im Prinzip nicht zu verbinden war, also die musste ihm 
zuhause den Rücken freihalten, wie es halt so herkömmlicherweise ist, war ja auch zum damaligen Zeitpunkt im Vergleich eine noch besser bezahlte Tätigkeit, als es das heute der Fall ist, und die Frauen waren also im Regelfall zuhause, haben dann teilweise noch für ihn mit Arbeiten erledigt und so. (Zz 13)

Das Godesberger Programm von 1959 war im Vergleich zum Aktionsprogramm von $1954^{347}$, den ersten programmatischen Leitsätzen der Nachkriegs-SPD, frauenpolitisch ein Rückschritt. Zwar galten in beiden Programmen Frauen als Opfer gesellschaftlicher Ungleichheit, deren Interessen und Rechte die SPD kenne und vertrete ${ }^{348}$, im Aktionsprogramm aber hatte das Recht der Frauen auf Berufstätigkeit und berufliche Entwicklung noch an vorderer Position gestanden. Im Godesberger Programm dagegen wurden diese Rechte dem Einsatz der Frauen in Familie und Haushalt nachgeordnet. Erst das Berliner Programm definierte 1989 die Geschlechterfrage zu einem gesamtgesellschaftlichen Thema und erklärte Geschlechtergerechtigkeit zu einem Leitziel der Partei.

In den Auseinandersetzungen und innerparteilichen Verhandlungen erlebten die Frauenaktivistinnen, dass diese drei Ausgrenzungsgeschehen diskursiv nur bedingt miteinander in Verbindung zu bringen waren. Weder schien das vermehrte Parteiinteresse an frauenpolitischen Themen in den Wahlkampfzeiten ab Mitte der 1970er-Jahre die Aufstellung von Wahlkandidatinnen zu fördern noch war eine größere Berücksichtigung weiblicher BewerberInnen grundsätzlich mit einem größeren Interesse an frauen- und familienpolitischen Themen in der Partei verkoppelt. Auch die programmatischen Bekenntnisse der Partei zur Geschlechtergerechtigkeit schienen für viele Mitglieder eher zu jener Schaufensterpolitik zu gehören, mit der sich die SPD an die Medien richtete und die ihr zur Profilierung gegen die politische Konkurrenz diente.

347 Aktionsprogramm der Sozialdemokratischen Partei Deutschlands, beschlossen auf dem Parteitag in Dortmund 1952 und erweitert auf dem Parteitag in Berlin 1954, in Dowe/Klotzbach 1990: 299-347.

348 Eine konservative Programmentwicklung gab es auch zum Thema Mündigkeit der BürgerInnen: Im Aktionsprogramm 1954 hieß es, dass eine ,junge Generation“ sich eigenverantwortlich ihren Platz im beruflichen und öffentlichen Leben erobern müsste und dabei von der Partei unterstützt werden sollte, im Godesberger Programm 1959 war dieser Passus gestrichen, eine politische Eigenständigkeit wurde Gewerkschaften und Verbänden zugedacht. 


\subsubsection{Differente Strömungen und „mühsame Solidarität" ${ }^{349}$}

In vielen Frauenarbeitsgemeinschaften fanden politische Flügelkämpfe ähnlich wie in der Gesamtpartei statt (vgl. Martiny 1986). Eine große Zahl von SPD-Frauen aber ordnete sich nicht den politischen Flügel der Partei zu, manche orientierten sich eher an christlich-humanistischen Werten, andere an feministischen Diskursen. Viele Frauen hatten überhaupt wenig Interesse an politischen Themen, sondern nutzten die Partei als sozialen Treffpunkt. Trotz dieses breit gefächerten Spektrums an Teilhabemotivationen war die ASF gekennzeichnet von lebendigen politischen Auseinandersetzungen, von Blockaden durch Fraktionierungen, aber auch von dem Interesse, mit einer starken Arbeitsgemeinschaft frauenpolitische Ziele in der Partei durchzusetzen.

Anfang der 1970er-Jahre bildete sich mit der Eintrittswelle jüngerer Frauen in die ASF eine linkssozialistische Opposition. Diese politikinteressierten Frauen trafen mit ihrem Auftreten und ihrer Debattierfreudigkeit in den bestehenden Frauenorganisationen zunächst meist auf Widerstände. Nach Ansicht vieler älterer Genossinnen bedrohten sie den Zusammenhalt nicht nur der ASF, sondern auch der Partei. Annemarie Renger beschuldigte die jungen Frauen, sie wollten unter dem Mantel der Frauenpolitik der Partei einen linksradikalen Kurs aufzwingen. Später räumte sie jedoch im Rückblick ein,

daß die kämpferischen und intellektuell gewandten Verfechterinnen des Feminismus auch durch ihre Übertreibungen und die Manier des Bürgerschrecks das öffentliche Interesse an Frauenpolitik verstärkt und mancher Routine die Sporen gegeben haben (Renger 1981: 224).

Persönlich blieb ihr allerdings die neue Generation mit dem lässigen Outfit, den Schlabberkleidern, ohne BH und „Frisur" immer fremd (vgl. Renger 1993: 246).

In der zweiten Hälfte der 1970er-Jahre begannen die frauenbewegten ASF-Aktivistinnen ${ }^{35^{\circ}}$, die Politik des ASF-Bundesvorstandes zu bestimmen, getragen von einer beträchtlichen Minderheit in der ASF-Mitgliedschaft. In den Bundesfrauenkonferenzen standen ihnen die Vertreterinnen der traditionellen, parteiführungsloyalen Frauengruppen als überwältigende Mehrheit gegenüber. Für die Integration der miteinander

349 Zitat von Zz 12.

350 Im Laufe der 1970er-Jahre bezeichneten sich die meisten Frauen dieses Flügels als „Feministinnen“, später dann als „sozialistische Feministinnen“. Für diese Selbstbezeichnung wurden programmatische Texte verfasst (vgl. ASF 1987a; Randio-Plath 1980; Konieczka 1983). 
streitenden Flügel war, so eine Zeitzeugin, der Bundesfrauenausschuss das wichtigste Gremium:

[D] as war immer ganz wichtig: Was bringen hier die Bezirksfürstinnen an. [...] [W] elche Diskussionen laufen hier in den einzelnen Bezirken und stimmt das hier mit dem überein, was wir auf Bundesvorstandsebene denken. Müssen wir etwas Neues mit aufnehmen oder müssen wir auch - das zum Zwecke der eigenen Machtsicherung - die Bezirke von unseren Überlegungen überzeugen. Das war schon so ein politischer Seismograph. (Zz 6)

Im Gegensatz zur Partei bestanden innerhalb der ASF jedoch keine organisierten Lager, eher repräsentierten die einzelnen Bezirke und Landesverbände spezifische politische Strömungen ${ }^{351}$. Den linkssozialistischen Bezirken wurden Hessen-Süd, Südbayern, Hamburg, Mittelrhein zugerechnet, dem rechten Parteiflügel zugehörig galten u.a. Ostwestfalen-Lippe, Nordhessen und als größter Bezirk das Westliche Westfalen. Da sich die Delegiertenzahl der Bezirke nach ihrer Mitgliederstärke richtete, hatte gerade diese Region auf den ASF-Konferenzen einen dominanten Einfluss. Sie konnten Beschlüsse durch ihre zahlenmäßige Dominanz blockieren und fühlten sich, schilderte eine Zeitzeugin, dazu auch berechtigt. Sie wären diejenigen gewesen,

[d]ie auch das Gefühl hatten: ,Wir sind das Herz der Republik, wir sind das Herz der Sozialdemokratie, wir liefern denen die Mehrheiten, mit denen was zu machen ist'. (Zz 11)

Die politische Auseinandersetzung wurde geprägt durch die Zuschreibung politischer Präferenzen zu regionalen Zugehörigkeiten, wie eine Zeitzeugin berichtete, und führte zu Vorurteilen und Missverständnissen:

[D]a gab es den Ausspruch vom Niederrhein, glaube ich: ,Da kommen die dicken Mamis vom westlichen Westfalen', und wir waren auch alles kernige Frauen, wirklich, große, stabile Frauen. Ja! (seufzt) Und wir galten als rechts, ne? Einfach immer rechts, patsch; ob der Einzelne oder die Einzelne dazugehörte oder nicht, wir galten als rechts. Wumms, ab in die Tonne. ( $\mathrm{Zz} \mathrm{12}$ )

Die politischen Fraktionierungen verliefen dabei weniger entlang der Generationen. Vielmehr fanden die jungen linken ASF-Aktivistinnen häufig die Unterstützung der politisch erfahrenen, älteren Genossinnen.

351 Meist waren die Regionen geprägt durch das Parteigeschehen in ihren großen Städten: „[D]ie Großstädte mit einem intellektuellen anderen Niveau, auch mit den Gewerkschaftszentralen und auch Unternehmenszentralen, das sind dann andere Frauen, die da kommen“ (Zz 11). 
Es waren keineswegs immer die Jüngeren, die die „fortschrittlichen“ Positionen vertraten, erzählte eine Zeitzeugin, die viele Jahre dem ASFBundesvorstand angehört hatte.

Diskriminierungs- und Ausschließungserfahrungen in den Auseinandersetzungen in und mit der Partei sowie die Anforderung, konkrete Politiken zu entwickeln, brachten die politisch gegnerischen Gruppierungen innerhalb der ASF immer wieder neu zusammen und machten die ASF „sehr dynamisch“ (Zz 7). Viele Themen, mit denen sich die ASFFrauen im Laufe der 1970er- und 1980er-Jahre auseinandersetzten, wie die Nachrüstungsdebatte, die Reproduktionstechnologien, das Pornographieverbot oder die Quote, ließen sich den bestehenden parteipolitischen Lagerbildungen nicht zuordnen und führten zu neuen Fragmentierungen und Koalitionen unter den ASF-Frauen.

Besonders den Zeitzeuginnen und ehemaligen Bundesvorstandsmitgliedern sind diese Entwicklungen, in denen sich Abgrenzungen verschoben, unterschiedliche politische Standorte veränderten oder relativierten und Verschwesterungen neu gefunden wurden, in lebendiger Erinnerung:

[W]ir haben dann weiter miteinander gearbeitet, uns aneinander gerieben, aber wir sind auch zusammengekommen. ( $\left.\mathrm{Zz}_{2}\right)$

Es gab eine richtige Frauensolidarität und es gab den Willen von vielen Frauen, nicht von allen Frauen, dazu auch zu stehen. (Zz 5)

Ich glaube, dass die Frauenprobleme immer an erster Stelle standen, für alle. (Zz 12)

[D]urch diese Reibung widerstreitender Interessen, die von ASF und Teilen der Mutterpartei jetzt ... diese Reibung, die da entstanden ist, die hat natürlich dann auch eine gewisse Stärke ausgemacht, hat auch ein großes Stück zusammengeschweißt, muss man auch sehen, und hat auch, sagen wir mal, Leute, die sonst vielleicht weniger miteinander anfangen können, hat die also dann schon zusammengehalten. (Zz 13)

Eine Studie von Beate Hoecker aus dem Jahr 1982 bestätigt den vergleichsweise hohen Grad an kollektiver Identität unter den sozialdemokratischen Frauen. In der repräsentativen Befragung konnten die weiblichen Parteimitglieder aller Bremer Parteien aus einer Liste die ihrer Ansicht nach wichtigsten politischen Themen auswählen. Die „Gleichstel- 
lung der Frau" wurde von den Sozialdemokratinnen nicht nur am meisten gewählt, sondern sie setzten dieses Thema auch an die erste Stelle 352 (vgl. Hoecker 1985: 92).

\subsubsection{Kulturelle Zwischenwelt und kollektive Selbstermächtigung}

Die Zusammenarbeit mit ihren Parteikollegen erlebten die Frauenaktivistinnen häufig als schwierig und begleitet von Unverständnis und Missachtung. Über ihre Mitarbeit in den von Männern dominierten Gremien berichtete eine Zeitzeugin:

Und ich kann mich ... ich sag jetzt mal ... im Laufe meines politischen Lebens an viele Situationen erinnern, wo ich mich ziemlich als Exotin gefühlt hab. Und ... ähm ... manchmal wirklich die Zweifel hatte, ob ich irgendwie so einen schiefen Blick habe. (Zz 14)

Dagegen bot die Frauenarbeitsgemeinschaft Orte der Verständigung und Bestärkung durch Gleichgesinnte. Eine Aktivistin erzählte, wie ihre Bundestagskandidatur an den mächtigen Netzwerken des Parteivorstandes scheiterte. Ohne die lokale Arbeitsgemeinschaft hätte sie sich - wie vermutlich viele Frauen nach solchen Ohnmachtserfahrungen - aus einem weiteren Parteiengagement zurückgezogen 353 .

[D]en inneren Zusammenhalt, das Sich-wechselseitig-Stützen, und damals die Niederlage [...] hätte ich, glaube ich, damals, ohne die Unterstützung der Frauen nicht so ohne Weiteres weggesteckt. Das war ja ziemlich ekelhaft gewesen. Und als dann da alle ankamen und sagten: ,[...] du hattest Recht, du musstest ... du warst ...', und so, ja (?), und ,jetzt stehn wir alle zusammen', also diese Solidarität, gerade in der Niederlage oder mal in einem Rückschlag, ist ungemein wichtig, gerade in der Frauengruppe. (Zz 11)

Die Frauenaktivistinnen erlebten ihre Situation in der Partei aus einer geschlechterdualistischen Perspektive, die auch die damaligen Diskurse in den Neuen Frauenbewegungen dominierten. Diese Verständigungen

352 Dagegen wählten die Christdemokratinnen „die Familie schützen“, die Freidemokratinnen „mehr Umweltschutz“ (Hoecker 1985: 77).

353 Um einen Kandidaten aus der Führungsriege zu platzieren, hatte die Parteispitze ein demokratisches Auswahlverfahren an der Parteibasis außer Kraft gesetzt. Vgl. Zz 6. 
verhalfen dazu, generationsübergreifend Gemeinsamkeiten der unterschiedlichen Fraueninteressen zu finden, und förderten die Selbstermächtigung der ASF-Aktivistinnen.

[I]m Grunde galt für die älteren und galt für die jüngeren Frauen ... ähm ... eine gleiche Situation, dass man nämlich sich in einer Männerwelt behaupten musste und das war eigentlich ein $\mathrm{Zu}-$ sammenschweißen der Frauen, die gesagt haben, wir verstehen uns untereinander eigentlich, merken aber, sobald wir in anderen Gremien sind, die männerdominiert sind, da tickt die Welt anders, die denken anders, die gehen anders mit bestimmten Themen um. Und die Rückvergewisserung in den eigenen Reihen bei den Frauen war immer wichtig, um auch stark zu sein in anderen Gremien, und das war das Bindeglied auch zwischen Älteren und Jüngeren.(Zz 14)

Die Frauenarbeitsgemeinschaften boten ihren Aktivistinnen aber nicht nur Rückhalt, sondern motivierten ihre aktiven Mitglieder zu politischen Karrieren, förderten sie durch Schulungen und Trainings und halfen ihnen dabei, ihre Reputation aufzubauen.

Wir haben gemeinsam eingeübt, die Referate, und dann sind wir in die Ortsvereine gegangen. Und das hat dann Früchte getragen; dann kamen die Frauen überhaupt erstmal dazu, gekannt und erkannt zu werden. (Zz 9)

Die Gemeinschaftlichkeit einer Frauenopposition, die sich in den ASFArbeitsgemeinschaften entwickelte, wurde von der Parteiführung lange Jahre nicht erkannt und verstanden. Noch 1974 hatte Parteivorstandsmitglied Dr. Katharina Focke erklärt: „Für Frauen, so sagen nicht nur Männer, sei das Wort Solidarität ein Fremdwort" (Katharina Focke, Zentralkonferenz der Sozialdemokratischen Frauen, Basel 15.06.1974 in: Dokumente 2/1974).

\subsubsection{Neue Formen politischer Kommunikation}

Nach den Vorstellungen der linkssozialistischen ASF-Aktivistinnen sollten in den Arbeitsgemeinschaften im Vergleich zur Gesamtpartei „freiere, losere, auf mehr Gleichberechtigung zielende Organisationsformen“ entwickelt werden, die ihre Mitglieder stärker politisieren könnten und 
ihnen eine „direktere Mitwirkung“ ermöglichte (Meinerts 1972: 6) ${ }^{354}$. Verändert werden sollte nicht die repräsentationsdemokratische Struktur der Organisation, aber die verfestigten Hierarchien und die bürokratischen Verfahren. Hier wollte die ASF von den „neuen Arbeits- und Gesellschaftsformen der autonomen Frauenbewegung lernen“ (Rechenschaftsbericht 1981: 17). Basisdemokratisch und offener sollten die Frauenarbeitsgemeinschaften werden:

Unsere Arbeit in der ASF muß zeigen, daß Frauen nicht die männlichen Rituale und politischen Ränkespiele übernehmen, sondern Politik erneuern. Wir können die Frauen nur dann für die Mitarbeit in der SPD und in den Parlamenten gewinnen, wenn sie sich nicht verbiegen müssen. (Rechenschaftsbericht 1987 zit. n. Dokumente 27/1987: 55) 355

Um innerhalb der ASF eine „demokratischere Gegenkultur“ (HempelSoos o. J. [1984]) zum Parteileben in der SPD aufzubauen, wurden vielerlei kommunikationspolitische Initiativen entwickelt, auch auf Bundesebene. Kurz nach der Neugründung der ASF 1973 im Sommer 1974 wurde von einer Arbeitsgruppe des Bundesvorstandes eine Fragebogenaktion in den Bezirken und Unterbezirken durchgeführt. Aus dieser Befragung sollte das neu zu verfassende ASF-Frauenprogramm entstehen, denn dieser Text sollte nicht wie die parteiüblichen Programmtexte über der Organisation schweben, sondern die Frauenarbeit an der Basis der Arbeitsgemeinschaften abbilden (vgl. Programmkommission der ASF 1975). Organisationsintern wurden verschiedene teamorientierte Verfahren ausprobiert ${ }^{356}$. So fand die Bundeskonferenz 1981 ohne die üblichen Vorlagen vorgefertigter Thesenpapiere und Leitanträge statt; stattdessen wurden die Delegierten aufgefordert, in Arbeitsgruppen gemeinsam politische Konzepte und Anträge zu erarbeiten. Auf der Bundeskonferenz 1985 wurde unter der Devise „Weg mit den Mikrofonen“ auf die parteiüblichen Plenumsberatungen verzichtet und die politischen Diskussio-

354 Eva Meinerts schrieb in der Juso-Zeitschrift 1972: „Wer in seiner Frauengruppe alle zwei Jahre einen Vorstand wählen darf, [...] wer bei allen Veranstaltungen den Vorstand oben sitzen und die Frau Vorsitzende mit Gewandtheit agieren sieht, der ist seiner eigenen Emanzipation nicht wesentlich näher gekommen, auch wenn er sich statt mit Wäschepflege mit Außenpolitik beschäftigt" (Meinerts 1972: 6).

355 Die ASF hätte ähnliche Kommunikationsformen wie die Partei, kritisierte die ASF-Bundesvorsitzende Anfang der 1980er-Jahre: „In seinen Strukturen und Gesellungsformen ist das Parteileben frauen- und familienfeindlich. Das gilt in abgeschwächter Weise auch für die ASF-Arbeit." (Dokumente 15/1981: 17)

356 Im Juli 1970 war bereits in einem Seminar der Friedrich-Ebert-Stiftung zur Qualifizierung von Funktionärinnen mehr „Teamwork“ zwischen Vorstand und Frauengruppen gefordert worden (vgl. fes 1970). 
nen wurden in Kleingruppen organisiert. In welchen politischen Verwaltungen neue Kommunikationsformen von den Sozialdemokratinnen vorgeschlagen und durchgesetzt wurden, ist nicht dokumentiert, außer in Münster: Dort hatten die Frauen 1983 durchgesetzt, dass sich die Stadtratsfraktion im Stuhlkreis traf.

Nicht nur für die Arbeitsformen, sondern auch bei der politischen Präsentation der Partei wurde Neues ausprobiert. Üblicherweise übernahmen die Genossinnen bei Wahlkämpfen Zuarbeiteraufgaben. Sie waren an den Wahlkampfständen für das Kaffeekochen und Waffelbacken zuständig, die Männer diskutierten mit dem Publikum. Bald nach der ASF-Neugründung traten die Sozialdemokratinnen mit eigenen Wahlkampfaktivitäten und -ständen an die Öffentlichkeit. Im Europawahlkampf 1984 fuhren acht Wahlkandidatinnen mit einem „Frauen-Mobil“ zu den täglichen Auftritten. Der audiotechnisch ausgerüstete VW-Bulli wurde auf diesen Wahlkampftouren ausschließlich von Frauen gefahren und gewartet. In der späteren Wahlkampfphase zog Kandidatin Dr. Katharina Focke mit einem Wanderzirkus durch die BRD. Die Tageskasseneinnahmen wurden den jeweiligen örtlichen sozialen Initiativen gespendet. Die Botschaft von „Katharinas Circus“ war: „Wir brauchen die Manege, um an das Unmögliche - an unsere Wünsche - glauben zu können" (Hempel-Soos o. J. [1984]). Auf dem Münsteraner Parteitag, der 1988 die Aufnahme der Quote in die Statuten der Partei beschloss, zog eine Gruppe von Frauen als Suffragetten verkleidet auf das Podium und präsentierte den Medien den Parteibeschluss als Erfolg eines langen Kampfes und als Ergebnis frauenpolitischer Gegenmacht.

Als eine besonders öffentlichkeitswirksame Aktivität entwickelte sich der Internationale Frauentag. 1979 hatte die Bundesfrauenkonferenz in Erlangen beschlossen, den 8. März als Internationalen Frauentag zu feiern. Obwohl die ASF dafür die politische Rückendeckung der Socialist International Women (SIW) hatte ${ }^{357}$, musste sie mit einem erheblichen Widerstand des Parteivorstandes rechnen. Eine Zeitzeugin erinnerte sich an massive Drohungen aus der Parteiführung:

Da hat die Partei gesagt: ,Das ist ja ein kommunistischer Feiertag, das dürft ihr nicht machen, wir verbieten das, keinen Pfennig Geld, nichts. Und wenn ihr das organisiert, bitte sehr, es gibt auch so was wie Parteiordnungsverfahren.' Das war der zweite Punkt, wo wir die Drohung bekommen haben: einmal bei den

357 Die Initiative war von der Sozialistischen Fraueninternationale (SIW) in Vancouver 1978 vorbereitet worden. Eine Konferenz, an der auch die ASF teilgenommen hatte, beschloss, den Internationalen Frauentag als Kampftag der Frauen für Frauenrechte und Frieden international zu begehen. Eine Zeitzeugin (Zz 6) erinnert die ASF-Initiative auch als Gegengründung zum Muttertag, in den Dokumenten findet sich darauf jedoch kein Hinweis. 
Friedensdemos und dann beim Internationalen Frauentag. Da haben wir gesagt, und wir machen's. (Zz 9)

Der Festtag begann zunächst mit kleinen Kundgebungen ${ }^{358}$, entwickelte sich aber bald zu einem frauenpolitischen Event, an dem sich Frauenverbände, Gewerkschaftsfrauen und frauenpolitische Initiativen aus der autonomen Frauenbewegung beteiligten. Eine Zeitzeugin berichtete:

Wie wir angefangen haben ... die ersten internationalen Frauentage waren also ziemlich geschlossene Gesellschaften, ganz schlichte Anfänge, bis die dann also ... dann haben wir Verbündete bekommen, dann kamen die Gewerkschaftsfrauen dazu, da kamen Frauen aus Verbänden dazu. Heute ist internationaler Frauentag etwas, was nicht mehr nur mit der SPD zu tun hat, aber wiedergegründet hat das die ASF. (Zz 9)

Die Internationalen Frauentage in Essen 1981 „Gewalt gegen Frauen hat viele Gesichter" und in Hagen 1982 "Menschenrechte = Frauenrechte“ wurden von 2.500 bis 3.000 TeilnehmerInnen besucht. In den Folgejahren richteten die Sozialdemokratinnen diesen Tag auch als wichtiges parteipolitisches Ereignis aus. 1986 wurde der 75. Internationale Frauentag mit Beteiligung des Parteivorstandes im Erich-Ollenhauer-Haus begangen. Am 8. März 1986 mobilisierte die ASF 20 dezentrale Veranstaltungen mit ca. 4.0oo Frauen, zur zentralen Großveranstaltung in Wiesbaden kamen 1.0oo Frauen. Frauendelegationen aus El Salvador, Nicaragua und Südafrika traten als internationale Gäste auf, Winnie Mandela sandte eine Grußadresse. Gleichzeitig nutzte die ASF den Tag für den Wahlkampf zur Bundestagswahl 1987. Kanzlerkandidat Johannes Rau engagierte sich in mehreren Talkrunden und ließ sich als Ansprechpartner für die Frauen präsentieren. Der ASF-Vorstand berichtete auf der nächsten Bundesfrauenkonferenz über die gelungene Ausrichtung des Frauentags: „Der Versuch, als Sozialdemokratinnen den 8. März zu ,besetzen', aber auch andere Frauengruppen und insbesondere die Gewerkschafterinnen mit einzubeziehen, ist gelungen“" (Dokumente 27/1987: 49).359

Innerparteilich stärkte der Internationale Frauentag die politische Bedeutung der ASF. Er repräsentierte die erfolgreiche Netzwerkarbeit der ASF und die gewachsene Aufmerksamkeit der Presse. Zum Internationalen Frauentag 1986 berichtete die ASF-Vorsitzende: „Ein Jahr vor

358 In den Gewerkschaften war den Kreisfrauenausschüssen eine Mitwirkung vom DGBHauptvorstand untersagt worden.

359 Das sozialdemokratische Dominieren des Tages hatte bei den Mitveranstalterinnen zu heftigem Unmut geführt (vgl. taz 1986). 
der Bundestagswahl fand die Frauentagsidee in den Medien eine Resonanz wie nie zuvor." (Rechenschaftsbericht 1987: 7)

Auch mit dem Jubiläum „70 Jahre Frauenwahlrecht“ im Herbst 1988 gelang es der ASF, ein großes mediales Interesse zu erreichen, um das sie im Schatten der Partei immer hatte ringen müssen. Zu dem Jubiläum hatte der ASF-Bundesvorstand einen Plakatwettbewerb ausgelobt, dessen Ergebnisse auf dem Münsteraner Parteitag präsentiert wurden. Auf dem Festakt in der Bad Godesberger Stadthalle erklärte die Vorsitzende Inge Wettig-Danielmeier den über 500 prominenten Gästen, dass die ASF mit ihrem Kampf für die gesellschaftliche Gleichheit der Frau den Kampf um das Frauenwahlrecht fortsetzte. Im folgenden Neujahrsempfang des Parteivorstandes, Januar 1989, bekam der Bundesvorstand der ASF Gelegenheit, die frauenpolitischen Ziele unter dem Titel „Frauenwahlrecht" einem Publikum aus internationalen Gästen und SpitzenpolitikerInnen anderer Parteien zu präsentieren (vgl. Rechenschaftsbericht 1990: 7).

Mit diesen Initiativen präsentierte sich die ASF als eine innerparteiliche Frauenopposition. Im gleichen Zeitraum wurde von der ASF eine Fülle frauen- und familienspezifischer Politiken erarbeitet, die im folgenden Kapitel vorgestellt werden.

\subsection{Programmatische Orientierungen und Politiken der ASF}

Wolfgang Pausch sieht in seiner Studie über die ASF das Fehlen einer programmatischen Selbsterklärung als den entscheidenden Grund für die politische Schwäche der ASF in der Partei an (vgl. Pausch 1985). Auch die ASF-Aktivistinnen hielten die Entwicklung eines frauenpolitischen Grundsatzprogramms für ihre vordringlichste Aufgabe, als sie Anfang der 1970er-Jahre zu einer neuen sozialdemokratischen Frauenpolitik aufbrachen. Dies entsprach der sozialdemokratischen Tradition, nach der sich die SPD als eine Programmpartei versteht und Grundsatzprogramme als eine Art heiliges Schriftstück gelten, in dem die Kohärenz der politischen Konzepte erklärt, politische Traditionen und Erfahrungen gespeichert und der Parteizusammenhalt nach außen präsentiert werden. Das Vorhaben, ein sozialdemokratisches Frauenprogramm aufzustellen, wurde von den linkssozialistischen ASF-Frauen jedoch nach verschiedenen Versuchen aufgegeben. Statt programmatischer Selbsterklärungen bildeten die beiden Ziele, die Frauenpolitik der Partei zu verändern und den Anteil der Frauen in der Partei zu erhöhen, den politi- 
schen Rahmen, innerhalb dessen die ASF einen breiten Katalog gesellschaftlicher Kritiken und Gegenentwürfe sowie pragmatischer Veränderungsideen und politischer Forderungen entwickelte. Diesen brachte sie in die politischen Debatten ein und konnte vielerlei davon - wenn auch erst nach Jahren - in der Partei durchsetzen.

\subsubsection{Der Streit um ein frauenpolitisches Programm}

Auf der ersten ASF-Bundeskonferenz 1973 erläuterte die Vorsitzende Annemarie Renger ihre Vorstellungen von den Aufgaben der neuen Arbeitsgemeinschaft. Danach sollte sich die ASF besonders „um die am meisten benachteiligten Schichten kümmern“ und „den un- und angelernten Frauen politische und soziale Hilfestellung geben“360 (f 12 (1973): 8). Diese Zielstellung lehnten die frauenbewegten ASF-Aktivistinnen als Variation weiblicher Fürsorge vehement ab. Sie forderten „Selbstbestimmung“: Frauen müssten in der Gesellschaft und in der Partei „ihre Sache selbst in die Hand“ (Dorothee Vorbeck in f 12 (1973): 47f.) nehmen. ,,,Wir sollten nicht in erster Linie Politik für die Frauen machen, sondern wir sollten in erster Linie selber Politik machen" (Lenelotte von Bothmer in f 12(1973): 53), befand auch Bundestagsmitglied Lenelotte von Bothmer.

Diese radikalen Losungen, mit denen sich Anfang der 1970er-Jahre eine neue Strömung von ASF-Aktivistinnen artikulierte, entsetzten die etablierten ASF-Funktionärinnen und ASF-Vorstandsvertreterinnen. Sie waren geschockt von den Ideen einer Gruppe Juso-Aktivistinnen, die auf einem Frauenseminar in Kassel im November 1971 „Frauensolidarität“ propagiert und gefordert hatten, Frauen bei Wahlen unabhängig von ihrer Parteizugehörigkeit zu unterstützen (vgl. hierzu Pausch 1985).

Die neuen ASF-Aktivistinnen forderten ein anderes sozialdemokratisches Frauenprogramm, weil das Godesberger Programm Frauen das Recht auf Berufstätigkeit nur eingeschränkt zugestand und sich damit nach Ansicht der Aktivistinnen gegen ein Grundelement weiblicher Emanzipation richtete ${ }^{361}$. Die Ludwigshafener Bundesfrauenkonferenz 1973 beauftragte eine Kommission mit dieser Aufgabe. In den folgenden

36o Diese Ausrichtung der ASF wurde auf der Bundesfrauenkonferenz 1973 auch von Dr. Katharina Focke, Bundesministerin für Jugend, Familie und Gesundheit, unterstützt.

361 Auch die Parteiführung war mehrheitlich der Meinung, dass das Programm einer Überarbeitung bedürfe. Die Jusos hatten zu verschiedenen politischen Themen politische Diskussionen in die Partei hineingetragen (vgl. Faulenbach 2011). 
Monaten erarbeiteten Vertreterinnen aus 15 Bezirken und dem Bundesvorstand in parallelen Themengruppen ${ }^{362}$ eine Vielzahl programmatischer Texte und erstellten einen Programmentwurf Grundsätze für die Arbeit sozialdemokratischer Frauen, der auf der nächsten Bundesfrauenkonferenz 1975 in Braunschweig vorgelegt werden sollte. Parallel dazu aber traf sich die ASF-Führung mit 25 führenden Genossinnen und vereinbarte gemeinsam, solche Grundsatzdebatten in der ASF baldmöglichst zu beenden. Programmatische Diskussionen hatten nach ihren Auffassungen in den Reihen der Partei stattzufinden, die Frauenarbeitsgemeinschaft dagegen sollte sich mit praktischen Politiken auseinandersetzen (vgl. Lepsius 1987). Zudem hatten sich im Vorfeld der kommenden Bundesfrauenkonferenz die Parteihistorikerinnen Susanne Miller und Helga Grebing in die Programmarbeit eingeschaltet und überzogen den Kommissionsentwurf, insbesondere seine antikapitalistischen Textpassagen, mit einer heftigen polemischen Kritik (vgl. Grundsätze der Arbeit 1975). Eine Zeitzeugin erinnerte sich:

Danach waren die Jungen stumm, die Intervention war vernichtend. (Zz 6)

Die Auseinandersetzungen um ein neues Frauenprogramm waren damit beendet. Die Debatten zwischen den verschiedenen politischen Strömungen der ASF und ihre Machtkämpfe untereinander wurden in den Folgejahren zu konkreten politischen Themen und Forderungen ausgetragen. Die politischen Mehrheitsverhältnisse in der ASF spiegelten sich in der Auswahl ihrer Führungsfrauen. 1977 löste die Gewerkschafterin Elfriede Hoffmann die erste Vorsitzende der 1973 neu gegründeten ASF, Elfriede Eilers, ab. Nach vier-Jahren übernahm 1981 Inge Wettig-Danielmeier, die sich als feministische Sozialistin bezeichnete, den Vorsitz der ASF und leitete 11 Jahre lang bis 1992 die Frauenarbeitsgemeinschaft. Mit diesem Vorstandswechsel 1981 war die ASF, so bestätigten die Zeitzeuginnen übereinstimmend, dem linken Flügel der Partei zuzuordnen:

Da konnte man nicht für den Bundesvorstand kandidieren, ohne bei der Vorstellung nicht erst mal ein Bekenntnis gegen den Nato-Doppelbeschluss abzugeben. (Zz 6)

Die linke Führung der ASF wurde durch den Zuspruch der Wählerinnen und die stetig wachsende weibliche Mitgliederzahl der SPD gestärkt. Auch als Organisation entwickelte sich die ASF durch die stete Neubildung weiterer ASF-Arbeitsgemeinschaften. Bereits 1983 berichtete die Vorsitzende Inge Wettig-Danielmeier auf der Bundesfrauenkonferenz in

362 Als Bundesvorstandsmitglied nahm Ute Canaris, als ständig beratendes Kommissionsmitglied Christine Schmarsow teil. Im Laufe der Auseinandersetzungen dezimierte sich der Kreis auf ca. ein Dutzend Personen (vgl. Programmkommission der ASF 1975). 
Bonn: „Keine Arbeitsgemeinschaft der SPD ist so weit bis in die Untergliederungen durchorganisiert wie die ASF." (Rechenschaftsbericht 1983: 25)

Wenn auch der programmatische Streit in der ASF beendet war, bestimmten doch verschiedene fundamentale Konfliktlinien die politischen Diskurse und festigten und bestätigten die gegensätzlichen Lager.

Eine Konfliktlinie betraf die politische Möglichkeit der weiblichen Emanzipation. Nach Überzeugung traditioneller sozialdemokratischer Frauenpolitikerinnen war eine Befreiung der Frau nur in Folge gesellschaftlicher Emanzipationsbewegungen denkbar. Frauenpolitik hatte sich deshalb den strategischen Ausrichtungen der Partei anzupassen:

Je mehr sich der Klassencharakter unserer Gesellschaft zurückgebildet hat, je mehr Mitbestimmung und je weniger Herrschaft es gibt, desto näher sind wir auch der Gleichberechtigung der Frau gekommen. Wenn die politische Demokratie die Gesellschaft vollständig durchdrungen hat, wird auch die Gleichberechtigung der Frau erreicht sein. (Renger 1981: 244)

Das frauenbewegte und feministische Lager in der ASF dagegen kämpfte dafür, dass die Überwindung der Geschlechterhierarchie und die Durchsetzung der Gleichstellung als eigenständige politische Ziele der Partei anerkannt wurden. Diese Strömung setzte sich in der ASF und der Partei letztlich durch ${ }^{363}$. Im Berliner Programm 1989 wurde die „tatsächliche Gleichstellung der beiden Geschlechter" (Berliner Programm 1989: 380) zu einem eigenständigen sozialdemokratischen Grundwert erklärt.

Eine Konfliktlinie betraf das „Verhältnis von Theorie und Praxis“. Hier standen, besonders in den ersten Jahren der ASF-Neugründung, die linkssozialistischen theorieinteressierten Frauen, die sozialdemokratische Frauenpolitik aus einer kritischen Gesellschaftsanalyse heraus entwickeln wollten, den eher konservativen und pragmatischen Genossinnen gegenüber, die Theoriediskussionen für unpolitische Zeitverschwendung hielten ${ }^{364}$. Diese Konfrontation löste sich in den 1970er-Jahren zugunsten politiknaher Diskurse weitgehend auf.

363 Dazu Eva Rühmkorf: „Mir scheint, dass wir, jedenfalls die Generation, der ich angehöre, stark geprägt sind von dieser Nebenwiderspruchstheorie: Nämlich, wartet nur ab, wenn der Sozialismus kommt, wird der Rest sich von alleine regeln und dann seid ihr Frauen da, wo ihr eigentlich hinwollt. Die von der neuen Frauenbewegung beeinflusste und auch in uns hineingetragene Feminismus-Diskussion ist auch ein Versuch, das scheinbar Unvereinbare zu vereinbaren." (Eva Rühmkorf im Streitgespräch zwischen Frauen zum neuen Grundsatzprogramm der SPD, Veranstaltung der ASF am 14.08.1987 im Erich-Ollenhauer-Haus, Bonn, zit. n. Jahrbuch der SPD 1987: 232)

364 Auch Willy Brandt hatte einmal die Jusos ermahnt, dass die SPD kein „Debattierclub“ (Willy Brandt zit. n. Faulenbach 2011: 298) sei. Zur Debatte über die Bedeutung von Theoriediskussionen in der ASF vgl. ASF 1970a. 
Eine zentrale Konfliktlinie in der ASF bezog sich auf die Bedeutung der weiblichen Berufstätigkeit für die gesellschaftliche Stellung der Frau und ihre Emanzipation (vgl. Rechenschaftsbericht 1981: 16). Während das eine Lager für eine gesellschaftliche Anerkennung von Hausfrauen eintrat, den Hausfrauenlohn forderte und für eine Wahlfreiheit von Frauen zwischen Beruf und Familie eintrat, lehnte das frauenbewegte Lager die Familienfrau als Bezugspunkt für Frauenpolitik ab. Fürsorgearbeiten, wie sie z.B. in der Arbeiterwohlfahrt geleistet wurden, galten nicht als politisch. Die ehrenamtlich engagierten Genossinnen wurden deshalb von ihnen wenig geschätzt und nach und nach aus den Frauengruppen herausgedrängt (vgl. Wettig-Danielmeier 1984b). So zogen sich selbst bedeutende Genossinnen wie Marta Schanzenbach ${ }^{365}$ und Helene Schoettle ${ }^{366}$ bald aus der ASF und der Frauenpolitik zurück (vgl. Martiny 1984). In den 1980er-Jahren löste sich diese Konfliktlinie jedoch auf. Die ASF-Feministinnen definierten die privat geleisteten Care-Arbeiten als gesellschaftliche Tätigkeiten, gleichwertig zu beruflichem und politischem Engagement. Viele ASF-Aktivistinnen wurden Mitglied der AWO. Allerdings wurden auch weiterhin die Forderungen und Politiken maßgeblich aus der Perspektive der „Berufsfrauen“ entwickelt.

Eine weitere Konfrontationslinie betraf das feministische Paradigma der weiblichen Selbstbestimmung mit dem Recht auf individuelle Lebensgestaltung. Die ASF-Frauen unterstützten mehrheitlich den freien Zugang zu Berufen, zu Machtpositionen in Wirtschaft und Politik, die Wahl der Ehe und Lebensgemeinschaft, die Freiheit sexueller Identität und Beziehung und traten dafür ein, dass sich diese Forderungen in der Partei durchsetzten. In der Auseinandersetzung um die Straffreiheit der Abtreibung allerdings lehnte die Mehrheit der Frauen die Selbstbestimmungsperspektive ab. Die Forderung der ASF-Feministinnen nach ersatzloser Streichung des $§ 218$ ließ sich auch nach langjährigen Debatten nicht durchsetzen.

365 Marta Schanzenbach war Mitglied des Bundestags von 1949 bis 1972, ab 1958 Mitglied des Parteipräsidiums, später Frauenbeauftragte des Parteivorstandes, lange Jahre frauenpolitische Sprecherin der SPD-Bundestagsfraktion (vgl. Kurzbiographien des fes-Archivs, https://www.fes.de/archiv/adsd_neu/inhalt/nachlass.htm [Zugriff: o8.10.2013].

366 Helene Schoettle emigrierte 1933 nach England, baute nach dem Krieg 123 Nähstuben als Hilfe zur Selbsthilfe auf, war von 1951 bis 1975 Stadträtin in Stuttgart (vgl. www.helene-schoettle-schule.de [Zugriff: 08.10.2013]). 


\subsubsection{Grundlinien des sozialistischen Feminismus}

Die linkssozialistischen ASF-Aktivistinnen, die Ende der 1970er-Jahre die ASF-Bundesvorstandspolitik bestimmten und in den 1980er-Jahren immer stärker die Politik der ASF und ihre Stellungnahmen prägen konnten, bezeichneten sich in den Dokumenten selbst als „sozialistische Feministinnen“. Viele Frauen aus dieser Strömung waren bei den Jusos politisiert worden und orientierten sich an der Idee der „Doppelstrategie ${ }^{367}$ Sie teilten die kritische Sicht auf die eigene Regierungspolitik, das Bekenntnis zum Marxismus und den Wunsch nach einer "Rückkehr“ der Partei zur Klassenpartei. Im Gegensatz zur Juso-Mehrheit bestanden die Frauen aber auch auf einer Veränderung von privaten Lebenswelten, die von den linken Konzepten zu Strukturreformen und Besitzstandsänderungen nicht berührt wurden. Solche gesellschaftlichen Veränderungen waren nach den Vorstellungen der ASF-Frauen durch staatliches Handeln wesentlich beeinflussbar und konnten in kleinen, konkreten Reformschritten erreicht werden. Gleichzeitig waren die sozialistischen Feministinnen der ASF inspiriert von den Neuen Frauenbewegungen und nahmen deren Ideen zur Emanzipation und Herrschaftskritik auf, um patriarchale Strukturen in der Partei und den Ausschluss von Frauen aus Ämtern und Funktionen zu überwinden. Mit ihrer Selbstbezeichnung grenzten sie sich einerseits von den autonomen Feministinnen ab, denen sie vorwarfen, die Gestaltungsmacht der ökonomischen Verhältnisse zu verkennen (vgl. Randzio-Plath 1980; Konieczka 1983), andererseits wollten sie sich damit den Neuen Frauenbewegungen zuordnen und von der CDU-Frauenunion abgrenzen:

Die ASF ist mehr als nur eine nach den Richtlinien der SPD vorgesehene Arbeitsgemeinschaft der SPD. Im Gegensatz zur CDUFrauenvereinigung versteht sie sich nicht als der Erfüllungsgehilfe der Partei. Während die CDU-Frauenvereinigung mit dafür sorgt, daß die Gesamtpartei in der öffentlichen Auseinandersetzung und Darstellung zum traditionellen Frauenbild zurückkehrt, versteht sich die ASF als ein Teil der Frauenbewegung und

367 Mit der sog. Doppelstrategie, der Übernahme von Machtpositionen in der Partei und der außerparteilichen Mobilisierung von ArbeiterInnen, StudentInnen, Lehrlingen, sollten systemüberwindende Reformen durchgesetzt werden, um eine sozialistische Umgestaltung der deutschen Wirtschaft und Gesellschaft auf einem nicht gewaltsamen Weg der Veränderung zu erreichen (vgl. Thörmer/Einemann 2007; Faulenbach 2011: 290-301). 
hat bereits in einigen Regionen ein Selbstverständnis als feministische Sozialistinnen gewonnen. (Rechenschaftsbericht 1979: 29)

Die Debatten zur inhaltlichen Verschränkung von Feminismus und Sozialismus, die den Aktivistinnen als ein theoretischer "Spagat“ zwischen Arbeiterbewegung und Frauenbewegung erschien, wurden nicht nur in der ASF geführt, sondern es fanden dazu auch öffentliche Veranstaltungen statt ${ }^{368}$. An der Gesprächsrunde zum Thema „Feminismus und Sozialismus" am 23.06.1987 in Bonn kamen Vertreterinnen aus Gewerkschaften, Kirchen, Frauenprojekten und Arbeiterwohlfahrt zusammen. Die Jusos veranstalteten am 14.08.1987 eine Diskussionsrunde mit dem Titel „Ist Sozialismus ohne Feminismus möglich - gesellschaftliche Gleichheit - eine Utopie?", an der Gisela Erler, die Verfasserin des Müttermanifests, und Elisabeth Vogelheim ${ }^{369}$ teilnahmen.

Mehrere Jahre diskutierte die ASF über programmatische Fragen, dann verebbte diese Debatte Ende der 1980er-Jahre: „[I]rgendwo teilten wir die Erkenntnis, dass das uns nicht weiterbringt" (Zz 7$)$. Der Feminismus hatte unterschiedlichste Strömungen entwickelt und Anhängerinnen gewonnen, der Zusammenbruch des DDR-Regimes hatte den Sozialismus als gesellschaftliche Utopie diskreditiert und in der Partei hatten sich kontroverse Lager an neuen Themen formiert.

An einem politischen Profil, das die ASF gegenüber der Partei und den politisch konkurrierenden Frauenorganisationen identifizierbar machte, wurde allerdings weitergearbeitet. Frauenarbeitsgemeinschaften entwickelten politische Leitlinien ${ }^{370}$, verfassten politische Selbsterklärungen ${ }^{371}$ und zur Diskussion um ein neues Grundsatzprogramm in der Partei erschienen Extraausgaben des Sozialdemokratischen Informationsdienstes und mehrere Diskussionsmaterialien ${ }^{372}$, um die ASF-Gesamtorganisation in diese Auseinandersetzungen einzubeziehen. Die

368 „Sozialistinnen im Spagat?“ Juso-Fachtagung 15.02.1987, zit. n. Jahrbuch der SPD \{1986/87\}: 168 .

369 Elisabeth Vogelheim, Personalmanagement bei VW und IG-Metall-Funktionärin, später Mitglied im ÖTV-Vorstand.

370 Vgl. z.B. Antrag E3 auf der Bundesfrauenkonferenz 1981 (Dokumente 14/1981).

371 Vgl. z.B. ASF Bezirk Mittelrhein o.A.; ASF-UB Düsseldorf 1986.

372 Frauen diskutieren den Entwurf für ein neues Grundsatzprogramm der Sozialdemokratischen Partei Deutschlands. Arbeitsheft 1987; Materialienband Frauen brauchen mehr 1988; Dokumentation der Programmwerkstatt „Die Spaltung überwinden - zur gesellschaftlichen Gleichstellung von Frau und Mann“ am 27.04.1988 in Bonn; Materialien zur programmatischen Diskussion 1987/1988; Dokumentation der Gesprächsrunde „Ist Sozialismus ohne Feminismus möglich?" 23.06.1987. 
Programmdebatte der SPD war auch Schwerpunktthema der ASF-Bundeskonferenz 1987 „Wer die menschliche Gesellschaft will, muss die männliche überwinden"373.

Als Strömung der Neuen Frauenbewegungen lässt sich das sozialistisch-feministische Lager der ASF durch drei Grundausrichtungen definieren, deren Verschränkungen von marxistisch/klassenorientiert, staatsmachtbezogen/wohlfahrtsstaatlich reguliert und geschlechterdualistisch/gleichheitsfeministisch ihre normativen Orientierungen, politischen Stellungnahmen, Forderungen und die Anschlusspunkte bestimmten, mit denen die ASF-Aktivistinnen versuchten, ihre Vorstellungen einer anderen Geschlechterordnung in der Partei durchzusetzen. In einem Beitrag zum 10-jährigen Bestehen der ASF formuliert die Vorsitzende Inge Wettig-Danielmeier diese Ausrichtung wie folgt:

Die in allen Ländern entstehende Frauenbewegung Anfang der 7oer-Jahre hat die Sozialdemokratinnen deutlicher erkennen lassen als je zuvor, daß zwar nur eine sozialistische Partei ihre Vorstellungen von Demokratie verwirklichen kann, daß aber auch nur ein aktiv vertretener Feminismus diesen Sozialismus zu seiner demokratischen Vollendung bringen kann. (WettigDanielmeier 1984b: 173)

\section{Marxistisch-klassenorientierte Dimension}

„Frauen und Arbeiter haben gemein, Unterdrückte zu sein“ (Bebel 1964: 35). Diese Aussage von August Bebel ordnete die Frauenpolitik in einen systemüberwindenden Bewegungszusammenhang ein. Hieran anknüpfend wandten sich die ASF-Aktivistinnen gegen eine Frauenpolitik der Partei, die die Geschlechterordnung als „natürlich“ gegeben ansah und für welche die wichtigsten Fraueninteressen Familienthemen betrafen. Die Juso-Bundeskonferenz 1973 kritisierte das bürgerliche Kleinfamilienideal in der SPD (Juso 1977: 6f.). Für die Jusos war die Familie vielmehr „eine Institution des Klassenstaats (vgl. Juso 1977)“. So würden in der Familie Verhaltensweisen gelernt und adaptiert, die für das Funktionieren der kapitalistischen Produktionsweise und des Systems notwendig wären. Der Kapitalismus wäre von einem „absoluten Gegensatz“ zwischen Familie und Berufsleben geprägt, der den Frauen den Familienbereich, den Ehemännern die Rolle des Alleinversorgers und damit auch den Zugang zum „öffentlichen Bereich“ zuwiese und sicherte. Unabhängig von der Klassenzugehörigkeit sorgte eine geschlechterspezifische Erziehung 
für die Reproduktion dieser Verhältnisse. Sie richtete die jungen Mädchen auf die Mutterrolle aus, stattete sie mit geringer Bildungsmotivation aus und legte damit die Grundlage für ihre spätere Benachteiligung in der Berufswelt. Die schlechten Erwerbschancen wiederum drängten die Frauen in die Familienrolle und stärkten die Vorherrschaft des Mannes, in der Gesellschaft wie in der Familie. Unterprivilegierung und Doppelbelastung wären deshalb keine Folgen unterschiedlicher geschlechtlicher Veranlagungen, sondern Ergebnis gesellschaftlich geschaffener Bedingungen ${ }^{374}$.

Der Emanzipationskampf der Frauen hätte eine für das kapitalistische System transzendierende Bedeutung, weil er die Auflösung von Hierarchien und Diskriminierungen außerhalb des Klassengegensatzes Kapital und Arbeit thematisierte. Damit könnten die Frauen „zu Anwälten all derer werden, für die in unserer Gesellschaft niemand spräche: der Alten, Kranken, Kinder, Jugendlichen, Behinderten und Benachteiligten" (Juso-Bundeskongress 1973: 16). Frauen sammelten mit diesen Gruppen vergleichbare Ausschließungserfahrungen: „Diskriminierungen und Benachteiligungen, unter denen wir leiden, treten bei uns nur gehäuft auf; sie sind Probleme vieler benachteiligter Gruppen in dieser Gesellschaft" (ASF-Bezirksvorsitzende Südbayern Sigrid Skarpelis-Sperk auf dem Parteitag 1975 zit. n. Parteitag der SPD 1975: 159).

Allerdings müsste der Kampf um weibliche Emanzipation dem sozialdemokratischen Ziel, für eine größere soziale Gerechtigkeit zu kämpfen, verbunden sein:

Frauenarbeit darf nicht zum Selbstzweck werden. Ihre Aufgabe ist es, die Probleme aus der Bevölkerung aufzugreifen und mit den betroffenen Gruppen an deren Lösung zu arbeiten (Bürgerinitiativen, Betriebsrätinnen, Frauenzentren, Elternbeiräte). (Juso, Bundesvorstand 1977: 75).375

Diese Konstruktion gemeinsamer Unterdrückung von Frauen und Lohnabhängigen richtete die sozialdemokratische Frauenpolitik auf eine

374 Der frauen- und familienpolitische Diskurs der SPD dagegen, so die ASF-Aktivistinnen, verhandelte die Vereinbarkeit von Familienpflichten und Beruf allein als frauenspezifisches Thema und setzte damit die Ungleichheit der Geschlechter voraus (vgl. AKE 1973).

375 Emanzipation schien nur unter veränderten gesellschaftlichen Verhältnissen möglich: „[D]as Bemühen der Frauen um Emanzipation, um ein Leben in Selbstbestimmung, wird nur Erfolg haben, wenn die Emanzipation der Frauen als Teil der gesellschaftlichen Befreiung von Fremdbestimmung gesehen wird." (Grundsätze für die Arbeit 1975: 3). Vgl. dazu auch die Vorlage zur Juso-Fachtagung zum „Jahr der Frau 1975“ (Juso, Bundesvorstand 1977: 73-75). 
Bündnispolitik mit den Gewerkschaften ${ }^{376}$ aus. Eine enge Kooperation mit den DGB-Gewerkschaften wurde über die Juso-Frauen hinaus von der Mehrheit der ASF-Frauen angestrebt, einen „feministischen Geschlechterkampf" lehnten sie ab ${ }^{377}$.

Individuelle Emanzipation schien den Sozialdemokratinnen nur durch die persönliche ökonomische Unabhängigkeit und mithin durch eine eigene Berufstätigkeit möglich. Ein zentrales politisches Anliegen der ASF war deshalb die Öffnung der Berufs- und Arbeitswelt für Frauen. Die Gleichstellung von Frauen in diesem gesellschaftlichen Segment bildete ein Kernthema ihrer Politikentwicklung, wobei Ideen und Forderungen vorrangig auf die Bedürfnisse und Interessen der einheimischen, uneingeschränkt arbeitsfähigen, weiblichen Erwerbstätigen mit und ohne Familienaufgaben ausgerichtet waren.

\section{Staatsmachtbezogene, wohlfahrtsstaatlich regulierende Dimension}

Im Staat sahen die ASF-Aktivistinnen den wichtigsten Akteur für die Umsetzung und Sicherung des Gemeinwillens, die parlamentarische Demokratie galt ihnen als Ort für die Aushandlung gesellschaftlicher Interessen, auch derjenigen der Frauen ${ }^{378}$. Diese Vorstellungen kennzeichnen das damalige wie aktuelle politische Grundverständnis der Zeitzeuginnen:

[V]or allen Dingen wird das Patriarchat ja insbesondere dann, wenn es Gesetze gibt, auch an Regeln gebunden, und diese Regelgebundenheit, die eben autonome Frauen abgelehnt haben, weil es Herrschaftsinstrumente sind, das sind ja nicht nur männliche Herrschaftsinstrumente, ne(?), das sind Herrschaftsinstrumente, die in demokratischen Systemen ihre Berechtigung und ihre Legitimation haben. (Zz 7 )

Gesellschaftliche Veränderungen mussten deshalb durch staatliche Verordnungen durchgesetzt oder gesichert werden:

376 Die Bündnispolitik war nicht kritiklos. Als im November 1977 der DGB in Dortmund eine Großdemonstration für Kernenergie mit 40.ooo Teilnehmenden mobilisierte, gehörte die ASF zum minderheitlichen Lager der innerparteilichen KritikerInnen, die zunächst die staatliche Kontrolle der Technologie forderten, um Folgeprobleme und wirkungen zu steuern, wenig später aber den Ausstieg aus der Kernenergie.

377 Vgl. Randzio-Plath 1980 zit. n. Lenz 2008: 353.

378 Dagegen galt der Staat den autonomen Frauenbewegungen der 1970er- und 1980erJahre eher als Gesamtpatriarch, der in seiner Substanz einen Männerbund (vgl. Kreisky 1995) bildete und die asymmetrische Verteilung von Macht und Ressourcen zwischen den Geschlechtern zuungunsten von Frauen schützte und reproduzierte (vgl. Biester et al. 1991). 
[W]enn man etwas ... wenn man gesellschaftliche Verhältnisse ändern will, dann kommt doch irgendwann der Punkt, wo man auch ein Gesetz ändern muss. (Zz 6)

Politik bedeutete für die linkssozialistischen ASF-Aktivistinnen, konkrete Forderungen und pragmatische Maßnahmen für eine Veränderung der Geschlechterordnung zu entwickeln, ggf. alternative Strukturen und Reglements zu definieren und Mehrheiten in den Parteigremien zu gewinnen, um über die MandatsträgerInnen gesetzliche Änderungen und einen Wandel im staatlich-institutionellen Handeln durchzusetzen:

[...] [D]ie autonome Frauenbewegung hat VIEL dazu beigetragen, gesellschaftliche Bewusstseinsprozesse zu verändern, aber die harte Arbeit in den Niederungen der Politik, die muss ja auch gemacht werden. Und da wir ja alle IN der SPD waren und aus der SPD kamen, WUSSTEN wir das auch. (Zz 6)

Die ASF-Aktivistinnen hielten deshalb den Vorwurf von autonomen Feministinnen, der lange Marsch durch die Institutionen ende als Selbstaufgabe(379, für elementar unpolitisch. Vielmehr schätzten sie ihre Arbeit in der Partei als unverzichtbares Veränderungshandeln ein: „Wir dürfen unsere Verdienste als Frauen in der SPD nicht unterbewerten. Wir waren diejenigen, die vielfach die inhaltlich gleichen Ziele parallel zur Frauenbewegung umsetzten." (Randzio-Plath 1980: 354) Dabei waren sie überzeugt von der „Erneuerungskraft von Parteien“ (ebd.) und sahen sich als Mitakteurinnen in einem zutiefst demokratischen Prozess, wie eine Zeitzeugin erklärte:

[I]ch persönlich habe es immer als Herausforderung gesehen ... auf der einen Seite neue Ideen, neue Gedanken zu entwickeln, aber die auch möglichst so zu VERMITTELN, also Leute hinter sich zu bringen, dass man sie auch dem normalen Menschen im Ortsverein verklickern kann. (Zz 14)

Den autonomen Frauenbewegungen warfen die ASF-Aktivistinnen Flucht vor der Macht vor (vgl. Martiny 1986). Um die Gefahr der Anpassung zu umgehen, verzichteten sie, so der Vorwurf, auf politische Entscheidungspositionen und unterstützten damit Macht und Machtmythos der Männer.

Aus Enttäuschung über die geringen Veränderungen in der SPD verlor das feministische ASF-Lager einige Mitkämpferinnen an die autonomen Frauengruppen, die Mehrheit aber blieb der Partei tief verbunden. Für sie konnte nur die SPD eine gesellschaftsverändernde Frauenpolitik 
umsetzen, wie Christa Randzio-Plath, eine der feministischen ASF-Aktivistinnen, erläuterte: Nur die SPD

bietet den Rahmen für Übersetzungsversuche, die wir Frauen gestartet haben. [...] Nur in den bestehenden Organisationen aus der Arbeiterbewegung stimmen die Ziele und nur dort geht es um die Beteiligung an der Gestaltung der Gesellschaft, um die es uns Frauen geht. (Randzio-Plath 1980: 355)

Die ASF und ihre unterschiedlichen Strömungen waren deshalb auch bei zeitweilig scharfer öffentlicher Distanzierung von Politiken der eigenen Partei immer der Unterstützung der SPD und ihrem Kampf um die Regierungsmacht verpflichtet.

Geschlechterdualistische, gleichheitsfeministische Dimension

Anders als in der alten Frauenbewegung des 19. und frühen 20. Jahrhunderts hatte in den Neuen Frauenbewegungen das individuelle Recht auf Selbstbestimmung eine zentrale Bedeutung (vgl. Gerhard 1991, 1999). „Selbstbestimmung der Frau“ hieß für die ASF-Aktivistinnen dabei sowohl die Gleichwertigkeit und Eigenständigkeit des Emanzipationskampfes der Frauen im Vergleich zu anderen gesellschaftspolitischen Konflikten als auch das Selbstvertretungsrecht von Frauen in politischen Entscheidungsstrukturen.

Die Parole der Neuen Frauenbewegungen „Das Private ist politisch“ übersetzten die ASF-Aktivistinnen in doppelter Weise. Sie forderten die Abkehr von einer Politik, die sich vorrangig auf „männliche“ Lebenswelten bezog und die die Familien- und Geschlechterbeziehungen zur Privatsphäre erklärte, und sie forderten eine Änderung des alltäglichen Umgangs der männlichen Parteimitglieder mit Frauen, den Genossinnen, ihren Ehefrauen oder Partnerinnen. Dies führte zu heftigen Streits, wie eine Zeitzeugin von einem Treffen der Programmkommission 1986 berichtete:

Oh, da weiß ich noch, dass ich gesagt habe [...] NATÜRLICH bist du für die Gleichstellung, NATÜRLICH bist du für die ... für die Berufstätigkeit der Frau und dann schickst de deine Frau aufs Land, setzt se in eine GRÜNE Villa und machst ihr drei Kinder und sagst'de: wenn sie will, kann se ja'. Und der ist mir bald ins GESICHT gesprungen. Ich habe das ,DU‘ eigentlich wie ,MAN ${ }^{\star}$ gebraucht. Und es hat ihn so genau getroffen (lacht), ich kannte dessen Verhältnisse gar nicht so gut, aber ich hatte genau getroffen. Also es gab einen riesen Tohuwabohu. (Zz 5) 
ASF-Politikkonzepte gründeten stets auf einem geschlechterdualistischen Gesellschaftsbild ${ }^{30}$, in 1980er-Jahren veränderte sich jedoch der Blickwinkel. Frauenzentrierte Konzepte wurden durch geschlechterbezogene abgelöst. Männer und Frauen galten damit als gleichermaßen diskriminiert und in ihren Geschlechterrollen beschädigt: „Weder Männer noch Frauen dürfen ihre Fähigkeiten und Eigenschaften, ihre Gefühle voll leben - soweit sie nicht typisch männlich oder typisch weiblich sind." (Wettig-Danielmeier zit.n.: Jahrbuch der SPD \{1986/87\}: 726)

Männer waren mit dieser Umkonzipierung der Zweigeschlechtlichkeit - zumindest theoretisch - Bündnispartner im Kampf um die Überwindung einer gespaltenen Gesellschaft:

Wir wollen eine Gesellschaft, die nicht mehr gespalten ist in Menschen mit, weiblichen' und in Menschen mit ,männlichen' Denk- und Verhaltensweisen, eine Gesellschaft, in der Arbeit nicht mehr gespalten ist in Erwerbsarbeit und in Haus- und Familienarbeit; in der Erwerbsarbeit nicht mehr Männern zugeordnet und daher hoch bewertet wird und Haus- und Familienarbeit Frauen zugewiesen und damit niedrig bewertet wird. Wir wollen eine Gesellschaft, in der jeder Mensch sowohl emotional als auch rational sein darf und sein soll, in der nicht die eine Hälfte der Menschen dazu erzogen wird, die andere zu unterdrücken und in der nicht die andere Hälfte dazu erzogen wird, sich unterdrücken zu lassen. (Wettig-Danielmeier 1985b: 17)

Die Dekonstruktion der Geschlechter sollte Maßgabe der Politik ${ }^{381}$ sein, statt durch wohlfahrtsstaatliche Leistungen die Geschlechtertrennung $\mathrm{zu}$ reproduzieren und zu stabilisieren.

Ein wichtiges Dokument für den Gleichheitsfeminismus war das 1979 erschienene Frauenprogramm. Hierin hatte Marie-Louise Janssen-Jurreit Reformen und Maßnahmen zur Gleichstellung der Geschlechter zusammengetragen, um zu beweisen, dass konkrete Veränderungspolitiken möglich waren (vgl. Janssen-Jurreit 1979) ${ }^{382}$. Unter der gleichstellungspolitischen Rahmung wurden jedoch vorwiegend frauenspezifische Förderungsmaßnahmen aufgeführt.

Von ihrer eigenen Partei erwarteten die ASF-Frauen Frauenförderpläne und konkrete Aktivitäten. In der SPD sollten weibliche Mitglieder

380 Zu Leitbildern über Geschlechterverhältnisse in der Politik vgl. Rosenbauer/Sauer 2004.

381 Hinweise auf Diskurse über Strategien der Dekonstruktion waren in den Dokumenten, die im Forschungszeitraum erstellt waren, nicht zu finden.

382 Anlass war die Umsetzung des Weltaktionsplans von Mexico City und der Europäischen Gleichbehandlungsrichtlinie in nationalen Politiken. An der Erstellung des Buches waren unter anderem ASF-Frauen beteiligt. 
bessere Mitsprache- und Entwicklungschancen finden, als sie in der Gesellschaft angeboten wurden.

Mit dieser Forderung nach größerer Partizipation der Frauen an Partei und Politik verbanden die SozialdemokratInnen unterschiedliche Vorstellungen. Für die einen erweiterte die Teilhabe der Frauen die Legitimation und Wirksamkeit demokratischer Systeme (vgl. RandzioPlath 1980), andere - und auch dazu gehörten männliche Mitglieder (vgl. Hoecker 1985) - erhofften sich von der Teilhabe der Frauen eine kulturelle Veränderung der Partei, weibliche Mitwirkung sollte für mehr Wärme und Menschlichkeit in der Politik sorgen ${ }^{383}$.

Den meisten ASF-Feministinnen war es wichtig, in den Parteigremien nicht als Frauenpolitikerinnen etikettiert zu werden, die sich ausschließlich um die soziale Lage der Frauen kümmerten oder dafür zuständig waren; vielmehr hatte sich der frauenpolitische Blick auf alle gesellschaftlichen Themen zu richten. Die Abgrenzung von einer Personengruppenpolitik definierte die feministische SPD-Bundestagsabgeordnete Anke Martiny als wichtige Differenz zu den autonomen feministischen Frauengruppen:

[...] [I]n unserer Gesellschaft gibt es noch weit Schlimmeres, als eine Frau zu sein. Muß man nicht froh sein, daß man weder Ausländer, behindert, politischer Flüchtling, alt oder psychisch krank ist? Als Frau in der SPD will ich mein Recht (und ich kriege es oft nicht); ich will aber auch, daß andere Schwache ihr Recht kriegen. (Martiny 1980: 36)

\subsubsection{Die Logos der ASF}

Im Verlauf der 1970er- und 1980er-Jahre verwendete die ASF unterschiedliche Logos. Mit Logos wurden bundesweite Dokumente und Veröffentlichungen, wie Broschüren, Plakate und Flugblätter, sowie interne Schriften gekennzeichnet. Die veränderten Logos symbolisieren die unterschiedlichen Verortungen der ASF bezüglich der Frauen- und ArbeiterInnenbewegung und ihr Selbstverständnis in der Partei. Die Logos wurden in unterschiedlichen Zeitetappen verwendet, allerdings nicht immer einander ausschließend ${ }^{384}$ :

383 Eine Vorstellung, die sich durch den gesamten Partizipationsdiskurs zog und sowohl vom konservativen als auch vom links-feministischen Lager geteilt wurde.

384 Leider war nur eine ungefähre historische Zuordnung der Logos möglich. 
Abb. 2: Die Logos der Arbeitsgemeinschaft Sozialdemokratischer Frauen

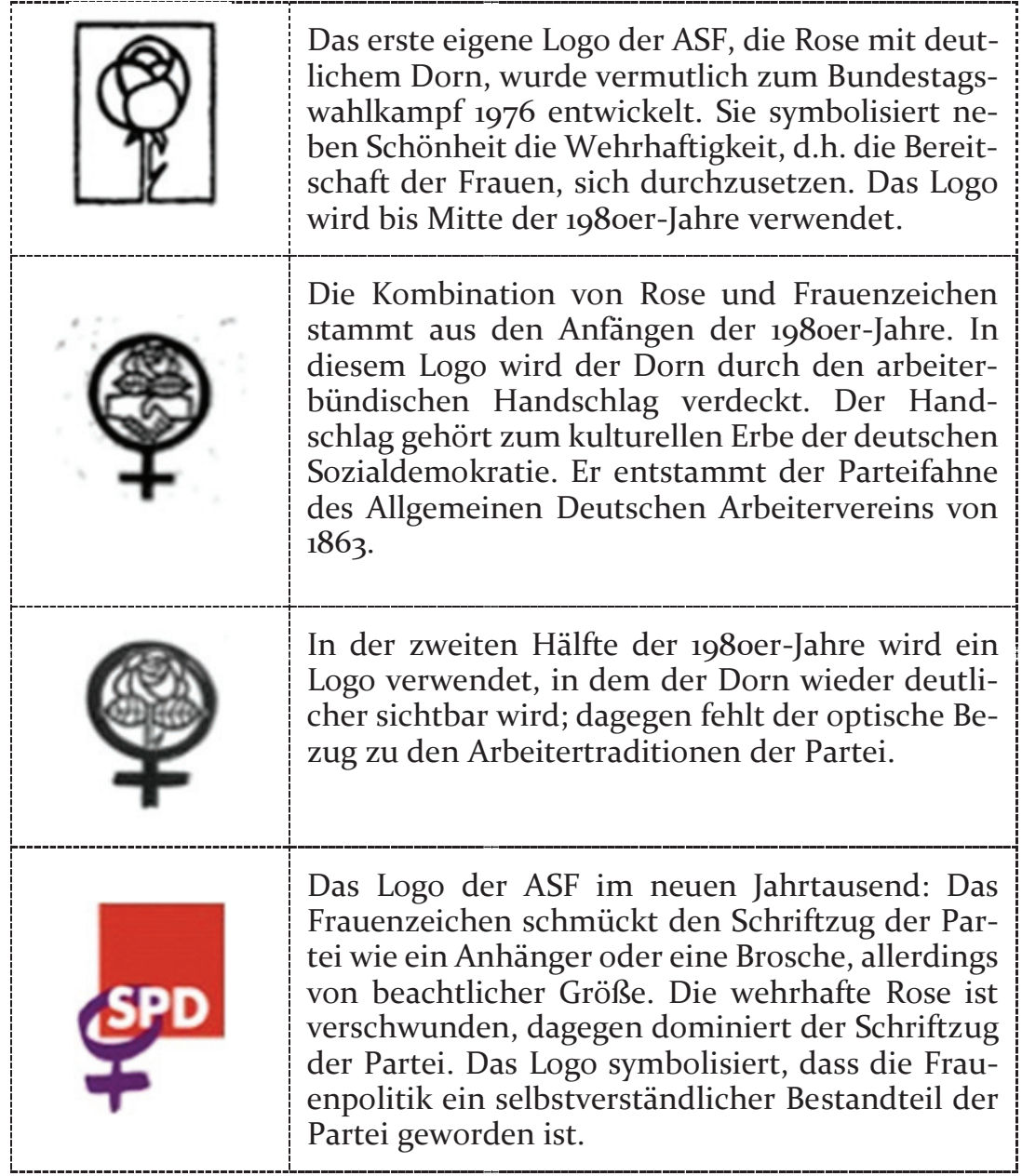

Quellen: (1) Rose mit Dorn = Flugschrift Aktuelles für Frauen \$218 StGB aus dem Jahre 198o. https://fmt-bildarchiv.faust-web.de/zvimg.FAU?sid=38F8186o\&dm=1\&qpos=3585\&erg=H \&ipos=1\&rpos=faust.jpg\&hst=1 [Zugriff: 03.02.2014]. (2) Rose mit arbeiterbündischem Handschlag = Rechenschaftsbericht 1985: Deckblatt. (3) Rose mit Blattwerk ohne Handschlag = Rechenschaftsbericht 1987: Deckblatt. (4) Frauenzeichen kombiniert mit SPDSchriftzug = ASF-Flyer 2006 . 


\subsubsection{Politikfelder der ASF}

1977 erschien der Text Grundforderungen der Arbeitsgemeinschaft Sozialdemokratischer Frauen (Dokumente o7 und 08/1977), den der ASFBundesvorstand nach der gescheiterten Programmdebatte auf der Braunschweiger Frauenkonferenz 1975 herausgab, um dem Wunsch nach einem politischen Profil der ASF nachzukommen. Unter den Leitforderungen „Gleichberechtigte Erwerbsarbeit der Frauen“, „Humanität und Solidarität in allen gesellschaftlichen Bereichen“, „Beteiligung aller an Willens- und Entscheidungsprozessen“ fand sich unterteilt nach „Arbeitswelt", „Bildung" und „Familie, Wohnen und Erholung“ eine Sammlung frauenpolitischer und sozialdemokratischer Forderungen. In den Folgejahren wurde der Text jedoch nicht weiter überarbeitet. Weitere programmatische Positionen und Politikkonzepte z.B. zur Rentenreform, zu einem Antidiskriminierungsgesetz o.ä. sowie Einzelforderungen wurden auf themenspezifischen Fachtagungen entwickelt und zusammengetragen. Sie wurden in den Schriftenreihen Reihe Frauenpolitik und Frau und Gesellschaft, später Sozialdemokratischer Informationsdienst. Frau und Gesellschaft, ab Dokumente Nr.25/1986 als Sozialdemokratischer Informationsdienst. Frauen in der SPD dokumentiert und vom ASF-Bundesvorstand herausgegeben ${ }^{385}$. Diese Quellen wurden für die folgenden Unterkapitel ausgewertet.

\subsubsection{Erwerbstätigkeit und Arbeitswelt}

Die Berufstätigkeit galt zunächst nicht als Schlüssel zur Emanzipation der Frau. Die Partei trat für eine Wahlfreiheit zwischen Familie und Beruf ein und auch die erste ASF-Vorsitzende nach der Neugründung der ASF 1973, Elfriede Eilers, unterstützte diese Position (vgl. Eilers 1974a). Wahlfreiheit forderte auch die zweite Bundesfrauenkonferenz der ASF 1975 (vgl. Wettig-Danielmeier 1984b). Dies geschah jedoch bereits gegen ein anwachsendes Lager kritischer Gegenstimmen, das durch die Neueintritte junger ausgebildeter erwerbstätiger Sozialdemokratinnen gestärkt wurde. Für sie bedeutete die Berufstätigkeit, sich einen Weg aus der Isolation der Kleinfamilien in ökonomische Unabhängigkeit und gesellschaftliche Anerkennung zu schaffen. Die Anhängerinnen der Wahlfreiheit aber fürchteten, dass die SPD mit einer Forderung nach Erwerbstätigkeit viele weibliche

385 Als Literaturhinweise werden die beiden Schriftenreihen mit ihren Nummerierungen angegeben: die Reihe Frauenpolitik unter $f$, die Reihe Frau und Gesellschaft mit den folgenden Umbenennungen unter Dokumente. 
Beschäftigte nicht erreicht könnten, weil für sie in der Erwerbsarbeit nur ökonomischer Zwang und Entfremdung, aber keine Selbstentfaltung zu entdecken wäre ${ }^{386}$. Den frauenbewegten ASF-Aktivistinnen galt aber die Wahlfreiheit als „Lebenslüge der Männergesellschaft" (WettigDanielmeier 199ob: 9) ${ }^{387}$ :

Im Gewande eines oberflächlichen Fortschritts zementiert die Wahlfreiheit für die Frauen die alten Rollen. Die einen müssen sich der Mehrfachbelastung aussetzen, weil das Familieneinkommen nicht reicht. Die anderen werden mehr als Rabenmütter verteufelt, weil sie nicht auf Erwerbstätigkeit verzichten, obwohl sie sich das leisten könnten. (ebenda)

Obwohl diese Auseinandersetzung noch in den 1980er-Jahren die Debatten in der ASF prägte, beschloss die Bundesfrauenkonferenz in Siegen 1977, die unter dem Motto „Recht auf Arbeit - Frauen in die Politik“ stattfand, mit Mehrheit, dass die Erwerbstätigkeit für die Frauen ein unabdingbarer Schritt zur persönlichen Emanzipation wäre: „Arbeit bedeutet für Sozialdemokraten mehr als Vollbeschäftigung und Geldverdienen. Das heißt, daß der Mensch sich durch seine Arbeit verwirklichen können soll“" (Dokumente o6/1977: 6). Für Frauen bedeutete Berufstätigkeit mehr als ökonomische Unabhängigkeit, die Arbeitsbeziehungen schafften persönliche Kontakte ${ }^{38}$ und öffneten den Frauen Zugang zu Verbänden und politischem Engagement, sie gab ihnen Selbstbewusstsein und bewahrte sie vor der Altersarmut ${ }^{389}$. Mit dieser Neukonzipierung erhielt die ASF ein gegenüber der CDUFrauenunion deutlich differentes politisches Profil, denn im Aktionspro-

386 Hierzu auch Katharina Focke: „[W]as wir nicht wollen, das ist, ein veraltetes Leitbild, das die Frau ausschließlich als Mutter, Ehefrau und Hausfrau darstellte, durch ein neues ersetzen, etwa das der in jedem Fall berufstätigen Frau." (Katharina Focke zit.n. Dokumente 2/1974: 5, vgl. auch Renger 1993)

387 Das Recht auf uneingeschränkte Berufstätigkeit für Frauen war in der Parteiengeschichte der SPD häufig umstritten. Der starke Flügel der Lassallianer trat für ein Verbot der Frauenarbeit ein, weil Frauen als Konkurrentinnen und Lohnsenkerinnen angesehen wurden. Immer wieder wurde in der Sozialdemokratie über Zulassungsbeschränkungen diskutiert. Das Recht auf freie Erwerbstätigkeit gehört nach Ute Gerhard eher in die bürgerlich-frauenrechtlerische Tradition als in die der ArbeiterInnenbewegung (vgl. Gerhard 1991; Wettig-Danielmeier 1984b).

388 Dies wurde durch die Untersuchung Working Wives von Viola Klein aus dem Jahr 1960 unterstützt. Der Mangel an Sozialkontakten war das am häufigsten genannte Motiv der Frauen für ihre Erwerbstätigkeit (vgl. Lepsius 1968: 31).

389 Der Zwischenbericht der Frauen-Enquête-Kommission des Deutschen Bundestages unter dem Vorsitz von Dr. Helga Timm kam 1976 zu vergleichbaren Ergebnissen (vgl. Pausch-Gruber 1978). 
gramm der Konservativen Wahlfreiheit sichern - Partnerschaft verwirklichen 1978 wurde weibliche Berufstätigkeit als eine gleichwertige Wahloption zur Familienarbeit definiert ${ }^{390}$.

Auf der Bundeskonferenz in Siegen 1977 stellte die ASF eine Reihe von Forderungen auf, die fortan in das politische Portfolio der ASF gehörten. Ziel der ASF war es, zum einen die Diskriminierungssysteme in der Arbeitswelt abzuschaffen, darunter die Beschäftigungs- und Berufsverbote für Frauen ${ }^{391}$, und zum anderen Maßnahmen zu definieren, mit denen die bestehenden geschlechtsspezifisch ungleichen Zugänge und Entwicklungmöglichkeiten auf dem Arbeits- und Berufsmarkt kompensiert werden könnten. Gefordert wurde gleicher Lohn für gleiche Arbeit, die Quotierung von Ausbildungs- und Arbeitsplätzen, die Beendigung der Lohndiskriminierungen durch eine Veränderung der Lohngruppensysteme und Leistungsbewertungen ${ }^{392}$, die Einführung eines Mindestlohns sowie Regelungen zur Vereinbarkeit von Beruf und Familie ${ }^{393}$. Sämtliche frauenspezifischen Arbeitsschutzregelungen lehnte die ASF bis auf die zum Mutterschutz ab. Dieser sollte zeitlich erweitert und in seiner arbeitsplatz- und statussichernden Funktion ausgebaut werden. Darüber hinaus nahm die ASF die gewerkschaftlichen Forderungen zur „Humanisierung der Arbeitswelt“ auf und forderte das Verbot von Überstunden, Akkord-arbeiten und die Verlängerung des Jahresurlaubs.

Als Mitte der 1970er-Jahre die Arbeitslosigkeit einen anwachsenden Anteil arbeitsfähiger Bevölkerung betraf, schloss sich die ASF der DGBForderung nach einem Vollbeschäftigungsgesetz an. Die dazu entwickelte Kampagne „Recht auf Arbeit“ sollte die Forderung nach einer entsprechenden Verfassungsänderung unterstützen. Sie wurde

390 Im Aktionsprogramm Wahlfreiheit sichern - Partnerschaft verwirklichen der Frauenvereinigung der CDU 1978 heißt es: „Die Emanzipation der Frau, verstanden als Befreiung von der Familie und als Freiheit durch Erwerbstätigkeit, hat in eine Sackgasse geführt. Die CDU setzt dagegen ihren Begriff Partnerschaft, der es Mann und Frau erlaubt, sich frei nach den eigenen Fähigkeiten und innerhalb der gesellschaftlichen Möglichkeiten zu entfalten. Deshalb fordert sie Wahlfreiheit. Die jeweils getroffene Wahl ist im Prinzip gleichwertig. So fügt sich die Politik der CDU für die Frau in ihre Gesellschaftspolitik ein." (Aktionsprogramm '78 1978)

391 Berufsverbote bestanden im Bergbau, bei der Polizei und beim Bundesgrenzschutz. Eine Öffnung der kämpfenden Einheiten für Frauen lehnte die ASF ab.

392 In den Lohngruppenhierarchien der Tarifsysteme wurden Arbeiten, die hohe Muskelkraft erfordern, höher bewertet und deshalb besser bezahlt als psychisch fordern-de Leistungen oder Dauerbelastungen. Darüber hinaus erhielten Männer häufig Familienzuschläge, die aber alleinerziehenden Frauen nicht gewährt wurden (vgl. Dokumente 11/1979).

393 Für das Vereinbarkeitsthema wurden erst in den 198oer-Jahren konkretere Forderungen entwickelt. 
aber vom Parteivorstand nicht genehmigt. Die Parteispitze stand mehrheitlich hinter der nachfrageorientierten Regierungspolitik Helmut Schmidts und verteidigte sie im wachsenden Konflikt mit den Gewerkschaften. Als der DGB die Forderung nach einer Gesetzesänderung zugunsten einer Strategie der Arbeitszeitverkürzung aufgab, schwenkte auch die ASF auf die Forderung nach einem „6-Stunden Tag“ um (vgl. Dokumente 15/1981)394.

Diese Verkürzung der täglichen Arbeitzeit hatte für die ASF eine familien- und eine emanzipationspolitische Dimension. Die Beteiligung an Familienarbeiten könnte, so die ASF-Frauen, von den Ehemännern und Vätern nur bei einer zeitlichen Verringerung des beruflichen Einsatzes erwartet werden. Nur ein verkürzter Arbeitstag könnte für Mütter Vollzeitbeschäftigung und damit eine vollwertige Erwerbstätigkeit ermöglichen. Teilzeitarbeit, wie sie von vielen Frauen als individuelle Lösung für die Vereinbarkeit von Beruf und Familien gewählt und gewünscht wurde, lehnte die ASF als Ausbeutungsverhältnis $395 \mathrm{ab}$, weil die Frauen diese Arrangements meist mit einer Arbeitsverdichtung und dem Verzicht auf berufliche Karriere bezahlten ${ }^{396}$. Außerdem konnte nur eine Vollzeitbeschäftigung im Alter ein Leben jenseits der Armutsgrenze garantieren 397 (vgl. Dokumente 23/1984).

Im Zuge der Programmdiskussion in der Partei in den 1980er-Jahren beteiligte sich die ASF an den Diskursen über das Ende der Arbeits-

394 Die Strategie war innerhalb der Gewerkschaften und damit auch der ASF umstritten. Angesichts von Rationalisierung und Technisierungswelle fürchteten viele, die Verdichtung der Arbeit mit einer Arbeitszeitverkürzung voranzutreiben (vgl. Dokumente 17/1982). Viele GewerkschafterInnen forderten stattdessen die Herabsetzung des Renteneintrittsalters, um das vorhandene Arbeitsvolumen auf mehr Beschäftigte zu verteilen (vgl. Diskurs zum Thema Arbeitszeitverkürzung auf den Fachtagungen „Arbeitszeitverkürzung und Gleichstellung der Frau“ 22./23.10.1982, dokumentiert in: Dokumente 21/1983; „Neue Technologien - Auswirkungen auf Lebenszusammenhänge von Frauen“ 26.-28.01.1984, dokumentiert in: Dokumente 23/1984; „Frauen und die Informations- und Kommunikations-Technologien" vom 26.04.1989, dokumentiert in: Dokumente 29/1989).

395 Vgl. dazu ASF 1979a. Die Ablehnung der Teilzeitbeschäftigung entsprach auch den gewerkschaftspolitischen Positionen des DGB.

396 Teilzeitbeschäftigung war in den Vorstellungen der ASF ausschließlich mit niedrig qualifizierten Arbeiten verbunden. Teilzeitarbeiterinnen wurden als Druckmittel gegen die Stammbelegschaften eingesetzt, die diese um ausgehandelte Arbeits- und Lohnbedingungen brachte. Diese grundsätzliche Ablehnung blockierte die konstruktive Auseinandersetzung mit den sich neu entwickelnden Arbeitsbedingungen.

397 Zwar entwickelten sich prekäre Arbeitsverhältnisse bereits in den 1980er-Jahren, aber die vollzeitarbeitenden Working poors galten als eine systemwidrige Randerscheinung, die einer vergangenen Etappe der Industriegesellschaft zuzuordnen war. 
gesellschaft ${ }^{398}$ und entwickelte verschiedene politische Initiativen dazu. Die Frauen waren von einem unabdingbaren Wandel der Arbeitswelt überzeugt:

Die Zukunft verlangt von uns allen, Frauen und Männern, vieles, was lange als weiblich galt: wir müssen uns in andere einfühlen, auf sie eingehen, unerwartete Schwierigkeiten mit Phantasie meistern, vor allem aber partnerschaftlich mit anderen arbeiten. 399 (Entwurf in: SPD-Parteivorstand 1989: 39)

Unter dem Stichwort „anders leben - anders arbeiten“ entwickelte die ASF in den 1980er-Jahren einen neuen Arbeitsbegriff ${ }^{400}$, mit dem vier Arbeitsformen - Erwerbstätigkeit, Haus-/Familien-/Eigenarbeit sowie Ehrenamt ${ }^{401}$ und politisches Engagement - als gesellschaftlich notwendige Tätigkeiten benannt wurden. Inge Wettig-Danielmeier erläuterte dazu in einer Presseerklärung vom 14.08.1987:

Wir gehen davon aus, dass die unterschiedliche Wertigkeit von Männern und Frauen gesellschaftlich bedingt und in der bisherigen Arbeitsteilung begründet ist. [...] Die Aufhebung der bisherigen Arbeitsteilung soll nicht nur die Ungleichheit der Geschlechter ausgleichen, sie soll den Stellenwert der Arbeit grundsätzlich verändern, Erwerbsarbeit erhält zwar ihren Stellenwert im Leben der Menschen, soll und muß aber ergänzt werden für alle durch Familienarbeit, Sozialarbeit, Eigenarbeit und gesellschaftliche Teilhabe. (Jahrbuch der SPD $\{1986 / 87\}$ : 726)

In der ASF änderte sich Anfang der 1980er-Jahre auch die Bewertung der Hausarbeit. Familienarbeiten wurden auch im ASF-Lager der Berufsfrauen nicht länger als isolierende und unentgeltliche Ausbeutungsverhältnisse abgelehnt, sondern als „selbstbestimmte Tätigkeiten" bezeichnet, die zu dem bezahlten, aber entfremdeten Arbeiten in Wirtschafts- und Verwaltungsorganisationen eine attraktive Alternative bieten konnten (vgl. Martiny 1984).

398 André Gorz' Abschied vom Proletariat erschien 1980 und war auch in den linken sozialdemokratischen Kreisen eine vielgelesene Schrift.

399 Vgl. Fachtagung „Frauen und die Informations- und Kommunikations-Technologien“, 26.04.1989 in der RWTH Aachen, in: Dokumente 29/1989.

400 Diskussionsforum „Zukunft der Arbeit: Anders leben - anders arbeiten“ auf der 7. Ordentlichen Bundesfrauenkonferenz „Schwestern zur Sonne, zur Gleichheit!“ am o4.o6.10.1985 in Hannover

401 Zur Aufwertung aller nicht erwerbsbezogenen Arbeiten sollten z.B. die ehrenamtlichen Engagements in beruflichen Bewerbungsverfahren, besonders bei Jugendlichen, Berücksichtigung finden. 
Der wichtigste Schlüssel zur Gleichstellung von Frauen in der Berufswelt waren für die ASF Bildung und Ausbildung. Die von der Arbeitsmarktforschung gestützte Vorstellung, dass gut ausgebildete Personen auch gut dotierte Stellen erwarten konnten, bestimmte die frauenpolitischen Diskurse der Sozialdemokratinnen dieser Zeit. Diese Überzeugung wurde Beginn der 1980er-Jahre erschüttert, als sich ein deutlicher Gap zwischen der Bildungsbeteiligung der Frauen und ihren beruflichen Entwicklungschancen abzeichnete: Schülerinnen überholten ihre Mitschüler in den Schulleistungen und -abschlüssen, aber es eröffneten sich den Mädchen dadurch keine vergleichbaren Beschäftigungschancen ${ }^{402}$. In der zweiten Hälfte des Jahres 1985 starteten ASF, Jusos, die Falken und das Jugendwerk der AWO die „Initiative 86 Ran an die Zukunft" ${ }^{\text {" } 03}$. Sie prangerte die gestiegene Jugendarbeitslosigkeit und insbesondere die schlechten Berufsaussichten junger Frauen an. Die Auftaktveranstaltung zur Kampagne ${ }^{404}$ am 29.04.1986 im Erich-OllenhauerHaus mobilisierte unerwartet viele Gruppierungen, Initiativen und junge Besucherinnen ${ }^{405}$

Die ungleich geringeren beruflichen Karrierechancen, die „Mangelware Frauenbosse“ (Randzio-Plath 1987: 49), war noch bis zum Ende der 1980er-Jahre nur ein marginales Thema in der ASF. Solchen Karrierewünschen haftete auch bei den Feministinnen der Sozialdemokratie etwas Unemanzipatorisches an, denn das individuelle Fortkommen in der Privatwirtschaft schien nur zum Preis der Anpassung an männliche Verhaltensformen erreichbar (vgl. dazu Pausch-Gruber 1978).

Im Fokus der wirtschaftspolitischen Debatten stand in der ASF die überproportional hohe weibliche Arbeitslosigkeit, die sich ab Mitte der 1970er entwickelte. Die Sozialdemokratinnen befürchteten, dass das Herausdrängen der Frauen aus der Arbeitswelt sowohl alle gleichstellungspolitischen Erfolge bedrohte als auch die Organisationsbereitschaft der Frauen verringerte und damit die innerparteiliche Position der ASF schwächte ${ }^{406}$. Aber diese Sorge stellte sich als unbe-

402 Zahlen dazu: vgl. Bund-Länder-Kommission 200o. Die prekäre Lage junger Frauen auf dem Arbeitsmarkt war im Oktober 1986 auch Thema der Sozialistischen Internationale.

403 In der Kampagne „Ran an die Zukunft“ organisierten die Jusos ein großes Fest am 19.07.1986 in Recklinghausen.

404 Der Presseaufruf wurde u.a. von Anke Brunn, Herta Däubler-Gmelin, Heidemarie Wieczorek-Zeul, Brunhilde Peter, Eva Rühmkorf, Inge Wettig-Danielmeier unterzeichnet und erschien in der Frankfurter Rundschau am 20.01.1986.

405 Die ASF-Vorsitzende kommentierte: „So rappelvoll war die Parteizentrale selten“ (Inge Wettig-Danielmeier zit. n. Jahrbuch der SPD \{1986/87\}: 75).

406 „Die schwache Position der Frauen im Arbeitsleben spiegelt sich wider in ihrer geringen Bedeutung in der Politik." (Jahrbuch der SPD $\{1975-77\}: 308$ ) 
gründet heraus, denn die Anzahl weiblicher Mitglieder stieg und vergrößerte den Frauenanteil in der Gesamtmitgliedschaft kontinuierlich ${ }^{407}$.

Der Einsatz neuer Technologien in der Arbeitswelt wurde in der ASF mit überwiegend ablehnender Skepsis diskutiert. Die Sozialdemokratinnen verbanden diese Entwicklungen eher mit neuen Formen entfremdeter Arbeit als mit der verheißenen Reduzierung des Arbeitstages:

Sie vernichten Arbeitsplätze in hoher Zahl und ermöglichen den ausbeuterischen Einsatz der (vor allem weiblichen) Arbeitskraft zu beliebigen Zeiten ohne hinreichenden sozialen Kontakt (ausgelagerte Fernarbeitsplätze) und ohne hin-reichende soziale Sicherung. (Bundeskonferenz 1985 zit. n. SPD-Parteivorstand 1989: 4f.)

Auch die gesellschaftlichen Wirkungen der Kommunikations- und Informationstechnologien wurden von den Sozialdemokratinnen vorrangig negativ beurteilt, z.B. fürchteten sie die Verkümmerung menschlicher Fähigkeiten bei Computerkids. An die Frauen und Familien erging deshalb der Appell, sich nicht „von Technik überrollen“ zu lassen (Dokumente 23/1984: 57).

Rückblickend schätzten die Zeitzeuginnen übereinstimmend die chancengerechte Gestaltung der Berufswelt und der Wirtschaftswelt als wichtiges, aber unzugängliches Politikfeld ein. Hier hätten die Frauen in und außerhalb der Parteien nur wenig Unterstützung gefunden und lediglich geringe frauenpolitischen Veränderungen durchsetzen können.

\subsubsection{Familie und Geschlechterregime}

Nach dem Godesberger Programm 1959 musste der Staat der Familie als Keimzelle der Gesellschaft einem besonderen Schutz gewähren. Die SPD sah es als ihre Aufgabe an, die „Erziehungskraft“ der Familien zu stärken. Mütter sollten sich deshalb bis zum Ende der Schulpflicht ausschließlich um ihre Kinder kümmern können, finanziell gefördert durch einen Hausfrauenlohn ${ }^{408}$. Familienarbeiten lagen somit aus-schließlich im Verantwortungsbereich der Frauen, Vaterschaft dagegen und ihre Vereinbarbeit mit dem Beruf waren kein Gegenstand öffentlicher

407 Von der gestiegenen Organisierungsbereitschaft der Frauen profitierten auch die Gewerkschaften des DGB. Seit den 1970er-Jahren traten vermehrt Frauen ein. 1981 stellten sie sogar 72,7\% aller Neumitglieder (vgl. Dokumente 23/1984: 40).

408 „Hausfrauenarbeit muß als Berufsarbeit anerkannt werden“ (Godesberger Programm 1959:363). 
Debatte und Regulierung, sondern gehörte zum individuell gestaltbaren Privatbereich.

Die Ideologisierung der Familie als Ort, der den Einzelnen „Schutz, Geborgenheit und Rückhalt“ in einer Gesellschaft gibt, die „geprägt ist von Leistungsdruck, Konkurrenzkampf, Vermassung, Industrialisierung und Hektik" (Katharina Focke zit. n. Dokumente 3/1974: 11), wurde Anfang der 1970er-Jahre von den frauenbewegten ASF-Aktivistinnen, insbesondere aus den Reihen der Jusos, scharf attackiert. Sie wollten die Institution Familie entmystifizieren, und zwar durch eine nüchterne Aufgabenbeschreibung. Familie übernahm danach unent-geltlich Aufgaben im „Widerspruch zwischen gesellschaftlicher Produk-tion als öffentlicher Tätigkeit und privater Wiederherstellung der Arbeit" (ASF 1975: 11) ${ }^{409}$. Die Familie leistete unentgeltlich gesellschaftlich notwendige Arbeiten ${ }^{410}$. Was die Erziehung und Förderung der Kinder anbetraf, war sie aber eine eher unzureichende Instanz; deshalb sollte der Staat diese öffentliche Aufgabe nicht länger auf den Privatbereich abwälzen. Außerdem herrschten in vielen Familien Streit und Gewalt aufgrund von Überforderung. Sozialdemokratische Frauen- und Familienpolitik hätte sich deshalb dafür einzusetzen, dass der Staat Verantwortung für die Aufgaben der Familie und den Schutz der Ehefrauen und Kinder übernimmt ${ }^{411}$. Außerdem müsste Familienpolitik die Emanzipation der Gesellschaft fördern und geschlechterspezifische Rollenverteilungen in der Familie und schichtenspezifische Unterschiede zwischen den Familien überwinden helfen (vgl. ASF 1975: 11-14)

Über die verschiedenen Familienbilder und die Aufgaben von Müttern und Vätern wurde in der SPD und in der ASF kontrovers

409 Auch marxistische Familienkritiken, nach denen die Familie als „Institution des Kapitals" galten und als Ort der gesellschaftlichen Unterdrückung abgelehnt wurden, waren in der ASF vertreten, allerdings nur minderheitlich und sie ließen sich in den Dokumenten der großen familienpolitischen Debatte Mitte der 1970er-Jahre nicht mehr finden (vgl. PV-Akten 13692; 9663).

410 Dazu zählten die wirtschaftliche Versorgung, die biologische Erhaltung der Gesellschaft, die Sozialisation der Kinder, die Wiederherstellung der Arbeitskraft, die emotionale Stabilisierung der Familienmitglieder, die sexuelle Bedürfnisbefriedigung und die Freizeitgestaltung. Die Pflege älterer Familienangehöriger sollten Altenheime übernehmen, in denen Pflege- und Betreuungsbedürftige eine neue Lebensperspektive finden konnten und die ihnen existenzielle Sicherheit und medizinische Versorgung bot. In einer späteren Fassung wurden die ,gesellschaftliche Arbeiten“ der Familie um die Betreuung von pflegebedürftigen Angehörigen erweitert (vgl. Dokumente 6/1977: 5).

411 Die ASF-Arbeitsgemeinschaften beteiligten sich an frauenpolitischen Initiativen für eine strafrechtliche Verurteilung der Vergewaltigung in der Ehe sowie der strengeren Ahndung des sexuellen Missbrauchs der Kinder. In den Dokumenten der 1970er- und 1980er-Jahre fanden sich aber noch keine Diskurse und Gesetzestextentwürfe dazu. 
diskutiert. Auf der familienpolitischen Konferenz der ASF sprach sich der Parteivorsitzende Willy Brandt für ein „freiheitliches Frauenbild“ aus und erklärte als sozialdemokratisches Politikziel: „[E]s muß der Frau leichter gemacht werden, die oft auf sie zukommende Doppelbelastung durch Haushalt und Beruf zu tragen"412 (Brandt 1974: 9). Die Ausrichtung der ASF-Aktivistinnen auf die Förderung der Berufstätigkeit von Frauen verurteilte er dagegen als „vorurteilsgeladene Ideologie“ (ebenda).

Im Vorfeld zur Reform des Ehe- und Familienrechts Mitte der 1970erJahre hatte sich die ASF vorgenommen, für die Partei „familienpolitische Grundsätze“ zu erarbeiten. Um die kontroversen Positionen zusammenzuführen, erarbeitete eine Kommission des Bundesfrauenausschusses eine Diskussionsvorlage, die innerhalb der Organisation und in mehreren Seminaren diskutiert wurde. Auf der familienpolitischen Konferenz vom 31.11. bis 01.12.1974 in Bremen lagen den 150 Delegierten dazu 400 Ergänzungs- und Änderungsanträge aus regionalen und lokalen Parteiorganisationen vor. Das sog. Familienpolitische Programm (Familienpolitik 1974) bot eine neue Familiendefinition an, die sich gegen das Godesberger Leitbild der bürgerlichen, patriarchalen Kleinfamilie richtete: „Unter Familien verstehen wir Sozialdemokraten auf Dauer angelegte Lebensgemeinschaften eines oder mehrerer Erwachsener mit Kindern" (ASF 1975: 1) ${ }^{413}$. Dies implizierte das Anrecht auf staatliche Förderung und Schutz für alle Lebensgemeinschaften von Erwachsenen mit Kindern, ob mit oder ohne Eheschein. Ehen ohne Kinder sollten dagegen den Förderstatus verlieren. Statt des Ehegattensplittings wurde ein Familiensplitting gefordert wie in Frankreich, das bei der Steuererhebung das Familieneinkommen durch die Anzahl der Familienmitglieder teilt und damit Mehrkindfamilien stärker begünstigt. Allerdings stellte das Familienpolitische Programm die gesellschaftliche Bedeutung der Familie und ihren geschützten Privatbereich nicht infrage; vielmehr sollten Familien in ihren gesellschaftlichen Aufgaben subsidiär vom Staat durch sog. familienergänzende Maßnahmen unterstützt, nicht aber substituiert werden (vgl. Wettig-Danielmeier 1984b).

Steuergelder sollten dabei weniger in einzelfamiliäre Hilfen fließen, sondern vorrangig die öffentliche Infrastruktur verbessern durch:

412 In diesem Sinne stritt die amtierende Familienministerin Dr. Katharina Focke (Bundesministerin 1972-1976) für die Gewährung von Erziehungsgeld. Durchsetzen konnte sie nur ein Kindergeld für das erste Kind von 50 DM (vgl. http://www.bmfsfj.de/ BMFSFJ/Ministerium/geschichte.html [Zugriff: 05.02.2012]).

413 Nach Gisela Notz wurde diese Familiendefinition schon von Marta Schanzenbach in den 1950er-Jahren vertreten (vgl. Notz 2007b: 28). 
- die flächendeckende Einrichtung von Familien-, Sexual- und Schwangerschaftsberatungen,

- den Ausbau staatlicher Kinderbetreuungseinrichtungen ${ }^{414}$, deren Öffnungszeiten sich an den Arbeitszeiten der Eltern orientieren sollten,

- die Bereitstellung von Tagesmüttern ${ }^{415}$,

- die Einrichtung von Ganztagsschulen,

- den Ausbau von Jugendfreizeitangeboten

- $\quad$ sowie Altenclubs und andere Angebote der offenen Altershilfe.

Gefördert werden sollten des Weiteren der Ausbau der Gesundheitsvorsorge und -beratung, der öffentliche Wohnungsbau mit einem familienfreundlichen Wohnumfeld, Spielplätze, kindgerechte Wohnungen, Wohnanlagen mit Gemeinschaftseinrichtungen, insbesondere für sog. soziale Randgruppen ${ }^{416}$. Darüber hinaus wurden auch individuelle Unterstützungsleistungen gefordert wie die Anhebung des Kindergelds in Abhängigkeit vom Einkommen und das SchülerInnen-BAföG sowie die steuerliche Abzugsfähigkeit aller Versorgungsaufwendungen für die Kinderbetreuung. Außerdem sollten die Erziehungszeiten auf die Rente angerechnet werden, unabhängig von einer bestehenden Erwerbstätigkeit. Ein „Erziehungsgeld“ sollte nach den Vorstellungen der ASF demjenigen Elternteil zustehen, das für ein Jahr seine Berufstätigkeit unterbricht und sich der Betreuung des Kleinkinds widmet ${ }^{417}$ (vgl. Dokumente 2/1974: 7).

Das Familienpolitische Programm führte verschiedene Handlungsfelder wie Erziehung und Bildung, Wohnungspolitik, Gesundheitspolitik, Gemeinwesenarbeit, Steuer- und Rechtspolitik auf. Es verknüpfte auf diese Weise Familienpolitik mit anderen Politikfeldern und sollte durch diese Verbindungen eine neue gesellschaftspolitische Dimension und Bedeutung für die Partei erhalten. Außerdem sollten in der SPD Frauenpolitik und Familienpolitik als jeweils eigenständige, voneinander unabhängige Politikfelder wahrgenommen werden.

414 Für die Bereitstellung einer ausreichenden Infrastruktur rückten die linkssozialistischen ASF-Frauen von ihrer Ablehnung privater Initiativen ab und befürworteten die Einrichtung von Betriebskindergärten (vgl. Scheer-Pontenagel 1981).

415 Tagesmütter waren in der SPD heftig umstritten. Mit einem Tagesmüttermodellversuch war die Familienministerin Käthe Strobel Anfang der 1970er-Jahre auf Kritik gestoßen, auch aus der eigenen Partei. Ministerin Strobel wollte mit dieser Infrastruktur die Vereinbarkeit von Beruf und Familie für Mütter unterstützen.

416 Dazu zählten Familien mit geringem oder fehlendem Einkommen aus Beschäftigung und einer entsprechenden Abhängigkeit von Transfereinkommen.

417 Später wurde diese Forderung zu einem Bestandteil konservativer Familienpolitik und verschwand aus dem sozialdemokratischen Politikportfolio. 
Auch die CDU hatte im Vorfeld der anstehenden Rechtsreform ein neues familienpolitisches Leitbild entwickelt. Mit einem Vorstandsbeschluss vom 07.04.1975 trat sie nun für die "partnerschaftliche Familie“ ein. Im Gegensatz zur Position der SozialdemokratInnen stand dabei die Förderung der einzelnen Familie im Fokus der christdemokratischen Politik (vgl. Aktionsprogramm '78) 418. $^{4}$.

Die Kritik an der patriarchal strukturierten und überforderten Kleinfamilie ${ }^{419}$ und der neue Familienbegriff waren nicht nur in der SPD $^{420}$, sondern auch in der ASF selbst hoch umstritten, auch wenn das Familienpolitische Programm zu einer programmatischen Grundlage der ASF wurden, auf dem im Weiteren Politiken und Maßnahmen zum Thema „Vereinbarkeit von Beruf und Familie“ entwickelt wurden (vgl. Dokumente 15/1981).

Erst in der zweiten Hälfte der 1980er-Jahre setzten sich in der ASF zum Familienthema stärker konsensuale Positionen durch. Die vormals in der ASF diskutierte Alternative zwischen staatlich finanzierter Infrastruktur und individueller Unterstützungsleistung wurde zugunsten einer Kombination unterschiedlicher Maßnahmen aufgegeben, die die unterschiedlichen Bedingungen der einzelnen Familien berücksichtigen sollten: „Es geht also nicht um ein System sich gegenseitig ausschließender Alternativen, also Erziehungsgeld oder Elternurlaub oder Krippenerziehung" (Rechenschaftsbericht 1985: 28), sondern um ein vielfältiges und kombinierbares Angebot. Wohlfahrtsstaatliche Leistungen sollten sich am Leitbild der Ehepartnerschaft orientieren, in der Frauen das Recht auf volle und qualifizierte Berufstätigkeit besäßen und Väter in die Pflicht genommen wären, sich an Hausarbeit und Kindererziehung

418 Als Forderungen waren im Aktionsprogramm '78 aufgeführt: ein Erziehungsgeld für Kinder bis zum dritten Lebensjahr, eine Verlängerung der Elternzeiten, die Berücksichtigung von Pflegeanforderungen, Servicehäuser als Entlastung für Kleinfamilien, eine eigenständige Alterssicherung für Frauen durch die Anrechnung von Erziehungszeiten, die gerechte Verteilung von Ausbildungsplätzen zwischen Jungen und Mädchen, Familiengründungsdarlehen, besondere steuerliche Berücksichtigung der sog. unvollständigen Familie, die Abschaffung des Ehegattensplittings, die freie Bestimmung des Familiennamens durch Vereinbarung der EhepartnerInnen.

419 Diese Kritik wandte sich dezidiert gegen den von der SPD 1972 erarbeiteten Entwurf Familienpolitik der SPD (vgl. hierzu Dokumente 03/1974)

420 So wurde auf dem Essener Parteitag 1984 die Familie weiterhin als „primärer Bildungsträger" definiert, der durch begleitende und integrierte staatliche Maßnahmen unterstützt werden sollte, z.B. durch Eltern-Kind-Gruppen zur Förderung der Erziehungskompetenz der Eltern, durch Kindergartenplätze, die 75 \% eines Geburten-jahrgangs abdecken sollten, durch sozialpädagogisch betreute Eingangsstufen für die Grundschule (vgl. Beschlüsse in Dokumente 22/1984) 
zu beteiligen ${ }^{421}$. Dazu forderte die ASF die Ausweitung des Elternurlaubs, die Umstellung der Familienförderung, in der das Kindergeld bei Bedürftigkeit als Festbetrag und nicht als einkommensabhängiger steuerlicher Freibetrag gewährt werden sollte (vgl. Resolution der Mannheimer Bundesfrauenkonferenz 1987 in Dokumente 27/1987: 15), familiengebundene Arbeitszeitverkürzungen und eine Familienlastenausgleichsstelle, die familienbedingte Einkommensaus-fälle oder -reduzierungen bei Geringverdienenden finanziell auffing. Finanziert werden sollten diese Maßnahmen u.a. durch die Abschaffung des Ehegattensplittings (vgl. SPD-Parteivorstand 1989: 8).

Die Auseinandersetzungen um die Familienpolitik der Partei fanden nicht nur auf programmatischer Ebene statt. Die Kritik der ASF-Frauen an der familiären Geschlechterordnung richtete sich auch gegen die Lebensführungen der Genossen. Die meisten Politikerehefrauen nämlich nahmen das „Los einer politischen Witwe“ auf sich (vgl. Hoecker 1987a: 110) und sorgten als Karrierehelferinnen ihrer Ehemänner für die Organisation der privaten Lebensumstände, die Sicherung des Haushalts und einen funktionierenden Familienalltag. Auf diese Weise wurde eine hohe Verfügbarkeit beim Führungspersonal der Partei sichergestellt. Für die politisch ambitionierten Genossinnen bildete aber diese Erwartung an das politische Engagement häufig eine unüberwindbare Einstiegsbarriere in die Parteiarbeit, wenn sie nicht durch ihren Lebenspartner auf ähnliche Weise unterstützt wurden ${ }^{422}$.

Programmatisch hatte sich das neue Familienverständnis in der SPD Ende der 1980er-Jahre durchgesetzt. Im Berliner Programm 1989 wurde

421 Strategien, wie sich die traditionellen Familienstrukturen durch staatliche Maßnahmen verändern ließen, wurden in der ASF nicht entwickelt; eigentlich hielt man die beruflichen Nachteile, die Männer unter den gegebenen Umständen bei einer partnerschaftlich geteilten Familienarbeit und einem ganz oder teilweise erfolgenden Ausstieg aus dem Beruf riskierten, für unzumutbar. Um Väter als Bündnispartner zu gewinnen, forderten die Sozialdemokratinnen den sog. Karenzurlaub nicht nur für Mütter, sondern auch für Väter zu ermöglichen. Er sollte auf beide Elternteile aufgeteilt werden, mit nicht übertragbaren Anrechten (vgl. Wettig-Danielmeier 199ob; Dokumente 13/1980; Dokumente 15/1981). Der Karenzurlaub wurde später als Erziehungsurlaub bzw. „Erziehungszeiten“ bezeichnet und regelt das Anrecht auf befristete Freistellung für die Kinderbetreuung mit Beschäftigungsgarantien für den Wiedereinstieg.

422 Die politisch nicht aktiven Ehefrauen der Leitungsgenossen sahen in den ASF-Aktivistinnen häufig Gegnerinnen: ,[A]lso die haben zuhause, die Männer, Feuer gekriegt von ihren Ehefrauen: ,was dieser Blödsinn eigentlich soll' und ,diese Emanzen, die kümmern sich doch nicht um ihre Kinder und schieben die irgendwohin ab' und so, und haben auf der anderen Seite Feuer gekriegt von uns“ (Zz 13). Die ASF-Frauen dagegen verhöhnten die Ehefrauen führender Genossen als „Gattinnen der Granden“ und bespöttelten sie, wenn sie im eleganten Outfit in Begleitung ihrer Ehemänner auf Feierlichkeiten oder Empfängen der Partei erschienen, als „Perlhühner“ oder „kuchenfressende Pelztiere“ (vgl. dazu Zz 9, Zz 6, Zz 13). 
der Anspruch auf staatlichen Schutz und Rechtssicherheit, der bis dahin nur für heterosexuelle Ehepaare galt, für alle „Lebens-gemeinschaften“, d.h. auch für gleichgeschlechtliche Paare, gefordert (vgl. Berliner Programm 1989: 22). Das veränderte Familienverständnis als Gemeinschaft von Erwachsenen mit Kindern war im Grund-satzprogramm der SPD 1989 eng verkoppelt mit einem Para-digmenwechsel im Verständnis der Geschlechter. Nun wurden Frauen nicht länger als gesellschaftlich Benachteiligte angesehen, die von einer stärkeren (Männer-) Gemeinschaft geschützt und gefördert werden mussten:

Viele Frauen gehen an gegen eine von Männern gestaltete Welt und gegen Männer, die diese erhalten wollen. Auch bei Männern wächst die Einsicht, daß die angeblich männliche Unterordnung von Gefühl und Phantasie unter Rationalität und Durchsetzungskraft sie ärmer oder gar krank macht. (Grundsatzprogramm der SPD 1989: 21) ${ }^{423}$

\subsubsection{Mutterschaft, sexuelle Selbstbestimmung und Repro- duktionstechnologien}

Die Auseinandersetzung um die Strafrechtsreform des § 218 hatte viele Frauen in der SPD und für die SPD mobilisiert. Dass die erste Strafrechtsreform 1969 lediglich das Strafmaß für Abtreibungen verminderte ${ }^{424}$, führte zu bundesweiten Protestbewegungen. Den offenen Brief der Frauenaktion 70 an Bundesfamilienministerin Käte Strobel, der die Streichung des $\S 218$ forderte, wurde von 1.000 Frauen unterzeichnet, darunter auch von der SPD-Landtagsabgeordneten Dorothee Vorbeck.

Die Partei dagegen unterstützte nur eine weitere Reform der strafrechtlichen Regelungen, die staatliche Kontrolle über die weibliche Gebärfähigkeit sollte in moderater Form erhalten bleiben. Auch die ASF unterstützte mehrheitlich die sog. Fristenlösung, die in der Sozialdemokratie politische Tradition hatte, denn bereits 1920 hatten sich 54 sozialdemokratische Abgeordnete im Reichstag für die Straffreiheit der Abtreibung in den ersten drei Schwangerschaftsmonaten eingesetzt ${ }^{425}$. Ergänzend forderte die ASF die Übernahme der Kosten für Beratung und den

423 Eine ergänzende Passage, die diese Differenz als Geschlechterkonflikt thematisierte, war aus dem Entwurf gestrichen worden. Sie hieß: „Frauen sehen sich vielfach gezwungen, gegen eine männlich bestimmte gesellschaftliche Wirklichkeit anzugehen und damit auch gegen Männer, die jene weiter aufrecht erhalten wollen." (Materialien 1989: 39)

424 Die Straferhöhung bei „besonders schwerem Fall“ wurde gestrichen und die Abtreibung wurde nicht mehr als Verbrechen, sondern als Vergehenstatbestand gewertet. 425 Vgl. Radbruch 1992: 191, 364, Anm. 191. 
medizinischen Eingriff durch die Krankenkassen sowie den freien Zugang zu Verhütungsmitteln, die Kostenübernahme für Sterilisierung und eine bessere und umfassende sexuelle Aufklärung der Gesellschaft, insbesondere der Jugendlichen.

Nach einem Bundesgerichtsurteil trat 1976 die sog. Indikationsregelung in Kraft. Sie führte jedoch zu unterschiedlichsten Handhabungen in den einzelnen Bundesländern und bedeutete für konservative Regionen und viele ländliche Gegenden in der Praxis eine Weiterführung des Abtreibungsverbots. Die ASF setzte sich deshalb gemeinsam mit der Arbeiterwohlfahrt für ein "Schwangerschaftsunterbrechungsgesetz" ein angelehnt an die Regelungen in der DDR -, um eine Rechtssicherheit bei der Versorgung durchzusetzen; außerdem sollten Kliniken bzw. Klinikabteilungen die Schwangerschaftskonfliktberatung und ggf. den Abbruch durchführen (vgl. Dokumente 30/1990) ${ }^{426}$.

In diesen Auseinandersetzungen kämpften innerhalb der ASF die Unterstützerinnen der Fristenlösung und die Befürworterinnen der ersatzlosen Streichung des $§ 218$ jahrelang gegeneinander. Erst auf der Bundeskonferenz 1987 wurde dieser Streit beigelegt. Das feministische Lager, das mit seinem Antrag auf ersatzlose Streichung bei der Konferenz nur knapp unterlag, schloss sich der Forderung nach einer Fristenlösung ${ }^{427}$ an. Vielen Frauen schien angesichts der gesellschaftlichen Debatte, dass eine gesicherte Straflosigkeit bei Schwangerschaftsabbrüchen nur mit einer eigenständigen Gesetzesregelung gewährleistet werden könnte (vgl. Dokumente 27/1987).

Eng verknüpft mit den Auseinandersetzungen über den § 218 waren die Auseinandersetzungen in der Partei zur Thematisierung von Sexualität durch die ASF-Aktivistinnen. Sie prangerten die Prüderie der Partei an und sahen in der Tabuisierung der Sexualität in der Politik auch eine Tabuisierung struktureller männlicher Gewalt gegen Frauen und Kinder.

426 Mehrfach versuchte die ASF, die Indikationsregelung mit Berichten über die regional ungleichen Behandlungen von Schwangeren und mithilfe tragischer Schicksale neu in die Diskussion zu bringen oder zumindest in ihrer Umsetzung zu liberalisieren. Ende der 1980er-Jahre versuchte eine überfraktionelle Fraueninitiative aus SPD, Grünen, FDP sowie aus Verbänden und Gewerkschaften mit einer Aktion von 30.000 Unterschriften ein „Schwangerenhilfegesetz“ ins Parlament einzubringen. Es sollte eine zeitlich begrenzte Straffreiheit des Abbruchs und eine freiwillige Beratung realisieren (vgl. Jahrbuch der SPD $\{1988-90\}:$ C 240).

427 Die psychosoziale Schwangerschaftsberatung sollte als freiwillige Leistung zur Verfügung stehen und nicht wie im geltenden Recht verpflichtend verordnet sein. Diese Forderung war zwischen den Kontrahentinnen immer Konsens gewesen. 
Solange sexuelle Unterdrückung und Bevormundung im Bereich der Privatheit blieben, hätten Frauen kein Anrecht auf staatlichen Schutz ${ }^{428}$. Die 1983 eingerichtete AG Gleichstellung der SPD-Bundestagsfraktion unter der Vorsitzenden Herta Däubler-Gmelin (später Renate Schmidt) nahm sich dieser Themen an. Sie setzte sich für eine Liberalisierung der Abtreibungspraxis ein und arbeitete an Gesetzesinitiativen zum Verbot ehelicher Gewalt und zum Verbot des Prostitutionstourismus.

Auch in die Debatten zu einem neuen Grundsatzprogramm der Partei brachte die ASF das Thema Sexualität ein. So hatte hatte die ASFVorsitzende Inge Wettig-Danielmeier bei der Erstellung des Irseer Entwurfs gefordert, „Liebe und Sexualität als gestaltendes Element menschlichen Lebens und menschlicher Beziehung" in das Parteiprogramm aufzunehmen, weil sie Thema des öffentlichen Diskurses werden mussten (SPD-Parteivorstand 1989: 11) ${ }^{429}$. Im April des gleichen Jahres organisierte die ASF ein Werkstattgespräch mit dem Titel „Leben und Lieben im Alter“, das großes Presseecho fand (vgl. Rechenschaftsbericht 1990: 20) ${ }^{430}$. In den autonomen Frauenbewegungen formierte sich in den 1980er-Jahren ein breiter Widerstand gegen die neuen Reproduktionstechnologien. Im April 1985 organisierten die Grünen dazu einen Kongress mit ca. 2.ooo TeilnehmerInnen, der die Gen- und Reproduktionstechnologien kritisierte und als Fortsetzung nationalsozialistischer Konzepte der Humangenetik anklagte (vgl. a.a.O.: 649). Auch die ASF war für ein weitgehendes Verbot dieser Technologien. Unter dem Motto „Nicht alles, was machbar ist, darf auch gemacht werden“ forderte die ASF ein Verbot der Erzeugung von Retortenbabys, Leihmutterschaft und Samenbanken und setzte sich dafür ein, diese Technologien nicht mehr öffentlich zu fördern. Stattdessen sollte mit diesen Geldern eine umfassende Risikoforschung finanziert werden, die die gesellschaftlichen Wirkungen dieser Technologien analysierte. Eine sorgfältige Aufklärung

4281977 hatte die Zeitschrift Emma gegen die Zeitschrift Stern beim Presserat eine Beschwerde gegen die pornographischen Darstellungen auf dem Cover eingelegt. Die Vorbereitung des Klagewegs, um ein gesetzliches Verbot durchzusetzen, wurde von Dorothee Vorbeck und dem ASF-Vorstandsmitglied Ursula Pausch-Gruber unterstützt (vgl. Emma 1978). Ende der 1980er-Jahre schloss sich der ASF-Vorstand der Kampagne von Alice Schwarzer zum Pornographieverbot an.

429 Im Berliner Programm 1989 lassen sich der Begriff „Liebe“, die Thematisierung männlicher Gewalt und das Recht der Frauen auf „sexuelle Selbstbestimmung“ finden (vgl. Berliner Programm 1989: Kap. IV.1, zit. n. Dowe/Klotzbach 1990: 392).

430 Marginale Bedeutung hatte in der ASF dagegen der Diskurs über Homosexualität. Zwar gab es in der Berliner ASF eine größere Lesbengruppe, die in den 1980er-Jahren auch eigene Fachtagungen organisierte, es entstanden jedoch daraus aber keine spezifisch sozialdemokratischen Politikkonzepte. Homosexuelle Gruppen fanden in dieser Zeit eher bei den Grünen eine politische Plattform (vgl. Lenz 2008: 675-705). 
sollte die Frauen über die „Risiken und die Qualen“ medizinisch eingeleiteter Schwangerschaften und Schwangerschaftskontrollen informieren $^{431}$ (vgl. Dokumente 24/1985). Der ASF-Bundesvorstand veranstaltete im Januar 1986 eine Fachkonferenz mit dem Titel „Biotechnologie Chancen oder Risiken für Frauen?" in Bonn, deren Ergebnisse er veröffentlichte (Dokumentation der Fachtagung „Biotechnologie - Chancen oder Risiken für Frauen?" in Dokumente 25/1986). Obwohl in den einzelnen Bezirks- und Landesverbänden Sprecherinnen für Biotechnologie benannt worden waren und eine Sprecherinnenkonferenz aus Bezirksund Landesverbänden am 20.03.1987 ein Positionspapier verabschiedete, blieb das Thema in der Gesamt-ASF aber eher ein politisches Spezialgebiet für eine kleine Gruppe von Expertinnen. Dies schilderte eine Zeitzeugin: „[D]as waren wirklich Spezialistinnen, die liefen fast Tournee in den Unterbezirken“432 (Zz 15).

Auch mit ihren Positionen zur Gen- und Reproduktionstechnologie gehörte die ASF zum technologiekritischen Lager in der Partei, das sich zum technologieaffinen Lager in einer Pattsituation befand. Auf dem Internationalen Frauentag in Mainz am 07.03.1987 mit mehr als 3.0oo Teilnehmerinnen kritisierten die ASF-Frauen das geplante Embryonenschutzgesetz der Bundesregierung, aber auch die alternativen Gesetzesentwürfe der SPD. Den Entwurf des Gengesetzes und den Gesetzesentwurf zur künstlichen Befruchtung der SPD lehnten die ASF-Frauen ab, sie fanden darin nur wenige ihrer frauenpolitischen Positionen und Forderungen wieder und hielten die Texte nicht für konsensfähig, weder für die autonomen Frauengruppen und die Frauenverbände noch für die kirchlichen AkteurInnen. Die ASF schloss sich in dieser Debatte der von verschiedenen Verbänden aufgestellten Forderung nach einer Verfassungsklage gegen das Gengesetz und der Einrichtung einer unabhängigen Ethikkommission an.

431 Die ASF lehnte die Embryonenforschung ab. Statt Retortenbabys forderte sie eine verstärkte medizinische Ursachenforschung, die sich auch mit der männlichen Sterilität beschäftigen sollte (vgl. Dokumente 25/1986).

432 Auch unter den Sozialdemokratinnen auf europäischer Ebene war das Thema in dieser Zeit noch unbedeutend. Im Manifest der linken Frauen der Europäischen Gemeinschaft vom 04.Februar 1989 wird es gar nicht erwähnt (vgl. Manifesttext in der Anlage zum Rechenschaftsbericht 1990). 


\subsubsection{Gleichstellung 433 und Antidiskriminierung}

Seit Mitte der 1970er-Jahre hatten sich Frauen in der ASF mit der Entwicklung eines Antidiskriminierungsgesetzes für Wirtschaft und Gesellschaft beschäftigt. Bis dahin waren solche Initiativen unter dem ASFBundesvorsitz von Annemarie Renger blockiert worden. Annemarie Renger wertete gesetzgeberische Maßnahmen wie Antidiskriminierungsverbote, wie sie bereits im angelsächsischen Raum existierten, oder Quotierungsauflagen als „Fremdkörper im deutschen Recht“ strikt ab (vgl. Dertinger 1980: 67f.). Nach ihrer Überzeugung sollte die Gleichstellung auf dem Klageweg erstritten werden. Deshalb unterstützte sie als Bundestagspräsidentin die Kampagne „Gleicher Lohn für gleiche Arbeit“ und ermutigte Frauen, Musterprozesse gegen Lohndiskriminierung zu führen. Als parlamentarische Geschäftsführerin der SPD-Bundestagsfraktion hatte sie als ein kleines Referat eingerichtet, das solche Diskriminierungstatbestände sammelte und dokumentierte (vgl. Renger 1993). Mit der Übernahme des ASF-Vorsitzes durch Inge Wettig-Danielmeier gehörte die Durchsetzung eines Gesetzes gegen Geschlechterdiskriminierung $\mathrm{zu}$ einem Kernstück des ASF-Zielkatalogs (vgl. Jahrbuch o.A. $\{1985\}$ : 262). Aber die ASF traf mit diesem Thema bei der SPD/FDPRegierung auf wenig Interesse, ein öffentlicher Appell der ASF für eine entsprechende Gesetzesinitiative in 1981 blieb selbst in der eigenen Partei ohne Resonanz (vgl. ASF 1981c).

Dagegen gewann das Konzept der Frauenbeauftragten immer mehr Anhängerinnen in der ASF und versprach größere Realisierungschancen. Eine Zeitzeugin erinnert sich an die Entstehung der Idee in einem kleinen Kreis aus Bundesvorstandsfrauen:

Und dann sind wir ganz vorsichtig dran gegangen, mal zu testen, ob die ASF überhaupt bereit und in der Lage war, diese Forderung aufzunehmen. Und dann hatten wir Angst vor unserer eigenen Courage, weil das ja die Forderung nach einem Stück Bürokratie war, und dann haben wir das gesponnen, die Idee, so wie der Datenschutzbeauftragte, so bräuchten wir einen Frauenbeauftragten oder einE Frauenbeauftragte. Und so nach und nach hat sich rausgestellt: Das machen wir, wir müssen auch mal den Mut haben, was zu fordern, was unbequem für die Strukturen ist. Und dann haben wir die Frauenbeauftragten gefordert. (Zz 9)

433 „Gleichstellung“ wurde in der ASF früh zum wichtigsten Leitbegriff und verdrängte den Begriff der „Emanzipation“. Leider gelang es nicht, die Entstehung dieses Begriffs und seine Etablierung zu klären. 
1977 forderte die Siegener Bundesfrauenkonferenz die Einrichtung einer Gleichstellungskommission auf der Ebene der Bundesregierung. Es sollte eine Behörde sein, die befugt war, Verletzungen von Gleichberechtigungs- und Gleichbehandlungsgrundsätzen zu verfolgen und zu sanktionieren. Ein entsprechender Antrag fand auf dem Bundesparteitag der SPD in Berlin 1979 jedoch keine Mehrheit. Angenommen wurde stattdessen ein Appell an die Landesbehörden, Gleichstellungsstellen einzurichten, die als beratende Stabsstellen für eine Beachtung und Umsetzung der Chancengleichheit in der Politik sorgen sollten ${ }^{434}$.

Auf Landesebene waren die neuen Strukturen eher durchsetzbar. Die erste Leitstelle zur Gleichstellung der Frau wurde 1979 auf Initiative des ASF-Landesverbands durch den Hamburger Senat eröffnet. Weitere Länder folgten: Bremen richtete 1981 eine Zentralstelle für die Verwirklichung der Gleichberechtigung der Frau ein, im gleichen Jahr Bayern die Leitstelle für die Gleichstellung der Frauen. Bereits 1982 besaßen alle Bundesländer Einrichtungen, Referate oder Stabstellen, die für Gleichstellung und Frauenfragen zuständig waren (vgl. dazu Krautkrämer-Wagner 1989; Sauer 1997; Hoff 1984). Bald darauf folgte ihre Einrichtung in den kommunalen Verwaltungen, die erste 1982 in Köln. Oftmals lag die Initiative bei den weiblichen sozialdemokratischen Ratsmitgliedern, manchmal auch gegen den Widerstand in den eigenen Parteireihen ${ }^{435}$. Häufig musste die Einrichtung der Gleichstellungsstellen gegen die CDU, die für eine ehrenamtliche Übertragung der Aufgaben innerhalb der Verwaltung votierte, durchgesetzt werden und fand - nach Darstellung des ASF-Bundesvorstands - keineswegs immer die Unterstützung der Grünen (vgl. Rechenschaftsbericht 1987: 42). 1989 war die Anzahl der kommunalen Gleichstellungsstellen in der BRD auf ca. 500 angewachsen (vgl. SPD-Parteivorstand 1989: 4).

434 Das CEDAW-Abkommen (Convention on the Elimitation of All Forms of Discrimination Against Women), das 1979 von der UNO verabschiedet wurde, empfahl den Mitgliedsstaaten einen Katalog von Antidiskriminierungsmaßnahmen, darunter die Einrichtung von solchen Strukturen.

435 So war z.B. in Düsseldorf 1984 die Einrichtung der kommunalen Gleichstellungsbeauftragten an der SPD-Ratsfraktion gescheitert. Erst eine veränderte Gemeindeordnung (vgl. Jahrbuch o.A.\{1987\}:568) und der Beschluss des Landtags, der die Einrichtung von Gleichstellungsbeauftragten bei den Kommunen als Verwirklichung des Verfassungsauftrags qualifizierte, sowie das eigene, vom SPD-Parteitag beschlossene Kommunalwahlprogramm 1984, das eine „ämterübergreifende ,Gleichstellungsstelle für Frauenfragen“ mit wirkungsvollen Kompetenzen“ (zit.n. ASF UB Düsseldorf 1986) forderte, konnten die SPD-Fraktion zu einem entsprechenden Antrag im Rat bewegen. Am 01.01.1986 nahm das Frauenbüro seine Arbeit auf (vgl. ASF UB Düsseldorf 1986). In Düsseldorf war - wie vermutlich in vielen Kommunen - der geschrumpfte kommunale Haushalt das Kernargument gegen die Einrichtung einer Gleichstellungsstelle (vgl. Parteitag der SPD 1984: 340f). 
Jedoch waren die Befugnisse der Gleichstellungsbeauftragten gering. Sie sollten dem verfassungsrechtlichen Gleichbehandlungsgebot mehr Geltung verschaffen und hatten deshalb eine Querschnittsfunktion, aber keine behördlichen Kompetenzen. Sie arbeiteten ausschließlich beratend, sollten die bisherigen Regelungen, Gesetze und Gesetzesvorhaben auf Diskriminierung überprüfen, Vorschläge zur Veränderung erarbeiten, Daten zur gesellschaftlichen Situation der Frauen zur Verfügung stellen und mit Interessengruppen außerhalb der Verwaltung zu Frauenbelangen kooperieren. Außerdem sollten sie Modellversuche zur Entwicklung von Gleichstellungsmaßnahmen und -strukturen durchführen sowie als Anlauf- und Beschwerdestelle für Betroffene zur Verfügung stehen (vgl. Krautkrämer-Wagner 1989). Die inhaltlichen Zielstellungen waren eher vage formuliert, genannt wurden Chancengleichheit in der Lebensgestaltung, Partnerschaft bei den Familienaufgaben, Abbau von Benachteiligungen und Unterrepräsentanz der Frauen in der Gesellschaft. Verglichen mit den Kompetenzen solcher Einrichtungen in anderen Ländern, z.B. in den USA, waren die deutschen Gleichstellungsbeauftragten nach Uta Krautkrämer-Wagner nur die „kleine Lösung“, ein politisches Zugeständnis, um ein Antidiskriminierungsgesetz zu verhindern (vgl. Krautkrämer-Wagner 1989). Für die Frauen- oder Gleichstellungsbeauftragten forderten die ASF-Frauen deshalb eine Erweiterung der Befugnisse und auf Landes- und Bundesebene den Ausbau zu Gleichstellungsressorts mit Kabinettsrang (vgl. Dokumente 16/1982).

Den ersten Entwurf eines Antidiskriminierungsgesetzes brachte die FDP 1982 gemeinsam mit der Humanistischen Union und feministischen Aktivistinnen ein und veranstaltete dazu ein öffentliches Hearin. Diese Initiative wies der ASF-Bundesvorstand scharf zurück: „nichts als Salbe“ (Wettig-Danielmeier zit. n. Dokumente 17/1982: 7). Nach eigenen erfolglosen Versuchen setzten die ASF-Frauen nun auf die Reform und Erweiterung bestehender Gesetze. Für die Privatwirtschaft sollte in das Betriebsverfassungsgesetz die verpflichtende Erstellung von geschlechterbezogenen Förderplänen aufgenommen werden, außerdem eine Geschlechterquotierung der Ausbildungsplätze, die Besetzung aller Beschäftigungsbereiche mit $40 \%$ des jeweils unterrepräsentierten Geschlechts, die Einrichtung eines Gleichstellungsausschusses ab einer Betriebsgröße von 150 Beschäftigten sowie ein Klagerecht des Betriebsrats bei Verletzungen des Gleichbehandlungsgebots. In das Arbeitsrechtliche EG-Anpassungsgesetz sollte eine Definition der Verstöße aufgenommen werden, die Beweislast umgekehrt auf die VerursacherInnen übertragen und Verbandsklagen zugelassen werden.

Aber noch im gleichen Jahr 1982 änderte der ASF-Bundesvorstand seine Haltung und setzte sich ebenfalls für ein eigenständiges Gleichstellungsgesetz ein. Mit Sanktionen verfahrend sollte ein grundgesetzliches 
Gleichstellungsgebot nicht nur zwischen Staat und BürgerInnen, sondern auch im Privatverkehr verbindlich gelten (vgl. Dokumente 16/1982: 6f.). Betriebe sollten ab einer gewissen Mindestgröße gegenüber einer Bundesbehörde berichtspflichtig werden. Außerdem sollte das Gesetz die verbindliche Einführung von Sondermaßnahmen zur Förderung des unterrepräsentierten Geschlechts in den verschiedenen Berufsfeldern regeln und die Einrichtung einer weisungsunabhängigen Bundesoberbehörde sicherstellen. Eine Kontrollstelle mit Sanktionsgewalt sollte Subventionsvergaben mit Auflagen belegen oder Geldbußen verhängen können ${ }^{436}$.

Auch wenn es nicht gelungen war, die Gleichstellungsbeauftragten mit weiteren Rechten und Zuständigkeiten auszustatten, rechneten die Zeitzeuginnen die Implementierung einer gleichstellungspolitischen Infrastruktur durch Gleichstellungsbeauftragte zum wichtigsten politischen Erfolg der ASF. Dazu eine Zeitzeugin:

Also, die Tatsache, die Einrichtung der Gleichstellungsstellen, halte ich für einen RIESENGROSSEN Schritt und das ist wirklich ein Verdienst der ASF und das finde ich gewaltig. [...] Die Identifikation mit diesem Kind, Gleichstellungsstelle, war UNGLAUBLICH groß. Alles, was an Frauenpolitik, an Ideen, an Visionen, vorhanden war, hat sich manifestiert in diesen Gleichstellungsstellen (Zz 14).

Im politischen Alltagsgeschäft bestanden zwischen den ASF-Politikerinnen und den Gleichstellungsbeauftragten enge Verbindungen. Die Mehrheit der ersten Gleichstellungsbeauftragten kamen aus den Neuen Frauenbewegungen, viele aus autonomen Frauengruppen. Die Kompetenz, eine „Vermittlung zwischen Verwaltung und lokaler Frauenszene“ herstellen zu können, war vielfach Einstellungskriterium (Rudolph/Schirmer 2004: 159). Die Gleichstellungbeauftragten arbeiteten

436 Nach dem Regierungsverlust 1983 arbeitete die SPD-Fraktion in dem neu gegründeten Arbeitskreis Gleichstellung an einer eigenen Gesetzesinitiative. Im Oktober 1986 legten zunächst die Grünen einen Entwurf für ein Antidiskriminierungsgesetz vor, fanden dafür aber keine Unterstützung in den großen Parteien. 1990 legte die SPD einen eigenen Entwurf für ein Gleichstellungsgesetz vor - er wurde in der Regierungsanhörung von der ASF-Vorsitzenden Inge Wettig-Danielmeier vorgetragen - und scheiterte ebenfalls an der Regierungskoalition (vgl. Jahrbuch der SPD \{1990\}: C234). In einigen Bundesländern konnten dagegen einzelne Regelungen aus den Gesetzesvorlagen durchgesetzt werden, wie z.B. auflagenbelegte Subventionsvergaben, die Quotierung von Ausbildungsplätzen in der öffentlichen Verwaltung und weitergehende Anhörungsrechte für Gleichstellungsbeauftragte. So wurden ab Mitte der 1980er-Jahre alle ministeriellen Referate in den Landesregierungen zu Leit- oder Zentralstellen, meist verbunden mit einem höheren Haushaltsansatz und mehr Personal. 
ressortübergreifend, konnten die „Frauenbelange“ selbst definieren und ihre Arbeitsschwerpunkte eigenständig festlegen, wobei sie immer in Bereichen agieren mussten, die durch die Zuständigkeiten anderer Verwaltungsstellen bereits besetzt waren (vgl. Haibach/Immenkötter/Rühmkorf 1986). Sie brauchten für ihre Initiativen meist UnterstützerInnen aus Parteien und Verbänden und ihre Handlungsfähigkeit hing von ihrer persönlichen Vernetzung mit einflussreichen frauenpolitischen AkteurInnen außerhalb der Verwaltung ab ${ }^{437}$. Viele Gleichstellungsbeauftragte verschafften sich in ihrer Kommune einen respektablen Einfluss und genossen frauenpolitische Anerkennung ${ }^{43^{8}}$. Deshalb trugen nach Uta Krautkrämer-Wagner die Gleichstellungsbeauftragten „wesentlich dazu bei[...], daß sich Frauenpolitik als neues Politikfeld etabliert hat" (Krautkrämer-Wagner 1989: 35) ${ }^{439}$.

In der ASF aber rückten in den 1980er-Jahren die politische und rechtliche Weiterentwicklung dieser Gleichstellungsstrukturen im Zuge der innerparteilichen Auseinandersetzungen um Quote und Programm aus dem politischen Fokus ${ }^{4{ }^{\circ}}$. Nach Ansicht einer Zeitzeugin ging das

437 In Baden-Württemberg, Bayern und Rheinland-Pfalz führte in den 1980er-Jahren die Gleichstellungsstelle des Landesministeriums die Geschäfte des Dachverbands der Frauenverbände. Die autonomen Bewegungsfrauen standen den Gleichstellungsbeauftragten eher kritisch gegenüber. Sie sahen in ihnen eine Verbürokratisierung der Frauenbewegung und fürchteten eine pragmatische Zerstückelung der frauenpolitischen Problemlagen. In deren Pragmatismus sahen sie einen Verlust der Fundamentalkritik an der strukturellen Machtungleichheit der Geschlechter. Allerdings entwickelten sich im Prozess der „doppelten Institutionalisierung“ der Neuen Frauenbewegungen, d.h. dem Engagement ehemaliger autonomer Frauenaktivistinnen in Parteien, Gewerkschaften und Verwaltungen und der Aufnahme frauenpolitischer Themen durch diese Organisationen (vgl. Blattert zit. n. Rudolph/Schirmer 2004: 153), begrenzte Kooperationsbeziehungen.

438 Dass die Frauen- oder Gleichstellungsbeauftragten schließlich als Expertinnen angesehen wurden, dazu trugen sicherlich auch die Frauenstudiengänge bei, die seit Beginn der 1980er-Jahre von einzelnen Universitäten angeboten wurden.

439 Die Etablierung der Gleichstellungspolitik in den Kommunen gelang im Zuge der Modernisierung der Verwaltungen in den 1980er-Jahren, mit ihr wurden neue Politikstrukturen mit BürgerInnenbeteiligung etabliert und Dienstleistungsangebote ausgebaut (vgl. Rudolph/Schirmer 2004; dazu auch Roth 1994).

440 So lassen sich in diesen Jahren keine Anträge zu Arbeitsanforderungen und Rahmenbedingungen der Gleichstellungsbeauftragten auf den Bundesfrauenkonferenzen finden. Trotzdem fanden im Forschungszeitraum verschiedene Aktivitäten statt wie 1986 die Gesprächsrunde mit Gleichstellungsbeauftragten des Bundes, der Länder und Kommunen, das Handbuch zur Frauenarbeit, das 1987 erschien und Basisinformation zur Arbeit der Gleichstellungsinstanzen bot, die Mai 1988 in Bonn veranstaltete sog. Elefantinnenrunde mit Gleichstellungsvertreterinnen der SPD aus Bund und Ländern und 1989 die frauenpolitische Konferenz der SPD-Bundestagsfraktion mit 250 Frauenbeauftragten aus Städten und Gemeinden (vgl. Frauenpolitische Konferenz der SPDBundestagsfraktion 1989; Jahrbuch der SPD \{1988-90\}). 
Interesse der ASF an den Gleichstellungsbeauftragten aber auch verloren, weil mit der schnellen Verbreiterung dieser kommunalen Einrichtungen die Stabstellen zunehmend durch Personal aus der Kommunalverwaltung besetzt wurden, d.h. mit Personen, die keine persönlichen Verbindungen zur Frauenbewegung hatten:

[E]s hat eine Entwicklung bei den Gleichstellungsstellen gegeben, die dann automatisch aus ... meiner Sicht eigentlich ... mit dazu beigetragen hat, die ASF dann auch zu schwächen. [...] Die Gleichstellungsstellen zu Beginn waren wirklich sehr politisch. Und mit einer, der wachsenden Forderungen nach Gleichstellungsstellen, überall und in jeder kleinen Gemeinde usw. ... ähm ... sind aber auch Gleichstellungsstellen entstanden ... das waren dann nicht mehr die Frauen der ersten Stunde, sondern die Gleichstellungsbeauftragte geworden sind, die sich aber mehr als Verwaltungsfrauen verstanden haben. [...] [U]nd die Frage: arbeitet man innerhalb der eigenen Stadtverwaltung oder arbeitet man gesellschaftspolitisch ... ähm ... war 'ne Entwicklung bei den Gleichstellungsstellen, die immer stärker aufgrund vieler Rahmenbedingungen und Faktoren sich in Richtung Verwaltung verschoben hat. (Zz 14)

\subsubsection{Soziale Sicherung individueller Lebensplanung}

Das System der sozialen Sicherung in der BRD ist an der Erwerbstätigkeit ausgerichtet. Die im Vergleich zur männlichen Bevölkerung geringere Erwerbsbeteiligung und die niedrigeren Verdienste von Frauen führen deshalb zu einer überdurchschnittlich hohen Altersarmut von Frauen, insbesondere Hausfrauen nach Ehescheidungen sind davon betroffen.

Die SPD setzte sich zwar stets für einzelne Maßnahmen zur Verbesserungen der sozialen Sicherung von Frauen ein, stellte aber die geschlechterhierarchischen, patriarchalen Strukturen des Sozialsystems nicht in Frage. Die Forderung der ASF nach Abschaffung des Ehegattensplittings, das die ungleichen Einkommen der Eheleute steuerlich begünstigte, wurde von der Partei nicht unterstützt, ebenso wenig wie die Umwandlung des Ehegattensplittings in ein Familiensplitting nach französischem Vorbild. Ebenso wurde die Abschaffung der Steuerklasse V, die die Zuverdienerinnenposition von Frauen verfestigte, wurde von der SPD abgelehnt.

Auch bei den Reformvorschlägen zur Alterssicherung, die auf ein geschlechtergerechteres Rentensystem und den Abbau männlicher Privilegien zielten, tat sich die Partei schwer. Das Rentenreformgesetz hatte Anfang der 1970er-Jahre zwar die Rentenkasse für Hausfrauen geöffnet, 
damit sie durch eigene Beiträge eine eigenständige Anwartschaft aufbauen konnten, insbesondere wenn sie die sog. Heiratserstattung ${ }^{441}$ in Anspruch genommen hatten; die dazu erforderlichen hohen Beitragsleistungen waren für die meisten Ehefrauen aber nicht aufzubringen. Während die SPD mit einer Grundrente die weibliche Altersarmut abmildern wollte, setzte sich die ASF für den Erwerb eigenständiger Rentenansprüche ein und forderte eine radikale Umgestaltung des Rentensystems. Die Bindung von Rentenleistungen an die langjährige Erwerbsarbeit sollte aufgehoben und das Umlageverfahren „Generationenvertrag" auf ein steuerfinanziertes System umgestellt werden. Über einen Systemwechsel im deutschen Rentensystem wurde in der SPD zwar ausführlich diskutiert, aber für konkrete Reformschritte waren in der Partei keine politischen Mehrheiten zu gewinnen.

1975 verpflichtete das Bundesverfassungsgericht den Gesetzgeber, die Ansprüche der Hinterbliebenen in der gesetzlichen Rentenversorgung bis 1984 neu zu regeln. Um für die innerparteiliche Auseinandersetzung und die 1982 anstehende Rentenreform gewappnet zu sein, hatte der ASF-Bundesvorstand 1977 die Kommission Soziale Sicherung eingerichtet. Als 1979 eine Sachverständigenkommission der Regierung mehrere Rentenreformkonzepte vorlegte, organisierte die ASF einen öffentlichen Protest. Die Kommission befürchtete aufgrund der zunehmenden Berufstätigkeit bei Frauen eine „Überversorgung“ der Witwen ${ }^{442}$; dagegen verwies die ASF auf die Sozialdaten der Bundesregierung. Hiernach bezogen die Hälfte der Rentnerinnen in diesen Jahren ausschließlich eine Witwenrente und $30 \%$ aller Rentnerinnen, 500.00o Frauen, verfügten auch mit zusätzlichen Rentenansprüchen als Hinterbliebene nur über ein Gesamteinkommen von unter 6oo DM im Monat.

Eine Rentenreform musste, so die ASF, nicht nur soziale Not abfangen, sondern auch die Grundlagen für eine individuelle und vielfältige Lebensgestaltung sicherstellen (vgl. Kramer 2013). Dazu sollten folgende Forderungen beitragen: eine Steigerung der Hinterbliebenenbezüge auf $75 \%$ der während der Ehe erworbenen Rentenansprüche, die nicht auf die von ihnen selbst erworbenen Rentenansprüche angerechnet wurden, die Bewertung der Arbeitsleistungen von Ehefrauen als anrechnungsfä-

$44190 \%$ der Ehefrauen nahmen diese Möglichkeit in Anspruch und ließen sich bei ihrer Heirat ihren bisher erworbenen Rentenanteil auszahlen. Dabei wurde ihnen allerdings nur der ArbeitnehmerInnenanteil erstattet (vgl. Dokumente 12/1980).

442 Der Anteil der Versicherungsrentnerinnen war von 1964 bis 1974 von $36 \%$ auf $49 \%$ der weiblichen Bevölkerung gestiegen, die Erwerbstätigkeit von Frauen hatte sich von 1950 bis 1975 verfünffacht und ließ einen weiteren Anstieg erwarten (vgl. DIW -Wochenbericht 1977 zit. n. Standfest 1979: 1036). 
hige Beiträge, die Anrechnung von Kindererziehungszeiten auf die weiblichen Rentenansprüche. ${ }^{443}$ Zur Abstimmung der frauenpolitischen Positionen zur Rentenreform beantragte der ASF-Bundesvorstand beim Parteivorstand die Finanzierung einer dreitägigen Fachkonferenz. Als diese von der Parteiführung verschoben wurde und schließlich nur noch die Kosten für die Hälfte der Delegierten übernommen werden sollten, sagte der ASF-Bundesvorstand die Veranstaltung ab. Er warf dem Parteivorstand vor, die ASF angesichts knapper Bundeskassen und Sparhaushalte aus dem Thema politisch abdrängen zu wollen (vgl. Rechenschaftsbericht 1981: 12).

Zum Rententhema hatte die Frauenunion in ihrer Partei mehr durchsetzen können: Im Wahlprogramm zur Bundestagswahl 1980 versprach die CDU/CSU, sich dafür einzusetzen, dass Müttern für jedes Kind fünf Jahre in der Rentenversicherung gutgeschrieben werden ${ }^{444}$; damit ließ sich mit vier Kindern ein eigenständiger, lebenskostensichernder Rentenanspruch erwerben. Außerdem wollte sie sich für die Einführung einer Hausfrauenrente einsetzen (vgl. Wahlprogramm der CDU/CSU 1980).

Den Sozialdemokratinnen gelang es vergleichsweise weniger, für ihre Vorstellungen in der Partei Gehör zu finden; auch die öffentliche Unterschriftenaktion der ASF zur Forderung „Gerechte Rente für Frauen“ fand in der eigenen Partei wenig Beachtung. Im Wahlkampfprogramm zur Bundestagswahl 1980 trat die SPD für eine Mindestrente für Geringverdienerinnen ein, aber die Kinderziehung sollte in der Rente nur mit einem Jahr pro Kind berücksichtigt werden ${ }^{45}$. Die Anrechnung dieses Babyjahres nahm Helmut Schmidt bereits in der ersten Regierungserklärung zurück (vgl. Der Spiegel 52/1981).

1986 realisierte die Kohl-Regierung mit dem Hinterbliebenenrentenund Erziehungszeitengesetz erstmals die Anerkennung nicht erwerbstätiger Arbeitsleistungen im Rentenrecht. ${ }^{446}$ Allerdings sollten die Kindererziehungszeiten in der Rentenberechnung zunächst nur für Mütter, die

443 Diese Forderungen waren in verschiedenen frauenpolitischen Zusammenhängen entwickelt worden und wurden von vielen Frauenverbänden unterstützt.

444 Rückwärtig sollte ein Jahr pro Kind angerechnet werden. Die FDP wollte zukünftig drei Jahre Anerkennungszeit pro Kind in der Rente anrechnen lassen.

445 Dagegen hatte die ASF nie eigene Vorstellung über die Höhe der Anrechnungszeiten für Kindererziehung definiert, sondern hatte nur die unscharfe Forderung „volle Anrechnung der Erziehungszeiten“ aufgestellt - möglicherweise, um eine weitere politische Zurückweisung durch die Partei zu vermeiden.

446 Dazu gehörte aber nicht die Pflege von Angehörigen. Zudem setzten alle Anrechnungen und Anhebungen eigenständige Versicherungsansprüche der Mütter voraus. Außerdem wurden mit der Gesetzesreform 1986 die Ansprüche der Witwer denen der Witwen gleichgestellt. Damit erhielten die Ehemänner über die eigenen Rentenbezüge 
nach 1920 geboren waren, berücksichtigt werden. Dass mit dieser Regelung 4,5 Mio. Frauen nicht berücksichtigt werden sollten, löste eine bundesweite Protestwelle aus, an der sich u.a. auch die Grauen Panther, der Deutsche Frauenrat sowie die ASF beteiligten. Sie erzwang 1987 eine Neuregelung mit einer stufenweise erfolgenden Einbeziehung aller Mütter (vgl. Kramer 2013: 222).

\subsubsection{Friedenspolitik als frauenpolitische Aufgabe}

Nach Angaben einer Zeitzeugin waren die vier großen Themen der ASF „Emanzipation, Gerechtigkeit, Gleichstellung und Frieden“ (Zz 6). Die Auseinandersetzung um den NATO-Doppelbeschluss ${ }^{447}$ sowie die Diskurse zur Sicherheits- und Friedenspolitik bewegten die ASF Ende der 1970er- bis Anfang der 1980er-Jahre.

Nach Wolfgang Pausch war die ASF die erste Parteieinheit, die sich gegen den NATO-Doppelbeschluss wandte (vgl. Pausch 1985: 234). Bereits die Bundesfrauenkonferenz 1979 widmete sich dem Thema. ${ }^{448}$ Ende des Jahres 1979 händigten ASF-Vorstandsfrauen dem Bundeskanzler ein Protestschreiben gegen die Stationierung der Mittelstreckenraketen aus,

hinaus auch Bezüge aus den Ansprüchen ihrer Ehefrauen (vgl. www.familienhandbuch.de/ cmain/f_programme/a_leistungen_fuer_fami-lien/s_562.html [Zugriff: 04.08.2010]).

447 Bundeskanzler Helmut Schmidt hatte im Mai 1979 die Parteispitze mehrheitlich auf die sog. Doppelstrategie der NATO, die Aufstellung atomwaffenfähiger Raketen und Verhandlungsangebote an die Sowjetunion, festgelegt. Der Parteitag 1979 in Berlin unterstützte diese Linie des Bundeskanzlers mit der Einschränkung, dass die Stationierung von Raketen und Marschflugkörpern an den Gang der Verhandlungen gebunden werden sollte, Abrüstungsaktivitäten der SU sollten die Aufrüstungsspirale beenden können (die sog. angestrebte „Nulllösung“). Zeitgleich entwickelten die USA die Neutronenbombe und verschafften sich damit die Option auf eine vorgeblich kontrollierbare atomare Kriegsführung.

448 Die Bundesfrauenkonferenz tagte vom 18. bis zum 20.05.1979 in Erlangen unter dem Titel „Frauen für den Frieden - Frauen für Europa“. Im September 1979 fand der erste Frauenkongress zur Umwelt- und Friedensbewegung statt (vgl. Lenz 20o8: 818). Im Dezember 1980 rief ein Krefelder Appell die Bundesregierung auf, die Rüstungsspirale zu beenden. Er fand viele Millionen UnterstützerInnen. Der Text war auf einer parteiübergreifenden Konferenz entwickelt worden, an der auch die Jusos, aber mehrheitlich die DKP und DKP-nahe Organisationen beteiligt waren. Deshalb brachten SozialdemokratInnen den sog. Bielefelder Appell heraus. Er entwickelte in der Friedensbewegung allerdings keine Bedeutung. Viele SozialdemokratInnen hatten vermutlich beide Appelle unterzeichnet (vgl. http://www.ag-friedensforschung.de/themen/Friedensgeschichte/krefeld.html [Zugriff: 02.08.2012]). Der Evangelische Kirchentag 1981 schloss sich mit einer eigenen Kampagne „Fürchtet Euch“ dem Protest an und stärkte den Appell mit weiteren 55.000 Unterschriften. 
für das sie 30.000 Unterschriften gesammelt hatten. Der ASF-Bundesvorstand schloss sich dem Komitee für Frieden, Abrüstung und Zusammenarbeit an und wurde Mitglied im Koordinationsausschuss der Friedensbewegung, obwohl in dem Komitee mehrheitlich SED- bzw. kommunistisch orientierte Gruppen vertreten waren. Die ASF grenzte sich von dieser Mehrheit durch eine „kritische Bejahung der NATO“ ab.

An der ersten großen Friedensdemonstration auf dem Bonner Hofgarten am 10.10.1981 nahm die ASF mit vielen Mitgliedern teil. In zahlreichen Städten gründeten sich Frauenfriedensgruppen, vielfach initiiert durch ASF-Gruppen ${ }^{449}$. Der ASF-Bundesvorstand war Mitveranstalterin des „Frauenforums“, das im Rahmen der Großdemonstration im Bonner Hofgarten 1983 stattfand. Zudem war die ASF im gleichen Jahr an der Frauen-Friedens-Konferenz in Genf beteiligt und repräsentierte auf der Veranstaltung „Parlament der Mehrheit“ am 21.11.1983 anlässlich der Bundestagsdebatte zur Pershing-II-Stationierung die Frauengruppen im Koordinationsausschuss (Dokumente 20/1983).

Für die ASF war Krieg und Frieden ein genuin frauenpolitisches Thema ${ }^{450}$ :

Frauen in der SPD haben sich seit jeher friedenspolitisch engagiert: gegen Kriegskredite und gegen den Krieg, gegen U-Booteund Panzerkreuzer-Bau, gegen NS-Terror und Faschismus, gegen die Remilitarisierung der Bundesrepublik Deutschland und die atomare Aufrüstung, gegen die Neutronenwaffen, SDI und die Stationierung der atomaren Mittelstreckenwaffen in Europa. (ASF 1979c)

Ihre Ablehnung der NATO-Sicherheitspolitik begründeten die ASFFrauen mit differenzfeministischen Topoi. Danach waren Frauen und Kinder die schuldlosen Opfer des Krieges dar, die leidvollen Erfahrungen ließen Frauen zu einer größeren Friedfertigkeit neigen und wären für den technologischen Wahn männlicher Militärstrategen weniger verführbar, außerdem besäßen sie als Gebärende eine natürliche Sensibilität für die Erhaltung des Lebens.

Die ASF beteiligte sich an dem außerparteilichen Frauenbündnis, das in der Friedensbewegung aus den autonomen Gruppen wie aus Kirchen

449 Dabei beteiligten sich die ASF-Frauen auch an Widerstandsaktionen. In Düsseldorf blockierte die ASF in einem Bündnis mit 4o Frauengruppen mit 3.00o Teilnehmerinnen in einer Menschenkette den innerstädtischen Verkehr. Dabei wurde ein zentraler innerstädtischer Platz in „Bertha von Suttner-Platz“ umbenannt. Drei Jahre später wurde diese Platzbenennung vom Rat der Stadt beschlossen.

450 In den 1950er- und 196oer-Jahren hatten sich Sozialdemokratinnen für die verarmten Kriegsopferwitwen und deren materielle Besserstellung engagiert. 
und Verbänden entstand und bundesweit Frauen mit unterschiedlichsten Mobilisierungsmotiven und -interessen zu gemeinsamen außerinstitutionellen Aktionen zusammenbrachte (vgl. Lenz 2008: 817-864) Solche Bündnisse schufen häufig Brücken zu weiteren politischen Kooperationen. So beteiligten sich die ASF-Frauen - als SozialdemokratInnen traditionell eher der evangelischen Kirche verbunden - im Zuge ihres friedenspolitischen Engagements an der Initiative Kirche von unten beim Katholikentag am 04.09.1982.

Im Verlauf des friedenpolitischen Diskurses radikalisierte die ASF ihre Ablehnung der NATO-Politik. Während sie 1979 noch „die schrittweise kontrollierte gegenseitige Abrüstung" gefordert hatte, befürwortete die ASF-Bundesfrauenkonferenz 1983 die Forderung nach einseitigen Abrüstungsschritten. Diesem Politikwechsel waren intensive politische Diskussionen in der ASF vorausgegangen. Die Bonner Bundesfrauenkonferenz 1981 hatte einen Arbeitskreis Friedens- und Sicherheitspolitik eingerichtet, der die Diskussionen zu „Alternativen Verteidigungsstrategien“ aufbereitete und Materialien zur Abrüstungsfrage, u.a. für ASF-interne Seminare, zur Verfügung stellte.

Die ASF kritisierte die Regierungskoalition, weil sie einen gestiegenen Wehretat befürwortet hatte, während der Bildungsetat aus wirtschaftskonjunkturellen Gründen zurückgefahren wurde. ${ }^{451}$ Ihre Kritik an der Sicherheitspolitik der Regierung verbanden die ASF-Frauen mit vielen gesellschaftspolitischen Themen und forderten ein aktives Handeln von unterschiedlichen gesellschaftlichen AkteurInnen. ${ }^{452}$.

Als GleichstellungspolitikerInnen für eine Öffnung der kämpfenden Einheiten der Bundeswehr für Frauen warben ${ }^{453}$, war für die ASF die friedenspolitische Dimension dieses Themas wichtiger als die frauenpolitische. Mit einer Unterschriftenaktion „Frauen in die Bundeswehr - mit

451 Für Empörung sorgte das Weißbuch, das im Etat des Bundesverteidigungsministeriums 1975/1976 die Kosten für den Kampfbomber MRCA Tornado mit einem Stückpreis von 85 Mio. DM aufführte. Dies entsprach den Personalkosten für 2.50o LehrerInnen im Jahr. Statt das Bildungssystem auszubauen, wurden 322 Kampfbomber angeschafft (vgl. Berg et al. 1976: 1028).

452 Dazu gehörten: der Verzicht auf Kernenergie wegen ihrer engen Verknüpfung mit militärischen Interessen; eine Friedenserziehung in der Schule mit interkulturellem SchülerInnenaustausch; die Pflege grenzüberschreitender kultureller Beziehungen und Patenschaften, besonders in die DDR und in osteuropäische Staaten; das Verbot von Kinderkriegsspielzeug; staatliche Initiativen zur industriellen Entwicklung der Anrainerstaaten und eine vermehrte Aufnahme von WanderarbeiterInnen aus diesen Ländern; das Recht auf Wehrdienstverweigerung und die Angleichung der Zivildienstdauer; die Einrichtung eines Friedensforschungsinstituts nach schwedischem Vorbild; die Benennung einer/eines Friedensbeauftragten in der Europäischen Gemeinschaft (aus dem Initiativantrag 11 zit. in SPD/ASF 1979a: 16).

453 Der DGB unterstützte diese Forderung, ebenso Alice Schwarzer. 
uns nicht“ im Jahr 1982 kritisierte sie diese Forderung als „Militarisierung der Gesellschaft“" (Antrag D22 in: Dokumente 21/1983:14)

Mit ihrem Friedensengagement wurde die ASF in der SPD, aber auch außerhalb der Partei, als Teil des linken Lagers der Partei deutlich sichtbar (vgl. Hansen 2013). Die Nachrüstungsdebatte, an der sich viele ASFAktivistinnen engagiert beteiligten, machte die ASF insbesondere für das regierungskritische Lager der SPD attraktiver und stärkte in der Frauenarbeitsgemeinschaft das linkssozialistische Lager. Das Friedensengagement stärkte zudem auch das Lager der Technologiekritikerinnen in der ASF und verlieh den europäisch und internationalistisch orientierten Politiken in der ASF eine neue Beachtung.

\subsubsection{Internationalistische Aktivitäten}

Für die ASF der 1980er-Jahre bestand eine enge Verbindung zwischen der Kriegsgefahr und dem wachsenden Wohlstandsgefälle auf der Welt. Sie unterstützte Willy Brandts Slogan „Entwicklungspolitik von heute ist die Friedenspolitik von morgen" und forderte nicht nur den Ausbau des Sozialstaates, sondern auch eine Erhöhung des Entwicklungshaushalts auf die UN-Maßgabe von 0,7 \% des Bruttonationaleinkommens.

1983 gründete die ASF eine eigene Entwicklungsinitiative. Der MarieSchlei-Verein, benannt nach der ersten sozialdemokratischen Entwicklungsministerin, förderte Selbsthilfeprojekte in Afrika, Asien und Lateinamerika, die Frauen bei der beruflichen Qualifizierungen halfen, damit sie ihre ökonomische Existenz durch eine andere Erwerbstätigkeit realisieren konnten als durch Dienstbotentätigkeiten und Prostitution ${ }^{454}$. Zur internationalen Solidaritätsarbeit der ASF gehörten die Ausrichtung des Internationalen Frauentags 455 und die Unterstützung nationaler Befreiungsbewegungen durch Empfänge, Pressekonferenzen und Diskussionsveranstaltungen mit Delegationen und RepräsentantInnen aus diesen Widerstandsbewegungen. Die ASF-Vorstandsmitglieder nahmen an Konferenzen der Socialist International Women (SIW) teil sowie regelmäßig an Meetings und Seminaren mit Frauen aus Verbänden und Parteien europäischer und außereuropäischer Länder. An den UNO-Frauenkonferenzen nahm ASF nicht teil; vergeblich hatte der ASF-Bundesvorstand versucht, bei der Parteiführung durchzusetzen, die deutsche Sozialdemokratie auf der UNO repräsentieren zu dürfen (vgl. dazu

454 Im Mai 1984 nahm der Verein unter dem Vorsitz von Christa Randzio-Plath seine Arbeit auf.

455 Später wurde der Internationale Frauentag vor allem von den kommunalen Gleichstellungsbeauftragten aufgegriffen, um den lokalen Fraueninitiativen ein öffentliches Forum zu organisieren. Er verlor damit seinen internationalen Bezug. 
Pausch 1985). Ab Mitte der 1980er-Jahre beteiligte sich die ASF an den NGO-Foren der Weltfrauenkonferenzen.

Die Berichterstattung des ASF-Bundesvorstands über den Verlauf und die Ergebnisse der internationalen Netzwerkarbeit innerhalb der Organisation war allerdings eher gering. Vermutlich sorgte die ASF-Leitung zwar für internationale Präsenz, aber für die eigenen Politiken und internen Diskurse hatten die nationalen Themen Priorität. ${ }^{456}$

Als Beitrag zu einer internationalistischen und friedensorientierten Politik verstand die ASF ihre Unterstützung innenpolitischer Konzepte, die die BRD als Einwanderungsland definierten und die kulturelle Bereicherung der Gesellschaft durch die Einwanderungen fördern wollten, und forderte Hilfen zur Familienzusammenführung von MigrantInnen und eine Integrationspolitik, die Migrationsfamilien mit besonderen Maßnahmen unterstützte, z.B. durch spezielle Bildungsangebote ${ }^{457}$. Die öffentlichen Debatten über die Integration von WanderarbeiterInnen, über die Freizügigkeit der Märkte oder einen Anwerbestopp und Grenzsicherungen nahm die ASF in eigenen Fachveranstaltungen auf, entwickelte aber auf Bundesebene in den 1980er-Jahren dazu keine geschlechterspezifischen Politikkonzepte oder frauenpolitischen Aktivitäten.

\subsubsection{Europa der Frauen}

Die deutschen Sozialdemokratinnen versprachen sich viel Unterstützung von der Europäischen Union. Grundlegende Veränderungen im deutschen Recht waren durch europäische Gleichbehandlungsregelungen initiiert worden. In den 196oer-Jahren war es die Gleichstellung der Frauen in der Familie, in den 1970er- und 1980er-Jahren verabschiedete die EU Richtlinien zur Lohngleichheit und Gleichstellung in der Arbeitswelt und forderte die Mitgliedsstaaten zu entsprechenden gesetzlichen Maßnahmen auf ${ }^{458}$.

456 Z.B. Diskussionen zu Aufgaben und Zielen des Internationalen Rats sozialdemokratischer Frauen (ICSDW), der sich für bessere Mitwirkungsmöglichkeiten für Frauen in der Sozialistischen Internationale einsetzte, waren weder in den Akten dokumentiert noch ergaben die Erinnerungszeugnisse dazu klärende Hinweise.

457 Heinz Kühn legte 1979 als erster Ausländerbeauftragte der Bundesregierung ein Memorandum vor, das sie aufforderte, mit einer neuen Integrationspolitik EinwanderInnen die Partizipation an Bildung, Arbeitsmarkt und Politik - z.B. durch ein kommunales Wahlrecht - zu erleichtern.

458 Die Richtlinie über Lohngleichheit (1975), über Gleichbehandlung (1976) in 79/7/EWG - ABI. L6 vom 14.02.1976; die Richtlinie über Gleichbehandlung im Bereich der sozialen Sicherheit (1979): $:$ spepin 79/7/EWG - ABI. L6 vom 10.01.1979; die Richtlinie über die Gleichbehandlung bei den betrieblichen Systemen der sozialen Sicherheit (1986) seppimit 
Für die ASF hatten die europäischen Gleichstellungserfahrungen eine wichtige Bedeutung sowohl für die eigene Politikfindung als auch für die Begründung frauenfördernder Maßnahmen in der SPD: Die Entscheidung für die Quote auf der Erlanger Bundesfrauenkonferenz 1979 fiel auch vor dem Hintergrund der Erfahrungen in der dänischen Schwesterorganisation, sie hatten eine ähnliche Debatte geführt und die Quote aus den gleichen Erwägungen zunächst abgelehnt; ob ein eigenständiges Frauenministerium mit einem geringen Etat politisch einflussreicher wäre als ein Frauenreferat in einem großen Ministerium, wurde anhand der Erfahrungen französischer Sozialdemokratinnen diskutiert; für die Durchsetzung innerparteilicher Förderpläne waren die Erfahrungen der norwegischen und schwedischen Sozialdemokratinnen eine wichtige Orientierung 459 . Die schwedische Sozialdemokratie hatte bereits vor der SPD die Einrichtung von Gleichstellungsbeauftragten befürwortet und innerparteilich Frauenförderpläne entwickelt. Bereits Anfang der 1980er-Jahre waren 30 \% ihrer Reichstagsmandate mit Frauen besetzt.

Dieser Erfahrungsaustausch bildete den Kern der europäischen Kooperation der ASF. ${ }^{460}$ Die Arbeit der Europaabgeordneten fand dagegen wenig Widerhall in der Frauenarbeitsgemeinschaft ${ }^{461}$, aber auch in der Partei. Der Antrag des ASF-Bundesvorstandes auf Einrichtung einer frauenpolitischen „Europakommission“ der ASF lehnte der Parteivorstand ab.

1989 gelang es den Frauen der sozialistischen und sozialdemokratischen Parteien Europas, gemeinsam ein Manifest der linken Frauen der Europäischen Gemeinschaft zu erstellen. Es war ein Appell an die eigenen Parteien, die Gleichstellung von Frauen im Zuge der Entwicklung des europäischen Binnenmarktes zu fördern. In dem sechsseitigen Dokument, das vor der Wahl zum dritten Europäischen Parlament veröffentlicht wurde, fanden sich alle wichtigen Forderungen der ASF wieder sowie ihre Kritik an der geschlechterdualistisch gespaltenen Gesellschaft. Ausgerichtet war es auf eine Veränderung der nationalen Ökonomien, im Fokus standen Themen der weiblichen Erwerbstätigkeit (vgl. Rechenschaftsbericht 1990: 10-15). Gefordert wurden:

den Änderungen 1996 in 86/378/EWG - ABI. L225 vom 12.08.1986; die Richtlinie über die Gleichbehandlung von Selbstständigen (1986) șeppin 86/613/EWG.

459 Dazu der Bericht der ASF-Vorsitzenden Inge Wettig-Danielmeier aus der Arbeitsgruppe Gleichstellung der Frau auf dem Parteitag 1984 (vgl. Parteitag der SPD 1984).

46o Die internationalen Reisen der ASF mussten bezahlt werden, worum zu Anfang gekämpft werden musste (vgl. Zz 7).

461 Die in das europäische Parlament eingebrachten frauenpolitischen Positionen waren Übernahmen deutscher Politiken zu Arbeitsrecht, VerbraucherInnenschutz und Entwicklungspolitik (vgl. Dokumente 19/1983). 
- Chancengleichheit in der Berufs- und Arbeitswelt ${ }^{462}$,

- Frauenförderpläne463,

- Maßnahmen zur Vereinbarkeit von Beruf und Familie wie die Umwandlung des Mutterschaftsurlaubs in den Elternurlaub, Tagesbetreuungen mit flexiblen Öffnungszeiten sowie die Verkürzung der Arbeitszeit für Väter,

- Entkriminalisierung des Schwangerschaftsabbruchs,

- Einstufung der Vergewaltigung in der Ehe als Straftatbestand,

- $\quad$ rechtliches Verbot der sexuellen Belästigung am Arbeitsplatz,

- eheunabhängiges Aufenthaltsrecht für ausländische Frauen,

- Maßnahmen gegen die wachsende Armut von Frauen,

- Maßnahmen für eine umweltschonende Energiepolitik,

- Maßnahmen für eine umfassende Friedenspolitik, die den Kampf gegen Ausbeutung, Hunger, Benachteiligung und die besondere Berücksichtung von Fraueninteressen in der Entwicklungsarbeit einschließt,

- internationale Solidarität.

Dazu forderten die europäischen Sozialistinnen die Einführung einer Quotierung in den sozialdemokratischen und sozialistischen Parteien ohne Größenangabe -, weil sie eine enge Verbindung zwischen der Durchsetzung frauenpolitischer Forderungen in der Partei und einer angemessenen Beteiligung von Frauen an politischen Ämtern und an innerparteilichen Entscheidungspositionen zogen.

\subsection{Repräsentation und Partizipation der Frauen in der SPD}

Die Forderung nach einer höheren Beteiligung der Frauen in politischen Entscheidungsstrukturen hatte nicht nur das Ziel, dass sich in der Sozialstruktur einer demokratischen Partei die Geschlechterverteilung der Gesellschaft widerspiegeln sollte, sondern die Partizipation der Frauen galt der ASF als notwendiges Mittel der Politik. Die Berücksichtigung frauenpolitischer Anliegen und die Durchsetzung frauenpolitischer Interessen setzte ihrer Überzeugung nach eine machtvolle Gruppe von FürsprecherInnen in den Gremien der Partei voraus, was sich nur mit

462 Unbezahlte Haus- und Familienarbeitarbeiten wurden zwar verurteilt, aber bei den Forderungen nicht weiter berücksichtigt.

4631986 hatte der DGB die Forderungen nach Frauenförderplänen sowie nach besonderen Fort- und Weiterbildungsmaßnahmen für Frauen zum beruflichen Aufstieg aufgenommen (vgl. DGB 2008). 
Hilfe einer Mindestteilnahme von Frauen erreichen ließ. Von weiblichen Politikerinnen erwartete die ASF, dass sie sich der frauenspezifischen Interessen annahmen, und auch in der Partei wurden jedem engagierten weiblichen Parteimitglied in den überwiegend von Männern besetzten Gremien qua Geschlecht frauenpolitische Interessen und Kompetenzen zugeschrieben ${ }^{464}$. Im Zuge der Lobbyisierung der Frauenpolitik übernahmen frauenpolitische Aktivistinnen in der Partei die Alleinzuständigkeit für die Entwicklung frauenpolitischer Problemdefinitionen und politischer Konzepte, ob eigeninitiativ oder durch Übertragung Zuschreibung von den Parteimitgliedern.

In den 196oer- und 1970er-Jahren gehörten Frauen für die Mehrheit der SozialdemokratInnen nicht in die Politik. Ende der 1980er-Jahre aber gehörte die öffentliche Präsentation hochrangiger Parteipolitikerinnen zum Wahlkampfrepertoire. Frauen waren zu einem Machtfaktor in der "Legitimationssphäre“ der Parteien geworden, so Birgit Meyer (vgl. Meyer 1988). Sie standen für eine andere Macht, die sich weniger auf männliche Hegemonie und mehr auf Konsens und Kooperation gründete (vgl. Meyer 1988). Auch die SPD symbolisierte mit ihren Politikerinnen die „Modernität“ der Sozialdemokratie und die Lebendigkeit einer Partei, die fähig war, gesellschaftliche Veränderungen zu reflektieren und anzunehmen. Sie sollten verdeutlichen, dass die Gleichstellung der Geschlechter zu einem zentralen Anliegen der SPD geworden war.

Dazu gehörte auch die Verankerung der Quote in der Parteisatzung. Im kollektiven Gedächtnis der Partei wird sie als der größte politische Erfolg der ASF gewertet (vgl. Lösche/Walter 1992; Faulenbach 2012; Potthoff/Miller 2002; Heimann 2002) ${ }^{465}$. Die Einführung der Quote erreichte eine überragende Resonanz in den zeitgenössischen Medien - Polemiken und Zustimmungen. Sie hatte Wirkungen über die Partei hinaus. Z.B. beschloss die Synode der Evangelischen Kirche in Deutschland (EKD) ein Jahr nach dem Parteibeschluss eine 40-\%-Quote, die auf allen Organisationsebenen innerhalb der nächsten Dekade erreicht werden sollte ${ }^{466}$.

464 Diese Vorstellungen korrespondierten mit dem in den Neuen Frauenbewegungen vertretenen „Recht auf Selbstvertretung“.

465 Diese Einschätzung zur Bedeutung der Quote teilten die meisten ZeitzeugInnen nicht. Die ehemaligen ASF-Funktionärinnen betonten dagegen die Bedeutung der politischen Konzepte, die die Partei übernahm, wie das familienpolitische Programm, die Gleichstellungsbeauftragten, die wichtige Transmissionsfunktion, die die ASF für frauenpolitische Forderungen erfüllte, wie zum § 218 oder zur Gewaltdiskussion, und die Fortschrittlichkeit der ASF bei der Ablehnung der Kernkraft und der Öffnung für eine nachhaltige Energiewirtschaft, der Anerkennung sozialer Bewegungen als demokratische AkteurInnen oder der Revision der Sicherheitspolitik.

466 Auf dem Bremer Parteitag 1991 berichtete Inge Wettig-Danielmeier, dass in vielen kirchlichen Gremien eine 30-\%-Quote bereits realisiert wäre (vgl. Gleichstellungsbericht 1991: 5). 
Selten wird über den konfliktreichen Prozess der Durchsetzung und die organisationspolitischen Wirkungen der Quote berichtet. Innerhalb der ASF war die Quote zunächst umstritten und wurde mehrfach hintereinander auf den Bundesfrauenkonferenzen abgelehnt. In den Rückblenden und Bilanzen der Zeitzeuginnen wurden verschiedene unerwünschte und auch unerwartete Folgen der Quotenregelung beschrieben. Einig waren sich die ZeitzeugInnen jedoch darin, dass die Quote dazu beigetragen hat, die Gleichstellungspolitik in den Strukturen und politischen Konzepten der SPD nachhaltig zu verankern.

\subsubsection{Der Frauenanteil in den Parteifunktionen}

In den 196oer-Jahren sank der Anteil der weiblichen Mitgliedschaft in der SPD auf ca. $17 \%^{467}$. Die geringe Attraktivität der Partei für Frauen entsprach der Vorstellung, dass sich Frauen grundsätzlich wenig für Politik interessierten, und wurde nicht als parteipolitisches Problem wahrgenommen. Als im Wahljahr 1972 der Partei über 10o.ooo Mitglieder beitraten, lag der Frauenanteil bei den Neueintritten aber bei rund $26 \%$ und damit wesentlich über dem bei der Mitgliedschaft; ein Trend, der sich in den Folgejahren stabilisierte. 1974 waren in der BRD 62,3 \% aller parteipolitisch gebundenen Frauen in der SPD organisiert, bei den Männern lag dieser Anteil dagegen nur bei 56,3\% ${ }^{468}$ (vgl. Hoecker 1987a: 42). Wissenschaftliche Studien, wie z.B. Umfragen des Allensbacher Instituts, wiesen nach, dass sich die Bereitschaft zum politischen Engagement zwischen den Geschlechtern bald anglichen haben werde (vgl. Hoecker 1987a: 55).

Nach 1976, als die SPD mit 1,02 Mio. ihren höchsten Mitgliederstand erreichte, begann die Partei zu schrumpfen, die Zahl der weiblichen Mitglieder jedoch stieg weiter an ${ }^{469} .1990$ organisierte die SPD mit ca. 251.00o weiblichen Mitgliedern mehr Frauen als alle anderen im Bundestag vertretenen Parteien zusammen (vgl. Boyer 2001). Laut der Mitgliederstudie für Nordrhein-Westfalen aus dem Jahr 1983 gewann die Partei dabei die weibliche Neumitglieder eher in den mittelschichtsorientierten großen Ortsvereinen als in solchen, die durch ArbeiterInnenwohngebiete geprägt waren (vgl. Becker et al. 1983).

467 Frauenanteil Ende 1966: 17,25\% (vgl. ASF 2015: 10).

468 Dieser Anteil verändert sich durch die Entwicklung der CDU zur Volkspartei, die ihre Organisation ausbaute und damit ihre Parteimitglieder von 249.0oo (1963) auf 725.00o (1983) fast verdreifachte.

469 Bis auf die Jahre 1980-1982, in denen die SPD vermutlich viele weibliche Mitglieder an die Grünen verlor, die sich in diesem Zeitraum gründeten, und an die DKP, die ihren Frauenanteil von $20 \%$ (1968) auf über $43 \%$ (1985) erhöhen konnte. 
In den 1970er-Jahren waren die Frauen in den Parteifunktionen auf allen Ebenen unterrepräsentiert. In der Landesorganisation NordrheinWestfalens z.B. waren Frauen zwar zu $26 \%$ in den Ortsvereinen vertreten, stellten aber nur zu $12 \%$ den stellvertretenden Vorsitz und nur zu $6 \%$ den Vorsitz der Ortsvereine (vgl. Becker/Hombach et al. 1983: 58). In den Vorständen engagierten sie sich meist als Schriftführerinnen, Beisitzerinnen und Kassiererinnen. Dies änderte sich bereits Anfang der 1980er-Jahre. Die Landesverbände meldeten einen kontinuierlichen Anstieg der Frauen in den Leitungen der Orts- und Kreisverbände sowie auf Unterbezirks-, Bezirks- und Landesebene, auch die weibliche Beteiligung an den Landesparteitagen und in den Kommissionen stieg (vgl. Jahrbuch der SPD 1986/1987: 570-574). In $36 \%$ der Bezirke entsprach der Anteil der Frauen in den Bezirks- und Landesvorständen schon vor dem ersten Quotenbeschluss von 1986 dem jeweiligen weiblichen Mitgliederanteil (vgl. Gleichstellungsbericht in Parteitag 1988: 889f.6). Ebenso stieg der Frauenanteil in der Parteispitze: 1977 gehörten nur zwei Frauen dem 36-köpfigen Parteivorstand (5,5 \%) an. 1984, zwei Jahre vor der Quote, hatte sich ihr Anteil bereits auf 17,5 \% erhöht (vgl. Hoecker 1995). Diese Folgen der Politisierungs- und Protestbewegungen ließen auch in anderen Bundestagsparteien die Frauen in Leitungsgremien aufrücken. So erhöhte sich der Anteil der Frauen von 1976 bis 1986 im CDU-Vorstand von 9,1 \% auf $17,1 \%$, in der CSU von $6,8 \%$ auf $12,8 \%$ und in der FDP von 12,1 \% auf 13,8 \% (vgl. Hoecker 1987: 56).

Trotzdem mussten nach Berichten der ZeitzeugInnen die SPDFrauen ihre Ansprüche auf höhere Präsenzen in allen Parteiebenen nachdrücklich anmelden. Die Parteidokumente belegen dazu aufreibende Auseinandersetzungen. Besonders bei den Besetzungen der Spitzengremien, wie z.B. des Parteivorstands, war die Bereitschaft der Parteimehrheit, Frauen zu berücksichtigen, gering. Erst Sondermaßnahmen der Parteiführung wie die Erweiterung der Vorstandssitze (1979) oder die Aufstellung von eigenen Kandidatinnenlisten (1984) führten zu einem höheren Frauenanteil.

Auch in den Kommissionen des Parteivorstands stieg der Anteil der weiblichen Kommissionsmitglieder kontinuierlich an, von 1981 mit $10 \%$ auf $16 \%$ im Jahr 1982 und auf 21,4 \% im Jahr 1984. Doch musste der ASFBundesvorstand den Erinnerungen der Zeitzeuginnen ${ }^{470}$ um jeden Sitz und jede Stimme ringen:

[D]ann wurden ... alle zwei Jahre die so genannten Fachkommissionen besetzt, die internationale Kommission, die Sicherheitskommission, die Was-weiß-ich-Kommission. Und das sind meis- 
tens so zehn bis fünfzehn. Und da ist es ... üblich ..., dass diejenigen, die also quasi die Chairmen der Kommissionen waren, da Namenslisten eingereicht haben, und über die hat dann der Vorstand beschlossen. Und - wie das Leben so spielte - waren das halt alles Männer mit dem Ergebnis - und das ist jetzt die Leidensgeschichte, die ich erzählen will -, dass unsere Gleichstellungsbeauftragte, also das war sehr lange die Inge, dann immer sagte - und das auch noch zu Zeiten, als Willy Brandt Vorsitzender war: ,Also, da hab ich folgende Vorschläge , 1 bis $15^{\text {' und zwar }}$ deswegen, weil die Männer als projektierte Vorsitzende DIESE personellen Vorschläge nicht von vornherein übernommen haben [...], weil sie meinten, da gäbe es geborene Männer, die da also nicht verdrängt werden durften, mit dem Ergebnis, dass wir IMMER wieder den Kampf hatten, und das ging KOMMISSION FÜR KOMMISSION so weiter. (Zz 8)

\subsubsection{Der Zugang zu öffentlichen Ämtern für Frauen}

Der Zugang zu öffentlichen Ämtern war für Frauen weit schwieriger als der Zugang zu Parteiämtern und -gremien. Besonders niedrig war die Zahl weiblicher Bundestagsabgeordneter. In der SPD war man überzeugt, dass sich Wahlkandidatinnen eher wahlschädlich auswirkten, denn Wähler und auch Wählerinnen schrieben Frauen keine ausreichenden politischen Kompetenzen, weniger Sachverstand und weniger Durchsetzungsfähigkeit zu. Frauen hatten in der SPD deshalb nur in persönlichen Ausnahmefällen Chancen, KandidatInnenlisten zu besetzen (vgl. Huber 1984). In der SPD-Fraktion sank der Frauenanteil ab der 3. Wahlperiode. Nach 1957 betrug er 12,2 \%, nach der Bundestagswahl 1972 sank er auf $5,4 \%{ }^{471}$ und lag damit im 7. Deutschen Bundestag unter dem der CDU/CSU von 6,4\%. Im 8. Deutschen Bundestag war der Anteil weiblicher Abgeordneter in der SPD-Fraktion sogar der niedrigste aller Fraktionen (vgl. Schindler 1999: 636). Erst nach der Bundestagswahl 1980 änderten sich diese Verhältnisse, ab der 9. Wahlperiode stieg der Frauenanteil in der SPD-Fraktion kontinuierlich und wuchs stärker als in den Fraktionen der beiden anderen Parteien ${ }^{472}$.

471 Durch Nachrückverfahren stieg der Anteil am Ende der Wahlperiode auf 6,2 \% (vgl. Tab. A1 unter DOI 10.3224/86388794A).

472 Steigerungsraten beim Frauenanteil der SPD-Fraktion: BTW 1976: 6,7 \%; BTW 1980: 8,3\% (+1,6\% zu 1976); BTW 1983: 10,4 \% (+2,1 \% zu 1980); BTW 1987: 16,1 \% (+5,7\% zu 1983); BTW 1990: 27,2 \% (+9,1\% zu 1987) (vgl. Hoecker 1995: 137; eigene Berechnungen). 
Die Kommunalparlamente waren für Frauen leichter zu erreichen. Der Anteil weiblicher Ratsmitglieder wuchs ab den 1970er-Jahren. Bereits 1987 war jedes fünfte Ratsmitglied eine Frau. Die höchste Frauenbeteiligung wurde in den Gemeinden mit mehr als 500.00o EinwohnerInnen verzeichnet, möglicherweise wegen der stärkeren Präsenz frauenpolitischer und anderer zivilgesellschaftlicher Initiativen und des größeren Anteils an Kandidatinnenangebots mit gefordertem Sozialkapital. Hier stieg der Frauenanteil im Forschungszeitraum von 12,35\% (1973) auf 28,5\% (1990). Dabei verzeichneten die kleineren Gemeinden einen sprunghaften Anstieg: in den Gemeinden mit 20.000-50.000 EinwohnerInnen von 6,9\% (1973) auf 18,3\% (1990); in den Gemeinden mit 100.000-200.000 EinwohnerInnen von 9,1 \% (1973) auf 25,1 \% (1990) (vgl. Daten in Hoecker 1995: 111).

Dagegen war der Zuwachs an weiblichen Landtagsabgeordneten vergleichsweise geringer. Diese Mandate besaßen eine sehr viel höhere Attraktivität, Landtagsabgeordnete hatten mit den Bundesdiäten vergleichbare Bezüge; zudem öffnete ein Landtagsmandat potenziell den Weg zum Bundestagsmandat (vgl. Hoecker 1995: 115f.). Erst Mitte der 1980er-Jahre überstieg der Frauenanteil im Landesparlament die 10-\%-Marge473 (vgl. Kinzig 2007: 48). In den SPD-Landtagsfraktionen konnten nur 6 der 11 SPD-Landtagsfraktionen einen höheren Frauenanteil vorweisen, die weibliche Präsenz unterschied sich je nach Bundesland erheblich (vgl. Gleichstellungsbericht 1984). Während der Frauenanteil in dieser Zeit in Schleswig-Holstein und Berlin $19 \%$ (1985) betrug, lag er in Baden-Württemberg bei $12 \%(1984)$ und in NRW sogar nur bei $7 \%$ (1985). Nach den Landtagswahlen im Saarland 1985 und in NRW 1986 war nur je eine Frau ins Kabinett berufen worden (vgl. Gleichstellungsbericht 1988: 892).

Um die Wahlchancen der Kandidatinnen zu erhöhen, setzte sich die ASF ab den 1980er-Jahren für eine Reform des Wahlrechts ein. Das Kumulieren und Panaschieren bei der Stimmvergabe sollte zugelassen sein, wie es in verschiedenen Bundesländern nach dem Kommunalwahlrecht möglich war.

Dass für Männer und Frauen im Hinblick auf das Erreichen eines öffentlichen Amtes höchst ungleiche Bedingungen herrschten, spiegeln die geschlechterspezifischen Sozialstatistiken zu den deutschen Bundestagsabgeordneten wider: Nach den Erhebungen Peter Schindlers hatten Politikerinnen in den 1960er- bis 1990er-Jahren eine kürzere Mandatsdauer

473 Bis 1990 war der Frauenanteil auf durchschnittlich $20 \%$ in den westdeutschen Bundesländern gestiegen, allerdings mit hohen regionalen Unterschieden. Am erfolgreichsten setzten sich die Frauen im Bundesland Schleswig-Holstein durch: 1988 ernannte Björn Engholm eine Ministerin für Bundesangelegenheiten, eine Finanzministerin und eine Kultusministerin. Schleswig-Holstein war das erstes Bundesland mit einer Ministerpräsidentin: Heide Simonis (SPD) übernahm das Amt 1993. 
als ihre männlichen Kollegen und wurden seltener als diese mehrfach hintereinander gewählt. Die Zahl der männlichen Mehrfachgewählten stieg in diesem Zeitraum sogar an. Für Frauen hatte die Wahl einer politischen Karriere auch andere persönliche Folgen. Weibliche Abgeordnete waren überdurchschnittlich alleinstehend, ledig, verwitwet oder geschieden und mehr als $30 \%$ der verheirateten weiblichen Abgeordneten hatten keine eigenen Kinder. Demgegenüber waren die Männer in der Mehrheit Familienväter (vgl. Schindler 1999; Hoecker 1987a: 88). Dass das Schaffen einer Vereinbarkeit von Familie und Politik vor allem auf den Frauen lastete, war vermutlich auch der Grund dafür, dass Frauen erst mit höherem Alter als die Männer in die Politik einstiegen

Erst in den 1990er-Jahren glichen sich die Chancen beider Geschlechter auf Mandat und parlamentarische Karriere an ${ }^{474}$. Allerdings blieben Spitzenpositionen wie die der/des parlamentarischen Staatssekretärin/Staatssekretärs, der/des Fraktionsvorsitzenden, der/des Ministerpräsidentin/Ministerpräsidenten oder Chefin/Chef der Staatskanzlei ebenso wie die ministeriellen Schlüsselressorts Inneres, Verteidigung, Wirtschaft und Finanzen noch Jahrzehnte später bevorzugt mit Männern besetzt (vgl. Edinger/Holfert 2005).

\subsubsection{Die Auseinandersetzung in der ASF um die Quote}

Die Einführung einer Quote war den ASF-Frauen bereits 1975 vom Parteivorstand der vorgeschlagen worden, auch die Arbeitsgruppe Gleichstellung der Frau des Parteivorstands riet 1977 zu einer solchen Maßnahme, aber die Frauen setzten auf die Einsicht der Partei, so Karin Junker, ,überzeugt, die Partei würde die innerparteiliche Gleichstellung freiwillig und aus innerer Überzeugung schaffen." (ASF 2008: 23). Deshalb lehnte die ASF-Bundesfrauenkonferenz eine Quotenregelung ab, und zwar viermal hintereinander, wenn auch mit schwindenden Mehrheiten. 475

Die Kritikerinnen sahen in der Quote die Wiedereinführung einer erneuten „Schutzklausel“ für Frauen, der Regelung, die seit 1908 eine weibliche Mindestpräsenz in den Führungsstrukturen sichern sollte und die der Parteitag 1971 auf Initiative linker Frauenaktivistinnen aus der Satzung gestrichen hatte. Eine solche statuarische Regelung schien den

474 Wird die Repräsentanz der Geschlechter nicht auf die Wahlberechtigten bezogen, sondern auf die Mitgliedschaft in den Parteien, sind Frauen in den Fraktionen der PDS, Bündnis 9o/Grüne, SPD sogar überrepräsentiert, in der CDU und FDP entsprechen sie der parteiinternen Geschlechterverteilung (Edinger/Holfert 2005).

475 Bundesfrauenkonferenzen der-Jahre 1977, 1979, 1981, 1983. 
Kampf für die Anerkennung der Frauen in der Politik geradezu zu desavouieren: „Die Einführung eines Quotensystems reduziert die Qualifikation von Frauen auf ihre Geschlechtszugehörigkeit. Dies ist diskriminierend“ (Antrag 327 der Bundesfrauenkonferenz 1979, zit. n. Dokumente 11/1979: 39). Außerdem befürchteten diese ASF-Aktivistinnen, dass mit einer Quote Parteigremien aus der Verantwortung wären, Frauen durch Fördermaßnahmen zu unterstützen.

Eine bloß numerische Berücksichtigung der Frauen bei Wahlen könnte zudem die Vertreterinnen der ASF schwächen, zum einen weil eher solche Kandidatinnen konsensfähig wären, die am wenigsten für eine Kursänderung einstanden, zum anderen weil an den gewählten Frauen von nun an der Makel der "Quotilde“ haftete und ihre Kompetenz, mit der sie sich gegen ihre männliche Konkurrenz durchgesetzt hatten, überschattete (vgl. Antrag 327 der Landesorganisation Hamburg zit.n. a. a. O.). Manche Genossin fürchtete sogar die Auflösung der Arbeitsgemeinschaft, weil ja dann die Statuten für eine ausreichende Beteiligung der Frauen in der Partei sorgten. Die Quote wäre zugestandenes Ghetto, warnte Bundesvorstandsmitglied Karin Hempel-Soos auf der Bundesfrauenkonferenz 1979 und forderte deshalb: „Laßt die Pfoten von den Quoten“ (zit. n. Wettig-Danielmeier 1997b: 7).

Auch führende Parteimitglieder wie NRW-Fraktionsvorstandsmitglied Anke Brunn argumentierten gegen die Quote: „Die Stärke unserer Arbeit ist kein Mengenproblem, sondern ist ein Problem der Stärke unserer Argumente." (ASF 1979b, Antragsblock D: 12) Ziel der ASF, so hieß es auf der Bundesfrauenkonferenz 1981, wäre nicht die Teilhabe, sondern die Veränderung einer Kultur.

[Der] notwendige Kampf der Frauen gegen die Vorherrschaft der Männer führt nur dann zu einer Vermenschlichung der Gesellschaft, wenn wir nicht nur formale Gleichstellung anstreben, etwa mit dem männlichen Größe- und Härtestreben, mit der Macht und Konkurrenzherrlichkeit, sondern wenn wir auch gleichzeitig gegen eine Vorherrschaft dieser sogenannten ,Männlichkeit’ angehen. (Dokumente 15/1981: 5)

Viele Frauen hielten die Quote darüber hinaus für undemokratisch, erinnert sich eine Zeitzeugin: „[A]lso so eine Zwangsgeschichte gefiel uns anfangs gar nicht." (Zz 1)

Die Quoten-Gegnerinnen stießen allerdings auf eine wachsende Opposition in den eigenen Reihen. Eine der Befürworterinnen der Quote erinnerte sich:

[I]ch habe sie [die Quotengegnerinnen - S.E.] gehasst wie die Pest, auch Inge Wettig-Danielmeier war damals dagegen. Und die ganzen Nordrhein-Westfälinge, einschließlich Karin Junker, 
setzten auf die Einsicht der Männer, ohne die könne das gar nicht gemacht werden ... Man muss schon mit jemandem paktieren, aber warum sollen Männer freiwillig ihre Machtpositionen aufgeben? Die Einzigen, die da Bündnispartner sind, sind die älteren Etablierten, die das in höherer Weise einsehen $(\mathrm{Zz}$ 11).

Anfang der 1980er-Jahre begannen einzelne ASF-Arbeitsgemein-schaften entgegen der ASF-Mehrheitsbeschlüsse, auf ihren jeweiligen Parteiebenen Quoten durchzusetzen. 1983 verpflichteten sich die Münsteraner SozialdemokratInnen, ihre Ratssitze zu quotieren ${ }^{476} .1985$ führte Südbayern als erster SPD-Bezirk eine Mindestquote von $25 \%$ ein ${ }^{477}$. Eine Zeitzeugin erinnert sich an dieses Unterlaufen der Quotenablehnung:

[W]ir waren sozusagen die Putschisten aus dem Süden, die ihnen die Quote aufgehängt haben und gesagt haben: Wenn ihr's nicht einsehen wollt, dann hängen wir's euch eben auf. ( $\mathrm{Zz}$ 11)

Weitere Ortsvereine schlossen sich an und übernahmen Quotenregelungen von $25 \%$ oder $30 \%$. Im Bezirk Hessen-Süd war die Quote als Sollbestimmung beschlossen worden ${ }^{47}$. Mit einer stufenweise erfolgenden Quotierung sollte die Zahl weiblichen Fraktionsmitglieder in den Gemeinderäten auf eine Drittelparität steigen (vgl. Dokumente 22/1984; Juso-Magazin 6/1986: 25). 1985 beschloss der Bremer Landesparteitag, den Anteil weiblicher Abgeordneter von 19 auf mind. 30 bis $40 \%$ zu steigern (vgl. Bericht der Bremer Delegierten Ursula Kerstein in Parteitag der SPD 1988: 107). Die ASF-starken Bezirke hatten 1986 erreicht, dass in der neugewählten Hamburger BürgerInnenschaft der Anteil der weiblichen Abgeordneten 32 \% betrug. 479 Bayern und Niedersachsen beschlossen, ein paritätisch zusammengesetztes Regierungsteam für die Landtagswahlen 1986 zu präsentieren. In der Arbeitsgemeinschaft der JungsozialistInnen war bereits 1983 eine 30-\%-Quote eingeführt worden (vgl. Lang 1989: 93).

476 Gespräch mit Brigitte Stresser, ISF Münster, am Rand einer Veranstaltung der ASF „20 Jahre Quote“ in Münster 2008.

477 „Schwestern, zur Sonne. Aufbruch der ,Enkelinnen': Die SPD soll Schluß machen mit der Unterrepräsentation der Frauen in Partei und Parlamenten." SPIEGEL 32/1985; http://www.spiegel.de/spiegel/print/d-13513776.html [Zugriff: 12.04.2012].

478 Hier stand die SPD in Parteienkonkurrenz zu den Grünen, die seit 1983 eine paritätische Quote anstrebten.

479 Vgl. Tab. 11 Landtagswahlen 1964-199o. Ergebnisse der SPD mit Frauenanteil bei den Abgeordneten unter DOI 10.3224/86388794A. 
Als die Bundesfrauenkonferenz der ASF 1985 die Quote beschloss, war die höhere Teilhabe der Frauen an Funktionen und Ämtern vielerorts in der Partei bereits akzeptiert oder sogar aktiv gefördert worden. Allerdings war der angestrebte Frauenanteil nicht definiert und nicht gesichert; selbst Oskar Lafontaine, Mitglied der gleichstellungspolitischen Arbeitsgruppe des Parteivorstands, holte 1985 nach einem spektakulären Wahlsieg, der ihn zum Ministerpräsidenten machte, nur eine Frau ${ }^{480}$ in sein 9-köpfiges Kabinett (vgl. Rechenschaftsbericht 1985: 15). So blieb für manche Parteieinheiten und -regionen, in denen die ASF-Arbeitsgemeinschaften schwächer organisiert oder eher von traditioneller Frauenarbeit geprägt waren, die Einführung der statuarischen Quote 1988 ein „Kulturschock“ (Zz 15).

Als sich die ASF-Konferenzmehrheit 1985 für die Quote entschied, war das weniger eine Folge des ASF-internen Diskurses; vielmehr wurde der Kurswechsel nach den Erinnerungen verschiedener Zeitzeuginnen ${ }^{481}$ ausgelöst durch eine Aktion der ASF-Vorsitzenden Inge Wettig-Danielmeier. Als bekannte Kritikerin der Quote schlug sie den Delegierten der Bundesfrauenkonferenz völlig unerwartet ihre Einführung vor und überzeugte die verdutzten Frauen mit der Forderung nach einer paritätischen Regelung (vgl. Wettig-Danielmeier 1997b: 13). Mit dieser 50-\%-Marge konnte sich die ASF an die Spitze der QuotenkämpferInnen setzen, denn diese Forderung toppte alle bisher eingeführten und diskutierten Quoten in der Partei. Mit der Forderung nach Semiparität richtete die ASF die Quotendebatte neu aus, denn die Leitgröße der Quoten richtete sich nun nicht mehr am weiblichen Mitgliederanteil aus, sondern am Anteil der Frauen an der Bevölkerung, an der Größe der Zielgruppe, die für die Partei als Wählerinnen und Mitglieder gewonnen werden sollten.

Der Zeitpunkt für eine Durchsetzung der Quote schien dem ASFBundesvorstand günstig. Nach dem Regierungsverlust der SPD 1983 setzte die Parteiführung besonders auf die Mobilisierung der Wählerinnen. Bereits in der Bundestagswahl 1980 hatten in allen Altersgruppen mehr Frauen als Männer die SPD gewählt und auch bei der Bundestagswahl 1983 stimmten mehr Wählerinnen als Wähler für die SPD. Dieses Wählerinnenpotenzial schien $\mathrm{zu}$ wachsen, denn die Regierung der CDU/CSU-FDP-Koalition drohte, eine Retraditionalisierung patriarchaler Geschlechterverhältnisse zu fördern, und in den Frauenbewegungen wurde vor diesem Backlash gewarnt (vgl. Susan Faludi 1991). Darüber hinaus hatte eine Studie der Bremer Hochschule dokumentiert, dass unter den drei Parteien CDU, SPD und FDP besonders die Sozialdemokratinnen eine stärkere weibliche Teilnahme am Parteigeschehen erwarteten (vgl. Hoecker 1985). Im Rückblick resümierte die ASF-Vorsitzende

48o Brunhilde Peters für das Ministerium für Arbeit, Gesundheit und Sozialordnung. 481 Zz 5, Zz 6, Zz 11, Zz 9. 
Inge Wettig-Danielmeier, dass die Quote in der Partei nur in einem solchen historischen Gelegenheitsfenster hatte durchgesetzt werden können, entstanden durch Parteienkonkurrenz, gesellschaftspolitische Gleichstellungsdiskurse und die Konfrontation zwischen den gesellschaftlichen Bewegungen und der konservativen Regierungspolitik: „1986 konnten wir Frauen in der SPD den damaligen gesellschaftlichen Rückenwind nutzen, um die Quote durchzusetzen. Ich bin mir nicht sicher, ob uns das heute wieder gelingen würde" (Wettig-Danielmeier in Die Welt vom 03.03.1994 zit. n. Wettig-Danielmeier 1995: 155) ${ }^{482}$.

\subsubsection{Die Bewertung der Quote als frauenpolitische Strategie}

Nach dem Beschluss der Bundesfrauenkonferenz 1985 zur Quote meldete die ASF ihre Forderung nach Teilhabe an allen Parteigremien und Parteifunktionen und ihre Berücksichtigung bei KandidatInnenaufstellungen verstärkt an. Auch die Spitzenpositionen wurden in den Fokus genommen, für deren Besetzungen im Vorfeld Rekrutierungsstrategien und Netzwerke entwickelt bzw. ausgebaut werden mussten.

Nach den Berichten einer Zeitzeugin entstanden in der SPD damit unterschiedliche frauenpolitische Zuständigkeiten. Während sich die ASF nun vor allem für die Vertretung der Frauen in der Partei einsetzte, wurde die Entwicklung sozialdemokratischer Frauenpolitiken und frauenpolitischer Parteiinitiativen eher von der Arbeitsgruppe Gleichstellung der SPD-Bundestagsfraktion geleistet:

Natürlich haben sie auch inhaltlich was gemacht, aber das Inhaltliche ist in einem hohen Ausmaß natürlich mit ... unter Abstimmung mit der ASF ist das in der Fraktion gemacht worden [...] und da sind dann sicherlich auch Ideen und Dinge, dann da eingeflossen, aber ich sage, dass also jetzt so die gesetzgeberische, inhaltliche Arbeit doch in einem hohen Ausmaß damals auf Seite der Fraktion gelegen hat und dass die ASF eben dazu, in diesem Bereich, eben, sag ich mal, Grundsätze sicherlich formuliert hat, aber sehr damit beschäftigt war, die Quote umzusetzen. (Zz 13)

Die ASF entwickelte sich mit dieser Aufgabe zu einer starken innerparteilichen Akteurin. Dabei wurde der Parteitagsbeschluss zur Aufnahme

482 Nach dem Anschluss der DDR wurde die Quote in die neue SPD übernommen, obwohl die Genossinnen der neuen Bundesländer die Emanzipationspolitiken der ASF eher ablehnten (vgl. dazu Zz 5). 
einer 40-\%-Quote ${ }^{483}$ in die Parteisatzung 1988 keineswegs in der gesamten Frauenarbeitsgemeinschaft als politischer Sieg gefeiert, denn das Lager der Skeptikerinnen in der ASF war groß. Für sie blieb die Quote ein bürokratisches Mittel, das drohte, die ASF in einen Streit um Formalitäten und bürokratische Verfahrensregeln zu verstricken. Cornelie Sonntag, Mitglied des Bundestages, forderte die Frauen deshalb auf, „diese klare und verpflichtende Regelung nicht als Verlegenheitslösung, sondern als Errungenschaft zu werten“ (Sonntag 1989: 36), denn die Zeit der folgenlosen Selbstverpflichtungen der Partei wäre nun vorbei: „Konnten bislang die Vorstandsmänner nach ein paar vergeblichen Appellen um stärkere Frauenbeteiligung ihre Aktivitäten beenden, raubt ihnen nun die Quote das gute Gewissen." (Sonntag 1989: 38)

Retrospektiv und nach über 20 Jahren wurden die Auswirkungen der Quote von den Zeitzeuginnen immer noch unterschiedlich eingeschätzt. Zwar befürworteten alle Zeitzeuginnen die Quote, aber in den Schilderungen wurden neben den positiven Wirkungen auch vielerlei negative Folgen und Begleiterscheinungen genannt. Nach der Grundüberzeugung der ASF war ein frauenpolitischer Wandel der Partei unmittelbar mit einer höheren Präsenz von Frauen in den Entscheidungspositionen verkoppelt. In der Praxis aber stellte sich dieser Zusammenhang als kompliziert dar, wie die unterschiedlichen Erfahrungsberichte der Zeitzeuginnen zeigen. Die Quote als Organisationsmaßnahme entwickelte sich eher parallel zum Diskurs und Bedeutungswandel frauen- und familienpolitischer Themen in der Partei. Sie musste mit hohem Engagement umgesetzt werden und erwies sich nicht immer unterstützend für die ASF und ihre politischen Anliegen.

Die Einschätzungen der Zeitzeuginnen unterschieden sich nicht nur in Bezug auf die Bedeutung der Quote für die Arbeitsausrichtung der ASF, die Veränderung der Parteistrukturen, die Veränderungen der Parteikulturen und die Förderung der frauenpolitischen Entwicklung der Partei, sondern auch hinsichtlich der Wirkungen der Quote auf die ASF selbst, denn durch statuarische Auflagen entstanden neue Anforderungen an die ASF und neue Arbeitsbeziehungen in der Arbeitsgemeinschaft. Die widersprüchlichen Zeuginnenberichte lassen nicht nur auf die regional unterschiedliche Akzeptanz der frauenpolitischen Ansprüche in der Partei zurückführen, sondern sie beziehen sich vermutlich auch auf unterschiedliche, aber nicht eindeutig definierbare Zeitphasen. Im Folgenden werden deshalb die divergenten Einschätzungen zur Quote unter verschiedenen organisationsrelevanten Aspekten nebeneinander aufgeführt.

483 Vgl. dazu Kap. 6.5. 


\section{Kandidatinnenauswahl}

Zugänge zu politischen Führungspositionen der Partei eröffneten sich Frauen häufig durch Quereinstiege aus Gewerkschaften, Verbänden oder durch persönliche Beziehungen zu führenden Genossen. Die Quote schuf für Frauen nun neue Karrierewege.

Viele Frauen, die sich vorher der wenig aussichtsreichen und vor allem demütigenden Konkurrenz nicht stellen mochten, zeigten sich nun bereit, für die SPD Funktionen und Mandate zu übernehmen. Wir haben mit der Quote Sackgassen geöffnet, bestehende Pfade verbreitert und mehr und mehr Frauen die Chance gegeben, auf den Karrierestraßen mitzufahren. (Wettig-Danielmeier 1992: 143)

Die meisten Sozialdemokratinnen engagierten sich zunächst eher in den Basisstrukturen der Partei und der Frauenarbeitsgemeinschaft. Wurde ihnen eine Mitarbeit in Arbeitsstrukturen höherer Parteivorstände eröffnet, konnte diese Teilnahme sie als potenzielle Kandidatinnen für parteiinterne Führungspositionen und Mandate sichtbarer machen und ihnen eher den Zugang zu innerparteilichen Nominierungsprozessen eröffnen:

[S]ie machen die Frauen ein bisschen bekannt. Viele Frauen haben deswegen keine Unterstützung, weil sie nicht bekannt sind (Zz 7).

Zwar wurden nach dem Quotenbeschluss 1988 für alle parteiinternen Gremien engagierte Fachfrauen verstärkt gesucht und berufen; wie stark profilierte Frauenaktivistinnen aber damit Zugang zu Entscheidungspositionen erhielten, wird von den Zeitzeuginnen widersprüchlich bewertet. Für die Kandidatinnen besaß die ASF kein Vorschlagsrecht. Auch geschlechtlich getrennte Wahlverfahren hatte sie nicht durchsetzen können (vgl. Wettig-Danielmeier 1997b). Deshalb, so beklagten die Sozialdemokratinnen, wurden in manchen Parteistrukturen die frauenpolitisch weniger profilierten und häufig eher zurückhaltenden Frauen, die "Ja-Sagerinnen" (Zz 12), ihren streithaften, feministischen Konkurrentinnen vorgezogen (vgl. Randzio-Plath 1987: 56-58) Emma 1980: 51) ${ }^{484}$. Auf der Mannheimer Bundesfrauenkonferenz 1987 berichtete der Bundesvorstand von solchen Hürden:

484 Eine Erfahrung, die Heidi Knake-Werner und Sonja Kiesbauer auch von den grünen Quotenfrauen schilderten. Sie hätten „mit dem Problem zu kämpfen, daß von der Quotierung vor allem die Frauen profitieren, die sich am weitesten vom Feminismus entfernt haben und Loyalitätskonflikte mit der Partei mehr scheuen als mit den Frauenzusammenhängen." (Knake-Werner/Kiesbauer 1995: 102) 
Schlimmer ist, dass ASF-Funktionärinnen, die mit vollem Einsatz für Frauen kämpfen, selbst häufig mit ihren Kandidaturen unterliegen. [...] Wir müssen durchsetzen, dass ASF-Arbeit genauso gewertet wird wie jeder andere Einsatz für die Partei. (Rechenschaftsbericht 1987: 9)

Haidi Streletz, ASF-Bundesvorstandsmitglied und Mitglied des hessischen Landtags, hielt die Quote deshalb sogar für "gefährlich“, denn sie lade opportunistische Karrieristinnen geradezu ein, sich für eine „Anpassung als Mittel“" zur Karriere zu entscheiden (Streletz 1992: 7 ) $^{485}$.

Streitbare Feministinnen hatten in der Partei, so einzelne Zeitzeuginnen, auch nach der Quoteneinführung wenig Wahlchancen. ${ }^{486}$ Dies berichtete eine Zeitzeugin, selbst ASF-Bezirksvorsitzende und langjähriges Mitglied der ASF-Leitungsstrukturen:

... [I]ch hab auf jedem Bezirksparteitag versucht, ordentliches Mitglied zu werden. Ich hab immer wieder auch für den Parteirat kandidiert, ich bin immer, immer, immer durchgefallen. Das würde heute gar nicht mehr passieren, dass man die ASF-Vorsitzende da durchfallen lässt. Aber nicht deswegen würde es heute nicht mehr passieren, weil man eine größere Einsicht hat, sondern weil man gar nicht genug hat. (Zz 6)

Andere Zeitzeuginnen berichteten von einer größeren Akzeptanz der engagierten ASF-Aktivistinnen in den Parteistrukturen. Die ASF wäre in ihrem Bezirk politisch einflussreich genug gewesen, erläuterte eine Zeitzeugin, um auch mit den Gegenkandidatinnen nach ihrer Wahl Kooperationsgespräche zu führen: „[D]ie hätten sich mal wagen sollen, nicht zu kommen“ (Zz 9). Auf der Essener Bundesfrauenkonferenz 1990 bilanzierte die ASF-Vorsitzende Inge Wettig-Danielmeier:

Die Sorge vieler ASF-Frauen, daß einige Genossen die Quote dadurch ,entschärfen' würden, daß sie vorrangig ihnen genehme, sogenannte ,pflegeleichte‘ Frauen gegen die ASF-Frauen

485 Die Veränderung der Parteipolitik wäre ihrer Frauenarbeitsgemeinschaft immer wichtiger gewesen als die bloße Realisierung einer Quote, erklärte eine der Zeitzeuginnen. Als der Landesvorsitz der SPD besetzt werden musste, entschied sich die ASF gegen eine Bewerberin, weil der männliche Konkurrent für Frauenpolitik offener war:

„Wir haben das an Inhalten festgemacht und hatten den Mut zu sagen: Die Frau bitte nicht - als ASF“ (Zz 9).

486 Von eigenen Niederlagen, die sie auf ihr frauenpolitisches Engagement zurückführen, berichten die Zeitzeuginnen Zz 6 und Zz 9. Auch die ASF-Bundesvorsitzende Inge Wettig-Danielmeier hätte sich durch ihr Engagement ihre politische Karriere zerstört. Als es in Niedersachsen im Kabinett Schröder um die Leitung des Kulturministeriums ging, wurde sie trotz ihrer Fachkenntnisse und einer erworbenen Anwartschaft übergangen (vgl. Zz 6; vgl. dazu auch Andretta 1996). 
ausspielen würden, hat sich als begründet, aber nicht als wirklich ernsthaftes Problem herausgestellt. Ohne die ASF-Frauen kann in der Regel die Quote nicht erfüllt werden. Und auch Frauen, die sich in der ASF-Arbeit nicht engagiert haben, entwickeln meist sehr schnell eine Sensibilität für Frauenfragen (Rechenschaftsbericht 1990: 6).

Die Verdrängungskonflikte schienen aber nicht allzu gering gewesen zu sein, denn im folgenden Jahr mahnte Inge Wettig-Danielmeier als Vorsitzende der Gleichstellungskommission in ihrem Bericht auf dem Bremer Parteitag 1991 Genossinnen an, dass sie zwar die Quote für ihre Karriere nutzten, aber nach ihrer Wahl nicht bereit wären, sich für frauenpolitische Belange einzusetzen (vgl. Gleichstellungsbericht 1991: 6).

\section{Rekrutierung der Kandidatinnen}

Die Umsetzung der Quote auf allen Ebenen der politischen Verwaltung und in den politischen Ämtern der SPD führte bald zu personellen Engpässen. Denn die Quote zu erfüllen, bedeutete für die Frauen, prozentual mehr geeignete Kandidatinnen aus den eigenen Reihen stellen zu können als die Partei unter den männlichen Mitgliedern rekrutieren musste. Offensichtlich hatten die Befürworterinnen der Quote das Interesse unter den Genossinnen zur politischen Mitgestaltung, zur Übernahme von Funktion oder Amt, überschätzt. Mancherorts waren nur schwer Kandidatinnen $\mathrm{zu}$ finden, wie eine Zeitzeugin berichtete:

[W]enn in ländlichen Bereichen ... wenn da ein Wahlkreis vakant ist, da finden sie auch manchmal gar keine Frau, die müssen erst eine ermutigen, die dann sagt: ,Na gut, ich mach's denn' ... es gab ja nicht nur einen Überandrang da, sondern manchmal gab's gar keinen Andrang und da war gar keine und da mussten wir also mit Mühe eine ausfindig machen. ... So einfach ist das Thema eben nicht ( $\mathrm{Zz} 1)$.

Nach Beate Hoecker trauten sich viele Mitglieder, besonders weibliche, nicht zu, in der Politik erfolgreich agieren zu können, weil es ihnen an politischen Erfahrungen und geschulten Fähigkeiten fehlte (vgl. Hoecker 1985). Diese Hürde, so eine Zeitzeugin, wäre in der Quotendiskussion nicht thematisiert worden:

Das ,Trau dich' ist meines Erachtens ein zentrales Problem, das haben wir damals weniger gesehen, aber es ist auch einleuchtend, denn es ging ja darum, zunächst einmal rechtliche Hürden zu beseitigen oder Spielräume gesellschaftlicher Art zu öffnen. ( $\mathrm{Zz}$ 11) 
Nach Meinung einer Zeitzeugin hielten die unfairen und unkollegialen Arbeitsbeziehungen in der Partei und Politik viele Frauen von einer politischen Karriere ab. Sie selbst hätte ihre „guten Chancen“ auf ein Landtagsmandat nicht genutzt und hätte ihren Beruf nicht zugunsten einer politischen Karriere aufgegeben - und das nicht nur aus Rücksicht auf die Familie:

Sie werden ja im Beruf - ich will nicht sagen geliebt, aber - akzeptiert ... da habe ich 'ne Menge Freundinnen gefunden. Das haben Sie in der Parteiarbeit in der Regel nicht. (Zz 12)

Ludwig Stiegler, Landesvorsitzender und MdL in Bayern, führte auf einer Tagung der SPD-Bundestagsfraktion 1988 ein weiteres Hindernis auf. Nicht für alle Genossinnen hatte die Quote eine Gerechtigkeitslücke geschlossen (vgl. Weis 1995), manche fürchteten vielmehr eine Eskalation innerparteilicher Konflikte und wollten nicht auf ihren neuen Chancen bestehen:

Da haben wir das Prinzip durchgesetzt: den Frauen jeder vierte Platz. Das würde aber bedeuten, daß in manchen Ortschaften die Frauen von ihren ,Ortsheiligen', den Ortsvereinsvorsitzenden, auf die Kreistagsliste platziert würden. Komischerweise kamen nicht die Männer zu mir, sondern die Frauen, die gefragt haben: ,Mensch, kann ich das tun, schaffe ich Unfrieden im Dorf und habe Unfrieden im Ortsverein?' Die Frauen neigen dazu, zu sagen: ,Da gebe ich lieber nach, bevor ich hier-Jahrelang Ärger habe.' Plötzlich muß man mit beiden Seiten raufen (Stiegler in Schmidt 1989: 49).

Die Suche und das Motivieren geeigneter Kandidatinnen und das Netzwerken vor den Wahlversammlungen, das nötig war, um den personellen Vorschlag durchzubringen, entwickelte sich zu einem ressourcenbindenden politischen Feld in den Frauenarbeitsgemeinschaften. ${ }^{487}$ Deshalb wurde in der ASF die Kritik laut, dass das Engagement für die Durchsetzung der Quote den inhaltlichen Kampf für die Gleichstellung abzulösen drohte. ${ }^{488}$

Gleichzeitig aktivierte und entwickelte die ASF unter der Quotenanforderung die Potenziale in ihren Reihen. Die akquirierten Kandidatinnen mussten auf ihre neuen Aufgaben vorbereitet werden; das erforderte Schulungsarbeit und die Unterstützung der jeweiligen Frauengruppen, denn besonders häufig fehlte ihnen die notwendige Redegewandtheit:

487 Dies berichteten neun der zwölf als Zeitzeuginnen befragten ASF-Aktivistinnen. 488 Christa Randzio-Plath zu diesen Vorwürfen: vgl. Parteitag der SPD 1988: 118. 
Woher sollten Frauen das, insbesondere, wenn sie zuhause waren, lernen? Konnten sie nicht, hatten sie Ängste. Und das haben wir dann also systematisch geübt und Leute ermuntert und so. Außerhalb der Studentinnen und Akademikerinnen war keiner geübt, frei zu sprechen oder seltener vor einem Publikum. (Zz 11)

Die ASF-Funktionärinnen bauten ihre Netzwerke aus, um geeignete Kandidatinnen zu finden. Gerade auf kommunaler Ebene entstand ein hoher Bedarf für politische Leitungsaufgaben in der kommunalen Verwaltung:

In den Kommunen war das ein solches desolates Gebiet, diese ... die Beteiligung von Frauen. Man kann aber eine Dezernentin oder eine Kandidatin nicht anbieten, wenn sie ÜBERHAUPT keine kommunale Erfahrung hat. [...] Deswegen habe ich wirklich - einhergehend mit der Quote - diese ... diese Frauenbeauftragte immer wieder geplündert für viele Dezernentenposten. (Zz 5)

Allerdings führten die personellen Engpässe, die besonders in ländlichen Regionen entstanden, auch zu Fehlbesetzungen. Dabei, so kritisierte eine Zeitzeugin, wurden auch solche Frauen mobilisiert, die persönlich nicht geeignet oder ausreichend vorbereitet waren, und manch eine gab bald nach der Wahl wieder auf:

Die Frauen, die, ich hätte fast gesagt, so mit ihren 40 Prozent GELOCKT wurden, dass da mehr Abgänger waren als von den gestandenen Frauen, die im Rat WAREN. Die haben sich etwas anderes .... , Ist ja nicht so viel', und dann wurde Schwiegermutter krank und hatte das Kind Masern und dergleichen. Und dann sind Leute aus der vollen Legislatur ausgeschieden, Frauen, ist unter diesen ... ich wusste, dass es die 40-Prozent-Klausel war ... SIND da EINIGE gewesen - ich will nicht sagen, die Menge aber doch mehr, als ich erwartet und erhofft hatte, nicht bei der Stange geblieben. ( $\mathrm{Zz} \mathrm{2}$ )

Diese Zeitzeugin zweifelte deshalb den strategischen Erfolg der Quote für die SPD an:

[W]enn ich mir heute ansehe, dass wir eine Quote haben von $40 \%$ und wie bei den Kommunalwahlen rumbetteln und bitten, dass sich Frauen finden, damit die $40 \%$ da eingehalten werden, da frage ich mich: Ist es besser, $23 \%$ engagierte Frauen von sich aus zu haben oder noch die $17 \%$ dazu zu animieren. (Zz 2) 
Nach Reiner Keller werden in politische Gremien „Wirklichkeitskonzeptionen" verhandelt (vgl. Keller 2007). Die Relevanz und Gültigkeit einzelner Konzepte werden durch Mehrheitsentscheide festgelegt, die Plausibilität der Konzepte und Argumente ist dabei an die Stimmenverhältnisse gebunden. Deshalb war auch die ASF-Vorsitzende überzeugt: „In einer Demokratie ist angemessene Repräsentation ein mindestens so hoher Wert wie Qualifikation“ (Wettig-Danielmeier auf dem Parteitag der SPD 1984: 314). Dies entspricht der Erfahrung einer Zeitzeugin:

Mindestens ebenso wichtig wie die Güte des Arguments ist die Quantität, in der es vertreten wird. Da führt die Quantität zu einer Qualität. (Zz 6)

Die Quote veränderte die Stimmenverhältnisse, die Zeitzeuginnen berichteten von deutlichen Wirkungen auf Arbeitsbedingungen und Arbeitsergebnisse der Gremien. Mehrere Zeitzeuginnen ${ }^{489}$ waren zudem der Meinung, dass die höhere Zahl der Frauen in den parteipolitischen und parlamentarischen Gremien ihre Durchsetzungsmöglichkeiten wesentlich verbesserte. Eine Zeitzeugin berichtete von einer hohen Bereitschaft der Frauen in den Gremien, sich untereinander zu verständigen, und davon, dass sich ihre Debattenbeiträge damit nicht mehr so leicht marginalisieren ließen:

[D]enn sobald eine Frau mehr dabei war - wir verstanden uns SOFORT - war vollkommen klar, es liegt nicht an mir, es liegt nicht daran, dass ich exotisch bin, sondern es liegt daran, dass die ANDEREN eine Wahrnehmung haben, die Stück weit borniert sind, die auf einem Auge blind war und das durchgängig so, ob es nun in politischen Gremien war oder im Landtag ... oder im Kabinett ... egal. Immer wieder die Erfahrung: Je mehr Frauen tatsächlich in diesen unterschiedlichen Gremien sind, desto eher ist es möglich, so 'ne gemeinsame Ausgangsbasis zu haben und nicht ständig dagegen ankämpfen zu müssen, zunächst mal überhaupt verstanden zu werden oder Gehör zu finden und Selbstzweifel zu haben, ob man nun das nicht selber auf den Punkt bringen kann, was man sagen will, sondern wirklich zu erleben, es sind unterschiedliche Brillen, mit denen Dinge betrachtet werden ... Und das führt oft dazu, dass es nicht zu einer Verständigung kommt. Und dass Frauen weggedrängt und nicht wahrgenommen werden. (Zz 14) 
Eine der Zeitzeuginnen schilderte, dass manche frauenpolitischen Themen erst durch die höhere Präsenz von Frauen auf die Agenda der Gremien gesetzt werden konnten:

... bestimmte Themen haben im Prinzip gar keine Chance gehabt, ohne Quote auf Bundesebene diskutiert zu werden, und auch der teilweise andere Blickwinkel von Frauen und die andere Lebenserfahrung von Frauen kam alleine durch die Quote zum Tragen [...] vor der Quote, bevor mehr Frauen in den Parlamenten waren, hat man IMMER die Schwierigkeit gehabt, dass man, wenn man Erfolg haben wollte, sich praktisch männlichen Denkmustern, männlichen Themen, bis hinein in die Sprache und die Verhaltensweisen, anpassen musste, sonst war man nicht erfolgreich. [...] es verschwindet auch ihre Lebenserfahrung und ihr Blickwinkel nicht in dem Maß, in dem er verschwunden ist, sag ich mal, vor Einführung der Quote. (Zz 13)

Die Quote veränderte auch die Arbeitsbedingungen des politischen Engagements. Forderungen wie die nach Kinderbetreuung bei größeren Parteiveranstaltungen hätten noch Anfang der 1980er-Jahre in der SPD keine Akzeptanz gefunden, schilderte eine Zeitzeugin:

... [A]lso, solche Themen wie Kinderbetreuung, überhaupt nur $\mathrm{zu}$ denken, dass dieses also etwas gewesen wäre, was wir auf Bundesebene hätten diskutieren können zum damaligen Zeitpunkt, ist also die reine Illusion, also die Männer hätten sich nur kopfschüttelnd ... in der eigenen Fraktion hätten sich nur kopfschüttelnd abgewandt. (Zz 13)

Eine andere Zeitzeugin erläuterte, dass der größere Anteil weiblicher Delegierter auf den Parteitagen nicht nur die Wahrnehmung frauenpolitischer Anliegen veränderte, sondern auch andere Verhandlungstaktiken eröffnete:

Wir haben dann ganz schnell gemerkt, wie die ersten Bundesparteitage liefen und die Frauenquote war durchgesetzt und es waren auf einmal 4o Prozent Frauen im Saal, dass es dann möglich war, auch frauenrelevante Themen zu diskutieren und $\mathrm{zu}$ entscheiden. Und die Männer, die sich ... die dagegen gesprochen haben, die haben einen Sturm der Entrüstung erlebt durch die vielen Frauen, die da waren. Wir haben vorher die Themen, wo wir uns einklinken, abgesprochen auf Bundesebene, in der ASF abgesprochen, wer zu welchem Punkt wann redet, und ungefähr den Inhalt, damit das also gezielt an bestimmten Stellen ankam. (Zz 9) 
Die durch die Quotenregelung erhöhte Anzahl der Frauen in den Gremien verschaffte in der Folge auch weiteren Genossinnen einen leichteren Zugang, der Anteil der Frauen in den Parteigremien wuchs in der Tendenz kontinuierlich an.

\section{Vertretung und Einflussnahmen}

Von einer höheren Repräsentanz und einem größeren Einfluss der Frauen auf die Partei versprachen sich viele Mitglieder nach Cornelie Sonntag, Mitglied des Bundestags, eine Verstärkung des „Kurses der energischen Reformen“ in der Politik der Parlamente. Cornelie Sonntag verwies auf die politische Themen, bei denen die ASF der Mehrheit in der Partei historisch voraus war: Friedenspolitik, Kritik der Atomenergie, Abwendung der Verschärfung des § 218, Kampf gegen Menschenhandel und Prostitutionstourismus, Arbeitszeitverkürzung 490:

Es wird also eine andere Politik geben in der SPD. Neue ungewohnte Fragen, andere Schwerpunkte, enge gedankliche Verzahnung zwischen Problemen, die unsere Gesellschaft bisher als ,häuslich-privat' klassifizierte, mit jenen der ,breiten Öffentlichkeit'. Vermutlich wird auch die strenge Orientierung an den sogenannten ,Sachzwängen' aufgeweicht ... eine andere Politik also, unverbrauchter, mehr von Humanität gespeist. (Sonntag 1989: 45)

Allerdings stellte Sandra Brunsbach in ihrer Studie über die Beziehung zwischen dem Anteil weiblicher Bundestagsabgeordneter und der parlamentarischen Verhandlung frauenpolitischer Themen fest, dass kein unmittelbarer,Zusammenhang zwischen deskriptiver und substantieller Repräsentation“ besteht (Brunsbach 2011: 24) ${ }^{491}$. Für Heidi Knake-Werner und Sonja Kiesbauer lag diese Diskrepanz in der institutionellen Einbindung der gewählten Vertreterinnen (vgl. Knake-Werner/Kiesbauer 1995). Eine Zeitzeugin berichtete, dass gerade für die streitbaren Feministinnen die ersten Erlebnisse in den hohen Ämtern oft ernüchternd waren, denn der neu gewonnene Zugang zu politischen Mandaten führte

490 Andere ASF-Führungsfrauen sahen das anders, für Christa Randzio-Plath stand und fiel eine positive Wirkung der Quote auf die Politik mit der Auswahl der Kandidatinnen (vgl. Randzio-Plath 1987: 118).

491 Sandra Brunsbach kommt in ihrer Studie anhand eines Vergleichs des 11. und 15. Bundestags zu dem Schluss, dass Parlamentarierinnen zwar eine höhere Affinität zu frauenspezifischen Themen haben, aber dass ihre zahlenmäßige Verstärkung im Parlament nicht generell die Repräsentation der Fraueninteressen erhöht (vgl. Brunsbach 2011). 
meist nicht zu der erwarteten politischen Handlungsfähigkeit. Meist fehlte es den Newcomerinnen an politischen Netzwerken, die sie stützen konnten, an Kontakten, mit denen sie ihre Initiativen vorbereiten konnten, und an Durchsetzungserfahrungen (vgl. dazu auch Lang 1989) :

[D]ie kommen alle in den Bundestag und denken, jetzt werden sie die Welt aus den Angeln heben, das ist alles Quatsch. Und die kriegen einen großen Frust, weil sie sehen nachher, wie wenig sie eigentlich machen können als Einzelperson, und da lernt man dann doch schon, also, dass man Teamwork braucht, dass man immer Bundesgenossen braucht und so, das lernt man dann. [...] Der Handlungsspielraum, der kommt ihnen riesig vor, und nachher sehen sie, wie groß er wirklich ist, nich? (Zz 1)

Diese Erfahrungen werden in einer Fülle feministischer Literatur, Biographien und Studien beschrieben, die die Erfahrungen von Politikerinnen in den männlich dominierten Parlamenten und ihren Ausschluss aus den männerbündischen Strukturen und den Anpassungsdruck reflektieren. ${ }^{492}$ Einflussreiche Politiker verfügen danach über Seilschaften, die sie im Zuge ihrer Kandidaturen entwickelt haben oder die bereits durch ihre beruflichen Tätigkeiten entstanden sind. ${ }^{493}$ Schwache Netzwerke und wenig mächtige BündnispartnerInnen dagegen setzen Politikerinnen einem hohen Anpassungsdruck im beruflichen Politikalltag aus. ${ }^{494}$

492 Vgl. dazu Hempel-Soos 1982; Huber 1984; Martini 1986, 1991; Lepsius 1987; Clemens 1996; Götte 1991; Schöler-Macher 1994; Hoecker 1987, 1994, 1995; Thörmer 1996; Rühmkorf 2002; Notz 2003, 2007; Edinger/Holfert 2005; Brunsbach 2011.

In diesen Publikationen werden vielfältige weitere Ausschließungsmechanismen beschrieben, die z.B. nach Bärbel Schöler-Macher Frauen in einer "Fremdheit der Politik“ (Schöler-Macher 1994) halten und sie nur als ,integrierte Außenseiterinnen“ (HollandCunz 2003: 178) agieren lassen.

493 In der geschlechtersegregierten und -hierarchischen Arbeitswelt hatten männliche Abgeordnete im Vergleich zu weiblichen häufig verantwortungsvollere berufliche Positionen inne, mit denen sie über einflussreichere Kontakte verfügen (vgl. Hoecker 2007; Ali 2003; Schöler-Macher 1994; Götte 1991; Fuchs 2006; Richter 2006).

494 Isabelle Kürschner sieht psychologische Gründe für den gegenüber Männern vergleichsweise höheren Einpassungsdruck der Frauen: „Sie halten es eher für unerlässlich, sich mit Abläufen, Spielregeln und Gepflogenheiten des politischen Tagesgeschäftes vertraut zu machen" (Kürschner 2009: 17f.). 


\subsubsection{Ungünstige Wirkungen der Quote auf die Entwicklung der ASF}

Die Einführung der Quote war nicht nur ein Erfolg der Frauen, sondern hatte für die ASF selbst ungewollte Folgen, auf die sie nicht vorbereitet war.

Jedoch äußert sich nur eine Zeitzeugin sehr ablehnend:

[M]eine Wahrnehmung ist in der Tat (...), dass die doch gestiegene Anzahl von Frauen durch die Quotierung in den Entscheidungsgremien den Einfluss der ASF geschmälert hat. (Zz 6)

Die anderen Zeitzeuginnen schildern zwar negative Auswirkungen der Quotenregelung, stehen ihr aber trotzdem positiv gegenüber. Sie hätten sich eine andere Umsetzung bzw. begleitende Maßnahmen gewünscht.

Die neuen Teilhabemöglichkeiten erzeugten einen Braindrain aus der ASF in die berufspolitischen Karrieren (vgl. Zz 11). Dies habe, wie eine andere Zeitzeugin schilderte, die ASF geschwächt: Ihre Machtposition „zerbröselte nachher auch, weil natürlich ein Teil des Vorstandes anschließend in wichtige Ämter ging" (Zz 11). Sie sah diesen Trend allerdings „als Folge eines Entwicklungsprozesses“ an, der durch die Quote forciert wurde (diess.).

Aber nicht nur die personelle Veränderung, das Nachrücken von weniger erfahrenen Genossinnen in die ASF-Leitungen, hätte, so eine Zeitzeugin, das frauenpolitisch engagierte Lager in der Partei geschwächt, sondern auch die zunehmende Zahl von Politikerinnen, die sich mit pragmatischeren, weniger strategischen oder theoretischen Diskursinteressen zu Wort meldeten:

[A]lso, die doch sehr viel zahlreicheren Frauen, die in Ämtern und Positionen, Entscheidungspositionen, sind, sind natürlich ganz anderen Zwängen ausgesetzt als die ... wir waren damals ja nicht in den Positionen, also wir konnten viel unbefangener und auch heftiger und ohne den Kompromiss schon im Kopf zu haben, argumentieren und fordern. (Zz 6)

Die Mehrheit der Zeitzeuginnen war der Meinung, dass die Quote und die durch sie geförderte zunehmende Integration der Frauen in verantwortliche politische Positionen besonders das kritische Potenzial in der ASF zerrüttet. 495

495 Diese Einschätzung teilten neun der 15 Zeitzeuginnen (Zz 4, Zz 5, Zz 6, Zz 7, Zz 9, Zz 11, Zz 12, Zz 15, Zz 16). 
Die durch die Quotierung höhere Anzahl von Parteiaktivistinnen in den ASF-Reihen bedrohte die kollektive Identität der Sozialdemokratinnen, die „Frauensolidarität“. Sie verpflichtete auch politisch zerstrittene Frauen zu taktischen Bündnissen und zu einer geschlossenen oppositionellen Interessensgemeinschaft, die die ASF nach außen und gegenüber der Partei zu repräsentieren beanspruchte. Über "Schwesternstreits“ schrieb Haidi Streletz in einem Konferenzpapier 1992:

Bisher waren es vereinzelte Frauen, die sich in Gremien engagieren konnten, jetzt müssen diese Frauen ... auch noch versuchen, die von Männern als bequem eingestuften Frauen in die notwendige Arbeit einzubinden. Nichts ist schlimmer, als wenn sich Frauen auseinander dividieren lassen (Streletz 1992: 3).

Aber die politische Schwächung der ASF geschah nach Meinung der meisten Zeitzeuginnen und ehemaligen ASF-Aktivistinnen weniger durch den Konflikt zwischen den gewählten Politikerinnen, die sich nicht mit der ASF-Politik identifizierten ${ }^{496}$, und den frauenpolitisch engagierten ASF-Aktivistinnen als durch den personellen Mangel an profilierten und politisch erfahrenen Kandidatinnen, der die ASF Anerkennung kostete. Die Quotenumsetzung konnte nicht mit ausreichenden parteiinternen Personalentwicklungsmaßnahmen begleitet werden, erläuterte eine Zeitzeugin:

Also, es kam dann ein plötzlicher Schub in den Führungspositionen ... es war nicht ganz ... also, durch die Quote hat es eher so einen Sprungverlust gegeben, es war kein ganz organisches Entwickeln und es hat anschließend gefehlt an einer wirklichen Entwicklungs- und Organisations- und Personalplanung, das systematisch aufzufüllen. (Zz 11)

Intern ASF verlor an Bedeutung als Ort des Austauschs und der frauenpolitischen Politikentwicklung. Die „kulturelle Zwischenwelt“ funktionierte für die Nachwuchsförderung und den Politikeinstieg, aber nicht als Kooperationsplattform für Parteifunktionärinnen, Parlamentarierinnen und die weiblichen Nachwuchskräfte. Eine ehemalige ASF-Aktivistin und langjährige Berufspolitikerin berichtete ${ }^{497}$ :

4961987 gaben 12 der 31 weiblichen Bundestagsabgeordneten eine ASF-Leitungstätigkeit in ihrer politischen Kurzbiographie an. Drei Parlamentarierinnen hatten ihre Mitarbeit im ASF-Bundesvorstand nicht einmal in ihre Biographie aufnehmen lassen (vgl. Kurzbiographien in Kürschner 1987).

497 Vermutlich war das Netzwerken mit Frauen anderer Fraktionen zweckdienlicher. So wurden z.B. der Rechtsanspruch auf Kinderbetreuung, der Straftatbestand der Vergewaltigung in der Ehe und die gesetzliche Frauenquote in der Privatwirtschaft durch fraktionsübergreifende Initiativen von Parlamentarierinnen durchgesetzt. 
[E]s war - ehrlich gesagt - nicht gleiche Augenhöhe, sondern es war so ... Ja, das sind dann so die Galionsfiguren, auf die man stolz ist. Da ist einfach so eine Macht- und Kompetenzverschiebung, die da stattfindet. Also, man gibt mit diesen Frauen auch Kompetenz ab, mit den Frauen, die in den verschiedensten Gremien sind. Und DAS ist auch oft diskutiert worden. Dass man im Grunde viele Frauen hat, die an allen möglichen Ecken jetzt arbeiten ... das ist ja auch wunderbar ... aber für die eigene Arbeit fehlen sie eigentlich. Nicht weil sie nix mehr damit zu tun haben wollen, sondern weil sie da natürlich jeweils aufgefressen werden in den Zusammenhängen. (Zz 14)

Mit der Übernahme politischer Funktionen gaben die Frauen ihre Mitarbeit in den Strukturen der ASF häufig auf. Dieses Entwachsen aus den Strukturen, erläuterte eine Zeitzeugin, führte bei anderen Frauen der Arbeitsgemeinschaft zu Verärgerung:

Das ist auch ein bisschen der Frust von den Frauen, dass die dann sagen, wir fördern sie, und dann sind sie weg (Zz 15).

Wiederholt wurde in der ASF zu einer besseren Vernetzung aufgerufen (vgl. Randzio-Plath 1987), aber die unterschiedlichen Anforderungen an die politische Arbeit der Frauenpolitikerinnen an der Parteibasis, die Parteifunktionärinnen und die Mandatsträgerinnen erschwerten das Verständnis füreinander und den Austausch zu gegenseitigem Nutzen $^{498}$. Ihre Zusammenkünfte mit den ASF-Aktivistinnen an der Parteibasis erinnerte eine Zeitzeugin und damalige Parlamentarierin oftmals als konfliktreiche Begegnungen:

... [D]er Konflikt war dann immer noch der: ,Mein Gott, und WANN kommt's und WANN macht ihr das?' Denn die Vorstellung von jungen Menschen ist ja immer, wenn's noch zu lange dauert, betrifft's uns nicht mehr, nich'? Und das war also diese Ungeduld ... [z.B. zur Freistellung bei der Erkrankung des Kindes - S.E.] ... dieses: 'Wieso nur acht Tage, das müssen doch mindestens vierzehn sein.' Ja, wenn's dann hieß: ,Das KANN ja auch sein, dass der Mann acht Tage und die Frau ...', dass die sagten:

498 Haidi Streletz wandte sich mit einem Appell an die Bundesfrauenkonferenz 1992, die ASF neu auszurichten und Treffpunkte zwischen ASF-Frauen, Frauen in Kabinetten und Fraktionen sowie Frauenbeauftragten in Behörden zur gegenseitigen Information und Unterstützung zu schaffen (vgl. Streletz 1992). Dieser Anspruch ist bis heute eine „Zukunftsaufgabe“: „Wir haben inzwischen viele kompetente Frauen, die auf allen möglichen Feldern unterwegs sind. Und was eigentlich jetzt so als Zukunftsaufgabe dasteht, ist eine Vernetzung so zu schaffen, dass man auch eine neue Plattform für diese Frauen hat, um zu einer Weiterentwicklung zu kommen." (Zz 14) 
,Tun die sowieso nicht', nich'? Also, das war alles etwas absoluter. Wo wir doch gelernt hatten, dass man über KOMPROMISSE stückweise weiterkommt und schließlich sagen kann: ,̈̈tsch, wir haben's doch durchgekriegt.' (Zz 2)

\subsubsection{Auswirkungen der höheren Repräsentanz auf parteiinterne Verfahren und Kommunikationskulturen}

Von einer höheren Anzahl an Frauen in den Gremien und den politischen Ämtern erhofften sich viele Parteimitglieder nicht nur eine Erweiterung und Humanisierung der Politik, sondern auch eine Veränderung der Kommunikations- und Verhandlungskulturen. So erklärte die saarländische ASF-Landesvorsitzende Brunhilde Peter ${ }^{499}$ auf der Bonner ASF-Bundesfrauenkonferenz 1981:

[D]er notwendige Kampf der Frauen gegen die Vorherrschaft der Männer führt nur dann zu einer Vermenschlichung der Gesellschaft, wenn wir nicht nur formale Gleichstellung anstreben, etwa mit dem männlichen Größe- und Härtestreben, mit der Macht und Konkurrenzherrlichkeit, sondern wenn wir auch gleichzeitig gegen eine Vorherrschaft dieser sogenannten ,Männlichkeit' angehen. (Peter 1981: 5)

Viele Rituale „hegemonialer Männlichkeit“, von denen die Zeitzeuginnen berichteten, entsprechen den Beschreibungen aus der Studie von Bärbel Schöler-Macher. Zu den Techniken der individuellen Selbstbedeutsamkeit zählen überlange Redezeit, das grundsatzpolitische Argumentieren, das Simulieren von Betroffenheit sowie das Blenden bei mangelnder Sachkenntnis, außerdem die präsentierte Verfügbarkeit durch das „Überall-dabei-sein-Müssen“, ebenfalls gehören auch die kollektiven Bedeutungsrituale dazu wie das zeitliche Ausdehnen der Sitzungen, ein positives Bilanzieren unproduktiver Kooperationen und die Verpflichtung aller Beteiligten zu vorgeblich freigewählter Informalität mit gemeinsamem Biertrinken und Freizeitunternehmungen, bei denen Vertrauensbildungen entwickelt und das Netzwerken gefestigt werden (vgl. Schöler-Macher 1994).

499 Dr. Brunhilde Peter war ASF-Landesvorsitzende und Landtagsabgeordnete. Im Kabinett Lafontaines 1985 wurde sie zur Ministerin für Soziales, Arbeit und Gesundheit ernannt sowie zur stellvertretenden Ministerpräsidentin (www.spd-saar.de). 
Die Kritik an solchen Ritualen in der SPD wurde auch von männlichen Parteimitgliedern vorgetragen. Auf dem Essener Parteitag 1984 beklagte der Stadtverordnete Dr. Werner Schuster: „Wir sitzen drei- bis viermal abends bei den Vereinen; wir wollen ja bürgernah sein. Wir kungeln um Positionen. Wir verbraten sehr viel Zeit. Der ganze Job ist männermordend." (Dr. Werner Schuster, Stadtverordneter Idstein, SPD Hessen-Süd in Parteitag der SPD 1984:338). Ein Antrag aus dem Landesverband Berlin auf dem Parteitag 1984 forderte eine „Humanisierung der Parteiarbeit" durch partizipativere Arbeitsformen und effektivere Entscheidungsfindung (vgl. Antrag 634 Antragsbuch in Parteitag der SPD 1984: 526).

Welche nachhaltigen Veränderungen der Gremienarbeit durch die höhere weibliche Partizipation erreicht werden konnten, beurteilten die ZeitzeugInnen unterschiedlich. An den Verhandlungsritualen sei wenig ändern, meinten verschiedene Zeitzeuginnen (vgl. dazu Zz 2, Zz 6, Zz 8, $\mathrm{Zz} 10$ ), weder an den anstrengenden, persönlich verletzenden Streitformen noch an der Ineffizienz der Meinungsbildung in den Parteigremien:

[A]lso dasselbe Thema in allen Gremien mit fast denselben Leuten wird immer wieder diskutiert und durchgekaut, und jeder muss was dazu sagen, auch wenn schon alles gesagt ist. (Zz 6)

Der Umgang mit den Frauen in der Partei verbessert sich nach mehrheitlicher Meinung der Zeitzeuginnen dagegen erheblich. Die Zeit vor der Quote, die sexualisierte Kommunikation, das persönliche Verächtlichmachen der Gegnerin statt die Widerlegung ihrer Argumente, resümierte eine Zeitzeugin mit dem Satz: „Der Umgang mit uns Frauen war unter aller Sau“ (Zz 5). Mit ihrer höheren Präsenz, darin waren sich alle Zeitzeuginnen einig, wurden Frauen eher als gleichberechtigte Verhandlungspartnerinnen wahrgenommen ${ }^{500}$ :

Von daher glaube ich, dass die Einführung der Quote ganz wichtig war. Einfach um die Männer daran zu gewöhnen: Die Frauen gehören dazu, die können das auch. [...] [D] esto mehr Frauen da hereinkommen, desto weniger hat man sie als Frauen wahrgenommen. Solange es noch zwei Frauen waren, gab es die Frage: Ja, kann die das denn? Aber nachher war das eine ziemliche Selbstverständlichkeit. (Zz 10)

Eine Zeitzeugin erläuterte, wie sie als Gruppe von Frauen in der Gremienarbeit die Wahrnehmung und Wertschätzung ihrer Beiträge und Stellungnahmen mit kollektiven Kommunikationsstrategien verstärkten: 
[W]enn eine Frau sich früher gemeldet hat, dann konnten Sie sicher sein, dass zwei Drittel der Männer so taten, als gäb's die gar nicht, und wenn's ein ganz kluger Beitrag war, wurde er nie zitiert. [...] Wir sind ja ganz gezielt dagegen angegangen, indem wir gesagt haben, so, wir zitieren uns jetzt gegenseitig. Wir haben das zum Teil in Vorstandssitzungen vorher abgesprochen, dass immer, wenn einer sagt, meldet sich die andere und sagt: ,Wie Inge' oder ,Wie die sehr richtig bemerkt haben', und ,da will ich jetzt weitermachen', einfach damit das in die Köpfe reingeht, gell? Das hat sich jetzt schon gehalten, also solche Dinge, die Selbstverständlichkeit, dass Frauen was zu sagen haben, hat schon die Parteien verändert. (Zz 8)

Als wichtigen Durchsetzungserfolg der ASF schilderte eine Zeitzeugin die Veränderung der Sprach-,NNormalitäten“501 in der Partei, die mit Hartnäckigkeit und Beharrlichkeit, aber auch durch die erhöhte Frauenpräsenz in den Gremien erreicht wurde:

Und eben weil sie lästig waren, haben sie auch viel erreicht. Wenn sie zum 3561-ten Mal sagen, da muss aber auch die männliche und die weibliche Form stehen, irgendwann sagt dann auch Johannes Rau: ,Als Sozialdemokrat muss ich wohl sagen Genossinnen und Genossen' - selbst wenn er diese Vorbemerkung macht, er hatte es begriffen, es war nicht seine Überzeugung, aber es musste sein. ( $Z z$ 10)

Große Veränderungen bewirkte die Quote besonders bei den Rekrutierungs- und Besetzungsverfahren für politische Ämter. Zwar hatte die Partei ihre Einführung in Stufen beschlossen, damit keine „bewährten Genossen“ ihre Mandate verlieren mussten (vgl. Wettig-Danielmeier 1987b), aber die Durchsetzung der Quote war trotzdem, so die Meinung einer Zeitzeugin, nur unter "Inkaufnahme männlicher Opfer“ (Zz 13) möglich. Ob die Quote in hoher Zahl männliche Karrierechancen einschränkte oder ob in vielen Fällen die Konkurrenz der BewerberInnen für Funktionen und Mandate gar nicht so groß war, wie von anderer Seite berichtet wurde (vgl. Zz 3), ist aus den Dokumenten nicht nachzuvollziehen. Allerdings fanden sich in den Archivalien Hinweise auf innerparteiliche Konflikte, in denen das neue Verfahren bis dahin übliche

501 Die performative Kraft der Sprache für die Reproduktion von Geschlechterungleichheiten war in den 1980er-Jahren ein Thema der Frauenforschung. Eine „geschlechtergerechte“ Sprache durchzusetzen wurde zu einem wichtigen Handlungsfeld der kommunalen Frauenbeauftragten. 
Besetzungsrituale ausgehebelt hatte, sodass andere BewerberInnen in die KandidatInnenauswahl kamen ${ }^{502}$.

Die vor dem Quotenbeschluss befürchtete Stigmatisierung aller gewählten Frauen als „Quotilden“503 traf nach Meinung aller Zeitzeuginnen nur in der Anfangsphase zu. ${ }^{504}$ Dass für alle Beteiligten das Quotieren als Teil des Auswahlverfahrens akzeptiert und als Umsetzung eines berechtigten Anspruchs auf Teilhabe angenommen wurde, stand in Verbindung mit dem Wandel der sozialdemokratischen Frauenpolitik in der Partei, der im nächsten Kapitel beschrieben und analysiert wird.

502 Auf einer Veranstaltung der SPD-Bundesfraktion 1989 „Die Frauenfrage als Männerfrage“ berichtete der Bundestagsabgeordnete Horst Peter von zwei solcher Ereignisse. In Kassel-Stadt kam der Fraktionsvorsitzende nicht mehr in den Magistrat der Stadt Kassel wie bisher üblich, stattdessen wurde der DezernentInnenposten ausgeschrieben und schließlich mit einer Frau besetzt, die nicht aus Kassel kam. In einem neu zu besetzenden Wahlkreis in Nordhessen bestimmte „nach ungeschriebenen Gesetzen“ bisher die Arbeitsgemeinschaft für Arbeitnehmer (AfA) die KandidatInnenauswahl, nun erhoben drei Bewerberinnen Ansprüche502 (vgl. Horst Peter zit. n. Schmidt 1989: 5154).

503 Bei dieser Stigmatisierung wurden alle neu ernannten Funktionärinnen oder Politikerinnen verdächtigt, nur als Platzhalterin und nicht aufgrund ihrer Kompetenzen gewählt worden. Nach der Alibifrau die Quotenfrau? Anachronistische Quotenregelung bremst Emanzipationsprozess titelte Annemarie Renger eine Presseerklärung gegen die Quote (vgl. Renger 1988).

504 Stigmatisierung wurde durch ironische Stellungnahmen der Quotenbefürworterinnen entschärft, wie: „Nun sind wir Frauen von der Alibi-Frau zur ,Quotilde‘ geworden“ (Anke Fuchs zit. n. Dowe/Schneider 2007: 71); ,ich will gerne Quotenfrau sein“ (Eva Rühmkorf zit. n Pausch-Gruber 1986: 90). „Mir würde es gar nichts ausmachen, als Quotenfrau in der Politik zu wirken. Erstens wäre ich dann nicht immer die einzige Frau in der Runde, zweitens brauchte ich nicht jedesmal den Nachweis zu führen, daß ich qualifiziert genug bin. Männer müssen das schließlich auch nicht." (Inge WettigDanielmeier zit.n. Roques: 47) 
$A b b$. 3: Als Sulfragetten verkleidete Mitglieder der ASF Münster beim SPD-Parteitag 1988

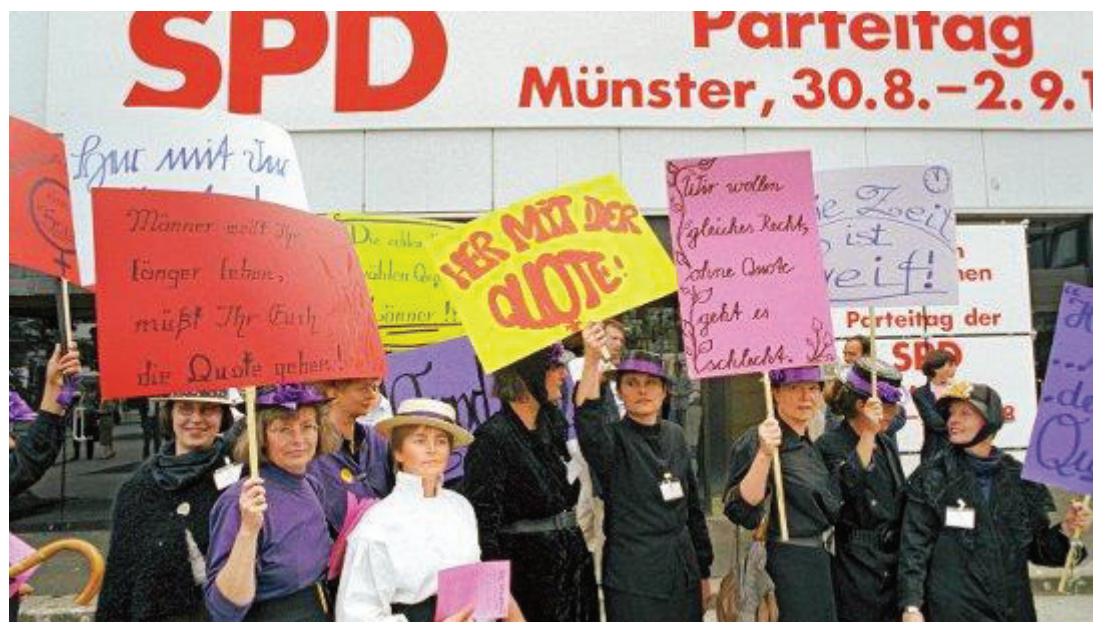

Quelle: DPA/Franz-Peter Tschauner. In: Vorwärts, 30.08.2013. http://www.vorwaerts.de/ 108250/frauenquote_Als_die_Quote_siegte_SPD_Parteitag-gleichstellung.html [Zugriff: 01.05.2014].

\subsubsection{Anmerkungen zur ASF als frauenpolitische Akteurin in der Partei heute}

Die Erzählungen der Zeitzeuginnen, insbesondere der ehemaligen ASFAktivistinnen, waren geprägt von einer Gegenüberstellung der ASF der 1970er- und 1980er-Jahre mit der heutigen Frauenarbeitsgemeinschaft. Die ASF-Frauen stellten heute, so ihr einhelliges Urteil, innerparteilich keine kritische Gegenmacht mehr dar. Für diese Einbuße an Bedeutung wurden in den Interviews unterschiedliche Gründen aufgeführt. Als externe Gründe vermuteten verschiedene Frauen den fehlenden gesellschaftliche Druck einer außerparlamentarischen Frauenbewegung sowie das weniger verbreitete Interesse junger Frauen am Feminismus. Als parteispezifische Gründe wurden die vielfältigen Möglichkeiten der Mitwirkung für engagierte Genossinnen und Expertinnen in der Partei genannt, aber auch die größere Anzahl politisch teilhabender, gewissermaßen vom Apparat beschlagnahmter Führungsfrauen, die die Widerspenstigkeit der ASF verhinderten. Zudem fehle der Frauenarbeitsgemeinschaft das Potenzial kampfbereiter und -erfahrener Frauen, seitdem die Quote 
die meisten Hürden beseitigt hätte. ${ }^{505}$ Die ASF stehe heute nicht mehr für bedeutende frauenpolitische Anliegen, so das Urteil der Zeitzeuginnen. Sie nehme sich keine „großen Themen“ mehr vor und habe ihre politische Dynamik verloren. ${ }^{506}$

Auch die Gleichstellungspolitik, die gewissermaßen zum Markenzeichen des sozialdemokratischen Feminismus geworden war, hätte mittlerweile - nach Meinung dieser Zeitzeuginnen - an Attraktivität verloren. Junge Frauen erlebten das eigene Geschlecht nicht mehr als solchermaßen performativ und als ein so eingrenzendes biologisches Schicksal, wie es die Gründerinnen der Gleichstellungspolitik erfahren hätten; vielmehr erschienen ihnen die Geschlechterleitbilder in ihren Lebensentwürfen gestaltbar zu sein. Eine Gleichstellungspolitik aus den 1980erJahren könnte deshalb die Konflikte und Lebensprobleme der jüngeren Genossinnen wenn überhaupt, so nur marginal erreichen, sie bietet ihnen keinen Anreiz zu mutigen neuen Selbstentwürfen und kollektiver Mobilisierung.

Während in der feministischen Wissenschaft in diesem Zusammenhang über eine Flexibilisierung der Geschlechterordnung (vgl. Lenz 2014: 26f.) und über Entwürfe eines neues „kritischen Feminismus“ mit einem erweiterten Emanzipationshorizont ${ }^{507}$ diskutiert wird, blieben die Zeitzeuginnen allerdings bei ihrer differenztheoretischen, geschlechterdualistischen Weltsicht. Sie wünschten sich eine neue und offensivere Gleichstellungspolitik der ASF und waren überzeugt, damit auch junge Frauengenerationen erreichen zu können, denn diese würden im Laufe ihrer beruflichen Karriere die Wirkmächtigkeit männlicher Dominanz und die Allgegenwärtigkeit von Geschlechterhierarchien in der Arbeitswelt schließlich auch erfahren.

505 Unter 13 ehemaligen ASF-Bundesvorstandsmitgliedern berichten acht von der geringeren Durchsetzungsstärke der ASF. Sechs Zeitzeuginnen meinten, dass es der ASF an Kritikfähigkeit oder/und Mut fehlte (Zz 5, Zz 6, Zz 7, Zz 8, Zz 9, Zz 12), zwei Zeitzeuginnen sahen die Schwäche der ASF vorrangig in einer Verzettelung ihrer Kräfte und einem fehlenden Gesamtprojekt in ihrer Politik (Zz 11, Zz 14).

506 Vgl. dazu Zz 4, Zz 5, Zz 6, Zz 7, Zz 9, Zz 11.

507 Emanzipationsbewegungen sollten nach Iris Young als „Regenbogenkoalitionen“ entworfen werden, die sich auf der Basis gegenseitiger Anerkennung zwischen den unterschiedlichen Koalitionsteilnehmenden formieren (vgl. Becker-Schmidt/Knapp 2003: 116). Nach Nancy Fraser muss der kritische Feminismus die Dimensionen Umverteilung, Anerkennung und Repräsentation aufnehmen (vgl. Fraser 2009); nach Frigga Haug Zeitregime, Verteilungsgerechtigkeit sowie das Menschenrecht auf Integration, Entwicklung und demokratische Partizipation (vgl. Haug 2009). An diesen Diskursen scheinen sich die ASF-Frauen nicht mehr zu beteiligen. 


\section{Entwicklung und Veränderung der Frauenpolitiken in der SPD}

Nachdem die ASF im vorangegangenen Kapitel als innerparteiliche Akteurin vorgestellt wurde, wird in den folgenden Abschnitten der sozialdemokratische Wandel der SPD rekonstruiert und analysiert. Dabei wird eine enge Verbindung zwischen der Resonanz in der Partei auf die Forderungen und Aktivitäten der ASF-Frauen und dem Bedeutungswandel der sog. Frauenthemen in der SPD auf der einen Seite und der politischen Krise der Partei in der Regierung auf der anderen Seite gezogen. Die keynesianischen Steuerungskonzepte der Sozialdemokratie schienen im Verlauf der 1970er-Jahre nicht mehr zu funktionieren, sie boten keine Strategie gegen Staatsverschuldung und Massenarbeitslosigkeit. Die SPD verlor zunehmend WählerInnen und Mitglieder ${ }^{508}$. In dieser Zeit bildeten sich in der Partei unterschiedliche Strömungen mit kontroversen Konzepten, um eine sozialdemokratische Lösung der Krise zu entwickeln. Diese historische Phase der Neuorientierung der Partei bot den ASF-Aktivistinnen ein "historisches Gelegenheitsfenster“ (Roth/Rucht 2008), um Themen, die in den Neuen Frauenbewegung diskutiert wurden, mit mehr Resonanz in die Partei einzubringen. Doch frauen- und familienpolitische Anliegen blieben für die Partei zunächst nur Wahlkampfthemen und für das sozialdemokratische Parteiprofil wenig bedeutsam. Der Regierungsverlust der SPD verschaffte dem innerparteilichen Modernisierungsdiskurs einen anderen Raum und öffnete die Partei stärker für die Themen der Umwelt-, Friedens- und Frauenbewegung. In der Zeit der Umorientierung veränderte sich auch die Teilhabe der Frauen an der Parteipolitik: Sie wurden in der Öffentlichkeit sichtbarer und sollten als neue Botschafterinnen einen parteipolitischen Wandel präsentieren.

Die Entwicklung der Frauenpolitik der SPD wird in fünf Zeitetappen gegliedert, um die Veränderungen zu verdeutlichen. Jede Etappe ist geprägt von spezifischen Ereignissen, die sich auf die politische Bedeutung der Frauenarbeit für die Partei, auf Aktivitäten und neu geschaffene Aktionsräume der ASF, neue gleichstellungspolitische Strukturen und Gremien in der Partei oder auf neue sozialdemokratische Politikentwicklungen beziehen. Jeder Etappendarstellung ist eine Zusammenfassung vorangestellt, in der die Besonderheit des Zeitabschnitts skizziert wird; die

508 Thomas Meyer schildert diese Krise der Sozialdemokratie als europäisches Phänomen

(vgl. Meyer 1998: 63-86) 
Jahresangaben sind als zeitliche Orientierung, nicht als trennscharfe Markierungen zu verstehen.

\subsection{Die Demokratisierung und Aktivierung der sozialdemokratischen Frauenstrukturen in der Partei (1970-1975)}

Die programmatische Neuausrichtung der Partei von der Arbeiter- zu einer Volkspartei, wie sie im Godesberger Programm 1959 entworfen worden war, vollzog sich nach Oliver Nachtwey erst Ende der 1960er-/Anfang der 1970er-Jahre, als die zahlreichen jungen Mitglieder aus den neuen Mittelschichten jenseits der IndustriearbeiterInnenschaft in die Partei strömten (vgl. Nachtwey 2009). In dieser Zeit wurden große Organisationsreformen wie die Einrichtung der Arbeitsgemeinschaften beschlossen. Sie waren Grundlage für die Umwandlung der parteieigenen Frauenversammlungen zu einer demokratisch strukturierten Organisation. Ihre Vertreterinnen meldeten sich nun mit einem neuen politischen Gewicht, nämlich im Namen aller weiblichen Mitglieder, in der Partei zu Wort.

In der im Folgenden vorgestellten Zeitphase entstehen in der Frauenarbeitsgemeinschaft erste Entwürfe für eine neue Frauenpolitik. Mit ihren Grundsätzen zur Familienpolitik leiteten die ASF-Frauen eine programmatische Umorientierung der Partei ein. Auch erkämpften sich die Frauen Sitze in der Kommission der Partei zur Überarbeitung des Godesberger Programms. Allerdings führten diese Erfolge und der Bedeutungsgewinn der ASF nicht zu einer stärkeren Berücksichtigung der Frauen bei der Aufstellung von KandidatInnenlisten für Parteifunktionen oder politische Ämter.

\subsubsection{Alte Parteikonzepte und neue Ansprüche}

Ab Mitte der 196oer-Jahre fand die SPD mehr Resonanz bei der weiblichen Bevölkerung, die Wählerinnenzustimmung für die SPD wuchs und bei den Neumitgliedern lag der Frauenanteil erheblich über dem in der gesamten Mitgliedschaft.

Von der Mehrheit der SPD-Organisationseinheiten wurde diese Entwicklung aber nicht wahrgenommen. Ihre Frauenarbeit blieb vorrangig auf gesellige Angebote ausgerichtet und wurde eher vom Politikbetrieb der Partei getrennt. Noch 1966 auf dem Dortmunder Parteitag hatte der 
Bezirksvorsitzende Südbayerns und Landtagsabgeordnete Dr. Jürgen Böddrich in der Satzungsdebatte erläutert: „Die Frau ist doch wohl - ich glaube, das als Lehrer an einem Mädchengymnasium sagen zu können ein musisches und sensibel veranlagtes Wesen und für verräucherte Gaststuben einfach nicht zu haben." (Parteitag der SPD 1966: 591) Die Senatorin Ella Müller aus Bremen pflichtete ihm bei: „[I]ch sage immer: an einer Frau muß alles Herz sein, sogar der Kopf." (a. a. O.: 633).

Doch bald meldeten sich besonders in den Ortsvereinen der Städte die jungen weiblichen Neumitglieder zu Wort. Sie hatten Interesse an der Organisierung konkreter gesellschaftspolitischer Veränderungen und sie hatten die Erwartung an die Partei, Politik mitgestalten zu können.

Zum ersten Eklat kam es auf der Bundesfrauenkonferenz in Saarbrücken $1968^{\circ 09}$. Einige Frauen hatten ein Rosa-Luxemburg-Bild aufgehängt - das von der Vorsitzenden der Frauenarbeit und Versammlungsleiterin Annemarie Renger umgehend entfernt wurde (vgl. Renger 1993: 242). Dann trat eine junge Teilnehmerin ans Rednerpult, kritisierte die Eröffnungsrede der Bundesvorsitzenden Annemarie Renger und stellte einen Antrag zur Einführung demokratischer Wahlen, besonders für die Besetzung der Vorstände. Die Anwesenden waren geschockt, es verletzte die informellen Regeln, nach denen von jungen Genossinnen eher bescheidene Zurückhaltung erwartet werden konnte. „Wie die Hyänen“ sei die Konferenz über die junge Genossin Inge Wettig-Danielmeier hergefallen, berichtete eine Zeitzeugin im Rückblick. Der erste Aufstand der neuen Frauengeneration habe deshalb mit der Flucht der Rebellin auf die Toilette geendet (vgl. Zz 5).

Zur nächsten Bundesfrauenkonferenz in Nürnberg $1970^{510}$ hatte sich die neue Frauenopposition bereits im Vorfeld vernetzt, um ihre Anträge auf eine politische Neuausrichtung der Frauenarbeit und eine Demokratisierung der Strukturen erfolgreicher einbringen zu können. Diese Anträge waren aber nicht vor der Konferenz dem Parteivorstand vorgelegt und genehmigt worden. Sie erfüllten somit nicht die vorschriftsmäßigen Regularien und wurden mit dieser Begründung durch die Konferenzleitung Annemarie Rengers abgelehnt (vgl. Ries-Augustin 1983; Spiegel 1970). Unterstützt wurde diese Entscheidung durch die beiden GastrednerInnen der Konferenz und RepräsentantInnen der Parteiführung, Bundesgesundheitsministerin Käte Strobel und Bundesgeschäftsführer Jürgen Wischnewski. Jedoch hatte die Parteiführung den Unmut unterschätzt. Umgehend organisierten sich ca. 40 Genossinnen in einer selbsternannten Arbeitsgruppe D und händigten der Konferenzleitung am

509 Bundesfrauenkonferenz Saarbrücken, 7.-9. Juni 1968, „Mit uns die Zukunft bauen“.

510 Bundesfrauenkonferenz Nürnberg, 22.-25. Oktober 1970, „Gleiche Bildungschancen Auftrag der Demokratie“. 
nächsten Konferenztag eine nächtens verfasste Erklärung aus (vgl. Spiegel 1970; Pausch 1985). Als Annemarie Renger die Verlesung und Vervielfältigung des Papiers verweigerte, stand die „illegale“ Arbeitsgruppe im Mittelpunkt des Kongressinteresses (vgl. Renger 1993: 243) und der Text kursierte auf der Konferenz ohne Vorstandsgenehmigung. Nach einem Handgemenge auf der Bühne um das Mikrofon zwischen Annemarie Renger und Birkhilde Nicolai, einer Jungsozialistin aus Niedersachsen, hatte die junge Opposition - anders als auf der letzten Konferenz - die Mehrheit der Delegierten für sich gewonnen. Mit 84 gegen 8o Stimmen stimmten die Konferenzteilnehmerinnen für eine Verlesung des Selbstverständnis-Textes (vgl. Ries-Augustin 1983)51․ Anschließend beschloss die Konferenz mehrheitlich eine Demokratisierung der Strukturen ${ }^{512}$ und beauftragte die Frauenvorsitzenden mit der Neuorganisation der Frauenarbeit.

Mit dieser Konferenz 1970 meldete sich eine neue politische Kraft in der Partei zu Wort und wurde für die Presse sichtbar (vgl. Spiegel 1970). Im folgenden Jahr 1971 beschloss der außerordentliche SPD-Parteitag in Bad Godesberg die Einrichtung von Arbeitsgemeinschaften für die Mitgliedergruppen der ArbeitnehmerInnen und der Frauen. Richtlinien und Satzung dafür waren vom Parteivorstand ausgearbeitet worden, sie gaben den Arbeitsgemeinschaften Versammlungsrecht und demokratische Strukturen, aber nur beratende Funktionen. 1973 tagte die erste ASFBundesfrauenkonferenz mit gewählten Delegierten.

\subsubsection{Die Formierung einer frauenpolitischen Opposition in den Frauenstrukturen der Partei}

Die unerwartet hohe Zustimmung auf der Nürnberger Konferenz 1970 stabilisierte die kleine Frauenopposition. Da viele ihrer Aktivistinnen Mitglieder der Jusos waren, fand der neu gegründete Arbeitskreis Emanzipation (AKE) die Unterstützung des Juso-Vorstands. Er entwickelte ab Dezember 1970 die ersten Konzepte zur „Politisierung der Frauenarbeit"513 (AKE 1971: 5). Im AKE gingen die Meinungen zur Mitarbeit in der

511 Originaltext nicht mehr auffindbar.

512 Im Juli 1970 war bereits in einer Veranstaltung der Seminarreihen, die die FriedrichEbert-Stiftung für die Qualifizierung der Funktionärinnen anbot, mehr „Teamwork“ zwischen Vorstand und Frauengruppen sowie eine bessere politische Integration durch mehr Informationsmaterialien und dezentrale Veranstaltungen gefordert worden (vgl. fes 1970).

513 Ziel der Arbeitsgruppe war die Erstellung einer „Analyse der Situation der Frau in der Gesellschaft“. Auf ihrer Grundlage sollten in einem Bundesseminar Handlungsfelder und Aktionspläne einer neuen Frauenpolitik sowie Konzepte für eine politische Bildungsarbeit entwickelt werden. 
Frauenorganisation der Partei jedoch weit auseinander: Für die einen war die Frauenarbeit der Partei eine „Betroffenenpolitik“, die sich bloß besonderer Missstände annahm und sich einer notwendigen Systemveränderung nicht stellte, und sie waren deshalb für den Aufbau einer parallelen Arbeitsstruktur zur ASF; für die anderen war eine neue Frauenpolitik der SPD wegen der bestehenden inaktiven sozialdemokratischen Frauengruppen nur durch die Auflösung der ASF denkbar und sie plädierten für einen Neuaufbau der Frauenorganisation. Die dritte und zahlenmäßig stärkste Gruppe sah im AKE ausschließlich einen Vernetzungskreis, ihre Mitglieder waren sowohl im AKE als auch in der ASF aktiv. Aus Teilen des AKE bildete sich in den Folgejahren eine feministische Struktur bei den Jusos, die vornehmlich auf die Politik der Jugendorganisation gerichtet war (vgl. Ries-Augustin o.J.) ${ }^{514}$

In der Frauenorganisation der Partei waren zunächst nur wenige Mitglieder des Bundesfrauenausschusses bereit, das Gespräch mit den jungen Genossinnen zu suchen. Die Mehrheit lehnte die neue Opposition als parteischädigend $a b^{515}$. Sie hielten die Gruppierung für eine Minderheit, die das politische Geschäft nicht verstand und die nicht integriert werden sollte (vgl. Ries-Augustin o.J.). Nur einzelne Genossinnen, darunter die stellvertretende Bundesvorsitzende Elfriede Eilers, sahen in ihnen Vertreterinnen einer gesellschaftlichen Veränderung, von deren neuen Ideen und Impulsen die Partei profitieren könnte. Manche, wie die Bundesvorsitzende Annemarie Renger, wünschten sich zwar die Isolierung dieser aufsässigen, führungskritischen Stimmen, aber wollten die Frauenarbeit der SPD nicht durch parallel entstehende Arbeitsstrukturen gefährden(vgl. ASF 197ob; ASF 1970c.). Den AKE-Mitgliedern wurden von der ASF-Führung deshalb zunächst keine Kooperationsangebote gemacht ${ }^{516}$.

514 Sie wurde in den 1980er-Jahren durch die Auseinandersetzungen zwischen „Stamokap“ und „Antirevisionisten“" weitgehend marginalisiert oder vereinnahmt. In den Dokumenten der ASF fanden sich nur wenige frauenpolitische Initiativen der Jusos, wie z.B. die Kampagne „Ran an die Zukunft“ und die Quotierung der Juso-Leitungsfunktionen.

515 Vor der Bundesfrauenkonferenz war dem Bundesvorstand zugetragen worden, „daß eine Störung bzw. sogar Sprengung des Kongresses auf jeden Fall beabsichtigt war.“ (ASF 1970c: 2)

516 Verschiedene Aktivitäten der neuen ASF-Aktivistinnen scheiterten an der Vorstandsmehrheit. Der Entwurf eines Arbeitsheftes für die ASF von Christine Schmarsow wurde als zu wenig praxisbezogen zurückgewiesen; die Zusage, zu einem späteren Zeitpunkt einen programmatischen Text zu erstellen, wurde nicht eingehalten. An einem Frauenseminar, das der AKE vom 12. bis 14.11.1971 organisiert hatte, beteiligten sich zwar zahlreiche ASF-Funktionärinnen, die aber, so Wolfgang Pusch, keineswegs den Konsens mit den Veranstalterinnen suchten (vgl. Pausch 1985: 173-177.). 


\subsubsection{Initiativen für eine neue sozialdemokratische Frauenpolitik}

Das Tagungsmotto der ersten delegiertenbasierten Ludwigshafener ASFBundeskonferenz 1973 lautete: „Unser Ziel: Benachteiligungen überwinden“. Die AKE-Frauen kritisierten, dass diese Parole den defensiven und begrenzten Kurs der sozialdemokratischen Frauenarbeit ausdrückte, und forderten eine Grundsatzdebatte über frauenpolitische Ziele und Orientierungen. Eine solche Debatte hatte der Parteivorstand für die Konferenz aber nicht vorgesehen. Als die GastrednerInnen Dr. Hans-Jochen Vogel ${ }^{517}$ als Vertreter der Parteiführung und die Bundesministerin Dr. Katharina Focke ${ }^{518}$ an die Anwesenden appellierten, die eigenen Partikularinteressen zugunsten der Unterstützung besonders benachteiligter Gruppen zurückzustellen, rief dies hörbaren Unmut im Publikum hervor (vgl. f 12 1973). Als diesmal die Vorsitzende Annemarie Renger wie bisher üblich - die parlamentarischen Verhandlungsergebnisse $\mathrm{e}^{19}$ als Erfolge präsentierte, obwohl die ASF an deren Erarbeitung gar nicht beteiligt gewesen war, stieß sie auf Widerspruch. Mit dem Slogan „Alles ist besser als Annemarie“ protestierten Delegierte gegen eine ASF im „Kielwasser der Partei“ ${ }^{\prime 520}$ und wählten einen Neuanfang. Elfriede Eilers wurde zur neuen Bundesvorsitzenden ernannt und eine Programm- und Strategiekommission eingesetzt, die ein neues Selbstverständnis sozialdemokratischer Frauenarbeit entwickeln sollte. Elfriede Eilers hatte zwar als die Stellvertreterin Annemarie Rengers die alte Frauenarbeit mitverantwortet, aber sie verkörperte als unverheiratete Frau, mit Berufsausbildung und ihrer Karriere in der Arbeiterwohlfahrt, ein neues Leitbild. Politisch war sie eher dem rechten Flügel der SPD zuzuordnen, aber sie

517 Bundesminister für Raumordnung, Bauwesen und Städtebau und stellvertretender Parteivorsitzender.

518 Bundesministerin für Jugend, Familie und Gesundheit.

519 Dazu gehörten die Reform des Ehe- und Familienrechts mit verschiedenen Gesetzentwürfen, die Rentenreform mit der Öffnung für Hausfrauen, die Initiative zur Einsetzung von Mindesteinkommen als Ausgleich für Lohndiskriminierungen, der Gesetzentwurf zur Neubewertung der Strafbarkeit von Schwangerschaftsabbrüchen und der Kostenübernahme durch die Krankenkassen, der Gesetzentwurf für Arbeitsbefreiung im Falle der Erkrankung eines Kindes, der Druck auf die Tarifparteien, um das Prinzip „Gleicher Lohn für gleiche Arbeit“ durchzusetzen, die Einrichtung eines Frauenreferats im Ministerium für Jugend, Familie und Gesundheit, der Ausbau von Kindergärten und der Vorschulen als Elementarstufe, der Einbau der integrierten Gesamtschule in den Bildungsgesamtplan der Bundesregierung, die Reform des Familienlastenausgleichs, der auch das erste und zweite Kind mit einschließt, die Überprüfung bestehender Arbeitsschutzvorschriften und bestehender Beschäftigungsverbote und -beschränkungen für Frauen.

520 Hannelore Benz: Bezirk Hessen-Süd (vgl. f 12 1973: 74). 
unterstützte die Aktivierung der Frauenarbeit und den Wunsch nach Demokratisierung ihrer Strukturen ${ }^{521}$. Deshalb kommentierte eine Zeitzeugin, ehemaliges AKE-Mitglied, den Leitungswechsel: „Das war Elfriede Eilers, damals. Und dann fing die ASF-Arbeit an.“ (Zz 9)

Mit der Einrichtung der Programmkommission erhielten die Mitglieder des AKE ein Forum, in dem sie sich auf Bundesvorstandsebene einbringen konnten. In dieser 16-köpfigen Kommission waren zudem alle 15 Bezirke und der ASF-Bundesvorstand vertreten. Die Kommissionsvorsitzende Ute Canaris definierte auf der konstituierenden Sitzung am 27.08.1973 das Arbeitsziel: „Raus aus der Frauenecke“. Dazu sollte Frauenpolitik in der Partei als Gesellschaftspolitik verstanden werden und Frauen sollten sich gesellschaftspolitisch mehr zu Wort melden (vgl. Canaris 1975). Das neue Strategiekonzept für die ASF wollten die Kommissionsmitglieder aus der Basisarbeit der Frauenarbeitsgemeinschaften entwickeln. Sie organisierten deshalb eine bundesweite Befragungsaktion in der ASF, die allerdings wenig verwendbare Ergebnisse brachte ${ }^{522}$.

\subsubsection{Neue Einmischungen der ASF in die Parteipolitik}

Zwar hatten sich die Delegierten auf der Ludwigshafener Bundesfrauenkonferenz 1973 für eine Selbstfindungsdiskussion entschieden, um neue, eigenständige Handlungsfelder der sozialdemokratischen Frauenarbeit zu entwickeln, im neu gewählten Bundesvorstand aber war mehrheitlich die traditionelle sozialdemokratische Frauenpolitik vertreten. Im Vordergrund seiner Arbeit standen die Werbung für die frauenpolitischen Aktivitäten der sozialdemokratischen Regierungspolitik und die Kritik an der Frauenpolitik anderer Parteien und Verbände ${ }^{523}$.

521 Mit der Kandidatur Elfriede Eilers waren nicht alle Delegierten einverstanden. Herta Däubler-Gmelin, damals noch unbekannt und den Jusos nahestehend, stellte sich deshalb spontan als Gegenkandidatin zur Wahl. Zwar scheiterte sie, aber das relativ schlechte Wahlergebnis Elfriede Eilers - Herta Däubler-Gmelin erhielt 6o Stimmen, die Kandidatin des Parteivorstandes 89 Stimmen - drückte den Unmut der Delegierten gegenüber der ehemaligen ASF-Führung und ihr Interesse an einem politischen Wechsel aus (vgl. Ries-Augustin o. J.: 158).

522 Von den ca. 1.ooo ASF-Frauengruppen schickten nur 48 ausgefüllte Fragebögen zurück. Der Grund für die geringe Rückmeldung ließ sich nie klären. Vermutet wurde, dass die Fragebögen nur an ausgewählte Gruppen verschickt worden waren - diese Versendung erfolgte über das Frauenbüro beim Parteivorstand - oder dass die Unterlagen innerhalb der Partei nicht an die Frauengruppen ausgehändigt worden waren (vgl. Unterlagen dazu in PV-Akten 13692).

523 Vgl. Pressearbeit des ASF-Vorstandes in der Publikationsreihe Sozialdemokratischer Pressedienst. 
Der frauenbewegte Elan der AKE-Aktivistinnen wurde bald ausgebremst. Sie hatten in der Programmkommission recht erfolgreich ihre gesellschaftspolitischen Positionen durchgesetzt, aber ihr Plan, über eine Programmdiskussion den Kurs der ASF-Politik zu verändern, scheiterte. Das in vielen Monaten mühsam erarbeitete Dokument ${ }^{524}$ wurde auf der folgenden Bundesfrauenkonferenz in Braunschweig 1975 in den politisch-strategischen Teilen als Materialien für die politische Bildungsarbeit eingestuft und abgelegt. Damit war eine weitere Programm- und Selbstverständnisdebatte in der ASF beendet. Als es der AKE-Gruppe auf dieser Konferenz auch nicht gelang, die gewünschte Zahl von Vertreterinnen bei den ASF-Bundesvorstands-wahlen durchzusetzen, zog sie ihre vier bereits gewählten Vorstands-frauen aus Protest zurück (vgl. Pausch 1985: 193-196; Ries-Augustin o. J.). Nach dieser Konferenz, schrieb das ASF-Vorstandsmitglied Ursula PauschGruber später, sah es so aus, als würde sich die sozial-demokratische Frauenbewegung spalten (vgl. Pausch-Gruber 1978: 84) ${ }^{525}$.

Nach Berichten der Zeitzeuginnen entschieden sich die meisten AKEAktivistinnen nach und nach für eine Mitarbeit in der ASF, denn es gab keine andere Frauenstruktur mit Einfluss auf die Parteipolitik; außerdem zeigte sich, dass sie in der ASF frauenpolitische Initiativen als Sachthemen diskutieren und zu gemeinsamen Beschlüssen kommen konnten, wenn von den Beteiligten keine antikapitalistischen Bekenntnisse erwartet wurden (vgl. dazu Zz 11, Zz 5).

Zwei Hauptthemen beschäftigten die ASF-Arbeitsgemeinschaften in dieser Zeit: die Entkriminalisierung des Schwangerschaftsabbruchs und die Reform des Ehe- und Familienrechts ${ }^{526}$.

Bei der Reform des $\S 218$ unterstützte die ASF die von der kleinen Koalition im April 1974 verabschiedete Fristenregelung. ${ }^{527}$ Als das Bundesverfassungsgericht nach einer Klage von CDU und CSU die Verfassungswidrigkeit der Reform entschied, organisierte der ASFBundesvorstand eine Kundgebung mit Fackelzug und mobilisierte zur

524 Vgl. Programmkommission beim Bundesvorstand der ASF (1975): Grundsätze für die Arbeit der Sozialdemokratischen Frauen, Beschlussvorlage.

525 Bei den Jusos hatten die linkssozialistischen ASF-Aktivistinnen nach Ulrike RiesAugustin mehr Erfolg. Hier wurde bereits 1975 die Frauenarbeit als ein politisches Arbeitsfeld anerkannt (vgl. Ries-Augustin o.J.: 160)

526 Vgl. dazu die Ergebnisse bereits erwähnten Frauengruppenbefragung 1974. Danach fanden zu den Themen „Reform des §218“ bzw. „Abschaffung des § 218“ und „Ehe- und Familienpolitik“ die meisten Veranstaltungen der Frauenarbeitsgemeinschaften statt (vgl. AdSD 13692).

527 Zunächst hatte die kleine SPD/FDP-Koalition die sog. Fristenlösung verabschiedet. Durch sie war - wie in der DDR - der Schwangerschaftsabbruch bis zur 12. Woche straffrei. 
Urteilsverkündung ca. 5.0oo Frauen. Obwohl die ASF zur Frage der staatlichen Kontrolle von Schwangerschaften und bei dem Alleinbestimmungsrecht der Mütter tief gespalten war, teilten die Frauen die Auffassung der Partei, dass der Schutz des werdenden Lebens nicht mit Strafmaßnahmen gegen Mütter durchgesetzt werden dürfte. Deshalb lehnte die ASF Indikationsregelungen ${ }^{528}$ zunächst ab. Als sie per Gesetz 1976 in Kraft traten, beteiligten sich viele ASF-Frauengruppen beim Unterlaufen der Härtefallregelungen ${ }^{529}$. In einer Broschüre dokumentierte die ASF die chaotische Rechtslage unter dem neuen Gesetz, denn für viele Frauen in konservativen und eher ländlichen Regionen gab es auch nach dem neuen Gesetz keine Möglichkeit eines straffreien Schwangerschaftsabbruchs. In Kooperation mit autonomen Fraueninitiativen beteiligten sich ASF-Gruppen und einzelne Sozialdemokratinnen an Kontaktnetzwerken, um den Hilfe suchenden Schwangeren einen Abbruch zu ermöglichen. Frauen aus dem ASF-Bundesvorstand und aus Bezirksvorständen boten sich für diese Hilfe öffentlich als Ansprechpartnerinnen an (vgl. Rechenschaftsbericht 1975).

Die geplante Reform des Ehe- und Familienrechts stellte die neu gegründete ASF vor „ihre erste große Aufgabe“, wie die Bundesvorsitzende Elfriede Eilers der Presse erklärte (vgl. Eilers 1974c: 2). Unter Beteiligung der gesamten Organisation erarbeitete die ASF programmatische Grundsätze für eine Neuorientierung sozialdemokratischer Familienpolitik: Als „Familien“ sollten nur die Gemeinschaften von Erwachsenen mit Kindern gelten, nicht mehr die kinderlosen Ehen, eine steuerliche Begünstigung der Hausfrauenehe wurde damit abgelehnt. Nichteheliche Lebensgemeinschaften waren mit ehelichen gleichzustellen. Mütter sollten ein uneingeschränktes Recht auf eine Berufstätigkeit erhalten. Die Grundsätze thematisierten auch die innerfamiliären Gewaltverhältnisse und forderten eine staatliche Intervention und Hilfe bei familiären Sozialisationsproblemen. Diese politischen Positionen, die die ASF 1974 der Partei vorlegte, prägten die sozialdemokratische Familienpolitik nachhaltig.

In den Wahlkämpfen der SPD wurden ab Mitte der 1970er-Jahre frauen- und familienpolitische Themen sichtbarer: Beim Wahlkampf zu den Landtagswahlen 1975 in NRW engagierten sich die Genossinnen an

528 Mit der Indikationsregelung blieb der Schwangerschaftsabbruch als Straftatbestand im Strafgesetzbuch erhalten und war nur in Härtefällen straffrei. Die Härtefälle waren durch staatlich legitimierte Instanzen zu prüfen und zu bescheinigen. Um die Definition dieser Indikationen wurde in den Folgejahren politisch gestritten, denn ihre Auslegung variierte zwischen den Bundesländern erheblich, und zwar abhängig von den jeweiligen politischen Regierungsmehrheiten.

529 Auch die AWO-Schwangerschaftsberatungen halfen Frauen, die eine Abtreibung vornehmen lassen wollten, die notwendigen Bescheinigungen ohne die geforderten Rechtfertigungen zu erhalten. 
den Wahlkampfständen nicht nur mit Waffelbacken, Dekorieren und anderen Zuarbeiten, sondern auch mit einer eigenen Broschüre Mehr Frauen in die Parlamente. Im Bundestagswahlkampf 1976 warb ein Wahlplakat mit den Sozialleistungen für Frauen und Mütter als Beitrag zum „Modell Deutschland“ (Grebing/Junker 2001: 255). Anlässlich des von der UNO ausgerufenen Internationalen Jahres der Frau 1975 organisierte der SPD-Parteivorstand im nordrhein-westfälischen Vorwahlkampf eine frauenpolitische Großveranstaltung. $\mathrm{Zu}$ diesem Westfalentag trafen sich 1975 rund 10.000 Teilnehmerinnen in der Dortmunder Westfalenhalle (vgl. Rechenschaftsbericht 1975: 28f.). Beim inhaltlichen Verlauf dieser Veranstaltung war von einem Aufbruch der sozialdemokratischen Frauenarbeit allerdings noch wenig zu spüren: SPDSpitzenpolitikerInnen ${ }^{530}$ präsentierten die Erfolge sozialdemokratischer Regierungspolitik und die bekannten Parteiforderungen nach ausreichender Kinderbetreuung, der Reform der Ehe- und Familienpolitik und dem Ausbau der sozialen Sicherung.

\subsubsection{Streiten um die politische Mitgestaltung}

Während die Zahl der weiblichen Parteimitglieder seit Mitte der 196oerJahre kontinuierlich bis 1972 auf über $18 \%$ angestiegen war, war die Beteiligung der sozialdemokratischen Frauen in der Politik kontinuierlich gesunken. Seit den 1950er-Jahren hatte die Zahl der weiblichen SPD-Abgeordneten im Bundestag stetig abgenommen und lag 1972 anteilig sogar unter dem Prozentsatz anderer Parteien. Auch in den meisten Länderparlamenten lag der Anteil der Frauen in den SPD-Fraktionen unter den Anteilen der politischen Konkurrenz (vgl. Hoecker 1995: 123-133). Nur in den Kommunalparlamenten war der Frauenanteil mit durchschnittlich 8,3 \% (1973) bei den SozialdemokratInnen höher als bei den anderen Parteien (vgl. ebd.). Die Forderungen nach einer stärkeren innerparteilichen Berücksichtigung der Frauen bei der Personalauswahl und die Integration der Genossinnen in die Politikgestaltung der Partei hatten nach Darstellung einer der Expertinnen nur verbale, folgenlose Appellen an die Partei zur Folge (vgl. Zz 5).

530 Parteivorsitzender Willy Brandt, Ministerpräsident von NRW Heinz Kühn, als Vertreterin der Sozialistischen Internationale Irene Petry, ASF-Landesvorsitzende Inge Donnep, parlamentarische Staatssekretärin im Bundeskanzleramt Marie Schlei, ASFBundesvorsitzende Elfriede Eilers. 
Mit der Neugründung der ASF änderte sich die Präsenz der Frauen in der Partei. Eine häufigere Berichterstattung über ASF-Aktivitäten im Sozialdemokratischen Pressedienst sorgte für eine größere Sichtbarkeit. Ab 1973 präsentierte sich die ASF in den Jahrbüchern der Partei mit mehreren Seiten. In diesen Berichten wurden nicht nur - wie bisher üblich Mitgliederzahlen und Kongressteilnahmen gelistet, sondern auch die frauenpolitischen Pläne vorgestellt und die Arbeitsschwerpunkte der ASF erläutert. ${ }^{53}$

Den ersten erstrittenen Partizipationserfolg erreichte die ASF mit ihrer Beteiligung an der Programmkommision. 1970 hatte der SPDParteitag in Saarbrücken beschlossen, eine Programmdebatte zu beginnen mit dem Ziel, das Godesberger Programm aus dem Jahr 1959 an veränderte politische Verhältnisse anzupassen. Eine Teilnahme der ASF an der dazu eingerichteten Programmkommission ${ }^{52}$ war nicht vorgesehen. Der Entwurf eines ökonomisch-politischen Orientierungsrahmens 1973 bis 1985 - in der Kurzform OR '85 - lag der Partei in seiner ersten Fassung 1972 vor. Er behandelte in den frauenpolitischen Textpassagen vor allem Themen der Familienfürsorge wie Sorgerechte, Erziehungsansprüche und -hilfen sowie die Altersversorgung von Frauen und den Bildungsbedarf bei Mädchen. Forderungen nach ökonomischer Unabhängigkeit und freier Berufswahl für Frauen fehlten in dem Text (vgl. Scharping/Wollner 1973). Als mehrfache Appelle des ASF-Bundesvorstands an die Parteiführung, die weiblichen Mitglieder an der Programmgestaltung zu beteiligen, erfolglos blieben, protestierten die Vorstandsfrauen mit einer Presseerklärung (vgl. Rechenschaftsbericht 1975: 24). Daraufhin wurden Vertreterinnen des ASF-Vorstands am 2. Entwurf des $O R$ ' $85^{533}$ beteiligt und konnten das Grundsatzdokument wesentlich verändern. In dem Programmtext, der dem Mannheimer Parteitag $1975^{534}$ vorlag, war zum ersten Mal in einem sozialdemokratischen Programmtext die Geschlechterhierarchie als ein zentraler gesellschaftlicher Widerspruch aufgenommen worden (vgl. OR '85 1975: 1.4). Desweiteren gab es ein Kapitel Die Gleichstellung der Frauen, an

531 Im Vergleich zur Arbeitsgemeinschaft für Arbeitnehmer war die Berichterstattung der ASF Anfang der 1970er-Jahre sehr viel ausführlicher. Sie präsentierte sich als eine aktivere, vielfältigere und integrative Arbeitsgemeinschaft (vgl. Jahrbücher 1973-1975).

532 Die Kommission, bestehend aus je einem Vertreter der Bezirke und acht Vertretern aus dem Parteivorstand, tagte unter dem Vorsitz Helmut Schmidts sowie seinen Stellvertretern Hans Apel und Jochen Steffen. Weibliches Mitglied war Gerda Hesse, Bundesvorstandsmitglied der Deutschen Angestellten Gewerkschaft (DAG).

533 Der Anhang des OR '85 illustriert eindrucksvoll die zeitgenössischen Vorstellungen von der Steuerungsmächtigkeit des Staates. Seine Aufgabe war es, auf der Grundlage konkreter Daten der wirtschaftlichen Entwicklung des Bruttosozialprodukts die wirtschaftlichen Prozesse mit Investitionslenkungen zu bändigen und zu fördern.

534 11.11.-15.11. 1975, Parteitag in Mannheim. 
dessen Erstellung die ASF-Frauen beteiligt worden waren (vgl. Rechenschaftsbericht 1975: 24). Frauenpolitische Anliegen hatten damit eine neue Bedeutung in der programmatischen Ausrichtung der Partei gewonnen. Zum ersten Mal wurde in einem sozialdemokratischen Programmdokument eine Verantwortung der Männer für die Überwindung der geschlechtlichen Arbeitsteilung definiert. Die ASFFrauen hatten erstritten, dass sich Väter vermehrt bei der Kindererziehung engagieren sollten - z.B. mit einer verkürzten Arbeitszeit. Die Berufstätigkeit von Frauen wurde nun als eine "Chance zur Selbstverwirklichung" definiert, die den Frauen materielle Unabhängigkeit und höhere Anerkennung auch in der Familie brächte. Außerdem appellierte der Text an die eigene Organisation, dass die Glaubwürdigkeit der Partei von der Realisierung der Gleichstellung in den eigenen Reihen abhinge (vgl. OR '85:4.6).

Neben diesen Neuerungen blieben auch traditionelle Programmelemente im Text erhalten: Frauen wurden nicht in ihrem Aufbruch thematisiert, in dem sie Anliegen und Ansprüche neu anmeldeten, sondern sie wurden weiterhin als eine benachteiligte gesellschaftliche Gruppe definiert ${ }^{535}$. $\mathrm{Zu}$ ihrem geringen gesellschaftlichen Status trügen sie selbst bei, weil sie vorgegebene geschlechtliche Rollenverteilungen aktiv reproduzierten, indem sie „nicht nur Benachteiligungen für sich selbst widerspruchslos hinnehmen, sondern als Erzieher diese Selbstverständlichkeit an die Kinder weitergeben" (OR '85: 4.6.2). Der Text verwahrte sich gegen separatistisch orientierte Frauenaktivistinnen - nur Männer und Frauen gemeinsam könnten gesellschaftliche Veränderungen realisieren - und verwies auf die Langwierigkeit des Wandels, denn der erforderliche Umdenkungsprozess in der Gesellschaft könne durch staatliche Regulationen wie Gesetze und materiellen Ausgleich nicht wesentlich beschleunigt werden. Schließlich war auch der Passus des Godesberger Programms, dass der Verwirklichung der Gleichberechtigung ,natürliche' Grenzen in den psychologischen und biologischen Eigenarten der Frau gesetzt seien, in das neue Parteidokument aufgenommen worden. ${ }^{536}$

Die frauenpolitischen Neuerungen des Programmtextes war den ASF-Frauen vorrangig machtstrategisch, d.h. durch die Mitarbeit in der Kommission, gelungen, in der Parteiorganisation hatten sie dagegen nur wenig Unterstützung mobilisieren können. Nur der Bezirk Südbayern

535 Die an Defiziten und nicht an Potenzialen orientierte Beschreibung weiblicher Interessen entsprach in dieser Zeit allerdings auch mehrheitlich den ASF-Selbstbegründungen.

536 Allerdings gab es in der Kommission eine große Gruppe von KriterInnen an dieser Passage (dokumentiert in Oertzen von/Ehmke/Ehrenberg 1976:180-197). 
stellte auf dem Mannheimer Parteitag 1975 einen frauenpolitischen Antrag und forderte, den Programmtext um einen Katalog gleichstellungsorientierter Ziele in den Bereichen Arbeitswelt, Bildung und Familie zu erweitern. 537

Nach dem Mannheimer Parteitag fand diese neue Öffnung der Partei für frauenpolitische Themen allerdings nur dann Berücksich-tigung, wenn frauenpolitische AkteurInnen in den verantwortlichen Gremien dafür stritten ${ }^{538}$.

Auch die wiederholte Selbstverpflichtung der Partei, die Partizipation der weiblichen Mitglieder zu erhöhen, wurde in den folgenden innerparteilichen Prozessen und Verfahren immer wieder ignoriert. Selbst auf dem Mannheimer Parteitag 1975 waren trotz der Mahnung Willy Brandts nur drei Frauen in den 36-köpfigen Parteivorstand gewählt worden. Damit sank der Frauenanteil in diesem Leitungsgremium unter die ehemalige Schutzklausel, die statuarisch vier Frauen in jedem Leitungsgremium vorgeschrieben hatte ${ }^{539}$. Zwar war den ASF-Frauen in den Monaten von dem Parteitag vom Parteivorstand und vom Parteivorsitzenden persönlich zugesichert worden, für eine größere Präsenz der Frauen in den Führungsgremien zu sorgen, aber die Parteiführung beschränkte sich ausschließlich auf Appelle an die Mitglieder.

Trotz dieser Erfahrungen setzten auch die feministischen ASFAktivistinnen weiterhin auf eine Veränderung der Partei durch Sensibilisierung der Organisation im Diskurs. Ihr Ziel war es, die Partei von der Notwendigkeit einer Veränderung der Geschlechterverhältnisse zu überzeugen, damit die „Frauenfrage“ in den „gesamtgesellschaftlichen Überlegungen“ der Partei ihren Platz fand (vgl. ASF-Programmkommission o.J.: 21).

537 Der Antrag wurde von den Delegierten des Mannheimer Parteitags angenommen (Parteitag der SPD 1975).

$538 \mathrm{Im}$ Regierungsprogramm für den Bundestagswahlkampf 1976 wurden keine frauenpolitische Forderung oder Zielsetzung aus dem OR-'85-Katalog aufgenommen. 539 Sitzung des Parteivorstands vom 17.03. 1975 (vgl. Rechenschaftsbericht 1975: 24). 


\subsection{Die innerparteiliche Frauenbewegung im Streit um die Mitwirkung an der Parteipolitik}

(1975-1979)

In vielen Arbeitskommissionen und Fachtagungen hatte die ASF die sozialdemokratische Programmatik frauenpolitisch überarbeitet und ein breites Spektrum neuer Ideen und Forderungen formuliert. Allerdings fanden sie in den Partei nicht die Beachtung, die die Frauen erwarteten. Verglichen mit dem Engagement in der Partei und bei Wahlkämpfen und der wachsenden Unterstützung der Partei durch Wählerinnen ${ }^{540}$ erschien den ASF-Frauen ihre weiterhin geringe Beteiligung an Parteifunktionen und an politischen Ämtern immer ungerechter. Verschiedene Konflikte mit der SPD-Führungsspitze stärkten in der zweiten Hälfte der 1970er-Jahre den Unmut in der ASF und mit ihm das Lager der linkssozialistischen feministischen Aktivistinnen. Ende der 1970er-Jahre konnte die ASF dem an Einfluss gewinnenden linken Lager in der SPD zugerechnet werden. Mit ihrem Engagement bei Bürgerinitiativen und Frauenprojekten, in der Friedensbewegung und mit der Organisation des Internationalen Frauentags wurde die ASF in vielen Regionen und Kommunen nach außen als eine linkssozialdemokratische, aktive Frauenorganisation sichtbar.

\subsubsection{Wachsender Unmut unter den Frauen gegen die Parteiführung}

1975 hatte die ASF zum ersten Mal eine eigene Arbeitsgruppe Wahlkampf durchgesetzt und organisierte mehrere Großveranstaltungen zur Bundestagswahl 1976 (vgl. Pausch 1985: 206). Ihre Veröffentlichungen erschienen mit einem neuen Signet, der Rose mit deutlich sichtbarem Dorn ${ }^{541}$. Ihre Wahlkampfaktivitäten werteten die ASF-Aktivistinnen als Erfolg. Auch wenn die SPD bei den Frauen Stimmen an die konservativen Parteien verloren hatte und mehrheitlich nur von den Wählerinnen

540 Das Wahlprogramm zur Bundestagswahl 1972 beschränkte sich frauenpolitisch auf die Reform des Ehe- und Familienrechts sowie die Straffreiheit für Schwangerschaftsabbrüche in den ersten drei Monaten (vgl. Parteitag der SPD 1972: 473). Andere frauenpolitische Themen, wie sie im 2. Bericht der Bundesregierung (BT-Drs.VI/3689) aufgeführt waren, z.B. das Bildungsgefälle zwischen den Geschlechtern, die weibliche Altersarmut, die Förderung der weiblichen Berufstätigkeit, fanden sich im Wahlprogramm nicht. Trotzdem erhielt die SPD bei dieser Bundestagswahl zum ersten Mal die Stimmenmehrheit bei den Wählerinnen in den Altersgruppen bis 45 Jahre.

541 Vgl. dazu Kap. 5.4.3. 
unter 35 Jahren gewählt worden war, hatte die Wahlkampfsonderinfo Frau aktuell großes Interesse gefunden, war in einer Millionenauflage erschienen, bald vergriffen und konnte nur aus finanziellen Gründen nicht nachgedruckt werden (vgl. Jahrbuch der SPD \{1975-77\}). Zwar hatte die SPD insgesamt Stimmen verloren, aber bei den Bürgern (1972 zu 1976: 3,3\%) deutlich mehr als bei den Bürgerinnen (1972 zu 1976: -2,4 \%). Auch der Anteil der weiblichen SPD-Mitglieder stieg in der Partei stetig an (1970: 18 \%, 1974: 28 \%, 1977: 33\%). Im neugewählten Parlament der 8. Wahlperiode ${ }^{542}$ aber - und auch in den meisten Landtagen - lag der Anteil der weiblichen SPD-Abgeordneten unter dem Frauenanteil aller anderen vertretenen Parteien.

Tab. 2: Frauenanteil in den Landesparlamenten (1973-1976) (Angaben in Prozent)

\begin{tabular}{|l|l|l|l|l|l|l|}
\hline & & Gesamt & SPD & & gesamt & SPD \\
\hline $\mathbf{1 9 7 4}$ & Hamburg & $\mathbf{1 2 , 5}$ & $\mathbf{1 2 , 5}$ & Bayern & 6,9 & 4,2 \\
\hline & Niedersachsen & 3,9 & $\mathbf{2 , 9}$ & Hessen & 8,2 & 6,1 \\
\hline $\mathbf{1 9 7 5}$ & Berlin & 6,6 & 7,5 & NRW & 5,5 & 5,5 \\
\hline & Rheinland-Pfalz & 7 & 5 & Saarland & 6 & 4,5 \\
\hline & Schleswig-Holstein & 5,5 & 10 & Bremen & 15 & 19,2 \\
\hline & $\begin{array}{l}\text { Baden-Württem- } \\
\text { berg }\end{array}$ & 4,9 & 4 & & \multicolumn{3}{|l}{} \\
\hline
\end{tabular}

Quelle: Hoecker 1995: 123-133, Auszüge aus den Tabellen.

Bereits auf dem Mannheimer Parteitag 1975 hatten die ASF-Frauen öffentlich gegen die Nichtbeteiligung der Frauen in der Partei protestiert und waren mit Transparenten ${ }^{543}$ vor den Parteitag gezogen. Auf dem Büchermarkt erschienen Publikationen über die Diskriminierung der Frauen in der Partei, verfasst von führenden Sozialdemokratinnen (vgl. Riedel-Martiny 1975; Bothmer von 1976). Die Siegener ASF-Bundesfrauenkonferenz $1977^{544}$ widmete sich diesem Thema mit dem Konferenztitel

542 Anteil der Frauen in den Fraktionen der 8. Wahlperiode (1976-1980): CDU: 7,5 \%; SPD: 6,7 \%; FDP: 10,0 \% (Hoecker 1995: 137).

543 Frauen hielten Transparente mit den Aufschriften „Mehr Frauen in die Parlamente“, „Letzter Satz OR '85 verwirklichen“, „, Gretchenfrage: Wie hältst Du, SPD, es mit den Frauen?" hoch und übergaben Willy Brandt eine Erklärung (vgl. Frau und Gesellschaft 10/1975: Aktenauszug SPD-PV 10382).

544 ASF-Bundeskonferenz in Siegen vom 3. bis 5. Juni 1977. 
„Recht auf Arbeit - Frauen in die Politik ${ }^{545}$. Auf der Konferenz lagen verschiedene Anträge vor, die die Missachtung von Fraueninteressen anprangerten; es wurden eine höhere Eigenständigkeit der Arbeitsgemeinschaften mit Publikationsrechten und ein eigenes Budget gefordert (vgl. ASF 1977: Antragsblock B, S. 138-140).

Dass diese Siegener Konferenz zu einem Fanal des zunehmenden Unmuts der Frauen gegen die Parteiführung wurde, lag allerdings am Auftritt der Parteiführung. Dass der amtierende Bundeskanzler Helmut Schmidt als Gastredner auf einer Bundesfrauenkonferenz sprach, war ungewöhnlich und eigentlich eine hohe Anerkennung und Ehre für die Arbeitsgemeinschaft, auch wenn gerade er in der Vergangenheit für frauenpolitische Anliegen wenig Interesse und Verständnis gezeigt hatte. Als Helmut Schmidt nun den Delegierten erklärte, dass die ASF nur eine akademische Minderheit innerhalb der Frauen repräsentiere, denn die Mehrheit der Frauen sehne sich nach Kindern und Familienglück und nicht nach Berufstätigkeit, eskalierte der schwelende Konflikt. Eine Zeitzeugin erinnert sich an die Empörung und Wut der Delegierten, ein „FURCHTBARES Pfeifkonzert" brauste auf ${ }^{546}$ :

Es wurde gebuht, gepfiffen und geschrien: ,Aufhören' und so, also auf jedenfalls was in den damaligen Parteikreisen nicht üblich war - es ist auch heute nicht üblich, muss man sagen. (Zz 5)

Mit seinen Ausführungen hatte die wichtigste Führungsperson der Partei eine elementare politischen Leitlinie der ASF, die Förderung der weiblichen Erwerbstätigkeit und die partnerschaftlich geführte Ehe, in Frage gestellt (vgl. Pausch 1985: Anlage4,5). In den anschließenden Wahlen zum Bundesvorstand der ASF unterstützten die Delegierten das re-

545 Auf der Siegener Konferenz 1977 wurden fünf thematische Arbeitsgruppen angeboten: AG 1: Recht auf Arbeit, AG 2: Volkswirtschaftliche Rahmenbedingungen und Arbeitschancen für Frauen, AG 3: Bildung und Ausbildung, AG 4: Arbeit in der Familie - Leistung für die Gesellschaft, AG 5: Frauen in die Politik - Mut zur Macht. Diskutiert wurden in parallelen Arbeitsgruppen politische Positionspapiere zu Maßnahmen der Frauen- und Mädchenförderung, zur geschlechterquotierten Personalpolitik öffentlicher Verwaltungen, zu einer geschlechterquotierten Ausbildungsplatzvergabe in der privaten Wirtschaft, zur Einführung frauenbeschäftigungsfördernder Auflagen bei der Vergabe staatlicher Aufträge und anderer öffentlicher Fördermaßnahmen sowie zu steuerungspolitischen Reformen und zur antikapitalistischen Strukturkritik (vgl. Dokumente 6/1977).

546 Eine solche Konfrontation findet sich im offiziellen Protokoll der Bundeskonferenz nicht (vgl. ASF 1977), wohl aber in den Archiven. Nach der Konferenz schrieben viele Funktionärinnen und Frauenarbeitsgemeinschaften empörte Protestbriefe an den Parteivorstand (vgl. AdsD SPD-PV 10342). 
gierungskritische Lager und wählten die Linkssozialistinnen Inge Wettig-Danielmeier ${ }^{547}$ und Ursula Pausch-Gruber zu stellvertretenden Bundesvorsitzenden ${ }^{548}$. Zur Bundesvorsitzenden wurde Elfriede Hoffmann ${ }^{549}$ gewählt. Die der SPD-Rechten zugehörige DGB-Funktionärin war eine Vertreterin der traditionellen Sozialdemokratie. Sie sollte zur Integration der ASF-Lager beitragen und der Arbeitsgemeinschaft eine gewerkschaftsnahe Stimme geben. Eine Zeitzeugin erklärte:

[D]ie hat zu den strategischen und konzeptionellen Weiterentwicklungen im Grunde nichts beigetragen, aber sie hat durchaus ein bisschen dazu beigetragen, dass die Flügel ein bisschen austariert waren, und für die AfA ${ }^{55^{\circ}}$ war es natürlich auch eine Herausforderung, dass eine Gewerkschaftsfrau auf einmal Vorsitzende ist. ( $\mathrm{Zz} 6)$

Die beiden Stellvertreterinnen sollten die Arbeit des ASF-Vorstands jedoch bald stärker prägen als die Vorsitzende. Z.B. protestierte die neue ASF-Führung gegen das Parteiordnungsverfahren gegen 56 Hamburger Mitglieder, die einen Solidaritätsaufruf für den damaligen Juso-Bundesvorsitzenden Klaus-Uwe Benneter unterschrieben hatten ${ }^{55^{1}}$. In dem ASFSchreiben an den Parteivorstand hieß es, die Geschlossenheit der Partei nach außen wäre weniger durch abweichende Meinungen der Basis gefährdet als durch „undiszipliniertes und von den Grundsätzen der Partei abweichendes Verhalten von Führungskräften“, und er zog damit eine Verbindung zum Auftritt Helmut Schmidts in Siegen (Pausch 1985: Anlage 4.5 „Schreiben des ASF-Bundesvorstands an Willy Brandt vom 14.07.1977").

Auf der folgenden ASF-Bundeskonferenz 1979 erklärte der ASF-Bundesvorstand die Neuorientierung der ASF und forderte von der Partei die

547 Inge Wettig-Danielmeier erhielt mit 181 Ja-Stimmen und Ursula Pausch-Gruper mit 145 Ja-Stimmen mehr Unterstützung als die Vorsitzende Elfriede Hoffmann (138 Ja-Stimmen).

548 Anni Jansen, die Frauenreferentin beim Parteivorstand, berichtete dem Parteivorstand im Vorfeld der Konferenz von zu erwartenden „Schwierigkeiten“. Ein „Neuling“ - gemeint war Inge Wettig-Danielmeier - kandidiere, die als „Vertreterin einer starken Minderheit gelte“ und an deren Person „alte Differenzen neu aufbrechen [gemeint waren die Auseinandersetzungen mit den Jusos; S.E.] und zu Frontenbildung führen“ könnten (Jansen o. J. [1979a])

549 Elfriede Hoffmann war stellvertretende Leiterin der Abteilung Frauen beim DGB-Bundesvorstand, später Vorstandsmitglied der HBV.

550 Arbeitsgemeinschaft für Arbeitnehmerfragen in der SPD.

551 Klaus-Uwe Benneter war 1977 wegen des Verstoßes gegen das Zusammenarbeitsverbot mit KommunistInnen aus der Partei ausgeschlossen worden. 
Anerkennung der Frauenarbeitsgemeinschaft als eigenständige Lobby 552 . Vorbild dafür war die schwedische Sozialdemokratie, in der die Frauenorganisation parteiunabhängig Mitglieder aufnehmen und eigene Beiträge erheben konnte, über die sie eigenverantwortlich verfügte. Die Delegierten beschlossen, von der Partei Beteiligungsgarantien an Kommissionen sowie eigene frauenpolitische Etats auf allen Parteiebenen, Antragsrechte zu den Parteitagen, Frauenreferate in allen Parteieinheiten ab der Bezirksebene und ein frauenspezifisches Bildungsprogramm mit Kinderbetreuung zu fordern. Die Einführung einer Quote, wie sie bereits auf der Siegener Bundesfrauenkonferenz $1977^{553}$ vorgeschlagen worden war, lehnten die Bundesdelegierten 1979 erneut ab (vgl. Antrag D 5b in: Dokumente 11/1979). 554

Auf dieser Konferenz bekannten sich die beiden stellvertretenden Bundesvorsitzenden Inge Wettig-Danielmeier und Ursula Pausch-Gruber dazu, dem Feminismus näher zu stehen als einem linken Sozialdemokratismus. Eine Vertreterin des feministischen Lagers warf sogar die Frage auf, ob die SPD der richtige Ort wäre, um für Geschlechtergerechtigkeit zu kämpfen:

Wir feministischen Frauen erhoffen uns von dieser Bundeskonferenz, dass Zeichen gegeben werden für eine offensive und konfliktbereite Frauenarbeit in der ASF. Wenn dieses nicht zu erkennen ist, wenn wir nicht anfangen uns zu weigern, Wahlkampfveranstaltungen durchzuführen und Steigbügelhalter für Genossen zu sein, ohne dass unsere Forderungen von der Partei und von der Regierung durchgesetzt werden, dann werden wir für die Gründung einer Frauenpartei mit verantwortlich sein (Edith Mecke-Harbeck, Landesvorsitzende der ASF SchleswigHolstein, auf der Bundeskonferenz 1979, zit. n. SPD-PV 9925).

Dieses Lager fand in der ASF Gleichgesinnte auf der Bezirks- und Landes- und Bundesebene, aber auf den Bundesfrauenkonferenzen und auch im Bundesfrauenausschuss konnten die Feministinnen keine

552 Die Bundesvorsitzende Elfriede Hoffmann unterstützte diese Neuausrichtung nicht, für sie blieb die ASF ein zielgruppenspezifisches Beratungsgremium der Parteiorganisationen: „ASF-Arbeit ist nicht Repräsentation, sondern Information und Überzeugungsarbeit innerhalb und außerhalb der Partei." (Hoffmann 1979: 6)

553 Im Arbeitspapier der Arbeitsgruppe 5 war eine Quote für die Besetzung von Mandaten und Funktionen entsprechend dem weiblichen Mitgliederanteil vorgeschlagen worden (vgl. Dokumente 6/1977).

554 Die ASF erwarte von der Partei und deren Einsatz für eine gerechtere Gesellschaft mehr Engagement als eine bürokratische Maßnahme, erklärte die Hamburger ASF-Vorsitzende und Beisitzende im ASF-Bundesvorstand Christa Randzio-Plath (vgl. RandzioPlath 1979). 
Mehrheiten erreichen. ${ }^{555}$ Ihnen stand das mächtige Lager der parteiführungsloyalen, geschlechtertraditionellen Sozialdemokratinnen gegenüber, bei denen die Selbstbezeichnung „feministisch“ auf heftigen Widerspruch stieß (vgl. z.B. Maria Bayer, Bezirk Weser-Ems, zit. n. AdsD SPD-PV 9923). ${ }^{556}$ Die Bundesfrauenkonferenz 1979 wählte deshalb Elfriede Hoffmann - wenn auch mit knappem Ergebnis (138:117) - erneut zur ASF-Bundesvorsitzenden, und zwar gegen Karin Junker, die Kandidatin der ASF-Feministinnen (vgl. Jansen 1979b).

Trotz Streits und tiefer Gräben zwischen den Lagern beschloss die gleiche Bundeskonferenz, den 8. März als Internationalen Frauentag von der Partei zu fordern, und war bereit, dafür erhebliche Konflikte mit dem Parteivorstand einzugehen ${ }^{557}$.

\subsubsection{Initiativen zur Neukonzipierung sozialdemokratischer Familienpolitik}

Mit den Familienpolitischen Grundsätzen (Familienpolitik 1974) der ASF sollte der SPD ein modernes familienpolitisches Profil gegeben werden. Die Kritik an der Ein-Ernährer-Familie sowie die Förderung der weiblichen Berufstätigkeit waren allerdings in der Partei heftig umstritten ${ }^{558}$. Der Parteivorstand verschob deshalb die Befassung mit den Familienpolitischen Grundsätzen auf den Hamburger Parteitag $1977^{559}$ und damit

555 Die Bundesfrauenkonferenz in Erlangen 1979 habe ein „Bekenntnis zum Feminismus“ (Pausch 1985: 222) abgelegt, schreibt Wolfgang Pausch in seiner Dissertation über die ASF. Ein solches „Bekenntnis“ aber ist nur in den Stellungnahmen einzelner Delegierter und der Erklärung des ASF-Bundesvorstands zu finden. Ein entsprechender Antrag oder eine Erklärung wurde weder auf dieser noch auf den folgenden Bundesfrauenkonferenzen verabschiedet.

556 Zwischen den Lagern wurden stets heftige Streits ausgeführt. Davon zeugt auch ein Appell an solidarische Umgangsformen (vgl. Antrag E3 auf der Bundesfrauenkonferenz 1981 in Dokumente 15/1981: 17f.).

557 Der DGB-Hauptvorstand verbot aus den gleichen Gründen den Kreisfrauenausschüssen zunächst die Mitwirkung an dieser Veranstaltung.

558 Auch der öffentliche gesellschaftspolitische Diskurs war widersprüchlich. Einerseits wurde im Zweiten Familienbericht 1975 die Berufstätigkeit bzw. -rückkehr der Mütter nicht nur zu einem individuellen Recht, sondern auch zu einem wichtigen Erfolgsfaktor für die familiären Sozialisationsleistungen erklärt, andererseits wurde die gestiegene Berufstätigkeit - und auch das gestiegene Bildungsniveau - der Frauen für eine sinkende Gebärbereitschaft der Frauen und damit für die negative demographische Entwicklung der deutschen Bevölkerung verantwortlich gemacht. Die Geburtenrate in der BRD war mittlerweile eine der niedrigsten aller Industrieländer und zudem seit den 196oer-Jahren kontinuierlich gesunken. Seit 1972 lag sie unter der Sterberate. Der Einfluss der Väter auf die Kinderwunschentscheidung wurde in dieser Zeit nicht in den Blick genommen.

559 SPD-Parteitag 15.-19.11.1977 Hamburg. 
auf einen Zeitpunkt, in dem die Reform des Ehe- und Familienrechts das Parlament bereits passiert hatte.

Auf dem Parteitag wurden die Familienpolitischen Grundsätze als Antrag des Parteivorstands vorgelegt. Die Vorlage der ASF war dabei erheblich konservativ überformt worden: Nun wurden die Grundsätze eingeleitet mit einem Bekenntnis zur Ehe und zur Familie; im Mittelpunkt sozialdemokratischer Familienpolitik stand nun das sog. Kindswohl, das durch vorsorgende Familienplanung und -beratung der Eltern zu fördern wäre; statt einer beruflichen Förderung sollten Mütter ihre Emanzipationsansprüche an den „besonderen Schutz des Kindes“ anpassen (Familienpolitik 1977: 11). Auch die im ASF-Dokument erwähnten innerfamiliären patriarchalen Konflikte waren ersatzlos gestrichen worden. Übernommen worden war die neue Familiendefinition der ASF. Damit wurde die Gleichwertigkeit verschiedener familiärer Lebensformen anerkannt. Auch wurden alle rechtlichen Regelungen zur Kleinstkinderbetreuung erstmals für beide Elternteile formuliert. Auch für Väter war nun die Option benannt worden, für die Kindererziehungsphase ganz oder teilweise aus dem Beruf auszusteigen (vgl. Antrag 320 in Parteitag der SPD 1977: 851)

Der Hamburger Parteitag behandelte das Thema Familienpolitik aber nur am Rande. Zwar kündigte der Vorstand zum Parteitagsauftakt die Familienpolitik als „Zukunftsfrage“ (Parteitag der SPD 1977: 12) an, im Tagungsablauf war aber für die Diskussion und Befassung des Antrags kein Raum vorgesehen worden. Die ASF erhielt deshalb keine Gelegenheit, ihre Grundsätze vorzustellen und zu erläutern; stattdessen wurde der Antrag am späten Abend eines langen Sitzungstags zwar angenommen, aber eher durchgewunken ${ }^{560}$. Auch frauenpolitischen Initiativen gegenüber zeigte sich der Parteitag 1977 wenig aufgeschlossen. Verschiedene ASF-Gruppen hatten im Vorfeld erreicht, dass ihre Forderungen in Anträgen von Unterbezirken, Bezirken und Landesverbänden aufgenommen worden waren. Von der Mehrheit der Delegierten aber wurden die Anträge zur Quotierung von Arbeits- und Ausbildungsplätzen in öffentlichen Unternehmen, zur Bestellung von besonderem Beratungspersonal für Frauen beim Arbeitsamt und zu frauenbeschäftigungsfördernden Auflagen für Firmen bei der öffentlichen Auftragsvergabe entweder abgelehnt oder als Materialien an die Bundesfraktion oder den Vorstand

56o Eröffnet wurde die Debatte auf dem Parteitag dazu erst am vierten Verhandlungstag kurz vor 24:0o Uhr, sodass ein verkürztes Verfahren entschieden wurde. Als die ASFVorsitzende Elfriede Hoffmann dagegen protestierte, kommentierte der Vorsitzende Armin Clauss, „es hat somit auch einer dagegen gesprochen“, und stellte den Antrag zur Abstimmung (vgl. Parteitag der SPD 1977: 632). 
überwiesen ${ }^{561}$. Trotzdem wertete die ASF die Annahme des familienpolitischen Antrags als politischen Erfolg. Sie musste allerdings bald feststellen, dass die neuen familienpolitischen Grundsätze von der Partei weitgehend ignoriert wurden und sich in den sozialdemokratischen Programmen und Politikentwicklungen selten wiederfanden. Um die familienpolitische Neuausrichtung der Partei auf die parteiinternen Agenden zu setzen, forderte die Siegener ASF-Bundeskonferenz 1979 den Parteivorstand auf, das Thema Familienpolitik erneut auf die Tagesordnung des nächsten Parteitags ${ }^{562}$ zu setzen. Aber auch auf diesem Parteitag fand die Familienpolitik wenig Interesse. Nach einem Referat Antje Hubers zu bereits fortgeschrittener Stunde ließ die Tagungsleitung die Redezeit halbieren, um in dem sich leerenden Saal überhaupt noch eine Diskussion zu realisieren.

An dieser beteiligten sich fast nur Genossinnen (vgl. Vorstand der SPD 1980). Auch eine auf dem Parteitag von Willy Brandt angekündigte Familienkonferenz fand nicht statt (vgl. Parteitag der SPD 1979: 45.).

Nach dem Wahlkampf 1980 resümierte der ASF-Bundesvorstand bitter, die SPD habe die Chance verpasst, den familienpolitischen Konzepten der CDU/CSU politisch entgegenzutreten und sich gegen den konservativen Antifeminismus als politische Alternative zu profilieren (vgl. Rechenschaftsbericht 1981: 12f). Zum Unmut der ASF trug erheblich bei, dass sie bei diesem Wahlkampf auch nach mehrfachen Anfragen nicht an der Wahlkampfkommission beteiligt worden war und die ASF-Materialien und Broschüren zum Wahlkampf über die Partei vergleichsweise schlecht verteilt wurden (vgl. Rechenschaftsbericht 1981: 21f.).

Die geringe Beachtung ihrer politischen Initiativen war für die ASF auch gemessen an der Resonanz der Frauenunion in der CDU unakzeptabel. Von der CDU wurde seit 1979 ein Institut Frau und Gesellschaft unter der Leitung von Rita Süssmuth finanziert, das den Auftrag hatte, politische Konzepte der Gleichberechtigung auf der Basis des Wahlfreiheitsparadigmas zu entwickeln. 1985 wurde ein CDU-Bundes-parteitag ${ }^{563}$ organisiert, der sich schwerpunktmäßig mit frauenpolitischen

561 Vgl. folgende Anträge: Antrag 352 Landesverband Schleswig-Holstein in Parteitag der SPD 1977: 341; Antrag 518 LV Baden-Württemberg in a.a.O.: 911; Antrag 590 UB Gelsenkirchen in: a.a.O.: 937; Antrag 593 Bezirk Franken in a.a.O.: 938.

562 Außerordentlicher Parteitag vom 9.bis 10.06.1980 in Essen.

563 Der 33. Bundesparteitag der CDU in Essen am 20. 03. 1985 stand unter dem Motto „Die neue Partnerschaft - Frauen in Beruf, Familie, Politik“. Er verabschiedete den Leitantrag „Partnerschaft 2000“. In dem mehrseitigen Dokument forderte der Parteitag die Überwindung der Geschlechterrollen in Beruf und Familie sowie die staatliche Förderung der beruflichen Chancengleichheit für Frauen. Gefordert wurden auch eine erhöhte Partizipation der Frauen in der eigenen Organisation und eine Würdigung der 
Themen beschäftigte - einen solchen Parteitag forderte die ASF erfolglos von ihrer Parteiführung. Auf diesem CDU-Parteitag wurde beschlossen, bei Mandaten und in Funktionen eine Repräsentanz der Frauen entsprechend ihrem Mitgliederanteil anzustreben ${ }^{564}$.

\subsubsection{Politiken gegen Frauenarbeitslosigkeit und Arbeitsmarktdiskriminierung}

Die Arbeitslosigkeit, die sich seit Anfang der 1970er-Jahre entwickelte, betraf besonders Frauen, sowohl auf dem Ausbildungsmarkt als auch auf dem Arbeitsmarkt ${ }^{565}$. Zunehmend entstand für Frauen ein Markt der Teilzeitbeschäftigungen, verbunden mit geringerer Entlohnung und wenig beruflichen Entwicklungsmöglichkeiten. Die ASF fürchtete, dass Frauen vermehrt in die sog. stille Reserve abwanderten, weil sie sich aufgrund ihrer aussichtslosen Erwerbswünsche als Arbeitssuchende abmeldeten (vgl. Dokumente 15/1981). Die Siegener Bundeskonferenz 1977 verabschiedete einen Forderungskatalog zur Verbesserung der weiblichen Erwerbstätigkeit. Für seine Realisierung setzte die ASF auf eine Kooperation mit Gewerkschaftsfrauen. Sie hatten sich im DGB und den großen Einzelgewerkschaften zunehmend Gehör verschaffen können ${ }^{566}$. Gemeinsam mit den Gewerkschaftsfrauen wollte die ASF die Abschaffung der Leichtlohngruppen ${ }^{567}$ erreichen sowie gegen den wachsenden Markt

Neuen Frauenbewegungen. Unverändert dagegen blieb die hohe gesellschaftliche Bedeutung der Familie, man sah sogar eine „Wiederentdeckung der Familie durch junge Leute“. Die „Gewalt gegen Frauen“ wurde verurteilt, aber die Familie und Ehe als vorherrschende Orte dafür nicht benannt. Die weibliche Berufstätigkeit wurde nicht als ein zentrales gesellschaftspolitisches Problem thematisiert, vielmehr war sie eine von mehreren möglichen Lebensoptionen von Frauen. Deshalb sollte die Wahlfreiheit zwischen Beruf und Familie erreicht und gesichert werden (vgl. Leitsätze CDU 1985).

564 Behrendt-Weiß o.A.\{2002\}

565 Gemeldete Arbeitslose im März 1980: Männer: 3,o \%, Frauen 5,o \% (vgl. Doormann 1980: 13).

566 Dazu trugen die vermehrten Gewerkschaftsbeitritte der Frauen bei. Während der Mitgliederstand der Männer im DGB von 1970 von 5,6 Mio. auf 6 Mio. wuchs, stieg die Mitgliederzahl bei den Frauen von 1970 1 Mio. auf 1989 1,8 Mio. und damit nahezu auf das Doppelte an (Zahlen aus Müller-Jentsch/Ittermann 2000: 93).

567 In den 1970er-Jahren waren - ungeachtet des EU-Rechts - noch in über 100 Tarifverträgen zwischen Arbeitgeberverbänden und Industriegewerkschaften Leichtlohngruppen ausgehandelt worden. Sie hatten den bis in die 1950er-Jahre üblichen Frauenlohn ersetzt. Die Tarife dieser Lohngruppen lagen bis zu $25 \%$ unter dem untersten Hilfsarbeiterlohn (vgl. Dokumente 4/1975: 5). Die SPD-Bundesfraktion unterstützte die Abschaffung dieser Niedriglöhne. Bundesarbeitsminister Walter Arndt 
der nichtversicherten Teilzeitbeschäftigungen angehen und forderte eine allgemeine Sozialversicherungspflicht. Die Unterstützung der Gewerkschaftsfrauen für die Sozialdemokratinnen blieb jedoch eher verhalten; eine arbeitsmarktpolitische Kampagne zur prekären Lage der Frauen in der Wirtschaftskrise konnte die ASF in der Partei auch wegen dieser geringen Resonanz aus den Gewerkschaften nicht durchsetzen ${ }^{568}$. Zur gleichen Zeit entwickelte sich die Jugendarbeitslosigkeit, sie war ein in der Wirtschaftskrise neu entstandenes gesellschaftspolitisches Thema. Auf einem Forum „Jugendarbeitslosigkeit" im Oktober $1979^{569}$ hatten die Sozialdemokratinnen durchgesetzt, dass besonders die überdurchschnittlich hohe Arbeitslosigkeit weiblicher Jugendlicher zum Kernthema der Tagung wurde (vgl. AdsD SPD-PV 10343). Eine von der ASF mit angestoßene Kampagne „Öffnung neuer Berufswege für Mädchen "im gleichen Jahr zielte auf eine veränderte Beratungspraxis bei den Arbeitsämtern und den AusbildungsberaterInnen der Industrie- und Handelskammern und Kreishandwerkerschaften und wurde durch die Bundesregierung finanziert. Ein Bundesprogramm finanzierte außerdem Modellprojekte, die Maßnahmen zur Erweiterung des Berufswahlspektrums für Mädchen entwickelten. Verschiedene Bundesländer starteten Initiativen, um Schulabgängerinnen auf gewerblich-technische Berufsausbildungen aufmerksam zu machen. Berufswechslerinnen konnten Umschulungen wahrnehmen, die ihnen Zugänge zu den bisher männerdominierten Berufen erschlossen ${ }^{570}$.

Viel Resonanz fand eine im gleichen Jahr 1979 durchgeführte Befragungsaktion der ASF zur „Diskriminierung der Frauen bei Ausschreibungen durch öffentliche Arbeitgeber" 571 . Die Veröffentlichung der Ergebnisse veranlasste verschiedene Bundesministerien, Landesbehörden und kommunale Spitzenverbände, ihre Rekrutierungsverfahren zu überprüfen und ihre zuständigen Fachkräfte anzuweisen, Stellenanzeigen zukünftig explizit für männliche und weibliche BewerberInnen auszuschreiben. In der SPD selbst war eine geschlechterbezogene Schreibweise bei Stellenangeboten bereits seit Mitte der 1970er-Jahre verbindlich. 1977 hatte der

gab ein Rechtsgutachten gegen die Praxis solcher Tarifeinführungen in Auftrag (vgl. ASF-Bundesvorstand 1975: 27).

568 Die Schwierigkeiten einer politischen Kooperation mit den Gewerkschaftsfrauen schildert die Zeitzeugin 11. In den Archiven finden sich keine Dokumente, die auf Kooperationsaktivitäten hinweisen.

569 25./26.10.1979 Forum „Jugendarbeitslosigkeit“.

570 Diese Maßnahmen zielten vor allem auf das Berufsentscheidungshandeln der Frauen, weniger auf eine Veränderung der Arbeitsbedingungen. In der Folge waren die InitiatorInnen mit hohen Abbrecherinnenquoten konfrontiert (vgl. Zahlen dazu in Stegmann/Kraft 1986).

571 Die Dokumentation war in den Archiven nicht mehr auffindbar. 
SPD-Bundesgeschäftsführer außerdem erklärt, Frauen bei gleicher Qualifikation bevorzugt einzustellen (vgl. Jahrbuch der SPD \{1977-79\}: 287).

\subsubsection{Frauen- und familienpolitische Reformen der sozialdemokratischen Regierungspolitik}

Während der sozialliberalen Regierungskoalition wurden in den 197oerJahren unterschiedlich erfolgreiche Reformgesetzgebungen zur Frauenund Familienpolitik realisiert.

Die Reform des § 218 durch eine Fristenregelung, die den Schwangerschaftsabbruch bis zur 12. Woche straffrei stellte, scheiterte an einer erfolgreichen Klage vor dem Bundesverfassungsgericht, die die CDU-Bundestagsabgeordneten und unionsregierte Bundesländer veranlasst hatten, und die anschließende Indikationsregelung erklärte den Schwangerschaftsabbruch erneut zur Straftat. Die öffentlichen Hilfen zur Berufsausbildung durch das neue Berufsausbildungsförderungsgesetz 1971 unterstützten die Fortführung der Ausbildung an weiterführenden und berufsbildenden Schulen. Sie sollten besonders das Bildungsniveau junger Frauen heben. Aber diese Maßnahmen wurden ebenso wenig genutzt wie die Fortbildungsangebote für Mütter, die ihre Wiedereingliederung unabhängig vom Einkommen des Ehemannes fördern sollten ${ }^{572}$ (vgl. Pross 1972; Janssen-Jurreit 1979: 55-100). Eine Rentenreform konnte der weiblichen Altersarmut wenig entgegensteuern ${ }^{573}$. Für Kriegswitwen brachte das Gesetz über die Anpassung der Leistungen nach dem Bundesversorgungsgesetz 1970 nur denjenigen Frauen eine Erhöhung der Rentenbezüge, die eine mehrjährige Erwerbstätigkeit nachweisen konnten (1. AnpG KOV). Das Rentenreformgesetz 1972/73 ließ Frauen mit rückwärtigen Rentenkasseneinzahlungen eigenständige Rentenansprüche aufbauen, die erforderlichen Aufwände dafür waren jedoch so erheblich, dass diese Öffnung des Rentensystems für Hausfrauen kaum in Anspruch genommen wurde.

572 Nach Claudia Pinl waren solche gesellschaftlichen Veränderungen nicht durch politische Maßnahmen oktroyierbar: „Frauen sind schlechter ausgebildet als Männer, weil die Gesellschaft sie nicht als Facharbeiterinnen oder leitende Angestellte braucht, sondern als Hausfrauen, Mütter und nicht ständig beschäftigte Hilfsarbeiterinnen. Reformerische Schritte sind daher nur erfolgversprechend, wenn eine starke Frauenbewegung sie begleitet" (Pinl 1979: 95).

573 Vor der Rentenreform 1972/73 lagen die Bezüge von 87 \% der Rentnerinnen im Durchschnitt unter 300 DM im Monat, im Vergleich dazu bezogen Rentner durchschnittlich 529 DM aus der Arbeiterrentenversicherung (vgl. SPIEGEL o.V. 1972b). 
Mit größerem Erfolg setzte die sozialliberale Koalition in dieser Zeit familienpolitische Reformen durch. Dazu zählte u.a. die Gleichstellung der nichtehelichen mit den ehelichen Kindern durch das Nichtehelichengesetz (NEhelG). Ab dem 1. Juli 1970 konnte die Mutter eines nichtehelichen Kindes nun das volle Sorgerecht beanspruchen ${ }^{574}$, ihr Kind erhielt gleichberechtigte Unterhaltsansprüche an den Vater sowie einen eingeschränkten Erbanspruch auf seinen Nachlass. Ab 1971 waren alle Kinder und ihre Begleitungen auf den Schulwegen kostenfrei unfallversichert. 1973 wurde das Mindestalter von Adoptionseltern herabgesetzt. Ab 1974 ermöglichte die Einführung von Pflegetagen eine Freistellung von bis zu fünf Tagen bei der Erkrankung eines Kindes unter acht Jahren, darüber hinaus das Recht auf Freistellung oder Teilzeitbeschäftigung bei der Betreuung pflegebedürftiger Familienangehöriger und die Finanzierung einer Haushaltshilfe bei Krankenhaus- oder Kuraufenthalt sowie bei der Betreuung behinderter Kinder. 1979 wurde der viermonatige Mutterschaftsurlaub mit Arbeitsplatzgarantie und Kündigungsschutz eingeführt, für den eine Lohnersatzleistung aus Bundesmitteln gezahlt wurde ${ }^{575}$. Weitere familienpolitische Reformen der 1970er-Jahre betrafen Unterstützungsleistungen, z.B. wurde ab 1975 das Kindergeld bereits ab dem ersten Kind bewilligt und der Steuerfreibetrag für Alleinerziehende erhöht. Für Alleinerziehende, zu über $80 \%$ Frauen $^{576}$, wurden in den Jugendämtern Unterhaltsvorschusskassen eingerichtet, die ab 1980 überbrückend Unterhaltszahlungen leisteten, falls das unterhaltspflichtige Elternteil die Zahlungen verweigerte.

Die Reform des Ehe- und Familienrechts $1977^{577}$ beendete das patriarchale Familienrecht und schrieb der Ehefrau die alleinige Entscheidungsverantwortung über ihre Berufstätigkeit zu. Durch die Reform des Namensrechts ${ }^{578}(1976,1979)$ konnte nun auch der Name der Ehefrau als Familienname gewählt werden. Mit dieser Reform konnten Ehen vor allem nun nach dem Zerrüttungsprinzip geschieden werden. Dafür zuständig waren neu eingerichtete Familiengerichte, eine aufwendige juristische Schuldfeststellung entfiel, gegenseitige Unterhaltsansprüche bemaßen sich an der Bedürftigkeit.

So hatte 1980 die sozialliberale Koalition für die Einrichtung von Unterhaltsvorschusskassen gesorgt, mit denen die Jugendämter die Zah-

574 Zuvor hatte generell das Jugendamt den „fehlenden“ männlichen Vormund ersetzt.

575 Vgl. Darstellung unter http://www.bmfsfj.de/BMFSFJ/ Ministerium/geschichte.html [Zugriff: 03.01.2011].

576 Vgl. Ausführungen dazu in Gender Datenreport 2005: 253.

577 1977: Erstes Gesetz zur Reform des Ehe- und Familienrechts (1. EheRG).

578 1976: Reform des Ehe- und Familienrechts - Einführung der Wahl des Ehenamens; 1979: Gesetz über die Änderung des Ehenamens (EheNÄndG). 
lungsunwilligkeit von EhepartnerInnen für den Kinderunterhalt überbrücken konnten. Als die Kohl-Regierung eine Einschränkung der Zahlungspflichten geschiedener Ehemänner vorbereitete, initiierte die SPDBundestagsfraktion zusammen mit der Rechtsanwältin Dr. Barbelies Wiegmann die Aktion „Kassensturz“. Mehr als 1.500 geschiedene Frauen schrieben Briefe an den Rechtsausschuss des Deutschen Bundestages, in denen sie ihre wirtschaftlich schwierige Situation nach der Scheidung schilderten (vgl. Jahrbuch der SPD \{1984-85\}: 70).

\subsection{Die Institutionalisierung der Gleichstellungspolitik und die neue Attraktivität der Frauenpolitik für das Parteiprofil (1979-1985)}

Das „Goldene Zeitalter“ der Sozialdemokratie kam nach Thomas Meyer im Verlauf der 1970er-Jahre an ein Ende (vgl. Meyer 1998: 63). Insgesamt verlor die SPD Wahlstimmen und Mitglieder, allerdings mit deutlichem Unterschied zwischen den Geschlechtern: Die Wählerinnenzustimmung ging zunächst weniger stark zurück ${ }^{579}$ und während die Partei ab 1976 insgesamt schrumpfte, stieg die Anzahl ihrer weiblichen Mitglieder an und ließ den Frauenanteil in der Parteimitgliedschaft kontinuierlich anwachsen.

579 Vgl. Tab. 8 Bundestagswahlergebnisse nach Geschlecht und Alter 1953-1987 unter DOI 10.3224/86388794A. Bei den Bundestagswahlen 1980 und 1983 stimmten mehr Frauen für die SPD als Männer. 
Abb. 4: Entwicklung des Frauen- und Männeranteils in der Mitgliedschaft der SPD580

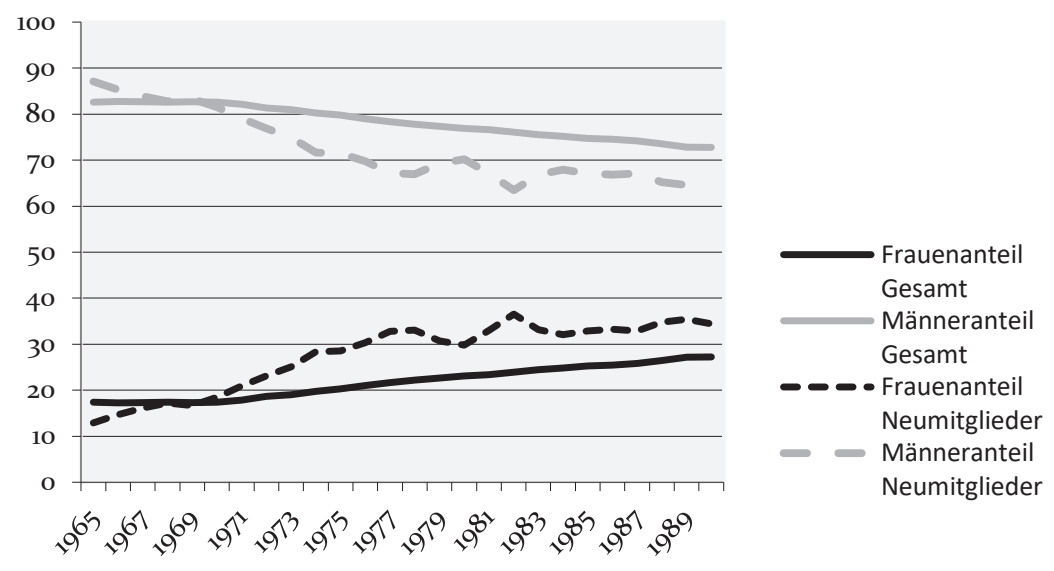

Quelle: Eigene Darstellung.

Die Frauenarbeitsgemeinschaft versuchte, diese positive Resonanz in der weiblichen Bevölkerung zu nutzen, um in der SPD ihre Forderungen nach Teilhabe und Veränderung der Frauenpolitik zu forcieren. In den Parteiführungen wuchs die Unterstützung gleichstellungspolitischer Ziele an, parteiintern aber blockierten eingespielte Ausschließungspraktiken vielfach weiterhin die Teilhabe der Frauen an der Partei und der Politikgestaltung.

Erst die Krise der Regierungspartei und die Suche der innerparteilichen Flügel nach einer politischen Neuausrichtung der Partei verschafften den frauenpolitischen AkteurInnen eine höhere politische Aufmerksamkeit und neue Mitwirkungsmöglichkeiten.

Die ASF gewann einflussreiche männliche Bündnisgenossen in verschiedenen politischen Lagern der Partei dazu. Diese Unterstützer sahen in den engagierten Frauen und ihren Ideen ein Potenzial für die Modernisierung der Partei. Mit diesen neuen Mehrheiten wurden erste institutionelle Maßnahmen eingeführt, die die Partei auf Gleichstellungspolitik verpflichteten. Parallel zu dieser parteiinternen Entwicklung entstand im öffentlichen Dienst eine gleichstellungspolitische Infrastruktur aus Frauen- oder Gleichstellungsbeauftragten. Zunächst in sozialdemokra-

580 Vgl. Tab. 5 Entwicklung der SPD-Mitgliedschaft nach Geschlecht unter DOI $10.3224 / 86388794$ A. 
tisch bestimmten oder mitbestimmten Landesverwaltungen implementiert, richteten im Verlauf der 1980er-Jahre auch immer mehr Kommunen Frauenbüros ein.

\subsubsection{Frauenförderung als Organisationsaufgabe}

Nachdem die UNO das Jahr 1975 zum „Jahr der Frau“ ausgerufen hatte, deklarierte die SPD Frauenpolitik als eigenständiges Handlungsfeld der vierten sozial-liberalen Regierungskoalition (vgl. Jahrbuch der SPD 19751977). Die Wahlen auf dem Hamburger Parteitagg ${ }^{581}$ ließen die Zahl der weiblichen Mitglieder im Parteivorstand auf zwei Frauen sinken, d.h. auf die nach den ehemaligen Statuten vorgeschriebenen Mindestzahl, der Frauenanteil der SPD-Fraktion im 8. Bundestag war der niedrigste aller regierungsbeteiligten Parteien ${ }^{582}$.

Nun richtete der Parteivorstand eine Kommission aus Mitgliedern des Parteivorstands und des ASF-Bundesvorstands ein, die ab Februar 1978 als Arbeitsgruppe Gleichstellung der Frau ${ }^{583}$ tagte. Sie erarbeitete eine organisationspolitische Reform, die dem nächsten Parteitag 1979 in Berlin $^{584}$ zur Abstimmung vorlag. Der sog. Gleichstellungsbeschluss (Antrag 325$)^{585}$ sah zwei Maßnahmen vor: Dazu zählte die Einführung eines Berichtswesens, das alle Organisationseinheiten verpflichtete, bis 1984 auf Bezirks-, Landes- und Bundesparteitagen Rechenschaftsberichte über den Stand der Beteiligung der Frauen auf der jeweiligen Parteiebene zu erstellen, und außerdem sollten frauenfördernde Aktivitäten auf allen Parteiebenen entwickelt und in Zwei-Jahres-Förderplänen mit expliziten Zielangaben ${ }^{586}$ konkretisiert werden.

581 Parteitag in Hamburg 15.-19.11.1977

582 Vgl. Tab 12 Frauenanteil bei den Abgeordneten im Deutschen Bundestag 1949-1994 nach Parteien (in Prozent) zu Beginn der Wahlperiode unter DOI 10.3224/86388794A.

583 Vorsitz: Willy Brandt, Elfriede Hoffmann; als Vertretung des Parteivorstands: Egon Bahr, Herbert Ehrenberg, Antje Huber, Werner Vitt, Hans-Jochen Vogel; als Vertreterinnen des ASF-Bundesvorstands: Karin Hempel-Soos, Inge Kräft, Ursula Pausch-Gruber, Sigrid Skarpelis-Sperk, Inge Wettig-Danielmeier (vgl. SPD-PV9921, Anlage 18).

584 Parteitag in Berlin 3.-7.12. 1979.

585 Antrag des Parteivorstands 325 (vgl. Parteitag der SPD 1979: 1588f.). Für die Berichte war zu erheben: weibliche Mitgliederanteile an Delegationen, Vorstand, Kommissionen sowie der Frauenanteil an Mandaten; Anteil der Frauen an der Außendarstellung; Beteiligung an den Schulungsangeboten.

586 Zielangaben umfassten den angestrebten Frauenanteil in Ämtern und Funktionen, die zukünftige Bestellung von Referentinnen, die Ausweisung finanzieller Mittel für die Frauenarbeit der Organisationseinheit sowie die kontinuierliche Behandlung frauenund familienpolitischer Themen auf Parteiveranstaltungen. Nach Christa Randzio- 
Zusätzlich zu diesem Antrag des Parteivorstands lag dem Parteitag eine Fülle weiterer frauenpolitischer Anträge ${ }^{587}$ vor, denn mittlerweile hatten die ASF-Frauen in den Bezirken und Landesverbänden zunehmend UnterstützerInnen gewinnen können. In ihnen wurden weitgehendere Partizipationsrechte der ASF gefordert, wie z.B. die Ausstattung der ASF-Arbeitsgemeinschaften mit eigenen Budgets, Sitz und Stimme für die ASF-Vertreterinnen in den Vorständen der Partei, gesicherte Beteiligung der ASF an allen Programmarbeiten und bei den KandidatInnenaufstellungen, Frauenreferate und Frauengruppen auf allen Parteiebenen, Kinderbetreuung bei allen Parteiveranstaltungen, die Finanzierung regelmäßiger Veranstaltungen, die die ASF-Frauen für die gesamte Partei und in Eigenverantwortung ausrichten sollten. Während der Berliner Parteitag 1979 den Antrag 325 des Parteivorstands - wenn auch ohne Debatte - annahm, wurden die Anträge aus der Partei als Materialien an die Bundestagsfraktion überwiesen, selbst wenn sie überwiegend organisationspolitische Forderungen enthielten ${ }^{588}$.

Auf dem folgenden Münchner Parteitag $1982^{589}$ wurde den Delegierten der erste Bericht zur Gleichstellung der Frauen in der Partei vorgelegt. Allerdings waren nur 13 der 22 Bezirke der gebotenen Berichtspflicht nachgekommen. In einzelnen Ortsvereinen waren Frauenförderpläne entwickelt worden, 1o Bezirke hatten Kommissionen bzw. Arbeitsgruppen zur Förderung der innerparteilichen Gleichstellung eingerichtet, aber kein Bezirk war der Aufforderung zu einer aktiven Förderung der Frauenarbeit nachgekommen (vgl. Pausch 19895: 251; Jahrbuch der

Plath konnten damit in einzelnen Parteigliederungen erstmals frauenpolitische Themen wie z.B. die Bedeutung der Frauenhäuser, die soziale Sicherung der Frauen im Alter, der Elternurlaub auf die politische Agenda gesetzt werden (vgl. Randzio-Plath 1980)

587 Antrag 326 Bezirk Hessen Gleichstellung der Frauen in der SPD, Antrag 327 Landesorganisation Hamburg Verbesserung der Stellung der Frau in der SPD, Antrag 432 Ortsverein Bonn-Nord Maßnahmen zum Abbau der Benachteiligung von Frauen, 435 Ortsverein Bonn-West Gleichstellungskommission, Antrag 436 Unterbezirk Duisburg Gleichstellung der Frau in der Arbeitswelt, Antrag 437 Ortsverein Eutingen Ausweitung des Mutterschutzurlaubsgesetzes auf Hausfrauen (750 DM für sechs Monate nach der Geburt auch an nicht Berufstätige), Antrag 438 Ortsverein Eutingen HausfrauenRente (gleiche Rentenansprüche für beide Ehepartner), Antrag 439 Kreisverband Rendsburg-Eckernförde Unterstützung gewerkschaftlicher Forderungen (gleicher Lohn für gleichwertige Arbeit), Antrag 440 Ortsverein Bonn-Nord Änderung von Ausweisungsverfahren (keine Bevorzugung binationaler Ehen mit deutschstämmigen Ehemännern).

588 Der Antrag 325 war Teil eines Antragspakets und rutschte im Abstimmungsverfahren ohne Debatte in die Annahme (vgl. dazu auch Honnen 1988). Möglicherweise wäre ein anderes Verfahren nicht erfolgreich gewesen, dieses aber trug sicherlich dazu bei, dass er in der Partei wenig Breitenwirkung hatte.

589 Parteitag in München 19.-23.04.1982. 
SPD \{1982-83\}). Aufgrund der geringen Beteiligung und der fehlenden gleichstellungspolitischen Aktivitäten beschloss der Parteivorstand, die Berichtspflicht von 1984 auf 1988 zu verlängern. Auf dem nächsten ordentlichen Parteitag in Essen ${ }^{590} 1984$ konnte die ASF-Vorsitzende Inge Wettig-Danielmeier von konkreten Förderplänen in verschiedenen Bezirken berichten.

\subsubsection{Ausschließungserfahrungen bei der KandidatInnenwahl für öffentliche Ämter}

Der Parteivorsitzende Willy Brandt ${ }^{591}$ unterstützte die Forderung nach einer größeren Partizipation und die Kritik der ASF, dass die geringe Beteiligung der Frauen an Partei und Politik durch aktive Ausschließung verursacht würde:

Wenn ich nicht sehr irre, beginnt sich bei zahlreichen Männern in unserer Partei so etwas wie betretene Unsicherheit breitzumachen: Unsicherheit darüber, ob es wirklich so weitergehen kann, dass Frauen bei der Besetzung öffentlicher Ämter - auch bei Wahlen zu den Körperschaften unserer Partei - in extremer Weise übergangen werden. (Willy Brandt 1974 zit. n. Dokumente 4/1974)

Aber im Parteialltag bestimmten etablierte informelle Netzwerke die Aufstellung der KandidatInnenlisten, deren Mitglieder sich gegenseitig die Posten sicherten:

[I]n unserem Bezirk war das doch so: Also wir hatten in den großen Wahlgremien, wenn also dann die Kandidaten gewählt wurden, dann hatten wir die IG Metall und die IG Bergbau und die ,IG Stadtverwaltung' (lacht), die hatten wir; und die hatten untereinander eine Quote, die hatten sich schon abgesprochen; [...] wer da mitschwamm, der hatte einen sicheren Platz, war also vollkommen klar. Und eine Frau brauchte immer eine Querbeetmehrheit; das heißt, [...] außerhalb dieser Ströme musste sie bekannt sein (Zz 1).

590 Parteitag in Essen 17.-21.05.1984.

591 Willy Brandt wird von den ZeitzeugInnen als wichtigster Unterstützer der ASF benannt. Er empfahl bereits Anfang der 1970er-Jahre eine Quotenregelung und setzte sich auf Parteitagen mehrfach für die Wahl weiblicher Vorstandsmitglieder ein. 
Zu ebenfalls nicht unüblichen parteiinternen Ausschließungspraktiken gehörte das Verdrängen weiblicher Kandidaten durch Spitzenpolitiker, nachdem diese nach dem mehrstufigen Wahlverfahren und meist auch aufgrund ihres persönlichen Einsatzes für die Partei aufgestellt worden waren. Einzelne spektakuläre Fälle wurden von der Presse aufgegriffen. Als z.B. Parteivorstands- und Präsidiumsmitglied Hans-Jochen Vogel im bayerischen Landtagswahlkampf 1974 eine junge Kandidatin ${ }^{592}$ von der Liste verdrängte, auch gegen den Protest der Landes-ASF beim Parteivorstand, kritisierte DER SPIEGEL die Eitelkeit eines Spitzenpolitikers, der eine junge Sozialdemokratin ausstach, um „seinen Spitzenplatz auf der bayrischen Landesliste auch noch mit einem Direktmandat zu garnieren“ (DER SPIEGEL 26/1976: 38). Die stellvertretende Bundesvorsitzende der ASF Christine Schmarsow fühlte sich vor der Bundestagswahl 1983 vom SPD-Parteivorstand "abserviert“ (Schmarsow 1982). Ihren als sicher geltenden Wahlkreis erhielt Ingrid Matthäus-Meier ${ }^{593}$, die sich für den ihrem Wohnsitz nahen Wahlkreis 64 entschied und ebenfalls den Widerspruch der ASF ignorierte ${ }^{594}$. Christine Schmarsow protestierte daraufhin mit einem offenen Brief in der Frankfurter Rundschau gegen dieses „unwürdige Manöver“ der Partei (a. a. O.) ${ }^{595}$. Auch dem Bundesgeschäftsführer Peter Glotz, der stets als Fürsprecher für eine stärkere Partizipation von Frauen in Partei und Politik auftrat, warfen bayrische ASFGenossinnen vor, eine aussichtsreiche Kandidatin durch seine Einsetzung „,von oben“, d.h. durch den Parteivorstand, verdrängt zu haben (vgl. Bericht Birgit Grube auf dem Parteitag der SPD 1984 in Parteitag 1984: 336).

Wurden Frauen als Kandidatinnen aufgestellt, erhielten nur wenige ein Direktmandat in einem aussichtsreicheren Wahlkreis, kritisierte die ASF-Vorsitzende Inge Wettig-Danielmeier auf dem Essener Parteitag 1984. Überdies würden die Wahlkandidatinnen eher solchen Wahlkreisen zugeordnet, die abgelegen und mit langen Wegstrecken verbunden waren oder in denen sie nur wenig aktive Parteieinheiten vorfinden

592 Sigrid Skarpelis- Sperk hatte sich an der Erstellung des Landeswahlprogrammes beteiligt.

593 Ingrid Matthäus-Meier war eine der abtrünnigen FDP-Abgeordneten, die nach dem Bruch der Regierungskoalition durch die FDP ihre Partei verließen. Für den Übertritt in die SPD hatte der Parteivorstand diesen Abgeordneten sichere KandidatInnenplätze für die nächste Bundestagswahl 1983 zugesagt.

594 Die Partei erhoffte sich von der in den Medien präsenten Ex-FDPlerin eine größere öffentliche Aufmerksamkeit und änderte ihre Personalentscheidung. Johannes Rau erklärte dazu auf einer Bezirksveranstaltung, sie „hätten ja Tinte gesoffen“, wenn sie auf diese Kandidatur verzichteten (aus einem Leserbrief: vgl. Hohenstein 1982).

595 Christina Schmarsow kandidierte nach diesen Erfahrungen nicht erneut für ein Bundestagswahlmandat. 
konnten ${ }^{596}$. Drei Viertel aller weiblichen Bundestagsabgeordneten des 10. Deutschen Bundestags waren deshalb über Listenplätze in ihre Position gelangt. Der Weg über die Parteiliste verringerte die Chancen der Frauen auf ein Mandat aber erheblich, denn die Hälfte der Parlamentssitze war per Gesetz den DirektkandidatInnen vorbehalten. Zudem koppelten sich die Aussichten auf ein solches Mandat an die Misserfolge der aufgestellten DirektkandidatInnen.

\subsubsection{Durchsetzungsprobleme bei der innerparteilichen Gleichstellungsverpflichtung}

Viele frauenpolitische Impulse gingen in den Zwischenräumen zwischen Antragerstellung, Beschlussfassung und Politikentwicklung verloren. Anträge konnten von den ASF-Arbeitsgemeinschaften in den Parteieinheiten erfolgreich durchgekämpft werden, hatten die selektiven Filter der Antragskommission erfolgreich passiert und fanden auf dem Parteitag mehrheitliche Zustimmung - und verschwanden wirkungslos, z.B. das Programm zur Meinungsbildung, eine Studie, mit der „überholte Vorstellungen von der Rolle der Geschlechter" erforscht und Maßnahmen zur Veränderung erarbeitet werden sollten (Parteitag der SPD 1979: Beschlüsse: 61). Parteibeschlüsse hatten nur dann eine Wirkung auf das innerparteiliche Geschehen oder gar auf die Regierungspolitik, wenn sich in den jeweils zuständigen Gremien ProtagonistInnen fanden, die für ihre Umsetzung sorgten.

Ab den 1980er-Jahren verstärkten die ASF-Frauen daher ihre Bemühungen, frauenpolitisch engagierte Kandidatinnen für Parteifunktionen und politische Ämter aufzustellen und für sie im Vorfeld der Personalentscheidungen durch vielfältige Netzwerkaktivitäten ausreichend Unterstützung zu organisieren. Mitstreiterinnen in den Gremien der politischen Gestaltung und Entscheidungsfindung in der Partei zu platzieren, war jedoch auch nach den beschlossenen gleichstellungspolitischen Selbstverpflichtungen der Partei schwer durchzusetzen.

Als auf dem Berliner Parteitag 1979 der Parteivorstand gewählt wurde, erhielten die vom Parteivorstand vorgeschlagenen Kandidatinnen trotz Gleichstellungsbeschluss nicht die erforderlichen Stimmen. Auf die Aufstellung dieser sechs Bewerberinnen hatten sich Partei- und ASF-Bundesvorstand im Vorfeld des Parteitags geeinigt597 (vgl. Pausch

596 Diese systematische Benachteiligung der Parteikandidatinnen durch ihre Aufstellung in wenig aussichtsreichen Wahlkreisen bestätigt Peter Schindler (vgl. Schindler 1999: 638f.; dazu auch Fuchs 2006).

597 Ursprünglich hatte die ASF 10 Kandidatinnen vorgeschlagen. 
1985). Sie waren auf dem Parteitag schließlich nur durchsetzbar, weil die Vorstandssitze von 36 auf 40 erweitert wurden (vgl. Rechenschaftsbericht 1981: 17-19). Diese „Balkonlösung“, wie sie die ASF-Frauen spöttisch nannten, symbolisierte, so ASF-Bundesvorstandsmitglied Christa Randzio-Platz, die scharfe Konkurrenz und die Akzeptanzhürden der Partei, die den Teilhabeansprüchen der Frauen entgegenstanden (vgl. RandzioPlath 1980). Auf dem nächsten ordentlichen Parteitag 1982 in München fiel ein Drittel der Kandidatinnen, d.h. drei der neun Bewerberinnen, durch, dagegen schaffte nur ein Zehntel der männlichen Bewerber nicht die Wahl in den Vorstand (vgl. Jahrbuch der SPD \{1982-83\}: 235). Auf den unteren Ebenen der Parteihierarchie waren die Hürden niedriger, hier hatte sich die Beteiligung von Frauen auf den Leitungsebenen der Ortsund Kreisverbände, Unterbezirke, Bezirks- und Landesverbände bereits erheblich erhöht. Diese Veränderungen setzten sich bald auch in den Wahlen zum Parteivorstand durch.

Für den Essener Parteitag 1984 stellte die Arbeitsgruppe Gleichstellung der Frauen den Delegierten zehn Bewerberinnen vor. Sieben Kandidatinnen wurden in den Parteivorstand gewählt und fast alle bereits im ersten Wahlgang ${ }^{598}$. Bei den anschließenden Präsidiumswahlen allerdings schaffte es nur eine Frau in das 11-köpfige Gremium (vgl. Rechenschaftsbericht 1985: 14). Erst 1988, auf dem sog. Quotenparteitag in Münster, wählten Parteitag und Parteivorstand so viele Kandidatinnen in ihre Leitungsgremien, dass der Frauenanteil in diesen Führungsgremien dem der weiblichen Mitglieder in der Gesamtorganisation entsprach.

Unberührt von dieser Entwicklung blieb der Parteiapparat in seiner personellen Zusammensetzung. Noch sechs Jahre nach dem Gleichstellungsbeschluss von 1979 beklagte die ASF-Bundesvorstandvorsitzende:

Frauen treffen außerhalb des Frauenreferats fast ausschließlich auf eine Männerorganisation. Die Frauenförderpläne für die eigene Organisation haben die hauptamtlichen Männerstrukturen kaum verändern können (Rechenschaftsbericht 1985: 2).

598 Drei Frauen wurden zurückgezogen, weil sie nicht die Unterstützung ihrer Bezirke und Landesverbände erhalten hatten. Die sieben gewählten Vorstandsmitglieder waren Elfriede Hoffmann, Herta Däubler-Gmelin (im 2. Wahlgang), Antje Huber, Anke Fuchs, Inge Donnep, Brigitte Traupe und Erika Wagner. Sie erhöhten die Frauenquote dieses Gremiums von $15 \%$ auf $17,5 \%$. 


\subsubsection{Die Einrichtung von Frauenbeauftragten in der öffentlichen Verwaltung}

Die Partei unterstützte die Schaffung speziell zuständiger Stellen, um Frauen und ihre besonderen Interessen in Organisationen besser zu berücksichtigen. Nach den Vorstellungen frauenpolitischer AkteurInnen in der SPD sollten solche Stabstellen auf allen Ebenen der öffentlichen Verwaltung, auch für das Bundeskanzleramt, eingerichtet werden (vgl. ASF 1977). Statt im Bundeskanzleramt aber ließ Helmut Schmidt eine Stabstelle Arbeitsstab Frauenpolitik beim Bundesministerium für Jugend, Familie und Gesundheit einrichten ${ }^{599}$. Unter der Leitung von Ministerin Antje Huber nahmen hier elf Mitarbeiterinnen ab dem 01.07.1979 die Arbeit auf, um Vorhaben der Bundesregierung in ihrer frauenpolitischen Wirkung zu prüfen, frauenrelevante Initiativen der verschiedenen Ressorts fachlich zu beraten und die Entwicklung der gesellschaftlichen Situation von Frauen wissenschaftlich zu evaluieren. Sie sollten Modellvorhaben zum Abbau von Benachteiligung durchführen und frauenpolitische Belange international vertreten. Besondere Arbeitsschwerpunkte waren: die berufliche Förderung von Frauen ${ }^{600}$, die partnerschaftlich geführte Familie, Gewalt gegen Frauen und die Prüfung einer Gleichstellungsgesetzgebung (vgl. Rechenschaftsbericht 1981, Anlage „Informationen für die Frau 2/1981"). Zudem sollte die Stabstelle als individuelle Beschwerdestelle agieren. Mit Befugnissen wurde diese Stelle nicht ausgestattet ${ }^{6 o 1}$, weder besaß sie Untersuchungs- und Klagerechte noch hatte

599 Unter den führenden Sozialdemokratinnen war diese Maßnahme umstritten. Antje Huber hatte sich für eine Stabstelle mit weitreichenden Kompetenzen eingesetzt, Annemarie Renger, damals Vizepräsidentin des Bundestags, unterstützte den Kurs Helmut Schmidts und die Einrichtung eines Ressorts mit zuarbeitenden Funktionen (vgl. www.zeit.de/1978/38/klagen-allein-helfen-nicht [Zugriff:02.02.2011]).

6 oo Frauenförderpläne in der privaten Wirtschaft, insbesondere für den beruflichen Aufstieg, sollten in der freien Entscheidung der Unternehmen liegen.

601 Solche Stabstellen sollten nach Forderungen der ASF einen Behördenstatus und Frauenförderpläne erstellen. Alle Vorhaben, Programme, Gesetze und Verordnungen sollten ihnen vor den Kabinettsentscheidungen zugeleitet werden müssen. Beschlussfassungen sollten sie durch Veto blockieren können. Außerdem sollten sie eigenständig agieren können, wie z.B. bei der Erfassung frauenrelevanter Sozialdaten, der Veröffentlichung von Diskriminierungstatbeständen und der Veröffentlichung von Gleichstellungsberichten. Weiterhin sollten sie eine Anlaufstelle für Beschwerden aus der Bevölkerung sein und eine Kontaktstelle für alle frauenpolitisch engagierten gesellschaftlichen Organisationen (vgl. Rechenschaftsbericht 1979: 8).

Vorbild waren Schweden und die USA, in denen solche Kommissionen durchgesetzt hatten, dass öffentliche Aufträge und Förderungen an gleichstellungspolitische Auflagen gebunden wurden (vgl. DER SPIEGEL 26.06.1978, http://www.spiegel.de/spiegel/print/d-40616271.html [Zugriff: 02.02.2011]). 
sie Zugang und Mitspracherechte bei Kabinettsentscheidungen. Vom Abdrängen der Gleichstellungsstelle in das Familienministerium wurde der ASF-Bundesvorstand, der im Vorfeld konzeptionell in die Entwicklung eines gleichstellungspolitischen Aufgabenprofils eingebunden war, erst nach der Entscheidung informiert. Damit zerfielen bei der ASF die Hoffnungen auf eine baldige Durchsetzung eines Antidiskriminierungsgesetzes, das mit der Einrichtung dieser Stelle politisch vorbereitet werden sollte. Bei der Vorlage zum Wahlprogramm der SPD $1980^{602}$ wurden Gleichstellungsstellen nur noch als Einrichtungen der Landesministerien und Gemeinden aufgeführt (vgl. Wahlprogramm der SPD 1980). Im Rechenschaftsbericht der Erlanger Bundeskonferenz 1979 bilanzierte der ASF-Bundesvorstand das Kleinschrumpfen der Gleichstellungsinstanz bitter als „symptomatisch für die politische Ohnmacht der ASF“ (ASFBundesvorstand 1979: 7).

In der zweiten Hälfte der 1970er-Jahre hatten sozialdemokratisch regierte und mitregierte Landesregierungen bereits frauen- oder gleichstellungspolitische Stellen eingerichtet, teilweise mit besseren Ausstattungen und erweiterten Kompetenzen als von der SPD gefordert ${ }^{603} .1982$ wurde das erste Frauenbüro in einer kommunalen Verwaltung in Köln eröffnet; viele größere Gemeinden richteten ähnliche Stellen ein, vielfach auf Initiative oder mit Unterstützung sozialdemokratischer KommunalpolitikerInnen. Es entwickelte sich daraus eine frauenpolitische Infrastruktur, aus der die ASF fachlich versierte Anwärterinnen für leitende Verwaltungspositionen, als Dezernentinnen oder Ministerinnen, rekrutieren konnte.

602 Das Programm wurde auf dem Wahlparteitag am 9./10.06.1980 in Essen verabschiedet.

603 Eine Frauenbeauftragte im gleichstellungspolitischen Sinne berief als erstes Bundesland NRW 1975, sie hatte den Rang einer Staatssekretärin (vgl. Krautkämper-Wagner 1989: 19). Barbara von Sell legte aber bereits nach wenigen Monaten ihr Amt nieder, um Elfriede Eilers zufolge der Karriere ihres Mannes nicht im Wege zu stehen (vgl. Eilers 1975c) Mit der Einrichtung gleichstellungspolitischer Beauftragter bzw. Referate folgten 1978 Hamburg, 1981 Bremen 1979 Hessen, 1984 Schleswig-Holstein, 198o Rheinland-Pfalz, Baden-Württemberg und Berlin, 1981 Saarland, 1982 Niedersachsen (vgl. Krautkämper-Wagner 1989: 21f.) In Nordrhein-Westfalen wurde Minister Friedhelm Farthmann 1978 als Frauenbeauftragter der Landesregierung ernannt. Diese Personalentscheidung galt auch in den Reihen der Partei als Missachtung der Gleichstellungspolitik. Er hatte sich für dieses Thema nie interessiert, zudem wurde kolportiert, dass er einmal die Politik der ASF als „Tittensozialismus“ bezeichnet hätte (vgl. Stephan 1987). 


\subsubsection{Regierungskrise und die programmatische Öffnung der Partei}

Mit Beginn der 1980er-Jahre änderte sich das Interesse der Partei an Frauenthemen grundlegend und die FrauenpolitikerInnen fanden sehr schnell eine größere Resonanz und Unterstützung für ihre Anliegen und Forderungen. Dies stand in engem Zusammenhang mit der Krise der SPD in der sozialliberalen Koalitionsregierung. Bei der Bundestagswahl 1980 konnte die SPD einen leichten Stimmenzugewinn von +o,2 \% erreichen ${ }^{604}$. Zum ersten Mal in der Geschichte der SPD war dieser Erfolg auf die Unterstützung der Frauen zurückzuführen. Ihr Stimmenanteil war höher als bei der letzten Bundestagswahl 1976 und es hatten mehr Wählerinnen für die Sozialdemokratie gestimmt als Wähler ${ }^{605}$.

Aber trotz des relativen Wahlerfolgs 1980 verloren die sozialdemokratischen Regierungsmitglieder immer mehr an Rückhalt in der Partei. Der marktwirtschaftliche Kurs und die sinkenden Reallöhne, der Abbau sozialstaatlicher Reformen in der 9. Wahlperiode (1980-1983), eine wachsende Ablehnung der Sicherheitspolitik Helmut Schmidts, der überraschende Wahlerfolg der Bürgerinitiativbündnisse in den Landtagswahlen, eine neue Parteigründung, die sich links von der SPD sozialdemokratischen Traditionsthemen wie Bildung, soziale Sicherheit, Wohlstand und Verteilungsgerechtigkeit annahm - diese Entwicklungen aktivierten die verschiedenen Lager der Partei bei der Suche nach einer politischen Neuausrichtung.

Dieser Zeitabschnitt, der in der Parteiengeschichte als innerparteiliche Erosion und sozialdemokratische Defensive (vgl. Faulenbach 2011), als Zeit der Zwistigkeit und Flügelkämpfe (vgl. Walter 2002; Miller/Potthoff 2002) beschrieben wird, erscheint in den Berichten der Zeitzeuginnen als Phase innerparteilicher Demokratie, verbunden mit einer hohen Mobilisierung und Integration der Mitglieder. Dazu eine Zeitzeugin:

Wissen Sie, wenn wir von heute aus urteilen, die SPD war bis Mitte der 9oer-Jahre eine WIRKLICH demokratische Partei. Das ist sie nicht mehr, würde ich jetzt mal so sagen. (Zz 5)

604 Die Regierungskoalition wurde vor allem durch den Stimmenzugewinn der FPD $(+2,7 \%)$ gestärkt.

605 SPD-Wählerinnen: 43,1 \% (1976) - 43,9 \% (1980), ein Stimmengewinn von +o,8 \% gegenüber dem Stimmenanteil der CDU/CSU-Wählerinnen von 43,8 \% (1980);

SPD-Wähler: 43,6 \% (1976) - 43,1 \% (1980), ein Stimmenverlust von -o,5 \% gegenüber dem Stimmenanteil der CDU/CSU von 44,2 \% (1980);

vgl. dazu Tab. 8 Bundestagswahlergebnisse nach Geschlecht und Alter 1953-1987 unter DOI 10.3224/86388794A. 
Die frauenpolitischen Forderungen und gesellschaftspolitischen Ziele der ASF waren nicht eindeutig einem politischen Lager in der Partei zuzuordnen und fanden deshalb in den innerparteilichen Auseinandersetzungen UnterstützerInnen in politisch unterschiedlichen und wechselnden Formationen. Dazu trug auch eine zunehmende öffentliche Aufmerksamkeit für Frauenthemen in den Medien sowie bei Buchverlagen bei. Frauen- und gleichstellungspolitische Themen wurden attraktiv für das politische Profil unterschiedlicher politischer Strömungen.

Auf dem Münchner Parteitag 1982 referierte die ASF-Bundesvorsitzende als Kommissionsmitglied zur Beschäftigungssituation von Frauen. Dass Inge Wettig-Danielmeier den zentralen Vortag zu einem brennenden gesellschaftspolitischen Thema halten durfte, wertete die ASF als großen Erfolg (vgl. Rechenschaftsbericht 1983: 18). Auf diesem Parteitag stimmten die Delegierten verschiedenen von der ASF initiierten frauenpolitischen Anträgen zu, wenn auch ohne weitere Diskussionen. Die wichtigsten waren die Einforderung eines Antidiskriminierungsgesetzes, die Novellierung des BetrVG, das Frauenvertretungen in Betriebsräten und die Entwicklung betrieblicher Förderpläne ${ }^{606}$ vorschreiben sollte, die Bindung öffentlicher Vergaben an gleichstellungspolitische Auflagen, eine geschlechtsbezogene Drittelquote für die Besetzung gewerblich-technischer Ausbildungsplätze bei öffentlichen ArbeitgeberInnen, Frauenförderpläne in allen öffentlichen Verwaltungen und die Einrichtung von Gleichstellungsstellen mit ausreichenden Kompetenzen ${ }^{607}$ in Kommune, Land und Bund. Den Münchner Parteitag 1982 wertete die ASF als Zeichen einer zunehmenden Unterstützung in der Partei, auch wenn bei der Wahl des Parteivorstands die Zahl der weiblichen Vorstandsmitglieder von sieben auf sechs sank (vgl. Rechenschaftsbericht 1983: 13-16).

Im Jahrbuch der SPD 1982-1983 spiegelte sich eine neue Wertschätzung der ASF durch die Partei wider: Die Arbeitsgemeinschaft sozialdemokratischer Frauen, hieß es dort, hätte einen wesentlichen Anteil an der Mitgliederentwicklung und durch ihre zielgruppenspezifische Arbeit für die Wahlerfolge gesorgt. Sie hätte frühzeitig die Bedeutung der neuen

606 Als Maßnahmen betrieblicher Förderpläne vorgeschlagen waren eine Geschlechterquote auf dem Ausbildungsmarkt, die Berücksichtigung geschlechtergerechter Chancen bei der Besetzung interner Stellen, betriebliche Bildungsmaßnahmen und die Förderung von Aufstiegschancen für Frauen (vgl. Jahrbuch der SPD \{1982-83\}: 483f.).

607 Dies waren Akteneinsicht bei Ermittlungen, Anordnungs- und Untersagungsbefugnis, Erlass von Bußgeldbescheidung und deren Vollzug, regelmäßige Berichterstattung an die Parlamente (vgl., Parteitag der SPD 1982: Antrag 422). 
sozialen Bewegungen ${ }^{608}$ erkannt und gezeigt, dass eine „Frauen-Pressure-Group“ in der SPD unentbehrlich wäre (vgl. Jahrbuch der SPD \{1982-83\}: 296).

$\mathrm{Zu}$ dieser Anerkennung als Frauenlobby trugen vermutlich auch die stets gut besuchten Veranstaltungen bei, die die ASF organisierte (vgl. Rechenschaftsbericht 1983: 16).

Noch bei der Bundestagswahl 1980 war die ASF in die Wahlkampforganisation nicht einbezogen worden. Im Vorwahlkampf fühlte sich die ASF vom Parteivorstand reglementiert und behindert. So war ihr eine eigene Pressekonferenz zur sozialen Sicherung vor dem Erich-Ollenhauer-Haus untersagt worden, Wahlkampfmaterialien waren von der Wahlkommission stark zensiert, die ASF-Materialien nicht über die Parteiorganisation verteilt worden. Zusagen der Parteiführung, den ASFBundesvorstand an Pressekonferenzen zu beteiligen, wurden nicht eingehalten und die Neuauflage der Selbstdarstellungsbroschüre ASF - Das sind wir Frauen in der SPD war entgegen der Vereinbarung nicht gedruckt worden (vgl. Rechenschaftsbericht 1981). Bei der Bundestagswahl 1983 aber wurde die Frauenarbeitsgemeinschaft zum ersten Mal an der Erstellung des Wahlprogramms beteiligt. Nun gehörte EINE sozialdemokratische Frauenpolitik zum Wahlkampfprofil der Partei. Ein Vergleich der Wahlprogrammtexte 1980 und 1983 zeigt diese Entwicklung.

\section{Exkurs: Vergleich der Wahlprogrammtexte 1980 und 1983}

Im SPD-Programm für die Bundestagswahl 1980 ist das Gleichstellungsthema nur in einer Randposition zu finden, im Abschnitt 10 gute Gründe SPD zu wählen ist es nicht erwähnt (vgl. Wahlprogramm der SPD 1980: 7-9). Im letzten Kapitel V des Wahlprogramms findet sich unter dem Stichwort "Zuversicht in die Zukunft" ein Abschnitt Gleichberechtigung der Frauen ${ }^{609}$, Teil eines Sammelkapitels über Familienpolitik, Bildung, Medien, Verkehr und Wohnungspolitik. Das einleitende Bekenntnis, dass die Gleichstellung der Geschlechter nur gemeinsam von Frauen und Männern erreicht werden kann, findet in diesem Text keine argumentative Fortsetzung, sondern das Kapitel schließt ab mit einer wenig systematischen Reihung aus Zielstellungen und Forderungen zu gleichstellungspolitischen Bedarfen. In dem Tätigkeitskatalog der Regierungspolitik für die neue Wahlperiode, markiert mit aktiven Formulierungen wie

608, ,.... [A] ußerhalb der Partei hat sie, lange bevor die Partei wieder entschiedener auf die Neuen Sozialen Bewegungen zuging, im Frauenbereich glaubwürdig ein Stück sozialdemokratischer Meinungsführerschaft behauptet und weiterentwickelt" (Jahrbuch der SPD $\{1982-83\}: 296)$.

609 Ein solcher Abschnitt steht 1980 allerdings zum ersten Mal in einem Bundestagswahlprogramm der SPD. 
„die SPD wird“, „die SPD muss“, „die SPD tritt ein für“, findet sich nur die Forderung nach einer nichtdiskriminierenden Anwendung der Indikationsregelung (vgl. Wahlprogramm der SPD 1980: 30).

Dagegen wird im Wahlprogramm 1983 das Gleichstellungsthema bereits im Eröffnungstext des Programms als eins der sechs Aufgabenfelder der Partei präsentiert (vgl. Wahlprogramm der SPD 1983: 162). Die Gleichberechtigung der Frau ist eines von vier großen Themen sozialdemokratischer Regierungspolitik, die drei weiteren sind Zukunft der Kinder, gesundes Leben und Frieden. Gleichstellung wird im Wahlprogramm 1983 in verschiedenen Unterkapiteln thematisiert. Die Geschlechtergerechtigkeit gilt als ein wichtiger Teil des sozialen Friedens und als Bedingung gesellschaftlicher Entwicklung. Auch eine Verurteilung von Gewalt in den Familien, der Misshandlung von Frauen und Kindern, findet sich im Programmtext. Arbeitszeitverkürzung wird nicht nur als beschäftigungsfördernde Maßnahme befürwortet, sondern auch als Chance auf eine bessere Vereinbarkeit von Beruf und Familie beschrieben. Der Abbau der Ausbildungsförderung wird als ein „Kreuzzug gegen die Chancengleichheit"610 (Wahlprogramm der SPD 1983: 178) verurteilt. Die SPD bezeichnet sich als der „entschiedenste Anwalt der Gleichstellung" (Wahlprogramm der SPD 1983: 175). Auch der eigene Nachholbedarf in der Partei wird genannt, in der Gleichstellung und die Aktivierung der Frauen zwar befördert werde, aber "oft nicht konsequent genug" (Wahlprogramm der SPD 1983: 175). Obwohl sich im Wahlprogramm Themen wie Ökologie, Umweltschutz, eine kritische Reflexionen zur Kernenergie und Technologisierung der Wirtschaft finden lassen, wird als zivilgesellschaftliche Bewegung nur die Neue Frauenbewegung explizit genannt, die „zu Recht“ auf die Gewalttätigkeit im privaten Bereich und die Probleme misshandelter Frauen aufmerksam gemacht habe (vgl. Wahlprogramm der SPD 1983: 185).

\subsubsection{Wenig Rückenwind für die Frauen aus Europa}

Bei den ersten Wahlen zum Europäischen Parlament 1979 wurde die SPD zum ersten Mal mit einer Quotenregelung konfrontiert. Willy Brandt hatte seine eigene Kandidatur an eine Frauenquote von $25 \%$ auf der

610 Die ersten Einschränkungen der Bildungsförderungen hatte die SPD selbst vorgenommen. Bereits 1981 wurden die Leistungen reduziert und die Quote Geförderter sank bei ansteigender Studierendenzahl (vgl. Entwicklung der Förderung nach dem BAFöG im Hochschulbereich - Antwort der Bundesregierung auf eine Kleine Anfrage, 07.02.1985, Drucksache 10/2847, http://dipbt.bundestag.de/dip21/btd/10/028/1002847.pdf [Zugriff: 02.02.2012]). 
KandidatInnenliste geknüpft (vgl. Dertinger 1980a; Pausch 1985). Gewählt wurden 35 SPD-Abgeordnete, darunter sieben Frauen, d.h. $20 \%$. Das sozialdemokratische Europaprogramm, beschlossen auf dem außerordentlichen Parteitag in Köln im Dezember 1978, hatte der Frauenpolitik ein eigenes Kapitel gewidmet. Frauenarbeitslosigkeit wurde dort als ein „Kernproblem“ europäischer Politik bezeichnet und Maßnahmen zur Gleichstellung von Frauen in Familie, Beruf und Gesellschaft wurden aufgeführt (vgl. Europawahlprogramm der SPD 1979: 25f.). Gefordert wurden ein 18-monatiger Elternurlaub, Richtlinien zur Aufhebung des geschlechtssegmentierten Arbeitsmarktes und gemeinschaftliche Programme zur beruflichen Qualifizierung von Frauen. Institutionalisiert werden sollte Frauenpolitik durch die Einrichtung einer Gleichstellungskommission, die die Mitgliedsstaaten bei der Umsetzung der EG-Richtlinien kontrollierte, sowie durch ein Frauenbüro mit dem Status einer Generaldirektion $^{611}$. Die Verteilung von Fördergeldern für arbeitsmarktpolitische Maßnahmen aus dem Sozial- und Regionalfonds sollte an Quotierungen gebunden werden, um positive Beschäftigungswirkungen zugunsten von Frauen zu erreichen ${ }^{612}$.

Bei der nächsten Europawahl 1984 mit Katharina Focke als Spitzenkandidatin stieg der Frauenanteil bei den SPD-Europaabgeordneten auf $25 \%$ (vgl. Rechenschaftsbericht 1985: 16).

Die frauenpolitischen Erfolge auf europäischer Ebene brachten der ASF allerdings wenig für die innerparteilichen Auseinandersetzungen in der SPD. Europa galt in dieser Zeit eher als ein politisches Abstellgleis ${ }^{613}$. Die männliche Konkurrenz bei Kandidaturen war deshalb gering. Auch die deutsche Bevölkerung interessierten die Europawahlen relativ wenig. Die Wahlbeteiligung der Deutschen lag bei unter 6o \% - niedriger als im europäischen Durchschnitt ${ }^{614}$ - und damit unter den durchschnittlichen Wahlbeteiligungen bei Landtags- und Kommunalparlamenten.

Frauenpolitik und Gleichstellungspolitik standen allerdings auch bei den europäischen Sozialdemokratinnen nicht an der Spitze ihrer politischen Agenden. Bis in die Mitte der 1980er-Jahre beschäftigte sich ihre

611 Zur Bedeutung der EG für die nationalen Frauenförderprogramme vgl. Hoff 1984.

612 Die Forderungen wurden begründet mit der gesellschaftlichen Benachteiligung der Frauen und nicht aus einer Kritik an der Geschlechterhierarchie. Diese entwickelte die ASF in den 198oer-Jahren.

613 Parlamentarische Aufgaben waren relativ gering vergütet und mit aufwendigen Fahrwegen verbunden. Europäische Parlamentsbeschlüsse hatten keine rechtliche Bindung. Laut einer Zeitzeugin hieß es zu Europa: „Hast Du einen Opa, schick ihn nach Europa" (Zz 6).

614 Vgl. http://www.bpb.de/nachschlagen/zahlen-und-fakten/europawahl/6o473/ wahlbeteiligung-1979-2009 [Zugriff: 05.06.2012]. 
Europapolitik eher mit Fragen alternativer Verteidigung, einem atomwaffenfreien Europa, mit regionalen Abrüstungsinitiativen, der Entwicklung der Friedenserziehung und der Förderung von Entwicklungspolitik. Erst im Februar 1989 wurde ein frauenpolitischer Zielkatalog sozialdemokratischer Forderungen zu Arbeitsmarkt, Familie und Gewalt, sozialer Sicherung, Entwicklungspolitik, Migrantinnen, umweltschonender Energiepolitik, Frieden und Abrüstung aufgestellt ${ }^{615}$.

\subsection{Frauen- und Gleichstellungspolitik der Bundestagsfraktion und erste Quotenregelungen in der Partei (1983-1986)}

Der Regierungsverlust der SPD nach den Bundestagswahlen 1983 verstärkte die frauenpolitische Öffnung in der Partei. Nun sollte auch die Fraktion für ein starkes frauenpolitisches Profil der Partei sorgen, um für Wählerinnen attraktiver zu sein. Eine frauenpolitische Kommission der Fraktion entwickelte zu vielerlei Themen gesetzliche Initiativen und organisierte öffentlichkeitswirksame Foren und Veranstaltungen. Die Nachfrage nach frauenpolitischer Expertise stieg und verschaffte auch den ASF-Frauen neue Auftrittsmöglichkeiten. In der Partei wurden erste Quotenregelungen eingeführt. Damit sollte auch vermehrt für mehr Repräsentantinnen der Partei und mehr Kandidatinnen bei Wahlen gesorgt werden. In sozialdemokratisch regierten oder mitregierten Ländern wurden die ersten Landesgleichstellungsgesetze eingeführt und Frauenförderpläne aufgestellt. Darüber hinaus wuchs die Landschaft frauen- und gleichstellungsorientierter Initiativen und Projekte durch kommunale Förderung.

\subsubsection{Verstärkte Bewerbung von Wählerinnen}

Nach der Annahme des konstruktiven Misstrauensvotums der Opposition gegen Helmut Schmidt am 01.10. 1982 wurden die Bundestagswahlen vorgezogen und auf März 1983 angesetzt. Um die Regierungsmacht zurückzugewinnen, wollte die SPD verstärkt Wählerinnen werben. Bereits

615 Ein Manifest der linken Frauen der Europäischen Gemeinschaft sollte die Initiative zu einer europäischen Frauenpolitik geben (vgl. Manifest 1989). Zu untersuchen wäre, ob dieses Manifest eine Kooperation auf europäischer Ebene verstärkte und eine neue Phase koordinierter frauenpolitischer Aktivitäten einleitete. 
bei Landtagswahlkämpfen waren den Frauenpolitikerinnen vermehrt Bühnen zur Verfügung gestellt worden.

Im hessischen Landtagswahlkampf konnte die ASF zum Hessen-Treffen in Wiesbaden 1982 einen von fünf politischen Programmpunkten gestalten. Die Wahlniederlage der FDP - mit 3,08 \% scheiterte die Partei an der 5-\%-Hürde - führte in Hessen zur ersten rot-grünen Regierungskoalition. Die neue Regierung richtete einen parlamentarischen Frauenausschuss ein und verabschiedete mit starker Beteiligung der ASF ein Hessisches Aktionsprogramm für Frauen ${ }^{616}$. Für den schleswig-holsteinischen Landtagswahlkampf 1983 präsentierte sich die SPD gleichstellungspolitisch und hatte eine paritätisch besetzte Regierungscrew aufgestellt $^{617}$. In der Bundestagswahl 1983 stellte Kanzlerkandidat Hans-Jochen Vogel eine Regierungsmannschaft mit drei Ministerinnen und fünf Staatssekretärinnen vor (vgl. Jahrbuch der SPD \{1982-83\}: 314f.). Auf der Bonner Bundesfrauenkonferenz 1983 berichtete der ASF-Vorstand von einer wachsenden Nachfrage nach Referentinnen für Wahlveranstaltungen der Partei (vgl. Rechenschaftsbericht 1983: 18f.).

Das Frauenbüro im Parteivorstand wurde trotz knapper Kassen personell aufgestockt. Zum ersten Mal wurde einer Frau eine Abteilungsleitung im Parteivorstand übertragen. Der ASF-Bundesvorstand berichtete von einer „Öffnung“ und besseren Zusammenarbeit mit der Parteispitze (vgl. Rechenschaftsbericht 1983).

Bei der Bundestagswahl 1983 wählten - wie bei der vorangegangenen Wahl 1980 - erneut mehr Frauen als Männer die SPD; trotzdem ließen sich auch in den Wählerinnengruppen massive Stimmeneinbußen erkennen. ${ }^{618}$ Besonders dramatische Stimmverluste hatte die SPD bei den jungen WählerInnen bis 35 Jahre zu verzeichnen, einer Gruppe, die der Partei bisher die höchsten Zustimmungsraten gebracht hatte und seit

616 Dieses Aktionsprogramm sah u.a. die institutionelle Förderung der Frauenhäuser und Notrufe vor. Frauen, die Opfer von Gewalt geworden waren, sollten besonders unterstützt und beruflich gefördert werden. Eingerichtet werden sollte eine Professur für Frauenforschung an der Wolfgang-Goethe-Universität. Vorgesehen war die Förderung bildungspolitischer Projekte für Mädchen und Frauenförderpläne in den öffentlichen Verwaltungen. Ein kostenfreier Schwangerschaftsabbruch sollte sichergestellt werden (vgl. Hessisches Aktionsprogramm 1984; dazu auch Zz 9). Kommentar der ASF-Vorsitzenden Inge Wettig-Danielmeier dazu: „Wir begrüßen den hessischen Aktionsplan für Frauen sehr, aber wir wären glücklicher, wenn die 10 Jahre alten Forderungen der SPDFrauen nicht durch die Hintertür der Grünen durchgesetzt worden wären." (WettigDanielmeier auf dem Parteitag der SPD 1984:312)

617 Bei Hinzurechnung der StaatssekretärInnen und StellvertreterInnen des Ministerpräsidenten.

618 Vgl. Tab. 8 Bundestagswahlergebnisse nach Geschlecht und Alter 1952-1987 und Tab. 9 Bundestagswahlen 1953-1987. Wahlbeteiligung nach Alter und Geschlecht in DOI $10.3224 / 86388794$ A. 
1972 mehrheitlich die Sozialdemokratie unterstützte. In dieser Altersgruppe hatten sich die Stimmen für die Partei Die Grünen mehr als vervierfacht und waren bei den Frauen stärker als bei den Männern gestiegen $^{619}$. Der ASF-Bundesvorstand machte dafür die jahrelange Marginalisierung frauenpolitischer Interessen in der Partei und ihrer Politik verantwortlich und berief sich auf eine Infrateststudie zur Wahlanalyse, nach der den Grünen in der Gleichstellungsfrage und zur Frauenpolitik mehr Kompetenz und Glaubwürdigkeit zugesprochen wurde als der SPD (vgl. Rechenschaftsbericht 1985: 13).

Auf dem folgenden Essener Parteitag 1984 wurde die erstmals 1978 beim Parteivorstand eingerichtete Arbeitsgruppe zur Gleichstellung ${ }^{620}$ erneut besetzt. Der Parteivorstand beschloss, die SPD zur nächsten Bundestagswahl mit einem dezidierteren frauenpolitischen Profil antreten zu lassen. Frauenpolitik sollte in der neuen sozialreformerischen Programmatik größere Bedeutung erhalten.

Die Mitwirkungsmöglichkeiten frauenpolitischer Aktivistinnen verbesserten sich, denn nach ExpertInnenwissen zu Frauenpolitik wurde in der Partei nun gefragt ${ }^{621}$ (vgl. Rechenchaftsbericht 1985: 15). Dazu trug auch bei, dass der Essener Parteitag den weiblichen Parteimitgliedern ein Recht auf Selbstvertretung zusprach; damit hatte die Partei sicherzustellen, dass Frauen ,ihre Interessen, ihre Erfahrungen auch selbst einbringen und vertreten " könnten (Antrag 596 in: Parteitag der SPD 1984: 789f.). Ab Mitte der 1980er-Jahre finanzierte die Partei ASF-Veranstaltungen zu gesellschaftlich noch weitgehend tabuisierten Themen wie der Zwangsprostitution von illegalen weiblichen Flüchtlingen, Gewalt in Ehe und Familie, homosexuellen Lebensformen oder der Sexualität im Alter.

Neben dieser politischen Öffnung der Partei für frauenpolitische Themen blieb der Zugang der Genossinnen zu politischen Mandaten jedoch weiterhin ein Feld harter Verteilungskämpfe. Nach der ASF-Vorsitzenden Inge Wettig-Danielmeier wuchs der Anteil weiblicher MandatsträgerInnen - außer im Europaparlament - erheblich langsamer als der Anteil der Frauen in der Mitgliedschaft.

619 Vgl. Tab. 8 Bundestagswahlergebnisse nach Geschlecht und Alter 1952-1987 in DOI $10.3224 / 86388794$ A.

620 Der Vorsitz wurde paritätisch besetzt mit Inge Wettig-Danielmeier und Peter Glotz.

621 ASF-Bundesvorstandsmitglied Brunhilde Peter konfrontierte die Partei mit ihrem selbst verursachten Wissensdefizit: „Ihr müsst Euch also über unsere Ausbildungskonzepte und die Forderungen nach Wiedereingliederung in den Beruf informieren, über die Frauenforschung, über die Frauenbilder in den Lesebüchern bis hin zu den Frauenförderplänen im öffentlichen Dienst und den Problemen der Benachteiligung durch die Arbeitszeitformen." (ASF-Bundesvorstandsmitglied und spätere saarländische Ministerin Brunhilde Peter auf dem Parteitag der SPD 1984:326) 
Auf einer Sondersitzung des Parteirats im September $1985^{622}$ forderte der Parteivorsitzende Willy Brandt von den VertreterInnen der Bezirke und Landesverbände, bei der kommenden Bundestagswahl für mehr weibliche Präsenz in Wahlkreisen und auf Listenplätzen zu sorgen. Daraufhin lehnte der Parteirat die Vorlage des Präsidiums ab, nach der nur in den frei werdenden Wahlkreisen verstärkt Kandidatinnen berücksichtigt werden sollten, und gab stattdessen eine Zielgröße für die Partizipation der Frauen vor:

Der Parteirat ist sich einig, daß es unser nächstes Ziel sein muß, in die Bundestagsfraktion 1987 mindestens so viel Frauen zu entsenden, wie es ihrem Anteil an der Mitgliedschaft entspricht. (Sozialdemokrat Magazin 1985: 9)

Auch auf dieser Sitzung, sechs Jahre nach dem Gleichstellungsbeschluss, zeigte sich die nach wie vor unterschiedliche Akzeptanz des Gleichstellungsthemas in der Partei: Neun Bezirke wehrten sich grundsätzlich gegen gleichstellungspolitische Zielvorgaben. Für sie standen die Partizipationsforderungen der ASF-Frauen den AfA-Ansprüchen mit den angestammten Plätzen renommierter Anwärter gegenüber, sie sahen ihre Wahlkreise gefährdet und hielten außerdem eine Steuerung der KandidatInnenaufstellung über Leitungsgremien für nicht möglich. Fünf Bezirke zeigten eher wenig Interesse an dem Thema. Nur acht Bezirke sahen eine große Chance in einer höheren Frauenpartizipation und wollten mit Frauenförderplänen und Zielaushandlungen dazu beitragen. Nach der Sondersitzung erklärte der Parteirat in der Presse:

Gesellschaftlicher Wandel, Selbstbewusstsein und Aktivität der Frauen und auch Einsichtsbereitschaft auf Seiten der Männer, Erfahrungen und Diskussionen haben die Haltung der Partei verändert [...] Der Parteirat unterstützt alle Bezirke, die beschlossen haben, die Beteiligung der Frauen an Funktionen und Mandaten entsprechend ihrem Anteil an der Mitgliedschaft und in weiteren Schritten in den neunziger-Jahren entsprechend ihrem Anteil an der Bevölkerung zu verwirklichen. (SPD-Parteirat 1985: 4f.)

Am gleichen Tag rief der ASF-Bundesvorstand die Partei in einer Presseerklärung zur Einlösung ihres "Jahrhundertversprechens an die Frauen“ (Wettig-Danielmeier 1985c:3) auf. Dazu appellierte die ASF-Vorsitzende Inge Wettig-Danielmeier auch an die Streithaftigkeit der Frauen:

622 Auf der Sitzung am 19.09.1985 gab es einen eigenständigen Tagesordnungspunkt „Repräsentanz der Frauen bei der Kandidatenaufstellung“. 
Wir müssen aber auch bedenken, daß dieser neue und für die SPD ungewöhnliche Verteilungskampf nicht nur von der Partei, von ihren aktiven Mitgliedern in den Ortsvereinen bis zu Spitzenfunktionären, menschliche Reife verlangt. Er erlegt den Frauen eine neue Last auf. Sie werden in ihrer Rolle als aktive Streiterinnen für die Umsetzung der Parteibeschlüsse z.T. unverhüllte Aggressionen der Männer bis zu persönlichen Drohungen auf sich ziehen, denn im Kampf um Mandate, vor allem um die wichtigen, sollen und müssen Frauen auf Zeit bevorzugt werden (Wettig-Danielmeier 1985c: 2).

Im Oktober des gleichen Jahres 1985 beschloss die ASF-Bundesfrauenkonferenz in Hannover die Forderung nach einer 40-\%-Quote. Die ersten Parteieinheiten hatten bereits solche verbindlichen Teilhaberegelungen eingeführt (vgl. Rechenschaftsbericht 1985).

\subsubsection{Die neue Frauenpolitik der Bundestagsfraktion}

Die Aufgabe der AG Gleichstellung der SPD-Bundestagsfraktion ${ }^{623}$ war die „Erbringung, Berücksichtigung, Koordinierung und Umsetzung aller frauenpolitisch relevanten Gesichtspunkte der gesamten Parlamentsund Fraktionsarbeit" (Jahrbuch der SPD $\{1982-83\}$ : 6o) ${ }^{624}$. Unter der Leitung der stellvertretenden Fraktionsvorsitzenden Herta Däubler-Gmelins standen besonders die Diskriminierungen und Förderungen der Frauen auf dem Arbeits- und Berufsmarkt sowie die soziale Absicherung von verheirateten Frauen nach der Scheidung oder als Witwen auf der politischen Agenda ${ }^{625}$ (vgl. Jahrbuch der SPD \{1982-83\}: 59f.; Jahrbuch der SPD $\{1984-85\}$ : 67f.).

623 Bis dahin hatten sich eher wenige SPD-Abgeordnete für frauenpolitische Themen interessiert. Um die frauenpolitischen Aktivitäten im Parlament zu stärken organisierte die ASF Netzwerkinitiativen wie das „Parlamentarierinnen-Treffen“ in Wiesbaden 1982, zu dem die ASF weibliche SPD-Abgeordnete aus Landes-, Bundes- und Europaparlament einlud, oder die „Bonner Runde“, ein überparteiliches Treffen von Politikerinnen, Gewerkschafterinnen, Journalistinnen, Wissenschaftlerinnen, das Karin Hempel-Soos 1983 auszubauen versuchte. Meist aber funktionierten diese Initiativen aufgrund der Termin- und Aufgabenüberlastungen sowohl bei den Gästen als auch bei den Einladenden nicht über einen längeren Zeitraum.

624 Auch in Landesfraktionen entstanden Arbeitsgruppen, die sich mit Frauenpolitik beschäftigten, wie z.B. in Baden-Württemberg, Niedersachsen, Rheinland-Pfalz.

625 Die Realisierung des straffreien Schwangerschaftsabbruchs war ein durchgängiges Thema der sozialdemokratischen Opposition in der Kohl-Ära. 
Mit der Gründung der AG Gleichstellung in der Bundestagsfraktion 1983 lag die Entwicklung sozialdemokratischer Frauenpolitiken nun weitgehend in den Händen der Fraktion ${ }^{626}$.

Die frauenpolitischen Aktivitäten der SPD-Fraktion wurden ausführlich in den Jahrbüchern der Partei dokumentiert. Entlang ausgewählter Themen wurden die Initiativen der Fraktion aufgeführt und Kursänderungen sozialdemokratischer Frauenpolitik erläutert. Frauenpolitik war zu einem Teil des Parteiprofils geworden, mit dem sich die SPD von der "geistig-moralischen Wende" abgrenzte, die die Regierungskoalition aus CDU/CSU und FDP angekündigt hatte und von der sich Kanzler Helmut Kohl für die Bundesrepublik eine „geistige Erneuerung“ erwartete $^{627}$.

Zur konservativen Wende der CDU/CSU/FDP-Regierung gehörte die besondere Förderung der Mutterschaft. Zwar propagierte die CDU seit 1978 die „Wahlfreiheit“ für Frauen, d.h. die Entscheidungsfreiheit zwischen Beruf und Familie ${ }^{628}$, aber sie erwartete von den jungen Müttern die Familie vor ihre beruflichen Entwicklungswünsche zu setzen und für die Kinder gegebenenfalls ein Herausdrängen aus dem Berufsleben in Kauf zu nehmen. 1984 gründete die Bundesregierung die Bundesstiftung Mutter und Kind, die mit finanziellen Anreizen versuchte, Schwangerschaftsabbrüche zu verhindern. ${ }^{629}$ Darüber hinaus entwickelten die konservativen Parteien auf Landesebene Gesetzesinitiativen und länderspezifische Verordnungen, um die Anwendung der Indikationsregelung in der Beratungspraxis zum § 218 einzuschränken.

Dagegen präsentierte sich die SPD als moderne Volkspartei, zu deren Selbstverständnis die Gleichstellung der Geschlechter gehörte. Hatte noch unter der SPD/FDP-Regierung das EG-Anpassungsgesetz 1980 das

626 In den Rechenschaftsberichten des ASF-Bundesvorstands finden sich keine Hinweise darauf, dass nach dieser Arbeitsgruppengründung verstärkt Kooperationsaktivitäten zwischen der Fraktion und dem ASF-Bundesvorstand stattgefunden hätte.

627 Sie sollte durch die Förderung der Eigenverantwortlichkeit und den Abbau sozialstaatlicher Unterstützungsleistungen erreicht werden. Ausbildungsförderung, Arbeitslosenunterstützung, Rentenleistungen, das Mutterschafts- und Kindergeld sowie die Arzneimittelkostenbeteiligung sollten gekürzt werden. Das betraf besonders GeringverdienerInnen und Arbeitslose mit ihren Familien und damit vorrangig Frauen, die in diesen Gruppen überproportional stark vertreten waren. Vgl. Regierungserklärung von Helmut Kohl unter http://www.mediaculture-online.de/fileadmin/bibliothek/kohl_RE_1983/kohl_RE_1983.pdf [Zugriff: 02.03.2010].

628 Vgl. Aktionsprogramm '78.

629 Die Vergabe der Stiftungsmittel richtete sich nach den jeweiligen Vorstellungen der Zuwendungsempfänger auf Landesebene. Damit erhöhten sich die Ungleichbehandlung der Mütter und die politische Willkür bei ihrer Unterstützung, vgl. http://www.bundesstiftung-mutter-und-kind.de/ziel-und-zweck.html [Zugriff: 05.06.2011]. 
Parlament passiert, das den Frauen bei Diskriminierungen am Arbeitsplatz kaum Rechtsschutz bot, nahm die SPD nach dem Regierungsverlust 1983 das Thema Gleichstellung in Beruf und Wirtschaft neu auf. Im April 1984 beantragte sie eine Bundestagsdebatte zur Gleichstellung auf dem Arbeitsmarkt mit dem Ziel, einen Gesetzesentwurf gegen die Deregulierungsfolgen vorzubereiten. Sie forderte die rechtliche Gleichstellung der Teilzeitarbeit mit der Vollzeitarbeit ${ }^{630}$ sowie ein gesetzliches Verbot der Beschäftigungsformen zur Flexibilisierung der Arbeit, z.B. ein Verbot der Arbeit auf Abruf und der Teleheimarbeit (vgl. Jahrbuch der SPD \{1986\}: 67). Im August 1984 organisierte die SPD-Bundestagsfraktion eine öffentliche Anhörung zum Thema „Den Männern die Arbeitsplätze - den Frauen das Ehrenamt?"“. Im April 1985 fand eine Anhörung zur „beruflichen Förderung von Frauen“ statt. Mit einer Großen Anfrage zu „Frauen im Öffentlichen Dienst“ wurde eine bevorzugte Einstellung, Ausbildung und Beförderung von Frauen in der öffentlichen Verwaltung vorbereitet.

Als 1987 Renate Schmidt die Leitung der AG Gleichstellung übernahm, stand die prekäre Situation von Familienfrauen im Fokus der sozialdemokratischen Frauenpolitik ${ }^{631} .90 \%$ aller Mütter trafen bei ihrem

630 Bereits Anfang der 1980er-Jahre weitete sich die Teilzeitarbeit aus. Nach 1986 war 8o \% des Beschäftigungszuwachses auf eine Ausweitung der Teilzeitbeschäftigung zurückzuführen (vgl. Grötemaker 2004: 327).

631 Die Aufgaben und Ziele des Arbeitskreises Gleichstellung waren insgesamt breiter gefasst: Gleichstellung der Frauen im Berufsleben, arbeitsrechtliche Sicherung der beruflichen Wiedereingliederung, Vereinbarkeit von Kindern und Beruf für Frauen und Männer, gesellschaftliche Anerkennung der Familienarbeit, Ausbau des Invaliditätsschutzes, Abbau der Benachteiligungen von Frauen in allen gesellschaftlichen Bereichen, Erarbeitung eines Gleichstellungsgesetzes für das Berufsleben, Förderung von Modellversuchen zur beruflichen Wiedereingliederung, Erziehungsurlaub mit Arbeitsplatzgarantie bis zu drei Jahren, staatliche Lohnersatzleistung im Erziehungsurlaub, Verpflichtung beider EhepartnerInnen zur gemeinsamen Haushaltsführung und ggf. Kinderbetreuung bei gemeinsamer Erwerbstätigkeit, Anerkennung der Pflegezeiten in der Rentenversicherung, Ganztagsbetreuung und Ganztagsschulen, bundesweite und gesicherte Frauenhausfinanzierung, Bekämpfung des Prostitutionstourismus und der sog. Heiratsvermittlung, Strafbarkeit ehelicher Vergewaltigung, Erhöhung der Frauenpräsenz in Parlamenten und in den Entscheidungs-, Förderungs- und Aufsichtsgremien, Schutz vor die Menschenwürde verletzenden Darstellungen in der Werbung. Darüber hinaus sollten Studien über die Lebensbedingungen von Frauen in Auftrag gegeben werden, um die Datenlage über weibliche Lebensbedingungen zu verbessern: Frauen in Altenheimen, Alleinerziehende und Alleinstehende, in eheähnlichen Gemeinschaften lebende Frauen, in der BRD lebende ausländische Mädchen und Frauen, Frauen in gemischtnationalen Ehen, internationale Studien über „Frauen in der Dritten Welt" sowie Studien über den Ausbau des Einflusses der Verbraucherinnen auf Produktion und Absatz (Zusammenstellung aus Unterlagen in: Deposita Streletz 99 $\{1987\})$ 
Wiedereinstieg in den Beruf auf Schwierigkeiten, für viele war eine Rückkehr nur mit erheblichen Einbußen an Gehalt und Qualifikationsanforderung möglich. Im August 1987 organisierte die SPD-Bundestagsfraktion deshalb die Anhörung „Raus aus dem Beruf, rein in die Familie, zurück in den Beruf?" und diskutierte mit ExpertInnen aus Politik, Wirtschaft, Wissenschaft, Arbeitsverwaltung, Gewerkschaften, Weiterbildungsträgern und Verbänden. Außerdem stellte sie ein Programm zur beruflichen Eingliederung nach Zeiten der Kindererziehung vor (vgl. Jahrbuch der SPD \{1988\}: 303). Zum Thema Familie war es Renate Schmidt ein besonderes Anliegen, „die öffentliche Diskussion über die Mitverantwortung der Männer und der männlich geprägten Institutionen für Problembereiche, die bisher als ,Frauensache' angesehen wurden, voranzutreiben“ (Renate Schmidt auf der Veranstaltung „Die Frauenfrage als Männerfrage“, Juni 1989 zit. n. Schmidt 1989: 5) ${ }^{632}$. Renate Schmidt plädierte für eine Enquetekommission Mann und Familie (vgl. Jahrbuch der SPD \{1991\}: 235f.; Schmidt 1989: 19) und forderte eine gesetzlich verpflichtende Arbeitsteilung der Familienarbeit zwischen den EhepartnerInnen $^{633}$. Ende November 1989 organisierte dazu auch die SPD-Arbeitsgruppe Fortschritt '9o einen Fachkongress mit dem Thema „Ist das ein Traum? - Familie und Beruf für Männer und Frauen“634.

Darüber hinaus setzte sich die SPD-Bundestagsfraktion unter Leitung Renate Schmidts für eine bessere Anerkennung der Familienarbeit ein. Der Arbeitskreis der Fraktion erarbeitete hierfür einen Gesetzentwurf für ein Erziehungsgeld ${ }^{635} .1984$ hatte eine Neuordnung der Hinterbliebenenrente zwar die Anrechnung der Kindererziehungszeiten von einem halben auf ein Jahr erhöht, allerdings nur für die Geburtsjahr-

632 Die Gleichstellung, so die Bilanz der Tagung, würde erst durchgesetzt werden können, wenn auch die Männer ihren Leidensdruck erkennten, ihre Geschlechterpolitik in Frage stellten und eine partnerschaftliche Familienarbeit anstrebten (vgl. Schmidt 1989).

633 Vgl. Anhörung am 14./15.3.1988, Titel: „... das bisschen Haushalt, sagt mein Mann“ zur Anerkennung der Familienarbeit. Gefordert wurden hier ebenfalls eine Ausweitung des Elternurlaubs auf bis zu drei Jahre, eine erweiterte Anrechnung der Erziehungszeiten auf die Rente und der Rechtsanspruch auf befristete Teilzeitbeschäftigung für beide EhepartnerInnen.

634 Renate Schmidt über die Tagung: „Die gesellschaftliche Entwicklung erfordert neues Denken und Veränderung, nicht nur von Frauen, sondern insbesondere von Männern, die ihren Beitrag zur Arbeit in der Familie, zur Erziehung der Kinder, endlich auch leisten müssen. Es gilt, die gesetzlichen und gesellschaftlichen Grundlagen dafür zu schaffen, daß die Vereinbarkeit von Kindern und Beruf für Frauen und Männer nicht nur auf dem Papier, sondern auch in der Realität ermöglicht wird." (Jahrbuch der SPD \{1988-90\}: A9)

635 Dies war eine Vorlage für das spätere Kindererziehungsleistungsgesetz. 
gänge ab 1921. Die SPD setzte sich mit Anhörungen, Anfragen und Plenardebatten für eine uneingeschränkte Anrechnung der Erziehungszeiten für alle Frauen und Männer ein. Ab dem 1. Oktober 1987 trat das Kindererziehungsleistungsgesetz in Kraft, das Leistungen auch Eltern gewährte, die keine Ansprüche auf gesetzliche Rentenleistungen hatten (vgl. Cornelißen 2005: 439-452)

Im November 1987 organisierte die SPD-Fraktion eine Große Anfrage ${ }^{636}$ zur Arbeitslosigkeit unter weiblichen Erwerbstätigen, denn Frauen wurden von der Rezession und Rationalisierung in dieser Zeit vorrangig aus dem Arbeitsmarkt gedrängt; gefordert wurde von der Bundesregierung eine Berichterstattung über die Entwicklung der Frauenarbeitslosigkeit und entsprechender beschäftigungspolitischer Maßnahmen. Im Juli 1989 stellte die SPD-Fraktion die Idee eines EG-weiten frauenspezifischen Gesetzgebungsplans ${ }^{637}$ vor, der mit frauenspezifischen Fördermaßnahmen und EU-weiten Regularien zur Vereinbarkeit von Beruf und Familie die weitere verstärkte Freisetzung weiblicher Arbeitskräfte verhindern sollte. Sie wurde als Folge der neuen Anforderungen des EG-Binnenmarktes an eine erhöhte ArbeitnehmerInnenmobilität und an eine wachsende Qualifikation der Arbeitskräfte erwartet.

Ab 1985 arbeitete die AG Gleichstellung der SPD-Fraktion an einem „Gesetz zur tatsächlichen Gleichstellung von Frau und Mann im Berufsle-

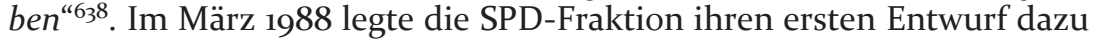
vor. 1986 hatten allerdings bereits die Grünen dem Bundestag ihre Version eines Antidiskriminierungsgesetzes ${ }^{639}$ vorgestellt. Die SPD-Vorlage für das Gleichstellungsgesetz deckte sich weitgehend mit dem Entwurf der Grünen, beinhaltete aber darüber hinaus konkrete Maßnahmen wie die steuerliche Anerkennung der Familienarbeit und die steuerfinanzierte Bereitstellung familienbegleitender Infrastrukturhilfen. Der Gesetzentwurf der SPD wurde in 1. und 2. Lesung beraten und am 22. Juni 1990 von der Regierungskoalition abgelehnt (vgl. Jahrbuch der SPD \{1988-90\}: C234).

Auch die öffentlichen Auseinandersetzungen um die Freigabe der Abtreibung fanden in der SPD-Führung nun eine größere Beachtung. Sie dokumentierte 1984 das Unterlaufen der Indikationsregelung beim

636 Analyse der und Berichterstattung über Frauenarbeitslosigkeit, 04.11.1987. DS 11/1086, http://dip21.bundestag.de/dip21/btd/11/o10/1101087.pdf [Zugriff: 22.10.2012].

637 In einer Großen Anfrage zum Thema „Binnenmarkt und Frauenpolitik“, 31.07.1989. DS 11/5024, http://dip21.bundestag.de/dip21/btd/11/050/1105024.pdf [Zugriff: 22.10.2012].

638 Die Realisierung eines solchen Gesetzesvorhabens war zu einem der vier Arbeitsschwerpunkte der SPD-Fraktion geworden. in: AdsD, Deposita Streletz 126

639 Der Entwurf des Antidiskriminierungsgesetzes bezog sich auf eine Initiative der Humanistischen Union von 1978, das Frauenprogramm von Marielouise Janssen-Jurreit und ein erstes Hearing zum Gesetzesvorhaben 1982 (vgl. dazu Lenz 2008: 596-6o1). 
Schwangerschaftsabbruch in den Bundesländern ${ }^{64^{\circ}}$ mit einer Tagung, auf der sie verschiedene ExpertInnen und 50 VertreterInnen von Schwangerschaftskonfliktberatungsstellen zu Wort kommen ließ, und reichte dazu eine Große Anfrage an die Bundesregierung ein. In der verschärften öffentlichen Konfrontation zwischen GegnerInnen und BefürworterInnen der Reglementierung hatten mittlerweile die Bundesfrauenkonferenzen des DGB und mehrere Einzelgewerkschaften (HBV, IG Metall, IG Drupa, ÖTV) für eine ersatzlose Streichung des § 218 (vgl. http://www.awo-schwanger.de/Der_218.html [Zugriff: 18.08.2010]) gestimmt. Diese Position war allerdings weder in der ASF noch in der Partei mehrheitsfähig.

Ende März 1987 stellte die SPD-Bundestagsfraktion einen Antrag an die Regierung, alle Gesetze auf ihre geschlechtsspezifischen Formulierungen hin zu überprüfen. ${ }^{611}$ Knapp ein Jahrzehnt vorher hatten die ASFFrauen eine solche Forderung an die sozialliberale Koalition vergeblich gestellt. Auch die damalige Aufforderung, Werbegrundsätze festzulegen sowie überholte Geschlechterrollen und entwürdigende Frauendarstellungen in den Publikationen der Bundesregierung zu verbieten, griff die SPD-Fraktion nun auf. ${ }^{642}$ Im September 1988 organisierte die SPD-Fraktion eine Anhörung ${ }^{643} \mathrm{zu}$ „Pornographie - Hinsehen oder Wegsehen“.

Männliche Gewalt gegen Frauen zu enttabuisieren und einen besseren Opferschutz zu schaffen, wurde ebenfalls zu einem Thema sozialdemokratischer Oppositionspolitik. Um die Gewalt in der Ehe strafrechtlich verfolgen zu können, brachte die SPD-Bundestagsfraktion im Juni 1987 einen neuen Gesetzentwurf ein. Er scheiterte allerdings ebenso wie

640 Die ungleiche Handhabung in den Bundesländern bezog sich auf die Hilfen und die staatliche Kontrolle der Schwangerschaftsunterbrechungen. Die Kostenübernahme des Schwangerschaftsabbruchs wurde z.B. in Bayern und Baden-Württemberg durch eine zusätzliche Verschärfung der Beratungsrichtlinien erschwert. In Bayern wurde darüber hinaus die Beihilfe für Beschäftigte im öffentlichen Dienst bei Schwangerschaftsunterbrechungen gestrichen (vgl. Jahrbuch der SPD $\{1986 / 87\}$ : 544). Bundesweit bekannt wurde ein Konflikt in Memmingen im Landkreis Unterallgäu. Hier hatte die Staatsanwaltschaft mehr als 38o Ermittlungsverfahren wegen illegalen Schwangerschaftsabbruchs eingeleitet und rund 200 Beschuldigte mit Geldstrafen von 900 bis 3.200 DM abgeurteilt. 1988 wurde der Memminger Gynäkologe Horst Theißen angeklagt. Er wurde wegen illegaler Abtreibungen bei 156 Frauen zu einer Gefängnisstrafe verurteilt, denn dieser Eingriff war in Bayern und Baden-Württemberg nur als Sonderregelung und nur in Kliniken erlaubt. Den betroffenen Patientinnen sprachen die Richter im Nachhinein die Notlage ab. Nach einem bundesweiten Protest gegen dieses Verfahren wurde in der Revision die Freiheitsstrafe des Arztes reduziert, auf Bewährung ausgesetzt und das Berufsverbot gegen ihn aufgehoben (vgl. DER SPIEGEL 1988b)

641 Jahrbuch der SPD 1 1986/87\}: 563; ebenfalls noch einmal im Antrag vom 09.05.1990.

642 Kleine Anfrage der SPD-Fraktion vom 04.02.1988.

643 Die Anhörung fand am 13./14.09.1988 statt. 
die entsprechende Gesetzesinitiative, die sie im Zuge einer Strafrechtsreform bereits 1972 vorgelegt hatte. ${ }^{644}$

Sexuelle Gewalt gegen Frauen war das Thema der Großen Anfrage der SPD an die Bundesregierung im Dezember 1984 zur Zunahme des Prostitutionstourismus 645 (vgl. Jahrbuch der SPD \{1984-85\}: 71). In einer Studie Tourismus. Prostitution. Entwicklung hatte das Stuttgarter Institut Zentrum für Entwicklungsbezogene Bildung der evangelischen Landeskirche in Württemberg auf eklatante Missstände und Menschenrechtsverletzungen bei den Betroffenen aufmerksam gemacht (Zentrum für Entwicklungsbezogene Bildung (1983).

Die frauenpolitische Profilierung der SPD stand unter starker Parteienkonkurrenz. Auf der konservativen Seite des Parteienspektrums präsentierte die CDU eine versierte Frauenpolitikerin, die Professorin für Erziehungswissenschaften Rita Süssmuth, die im September 1985 zur Bundesministerin für Jugend, Familie und Gesundheit ernannt wurde. 1986 richtete sie im Ministerium eine eigene Frauenabteilung ein ${ }^{646}$, die den Arbeitsstab Frauenpolitik ablöste. Obwohl das Ministerium geringe Zuständigkeitsbereiche hatte und auf die Kooperation mit anderen Fachministerien angewiesen war, setzte Frau Süssmuth manche Veränderungen durch, für die ihre sozialdemokratischen Vorgängerinnen erfolglos

644 Die Ablehnungen wurden damit begründet, dass kaum Aussicht bestünde, derartige "Störungen im Verhältnis der Ehepartner zueinander" (Regierungsentwurf zum Strafrechtsänderungsgesetzes, unter: http://dipbt.bundestag.de/doc/btd/13/024/130246 3.pdf:5 [Zugriff: 18.08.2010]) mit dem Mittel des Strafrechts in den Griff zu bekommen. Da geschlechtliche Beziehungen zum Wesen einer Ehe gehörten, wären die Aufklärungschancen für Gewaltanwendung oder Nötigung gering, wenn sich die Behauptungen der EhegattInnen gegenüberstünden (vgl. Sonderausschuss für die Strafrechtsreform, Drucksache VI/3121, zit. n. Waclaw 2003: 97f.). In die Ablehnungen 1987 flossen die Auseinandersetzungen um den $§ 218$ ein, eine eheliche Vergewaltigung könnte, so hieß es, behauptet werden, um eine Abtreibungsindikation zu erlangen. Erst 1997, im letzten Jahr der konservativen Regierungskoalition, und nach vielen weiteren kontroversen parlamentarischen Debatten wurde die Gewalt im privaten Raum als eine Rechtsverletzung gewertet. Erreicht wurde hierfür die Änderung der §§ 177 bis 179 StGB durch eine Initiative, die fraktionsübergreifend von den Frauen aller im Deutschen Bundestag vertretenen Parteien organisiert worden war (vgl. Waclaw 2003).

645 Die ASF hatte Gesetze gegen Menschenhandel gefordert. Den Opfern sollte ein zeitweiliges Aufenthaltsrecht gewährt und die Chance für eine Berufsausbildung eröffnet werden (vgl. Jahrbuch der SPD $\{1988-90\}$ : C233).

646 Nach dem Organisationserlass des Bundeskanzlers vom 5.6.1986 war im neuen Bundesministerium für Jugend, Familie, Frauen und Gesundheit zunächst ein neuer Zuständigkeitsbereich Frau und Beruf eingerichtet worden. Dieser wurde allerdings bereits einen Monat später wegen massiver Beschwerden aus dem Arbeitsministerium auf die Politikfelder Mutterschutz und Frauenförderung in der Bundesverwaltung reduziert (vgl. Schmidt 1989; www.gesetze-im-internet.de/bkorgerl_1986/BJNR1 o8640986.html [Zugriff: 22.06.2011]; www.gesetze-im-internet.de/bundesrecht/bkorgerl_1987/gesamt.pdf [Zugriff: 22.06.2011]. 
gekämpft hatten. Sie setzte sich dafür ein, die sog. Liebes-, Versorgungsund Pflegedienste der Mütter in der Familie als gesellschaftlich notwendige Tätigkeiten anzuerkennen und die geschlechtersegmentierten Formen gesellschaftlicher Arbeit arbeits- und versicherungsrechtlich zusammenzuführen. Rita Süssmuth unterstützte Maßnahmen zur Entwicklung der weiblichen Erwerbstätigkeit mit besonderen Förderprogrammen, z.B. bei der Berufswahlorientierung oder der Wiedereingliederung nach dem Erziehungsurlaub. Sie befürwortete betriebliche Frauenförderpläne und die Einführung von Geschlechterquoten im betrieblichen Personalmanagement - wenn auch auf freiwilliger Basis - und setzte sich für den Ausbau öffentlicher Betreuungseinrichtungen ein (vgl. Süssmuth 1989 zit. n. Lenz 2008: 615-619. ${ }^{647}$. Im sozialreformorientierten Parteienspektrum präsentierte sich die neu gegründete Partei Die Grünen geschlechterparitätisch und mit sichtbar einflussreichen Politikerinnen in den eigenen Reihen. In den Hamburger Bürgerschaftswahlkampf 1986 zog die Grün-Alternative Liste (GAL) mit einer reinen Frauenliste und dem Slogan „Einbruch in die Männerwelt“. Sie erreichte bei dieser Wahl den höchsten Stimmzuwachs aller Parteien von $+3,5 \%$ auf 10,4 \%, während die SPD mit fast -10 \% Stimmverlust die absolute Mehrheit im Senat verlor (Vgl. http://www.wahlrecht.de/ergebnisse/hamburg.htm [Zugriff: 05.05.2010] ${ }^{648}$. Für den Bundestagswahlkampf 1987 hatten Die Grünen eine paritätisch besetzte KandidatInnenliste aufgestellt und gewannen mit 8,3\% der Stimmen 15 Angeordnetensitze hinzu, während die SPD in der Opposition von 39,0 \% (1983) auf 38,1 \% (1987) WählerInnen verlor ${ }^{649}$.

647 Weitere Erfolge Rita Süssmuths waren: 1986 wurde eine Richtlinie zur beruflichen Förderung von Frauen in der Bundesverwaltung erlassen. Ab 1.1.1986 stand nach dem Bundeserziehungsgeldgesetz ein unbezahlter Erziehungsurlaub von 10 Monaten Vätern wie Müttern zu mit einer Arbeitsplatz- und nicht mehr nur einer Beschäftigungsgarantie. Außerdem erhielten beide Elternteile die Möglichkeit, in Teilzeit zu arbeiten. Der Mutterschaftsurlaub wurde als Beitragszeit in der Rentenversicherung anrechnungsfähig. Ab 1986 wurde in der Rentenversicherung ein Babyjahr gutgeschrieben, was 1972 am Widerstand der CDU gescheitert war. Die Aufhebung des kassenärztlichen Schutzes bei Abtreibungen wurde verhindert. 1987 trat das Opferschutzgesetz in Kraft, das Rechte und Schutz des Opfers im Strafverfahren regelte (vgl. Berghahn 2003; DäublerGmelin 1977). Unter ihrer Nachfolgerin Ursula Lehr, die das Ministerium 1988 übernahm, wurden im Juli 1989 das Erziehungsgeld und der Erziehungsurlaub auf 15 Monate erweitert, ein Jahr später auf 18 Monate. Die 9. Novelle des Arbeitsförderungsgesetzes 1989 sah vor, arbeitslose WiedereinsteigerInnen bevorzugt mit Einarbeitungszuschüssen zu unterstützen.

648 Vgl. Tab. 10 Ergebnisse der Landtagswahlen aller Parteien unter DOI $10.3224 / 86388794$ A.

649 Vgl. Tab. 8 Bundestagswahlergebnisse nach Geschlecht und Alter 1953-1987 unter DOI $10.3224 / 86388794 \mathrm{~A}$. 


\subsubsection{Frauenpolitische Institutionalisierungen der SPD auf Länderebene}

Auf Länderebene waren viele frauenpolitische Aktivitäten durch die sozialdemokratischen Landtagsfraktionen bereits eingeleitet worden, die in einer Fraktionsvorsitzendenkonferenz aus Bund- und Länderregierungen Ende des Jahres 1984 auf der Tagesordnung standen, beispielsweise die Einführung von Frauenförderungsplänen und die Finanzierung von Frauenprojekten (vgl. Jahrbuch der SPD \{1984-85\}: 84f.). In Hessen gab es ab 1985/86 eine eigenständige Landesbehörde Bevollmächtigte der Hessischen Landesregierung für Frauenangelegenheiten. In Hamburg, das seit 1979 über die Leitstelle für Gleichberechtigung der Frau als eigenständige Behörde verfügte, trat 1984 eine Richtlinie zur Förderung von Frauen im öffentlichen Dienst in Kraft. Im Januar 1988 ließ die Hamburger SPD-Bürgerschaftsfraktion die gesetzliche Verordnung einer Frauenförderung im öffentlichen Dienst verfassungsrechtlich prüfen. Andere Bundesländer orientierten sich an diesen Regelungen. Im Saarland wurde eine Leitstelle zur Durchsetzung der Gleichberechtigung in der Staatskanzlei geschaffen. In Niedersachsen war seit 1986 eine „Landesbeauftragte für Frauenfragen bei der niedersächsischen Landesregierung" mit Sitz in der Staatskanzlei tätig und ein Parlamentsausschuss für Gleichberechtigung und Frauenfragen eingerichtet. ${ }^{650}$ In RheinlandPfalz, Berlin, Nordrhein-Westfalen und Niedersachsen wurden Programme und Richtlinien verabschiedet und ein detaillierter Forderungskatalog zur Herstellung der Gleichberechtigung in verschiedenen gesellschaftlichen Bereichen aufgestellt (vgl. Jahrbuch der SPD \{1984-85\}: 573586.). In Bremen erließ der Senat 1988 eine Richtlinie zur Quotierung der Ausbildungsplätze, die 1990 in das Landesgleichstellungsgesetz aufgenommen wurde ${ }^{651}$. NRW verabschiedete als erstes Bundesland 1989 ein Frauenförderungsgesetz. Schleswig-Holstein richtete nach dem Wahlsieg der SPD 1988 landesweit kommunale Frauenbüros ein, sicherte die bestehenden Frauenhäuser finanziell ab und förderte den Aufbau von Notrufzentralen für vergewaltigte Frauen.

650 Darstellung nach Clemens 1996: 17f.

651 Vgl. § 31 LGG. In allen anderen Landesgleichstellungsgesetzen wurden Quotierungen entweder als „Ziel-“ oder „Entscheidungsquoten“ relativiert oder nach Ausbildungsgängen eingeschränkt, vgl. www.gew.de/binaris/Binary29488/ Landesgleichstellungsgesetz.pdf [Zugriff: 09.02.2013]. 


\subsection{Die Geschlechterpolitik im neuen Parteiprogramm und die Einführung der verbindlichen Quote (1986-1989)}

In der zweiten Hälfte der 1980er-Jahre setzte sich eine neue Frauenpolitik in der Partei durch. In Nürnberg beschloss der Parteitag 1986 die Einführung einer 40\%igen Quote als Selbstverpflichtung. Zwei Jahre später, 1988, nahm der Parteitag in Münster die Geschlechterquote in die Parteisatzung auf und überführte damit die Gleichstellungsverpflichtungen in verbindliche Verfahrensregeln. Dieser Parteitag war ganz auf den Quotenbeschluss ausgerichtet und präsentierte die SPD als eine Partei mit einer starken Frauenlobby.

Parallel dazu diskutierte die Partei ein neues Grundsatzprogramm. Die Auseinandersetzungen um eine bessere Berücksichtigung der Frauen bei der BewerberInnenauswahl waren eng verkoppelt mit Debatten um eine politische Neuausrichtung der Partei; in diesen Debatten um ein neues Grundsatzprogramm fanden die Frauenaktivistinnen vermehrt Foren für ihre Anliegen. Darüber hinaus wurde in dieser Zeit der ASF-Bundesvorstand von der Parteiführung mit einer besseren Ressourcenausstattung unterstützt.

Das neue Programm präsentierte die Partei als eine linke Volkspartei, die kritisch zu Themen der technologischen Entwicklung und der ökologischen Anforderungen an eine Industriegesellschaft, den Veränderungen der Arbeitswelt, der Gleichberechtigung der Geschlechter, zu Wettrüsten und internationalen Beziehungen Stellung bezog. Ein außerordentlicher Parteitag in Berlin nahm 1989 das neue Parteiprogramm an und ersetzte damit das Godesberger Programm von 1959.

Im Programmtext war die Frauenpolitik neu formuliert und an prominenter Position platziert. Auf dem Parteitag würdigte der Parteivorstand das langjährige frauenpolitische Engagement der ASF, denn es habe der SPD zu einer hohen Wählerinnenzustimmungen und einer wachsenden Zahl weiblicher Mitglieder verholfen. Die ASF sah im Berliner Programm das erste in der Geschichte der deutschen Sozialdemokratie, „das die gesellschaftliche Gleichheit von Frauen und Männern zu einer der drei großen Zukunftsaufgaben auf dem Weg zum demokratischen Sozialismus macht" (Rechenschaftsbericht 1990: 4). Die frauenpolitische Neuausrichtung der SPD wurde in vielen Auseinandersetzungen, aber auch mithilfe einiger taktischer Manöver errungen. 


\subsubsection{Sozialdemokratische Traditionen der Geschlechterquote}

Statuarisch definierte Mitwirkungsregelungen hatte es bereits in der SPD des 19. Jahrhunderts gegeben. 1890 beschloss der Parteitag in Halle, einen Mindestanteil von Frauen bei den Delegierten der Parteitage einzuhalten: War unter den drei Delegierten der Organisationseinheit nicht mindestens eine Frau, hatten die jeweiligen Frauenstrukturen sogar das Recht, eine eigene Delegierte zu bestimmen (vgl. § 9.1 des Parteistatuts in Sozialdemokratische Partei Deutschlands 1890: 6). 1908 beschloss die Partei, dass weibliche Mitglieder möglichst im Verhältnis zu ihrer Mitgliedschaft, mindestens jedoch mit einem Sitz in jedem Vorstand vertreten sein mussten. Auch nach der Satzung von 1925 sollte die Anzahl der Frauen in den Parteifunktionen dem Anteil der weiblichen Mitglieder in der Gesamtpartei entsprechen (vgl. Hoecker 1987: 118). Das Gebot einer Mindestrepräsentanz von Frauen in Parteivorstand und Parteirat wurde auch nach 1949 in die Satzung übernommen ${ }^{62}$ (vgl. ebenda). Auf dem Bad Godesberger Parteitag $1971^{653}$ wurde diese „Schutzklausel“ auf Betreiben der ASF-Frauen gestrichen. Zwar warnten erfahrenere Parteimitglieder wie Annemarie Renger oder Elfriede Eilers vor dieser Streichung (vgl. Parteitag der SPD, a.o. 1971), aber für die jungen ASF-Aktivistinnen war die Schutzregelung eine „leere Pralinenschachtel“ und diskriminierend, weil damit Genossinnen als Schutzbedürftige und „Alibifrauen“ erschienen, die in den Gremien nichts zur Politikgestaltung beitragen könnten (nach Darstellung von Inge Wettig-Danielmeier zit. n. Parteitag 1988: 86). Stattdessen kämpften die frauenbewegten Aktivistinnen der ASF darum, wegen ihrer politischen Kompetenzen und ihres Engagements in der Partei akzeptiert, gewählt oder aufgestellt zu werden. Dem Nürnberger Parteitag ${ }^{654} 1986$ lag erstmalig ein Antrag des Parteivorstands zur Einführung einer Quote vor (Antrag O1: vgl. PT 1986: 119, 911). Er war von der ASF weitgehend eigenständig ausgearbeitet worden und orientierte sich konzeptionell an den Konzepten der skandinavischen SozialdemokratInnen. In dem Antrag der ASF wurden die Partizipationsregelungen als Geschlechterquote bezeichnet und nicht als Frauenquote,

652 Nach $\S 13$ waren in allen Leitungen und Delegationen der Partei Frauen und junge Parteimitglieder zu berücksichtigen; nach § 24 mussten dem Parteivorstand mindestens vier Mitglieder angehören (vgl. Vorstand der SPD 1971: 395).

653 Außerordentlicher SPD-Parteitag am 17./18.12.1971 in Bonn-Bad Godesberg.

654 25.-29.8. 1986 in Nürnberg. 
wie sie die Partei Die Grünen bei ihrer Gründung 1979 eingeführt hatte. ${ }^{655}$

Im Parteivorstand selbst war die Quote zuvor nur gegen erhebliche Vorbehalte angenommen worden. Gegen die Vorlage stimmten zwar nur zwei Vorstandsmitglieder und eines enthielt sich, aber zur Abstimmung waren bloß 26 der 40 Beteiligten erschienen (vgl. Apel 1991: 451). Der folgende Parteitag nahm die Quote ohne kontroversen Debatten an. Auch in der Presse fand dieser Parteibeschluss wenig Interesse, einen ähnlichen hatte bereits die CDU im Vorjahr angenommen.

Eine Geschlechterrepräsentanz von $40 \%$ sollte von nun an in allen Parteigremien ${ }^{656}$ als Selbstverpflichtung gelten. Dem Mehrheitsentscheid war förderlich, dass der Nürnberger Parteitag im Vorwahlkampf stattfand und von ihm „ein Signal ausgehen“ (Parteitag der SPD 1986: 427) sollte; außerdem waren $26 \%$ der Delegierten Frauen. Damit hatte dieser Parteitag die höchste Frauenpräsenz in der Geschichte der SPD zu verzeichnen.

Auf dem Nürnberger Parteitag wurde auch ein Gleichstellungsplan angenommen, den Vorstand und Personalrat der SPD ausgehandelt hatten. Er sah vor, ab o1.11.1986 Frauen bei neu zu besetzenden Stellen so lange bevorzugt zu berücksichtigen, bis ein Beschäftigtenanteil von $50 \%$ erreicht war. In allen Organisationen und Unternehmen, in denen die Partei Personalvorschläge einbringen konnte, wie in Rundfunkräten ${ }^{657}$ oder in Organen der Rechtsprechung, sollte entsprechend verfahren werden.

Ziel der Quotenregelung war es, in den 1990er-Jahren eine paritätische Geschlechterrepräsentanz in der Partei erreicht zu haben. Diese Geschlechterverteilung sollte stufenweise durchgesetzt werden: Zunächst sollten die Geschlechter gemäß dem Mitgliederanteil berücksichtigt werden, jedoch sollten Frauen und Männer mindestens zu je $25 \%$ in allen Gremien vertreten sein. In den folgenden Jahren sollte die Quote sich sukzessive auf Parität erhöhen und damit der Bevölkerungsstruktur ent-

655 Die Grünen hatten durch ihre Geschlechterpolitik und Wahlerfolge Maßstäbe gesetzt: In der jungen Partei war schon 1980 die Frauenquote als Sollvorschrift eingeführt wurden. Ab 1986 wurde sie in die Statuten aufgenommen. Es galt eine verpflichtende geschlechterparitätische Besetzung für alle Ämter und Wahllisten, aber auch die Möglichkeit reine Frauenlisten aufzustellen. In parteiinternen Debatten wurden die RednerInnenlisten im Reißverschlussverfahren geführt, außerdem hatten Frauen bei Parteibeschlüssen ein aufschiebendes Vetorecht.

656 Die 40-\%-Quote entsprach einer semiparitätischen Quote, rechnerisch umgesetzt.

657 Willy Brandt nannte es einen „Skandal“, dass unter mehr als zo KommentatorInnen in der ARD nur eine einzige Frau beschäftigt war, und forderte die Sender zur Erstellung von Frauenförderplänen auf (vgl. Jahrbuch der SPD o.J. \{1991-1992\}: C237). 
sprechen. Um alle Parteieinheiten auf dieses Organisationsziel zu verpflichten, beauftragte der Nürnberger Parteitag 1986 den Parteivorstand, Sanktionen im Falle der Nichterfüllung zu entwickeln ${ }^{658}$ und einen Weg zur Veränderung der Wahlsysteme zu erarbeiten, denn der hohe Anteil der Ein-Personen-Wahlkreise stand einer geschlechterparitätischen Mandatsverteilung entgegen ${ }^{69}$. Außerdem hatte die Quotierung bei all den Landtagswahlen wenig Wirkung, bei denen die Nachrücklisten wegen der hohen Zahl der Direktmandate kaum zum Einsatz kamen.

\subsubsection{Die Bundestagswahlkampagne $1987 \mathrm{mit}$ frauenpolitischem Profil}

In den Ausgang der Bundestagswahl 1987 setzte die SPD viel Hoffnung, denn die Ergebnisse der Landtagswahlen seit dem Regierungswechsel 1983 ließen auf eine schrumpfende Unterstützung der konservativen Regierungskoalition durch die WählerInnen schließen. ${ }^{660}$ Alles deutete darauf hin, dass das Frauenthema ein dominantes Thema dieser Wahl 1987 werden würde. Im Regierungsprogramm der SPD für die 11. Wahlperiode war deshalb die Gleichstellungspolitik zu einem zentralen Handlungsfeld sozialdemokratischer Politik erklärt worden, die Zahl der weiblichen WahlkandidatInnen hatte sich mehr als verdoppelt. Die ASF-Leitung wurde durch eine verbesserte Ausstattung ihrer Ressourcen unterstützt. Das Büro des ASF-Bundesvorstands wurde auf drei Vollzeit- und zwei Teilzeitkräfte erweitert, dafür hatte der ASF-Bundesvorstand Jahre zuvor vergeblich gekämpft ${ }^{661}$. Für den Wahlkampf 1987 wurde außerdem eine Pressereferentin für Frauenfragen vom Parteivorstand eingesetzt. Darüber hinaus wurde die Gleichstellungskommission des Parteivorstands von einer vorübergehenden Arbeitsstruktur in eine feste Einrichtung umgewandelt.

In der Wahlkampfkampagne „Frauen auf Touren“ fuhr ein weibliches Wahlkampfteam aus Bundestagskandidatinnen, Europaabgeordneten und weiblichen Vorstandsmitgliedern. In einem Kleinbus ging es zu lo-

$658 \mathrm{Im}$ Gespräch waren z.B. die Aberkennung von Stimmrechten bei Delegationen oder die Reduzierung von Zuwendungen im innerparteilichen Finanzausgleich.

659 Als Wahlkreisreform schlug Bundesgeschäftsführer Peter Glotz den Zweierwahlkreis als Grundgröße vor (vgl. Glotz zit.n. Parteitag der SPD 1986: 431).

66o Vgl. dazu Tab. 12 Frauenanteil bei den Abgeordneten im Deutschen Bundestag 1949-1994 nach Parteien (in Prozent) zu Beginn der Wahlperiode unter DOI 10.3224/86388794A.

661 Diese Ressourcen wurden aber weitgehend von den aktivierten Bezirken und Landesverbänden in Anspruch genommen, in denen noch keine eigene Frauenreferate durchgesetzt worden waren, wie die ASF-Bundesvorsitzende anmahnte (vgl. Rechenschaftsbericht 1990: 2). 
kalen Wahlkampfveranstaltungen in 45 Kommunen. Fahrdienst und Audiotechnik wurden ausschließlich von Frauen organisiert (vgl. Rechenschaftsbericht 1987: 35f.). Bereits 1986 hatte sich der Parteivorstand am Internationalen Frauentag mit einer Veranstaltung im Erich-Ollenhauer-Haus beteiligt.

Auf der Bundesfrauenkonferenz im Oktober 1987 würdigte der Parteivorsitzende Hans-Jochen Vogel die ASF-Frauen als treibende Kraft für die Neuausrichtung der SPD, weil sie durch ihre

Impulse die Partei vorangebracht, zumindest aber verhindert haben, daß ihr die Füße einschliefen. Es waren Genossinnen, die zumeist früher als andere den Kontakt zu den neuen Bewegungen aufgenommen und in ihnen mitgearbeitet haben. Und zwar nicht nur in der Frauenbewegung, sondern auch in der Friedensbewegung, in der Ökologiebewegung und in der Dritte-Welt-Bewegung. Ebenso haben sich Frauen schon früh an den Diskussionen und Lernprozessen beteiligt, die zu den Nürnberger Beschlüssen auf dem Gebiet der Friedenssicherung und auf dem Gebiet der Energiepolitik und hier vor allem zum endgültigen Nein zur Atomenergie geführt haben. (Hans-Jochen Vogel, Gastrede auf der ASF-Bundeskonferenz 1987, Berlin X-21-ASF)

Doch die erhoffte Wählerinnenresonanz stellte sich nicht ein. Trotz des Stimmeneinbruchs bei der CDU/CSU sank der Anteil der SPD-Stimmen in dieser zweiten Bundestagswahl von 38,9\% (1983) auf 38,1\% (1987). Nennenswerte Stimmengewinne konnten 1987 nur die FDP und die Grünen verbuchen. Die SPD hatte insbesondere die Wählerinnen verloren, ihre Unterstützung lag mit 37,8 \% sogar wieder unter derjenigen der Wähler mit 38,5\%. Zwar blieb die SPD in der Altersgruppe bis 35 Jahre bei beiden Geschlechtern die meistgewählte Partei, aber der Stimmenzuwachs der Grünen war hier besonders prägnant: Bei den Frauen in der Altersgruppe 18 bis 25 Jahre lag er bei $+3 \%$ (bei den gleichaltrigen Männern: $+0,3 \%$ ) und in der Altersgruppe 25 bis 35 Jahre bei $+7,8 \%$ (bei den gleichaltrigen Männern: $+5,4 \%)^{662}$

Nach dieser Bundestagswahl entstanden in der Partei Zweifel an dem zielgruppenspezifischen, auf Frauen ausgerichteten Wahlkampfkonzept. Eine Wahlforschungsstudie von 1990 kam auf der Grundlage von Umfragen zu dem Ergebnis, dass nur für $13 \%$ der befragten Frauen und nur für 10 \% der Männer die Geschlechter der Kandidierenden bei der Wahlentscheidung eine Rolle spielte (vgl. Kinzig 2007). Insgesamt wurde

662 Vgl. Tab. 8 Bundestagswahlergebnisse nach Alter und Geschlecht 1953-1987 unter DOI $10.3224 / 86388794$ A. 
ein Trend zur Angleichung des weiblichen und männlichen Wahlverhaltens prognostiziert (vgl. Hoecker 1995: 63-65). Dagegen beklagte der ASF-Bundesvorstand eine schlechte Umsetzung des Nürnberger Quotenbeschlusses. Trotz der hohen Kandidatinnenzahl bei der Bundestagswahl 1987 berichtete er von großen Schwierigkeiten in den Auswahlverfahren und ungleichen Wahlchancen der Geschlechter (vgl. Rechenschaftsbericht 1987: 43): 88 \% der direkt Gewählten, d.h. in sicheren Wahlkreisen der SPD aufgestellten KandidatInnen, waren männlich. ${ }^{663}$ Aussichtslose Wahlkreise und schlechte Platzierungen der Kandidatinnen in den „Knautschzonen“ der Listen hatten dazu geführt, dass schließlich nur 31 der 186 SPD-Abgeordneten (16,1\%) im 11. Bundestag weiblich waren (vgl. Gleichstellungsbericht 1988: 887). ${ }^{664}$

Weniger kontrovers wurden in der Partei die positiven Wirkungen des frauenpolitischen Wahlkampfprofils der SPD auf die Entwicklung der Parteimitgliedschaft beurteilt. Der Mitgliederverlust und ein relativ hoher Frauenanteil von durchschnittlich 33 \% bei den Neueintritten hatten den Frauenanteil in der Gesamtmitgliedschaft kontinuierlich steigen lassen: von 17,8\% (1971), 20,25\% (1975), 23,08\% (1980) auf 27,23\% (1990). ${ }^{665}$ Die SPD gewann mehr weibliche Neumitglieder als ihre Parteikonkurrenz. 1986 hatte die Zahl der weiblichen SPD-Mitglieder mit 232.00o Personen die Rekordmarke von 1930 geknackt, 1990 war die Zahl auf 250.906 angestiegen. ${ }^{666}$

663 In den Bundestag 1987 wurden bei der SPD nur 58 \% über die Zweitstimme gewählt. Die anderen $42 \%$ der SPD-Abgeordneten waren Direktkandidaturen; vgl. Tab. 13 SPDMandate nach Direkt- und Listenwahl und Geschlecht. 11. Wahlperiode unter DOI $10.3224 / 86388794$ A.

664 Mit 31 Frauen saßen in der 11. Legislaturperiode für die SPD allerdings 50 \% mehr weibliche Abgeordnete im Bundestag als in der 10. Legislaturperiode mit 21 Mandatsträgerinnen (vgl. Gleichstellungsbericht 1988: 887). Bezog man die Repräsentanz der Geschlechter nicht auf die Wahlberechtigten, sondern auf die jeweilige weibliche Parteimitgliedschaft, waren Frauen in den Fraktionen der PDS, Bündnis 9o/Die Grünen, SPD sogar überrepräsentiert, in der CDU und FDP entsprachen sie der parteiinternen Geschlechterverteilung (vgl. Edinger/Holfert 2005); vgl. Tab. 11 Abgeordnete im 11. Bundestag unter DOI 10.3224/86388794A.

665 Vgl. Tab. 5 Entwicklung der SPD-Mitgliedschaft nach Geschlecht unter DOI $10.3224 / 86388794$ A..

666 Ab 1991 allerdings überwogen auch bei den Frauen die Abgänge die Neuzutritte und der Frauenanteil an der Mitgliedschaft stieg nur noch relativ aufgrund der hohen Mitgliederverluste bei den Männern (vgl. Tab. P2 Mitgliederentwicklung der Parteien. Neumitglieder. Frauenanteil unter DOI 10.3224/86388794A.). 


\subsubsection{Verfahren zur Umsetzung der Quote in der Partei}

Aufgrund der Erfahrungen im Vorfeld der Bundestagswahl 1987 forderte der ASF-Bundesvorstand nachdrücklich eine verbindliche Quotenregelung. Um die Quote in der Satzung zu verankern, beschloss der Parteivorstand, zwei unterschiedliche Quotenziele einzuführen. Sie sollten in mehrschrittigen Verfahren realisiert werden. ${ }^{667}$ Eines galt für alle innerparteilichen Funktionen. Hier sollte die paritätische Quote in zwei Etappen realisiert werden; für die Parteiämter galt ab 1988 eine 33-\%-Quote, ab 1994 eine 40-\%-Quote, wobei für deren Wahl getrennte Listen für männliche und weibliche KandidatInnen ${ }^{668}$ aufgestellt werden mussten. Das andere Verfahren war bei der Vergabe von Mandaten, $d$. h. bei den KandidatInnenwahlen zu Europa-, Bundestags-, Landtags- und Kommunalparlamenten, anzuwenden. Hier galt ab 1990 galt eine 25-\%-, ab 1994 eine 33-\%- und ab 1998 eine 40-\%-Quote und die Aufstellung der KandidatInnenlisten hatte von der Spitzenkandidatur aus nach Geschlechtern alternierend zu erfolgen. Die Rechtmäßigkeit der Quote, ihre Verfassungskonformität und ihre Vereinbarkeit mit dem Wahlrecht hatte der Parteivorstand von StaatsrechtlerInnen und PolitikwissenschaftlerInnen prüfen lassen. Auf einem Elisabeth-Selbert-Kolloquium am 28.10.1986 bekundeten VerfassungsjuristInnen öffentlich, dass ein Quotenverfahren der Gestaltungsfreiheit der Parteien entspräche, es sollte aber nach den Begutachtungen durch Prof. Dr. Ingwer Ebsen und Prof. Dr. Ernst Benda, dem ehemaligen Präsident des Bundesverfassungsgerichts, nur eine Anstoßfunktion haben. Deshalb wurde die Quotenregelung vom Parteivorstand auf einen Wirkungszeitraum von 15 Jahren begrenzt. Zunächst lief sie zum 31.12.2013 aus ${ }^{669}$ (vgl. Jahrbuch der SPD \{1988-90\}: C228). Als für den nächsten Parteitag eine entsprechende Änderung der Parteistatuten auf die Tagesordnung gesetzt wurde, entwickelte sich die Quote zum zentralen Thema der innerparteilichen Auseinandersetzung.

667 Sitzung vom 20.10.1987 in Akten des PV 1251.

668 § 8 der Wahlordnung Absatz 1: Bei Listenwahlen werden zunächst Frauen und Männer für je $40 \%$ der zu besetzenden Parteiämter mit getrennten Listen gewählt; für die restlichen $20 \%$ der zu besetzenden Parteiämter werden Frauen und Männer mit einer gemeinsamen Liste gewählt. Abweichend von Satz 1 können Bezirkssatzungen und Unterbezirksstatute ein anderes Wahlverfahren zur Mindestabsicherung von Frauen und Männern in Funktionen der Partei vorsehen (vgl. Dokumentation in Quotendebatte 1988).

669 Diese zeitliche Befristung wurde auf dem Bochumer Parteitag 2003 aufgehoben. 


\subsubsection{Quotenbeschluss auf dem Parteitag in Münster 1988}

1988 lag dem Münsteraner Parteitag ${ }^{670}$ ein Antrag zur Einführung der Quote in die Satzung vor. Damit sollte erreicht werden, so der Vorsitzende Hans-Jochen Vogel, den Frauen „die Repräsentanz einzuräumen, die ihrer Bedeutung gerecht wird“ (Hans-Jochen Vogel zit. n. Parteitag der SPD 1988: 52). Der gesamte Parteitag war auf den Quotenbeschluss ausgerichtet, er stand im Mittelpunkt der medialen Präsentation, selbst der Veranstaltungsort war danach ausgewählt worden, denn in Münster war die erste Quotenregelung in der Partei eingeführt worden. Im Vorfeld des Parteitags stieß die Quote in der Presse auf überwiegend auf positive Resonanz. ${ }^{61}$

Das Gleichstellungsthema stand bereits auf der Tagesordnung des ersten Verhandlungstages. Der Antrag des Parteivorstands O1 Die Gleichstellung von Männern und Frauen in der SPD wurde vom Parteivorstand als „historische Entscheidung“ (Heidemarie Wieczorek-Zeul zit. n. Jahrbuch der SPD \{1988-90\}: B13) inszeniert.

Für die Parteiführung ging es um einen „Glaubwürdigkeitsschub“ für die Partei: „Für die Frauenpolitik bedeutet diese Satzungsänderung das gleiche wie für die Energiepolitik der Ausstieg aus der Kernenergie." (Renate Schmidt zit. n. Parteitag der SPD 1988: 106) Trotzdem war die Quote in der Partei nach wie vor umstritten. Der Parteivorsitzende hatte deshalb vor dem Parteitag die Mehrheitsverhältnisse in Probeabstimmungen prüfen lassen. ${ }^{672}$

Für Hans-Jochen Vogel verbanden sich mit der Quote Hoffnungen auf eine Erneuerung und Belebung der Partei jenseits der Lagerbildung, er appellierte deshalb an die Delegierten:

... es wäre fatal, wenn wir auf der letzten Treppenstufe wieder umkehren ... Unsere Gesellschaft und unsere Politik können nur gewinnen, wenn sie - das gilt auch für große gesellschaftliche Organisationen - stärker als bisher von weiblichen Grunderfahrungen und weiblichen Denk- und Verhaltensstrukturen geprägt werden. Wer nur die quantitative Dimension sieht, greift zu kurz. (Parteitag der SPD 1988: 53)

670 Parteitag 30.08.-02.09.1988 in Münster.

671 Allerdings gab es auch ironische Kommentare. Die Stuttgarter Zeitung schrieb am 13.07.1988: „Ein Gespenst geht um. Unbedarft und ohne Weitblick für das Wesentliche kommt es auf Stöckelschuhen daher, lehrt selbst den mannhaften Bürger das Fürchten: die Quotenfrau“" (zit. n. Inge Wettig-Danielmeier in Parteitag der SPD 1988: 84).

672 Vgl. zur Angst vor einer Ablehnung der Quote auf dem Parteitag auch FR 27.05.1988: Die Koalition der Neinsager braucht nur jede dritte Stimme. 
Inge Wettig-Danielmeier versprach dazu für die ASF: „Das wird unsere Partei verändern. Das wird auch die Politik verändern [...][,] die Kreativität, die Ideen, die Spontaneität der zur Mitarbeit bereiten Frauen.“ (Parteitag der SPD 1988: 90).

Der Parteitag wurde durch eine unangemeldete Aktion unterbrochen. Eine Gruppe Münsteraner Frauen zog als Suffragetten verkleidet und mit Transparenten ausgestattet durch den Saal auf das Podium, nachdem sie zuvor den Sicherheitsdienst überlistet hatten. ${ }^{673}$ Mit dieser Kostümierung stellten die Genossinnen nicht nur einen Bezug her zwischen Quoten und demokratischen Grundrechten, sondern bekannten sich zu einer frauenrechtlerischen Tradition jenseits der Sozialdemokratie.

Obwohl die Satzungsänderung mit einer Mehrheit von $87 \%{ }^{674}$ angenommen wurde, galt der Quotenbeschluss als eine in der Partei „von oben durchgedrückte" Entscheidung. Zwar konnte der Parteivorstand im Allgemeinen mit einer hohen Loyalität der Delegierten gegenüber den politischen Vorlagen der Parteiführung rechnen, darüber hinaus war die Testabstimmung positiv verlaufen, aber der Parteivorsitzende wollte die notwendige 2/3-Mehrheit für eine Satzungsänderung unbedingt sicherstellen. Er setzte durch, dass die Abstimmung nicht geheim erfolgte, um den KritikerInnen und SkeptikerInnen den Mut für eine Ablehnung zu nehmen. Nur wenige Delegierte sprachen sich auf dem Parteitag offen gegen die Statutenänderung als „Muß-Quote“ oder „Zwangsquote“ 675 aus, auch wenn der Vertreter der Antragskommission, Peter von Oertzen, die mangelnde Akzeptanz im Vorfeld des Parteitags thematisiert

673 Die Münsteranerinnen hatten von ihrer geplanten Aktion im Vorfeld nur den Bundesvorstand der ASF informiert. Dieser war von der Aktion nicht begeistert, berichtet Brigitte Stresser, eine der Teilnehmerinnen, und hatte deshalb die Versammlungsleiterin Herta Däubler-Gmelin gebeten, auf jeden Fall zu verhindern, dass der Zug die Bühne erreicht. Die Vorstandsfrauen befürchteten, dass die Aktion das Lager der QuotengegnerInnen stärken könnte, weil die Delegierten die Aktion als unpassend und politisch unseriös empfinden könnten. Aber Herta Däubler-Gmelin weigerte sich. Brigitte Stresser schilderte den Verlauf der Demonstration: „Mit der Überwindung des Sicherheitsdienstes war sowieso alles zu spät. Wir waren im Saal und die Presse stürzte sich sofort auf den Umzug“" (Mündlicher Bericht auf der ASF-Festveranstaltung zur Quote 31.08.2008). Die Vorsitzende Herta Däubler-Gmelin unterbrach die Sitzung für das Pressefoto und kommentierte: „Die Kostüme sind ja wunderschön“ (Parteitag der SPD 1988: 90). Die Bilder der Aktion wurden zu zeitgeschichtlichen Dokumenten des Münsteraner Parteitags.

674 36,6 \% aller Delegierten auf dem Münsteraner Parteitag 1988 waren Frauen. Alle Teilnehmerinnen an der Debatte sprachen sich für die Quote aus.

675 Die KritikerInnen kamen aus Baden-Württemberg und Rheinland-Pfalz. 
hatte. ${ }^{676}$ Ludwig Stiegler ${ }^{677}$ erinnerte sich auf einer Veranstaltung der SPD-Fraktion rückblickend an die Zwänge und Vorbehalte bei der Abstimmung:

[D]iese Quotenregelung war eine strukturelle Revolution von oben. [...] Ich habe jedenfalls für mich gesagt, wenn schon diese alten Positionen nicht zu halten sind, weil es keinen nachvollziehbaren Grund gibt, sie zu halten, dann laß es uns gleich machen, damit wir es hinter uns haben (Ludwig Stiegler MdB zit. n. Schmidt 1989: 47).

Dabei war die Vorlage zur Satzungsänderung in wichtigen Aspekten entschärft worden: So war auf Sanktionen komplett verzichtet worden ${ }^{678}$; die Quotenregelung war zeitlich befristet; die scharfe Quotenregelung bezog sich nur auf die Besetzung der Parteifunktionen; das ursprüngliche Vorhaben, Quoten auch in all denjenigen Gremien einzuführen, an deren personeller Besetzung die Partei beteiligt war, wie z.B. bei den attraktiven Rundfunkräten, war fallengelassen worden.

Nach dem Parteitag, schilderte Ludwig Stiegler auf einem Seminar der SPD-Fraktion 1989, wären die Delegierten in den Unterbezirken oft scharf kritisiert worden:

[D]ie Kollegen sagen sich: ,schau mal diesen Sauhund an, Opportunist, will sich anwanzen' [...] das ist so ein ganz manifester Verdacht unter dem man steht [...][,] die Kollegen sagen: ,Hier bitte schön, Ihr einigt Euch da auf Kosten unserer Lebenschancen und Lebensvorstellungen' (Ludwig Stiegler MdB zit. n. Schmidt 1989: 47f.)

Der Münsteraner Parteitag, dem ein 21-seitiger Bericht zur Gleichstellung der Frauen in der Partei vorlag679, verabschiedete außerdem verschiedene gleichstellungs- und frauenpolitische Anträge zur familiengerechteren Gestaltung des Arbeitslebens und zur sozialen Sicherung von

676 Peter von Oertzen, Vorsitzender der Antragskommission: „Es ist hin und wieder darauf hingewiesen worden, dass die Zustimmung zur Quotenregelung nicht immer ganz frohen Herzens zustande gekommen sei“ (Parteitag der SPD 1988: 93).

677 Damals Vorsitzender der bayrischen Landesgruppe im Deutschen Bundestag.

678 Finanzielle Sanktionen schieden wegen der unterschiedlichen Finanzstärke der Bezirke aus. Eine Aberkennung von Delegierten bei nicht eingehaltener Quote drohte Parteistrukturen zu schwächen und Verfahrensabläufe zu stören.

679 Mit detailliertem Zahlenmaterial zur Beteiligung der Frauen an Mandaten, in den Entscheidungsgremien der Partei auf allen Organisationsebenen, den Aktivitäten als Referentinnen, Teilnehmerinnen in der Bildungsarbeit und ihrem Anteil an den hauptamtlich Beschäftigten. 
Müttern ${ }^{680}$. Sie blieben allerdings im Schatten der Quote und wurden in der Partei zunächst wenig beachtet.

Der Quotenbeschluss des Münsteraner Parteitags dagegen gilt als ein herausragendes historisches Ereignis in der Geschichte der deutschen Sozialdemokratie und als Vorreiter für andere große Organisationen und Verbände (vgl. Jahrbuch der SPD \{1988-90\}) ${ }^{681}$. Im Glückwunschtelegramm der CDU lobte Bundesfamilienministerin Rita Süssmuth die Quotenregelung als „Schubkraft für die Frauenpolitik insgesamt" 682 (dpa-Meldung vom 11.09.1988).

\subsection{5 „Die Partei ging schwer mit“: Die Quote als Karrierezugang für Frauen ${ }^{68}$}

Im Zuge der Quotierungsauflagen veränderte sich der Zugang für Frauen zu Spitzenpositionen in der Partei deutlich. Anke Fuchs ${ }^{684}$ war auf dem

680 Zur sozialen Sicherung von Müttern gehörte die Erweiterung der Freistellung im Krankheitsfall für beide Elternteile von 5 auf 10 Tage pro Jahr und Kind bis zu einem Alter von 12 statt bisher 8 Jahren; Kündigungsschutz für alle Berufe und bis zu vier Monate nach der Schwangerschaft, Erweiterung des Elternurlaubs auf drei Jahre, unterstützt mit Elterngeldern und Zuschüssen aus der Arbeitsverwaltung; Verlängerung der Mutterschutzfrist auf drei Monate; Aufstockung der Alterssicherung für Mütter durch die staatliche Finanzierung der ausgefallenen Rentenbeiträge während der Kindererziehungszeiten.

Auf das Arbeitsleben bezogen sich folgende Forderungen: Verpflichtung der Kommunen zur Frauenförderung durch quotierte Ausbildungsplätze; Frauenförderpläne als Vergabekriterium bei öffentlichen Aufträgen oder Subventionen; Bevorzugung von Frauen bei Einstellung und interner Besetzung bei gleicher Qualifikation; Verbesserung der Weiterbildung und Aufstiegsmöglichkeiten für weibliche Bedienstete; Einrichtung qualifizierter Teilzeitarbeiten; familiengerechte Arbeitszeiten; Umsetzung von frauenfördernden Maßnahmen als Beförderungskriterium für Führungskräfte (vgl. angenommender Antrag K3 Westl. Westfalen in Parteitag der SPD 1988: 823f.).

681 Im gleichen Jahr verabschiedete die Gewerkschaft Öffentliche Dienste, Transport und Verkehr (ÖTV), die mitgliederstärkste Gewerkschaft des DGB, auf einem Gewerkschaftstag die verbindliche Quotierung für alle Funktionsebenen.

682 Für ihre eigene Partei sah sie in der Quote keine Schubkraft. Eine Zeitzeugin erinnert sich an einen Kommentar von Rita Süssmuths: „[D]ie CDU brauche das nicht, weil die CDU-Männer wüssten, was sie an ihren Frauen hätten“ (Zz 8).

683 Zitat von Inge Wettig-Danielmeier auf der Festveranstaltung „Reicht's schon? 20 Jahre Quote“ der ASF und Jusos in Münster am 31.08.2008.

684 Die politische Karriere begann für Anke Fuchs, als die junge Juristin in den Vorstand der Gewerkschaft IG Metall gewählt wurde, zuständig für Frauenarbeit. 1977 ernannte sie Helmut Schmidt zur Staatssekretärin. 1980 wurde sie in den Bundestag gewählt und erhielt das Amt der Parlamentarischen Staatssekretärin beim Bundesministerium für Arbeit und Sozialordnung. Ihrem Wirken wird das Mutterschaftsurlaubsgesetz (4 Mo- 
außerordentlichen Parteitag 1987 in Bonn als erster Frau die Geschäftsführung der Partei übertragen worden. Auf dem Münsteraner Parteitag 1988 wurde mit Herta Däubler-Gmelin zum ersten Mal in der Geschichte der SPD eine Frau zur Bundesparteivorsitzenden gewählt - allerdings nur als Stellvertreterin und nachdem die StellvertreterInnenpositionen auf drei erhöht worden waren. Als Folge des Quotenbeschlusses von 1986 war der Frauenanteil im Parteivorstand auf $25 \%$ und im Präsidium auf $27 \%$ angestiegen (vgl. Gleichstellungsbericht 1986). Der auf dem Münsteraner Parteitag 1988 gewählte Parteivorstand ${ }^{685}$ holte vier Genossinnen in das elfköpfige Präsidium. Damit erzielte dieses Gremium einen Frauenanteil von über $36 \%$. Ab 1990 lag der Frauenanteil an den Bundesparteitagsdelegierten bei mindestens $40 \%$, auch wenn der Anteil zwischen den verschiedenen Bezirken erheblich schwankte, vergleichbar hoch stieg der Frauenanteil am Parteirat (vgl. Gleichstellungsbericht 1995: 238). In den Kommissionen des Parteivorstands hatte sich die Beteiligung der Frauen ebenfalls erhöht und lag bereits 1988 bei einer Rate von $26 \%$, allerdings ohne die klassischen Bereiche Soziales, SeniorInnen, Jugend, Gleichstellung, VerbraucherInnenschutz und Familienpolitik bei $20 \%$. Die im Herbst 1987 gegründete Parteischule startete quotiert mit einem Frauenanteil von 36,7\% im Vorstand und 28,7\% im Beirat (vgl. Rechenschaftsbericht 1990).

Auch auf niedrigeren Parteiebenen hatte sich die Partizipation der Frauen erhöht.

Zwei Jahre nach dem Münsteraner Beschluss berichtete Inge WettigDanielmeier im deutschen Bundestag, dass die Quote von 40 \%, die eigentlich erst ab 1994 für alle Funktionen in der SPD gelten sollte, bereits in der Mehrzahl der Bezirks- und Landesvorstände verwirklicht worden wäre $^{686}$ (vgl. Jahrbuch der SPD \{1988-90\}: C230). Allerdings hätten sich auch in den quotierten Wahlverfahren Geschlechterhierarchien umgesetzt: „Es hat sich die Faustregel durchgesetzt: Mann an der Spitze, Frau

nate Mutterschaftsurlaub mit Kündigungsschutz) von 1979 zugeschrieben, das als „soziale Komponente" zu den Konjunkturprogrammen der 1970er-Jahre und den unternehmensbezogenen Steuererleichterungen der Schmidt-Regierung durchgesetzt worden war (vgl. dazu Dowe/Schneider 2007). Anke Fuchs war keine ASF-Frau, trotzdem hatte die ASF bereits 1979 den Parteivorstand aufgefordert, Anke Fuchs zur stellvertretenden Vorsitzenden der SPD zu wählen (vgl. Initiativantrag 8 in SPD/ASF 1979a: 15). 685 Sitzung vom 12.09.1988.

686 Nach dem Gleichstellungsbericht 1991 lag der Frauenanteil in 20 der 27 Landes- und Bezirksvorständen über $40 \%$, wobei in acht der Vorstände der Anteil der Frauen bereits vor 1986 dem jeweiligen Mitgliederanteil entsprochen hatte. Nur in zwei neuen Bundesländern lag der Frauenanteil in den Landes- und Bezirksvorständen unter der vorgeschriebenen 25-\%-Marge. Die Zahl der weiblichen Unterbezirksvorsitzenden in der Partei hatte sich verdoppelt (vgl. Gleichstellungsbericht 1986: 239). 
als Vize. Quotierte Gremien wählen mehrheitlich einen Vorsitzenden und seine Stellvertreterin." (Wettig-Danielmeier zit. n. Weis 1995: 76) ${ }^{687}$ Trotz gleichstellungspolitischer Vereinbarungen ${ }^{688}$ waren die hauptamtlichen MitarbeiterInnen, bes. in Leitungsfunktionen, mehrheitlich männlich. 1991 lag der Frauenanteil in den Geschäftsführungen der Kreise und Unterbezirke bei knapp $12 \%$, die Geschäftsstellenleitungen der Bezirke und Landesverbände sowie die Abteilungsleitungen beim Parteivorstand wurden von Männer gestellt (vgl. Gleichstellungsbericht 1991: 33). ${ }^{689}$

Die größten Konflikte in der Partei um die Umsetzung der Quote aber entstanden um den Zugang der Frauen zu politischen Mandaten. Die Durchführungsbestimmungen der Quotenregelung sollten für einen moderaten Wandel sorgen und die Wahlchancen der Männer nicht verschlechtern (vgl. Wettig-Danielmeier 1998: 42), nur die Besetzung von KandidatInnenlisten wurde quotiert, Direktmandate blieben von der Quote ebenso unberührt wie Einzelbesetzungen ${ }^{60}$ (vgl. Junker 1993: 2). Trotzdem stellte die Quote manche gesetzte Anwartschaft infrage und die vermehrte politische Konkurrenz ließ vermutlich die Lebenspläne einiger junger Bewerber verwehen, die sich von ihrer Ochsentour durch die Parteibasis den gesicherten Einstieg in eine berufliche und Existenzsichernde Politikerkarriere versprochen hatten (vgl. zu dieser Entwicklung Beyme 2004). Die Besetzung der SPD-Mandate im 11. Bundestag (1987-1990) spiegelte die ungleiche Verteilung der Wahlchancen. Für den Wahlkampf waren in der SPD aus 100 Bewerberinnen 43 Direktkandidatinnen aufgestellt worden (vgl. Gleichstellungsbericht 1988: 887). 9

687 Auch neun Jahre nach dem Quotenbeschluss stelle sich die SPD noch als eine „Partei der Stellvertreterinnen“ dar, beklagt die ASF-Bundesvorsitzende in ihrem Gleichstellungsbericht 1995 (vgl. Gleichstellungsbericht 1995: 238). Zwei Jahre später dokumentierte der Gleichstellungsbericht, dass zwar der Frauenanteil in den Bezirksvorständen nur noch in einem Bezirk knapp unter der 40-\%-Marge lag, aber nur vier der 25 Landesverbände und Bezirke eine weibliche Vorsitzende besaßen (vgl. Gleichstellungsbericht 1997: 261f.).

6881988 schloss der Parteivorstand mit dem Betriebsrat der SPD eine Betriebsvereinbarung zur Gleichstellung ab, die sich allerdings im Wesentlichen an den bereits im öffentlichen Dienst bestehenden Regelungen orientierte (vgl. Abdruck in Gleichstellungsbericht 1991: 30-32).

689 Die Besetzung dieser Positionen hatte sich auch 20 Jahre später noch nicht geändert (vgl. Gleichstellungsbericht 2011: 36-38)

69o Direktmandate galten als nicht quotierungsfähig. In der Folge sank der Anteil weiblicher Abgeordneter nach erfolgreichen Wahlkämpfen, wie zuletzt bei den jüngsten Landtagswahlen in NRW am 13.05.2012; 14. WP: 41,89 \%, 15. WP: 28,36 \%, 16. WP:33,3\% (vgl. Daten aus http://regierungsforschung.spirito.de/data/korte_et_al._regieren_in_ nrw_kap_2.3.pdf; http://www.landtag.nrw.de/portal/WWW/GB_II/II.2/Archiv/ mdldat/Statistiken/Statistik_Geschlechter_16WP.jsp [Zugriff: o6.10.2012]). 
von ihnen wurden gewählt, das waren $31 \%$ der weiblichen sozialdemokratischen Abgeordneten. Die Wahlkandidaten waren dagegen in aussichtsreicheren Wahlkreisen aufgestellt worden, $44 \%$ der männlichen Abgeordneten waren über Direktmandate in den Bundestag gekommen. ${ }^{611}$ Insgesamt saßen für die SPD 31 Frauen in der 186-köpfigen SPDFraktion, das waren $16,1 \%{ }^{692}$. In gewisser Hinsicht waren nach Beate Hoecker in dieser Zeit die Wahlchancen von Frauen in der SPD sogar geringer als die der konservativen Parteikonkurrentinnen, denn weibliche CDU/CSU-Abgeordnete konnten häufiger als sie mit einem Direktmandat ins Parlament einziehen (vgl. Hoecker 1994).

Mit der Einführung der verbindlichen Quote änderten sich die Verhältnisse. Vom 11. Bundestag (1987-1990) zum 12. Bundestag (1990-1994) stieg der Frauenanteil in der SPD-Fraktion von 16,1\% auf 27,2 \% an. ${ }^{693}$ Zwar wurde 1991 nur 1 der 10 sozialdemokratisch besetzten Ausschussvorsitze von einer Frau geleitet und nur 3 der 23 SprecherInnen der SPDFraktion waren weiblich, aber im SPD-Fraktionsvorstand waren die Frauen 1991 mit 29,26 \% vertreten, stellten 3 der 9 stellvertretenden Fraktionsvorsitzenden $(33,3 \%)$ und 2 der 5 Parlamentarischen GeschäftsführerInnen (40 \%) (vgl. Gleichstellungsbericht 1991).

691 Vgl. dazu Tab. 13 SPD-Mandate nach Direkt- und Listenwahl und Geschlecht unter DOI $10.3224 / 86388794$ A.

692 Damit hatte in der 11. Wahlperiode die SPD allerdings 50 \% mehr Frauen im Parlament als in der 10. Wahlperiode mit 21 weiblichen Abgeordneten (vgl. Gleichstellungsbericht 1988: 887).

693 In der CDU/CSU und der FDP war der Frauenanteil unter den Abgeordneten ebenfalls erheblich, wenn auch nicht in gleichem Ausmaß, gestiegen: CDU: 7,7\% (11. BT) auf 13,8 \% (12. BT), FDP: 12,5 \% (11. BT) auf 20,3\% (12. BT). Gleichzeitig blieben Spitzenpositionen wie parlamentarische StaatssekretärInnen, Fraktionsvorsitzende, MinisterpräsidentInnen, ChefInnen der Staatskanzlei und die Schlüsselressorts wie das Innen-, Wirtschafts- und Finanzministerium usw. in der Regel von Männern besetzt (vgl. Edinger/Holfert 2005). 
$A b b$. 5: Frauenanteil unter den Abgeordneten des Deutschen Bundestags

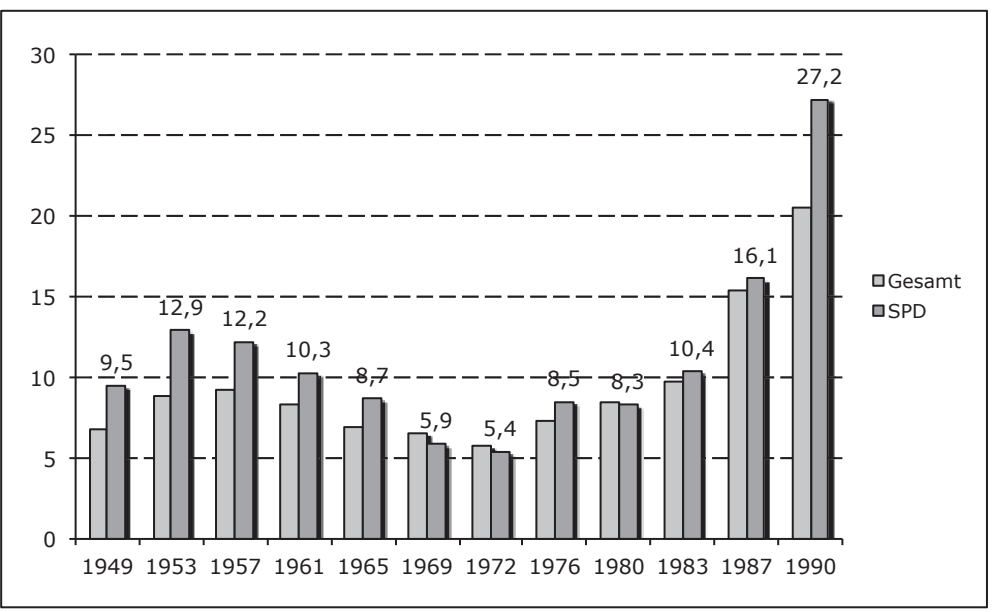

Quelle: Eigene Darstellung.

Bei der Besetzung kommunaler Ämter ließ sich die Quote je nach Größe der Gemeinden unterschiedlich erfolgreich realisieren. Zwar wurde in den großen Gemeinden mit mehr als 1.00o.ooo EinwohnerInnen der bis 1990 geforderte Frauenanteil von $25 \%$ unter den sozialdemokratischen Ratsmitgliedern schon vor Münster erreicht. In den kleineren Gemeinden mit bis 500.00o EinwohnerInnen aber betrug die Frauenquote in den sozialdemokratischen Ratsfraktionen im gleichen Jahr (1987) durchschnittlich knapp $17 \%$. In den Folgejahren stieg der Frauenanteil in den Gemeinden mit über 500.0oo EinwohnerInnen auf 32,4 \% (1993) und in den Gemeinden mit 20.000-50.000 EinwohnerInnen auf 23,0 \% (1993) und damit stärker als in den anderen Parteien CDU/CSU und FDP, die ebenfalls in dieser Zeitspanne einen Zuwachs an Kommunalpolitikerinnen verzeichnen konnten (vgl. Hoecker 1995: 112). Die Besetzung kommunaler Führungspositionen mit Frauen fiel dagegen geringer aus. 1987 waren von den 243 sozialdemokratischen OberstadtdirektorInnen, BürgermeisterInnen und LandrätInnen nur vier weiblich (vgl. Gleichstellungsbericht 1988: 891f.) ${ }^{694}$. Mehr als zehn Jahren später war der Frauen-

694 Die Zahl der weiblich besetzten DezernentInnenposten, führt der Gleichstellungsbericht auf, wäre dagegen angestiegen, aber nur Kassel verfügte über einen geschlechterparitätisch besetzten Magistrat (vgl. Gleichstellungsbericht 1988: 892). 
anteil an den 112 sozialdemokratisch besetzten OberbürgermeisterInnenposten auf $8 \%$ und bei den 92 Landräten auf 5,4 \% angewachsen (vgl. Gleichstellungsbericht 2001: 36).

Auf Landesebene hatte sich 1995 die vorgeschriebene Geschlechterquote von $33 \%$ in der Hälfte der SPD-Landtagsfraktionen realisiert, 6 von 16 Landtagsfraktionen hatten bis Juli 2001 die für 1998 angezielte Marge von $40 \%$ erreicht. Von den 70 MinisterInnen der zehn Landesregierungen, an denen die SPD beteiligt war, waren $31 \%$ weiblich (vgl. Gleichstellungsbericht 2001: 32f.). Mit Heide Simonis in Schleswig-Holstein wurde 1993 die erste Frau zur Ministerpräsidentin gewählt.

Im Europäischen Parlament stieg die Frauenquote bei den SozialdemokratInnen von 27,3\% (1988) auf 38,7 \% (1989) und auf 42,5\% (1994) (vgl. Hoecker 1995: 150) .

Insgesamt verschaffte die Quote also den Frauen in der Partei - wenn auch mit Hürden - eine sprunghafte Zunahme politischer Karrierechancen. ${ }^{695}$ Obwohl die ASF-Bundesvorsitzende Karin Junker auch noch 1995 über Konflikte und Satzungsübertretungen klagte und der ASF-Bundesvorstand mehrfach die Schiedskommission einschaltete (vgl. Gleichstellungsbericht 1995: 237f.), wurden die Quotenauflagen und -verfahren letztendlich von der Partei akzeptiert und umgesetzt.

\subsubsection{Die Durchsetzung einer neuen Frauenpolitik in der Partei und dem Grundsatzprogramm von 1989}

Parallel zu den Auseinandersetzungen um die Quote fanden in der Partei Diskussionen über ein neues Grundsatzprogramm statt, das das Godesberger Programm von 1959 ersetzen sollte. 696

Zwar hatte der Parteivorsitzender Willy Brandt dafür gesorgt, dass vier Frauen in der 16-köpfigen Programmkommission vertreten waren ${ }^{697}$,

695 Unter den Hauptamtlichen des Parteiapparates war es für Frauen schwieriger, Führungspositionen zu erreichen, obwohl für das parteiinterne Personalmanagement seit 1979 Frauen bevorzugt rekrutiert werden sollten. Noch 1997 gab es in der Partei keine Abteilungsleiterin, keine Leiterin eines Vorstandsbüros, keine Referatsleiterinnen und im ganzen Bund nur zwei leitende Landes-/Bezirksgeschäftsführerinnen (OWL, Hessen-Süd) (vgl. Gleichstellungsbericht 1997: 285f.).

696 Nach Einschätzung der Zz 5 wäre eine verbindliche Quote ohne diesen Diskussionsrahmen in der Partei nicht durchsetzbar gewesen.

697 Drei Frauen, die ASF-Bundesvorsitzende Inge Wettig-Danielmeier, Sigrid SkarpelisSperk und Heidemarie Wieczorek-Zeul, repräsentierten linke feministische Positionen, Ilse Brusis, das vierte weibliche Kommissionsmitglied, war eher dem konservativeren Gewerkschaftsflügel zuzurechnen, unterstützte aber die frauenpolitischen Anliegen der anderen. 
aber die Zusammenarbeit der Kommissionsmitglieder war „nicht immer von sozialdemokratischer Solidarität getragen" (Wettig-Danielmeier 1997b: 14), erinnert sich Inge Wettig-Danielmeier. Die Beiträge der ASFFrauen provozierten zeitweise „so heftig, dass beinahe die Kommission aufgeflogen wäre“ (Zz 5). Immerhin verfügten die Frauen im Gremium über eine respektable Minderheit, die ihr zu einer gewissen Durchsetzungsmacht verhalf: „[...] [E]s waren zum ersten Mal so viel, daß wir uns gegenseitig die Bälle zuspielen konnten“ (ASF 1987a: 2).

Die Programmkommission hatte die Aufgabe, in der politisch fragmentierten Partei, deren Flügel auch in öffentlichen Debatten um Mehrheiten rangen, einen Text zu entwickeln, der für alle Strömungen konsensfähig wäre, aber auch der Partei eine Perspektive gab. 1986 legte die Kommission der Partei die erste Version des neuen Grundsatzprogramms, den sog. Irseer Entwurf, vor. Frauenpolitisch unterschied sich dieser Programmentwurf deutlich von dem Vorläufertext, dem Orientierungsrahmen '85 (OR '85). Im OR '85 wurden Frauen als Verantwortliche für den Wandel der Geschlechterhierarchie definiert. Ihre Emanzipation scheitere, so hieß es da, an der eigenen Unterwerfungsbereitschaft, weil sie sich in die zugewiesene Bevormundung einfügen und als Mütter diese Geschlechtertraditionen reproduzieren. Im Irseer Entwurf dagegen wurde Frauendiskriminierung als ein gesellschaftspolitischer Missstand bewertet und ihre Bekämpfung zur Aufgabe aller.

Diese Passagen wurden in das Regierungsprogramm Aufbruch in die Zukunft zur Bundestagswahl 1987 aufgenommen. Den Programmtext hatte eine Kommission erarbeitet, die Johannes Rau, Vorsitzender und damaliger Kanzlerkandidat, paritätisch besetzt hatte. Darin hieß es:

Wer die menschliche Gesellschaft will, muß die männliche Gesellschaft überwinden. Das fängt damit an, daß Frauen ihre Belange selbst in die Hand nehmen und es geht damit weiter, daß weibliche Lebensperspektiven und weibliche Erfahrungen in unsere politischen Konzepte einbezogen werden (Nürnberger Beschlüsse 1986: 13) ${ }^{698}$.

Damit wurde die Geschlechterfrage zu einem Thema gesellschaftlicher Zukunftsgestaltung, zu dem auch ein Selbstvertretungsrecht und eine persönliche Teilhabe der Frauen an der Politikentwicklung der Partei gehörten.

Die 25-\%-Frauenquote sank 1986, als die Kommission um die VertreterInnen der Bezirke und Landesverbände erweitert wurde.

698 Bereits im Irseer Entwurf war die Textpassage zu finden: es „muß die männliche Gesellschaft überwinden, wer die menschliche Gesellschaft will“ (Irsee 1986: 16) 
Die ASF hatte sich von dem neuen Grundsatzprogrammtext noch deutlichere Bekenntnisse zur Gleichstellung erhofft und eigene Textvorlagen zum Irseer Entwurf entlang der von der ASF-Bundesfrauenkonferenz 1985 formulierten und verabschiedeten frauenpolitischen Ansprüche entworfen. Darin wurde gefordert, Gleichstellung zu einem bedeutenden Programmziel - gleichwertig zu Frieden und Demokratie - zu erklären. Der sozialdemokratische Grundwertekanon „Freiheit, Gerechtigkeit, Solidarität“ sollte durch „Freiheit, Gleichheit, Solidarität“ ersetzt werden ${ }^{699}$. Gleichstellung sollte von Gleichberechtigung abgegrenzt und als Umgestaltung einer Lebenswelt definiert werden, die „von uns allen -Männern und Frauen! - gelebt werden muß“ (Rechenschaftsbericht 1987: 4). Darüber hinaus kritisierten die ASF-Frauen, dass im vorliegenden Programmentwurf keine frauenpolitischen Forderungen außerhalb des Kapitels V Frau und Mann: Gesellschaftliche Gleichheit (vgl. Irseer Entwurf 1986) berücksichtigt worden waren ${ }^{700}$ (vgl. Kuhn 1987; WettigDanielmeier 1988). Außerdem mahnten sie in dem Text verschiedene Elemente konservativer Ideologien an, wie die überragenden Bedeutung der Erwerbsarbeit für die Gesellschaft und das Bekenntnis zum bürgerlichen Familienideal, und hielten den Text für prüde, weil in ihm „Sexualität" und „Liebe“ nicht vorkamen. Zudem warfen sie den VerfasserInnen vor, im gesamten Text geschlechtersensible Sprachformen missachtet zu haben.

An der mehrjährigen Programmdebatte in der Partei beteiligte sich die ASF mit hohem Engagement. Die Rechenschaftsberichte des ASFBundesvorstands weisen in der zweiten Hälfte der 1980er-Jahre durchschnittlich acht Termine pro Monat aus, einzelne Monate waren dabei bis zu $70 \%$ ausgebucht. An vielen der Termine waren Frauen anderer Organisationen beteiligt, Gewerkschafterinnen, Wissenschaftlerinnen, Journalistinnen und Vertreterinnen von Frauenverbänden und autonomen Frauengruppen, entweder als Diskussionsteilnehmerinnen oder als Mitveranstalterinnen. ${ }^{701}$

Eine veränderte Akzeptanz der Frauenpolitik in der Partei präsentierte auch die Arbeitsgemeinschaft für Arbeitnehmerfragen (AfA). Sie hatte wie die Gewerkschaften eine Distanz zu den Neuen Sozialen Bewegungen und trat der ASF stets reserviert und abweisend gegenüber (vgl. dazu Lösche/Walter 1992: 246-248). Nun gab sie mit der ASF eine ge-

699 „Freiheit, Gleichheit und Solidarität“ hatte die CDU-Frauenunion im Aktionsprogramm 1978 als „Grundwerte“ definiert (vgl. Aktionsprogramm '78: 2).

700 Das Kapitel zur Gleichstellung im Programmtext, zitiert die Zeitschrift DER SPIEGEL Sozialdemokratinnen, „schwimme wie ein Fettauge auf der Suppe“ (SPIEGEL 1987).

701 Vgl. Chroniken in den Rechenschaftsberichten ab 1986 (Rechenschaftsbericht 1987, 1990). 
meinsame Erklärung zur „familienfreundlichen Gestaltung der Arbeitswelt und für das Recht auf Erwerbsarbeit für alle" heraus (Jahrbuch der SPD $\{1986 / 87\}$ :305).

1989 lag dem Berliner Parteitag ein vielfach diskutierter und überarbeiteter Programmtext vor. Das Grundsatzprogramm spiegelte die Diskurse zur Individualisierung, zur Diversifizierung der Lebensformen (vgl. Ulrich Beck 1986) und zur neuen Unübersichtlichkeit (vgl. Jürgen Habermas 1985) ${ }^{702}$ wider: „Die SPD nimmt Abschied von einem Bild einer Gesellschaft, in der die Arbeit alles und alles andere nichts ist." (Jahrbuch der SPD \{1988-90\}: C31) Mit einem anderen Arbeitsbegriff wurden Erwerbsarbeit und unbezahlte Familien- und Gemeinschaftsarbeit als gesellschaftlich gleich notwendig bewertet (vgl. Grundsatzprogramm der SPD 1989: 399f.). Die Vorlage enthielt viele der von den ASF-Frauen entwickelten Textpassagen, u.a. den Slogan „Wer die menschliche Gesellschaft will, muß die männliche Gesellschaft überwinden" (vgl. Grundsatzprogramm der SPD 1989: 391-393). Die gesellschaftliche Gleichheit von Frau und Mann war in den sozialdemokratischen Grundzielkatalog ${ }^{703}$ aufgenommen worden:

Wir wollen eine Gesellschaft, die nicht mehr gespalten ist in Menschen mit angeblich weiblichen und angeblich männlichen Denk- und Verhaltensweisen, in der nicht mehr hochbewertete Erwerbsarbeit Männern zugeordnet, unterbewertete Haus- und Familienarbeit Frauen überlassen wird [...]. (Grundsatzprogramm der SPD 1989:392)

Die Ziele der Frauenbewegungen fanden sich in die sozialdemokratische Tradition verankert und gehörten nun zu den geistigen Wurzeln des „Demokratischen Sozialismus“704. Im Programmtext zeigt ein breiter Fächer frauenspezifischer Diskriminierungstatbeständen die Reformbedürftigkeit der Gesellschaft ${ }^{705}$. Nun müsste der rechtlichen die gesellschaftliche Gleichstellung folgen, und zwar nicht durch „die Integration

702 „Das Verhältnis von Individuum und Gesellschaft ändert sich. Der einzelne, ohne feste Einbindung und ohne die Erfahrung von Gemeinschaft, sieht sich oft allein einer fremden und anonymen Gesellschaft gegenüber, die ihn durch immer neue Wahlmöglichkeiten zugleich fasziniert und überfordert." (Grundsatzprogramm der SPD 1989:387f.)

703 Gleichheit von Frau und Mann stand nun neben Frieden, der gerechten Verteilung des Wohlstands, Kulturvielfalt, Demokratie und Technikbeherrschung (Grundsatzprogramm der SPD 1989: 373).

704 „Die Ideen der Frauenbefreiung sind bereits im 19. Jahrhundert von der Arbeiterbewegung aufgenommen und weiterentwickelt worden“ (Grundsatzprogramm der SPD 1989: 376 ).

705 Dazu gehören das nicht realisierte Verfassungsgebot der Gleichheit, die höhere Armutsbetroffenheit von Frauen, ihre Benachteiligung bei Ausbildung und Beruf, ihre 
der Frau in eine Männerwelt, sondern die Umgestaltung der Gesellschaft" (Grundsatzprogramm der SPD 1989: 392). Für eine gesellschaftliche Umgestaltung sollte z.B. eine andere Arbeitszeitorganisation geschaffen werden, und zwar durch die Verkürzung der täglichen Arbeitszeit und die partnerschaftliche Verteilung der Haus- und Familienarbeiten (vgl. Grundsatzprogramm der SPD 1989: 403). Ein Gleichstellungsgesetz sollte verabschiedet werden, das Lohndiskriminierung beendet und Frauenförderpläne vorschreibt. Die Überwindung der Dominanz einer männlich geprägten Kultur läge im Interesse aller, denn „auch bei Männern wächst die Einsicht, daß die angeblich männliche Unterordnung von Gefühl und Phantasie unter Rationalität und Durchsetzungskraft sie ärmer oder gar krank macht" (Grundsatzprogramm der SPD 1989: 392) $7^{706}$. Zur Umgestaltung einer männlichen Gesellschaft gehörte auch die Gleichstellung aller Formen von Lebensgemeinschaften, so auch die gleichgeschlechtliche mit der traditionellen Ehe (vgl. Grundsatzprogramm der SPD 1989: 394).

Die wichtigsten frauenpolitischen Forderungen der ASF waren in das Grundsatzprogramm aufgenommen worden ${ }^{707}$ : der Elternurlaub in den ersten drei Lebensjahren (vgl. Grundsatzprogramm der SPD 1989: 406), familiennahe Dienste mit vergemeinschaftenden Wohn- und Betreuungsangeboten (vgl. ebd.: 393), Auflagenbindung für öffentliche Auftragsvergaben, quotierte Ausbildungsplätze (vgl. ebd.: 396), Wiedereingliederungshilfen nach einer Familienphase (vgl. ebd.: 406), gleiche Beteiligungsmöglichkeiten für Frauen in den Gremien von Parteien, Ge-

Zurücksetzung in Wirtschaft, Wissenschaft, Kunst, Politik und Medien, ihre Zuweisung zu Haushalt, Kindererziehung und privatem Bereich, die Unterschlagung geschichtlich bedeutsamer weiblicher Persönlichkeiten, die höhere Bedrohtheit der Frauen durch sexuelle Gewalt, die Missachtung ihrer sexuellen Selbstbestimmung, die Gestaltung der Erwerbsarbeit und ehrenamtliche Tätigkeiten nach männlichen Zeitabläufen und Organisationsformen (Grundsatzprogramm der SPD 1989: 2of.).

706 Im Jahrbuch der SPD wird dieser Aspekt im neuen Programmtext hervorgehoben: „Die Zukunft verlangt von uns allen, Frauen und Männern, vieles, was lange als weiblich galt: Wir müssen uns in andere einfühlen, auf sie eingehen, unerwartete Schwierigkeiten mit Phantasie meistern, vor allem aber partnerschaftlich mit anderen arbeiten. Wer die menschliche Gesellschaft will, muß die männliche überwinden." (Jahrbuch der SPD \{1988-90\}: C13)

707 Einige wichtige ASF-Politiken fehlten: die Ablehnung der Reproduktionsmedizin, das Verbot der Pornographie in den Medien, die strafrechtliche Verurteilung der Gewalt gegen Frauen und Kinder in der Familie, die institutionelle Förderung der Frauenhäuser sowie die Streichung des § 175. Im Abschlusskapitel Unser Weg in die Zukunft werden sozialdemokratische Politikziele aufgelistet, unter den acht Visionen für eine besseren Gesellschaft ist die „Gleichheit und Solidarität zwischen Frauen und Männern“ aufgeführt, wenn auch erst an siebter Stelle (vgl. Grundsatzprogramm der SPD 1989: 445). 
werkschaften und Aufsichtsräten sowie bei der Besetzung von Ehrenämtern als LaienrichterInnen oder ElternvertreterInnen, notfalls gesetzlich reguliert, sowie eine Änderung der Wahlsysteme in Bund, Ländern und Gemeinden (vgl. ebd: 393).

Gegen das von der CDU-Regierung angestrebte Beratungsgesetz zur Schwangerschaftsüberwachung von Frauen wurde das Selbstbestimmungsrecht von Frauen gesetzt:

Die Strafbarkeit des Schwangerschaftsabbruchs hat nicht zum Schutz werdenden Lebens, sondern seit jeher mehr zur Bedrohung und Demütigung von Frauen geführt [...]. Wir wollen werdendes Leben schützen. Das kann nur mit dem Willen, nicht gegen den Willen der Frau geschehen. Deshalb erkennen wir die Verantwortung und das Selbstbestimmungsrecht der Frau an (vgl. Grundsatzprogramm der SPD 1989: 395).

Das neue Grundsatzprogramm wurde auf dem Berliner Parteitag $1989^{708}$ mit 441 Stimmen, einer Gegenstimme und 3 Enthaltungen angenommen (vgl. Jahrbuch der SPD \{1988-90\}: A12).

„Gleichstellung und Rollenveränderung von Frauen und Männern durchzog das gesamte Programmkonzept" (Wettig-Danielmeier 1997b: 14), resümierte die ASF-Bundesvorstandsvorsitzende. Noch heute gilt das Berliner Programm als „ein programmatischer Meilenstein für die Durchsetzung einer geschlechtergerechten Politik in der SPD“ (ASF 2006: 6).

Die historischen Umstände allerdings sorgten dafür, dass das Grundsatzprogramm für die weitere Politikgestaltung der Partei keine Bedeutung hatte ${ }^{709}$. Einen Monat vor dem Parteitag war die Mauer gefallen, der Zusammenbruch der DDR, die Auflösung der Sowjetunion und des Warschauer Paktes standen bevor. Diese einschneidenden Veränderungen der deutschen Gesellschaft trafen die SPD unvorbereitet. Weder die damit verbundenen neuen gesellschaftspolitischen Probleme noch eine Reflexion der politischen Folgen fanden sich im neuen Programmtext. Schon bei der Beschlussfassung gehörte das neue Grundsatzprogramm damit einer vergangenen Epoche der Bundesrepublik an.

708 Bundesparteitag der SPD 18.12.-20.12.1989 in Berlin.

709 Im Dezember 1994, fünf Jahre nach seiner Verabschiedung, bilanzierte Hans-Jochen Vogel, dass das Programm von der Partei kaum wahrgenommen wurde (vgl. Vogel 1994). 


\section{Eine Bilanz}

In der vorliegenden Studie wurde die Entwicklung einer institutionellen Teilbewegung der Neuen Frauenbewegungen erforscht. Es wurde rekonstuiert und analysiert, wie sich die älteste deutsche Partei, die durch zentralistische Strukturen und von einer patriarchal strukturierten Arbeitswelt geprägt war, in den 1970er- und 1980er-Jahren frauenpolitisch neu ausgerichtete und dabei Anliegen der Neuen Frauenbewegungen aufgriff und in sozialdemokratische Politikkonzepte umsetzte.

Um diesen frauenpolitischen Wandel der SPD zu erforschen, habe ich die parteiinternen Ereignisse im Zeitraum von der Nürnberger Frauenkonferenz 1970 bis zum Berliner Parteitag 1989 sowie die innerparteilichen frauenpolitischen Auseinandersetzungen und Organisationsentwicklungen dieser Phase im historischen Verlauf mithilfe von unterschiedlichen Datenquellen, zeitgenössischen Dokumenten, ExpertInneninterviews und wissenschaftlichen Forschungsergebnissen rekonstruiert. Unter Verwendung feministischer, soziologischer und politologischer Diskurse und Theorien wurden die Ereignisfolgen und das innerparteiliche Geschehen analysiert.

Im Zentrum der Forschungsarbeit stand dabei die Arbeitsgemeinschaft Sozialdemokratischer Frauen. Untersucht wurden die Mobilisierung der Frauen, ihr Wirken und ihr Einfluss auf das Parteigeschehen als frauenpolitische Akteurinnen.

Abschließend werden nun die wichtigsten Ergebnisse der Forschungsarbeit zusammengefasst. Zudem wird diese institutionelle Frauenbewegung im Spiegel feministischer Kritiken reflektiert.

\section{Die Formierung einer frauenpolitisch machtvollen Akteurin in der SPD}

Nach den vorliegenden Forschungsergebnissen wandelte sich die sozialdemokratische Frauenorganisation von einer parteivorstandsgesteuerten Mitgliederpflegeverwaltung zu einem innerparteilich einflussreichen frauenpolitischen Interessensverband. Die Auswertungen der Archivalien ließen darauf schließen, dass im Zuge der parteiinternen Auseinandersetzungen, in denen innerparteilich über frauen- und familienpolitische Politiken und die Partizipation der Frauen an der Politik gerungen wurde, in allen Bezirken der Partei neue Frauenarbeitsgemeinschaften entstanden bzw. bereits bestehende frauenpolitische Strukturen sich aktivierten. 
Durch die ExpertInneninterviews wurde ein zentrales Element dieser innerparteilichen Frauenmobilisierung deutlich: Während im sozialdemokratischen Selbstverständnis der Parteimehrheit die SPD als eine demokratische Organisation galt, verbreitete sich unter den weiblichen Mitglieder eine andere Vorstellung von Organisationswirklichkeit. Parteiaktivistinnen erlebten in der Partei verschiedene Formen von Ausschließungen. Sie protestierten gegen eine männliche Deutungsmacht in der Partei und die Marginalisierung von frauenpolitischen Anliegen und klagten öffentlich Diskriminierungsakte und sexistischen Übergriffe männlicher Parteimitglieder an.

Der organisationssoziologische Diskurs zur Schließung, insbesondere das Theoriekonzept von Eva Cyba ${ }^{710}$, eröffnete hermeneutische Zugänge für eine systematische Beschreibung der geschilderten Diskriminierungserlebnisse als Folgen informeller, in sich widersprüchlicher und unterschiedlich sozial legitimierter Praktiken, die strukturationstheoretisch analysiert als relativ stabile Phänomene ausgrenzenden Organisationshandelns beschrieben werden mussten.

In den Frauenarbeitsgemeinschaften gründeten sich Arbeitszirkel und Diskussionsforen, die verschiedene Diskursthemen der Neuen Sozialen Bewegungen und besonders der Neuen Frauenbewegungen aufgriffen. Zudem fanden sowohl Altgenossinnen als auch Neumitglieder in diesen Frauengruppen Orte gemeinschaftlicher Unterstützung und kultureller Zwischenwelten.

Damit entwickelte sich trotz der repräsentationsdemokratischen Strukturen und der bürokratischen Verfahren der ASF-Organisation eine innerparteiliche Frauenmobilisierung, die parteiuntypische Formierungsmerkmale aufwies. Mit Theorieansätzen der Neuen Sozialen Bewegungen ließen sich die innere Strukturiertheit der politischen Akteurin ASF, ihre Handlungsfähigkeit und ihre Wirkmächtigkeit ergründen.

Die gemeinsam ausgetauschten und reflektierten Ausschließungserfahrungen bildeten ein Kernelement kollektiver frauenpolitischer Identität unter den ASF-Frauen. Nach den Erinnerungen vieler Zeitzeuginnen trug dieser Bezugspunkt dazu bei, in der hoch fragmentierten ASF die Kommunikation untereinander zu ermöglichen und Aktions- und Entscheidungsfähigkeit zu erhalten. Mit den Appellen an eine gemeinsame „Frauensolidarität“ wurde diese kollektive Identität stetig aktualisiert. Sie verpflichtete alle Sozialdemokratinnen zu einer gegenseitigen Akzeptanz und hielt alle Genossinnen dazu an, nach gemeinsamen Positionen und pragmatischen Kooperationen zu suchen.

Statt wie in den politischen Lagerbildungen der Partei üblich die eigenen Politikvorschläge und die Erwartungen an die Partei aus einer 
konsensual abgestimmten, programmatisch niedergelegten Weltsicht und Selbstermächtigung abzuleiten, entwickelten die ASF-Frauen ihre Politiken in einem eher unscharfen, dreidimensionalen thematischen Feld. Mit dem Verzicht auf Vereinheitlichung (vgl. Roth 1998) verstrickten sich die ASF-Frauen weniger in kontroverse Welterklärungsdebatten, wie sie die Arbeitsgemeinschaft der JungsozialistInnen viele Jahre beschäftigten und lähmten. Damit trugen die ASF-Frauen der politischen Verfasstheit der ASF Rechnung, denn wenn sich auch in den 1970er- und 1980er-Jahren das linkssozialistisch-feministische Lager und sein Einfluss in den Führungsgremien der ASF vergrößerten, blieben die feminismuskritischen oder ablehnenden Frauen ein starkes Gegenlager.

In den 1970er-Jahren gelang es den ASF-Frauen, ein thematisch breites Spektrum variierender Erklärungsentwürfe zu Familien- und Geschlechterbeziehungen zu entwickeln sowie neben allgemeineren programmatischen Positionen vielerlei pragmatische Politikkonzepte mit einer Fülle dazugehöriger Forderungen aufzustellen. Sie warben für ihre Gegenentwürfe sozialdemokratischer Frauenpolitiken in der Partei im Vorfeld von Wahlkämpfen, Führungskrisen der Partei und programmatischen Debatten und fanden in unterschiedlichen innerparteilichen Lagern der SPD UnterstützerInnen und Verbündete.

In den Parteidokumenten der SPD wurde in den 1980er-Jahren, besonders nach dem Regierungsverlust, eine wachsende Wertschätzung der ASF und eine zunehmende Berücksichtigung frauenpolitischer Themen deutlich. Allerdings ließen die Auswertungen der Archivalien und der Zeitzeuginneninterviews darauf schließen, dass sich dabei zeitgleich die AkteurInnenfelder verschoben. Die Frauenpolitik der Parteiführung wurde nun eher von Machtzentren wie den frauenpolitisch interessierten Bundestagsabgeordneten und der AG Gleichstellung der Bundestagsfraktion bestimmt, während sich die ASF als eine starke frauenpolitische Lobby in der SPD vorrangig auf die Durchsetzung einer größeren Partizipation von Frauen an Ämtern, Parteifunktionen und in den Parteigremien konzentrierte.

\section{Die neue sozialdemokratische Geschlechterpolitik}

Die NFB stießen in allen gesellschaftlichen Organisationen auf Resonanz und veränderten in den beiden großen Volksparteien die politischen Koordinaten, aber die SPD wurde in ihrer frauenpolitischen Ausrichtung durch sie - wie die Programme, Mitgliederentwicklungen und steigenden Frauenanteile in Führungsgremien und bei politischen Mandaten zeigten - besonders stark erreicht. Dabei lässt sich der frauenpolitische Wandel der SPD nicht hinreichend als das Einsickern eines gesellschafts- 
politischen Paradigmenwechsels in eine Volkspartei beschreiben; vielmehr stellte er sich als Ergebnis von aktiven Einflussnahmen dar, das sich erst in mehrjährigen kontroversen Diskursen und Aushandlungsprozessen realisierte. Parteiinterne AkteurInnen trieben diese Entwicklung voran und erwirkten dabei eine nachhaltige Bedeutungsverschiebung frauen- und familienpolitischer Themen im Portfolio sozialdemokratischen Politik und Programmatik.

Dokumentenanalysen ergaben im Forschungszeitraum eine mehrfache Perspektivverschiebung auf Geschlechterungleichheit. Anfang der 1970er-Jahre wurde die Vorstellung einer natürlichen Geschlechtlichkeit aufgegeben, und zwar zugunsten einer sozial-kulturell geschaffenen, die deshalb auch durch sozialen Handeln verändert werden konnte. Die frauenspezifischen Politiken wurden aus einer Benachteiligtenperspektive heraus begründet. Im Fokus standen Maßnahmen, mit denen Frauen gefördert werden sollten, um sie zu befähigen, ihre Rechte, insbesondere auf Bildung und Ausbildung sowie wirtschaftliche Unabhängigkeit oder staatsbürgerliche Beteiligung, besser wahrnehmen zu können. Dabei war der Wunsch nach einer höheren Frauenpräsenz in politischen Entscheidungspositionen mit der Sehnsucht nach einer stärker humanistisch orientierten Politik verbunden. Die Durchsetzung dieser Frauenrechte wurde von den mächtigen AkteurInnen in der Partei und in den politischen Verwaltungen gefordert.

In den Dokumente der 1980er-Jahre war eine neue und andere Geschlechterkonstruktion zu finden. Sie setzte sich in den programmatischen Stellungnahmen der SPD durch und war von den FeministInnen der ASF mitentwickelt worden. Nun galten Männer und Frauen als gleichermaßen beschädigte Subjekte, denn sie waren beide durch die dualistische Geschlechterzuweisung auf meist diametral konstruierte männliche oder weibliche Eigenschaften eingeschränkt. Männer und Frauen besaßen zwar unterschiedliche Interessen, aber sie teilten auf gleiche Weise den Wunsch nach einer gesellschaftlichen Veränderung. Mit dieser differenztheoretischen Geschlechterkonstruktion verband sich das Recht auf Selbstvertretung und Repräsentanz der Frauen. Frauen wurden zu Verantwortlichen für Veränderung und waren an den Politikentwicklungen zwingend zu beteiligen, damit ihre Interessen authentisch eingebracht und ausgehandelt werden konnten. Dies gehört bis heute zum frauenpolitischen Selbstverständnis der Partei.

Ein Spezifikum des sozialdemokratischen Gleichheitsfeminismus war die Gleichstellungspolitik als strategisches Konzept. Sie zielte auf eine stetige Auflösung der Zweigeschlechtlichkeit der Gesellschaft, wobei die Gleichheit der Geschlechter nicht nur den Rechtsgrundsätzen nach realisiert, sondern in einer faktischen Gleichbehandlung bestehen sollte. 
Dazu wurden Maßnahmen zur Bevorzugung des diskriminierten Geschlechts unterstützt. Damit sie durch ExpertInnen als wirksame Interventionen entwickelt und umgesetzt werden konnten, setzten sich sozialdemokratische FrauenpolitikerInnen bereits in den 1970er-Jahren für die Institutionalisierung gleichstellungspolitischer AkteurInnen in gesellschaftlichen Organisationen und der politischen Verwaltung ein.

\section{Die Durchsetzung des Selbstvertretungsrechts der Frauen in der Partei}

Die Durchsetzung eines statuarisch gesicherten Vertretungsrechts der Frauen in der Partei stellte sich nach den hier vorgelegten Forschungsergebnissen als ein Prozess in Etappen dar, der sich durch vielfältiges strategisches Organisationshandeln mit vermehrt regulierenden Anteilen beschreiben ließ.

Zunächst wurde die Männerdominanz in den Funktionen und Gremien der Partei als eine Gerechtigkeitslücke identifiziert und als Geschlechterhierarchie in der Partei kritisiert. Die Gleichstellungsberichte des ASF-Bundesvorstands auf den SPD-Parteitagen verschaffte der Diskriminierung der Frauen in der Partei Öffentlichkeit. Durch regelmäßige Berichterstattungen in der Partei wurde dieses Thema zu einer eindringlichen Handlungsaufforderung für jede Parteieinheit inszeniert und sollte dezentral frauenfördernde Integrationsmaßnahmen auslösen.

Im weiteren Verlauf wurde die geringe Präsenz von Frauen in der Partei durch die Einrichtung der Gleichstellungskommission an der Parteispitze zu einem bedeutenden Organisationsproblem aufgewertet. Damit wurden zugleich die Beteiligung der Frauen in der Partei und ihr Anspruch auf Parteifunktionen und Mandate als eine Anforderung an die Organisationspolitik des Parteivorstands verstetigt.

Mit der Annahme von Gleichstellungsrichtlinien auf dem Berliner Parteitag 1979 wurden für alle Parteieinheiten Maßnahmen zur Steigerung des Frauenanteils in Ämtern und Funktionen vorgegeben.

1986 wurden mit einer Quote der Anspruch auf eine paritätische Repräsentanz der Geschlechter in der Partei festgelegt und Zeitziele für ihre Umsetzung vereinbart. Zwei Jahre später wurden mit der statuarischen Festschreibung der Quote alle Verfahren zur KandidatInnenauswahl und -aufstellung für Wahlen und bei der Besetzung von Parteifunktionen verbindlich reguliert.

Anhand innerparteilicher Statistiken ließ sich ablesen, dass diese Beteiligungsverpflichtung den Frauenanteil in allen Parteistrukturen und auch bei Mandaten sehr schnell erhöhen konnte. Allerdings verlangte die Umsetzung der Quote die stetige Intervention innerparteilicher Ak- 
teurInnen. Dabei setzten sich in den Besetzungsverfahren häufig die bisherigen Geschlechterhierarchien durch und prägten Rangordnungen und Wahlchancen.

Für die Entwicklung der Frauenarbeitsgemeinschaft als innerparteiliche Akteurin, so legten Forschungsergebnisse nahe, hatte die Quotenregelung sehr widersprüchliche Folgen. Einerseits stärkte die höhere Beteiligung der Frauen in Ämtern und Funktionen ihre Verhandlungsposition in der Partei, andererseits fand sich manche Frauenpolitikerin in Gremien von der Diskussion und Entscheidungsprozessen ausgesperrt oder es fehlte ihr für eine Einflussnahme die nötige Hausmacht. Bisweilen entschied sich die Parteieinheit für die weniger streithafte Kandidatin. Zudem belastete die Quote die Ressourcen der Frauenarbeitsgemeinschaften erheblich: So war die Rekrutierung frauenpolitisch engagierter Kandidatinnen oft überaus aufwendig; erfahrene und politisch ambitionierte ASF-Aktivistinnen nutzen die neuen Mitwirkungsmöglichkeiten und die Chancen für ihre politische Karriere und stellten infolgedessen ihr Engagement in der ASF weitgehend ein; bald boten sich für die frauenpolitisch engagierten Politikerinnen und Funktionärinnen attraktivere frauenpolitische Arenen in der Partei, als sie die Frauenarbeitsgemeinschaften bieten konnten.

\section{Der frauenpolitische Wandel der SPD}

In der SPD der 1980er-Jahre versuchten unterschiedliche Strömungen, die Partei neu auszurichten, und kämpften am „Ende des sozialdemokratischen Zeitalters“ (Bernd Faulenbach 2011: 778) dafür um Mehrheiten.

Die Auswertung der Parteidokumente ließ darauf schließen, dass die Parteilinke, die in der Partei in dieser Zeit an Einfluss gewann und in der Parteiführung der 1980er-Jahre stark vertreten war, die parteiinterne Frauenbewegung unterstützte, weil sie in ihr ein Erneuerungspotenzial für die Partei sah, und zwar in verschiedener Hinsicht: Ihre Verbindungen zu den außerparlamentarischen Bewegungen und ihre Affinität zu vielen Themen der NSB kamen einer gesellschaftspolitischen Entwicklung entgegen, die Thomas Meyer als eine „Abwanderung politischer Entscheidungen in die Gesellschaft“ (Meyer 1998: 125f.) beschrieb und die die etablierte Parteien zwang, sich für die außerparlamentarischen Initiativen als neue Formen der Partizipation zu öffnen (vgl. Meyer 2005: 2). Außerdem bildeten die ambitionierten Genossinnen ein Potenzial für die Elitenrekrutierung in der Partei. Sozialdemokratische Wahlkandidatinnen waren unbelastet von politischen Skandalen und Korruptionsvorwürfen und symbolisierten Integrität und Modernität der SPD. Zudem erschütterten die quotierten Wahlverfahren die undemokratischen Rekrutierungspraktiken mancher Parteieinheiten, sie verdrängten manchen 
weniger aktiven Altgenossen, der sich Posten und Einfluss verschafft und durch informelle Netzwerke gesichert hatte, aber die Parteibasisarbeit lähmte.

In der sozialdemokratischen Frauenpolitik fand ein Paradigmenwechsel statt. Unter Verwendung des Parteitypenmodells Elmar Wiesendahls ließ sich erkennen, wie ungleichzeitig sich dieser Prozess in den Bezirken und auf den verschiedenen Hierarchieebenen der Partei durchsetzte, obwohl die Interventionen des Parteivorstands oder des Parteivorsitzenden die politischen Diskurse und Beschlüsse der Parteitage als höchstem beschlussfassendem Gremium wesentlich beeinflussten.

Der feminist turn der SPD in den 1980er-Jahren musste an „,Grundannahmen' des Organisationsgedächtnisses“ (Kuhlmann/Kutzner/ Müller/Riegraf/Wilz 2002: 239) Anschluss finden. Neue frauenpolitische Konzepte oder Aktivitäten wie auch frauenspezifische Sonderregelungen wurden mit Anknüpfungen an sozialdemokratische Traditionen begründet oder als Fortführung sozialdemokratischer Diskurse und Politiken präsentiert. Sie wurden stets als eine Bereicherung oder Modernisierung der sozialdemokratischen Grundwerte ausgewiesen.

Die Auswertungen der parteieigenen Publikationen ließ darauf schließen, dass in der zweiten Hälfte der 1980er-Jahre die Frauenaktivistinnen in der Parteipresse und in den Führungsgremien der SPD eine so hohe Resonanz erreicht hatten, dass sie sich auch für konservativ-patriarchale Gatekeeper in der Partei zu ernstzunehmenden Bündnis- und Verhandlungspartnerinnen entwickelten. Damit fanden die frauenpolitischen Anliegen auch das Interesse derjenigen Parteimitglieder, denen Emanzipation und Gleichstellung als politische Themen fremd waren. Mit einem frauenpolitisch attraktiven Parteiprofil verbanden außerdem viele FunktionärInnen die Hoffnung, mehr Frauen für die Partei zu gewinnen. Seit den 1970er-Jahren war die Zahl der weiblichen Mitglieder gestiegen und im Gegensatz zu dem seit 1976 einsetzenden Mitgliederverlust weiter angewachsen ${ }^{711}$ (vgl. Vogel 1997: 233), zudem wurde die

711 Kurz unterbrochen wurde der Mitgliederrückgang durch den geringfügigen Zuwachs in den Jahren 1988 und 1989. Ende 1989 verzeichnete die SPD einen Zuwachs von über 9.500 Neumitgliedern, davon ca. 7.700 Frauen und ca. 1.80o Männer. Die GenossInnen taten sich in den angeschlossenen Bundesländern mit der Aufnahme von Neumitgliedern schwer. Befürchtet wurden Beitritte von „Wendehälsen“ und Stasitätern. Auf der Veranstaltung „Die geglückte Demokratie“ der Historischen Kommission vom 19.09.2008 berichteten ZeitzeugInnen von Stapeln unbearbeiteter Aufnahmeanträge, die in den Ortsvereinen lagerten. Möglicherweise hielt man Frauen für politisch unbelasteter und stimmte ihren Eintrittswünschen eher zu. Ab den 199oer-Jahren verlor die SPD in beiden Genusgruppen Mitglieder, bei den Frauen in relativ niedrigerem Maße, sodass der Frauenanteil an der Gesamtmitgliedschaft 2014 bei 31,84 \% lag. 
SPD seit Anfang der 1970er-Jahre bei den Bundestags- und in verschiedenen Landtagswahlen häufiger von den Frauen als von den Männern gewählt.

Die Neuausrichtung der Frauenpolitik in den 1980er-Jahren wurde als frauenpolitischer Wandel der SPD bezeichnet, weil die politischen und programmatischen Veränderungen in der Partei und ihre Organisationspolitik eine hohe Nachhaltigkeit entwickelten ${ }^{712}$. Seitdem beschäftigten gleichstellungspolitische Diskurse die Parteitage. Allerdings lassen die fast gleichlautenden oder inhaltlich vergleichbaren gleichstellungspolitischen Parteitagsbeschlüsse ${ }^{713}$ vermuten, dass es innerparteilich an change agents fehlt, um die beschlossenen Organisationspolitik nach dem Parteitag umzusetzen.

Der Wandlungsprozess der Partei erfüllt organisationstheoretisch die Kriterien eines Umbruchs (vgl. Miebach 2012; dazu auch Liebig 2014), so hat sich die Partei in ihren Organisationsregeln, den Beziehungen der Organisationsmitglieder untereinander, den Besetzungen von Gremien und Führungspositionen sowie dem symbolischen Rahmen frauenpolitisch deutlich verändert.

Der ASF-Bundesvorstand selbst wertete das Berliner Grundsatzprogramm als den frauenpolitischen Durchbruch in der Partei und den größten Erfolg der ASF (vgl. Wettig-Danielmeier 1990). Retrospektiv gesehen könnte aber die Quote eine vermutlich stärkere und nachhaltigere Veränderung in der Gesamtpartei bewirkt haben als dieser programmatische Erfolg. Die Quote veränderte kurzfristig die Konstellationen für die Interessensaggregation in der Parteiorganisation und setzte langfristig einen Daueranreiz im Identitätsfindungsprozess der SPD, dessen Entfaltung allerdings an den Einsatz einer handlungsfähigen innerparteilichen AkteurIn gebunden ist. ${ }^{14}$

712 Der Frauenanteil ist in Parteifunktionen weiter angestiegen und hat in den Vorständen der Partei durchschnittlich 40 \% (2015) erreicht, in den Parlamenten liegt der Frauenanteil eher darüber, in den politischen Spitzenfunktionen liegt der Frauenanteil bei Regierungsmitgliedern des Bundes bei über $50 \%$ (BundesministerInnen: $50 \%$, parlamentarische StaatssekretärInnen: 61,5\%), in den Landesregierungen im Mittel bei über 36 \%; auf kommunaler Ebene (LandrätInnen, OberbürgermeisterInnen) bei ca. $15 \%$. (vgl. Daten aus Gleichstellungsbericht 2015).

713 Unter der Parole „Die SPD weiblicher machen“ beschloss z.B. der Leipziger Parteitag 2013 einen gleichstellungspolitischen Maßnahmenkatalog für die Partei, darunter Förderprogramme, um Frauen erfolgreicher für Spitzenfunktionen und Mandate zu gewinnen und um die SPD-Führungsfrauen medial sichtbarer zu machen, und einen „Genderleitfaden“ für die ehrenamtliche Parteiarbeit und Gendertrainings für alle hauptamtlichen MitarbeiterInnen.

714 Als Zeichen für eine schwächere frauenpolitische Lobby in der SPD werteten ZeitzeugInnen auch die Verluste an weiblichen Mitgliedern und Wählerinnen. Tatsächlich verliert die SPD seit 1990 weibliche Parteimitglieder, wenn auch nicht in gleich hohem 
Die Bewertung des frauenpolitischen Wandels der SPD unter feministisch-emanzipationstheoretischen Gesichtspunkten

In der Studie wurde eine institutionelle Frauenbewegung vorgestellt, die in den 1970er- und 1980er-Jahren die Geschlechtervorstellungen und ordnungen in einer der etablierten großen Volksparteien veränderte. In dieser Bewegung agierten feministische Frauenpolitikerinnen, die ihre Ideen im Zuge der frauenpolitischen Auseinandersetzungen innerhalb und außerhalb der Partei entwickelten und in konkrete Emanzipationspolitiken umzusetzen versuchten. Wie ist ihr Wirken aus einer Perspektive feministischer Emanzipation zu bewerten?

Zunächst entstand durch die Neuen Frauenbewegungen eine Mobilisierung der Frauen in der Partei und mit ihr die Einrichtung einer Frauenarbeitsgemeinschaft mit demokratischen Strukturen. Sie eröffnete weiblichen Parteimitgliedern zusätzliche Arbeits- und Diskussionsforen und ermöglichte einen strukturierten Transfer neu entwickelter und ausgehandelter Frauenpolitiken in die Partei durch gewählte Sprecherinnen. Die Ziele der frauenbewegten ASF-Aktivistinnen, die neu gegründete Frauenarbeitsgemeinschaft zu entbürokratisieren, den Austausch zwischen den Hierarchieebenen durchlässiger zu gestalten und den Frauenarbeitsgemeinschaften ein spontaneres Agieren zu ermöglichen, gingen bis auf wenige Experimente im Verlauf der Ereignisse allerdings verloren.

In den innerparteilichen Auseinandersetzungen gelang es den FrauenaktivistInnen, partiell Deutungsmacht zu gewinnen. Die bis dahin als vorgegeben geltende, ungleiche Partizipation zwischen Männern und Frauen an der Politik wurde entnaturalisiert und als ein organisationsimmanentes Problem der Partei definiert, das sich durch aktives Handeln der Parteimitglieder lösen ließ.

Die Quote, die viele Jahre von den ASF-Frauen mehrheitlich abgelehnt wurde, erwies sich als ein wirksames Instrument der Veränderung. Bei der KandidatInnenrekrutierung und in den Aufstellungsverfahren hatten sich das ausschließende Handeln der AkteurInnen und die Organisationsregularien mehr als nur kontingent verkoppelt gezeigt (vgl. Wilz 2002), sowohl aufgrund der Auswahlkriterien als auch durch die informellen Einigungsverfahren im Vorfeld der Abstimmungen setzten sich männliche BewerberInnen bevorzugt durch. Mit der Quote konnte vielerorts der BewerberInnenkreis erweitert werden, was häufig auch

Maß wie männliche (vgl. Gleichstellungsbericht 2015: 10). Auch die Zahl der SPD-Wählerinnen nimmt ab, von 2002 bis zu den Bundestagswahlen 2013 war ihr Anteil an den Wählerinnenstimmen um ca. $40 \%$ gesunken (vgl. https://www.bundeswahlleiter.de/de/ bundestagswahlen/BTW_BUND_13/veroeffentlichungen/repraesentative [Zugriff: 03.09.2015]). 
eine Korrektur der Auswahlverfahren erforderte. Damit eröffneten sich vielen feministischen Frauenpolitikerinnen mehr Chancen, das ihnen zugesprochene Selbstvertretungsrecht in wirkmächtigeren Funktionen wahrzunehmen als vor der Quote.

Durch die institutionelle Frauenbewegung der 1970er- und 1980erJahre wurde nachhaltig eine innerparteiliche Gleichstellungspolitik angestoßen. Der Bochumer Parteitag 2003 entfristete die zunächst als Übergangsmaßnahme eingeführte Quote und nahm sie als strukturellen Bestandteil der Auswahl- und Besetzungsverfahren an. Die Parteireform 2011 ergänzte die Regelung mit einem Reißverschlussverfahren bei der Besetzung der KandidatInnenlisten.

Alle ZeitzeugInnen bestätigten, dass sich in den 1980er-Jahren der Umgang der Männer mit den Frauen in der Partei nachhaltig wandelte. Frauen diskriminierendes Verhalten wurde delegitimiert und konnte nun eine männliche Parteikarriere nachhaltig schädigen. Auch die Versammlungskultur an der Parteibasis veränderte sich. Sitzungen fanden nicht mehr in Gaststätten, sondern in Gemeindesälen oder anderen alkoholfreien Tagungsräumen statt, ein Kinderbetreuungsservice bei ganztägigen Parteiveranstaltungen galt als selbstverständlich ${ }^{715}$.

Die innerparteiliche Frauenbewegung setzte neue Themen auf die politische Agenda der Partei, wie z.B. die Diskriminierung in der Arbeitswelt, sexuelle Belästigung am Arbeitsplatz, Vergewaltigung in der Familie, internationaler Frauenhandel und sexuelle Selbstbestimmung ${ }^{716}$. Vielerorts setzten sozialdemokratische FrauenpolitikerInnen in den Kommunen durch, dass private Initiativen zur Selbsthilfe oder zur Unterstützung der Opfer mit öffentlichen Geldern gefördert wurden, und forcierten die Einrichtung von kommunalen Frauen- oder Gleichstellungsbeauftragten.

Gleichzeitig veränderten sich die feministischen Emanzipationsziele der linkssozialistisch-frauenaktivistischen Sozialdemokratinnen in den innerparteilichen Auseinandersetzungen. Ihre politischen Perspektiven wurden durch die Erfahrung geformt, die sie bei der Durchsetzung frauenpolitischer Politiken sammelten. Besonders die Distributionspolitiken zur Bekämpfung von wirtschaftlicher Armut und Prekarisierung waren in der Partei sowohl in der Phase der Regierungsbeteiligung als auch in der Opposition wenig anschlussfähig; verschiedene, neue Konzeptideen zur Steuergerechtigkeit, Rentenpolitik, Antidiskriminierung und Sozialpolitik wurden deshalb von den Akteurinnen nicht weiterentwickelt und

715 Ein solches Angebot wird heute - allerdings mangels Nachfrage - nicht mehr organisiert.

716 Zur Organisierung schwul-lesbischer Interessen in der Partei hatte sich 1978 ein Arbeitskreis gegründet. Er wurde auf dem Berliner Parteitag 2011 als Arbeitsgemeinschaft eingerichtet. 
weiterverfolgt. Diese Themen mobilisierten aber zugleich zu wenig Interesse und Resonanz in den Neuen Frauenbewegungen, um durch „unkonventionelle" Partizipation und gesellschaftspolitischen Druck von außen in die Parteien hineingetragen zu werden. Dagegen fanden leistungsorientierte Gleichstellungspolitiken, wie die einer gleichen Vergütung männlicher und weiblicher Arbeitsleistung oder eines geschlechtergerechten Zugangs zu Bildung sowie zu den Berufs- und Arbeitsmärkten oder auch solche, die das politische Engagement und die Übernahme von politischer Verantwortung förderten, in der Partei mehr Unterstützung.

Ilse Lenz bezeichnet die Institutionalisierung der Frauenbewegungen in Parteien, Verbänden und öffentlichen Verwaltungen als eine „differenzielle Integration“ (Lenz 2008: 582). Einerseits trug der Aufbau von Frauen- und Gleichstellungsstrukturen dazu bei, die Fraueninteressen sichtbar zu machen und zu legitimieren, und regelte auch eine begrenzte Einflussnahme der Vertreterinnen auf die Gesamtorganisation, andererseits aber schufen solche spezifischen Organisationsbereiche eine „Gendergrenze" und markierten geschlechterspezifische Zuständigkeiten, die es erschwerten, die Anliegen der Frauen in die Verantwortung der Gesamtorganisation zu bringen (Lenz 2008: 32, 588f.).

Die Gefahren einer solchen ausschließenden Einschließung durch die Institutionalisierung frauenpolitischer Sonderstrukturen wurden bereits in den Neugründungsdiskursen der ASF kontrovers erörtert. Viele der Befürchtungen schienen sich im Ereignisverlauf zu bestätigen. So blieben Frauen- und Gleichstellungspolitiken selbst nach der Aufwertung des Geschlechterthemas im Grundsatzprogramm der Partei weiterhin eher Spezialthemen von Frauenpolitikerinnen. Dies verstärkte die geschlechterspezifische Zuschreibung von Politikfeldern. Politikerinnen galten via Geschlecht noch dezidierter als Expertinnen für Frauen-, Familien-, Gesundheits-, Sozial- und Bildungspolitik und hatten oft einen schwierigeren Zugang zu anderen politischen Handlungsfeldern wie z.B. Wirtschaft, Verteidigung, Innenpolitik, Finanzen, selbst nach der verpflichtend quotierten Besetzung von Arbeitskreisen und Ausschüssen in der Partei.

Trotzdem legt der Verlauf der Kämpfe der SozialdemokratInnen für eine neue Frauenpolitik der SPD nah, dass in einer Partei der AkteurInnenvielfalt (vgl. Wiesendahl 2002) die Sichtbarkeit der politischen KontrahentInnen und ihrer divergierender Interessen nur durch eine identifizierbare Formierung von Parteimitgliedern erreicht wird, wie sie die Frauenarbeitsgemeinschaft darstellte, weil eine einflussmächtige Verhandlungsposition in der Partei stärker durch Repräsentationen und mediale Inszenierungen als durch Argumente erreicht werden kann. 
In dieser Studie wurde eine institutionelle Bewegung der NFB rekonstruiert und analysiert. Dokumentiert wurde die Mobilisierung und Formierung von überwiegend weiblichen Parteimitgliedern und PolitikerInnen, die emanzipatorische Visionen mit großem persönlichem Einsatz in eine Neuausrichtung der Partei einbrachten und die Modernisierung der Partei mitgestalteten. Die Forschungsergebnisse sollen dazu beitragen, die „Institutionenfrauen“ in den feministischen Diskursen und auch in der feministischen Bewegungsforschung stärker als bisher als ein eigenständiges und vermutlich erfolgreicher wirkendes gesellschaftsveränderndes Segment der Neuen Frauenbewegungen wahrzunehmen und zu würdigen, als das bisher geschehen ist. 


\section{Quellen und Literatur}

\subsection{Archivalien}

\subsubsection{Archive}

Archiv der Sozialen Demokratie der Friedrich-Ebert-Stiftung, Bonn

Bestand Parteivorstand / Referat Frauen

Bestand Parteivorstand / ASF

Bestand Parteivorstand / Frauen

SPD Parteivorstand, politisches Archiv am Willy-Brandt-Haus, Berlin

Bestand X-21-ASF

Bestand X-3-Frauen

Institut für Soziale Bewegung, Bochum

\subsubsection{Nachlässe und Privatarchive}

Nachlässe im Archiv der sozialen Demokratie: Karin Hempel-Soos, Dr. Haidi Streletz, Katharina Focke, Annemarie Renger.

Privatarchiv: Christine Schmarsow, Dr. Haidi Streletz, Renate Schmitt-Peters, Inge Stange.

\subsection{Gedruckte Quellen}

\subsubsection{Parteidokumente}

AKE (1971): Programm des Arbeitskreises Emanzipation. Bonn. In: AdsD Bundesfrauenausschuss 0263 .

AKE (1973): Frauen und Sozialismus. Sozialistische tribüne. Zeitschrift für sozialistische theorie 3-4 (4). Bundesvorstand der Jungsozialisten in der SPD (Hg.). Bonn: o.V.

AKE (o.J.): Frauen und Sozialismus. Dokumentation Tl.2. Texte des AKE. Bundesfrauenkommission der Jungsozialisten in der SPD (Hg.). Bonn: o.V.

Aktionsprogramm '78 (1978): "Wahlfreiheit sichern - Partnerschaft verwirklichen". Hg. Frauenvereinigung der CDU, im Internet unter: http://www. frauenunion.de/images/stories/docs/Chronik\%2oder\%2o Frauen\%2oUnion. pdf, [Zugriff: 02.01. 2011]. 
Arbeitsgruppe "Mitgliederentwicklung" (o.J. \{1996\}): Abschlussbericht der Arbeitsgruppe "Mitgliederentwicklung" des SPD-Parteivorstandes unter der Leitung von Christoph Zöpel, betreut von Reinhard Pauk Abteilung 1 - Parteileben/Parteiorganisation. Bonn. SPD-Parteivorstand, Abt. Organisation (Hg.), Materialien.

Arbeitsheft der ASF (o.J. \{1972\}): Arbeitsheft für Arbeitsgemeinschaften sozialdemokratischer Frauen. Reihe f. Vorstand der SPD/Referat Frauenpolitik (Hg.). Bonn: O.V.

Arbeitsgemeinschaft „Parteiorganisation“ (1970): Zusammengefaßte Niederschrift der Arbeitsgemeinschaft „Parteiorganisation, Partei- und Erziehungsaufgabe, Organisationsformen, die persönliche Antriebe zur Politik bilden“ Herdecke 11.7.1970 in: AdsD Frauen ASF 0263.

ASF (1970a): Protokoll der Zusammenkunft des Bundesfrauenausschusses am 22.09. 1970. Bundesfrauenausschuss. Bonn, Bundeshaus. Bundesvorstand der ASF. In: AdsD X Frauen ASF 0263.

ASF (1970b): Protokoll des Bundesfrauenausschuss 22.10. 1970. Nürnberg. Bundesvorstand der ASF. In: AdsD X Frauen ASF 0263.

ASF (1970c): Protokoll der Zusammenkunft des Bundesfrauenausschusses 11.12. 1970. Bundesfrauenausschuss. Bonn, Bundeshaus. Bundesvorstand der ASF. In: AdsD X Frauen ASF 0263.

ASF (1971C): Schlußbericht. Anlage zum Protokoll des Bundesfrauenausschusses o1. Juli 1971 Arbeitsgruppe "Arbeitsgemeinschaften" der Kommission zur Reform der Parteiorganisation. Bonn. Bundesvorstand der ASF. In: AdsD X Frauen ASF 0263.

ASF (1971d): Sitzung des Bundesfrauenausschusses 17. Oktober 1971. Bonn. Bundesvorstand der ASF. In: AdsD X Frauen ASF 0263.

ASF (1975): Ergebnisse der Familienpolitischen Konferenz der ASF, Bremen vom 30.11- 01.12.1974. Bundesfrauenkonferenz der Arbeitsgemeinschaft Sozialdemokratischer Frauen, Braunschweig 23-25. Mai 1975. In: PV-Akten F 679.

ASF (1977): ASF Protokoll Bundeskonferenz der Arbeitsgemeinschaft Sozialdemokratischer Frauen. „Recht auf Arbeit - Frauen in die Politik“, Siegen, 7.-5. Juni 1977, Vorstand der SPD (Hg.). Bonn: O.V.

ASF (1979a): Anträge zur Bundeskonferenz der ASF 18. bis 20. Mai 1979. Erlangen. In: AdsD PV-Akten 9921.

ASF (1979b): Berichte und Protokolle zur Bundeskonferenz der ASF 18. bis 20. Mai 1979. Erlangen. In: AdsD PV-Akten 9922.

ASF (1979c): „Frauen für den Frieden, Frauen für Abrüstung“. Unterschriftenliste der ASF. ASF-Bundesvorstand (Hg.) in: Deposita Streletz 126 o.A.

ASF (1981a): Entschließung zur Lage und zur Strategie der AsF. Ordentliche AsFBezirkskonferenz 21.03. 1981. Kerpen-Horem. Arbeitsgemeinschaft sozialdemokratischer Frauen, SPD-Bezirk Mittelrhein. In: AdsD 9621 Anträge.

ASF (1981b): Schwestern zur Sonne zur Gleichheit. ASF Frauen in der SPD. Internationaler Frauentag. Bundesvorstand der ASF (Hg.). Bonn: O.V. 
ASF (1981c): Stellungnahme der Arbeitsgemeinschaft Sozialdemokratischer Frauen (ASF) zu einem Gleichstellung- (Antidiskriminierungs-) Gesetz In: Sozialdemokratischer Pressedienst 36 (723/02.12), S.1-3.

ASF (1982a): Arbeitszeitverkürzung und Gleichstellung der Frau. Fachtagung der Arbeitsgemeinschaft Sozialdemokratischer Frauen am 22./23. 10. 1982. Berlin: o.V.

ASF (1982b): Beitrag der Arbeitsgemeinschaft sozialdemokratischer Frauen zur Diskussion um Veränderungen des Frauenarbeitsschutzes. Tagung "Frauenarbeitsschutz " vom 08.bis 10.Oktober 1982 Saarbrücken. Anlagen zum Rechenschaftsbericht des Bundesvorstandes der AsF 1981-1983. Bundesvorstand der ASF (Hg.). Bonn: O.V.

ASF (1985b): Die Zukunft ist weiblich. 75 Jahre Internationaler Frauentag. Bundesvorstand der ASF (Hg.). Bonn: O.V.

ASF (1987a): Ist Sozialismus ohne Feminismus möglich? Frauen diskutieren über ein neues Grundsatzprogramm. Dokumentation einer Gesprächsrunde, die am 23.06.87 auf Einladung des ASF-Bundesvorstandes im Erich-OllenhauerHaus stattfand. Bundesvorstand der ASF (Hg.). In: AdsD PV-Akten C94-0183. ASF (1987b): Handbuch zur Frauenarbeit der Arbeitsgemeinschaft Sozialdemokratischer Frauen. AsF-Bundesvorstand (Hg.). Bonn: O.V.

ASF (1988): Die Quotendiskussion in der SPD - eine Argumentationshilfe. März 1988. ASF Frauen in der SPD (Hg.). In: PV-Akten 1251.

ASF (2002): Beschlüsse. "Die ASF - Bündnis für Frauen". 15. ordentliche AsF Bundeskonferenz von 21. bis 23. o6.in Dortmund. ASF-Bundesvorstand (Hg.). Im Internet unter: http://www.asf.de/spd-webapp/servlet/ elementblob/455878/content, [Zugriff: 03.06.2012].

ASF (2006): Beschluss Nr. P 1 "Anforderungen an ein neues SPD-Grundsatz-programm aus frauenpolitischer Sicht. Wer die menschliche Gesellschaft will, muss die männliche überwinden". 17. Ordentliche Bundeskonferenz der Arbeitsgemeinschaft Sozialdemokratischer Frauen (ASF). 22. - 24. September 2006 Berlin. Im Internet unter: http://www.asf.de/spd-webapp/servlet/ elementblob/45588o/content, [Zugriff: 404.06.2012].

ASF (2008): Frauen Macht Politik. 9o Jahre Frauenwahlrecht und 20 Jahre Quotenbeschluss der SPD. Bundesvorstand der ASF (Hg.). Berlin: o.V.

ASF (2015): Gleichstellungsbericht. Bundestag der SPD in Berlin 10. bis 12. Dezember 2015. Berichterstatterin: Elke Ferner, MdB, Bundesvorsitzende der Arbeitsgemeinschaft Sozialdemokratischer Frauen. Im Internet unter: http://www.asf.de/spd-webapp/servlet/elementblob/19074177/content, [Zugriff: 02.02.2016].

ASF (o.J.\{1992\}): Frauen machen Politik. ASF Frauen in der SPD. Frauenreferat beim SPD-Parteivorstand (Hg.). Bonn: o.V.

ASF LO Bremen (1991): AsF Frauen in der SPD/ ASF in Bremen und Bremerhaven. Deutschlands, Sozialdemokratische Partei Bremen, ASF Landesorganisation. Bremen: o.V. 
ASF UB Düsseldorf (1986): Was wir wollen. Was wir tun. Düsseldorf. ASF (Hg.). In: PV-Archiv Berlin X21-ASF

ASF-Beschluss Nr. 59 (2004): Die Macht der Frauen entscheidet über die Zukunft. AsF Bundeskonferenz 14. bis 16.Mai 2004. Leipzig. AsF-Bundesvorstand. Im Internet unter: http://www.asf.de/spd-webapp/servlet/ elementblob/455881/content, [Zugriff: 03.06.2012].

ASF-Beschlüsse (1979): Beschlüsse der Bundeskonferenz der Arbeitsgemeinschaft sozialdemokratischer Frauen (ASF) Erlangen 18.-20. Mai 1979. Sozialdemokratischer Informationsdienst. Frau und Gesellschaft. In: AdsD SPD-PV 10334. ASF-Bezirk Mittelrhein (o.J. \{1979\}): ASF - das sind wir Frauen in der SPD. Was wir machen. Wie wir's machen. Was wir erreichen wollen. ASF (Hg.). Bonn: o.V.

ASF-Bundesvorstand (1981): Protokoll über die Sitzung der Antragskommission zur ASF-Bundeskonferenz 1981, Bonn, 9./10.Mai 1981. In: AsdD SPD-PV 9326.

ASF-Bundesvorstand (1981): Unkorrigiertes Protokoll des ASF-Bundesvorstandes am 3. Juni 1981 in Bonn, Erich-Ollenhauer-Haus. In: AdsD SPD-PV 9326.

ASF-Bundesvorstand (1983): vorläufiges Protokoll. Bundesvorstandssitzung der ASF vom 21. März 1983 In: PV-Archiv Berlin ASF 1248.

ASF-Bundesvorstand (2015): Paritätisch besetzte Doppelspitze jetzt ermöglichen! (Satzungsänderung §23 Organisationsstatut). Antrag zum Ordentlichen Bundesparteitag 10. - 12. Dezember 2015. Im Internet unter: http:// www.asf.de/ spd-webapp/servlet/elementblob/18719647/content, [Zugriff: 02.09.2015].

ASF-Flyer (2006): Arbeitsgemeinschaft Sozialdemokratische Frauen. Selbstdarstellung. Berlin.

ASF-Programmkommission (1974): Protokoll der Sitzung vom 30./31.März 1974. In: Nachlass Schmarsow.

Baader, Ottilie (1908): Bericht der Vertrauensperson der Genossinnen Deutschlands für die Zeit vom August 1907 bis Ende Juli 1908. Parteitag der Sozialdemokratischen Partei Deutschlands vom 13. bis 19. September. Protokoll über die Verhandlungen des Parteitages der Sozialdemokratischen Partei Deutschlands sowie Bericht über die 5. Frauenkonferenz am 11.12. September in Nürnberg 1908. Sozialdemokratische Partei Deutschlands (Hg.), S.99-116.

Behrendt-Weiß, Beate (o.A.\{2002\}): Geschichte der Frauen Union der CDU. Im Internet unter: http://www.frauenunion.de/images/stories/docs/Chronik\%2 oder\%2oFrauen\%2oUnion.pdf, [Zugriff: 02.01. 2011].

Beirat für Frauenpolitik der SPD (1970): Protokoll der Sitzung vom 13.3. 197o. In: AdsD PV-Akten Frauen 263.

Bielefelder Appell (1980) abgedruckt in: Plümer, Lutz (Hg.) (1981): Positionen der Friedensbewegung. Die Auseinandersetzung um den US-Mittel-streckenraketenbeschluß. Dokumente, Appelle, Beiträge. Im Internet unter: http://germanhistorydocs.ghi-dc.org/pdf/deu/Chapterı2Doc7KM.pdf, [Zugriff: 03.07.2012]. 
BFSFJ (2009): Von Alltagsheldinnen und Lokalexpertinnen. Kommunalpolitikerinnen im Porträt. Bundesministerium für Familie, Senioren, Frauen und Jugend (Hg.). Im Internet unter: http://www.frauen-macht-kommune.de/fileadmin/eaf/z_FrauenMachtKommune/Dokumente/ Broschuere_Kommunalpolitikerinnen_im_Portraet.pdf, [Zugriff: 07.10.2009].

Brandt, Willy (1969): Regierungserklärung von Bundeskanzler Willy Brandt vor dem Deutschen

Bundestag in Bonn am 28. Oktober 1969. Im Internet unter: www.willybrandt.de/fileadmin/ brandt/ Downloads/Regierungserklaerung_Willy_ Brandt_1969.pdf, [Zugriff: 12.04.2013].

Brandt, Willy (1974): Klagt nicht, organisiert Euch! In: Dokumente 03/1974, S. 49..

Brandt, Willy (1981): Grußwort des Vorsitzenden der Sozialdemokratischen Partei Deutschlands Willy Brandt anläßlich der Bundeskonferenz der Arbeitsgemeinschaft Sozialdemokratischer Frauen in Bonn - Bad Godesberg vom 15.-17. Juni 1981. Bundesvorstand der ASF (Hg.). Bonn: Broschüre.

Bundesfrauenausschuss (1971a): Sitzung des Bundesfrauenausschusses 25. April 1971. Aussprache über Organisationsfragen und Arbeitsprogramm. Bonn. In: AdsD PV-Akten 0263.

Bundesfrauenausschuss (1971b): Sitzung des Bundesfrauenausschusses 26. Juni 1971. Protokolle und Anlagen. In: AdsD PV-Akten 0263.

Bundesfrauenausschuss (1971C): Sitzung des Bundesfrauenausschusses o1. Juli 1971. Bonn, Erich-Ollenhauer-Haus. In: AdsD PV-Akten 0263.

Bundesfrauenkonferenz (1968): "Mit uns die Zukunft bauen". Bundesfrauenkonferenz der SPD in vom 7. bis 9. Juni. Saarbrücken. Vorstand der SPD / Referat Frauenpolitik (Hg.). Bonn: o.V.

Bundeswahlleiter, Der (2014): Wahl zum 18. Deutschen Bundestag am 22. September 2013. In: Heft 4 "Wahlbeteiligung und Stimmabgabe der Männer und Frauen nach Altersgruppen". Im Internet unter: http://www.bundeswahl-leiter.de/de/bundestagswahlen/BTW_BUND_13/veroeffentlichungen/

BTW2013_Heft4.pdf, [Zugriff: 20.11. 2014].

Bundeswahlleiter, Der (2015): Ergebnisse früherer Bundestagswahlen. Informationen des Bundeswahlleiters. Stand 3.August 2015. Im Internet unter: http://www.bundeswahlleiter.de/de/bundestagswahlen/ downloads| bundestagswahlergebnisse/btw_ab49_gesamt.pdf, [Zugriff: 20.o8. 2015].

CDA (1981): Leitsätze: Die sanfte Macht der Familie. 19. Bundestagung der Sozialausschüsse der Christlich-Demokratischen Arbeitnehmerschaft (CDA) "Familie, Freiheit, Zukunft" 9.-11. Oktober 1981, Mannheim. Sozialausschüsse der Christlich-Demokratischen Arbeitnehmerschaft (CDA). In: AdsD 2/PVAX oo0340. 
CDU (1985): Leitsätze der CDU für eine neue Partnerschaft zwischen Mann und Frau. 33. Bundesparteitag vom 20. bis 22. März 1985 in Essen. Im Internet unter: http://www.grundsatzprogramm.cdu.de/doc/ 1985_Essen_Leitsaetzeder-CDU-fuer-eine-neue-Partnerschaft-zwi.pdf, [Zugriff: 02.10.2011].

Dertinger, Antje (1992): Lila ohne Pause. Die ASF wird 20. Bundesvorstand der AsF (Hg.). Bonn: o.V.

DGB (20o8): Vereinbarkeit von Beruf und Familie. Forderungen des DGB in nahezu allen Politikfeldern. Zusammenstellung der Beschlüsse des DGB aus den Protokollen der Ordentlichen Bundeskongresse und Bundesfrauenkonferenzen (1968-2006). Bundesvorstand, Bereich Gleichstellungs- und Frauenpolitik (Hg.). Im Internet unter: http://www.DGB-Positionen-1968-2006\%2o(5).pdf, [Zugriff: 02.02.2014].

DGB (1989): Frauen haben Recht und Rechte! 12. Bundesfrauenkonferenz des DGB 29. Juni bis o1. Juli 1989, Osnabrück. Bericht über die Erledigung der von der 11. Bundesfrauenkonferenz des Deutschen Gewerkschaftsbundes 1985 angenommenen Anträge und Entschließungen. Düsseldorf: o.V.

Eilers, Elfriede (1968): Die SPD und die Frauen In: f 5. Reihe Frauenpolitik. Vorstand der SPD (Hg.). Bonn: O.V.

Eilers, Elfriede (1973): Aktivierung der Arbeitsgemeinschaft der SPD-Frauen In: Sozialdemokratischer Pressedienst. 26 (61/28. 03.), S.1-2.

Eilers, Elfriede (1974a): Eröffnungsrede der Bundesvorsitzenden der ASF Elfriede Eilers. In: Dokumente 03/1974.

Eilers, Elfriede (1974b): Die Hausfrauen in Deutschland. Feststellungen zu einem gesellschaftspolitischen Problem In: Sozialdemokratischer Pressedienst. 29 (42/01.03.), S.5-6.

Eilers, Elfriede (1974c): Konzept einer zeitgemäßen Familienpolitik. Zur Konferenz der Arbeitsgemeinschaft Sozialdemokratischer Frauen in Bremen In: Sozialdemokratischer Pressedienst. 29 (228/29.11.), S.1-2.

Eilers, Elfriede (1975a): Einen Denkprozeß auslösen. Nirgendwo sind die Frauen voll in die Gesellschaft integriert In: Sozialdemokratischer Pressedienst. 30 (4/21.01.), S.1-2.

Eilers, Elfriede (1975b): Polemik mit Makulatur. Zu einer sachlichen Auseinandersetzung mit der ASF-Bundes-konferenz reicht es in der Union nicht In: Sozialdemokratischer Pressedienst. 30 (101/02.06), S.2-3.

Eilers, Elfriede (1975c): Pressemitteilung In: Sozialdemokratischer Pressedienst. 30 (506/16.10.)

Europa-Dokument (1978): Europa-Dokument. Frauenausschuss beim Bund der Sozialisten (Hg.). In: PV-Archiv Berlin X-21 Frauen.

Europawahlprogramm der SPD (1979): Soziale Demokratie für Europa. Programm der Sozialdemokratischen Partei Deutschland für die erste europäische Direktwahl 1979. Vorstand der SPD (Hg.). In: Dokumente Nr.1. Im Internet unter: http://library.fes.de/pdf-files/netzquelle/o1794.pdf, [Zugriff: 25.20.2012]. 
Europawahlprogramm der SPD (1984): Europawahlprogramm 1984. Für ein starkes und solidarisches Europa. Beschlossen auf der gemeinsamen Sitzung von Parteivorstand, Parteirat und Kontrollkommission am 14. Februar 1984 in Fellbach. Vorstand der SPD (Hg.). Bonn: o.V.

Familienpolitik (1974): Ergebnis der Familienpolitischen Konferenz der ASF Bremen vom 30.11. bis 1.12. 1974. Bundesvorstand der ASF (Hg.). In: PV-Akten 13692.

Familienpolitik (1977): Familienpolitik der SPD. Beschluss des Hamburger Parteitags 15.-19.11.1977 Vorstand der SPD (Hg.), Informationen und Argumente. o.V.

Familienpolitik (1979): Familienpolitik der SPD. Informationen und Argumente. Politik. Aktuelle Informationen der Sozialdemokratischen Partei Deutschlands. Nr. 1, Januar 1979. Sozialdemokratische Partei Deutschlands (Hg.). In: PV-Archiv X-21-Frauen.

Faul, Angela (1976): Soll Genossin Gretchen nun zu den Frauen oder zu den Jusos geh'n? Sozialdemokrat Südbayern. Nr.1. In: AdsD Jusos 9661-9665.

FDP Frauenprogramm (1972): F.D.P. - Programm zur Gleichberechtigung der Frau. Beschluß vom 24. Oktober 1972. Bundesparteitag 23. bis 25.10. Freiburg/Br. In: Nachlass Streletz.

fes (1970): Umwelt-Partei-Organisation. Politische Arbeit in der Frauengruppe. Protokoll. Seminar der Friedrich-Ebert-Stiftung 10.-12.7. 1970 in Herdecke. Friedrich-Ebert-Stiftung (Hg.). In: AdsD PV-Akten Frauen 0277.

Focke, Dr. Katharina (1974): Rede (o.T.) auf der familienpolitische Konferenz der ASF in Bremen. In: Dokumente 03/1974, S.9-16.

Fortschritt 90 (1989): Fortschritt für die 9oer: Moderne Technik in einer humanen Arbeitswelt. Materialien zum Fachkongress. "Fortschritt 90 und neues Grundsatzprogramm: Elemente für eine neue Politik der Arbeit". Vorstand der SPD (Hg.). Im Internet unter: http://library.fes.de/pdf-files/netz-quelle/c9501256/o1.pdf, [Zugriff: 22.08.2013].

Fragebogenaktion (o.J. \{1974\}): Auswertung der Fragebögen. In: AdSD 13692

Frauenbüro (1950): Frauenorganisation der SPD. Von dem Frauenbüro der Sozialdemokratischen Partei Deutschlands zusammengestelltes Material für die Sozialistische Propaganda- und Organisations- Expertenkonferenz Dorking, Surrey vom 29. Oktober - 1. November 1950. Parteivorstand der SPD (Hg.). Bonn: o.V.

Frauenpolitische Konferenz der SPD-Bundestagsfraktion (1989): SPD-Politik für Frauen - Probleme und Lösungsansätze. Materialien. Vorstand der SPD (Hg.). Bonn: o.V.

Galm-Gräfe, Christa (o.J. (1974)): Ansätze zu einer politischen Didaktik. Programmkommission der ASF 1973/1974. In: Privatarchiv Schmarsow.

Gerhard, Ute (1988): Wo bleibt die selbstständige soziale Sicherung von Frauen? In: Parteivorstand der SPD/Frauenreferat (Hg.) (1989). a.a.O., S.25-27.

Gerhard, Ute (1990): Frauen und soziale Struktur. In: Dokumente 30/1990, S.4044 . 
Gleichstellungsbericht (1982): Bericht zur Gleichstellung der Frauen in der SPD. Parteitag der Sozialdemokratischen Partei Deutschlands 19. - 23.4. München. Vorstand der SPD (Hg.). In: Parteitag der SPD. Protokoll der Verhandlungen. Bd. II, A 46-54.

Gleichstellungsbericht (1984): Bericht der Arbeitsgruppe Gleichstellung der Frau vorgestellt durch Inge Wettig-Danielmeier. Parteitag der Sozialdemokratischen Partei Deutschlands. 17. - 21. Mai. Essen. Vorstand der SPD (Hg.). In: Parteitag der SPD. 3. Tag, S.307-315

Gleichstellungsbericht (1986): Bericht des Bundesgeschäftsführers und Bericht der Gleichstellungskommission. Parteitag der Sozialdemokratischen Partei Deutschlands 25.- 29.8. Nürnberg. Vorstand der SPD (Hg.). In: Parteitag der SPD. 4. Tag, S.427-434.

Gleichstellungsbericht (1988): Gleichstellungsbericht des SPD-Parteivorstandes. Parteitag der Sozialdemokratischen Partei Deutschlands 3o.8.- 2.9. Münster. Vorstand der SPD (Hg.). In: Parteitag der SPD. Anhang, S. 875 - 896.

Gleichstellungsbericht (1991): Frauen in der SPD deutlich auf dem Vormarsch: Der Gleichstellungsbericht des Parteivorstandes vorgelegt auf dem Bremer Parteitag am 28. Mai 1991. Parteitag der Sozialdemokratischen Partei Deutschlands 28. - 31.5. Bremen. In: Arbeitsgemeinschaft Sozialdemokratischer Frauen (Hg.), Frauenthemen. Nr.1.

Gleichstellungsbericht (1995): Schriftlich vorgelegt von Karin Junker, Gleichstellungsbeauftrage des SPD-Parteivorstandes und Bundesvorsitzende der Arbeitsgemeinschaft sozialdemokratischer Frauen. Parteitag der Sozialdemokratischen Partei Deutschlands Mannheim 14. - 17.November 1995. In: Vorstand der SPD (Hg.), Protokoll des Parteitags, S.237-273.

Gleichstellungsbericht (1997): Berichterstatterin Karin Junker, MdEP, Vorsitzende der Kommission Gleichstellungspolitik des SPD-Parteivorstandes und Vorsitzende der Arbeitsgemeinschaft sozialdemokratischer Frauen. Parteitag der Sozialdemokratischen Partei Deutschlands 2. bis 4. Dezember 1997. Hannover. In: Vorstand der SPD (Hg.), Protokoll des Parteitag, S.244-294.

Gleichstellungsbericht (2001): Berichterstatterin Karin Junker, MdEP, Bundesvorsitzende der Arbeitsgemeinschaft sozialdemokratischer Frauen (ASF) und Mitglied des Präsidiums der SPD. Parteitag der Sozialdemokratischen Partei Deutschlands 19. bis 22. November 2001. Nürnberg. Vorstand der SPD (Hg.). Im Internet unter: http://www.spd.de/spd-webapp/servlet/elementblob/456456/content, [Zugriff: 20.11. 2013].

Gleichstellungsbericht (2003): Karin Junker, MdEP, Bundesvorsitzende der Arbeitsgemeinschaft Sozialdemokratischer Frauen (ASF) und Mitglied des Parteivorstandes der SPD. Parteitag der Sozialdemokratischen Partei Deutschlands 17.-19.11.2003. Bochum. In: Vorstand der SPD (Hg.), Protokoll des Parteitags, S. 564-598.

Gleichstellungsbericht (2005): Berichterstatterin: Elke Ferner, MdB Bundesvorsitzende der Arbeitsgemeinschaft Sozialdemokratischer Frauen (ASF) Parteitag 
der Sozialdemokratischen Partei Deutschlands 14. bis 17. November. Karlsruhe. ASF-Bundesvorstand. Im Internet unter: http://www.asf.de/spdwebapp/servlet/elementblob/45646o/content, [Zugriff: 14.06. 2009].

Gleichstellungsbericht (2007): Berichterstatterin: Elke Ferner, MdB Bundesvorsitzende der Arbeitsgemeinschaft Sozialdemokratischer Frauen (ASF) Parteitag der Sozialdemokratischen Partei Deutschlands 26. bis 28. Oktober. Hamburg. ASF-Bundesvorstand. Im Internet unter: http://www.asf.de/spdwebapp/servlet/elementblob/456462/content, [Zugriff: 14.06. 2009].

Gleichstellungsbericht (2009): Berichterstatterin: Elke Ferner, MdB Bundesvorsitzende der Arbeitsgemeinschaft Sozialdemokratischer Frauen (ASF) Parteitag der Sozialdemokratischen Partei Deutschlands 13. bis 15. November. Dresden. ASF-Bundesvorstand. Im Internet unter: http://www.asf.de/spdwebapp/servlet/elementblob/456464/content, [Zugriff: 14.05. 2011].

Gleichstellungsbericht (2011): Berichterstatterin: Elke Ferner, MdB Bundesvorsitzende der Arbeitsgemeinschaft Sozialdemokratischer Frauen (ASF). Parteitag der Sozialdemokratischen Partei Deutschlands Bundesparteitag der SPD 04.bis o6. Oktober. Berlin. ASF-Bundesvorstand (Hg.). Im Internet unter: http://www.asf.de/spd-webapp/servlet/elementblob/11066713/content, [Zugriff: 20.11. 2013].

Gleichstellungsbericht (2013): Berichterstatterin: Elke Ferner, MdB Bundesvorsitzende der Arbeitsgemeinschaft Sozialdemokratischer Frauen (ASF). Parteitag der Sozialdemokratischen Partei Deutschlands Bundesparteitag der SPD 14.bis 16. Oktober. Leipzig. ASF-Bundesvorstand (Hg.). Im Internet unter: http://www.asf.de/spd-webapp/servlet/elementblob/17316246/content, [Zugriff: 20.11. 2013].

Gleichstellungsbericht (2015): Berichterstatterin: Elke Ferner, MdB Bundesvorsitzende der Arbeitsgemeinschaft Sozialdemokratischer Frauen (ASF). Parteitag der Sozialdemokratischen Partei Deutschlands Bundesparteitag der SPD 1o.bis 12. Dezember. Berlin. ASF-Bundesvorstand (Hg.). Im Internet unter: http://www.asf.de/spd-webapp/servlet/elementblob/19074177/content, [Zugriff: 20.11. 2013].

Glotz, Peter (1981): Die AsF und ihre Rolle in der SPD. Bundeskonferenz der Arbeitsgemeinschaft sozialdemokratischer Frauen in Bonn - Bad Godesberg vom 15. - 17. Juni 1981. ASF Bundesvorstand (Hg.). Bonn: o.V.

Grundsätze der ASF (1972): Grundsätze für die Tätigkeit der Arbeitsgemeinschaften in der SPD. beschlossen vom Parteivorstandes am 21. Februar 1972 in Bonn. In: Vorstand der Sozialdemokratischen Partei Deutschlands (Hg.), Jahrbuch der SPD (o.A. \{1970-72\}), S.583.

Grundsätze für die Arbeit (1975): Grundsätze für die Arbeit der Sozialdemokratischen Frauen. Beschlussvorlage der Programmkommission. In: Bundesvorstand der ASF (Hg.), Bundesfrauenkonferenz 23. bis 25. Mai 1975. Braunschweig. In: AdsD ASF 13692 
Grundsatzprogramm der SPD (1959): Grundsatzprogramm der Sozialdemokratischen Partei Deutschlands, beschlossen auf dem außerordentlichen Parteitag in Bad Godesberg 1959. In: Dowe, Dieter/Klotzbach, Kurt (Hg.). a.a.o., S.349370.

Grundsatzprogramm der SPD (1989): Grundsatzprogramm der Sozialdemokratischen Partei Deutschlands, beschlossen vom Programmparteitag in Berlin 1989. Bonn. In: Dowe, Dieter/Klotzbach, Kurt (Hg.).a.a.O., S.371-445.

Grundsatzprogramm der SPD (2007): Hamburger Programm. Das Grundsatzprogramm der SPD. beschlossen auf dem Hamburger Bundesparteitag der SPD am 28. Oktober 2007. Im Internet unter: http://www.spd.de/linkableblob/1778/data/hamburger_programm.pdf, [Zugriff: 23.05.2009].

Hempel-Soos, Karin (17.01.1990): Gerhard Schröder im Gespräch mit Karin Hempel-Soos. Vorlagetext für den Vorwärts. S.1-17. In: AdsD Depositum HempelSoos 1/KHAEoooo34.

Hempel-Soos, Karin (o.J. \{1984\}):): Katharinas Circus. Bericht. In: AdsD Depositum Hempel-Soos 1/ KHAEooooz6.

Hempel-Soos, Karin (o.J. \{1985\}): Frauen sind keine Enkel. Bericht. In: AdsD Depositum Hempel-Soos 1/ KHAEoooo36.

Hessisches Aktionsprogramm (1984): Hessisches Aktionsprogramm für Frauen. Vereinbarung zwischen SPD und Grünen für die 11. Legislaturperiode Wiesbaden. Im Internet unter: http://sarweb.hessen.de/cache/hessen/ koalitiionsvereinabrung_11.wp_spdgruene.pdf, [Zugriff: 05.06.2014].

Hoffmann, Elfriede (1979): Mündlicher Geschäftsbericht. Bundesfrauenkonferenz der Arbeitsgemeinschaft Sozialdemokratischer Frauen (ASF), 18. - 2o.Mai 1979. Erlangen Stadthalle. ASF-Bundesvorstand (Hg.). In: AdsD PV-Akten 9924.

Grundwertekommission der SPD (1987): Der Streit der Ideologien und die gemeinsame Sicherheit. In: Politik. Informationsdienst der SPD Nr. 3 vom o3. August 1987. Im Internet unter: http://library.fes.de/library/ netzquelle /ddr/politik/pdf/verfemte_4.pdf, [Zugriff: 23.06.2014].

Irsee-Entwurf (1986): Entwurf für ein neues Grundsatzprogramm der Sozialdemokratischen Partei Deutschlands. Irsee Juni 1986. Vorstand der SPD (Hg.). Bonn: o.V.

Jansen, Anni (1978): Notiz über das Gespräch der drei Vorsitzenden des Bundesvorstandes der ASF und Dr. Helga Timm, als Parlamentarische Geschäftsführerin der SPD-Bundestagsfraktion, mit dem Parteivorsitzenden Willy Brandt am 20. Januar 1978 10:0o Uhr. In: PV-Archiv X-21-Frauen.

Junker, Karin (1998): 25 Jahre ASF - Wir haben die richtigen Frauen. ASF-Bundeskonferenz 05. Juni 1998. Münster. ASF-Bundesvorstand (Hg). Im Internet unter: http://library.fes.de/cgi-bin/digibert.pl?id=027553\& dok=55/ 027553\&c=791, [Zugriff: 02.02.2010].

Kipp, Hilde (1968): Politische Einstellungen und Wahlverhalten von Frauen. Vorstand der SPD (Hg.). Bonn. In: AdsD PV-Akten 21 ASF Frauen. 
Lepsius, Renate (1964): Frau und Politik. a.o. Parteitag 15.bis 16.02. Bonn-Bad Godesberg. In: Vorstand der SPD (Hg.), Protokoll des SPD-Parteitags, S.95105.

Lepsius, Renate (1987): Frauenpolitik als Beruf. Gespräche mit SPD-Parlamentarierinnen. Hamburg: Hoffmann und Campe.

Manifest (1989): Manifest der linken Frauen der Europäischen Gemeinschaft, beschlossen am 04.02.89 in Mailand. In: Anlage zum Rechenschaftsbericht 1990

Mischnick, Wolfgang (1982): Bundestagsrede zum Regierungswechsel 1. Oktober 1982. Im Internet unter: http://www.politik-fuer-die-freiheit.de/files/77/Mischnick-Regierungswechsel_1.pdf?PHPSESSID= 8e73e8fde29oa3fi7b757b319093fi79 [Zugriff: 05.01.2007].

Nürnberger Beschlüsse (1986): Aufbruch in die Zukunft. Parteitag der Sozialdemokratischen Partei Deutschlands vom 25. bis 29.08. Nürnberg. Vorstand der SPD (Hg.). Im Internet unter: http://library.fes.de/prodok/fc87-o1867.pdf, [Zugriff: 02.03.2012].

OR '85 (1975): Dokumente: ökonomisch-politischer Orientierungsrahmen für die Jahre 1975-1985 in der vom Mannheimer Parteitag der SPD am 14. November 1975 beschlossenen Fassung. Sozialdemokratische Partei Deutschlands (Hg.). Bonn: o.V.

Otto, Eva (1955): Probleme der alleinstehenden Frau. Vortrag auf der SPD-Frauenkonferenz 7. bis 9. Oktober. Bad Hersfeld. In: Vorstand der SPD (Hg.), Schriftenreihe für Frauenfragen. Nr.1.

Parteitag der SPD 1959 (o.J.): Protokoll der Verhandlungen des außerordentlichen Parteitags der SPD vom 13. bis 15. November 1959 in Bad Godesberg. Vorstand der SPD (Hg.). Bonn: Neuer Vorwärts Verlag.

Parteitag der SPD 1960 (o.J.): Protokoll der Verhandlungen und Anträge vom Parteitag der Sozialdemokratischen Partei Deutschlands in Hannover vom 21. bis 25. November 196o Vorstand der SPD (Hg.). Bonn: Neuer Vorwärts Verlag.

Parteitag der SPD 1964 (o.J.): Protokoll der Verhandlungen. Parteitag der Sozialdemokratischen Partei Deutschlands vom 23. bis 27. November 1964 in Karlsruhe. Vorstand der SPD (Hg.). Bonn: o.V.

Parteitag der SPD 1966 (o.J.): Parteitag der Sozialdemokratischen Partei Deutschlands vom 1. bis 5. Juni 1966 in Dortmund. Protokoll der Verhandlungen. Anträge. Bonn: o.V.

Parteitag der SPD 1968 (o.J.): Protokoll der Verhandlungen. Parteitag der Sozialdemokratischen Partei Deutschlands vom 17. bis 21. März 1968 in Nürnberg. Vorstand der SPD (Hg.). Bonn: o.V.

Parteitag der SPD 1970 (o.J.): Parteitag der Sozialdemokratischen Partei Deutschlands vom 11. bis 14. Mai in Saarbrücken. Protokoll der Verhandlungen. Vorstand der SPD (Hg.). Bonn: o.V.

Parteitag der SPD 1972, a.o. (o.J.): Parteitag der Sozialdemokratischen Partei Deutschlands 12.- 13.Oktober in Dortmund. Vorstand der SPD (Hg.). Bonn: o.V. 
Parteitag der SPD 1973 (o.J.): Parteitag der Sozialdemokratischen Partei Deutschlands vom 10. bis 14. April 1973 in Hannover. Protokoll der Verhandlungen. Vorstand der SPD (Hg.). Bonn: o.V.

Parteitag der SPD 1975 (o.J.): Parteitag der Sozialdemokratischen Partei Deutschlands vom 11.-15.11.1975 in Mannheim Rosengarten. Protokoll der Verhandlungen. Vorstand der SPD (Hg.). Bonn: o.V.

Parteitag der SPD 1977 (o.J.): Parteitag der Sozialdemokratischen Partei Deutschlands vom 15.-19.November in Hamburg. Protokoll der Verhandlungen. Vorstand der SPD (Hg.). Bonn: o.V.

Parteitag der SPD 1979 (o.J.): Parteitag der Sozialdemokratischen Partei Deutschlands vom 3. bis 7. Dezember 1979 in Berlin ICC. Protokoll der Verhandlungen. Anlagen. Vorstand der SPD (Hg.). Bonn: o.V.

Parteitag der SPD 1982 (o.J.): Parteitag der Sozialdemokratischen Partei Deutschlands vom 19. bis 23. April 1982 in München. Protokolle der Verhandlungen. Anhang. Vorstand der SPD (Hg.). Bonn: o.V.

Parteitag der SPD 1984 (o.J.): Parteitag der Sozialdemokratischen Partei Deutschlands vom 17. bis 21. Mai 1984 in Essen. Protokolle der Verhandlungen. Anhang. Vorstand der SPD (Hg.). Bonn: o.V.

Parteitag der SPD (1986): Protokoll vom Parteitag der Sozialdemokratischen Partei Deutschlands in Nürnberg vom 25. bis 29.8.1986. Vorstand der SPD (Hg.). Bonn: o.V.

Parteitag der SPD (1988): Protokoll vom Parteitag der Sozialdemokratischen Partei Deutschlands in Münster vom 30.8. -bis 2.9. 1988. Vorstand der SPD (Hg.). Bonn: o.V.

Parteitag der SPD (1990): Protokoll vom Vereinigungs-Parteitag der Sozialdemokratischen Partei Deutschlands in Berlin vom 27. bis 28.9.2009. Vorstand der SPD (Hg.). Bonn: o.V.

Parteitag der SPD, a.o. 1971 (o.J.): außerordentlicher Parteitag der Sozialdemokratischen Partei Deutschlands vom 17. und 18. Dezember 1971 in Bonn-Bad Godesberg. Protokoll der Verhandlungen. Bonn. Vorstand der SPD (Hg.). Bonn: o.V.

Parteitag der SPD, a.o. 1972 (o.J.): außerordentlicher Parteitag der Sozialdemokratischen Partei Deutschlands 12.-13. Oktober in Dortmund, Westfalenhalle. Protokoll der Verhandlungen. Vorstand der SPD (Hg.). Bonn: o.V.

Parteitag der SPD, a.o. 1976 (o.J.): außerordentlicher Parteitag der Sozialdemokratischen Partei Deutschlands vom 18. und 19. o6., Dortmund Westfalenhalle. Protokoll der Verhandlungen. Dokumentarischer Anhang. Vorstand der SPD (Hg.). Bonn: o.V.

Parteitag der SPD, a.o. (1978): Bundesdelegierten-Konferenz und außerordentlicher Parteitag der Sozialdemokratischen Partei Deutschlands am 9.-10.12.1978 in Köln. Protokoll. Vorstand der SPD (Hg). Bonn: o.V.

Parteitag der SPD, a.o. (1983): Bundesdelegierten-Konferenz und außerordentlicher Parteitag der Sozialdemokratischen Partei Deutschlands amı8. und 19. 
November 1983 in Köln. Protokoll der Verhandlungen. Dokumentarischer Anhang. Vorstand der SPD (Hg.). Bonn: o.V.

Peter, Brunhilde (1981): Gleichheit in der Familie - sechs Punkte zu einer Perspektive. In: Dokumente 15/1981, S. 4-6.

Pfarr, Heide (1985): Das Verständnis der männlichen Parteimitglieder reicht nicht aus. Rede auf dem Landesparteitag der SPD in Hamburg November 1985. GEW, Referat Hochschule und Forschung (Hg.). In: Frankfurt a. Main.

Programmkommission der ASF (1975): Bericht über die Arbeit der Programmkommission der ASF. vorgestellt von Ute Canaris. Bundeskonferenz der Arbeitsgemeinschaft sozialdemokratischer Frauen. Braunschweig, 23.-25. Mai 1975. In: AdsD X-21 Frauen 9663.

Programmkommission (1974): Situationsanalyse der Frauen in Partei und Gesellschaft. Diskussionsvorlage für die Gliederungen der ASF. Bundesfrauenkonferenz 23. bis 25.Mai 1975. Braunschweig. Bundesvorstand der ASF (Hg.). In: AdsD ASF 13692.

Quotendebatte (1988): Dokumentation der Quotendebatte am 30. August 1988. Bundesparteitag der Sozialdemokratischen Partei Deutschlands. Münster. Arbeitsgemeinschaft Sozialdemokratischer Frauen (Hg.). In: dokumente Nr. 28. Sozialdemokratischer Informationsdienst. Frauen in der SPD. Bonn.

Randzio-Plath, Christa (1980): Sozialismus-Feminismus. Die autonome Frauenbewegung und wir. Unkorrigiertes telefon. durchgegebenes Manuskript 20.11. 1980. In: AdsD PV-Akten Frauen 9615.

Rechenschaftsbericht (1975): Arbeitsbericht des Bundesvorstandes der Arbeitsgemeinschaft Sozialdemokratischer Frauen für die Zeit vom 23.März 1973 bis 23. Mai 1975. Bundeskonferenz 23. bis 25. Mai 1975. Braunschweig. Bundesvorstand der ASF (Hg.). In: AdsD Frauen 13692.

Rechenschaftsbericht (1979): Mündlicher Geschäftsbericht der Bundesvorsitzenden der Arbeitsgemeinschaft Sozialdemokratischer Frauen, Elfriede Hoffmann, für die Zeit vom 6. Juni 1977 - 18. Mai 1979 . 4. ordentl. Bundeskonferenz 18. -20.Mai. Erlangen. AsF-Bundesvorstand (Hg.). In: AdsD SPD PV 9924.

Rechenschaftsbericht (1981): Rechenschaftsbericht des Bundesvorstandes der Arbeitsgemeinschaft Sozialdemokratischer Frauen für die Zeit vom 19. Mai 1979 - 14. Juni 1981. 5. ordentliche Bundeskonferenz. Bonn-Bad Godesberg. AsFBundesvorstand (Hg.). In: AdsD Frauen 9622.

Rechenschaftsbericht (1983): Rechenschaftsbericht 1981- 83. 6. ordentl. Bundeskonferenz der Arbeitsgemeinschaft Sozialdemokratischer Frauen. Bonn-BadGodesberg. Bundesvorstand der ASF (Hg.). In: AdsD PV-Akten Frauen 9920.

Rechenschaftsbericht (1985): Berichtszeitraum Juni 1983 bis September 1985. vorgelegt auf der 7. ordentl. ASF Bundeskonferenz 4. bis 6.10.1985. Hannover. AsF-Bundesvorstand (Hg.). In: AdsD Frauen 3/SHAB oo1548.

Rechenschaftsbericht (1987): vorgelegt auf der 8. Bundeskonferenz der Arbeitsgemeinschaft Sozialdemokratischer Frauen vom 16. - 18. Oktober '87. Mannheim. ASF-Bundesvorstand (Hg.). In: AdsD Frauen 2/PVBK ooo473. 
Rechenschaftsbericht (1990): vorgelegt auf der 9. Bundeskonferenz der Arbeitsgemeinschaft Sozialdemokratischer Frauen (ASF) vom 2. bis 4. Mai. Essen. ASF-Bundesvorstand (Hg.). In: AdsD Referat Frauen/18/Mai' 94.

Regierungsprogramm (1976): Regierungsprogramm 1976 - 1980. beschlossen auf dem a.o. Parteitag der Sozialdemokratischen Partei Deutschlands vom 18.06. bis 19.06. Dortmund. In: Parteitag der SPD 1976, S. 309-372.

Regierungsprogramm (1987): Zukunft für alle - arbeiten für soziale Gerechtigkeit und Frieden. Regierungsprogramm 1987-199o der Sozialdemokratischen Partei Deutschlands. Vorstand der SPD (Hg.).Bonn: o.V.

Richtlinien (1957): Richtlinien für die Tätigkeit der Arbeitsgemeinschaften in der SPD. Beschluss des Parteivorstandes vom 09.02. In: der SPD (o.J. \{1962\}), S.505.

Richtlinien (1961): Richtlinien sozialdemokratischer Familienpolitik. vom Parteivorstand beschlossen am 11.04.1961 Vorstand der Sozialdemokratischen Partei Deutschlands. In: Jahrbuch der SPD (o.J. \{1960/61\}), S.465-470.

Richtlinien der ASF (1972): Richtlinien der Arbeitsgemeinschaft für Frauen beschlossen vom SPD-Parteivorstand am 24.06. 1972 In: Jahrbuch der SPD (o.J. \{1970-72\}), S. $587-589$.

Richtlinien der ASF (1974): Richtlinien der Arbeitsgemeinschaft Sozialdemokratischer Frauen. beschlossen vom Parteivorstand am 18.01. 1974. Vorstand der SPD (Hg.). Bonn: o.V.

Richtlinien der ASF (1999): Richtlinien der Arbeitsgemeinschaft Sozialdemokratischer Frauen. beschlossen vom Parteivorstand der SPD am 07.06. 1999.

Ries, Ulrike (1974): Bildungssituation der Frau im 19. und 20. Jahrhundert. Diskussionspapier der Programmkommission zur Erarbeitung frauenpolitische Grundsätze für die ASF. In: Privatarchiv Schmarsow.

Schanzenbach, Marta (1964): Frau in Staat und Gesellschaft von heute. Parteivorstand der SPD (Hg.). In: Vorstand der SPD (Hg.), Protokoll des außerordentlichen Parteitags der Sozialdemokratischen Partei Deutschlands vom 15. bis 16. Februar in Bonn-Bad Godesberg, Bonn: Neuer Vorwärts-Verlag Nau \& Co., S.107-121

Scheer-Pontenagel, Irm (1981): Familienergänzende Einrichtungen, Maßnahmen und Dienste. In: Dokumente 15/1981, S.6-7.

Schmarsow, Christine (1971): Diskussionsbeitrag zur politischen Frauenarbeit in der SPD. In: AdsD PV-Akten ASF 277.

Schmarsow, Christine (1973): Diskussionspapier zur Problematisierung der Frage: wie AsF-Arbeit und warum AsF-Arbeit. Erstfassung von Christine Schmarsow, Bonn Mai 1973, überarbeitet von Anke Brunn für Schulungszwecke im Bezirk Mittelrhein. In: Privatarchiv Schmarsow.

Schmarsow, Christine (1981): Gegen die Arbeiterquote. Ein Kurieren an Symptomen hebt die Ursachen der Unterrepräsentation nicht auf. In: Sozialdemokratischer Pressedienst. 36 (246/28.12) S.5-7. 
Schmarsow, Christine (1982): Rede auf der Gleichstellungstagung des SPD-Bezirks Mittelrhein am 11. Dezember 1982 in Troisdorf. unveröffentl. Manuskript. In: Privatarchiv Schmarsow.

Schmarsow, Christine (1982): Rede auf der Gleichstellungstagung des SPD-Bezirks Mittelrhein, 11. Dezember 1982. Troisdorf. Manuskript, unveröffentl. In: Privatarchiv Schmarsow.

Schmarsow, Christine (o.A. \{1974\}): Überlegungen zu einer Strategie der Vermittlung gesellschaftlicher Ziele und Inhalte politischer Frauenarbeit in der SPD. In: AdsD Frauen 13692.

Schmidt, Renate (1989): Die Frauenfrage als Männerfrage. Gleichstellungspolitik zwischen Lippenbekenntnis und Verweigerung - haben Männer (k)ein Eigeninteresse an der Gleichstellung von Frau und Mann? Dokumentation der Anhörung vom 28./29. Juni 1989. Bonn. Fraktion der SPD im Deutschen Bundestag (Hg.). Bonn: o.V.

Sozialpolitisches Programm (1988): Sozialpolitisches Programm der SPD. beschlossen auf dem Parteitag der SPD vom 30.8. bis 2.9. . Münster Parteivorstand der SPD (Hg.). Im Internet unter: http://library.fes.de/prodok/fc9o00779.pdf, [Zugriff: 20.05.2013].

SPD (1979b): Frauen für Europa. Parteivorstand der SPD (Hg.), Europa-Informationen 3. Bonn: o.V.

SPD (1982): Die Arbeiterbewegung und der Wandel gesellschaftlichen Bewußtseins und Verhaltens. In: Vorstand der SPD, Abt. Presse und Information, Theorie und Grundwerte (Hg.), Reihe "Theorie und Grundwerte" des SPD-Parteivorstands. Bonn: o.V.

SPD (o.A. \{1956\}): Probleme der alleinstehenden Frau. Die psychologische Situation der alleinstehenden Frau. In: SPD-Parteivorstand (Hg.), Schriftenreihe für Frauenfragen. Nr.ı. Bonn: o.V.

SPD (o.A. \{1980\}): Das Märchen vom Wahlverhalten der "progressiven Frauen". Aktuelles für Frauen. Parteivorstand der Sozialdemokratischen Partei Deutschland (Hg.). In: Bonn: o.V.

SPD- Parteivorstand, Referat Frauenpolitik (Hg.) (1968): Frauen 1968: Regionalkonferenzen der SPD. Bonn: o.V.

SPD-Parteivorstand (1989): "Frauen brauchen mehr! " Beiträge zur sozialdemokratischen Programmdiskussion. Materialien "Frauen brauchen mehr!". Beiträge zur sozialdemokratischen Programmdiskussion. Vorstand der SPD, Referat Öffentlichkeitarbeit (Hg.). Bonn: o.V.

SPD-Parteirat (1985): Protokoll der Sitzung vom 16. September. In: AdSD SPD/PV 1248.

Statut der SPD (1890): Die Organisation der Partei. Parteitag der Sozialdemokratische Partei Deutschlands vom 12. bis 18. Oktober. Protokoll über die Verhandlungen. Halle a.S. S.5-8. Im Internet unter: http://library.fes.de/parteitage/ pdf/pt-jahr/pt-189o.pdf, [Zugriff: 02.04.2012]. 
Statut der SPD (1908): Organisation der Sozialdemokratischen Partei Deutschlands. Beschlossen auf dem Parteitag in Jena 1905. Parteitag der Sozialdemokratischen Partei Deutschlands vom 13. bis 19. September. Nürnberg Vorstand der SPD (Hg.). Im Internet unter: http://library.fes.de/partei-tage/pdf/ptjahr/pt-1908.pdf, [Zugriff: 02.04.2012].

Statut der SPD (1925): Organisationsstatut beschlossen auf dem Parteitag der Sozialdemokratische Partei Deutschlands vom 13. bis 18.09. Protokolle mit dem Bericht der Frauenkonferenz. Heidelberg, S.11-18. Im Internet unter: http://library.fes.de/parteitage/pdf/pt-jahr/pt-1925.pdf, [Zugriff: 02.04.2012].

Streletz, Haidi (1976): Mehr Frauen in die Verantwortung. Diskussionspaper von Dr. Haidi Streletz 07.07. 1976. In: AdsD SPD PV10409.

Streletz, Haidi (o.A. \{1987\}): Einführung in die Biotechnologie. AsF (Hg.). Bonn: o.V.

Streletz, Haidi (o.A. \{1991\}): Lehr-(Leer)- Stück Demokratie. Der Fall Haidi Streletz. Ablauf, Hintergründe, Konsequenzen. Manuskript. Privatarchiv Dr. Streletz.

Streletz, Haidi (1992): Die Quote und ihre Folgen oder: Quo vadis ASF? vorgelegt auf der Bundesfrauenkonferenz in Berlin 1992. Manuskript. Privatarchiv Dr. Streletz.

Süßmuth, Rita (1988): dpa Meldung vom 11. September 1988: Rita Süßmuth: Frauenquote ist letztes Mittel. PV-Archiv Anlage Telefax der Sitzung PR 12.9. 1988. In: AdsD 2/PVAX ooo618.

Vogel, Hans-Jochen (1994): Ein Programm als Geheimpapier? Zum 5. Jahrestag der Verabschiedung des Berliner Grundsatzprogramms. In: Sozialdemokratischer Pressedienst. 49 (240/15.12) S.1-3.

Vogel, Hans-Jochen (1997): Nachsichten. Meine Bonner und Berliner-Jahre. München/Zürich: Piper.

Wahlparteitag (1983): Wahlparteitag der Sozialdemokratischen Partei Deutschlands. 21. Januar 1983. Protokoll der Verhandlungen. Anlagen. O.V. Vorstand der SPD. Im Internet unter: http://library.fes.de/pdf-files/bibliothek/retroscans/fxo1275_1983.pdf, [Zugriff: 14.03.2012].

Wahlprogramm der CDU/CSU (1980): Für Frieden und Freiheit in der Bundesrepublik Deutschland und in der Welt. Wahlprogramm der CDU und CSU für die Bundestagswahl 1980. verabschiedet auf dem 28. Bundesparteitag der CDU 18.- 20. Mai 1980 in Berlin sowie vom Parteiausschuß der CSU am 17. Mai 1980 in Ingolstadt. CDU Bundesgeschäftsstelle (Hg.). In: http://www.kas.de/upload/ACDP/CDU/Programme_Bundestag/198o_FuerFrieden-und-Freiheit.pdf, [Zugriff: 14.03.2012].

Wahlprogramm der SPD (1972): Mit Willy Brandt für Frieden, Sicherheit und eine bessere Qualität des Lebens. beschlossen vom außerordentlichen Parteitag der Sozialdemokratischen Partei Deutschlands am 13. Oktober 1972 in Dortmund. Im Internet unter: http://library.fes.de/pdf-files/biblio-thek/retroscans/fa92-02386.pdf, [Zugriff: 23.06.2012]. 
Wahlprogramm der SPD (1976): Weiterarbeiten am Modell Deutschland. Regierungsprogramm 1976-1980. Beschluß des außerordentlichen Parteitags in Dortmund 18. und 19. Juni 1976 in Dortmund. Vorstand der SPD (Hg.). Im Internet unter: http://library.fes.de/pdf-files/bibliothek/retro-scans/fc02947.pdf, [Zugriff: 23.10.2011].

Wahlprogramm der SPD (1980): beschlossen von der Sozialdemokratischen Partei Deutschlands auf dem Wahlparteitag in Essen am 9. undıo. Juni in Essen. Unkorrigiertes Protokoll. Vorstand der SPD (Hg.). Im Internet unter: http://library.fes.de/pdf-files/bibliothek/retro-scans/a8o-03353.pdf, [Zugriff: 24.05.2011].

Wettig-Danielmeier, Inge (1981b): Von der Doppelbelastung zur Partnerschaft. Vereinbarkeit von Beruf und Familie. In: Dokumente 15/1981, S.1-4.

Wettig-Danielmeier, Inge (1982): Arbeitszeitverkürzung und gesellschaftlicher Wertewandel. Forum Arbeitszeitverkürzung 05.11. 1982. In: AdsD Frauen 9883.

Wettig-Danielmeier, Inge (1984): Scheidungsrecht. Stellungnahme. In: AdsD SPD-PV 9389.

Wettig-Danielmeier, Inge (1985a): Rede "Politische Arbeit und Perspektiven der ASF". In: Dokumente 24/1985, S.27-31.

Wettig-Danielmeier, Inge (1985b): anders leben, anders arbeiten. Gesellschaftliche Gleichheit von Frau und Mann. Frauen diskutieren den Entwurf für ein neues Grundsatzprogramm der Sozialdemokratischen Partei Deutschlands. In: SPD-Parteivorstand Frauenreferat (Hg.), Arbeitsheft Juni 1987. Bonn, S.1720.

Wettig-Danielmeier, Inge (1988): Der Irseer Entwurf - Ein Programm für Frauen? Materialien "Frauen brauchen mehr" Beiträge zur sozialdemokratischen Programmkommission. In: Parteivorstand der SPD (1989), a.a.O., S 10-11.

Wettig-Danielmeier, Inge (1990b): Der Schnecke Fortschritt Beine gemacht! Rede am 2. März 1990 zum Auftakt der 9. ordentlichen Bundeskonferenz der Arbeitsgemeinschaft Sozialdemokratischer Frauen (ASF) vom 2. bis 4. März in Essen. Presseservice der SPD. In: AdsD 2/PVAX ooo454.

Wettig-Danielmeier, Inge (1997a): 'Wer die menschliche Gesellschaft will, muß die männliche überwinden ' - Bilanz sozialdemokratischer Gleichstellungspolitik. Rede anläßlich der Konferenz "Grenzen des Wachstums - Grenzen der Gleichheit" Bonn. Müntefering, Franz (Hg.). In: Presseservice der SPD 263/97, 23. Juni 1997.

Wieczorek-Zeul, Heidemarie (1973): Referat auf der außerordentlichen Bezirkskonferenz der AsF Hessen-Süd. Offenbach. In: AdsD ASF 13148.

\subsubsection{Zeitschriften}

f 1 (1968): Timm, Helga: Das gesellschaftspolitische Problem der Frau heute und morgen. Reihe Frauenpolitik. Vorstand der SPD (Hg.). Bonn: o.V. 
f 2 (1970): Der Mensch und seine Freizeit in der modernen Industriegesellschaft. Bundesfrauenkonferenz Saarbrücken 1968. Reihe Frauenpolitik.Vorstand der SPD (Hg.). Bonn: o.V.

f 3 (1970): Strobel, Käte: Politik für morgen. Bundesfrauenkonferenz Saarbrücken 1968. Reihe Frauenpolitik. Vorstand der SPD (Hg.). Bonn: o.V.

$\mathrm{f}_{4}$ (1970): Müller, Alex: In der Politik fehlen die Frauen. Reihe Frauenpolitik. Vorstand der SPD (Hg.). Bonn: o.V.

f 5 (1968): Eilers, Elfriede: Die SPD und die Frauen. Nachdruck eines Referats, gehalten auf der Regionalkonferenz im März 1968 in Hannover. Reihe Frauenpolitik. Vorstand der SPD (Hg.). Bonn: O.V.

f 6 (1968): Junker-Seeliger, Hilde: Die erwerbstätige Frau in der industriellen Gesellschaft. Reihe Frauenpolitik. Vorstand der SPD (Hg.). Bonn: o.V.

f 9 (1970): Die Frauenpolitik der SPD. Arbeitsbericht aus dem Jahrbuch der SPD 1968/69, ergänzt um die Monate Januar bis Oktober 1970. Reihe Frauenpolitik. Vorstand der SPD (Hg.). Bonn: o.V.

f 10 (1970): Gleiche Bildungschancen - Auftrag der Demokratie. Bundesfrauenkonferenz 22.-25.10. 1970 Nürnberg. Reihe Frauenpolitik. Vorstand der SPD (Hg.). Bonn: o.V.

f 12 (1973): Benachteiligungen überwinden. Bundesfrauenkonferenz 1973 Ludwigshafen/Rhein vom 23. - 25. März 1973. Reihe Frauenpolitik. Vorstand der SPD (Hg.). Bonn: o.V.

f 13 (1976): Bundesfrauenkonferenz der Arbeitsgemeinschaft Sozialdemokratischer Frauen vom 23. - 25. Mai 1975 in Braunschweig. Reihe Frauenpolitik. Vorstand der SPD (Hg.). Bonn: o.V.

Dokumente (o1/1974): Familienplanung und Familienberatung. Arbeitsgemeinschaft sozialdemokratischer Frauen (Hg.), Frau und Gesellschaft. dokumente Nr. 1. Bonn.

Dokumente (02/1974): Der Weg zur Gleichberechtigung der Frau in der Bundesrepublik Deutschland.

Dokumente (03/1974): Familienpolitische Konferenz der ASF in Bremen. Arbeitsgemeinschaft sozialdemokratischer Frauen (Hg.), Frau und Gesellschaft. dokumente nr. 3. Bonn.

Arbeitsgemeinschaft sozialdemokratischer Frauen (Hg.), Frau und Gesellschaft. dokumente Nr. 2. Bonn.

Dokumente (04/1975): Frauen wollen freier werden. Arbeitsgemeinschaft sozialdemokratischer Frauen (Hg.), Frau und Gesellschaft. dokumente Nr. 4. Bonn.

Dokumente (05/1975): Grundsätze des Versorgungsausgleichs in der Reform des Ehe- und Familienrechts. Arbeitsgemeinschaft sozialdemokratischer Frauen (Hg.), Frau und Gesellschaft. dokumente Nr. 5. Bonn.

Dokumente (06/1977): Recht auf Arbeit - Frauen in die Politik. Arbeitsgemeinschaft sozialdemokratischer Frauen (Hg.), Frau und Gesellschaft. dokumente Nr. 6. Bonn. 
Dokumente (o7/1977): Grundforderungen der Arbeitsgemeinschaft Sozialdemokratischer Frauen. Arbeitsgemeinschaft sozialdemokratischer Frauen (Hg.), Frau und Gesellschaft. dokumente Nr. 7. Bonn.

Dokumente (o8/1977): Grundforderungen der Arbeitsgemeinschaft Sozialdemokratischer Frauen (Teil II). Arbeitsgemeinschaft sozialdemokratischer Frauen (Hg.), Frau und Gesellschaft. dokumente Nr. 8. Bonn.

Dokumente (09/1978): Das neue Ehe- und Familienrecht - ein Frage- und Antwortkatalog -. Arbeitsgemeinschaft sozialdemokratischer Frauen (Hg.), Frau und Gesellschaft. dokumente Nr. 9. Bonn.

Dokumente (10/1978): Europa der Arbeitnehmer - Eine Chance für Frauen. Arbeitsgemeinschaft sozialdemokratischer Frauen (Hg.), Frau und Gesellschaft. dokumente Nr. 10. Bonn.

Dokumente (11/1979): Beschlüsse der Bundeskonferenz der Arbeitsgemeinschaft Sozialdemokratischer Frauen (ASF) Erlangen 18.-20. Mai 1979. Arbeitsgemeinschaft sozialdemokratischer Frauen (Hg.), Sozialdemokratischer Informationsdienst. Frau und Gesellschaft. dokumente Nr. 11. Bonn.

Dokumente (12/1980): Der Versorgungsausgleich im Ehe- und Familienrecht. Arbeitsgemeinschaft sozialdemokratischer Frauen (Hg.), Sozialdemokratischer Informationsdienst. Frau und Gesellschaft. dokumente Nr. 12. Bonn.

Dokumente (13/1980): Stichworte zur Familienpolitik. Arbeitsgemeinschaft sozialdemokratischer Frauen (Hg.), Sozialdemokratischer Informationsdienst. Sozialdemokratischer Informationsdienst. Frau und Gesellschaft. dokumente Nr. 13. Bonn.

Dokumente (14/1981): Beschlüsse der Bundeskonferenz der Arbeitsgemeinschaft sozialdemokratischer Frauen Bonn-Bad Godesberg 13.-15. Juni 1981. Arbeitsgemeinschaft sozialdemokratischer Frauen (Hg.), Sozialdemokratischer Informationsdienst. Frau und Gesellschaft. dokumente Nr. 14. Bonn.

Dokumente (15/1981): Vereinbarkeit von Beruf und Familie. Stellungnahmen und Reden von der Bundeskonferenz der Arbeitsgemeinschaft Sozialdemokratischer Frauen (ASF) 1981 - Grundsatzbeschlüsse zur Vereinbarkeit von Beruf und Familie. Arbeitsgemeinschaft sozialdemokratischer Frauen (Hg.), Sozialdemokratischer Informationsdienst. Frau und Gesellschaft. dokumente Nr. 15. Bonn.

Dokumente (16/1982): Die Stellungnahme der Arbeitsgemeinschaft Sozialdemokratischer Frauen zum Gleichstellungsgesetz. Arbeitsgemeinschaft sozialdemokratischer Frauen (Hg.), Sozialdemokratischer Informationsdienst. Frau und Gesellschaft. dokumente Nr. 16. Bonn.

Dokumente (17/1982): Ergebnisse des Münchner Parteitags 1982 für die Frauen. Arbeitsgemeinschaft sozialdemokratischer Frauen (Hg.), Sozialdemokratischer Informationsdienst. Frau und Gesellschaft. dokumente Nr. 17. Bonn.

Dokumente (19/1983): Frauen und Europa. Arbeitsgemeinschaft sozialdemokratischer Frauen (Hg.), Sozialdemokratischer Informationsdienst. Frau und Gesellschaft. dokumente Nr. 19. Bonn. 
Dokumente (20/1983): Beschlüsse der Bundeskonferenz der Arbeitsgemeinschaft sozialdemokratischer Frauen (AsF). Bonn-Bad Godesberg vom 10. bis 12. Juni 1983 "Gleichheit jetzt". Arbeitsgemeinschaft sozialdemokratischer Frauen (Hg.), Sozialdemokratischer Informationsdienst. Frau und Gesellschaft. dokumente Nr. 20. Bonn.

Dokumente (21/1983): Arbeitszeitverkürzung und Gleichstellung der Frau. Fachtagung der Arbeitsgemeinschaft sozialdemokratischer Frauen am 22./23.10. 1982 in Bonn. Arbeitsgemeinschaft sozialdemokratischer Frauen (Hg.), Sozialdemokratischer Informationsdienst. Frau und Gesellschaft. dokumente Nr. 21. Bonn.

Dokumente (22/1984): Ergebnisse des Essener Parteitags der SPD für die Frauen. Parteitag der Sozialdemokratischen Partei Deutschlands. 17. bis 21. Mai. Essen. Arbeitsgemeinschaft sozialdemokratischer Frauen (Hg.) Sozialdemokratischer Informationsdienst. Frau und Gesellschaft. dokumente Nr.22. Bonn.

Dokumente (23/1984): "Neue Technologien - Auswirkungen auf Lebenszusammenhänge von Frauen". Fachtagung der Arbeitsgemeinschaft Sozialdemokratischer Frauen (ASF) in Bonn, im Erich-Ollenhauer-Haus. Arbeits-gemeinschaft sozialdemokratischer Frauen (Hg.), Sozialdemokratischer Informationsdienst. Frau und Gesellschaft. dokumente Nr. 23. Bonn.

Dokumente (24/1985): Schwestern, zur Sonne zur Gleichheit! Beschlüsse der Bundeskonferenz der Arbeitsgemeinschaft sozialdemokratischer Frauen Hannover vom 4. bis 6 . Oktober 1985. Arbeitsgemeinschaft sozialdemokratischer Frauen (Hg.), Sozialdemokratischer Informationsdienst. Frau und Gesellschaft. dokumente Nr. 24. Bonn.

Dokumente (25/1986): Frauen in der SPD. Arbeitsgemeinschaft sozialdemokratischer Frauen (Hg.), Sozialdemokratischer Informationsdienst. Frau und Gesellschaft. dokumente Nr. 25. Bonn.

Dokumente (26/1986): SPD- Bundesparteitag Nürnberg 1986, SPD-Wahlparteitag Offenburg 1986, Ergebnisse und Dokumente für Frauen. Arbeitsgemeinschaft sozialdemokratischer Frauen (Hg.), Sozialdemokratischer Informationsdienst. Frauen in der SPD. dokumente Nr. 26. Bonn.

Dokumente (25/1986): Biotechnologie - Chancen oder Risiken für Frauen? Dokumentation der Fachtagung vom 22.Januar 1986 in Bonn. Arbeitsgemeinschaft sozialdemokratischer Frauen (Hg.), Sozialdemokratischer Informationsdienst. Frauen in der SPD. dokumente Nr. 25. Bonn.

Dokumente (24/1987): Wer die menschliche Gesellschaft will, muß die männliche überwinden. 8. ordentliche Bundesfrauenkonferenz 16. bis 18.10. 1987 in Mannheim. Arbeitsgemeinschaft sozialdemokratischer Frauen (Hg.), Sozialdemokratischer Informationsdienst. Frauen in der SPD. dokumente Nr. 24. Bonn.

Dokumente (29/1989): Frauen und die Informations- und KommunikationsTechnologien. Dokumentation einer Fachtagung vom 26. April 1989 in der 
RWTH Aachen. Arbeitsgemeinschaft sozialdemokratischer Frauen (Hg.), Sozialdemokratischer Informationsdienst. Frauen in der SPD. dokumente Nr. 29. Bonn.

Dokumente (30/1990): "Frauen und Wirtschaft... Das Ende der Herrenjahre". Dokumentation der 9. Ordentlichen Bundesfrauenkonferenz vom 2. bis 4. März 1990 in Essen. Arbeitsgemeinschaft sozialdemokratischer Frauen (Hg.), Sozialdemokratischer Informationsdienst. Frauen in der SPD. dokumente Nr. 30. Bonn.

\subsubsection{Jahrbücher}

Jahrbuch der SPD (o.J. \{1958/59\}): Vorstand der Sozialdemokratischen Partei Deutschlands (Hg.), Jahrbuch der Sozialdemokratischen Partei Deutschlands. Bonn: Neuer Vorwärts-Verlag Nau \& Co.

Jahrbuch der SPD (o.J. \{1960/61\}): Vorstand der Sozialdemokratischen Partei

Deutschlands (Hg.), Jahrbuch der Sozialdemokratischen Partei Deutschlands 1960/61. Bonn: Neuer Vorwärts-Verlag Nau \& Co.

Jahrbuch der SPD (o.A. \{1962/63\}): Vorstand der Sozialdemokratischen Partei

Deutschlands (Hg.), Vorstand der Sozialdemokratischen Partei Deutschlands

(Hg.), Jahrbuch der Sozialdemokratischen Partei Deutschlands 1962/63.

Bonn: Neuer Vorwärts-Verlag Nau \& Co.

Jahrbuch der SPD (o.A. \{1964/65\}): Vorstand der Sozialdemokratischen Partei

Deutschlands (Hg.), Vorstand der Sozialdemokratischen Partei Deutschlands

(Hg.), Jahrbuch der Sozialdemokratischen Partei Deutschlands 1964/65.

Bonn: Neuer Vorwärts-Verlag Nau \& Co.

Jahrbuch der SPD (o.A. \{1966/67\}): Vorstand der Sozialdemokratischen Partei

Deutschlands (Hg.), Vorstand der Sozialdemokratischen Partei Deutschlands

(Hg.), Jahrbuch der Sozialdemokratischen Partei Deutschlands 1966/67.

Bonn: Neuer Vorwärts-Verlag Nau \& Co.

Jahrbuch der SPD (o.A. \{1968/69\}): Vorstand der Sozialdemokratischen Partei

Deutschlands (Hg.), Jahrbuch der Sozialdemokratischen Partei Deutschlands 1968/1969. Bonn: Neuer Vorwärts-Verlag Nau \& Co.

Jahrbuch der SPD (o.J. \{1970-72\}): Vorstand der Sozialdemokratischen Partei

Deutschlands (Hg.), Jahrbuch der Sozialdemokratischen Partei Deutschlands 1970-1972. Bonn: Neuer Vorwärts-Verlag Nau \& Co.

Jahrbuch der SPD (o.J. \{1973-75\}): Vorstand der Sozialdemokratischen Partei Deutschlands (Hg.), Jahrbuch der Sozialdemokratischen Partei Deutschlands 1973-1975. Bonn: Neuer Vorwärts-Verlag Nau \& Co.

Jahrbuch der SPD (o.A.\{1975-77\}): Vorstand der Sozialdemokratischen Partei Deutschlands (Hg.), Jahrbuch der Sozialdemokratischen Partei Deutschlands 1975-1977. Bonn: Neuer Vorwärts-Verlag Nau \& Co. 
Jahrbuch der SPD (o.J.\{1977-79\}): Vorstand der Sozialdemokratischen Partei Deutschlands (Hg.), Jahrbuch der Sozialdemokratischen Partei Deutschlands 1977-1979. Bonn: Neuer Vorwärts-Verlag Nau \& Co.

Jahrbuch der SPD (o.A. \{1979-81\}): Vorstand der Sozialdemokratischen Partei Deutschlands (Hg.), Jahrbuch der Sozialdemokratischen Partei Deutschlands 1979-1981. Bonn-Bad Godesberg: Vorwärts-Verlag.

Jahrbuch der SPD (o.J. \{1982-83\}): Vorstand der Sozialdemokratischen Partei Deutschlands (Hg.), Jahrbuch der Sozialdemokratischen Partei Deutschlands 1982-83. Bonn: Neuer Vorwärts Verlag.

Jahrbuch der SPD (o.J. \{1984-85\}): Vorstand der Sozialdemokratischen Partei Deutschlands (Hg.), Jahrbuch der Sozialdemokratischen Partei Deutschlands 1984-85. Bonn: Vorwärts Verlag.

Jahrbuch der SPD (o.J. \{1986/87\}): Vorstand der Sozialdemokratischen Partei Deutschlands (Hg.), Jahrbuch der Sozialdemokratischen Partei Deutschlands 1986/87. Bonn: Vorwärts-Verlag.

Jahrbuch der SPD (o.J. \{1988-90\}): Vorstand der Sozialdemokratischen Partei Deutschlands (Hg.), Jahrbuch der Sozialdemokratischen Partei Deutschlands 1988-1990. Bonn: Vorwärts-Verlag.

\subsubsection{Literatur}

2. Familienbericht (1974): Familie und Sozialisation - Leistungen und Leistungsgrenzen der Familie hinsichtlich des Erziehungs- und Bildungsprozesses der jungen Generation. Bericht der Sachverständigenkommission. Deutscher Bundestag 7. Wahlperiode Drucksache 7/3502.

Abels, Heinz (2007): Interaktion, Identität, Präsentation : kleine Einführung in interpretative Theorien der Soziologie. 4. Aufl. Hagener Studientexte zur Soziologie. Wiesbaden: VS Verlag für Sozialwissenschaften.

Abelshauser, Werner / Matthöfer, Hans (2009): Nach dem Wirtschaftswunder : der Gewerkschafter, Politiker und Unternehmer Hans Matthöfer. Bonn: Dietz.

Abraham, Martin Büschges, Günter (2009): Einführung in die Organisationssoziologie. Lehrbuch. 4. Aufl. Wiesbaden: VS Verlag für Sozialwissenschaften. Kap. 2

Acker, Joan (1990): Hierarchies, Jobs, Bodies: A Theory of Gendered Organizations In: Gender and Society. 4 (2), S.139-158. Im Internet unter: http://www.jstor.org/stable/189609, [Zugriff: 12.06.2008].

Ackermann, Ulrike (1989): Erfahrung der Ambivalenz. Geschlechtertrennung Geschlechterdifferenz In: Die Neue Gesellschaft. 36 (3), S.246-249.

Albert, Hans (1975): Aufklärung und Steuerung. Gesellschaft, Wissenschaft und Politik in der Perspektive des kritischen Rationalismus. In: Lührs, Georg / Sarrazin, Thilo / Spreer, Frithjof / Tietzel, Manfred (Hg.), Kritischer Rationalismus und Sozialdemokratie. 2. Aufl. Bonn-Bad Godesberg: S.Dietz Nachf. Alemann, Ulrich von (1995): Parteien. Reinbek bei Hamburg: Rowohlt. 
Alemann, Ulrich von / Godewerth, Thelse (2005): Die Parteiorganisation der SPD. Erfolgreiches Scheitern? In: Schmid, Josef / Zolleis, Udo (Hg.), a.a.O., S.158171.

Alexander-Floyd, Nikol G. (2007): Gender, race and nationalism in contemporary black politics. Comparative feminist studies. New York u.a.: Palgrave Macmillan.

Ali, Anwar Syed (2003): Karrierewege und Rekrutierungsmuster bei Regierungsmitgliedern auf Bundesebene von 1949-2002. Diss. der Philosophischen Fakultät der Martin-Luther-Universität Halle-Wittenberg.

Allmendinger, Jutta (2010): Verschenkte Potenziale? Lebensverläufe nicht erwerbstätiger Frauen. Frankfurt a. M. / New York: Campus.

Andersen, Arne (1997): Der Traum vom guten Leben. Alltags- und Konsumgeschichte vom Wirtschaftswunder bis heute. Frankfurt a. M. / New York: Campus.

Andretta, Gabriele (1996): "...aber geliebt wurde ich nicht. Ich war zu sehr Emanze. Inge Wettig-Danielmeier". In: Clemens, Bärbel, a.a.O., S.140-155.

Angermüller, Johannes (2001): Einleitung: Diskursanalyse, Tendenzen, Perspektiven. In: Angermüller, Johannes / Bunzmann, Katharina / Nonhoff, Martin (Hg.), Diskursanalyse: Theorien, Methoden, Anwendungen. (S.7-22). Hamburg: Argument.

Apel, Hans (1991): Der Abstieg. Politisches Tagebuch eines Jahrzehnts. München: Droemersche Verlagsanstalt Th. Knaur Nachf.

Apitzsch, Ursula (2003): Biographieforschung. In: Orth, Barbara / Schwietring, Thomas / Weiß, Johannes (Hg.), a.a.O., S.95-110).

Appelt, Erna (1999): Geschlecht - Staatsbürgerschaft - Nation : politische Konstruktionen des Geschlechterverhältnisses in Europa. Reihe "Politik der Geschlechterverhältnisse". Frankfurt a. M. / New York: Campus.

Arlt, Monika (1979): Solidarität mit den Frauen an der Basis In: Die Neue Gesellschaft. 26 (2), S.251-252.

Arold, Antje / Schenk, Sylvia (1980): Frauen in der SPD In: Die Neue Gesellschaft. 27 (2), S.107-110.

Aulenbacher, Brigitte (2005): Rationalisierung und Geschlecht in soziologischen Gegenwartsanalysen. 1. Aufl. Geschlecht \& Gesellschaft. Wiesbaden: VS Verlag für Sozialwissenschaften.

Baer, Susanne / Kletzing, Uta (2004): Strategien der Geschlechterpolitik - zur Debatte um Gender Mainstreaming In: Zeitschrift für Frauenforschung \& Geschlechterstudien. 22 (4), S.3-20.

Baur, Nina (2008): Handbuch Soziologie. Wiesbaden: VS, Verlag für Sozialwissenschaften.

Beauvoir, Simone de (2005): Das andere Geschlecht. Sitte und Sexus der Frau. 5. Aufl. Reinbek bei Hamburg: Rowohlt Taschenbuch.

Bebel, August (1964): Die Frau und der Sozialismus. Berlin: Dietz Verlag. 
Beck, Ulrich (1986): Risikogesellschaft. Auf dem Weg in eine andere Moderne. Frankfurt a. Main: Suhrkamp Verlag.

Beck, Ulrich (1996): Wissen oder Nicht-Wissen? Zwei Perspektiven ,reflexiver Modernisierung'. In: ders. /Giddens, Anthony / Lash, Scott (1996): Reflexive Modernisierung. Eine Kontroverse. Frankfurt a. Main: Suhrkamp Verlag, S.289-315.

Beck, Ulrich / Giddens, Anthony / Lash, Scott (1996b): Reflexive Modernisierung. Eine Kontroverse. Frankfurt a. M.: Suhrkamp Verlag

Beck, Ulrich/ Beck-Gernsheim, Elisabeth (1994): Individualisierung in modernen Gesellschaften - Perspektiven und Kontroversen einer subjektorientierten Soziologie. Diess.(Hg.), Riskante Freiheiten. Individualisierung in modernen Gesellschaften. (S.10-39). Frankfurt a. Main: Edition Suhrkamp.

Becker, Bernd (1999): Innerparteiliche Reformmöglichkeiten für die deutschen Parteien: Von Großbritannien lernen In: Zeitschrift für Parlamentsfragen. 30 (2), S.447-466.

Becker, Horst / Hombach, Bodo / Huppertz, Franz / Kompe, Gerd / Otten, KarlHeinz / Wulfmeier, Helmut (1983): Die SPD von innen : Bestandsaufnahme an der Basis der Partei; Auswertung und Interpretation empirischer Untersuchungen in der SPD Nordrhein-Westfalen. Sonderausg. für den SPD-Landesverband Nordrhein-Westfalen. Bonn: Verlag Neue Gesellschaft.

Becker, Ruth / Kortendiek, Beate (Hg.) (2004): Handbuch Frauen- und Geschlechterforschung. Theorie, Methoden, Empirie. Wiesbaden: VS Verlag für Sozialwissenschaften.

Becker-Schmidt, Regina (1987): Die doppelte Vergesellschaftung - die doppelte Unterdrückung. Besonderheiten der Frauenforschung in den Sozialwissenschaften. In: Unterkircher, LiloWagner, Ina (Hg.), Die andere Hälfte der Gesellschaft: Österreichischer Soziologentag 1985: Soziologische Befunde zu geschlechtsspezifischen Formen der Lebensbewältigung. (S.10-25). Wien: Verlag des Österreichischen Gewerkschaftsbundes.

Becker-Schmidt, Regina / Knapp, Gudrun-Axeli (2003): Feministische Theorien zur Einführung. 3. Aufl. Hamburg: Junius.

Beck-Gernsheim, Elisabeth (1981): Der geschlechtsspezifische Arbeitsmarkt: zur Ideologie und Realität von Frauenberufen. 2. Auflage. Frankfurt a. M. / New York: Campus.

Beck-Gernsheim, Elisabeth (1985): Das halbierte Leben. Männerwelt Beruf, Frauenwelt Familie. Frankfurt a. Main: Fischer Verlag.

Beer, Ursula (1984): Theorien geschlechtlicher Arbeitsteilung. Frankfurt a. M. / New York: Campus.

Beer, Ursula (1990): Geschlecht, Struktur Geschichte. Soziale Konstituierung des Geschlechterverhältnisses. Frankfurt a. M. / New York: Campus.

Beer, Ursula (2004): Sekundärpatriarchalismus: Patriarchat in Industriegesellschaften. In: Becker, Ruth / Kortendiek, Beate (Hg.) a.a.O.: S. 56-61. 
Beer, Ursula / Rode, Hildegard (Hg.) (1986): Kontroverse Politikstrategien der Frauenbewegung : institutionelle Einbindung vs. Autonomie . Abschlußbericht. Forschungsvorhaben im Rahmen eines Werkvertrages mit der Universität Bielefeld. Bielefeld: Universitätsverlag.

Behrend, Hanna (1999): Marxismus und Feminismus - inkompatibel oder verwandt? In: UTOPIE kreativ. 10 (109/110), S.162-173.

Benford, Robert.D. / Snow, David A. (200o): Framing Processes and Social Movements: an Overview and Assessment In: Annual Review of Sociology. 26 (o.A.), S.611-639. Im Internet unter: http://dcpis.upf.edu/ raimundoviejo/docencia/girona/Benford_et_al_20oo_frame.pdf, [Zugriff: 10.06.2011].

Bennholdt-Thomsen, Veronika / Mies, Maria / Werlhof, Claudia von, (1983): Frauen, die letzte Kolonie. Reinbek bei Hamburg: Rowohlt.

Bennholdt-Thomsen, Veronika (1985): Zivilisation, moderner Staat und Gewalt. Eine feministsiche Kritik an Norbert Elias' Zivilisationstheorie. In: beiträge zur feministischen theorie und praxis. 8 (13), S.178-187.

Berg, Marie-Louise / Kettig, Alma / Proft, Hildegard / Steinmann, Elly (1976): Feststellungen und Forderungen der demokratischen Frauenbewegung in der Bundesrepublik In: Blätter für deutsche und internationale Politik. 21 (9), S.1018-1029.

Berghahn, Sabine (2003): Der Ritt auf der Schnecke - Rechtliche Gleichstellung in der Bundesrepublik In: gender...politik...online Im Internet unter: http://www.fu-berlin.de/gpo/pdf/berghahn/ Ritt_auf_der_Schnecke.pdf, [Zugriff: 12.01.2008].

Bergmann, Werner / Erb, Rainer (1998): 'In Treue zur Nation'. Zur kollektiven Identität der rechtsextremen Bewegung. In: Hellmann, Kai-Uwe / Koopmans, Ruud (Hg.), a.a.O., S.149-165.

Besser, Ursula (1981): Frauenvereinigung der CDU. In: Gassen, Gisela, a.a.O., S.163-174.

Beyme, Klaus von (2000): Parteien im Wandel : von den Volksparteien zu den professionalisierten Wählerparteien. Wiesbaden: Westdeutscher Verlag.

Beyme, Klaus von (2004): Das politische System der Bundesrepublik Deutschland. Eine Einführung. 10. Auflage. Wiesbaden: VS Verlag für Sozialwissenschaften.

Bezirk Franken (1979): Entschließung zu den Grundsätzen der SPD, zur Zukunftsfrage und zur Erneuerung der Parteiorganisation Antrag 447 In: Die Neue Gesellschaft. 26 (8), S.68o-695.

BFSFJ (2007): 20 Jahre Bundesministerium. Rollen erweitern. Perspektiven gewinnen. Gleichstellung verwirklichen. Bundesministerium für Familie, Senioren, Frauen und Jugend (Hg.). Im Internet unter: http://www. bmfsfj.de/RedaktionBMFSFJ/Abteilung4/Pdf-Anlagen/2o-jahre-frauenministerium,property=pdf, bereich=bmfsfj,sprache=de,rwb=true.pdf, [Zugriff: 04.06.2012] . 
Biehl, Heiko (2005): Parteimitglieder im Wandel : Partizipation und Repräsentation. Wiesbaden: VS Verlag für Sozialwissenschaften. Kap.: Theorien politischer Partizipation

Biester, Elke / Holland-Cunz, Barbara / Sauer, Birgit (Hg.) (1994): Demokratie oder Androkratie? Theorie und Praxis demokratischer Herrschaft in der feministischen Diskussion. Frankfurt a. Main / New York: Campus.

Blaschke, Sabine (2008): Frauen in Gewerkschaften. Zur Situation in Österreich und Deutschland aus organisationssoziologischer Perspektive. München: Rainer Hampp Verlag, München u. Mering.

Bock, Gisela / Duden, Barbara (1976): Arbeit aus Liebe - Liebe als Arbeit: Zur Entstehung der Hausarbeit im Kapitalismus. In: (Hg.), Gruppe Berliner Dozentinnen, Frauen und Wissenschaft. Beiträge zur Berliner Sommeruniversität für Frauen. Berlin (S.118-199). Berlin: Courage.

Bock, Ulla / Witych, Barbara (1980): Thema: Frau. Bibliographie der deutschsprachigen Literatur zur Frauenfrage 1949-1979. Bielefeld: AJZ-Druck und Verlag.

Boeßenecker, Karl-Heinz / Bühler, Theo (1991): Neue Verbände - Neue Unübersichtlichkeiten In: Forschungsjournal Neue Soziale Bewegungen. 4 (3), S.6876.

Bogner, Alexander / Littig, Beate / Menz, Wolfgang (Hg.) (2005): Das Experteninterview: Theorie, Methode, Anwendung. 2. Aufl. Wiesbaden: VS Verlag für Sozialwissenschaften.

Bogner, Alexander / Menz, Wolfgang (2002): Wissenschaftliche Politikberatung? Der Dissens der Experten und die Autorität der Politik In: Leviathan. 30 (3), S.384-399.

Bogner, Alexander / Menz, Wolfgang (2005): Das theoriegenerierende Experteninterview. Erkenntnisinteresse, Wissensformen, Interaktion. In: dies. / Littig, Beate (Hg.), a.a.O., S.33-70.

Bogumil, Jörg / Schmid, Josef (20o1): Politik in Organisationen: organisationstheoretische Ansätze und praxisbezogene Anwendungsbeispiele. Grundwissen Politik ; 31. Opladen: Leske+Budrich.

Bohnsack, Ralf (2007): Rekonstruktive Sozialforschung : Einführung in qualitative Methoden. 6. durchges. und aktual. Aufl. Opladen u.a.: Budrich.

Börner, Holger / Sozialdemokratische Partei Deutschlands (1973): Bundestagswahlkampf 1972 : ein Bericht der Sozialdemokratischen Partei Deutschlands. Bonn-Bad Godesberg: Vorstand d. SPD, Abt. Öffentlichkeitsarbeit.

Borchert, Jens / Golsch, Lutz / Jun, Uwe / Lösche, Peter (1996): Einleitung: Das sozialdemokratische Modell - Krise und Perspektiven. In: diess. (Hg.): Das sozialdemokratische Modell. Organisationsstrukturen und Politikinhalte im Wandel. (S.7-20).Opladen: Leske+Budrich.

Bortfeld, Barbara (1980): Stachel im Fleisch In: Die Neue Gesellschaft. 27 (2), S.100-103. 
Bothmer, Lenelotte von (1976): Frauen und Politik. In: Berger, Lieselotte / Bothmer, Lenelotte von / Schuchardt, Helga, Frauen ins Parlament? Von den Schwierigkeiten, gleichberechtigt zu sein. (S.7-38). Hamburg: Rowohlt.

Bourdieu, Pierre (1997): Die männliche Herrschaft. In: Dölling, Irene / Krais, Beate (Hg.), Ein alltägliches Spiel. Geschlechterkonstruktion in der Sozialen Praxis. (S.153-218). Frankfurt a. Main: Suhrkamp.

Bourdieu, Pierre (2001): Das politische Feld : zur Kritik der politischen Vernunft. Aus dem Französischen von Roswitha Schmid. édition discours. Konstanz: UVK Verlagsgesellschaft mbH.

Bourdieu, Pierre / Steinrücke, Margareta (Hg.) (2005): Die verborgenen Mechanismen der Macht. Unveränd. Nachdr. der Erstaufl. von 1992. Aus dem Französischen v. Jürgen Bolder u.a.. Schriften zu Politik \& Kultur. Hamburg: VSA Verlag.

Bouvier, Beatrix W. (1993): Auf der Woge des Zeitgeistes? Die SPD seit den 6oerJahren. In: Dowe, Dieter (Hg.), Partei und soziale Bewegung: kritische Beiträge zur Entwicklung der SPD seit 1945. (S.81-99). Bonn: J.H.W. Dietz Nachf. Boyer, Josef (2001): Die SPD in der Gesellschaft der Bundesrepublik. Mitgliederstrukturen und Machtchancen. In: Recker, Marie-Luise / Jellonnek, Burkhard / Rauls, Bernd (Hg.), Bilanz: 50 Jahre Bundesrepublik Deutschland. (S.109119). St. Ingbert: Röhrig Universitätsverlag.

Boyer, Josef / Kössler, Till (Bearb.) (2005): SPD, KPD, Parteien des linken Spektrums sowie DIE GRÜNEN. Mitgliedschaft und Sozialstruktur 1945-1990 In: Recker, Marie-Luise / Tenfelde, Klaus (Hg.), Handbuch zur Statistik der Parlamente und Parteien in den westlichen Besatzungszonen und in der Bundesrepublik Deutschland. Bd. 12. Düsseldorf: Droste Verlag.

Bradisch, Paula / Feyerabend, Erika / Winkler, Ute im Auftrag der Kongreßvorbereitungsgruppe (Hg.) (1989): Frauen gegen Gen- und Reproduktionstechnologien. Beiträge vom 2. bundesweiten Kongreß, Frankfurt, 28.-30.10.1988. München: Frauenoffensive.

Brand, Karl-Werner (1998a): Humanistischer Mittelklassen-Radikalismus. Die Erklärungskraft historisch-struktureller Deutungen am Beispiel der 'neuen sozialen Bewegungen'. In: Hellmann, Kai-Uwe / Koopmans, Ruud (Hg.), a.a.O., S.33-50.

Brand, Karl-Werner (1998b): Neue Soziale Bewegungen: Europäische Erklärungskonzepte In: Forschungsjournal Neue Soziale Bewegungen. 11 (1), S.63-79.

Brandt, Peter / Lehnert, Detlef (2013): 'Mehr Demokratie wagen' Geschichte der Sozialdemokratie 1830-2010. Berlin: Vorwärts. Kap. "Auf Profilsuche in den 8oer-Jahren" S. 230-244

Brandt, Willy (1976): Aufruf des Vorsitzenden der SPD Brandt und des Bundeskanzlers Schmidt an die Wählerinnen und Wähler 25. August 1976. In: Grebing, Helga / Gregor Schöllgen / August Winkler (Hg.) (2002): Willy Brandt. Berliner Ausgabe Bd. 5 „Die Partei der Freiheit Willy Brandt und die SPD 1972 - 1992" (S.220-225). Bonn: J.H.W. Dietz Nachf. 
Braun, Hans (1989): Helmut Schelskys Konzept der „nivellierten Mittelstandsgesellschaft" und die Bundesrepublik der 5oer-Jahre. In: Archiv für Sozialgeschichte 29, S.199-223.

Bremme, Gabriele (1956): Die politische Rolle der Frau in Deutschland. Schriftenreihe des UNESCO-Instituts für Sozialwissenschaften Köln, Bd.4. Göttingen: Vandenhoeck\&Ruprecht.

Brück, Brigitte / Kahlert, Heike / Krüll, Marianne / Milz, Helga / Osterland, Astrid / Wegehaupt-Schneider, Ingeborg (1997): Feministische Studien. Eine Einführung. Frankfurt a. M. / New York: Campus.

Brückner, Margrit (2000): Vernetzung zwischen politischem Anspruch und professionellen Erfordernissen - Überlegungen zur Entwicklung der autonomen deutschen Frauenprojektbewegung. In: Lenz, Ilse / Mae, Michiko / Klose, Karin, Frauenbewegung weltweit. Aufbrüche - Kontinuitäten - Veränderungen. (S.75-93). Opladen: Leske+Budrich.

Brückner, Margrit (2004): "Re-" und "De-gendering" von Sozialpolitik, sozialen Berufen und sozialen Problemen In: Zeitschrift für Frauenforschung \& Geschlechterstudien. 22 (2+3), S.25-29.

Brumlop, Eva (1994): Betriebliche Frauenförderung. Bisherige Konzepte, Umsetzungserfahrungen, notwendige Neuorientierungen In: Gewerkschaftliche Monatshefte. 45 (7), S.458-468.

Brunn, Anke (1972): Die SPD und die Emanzipation der Frau. In: Bundesvorstand der Jungsozialisten (Hg.), a.a.O., S.62 - 65.

Brunsbach, Sandra (2011): Machen Frauen den Unterschied? Parlamentarierinnen als Repräsentantinnen frauenspezifischer Interessen im Deutschen Bundestag In: Zeitschrift für Parlamentsfragen. 42 (1), S.3-24.

Brusis, Ilse (1989): Annäherung an die Zukunft. Zum Entwurf eines neuen Grundsatzprogramms der SPD In: Gewerkschaftliche Monatshefte. 40 (4), S.193-202.

Brusis, Ilse / Wettig-Danielmeier, Inge (Hg.) (2008): Wir haben etwas bewegt. 110 Lebensläufe von Sozialdemokratinnen und Sozialdemokraten. Berlin: Vorwärts Buch.

Brüssow, Gaby (1996): Frauenpolitik : zum Verhältnis von Frauen und Politik am Beispiel von Frauenorganisationen der Parteien SPD und DIE GRÜNEN. Internationale Hochschulschriften; 220. Münster u.a.: Waxmann.

Bundesvorstand der Jungsozialisten (1977): Frauenarbeit. Materialsammlung. Juso-Argumente Problem 25. Bonn: Neuer Vorwärts-Verlag.

Bund-Länder-Kommission (2000): Verbesserung der Chancen von Frauen in Ausbildung und Beruf - Ausbildungs- und Studienverhalten von Frauen -. Materialien zur Bildungsplanung und zur Forschungsförderung. Hft. 8o. Bonn: Selbstverlag.

Burrell, Gibson (1992): Sexualität und Organisationsanalyse (1984). In: Krell, Gertraude / Osterloh, Margit, Personalpolitik aus der Sicht von Frauen - Frauen aus der Sicht der Personalpolitik. Was kann Personalforschung von der Frauenforschung lernen? (S.122-147). München und Mehring: Rainer Hampp. 
Butler, Judith (1991): Das Unbehagen der Geschlechter. Frankfurt a. Main: edition suhrkamp.

Buzzanell, Patrice M. / National Communication Association (2000): Rethinking organizational \& managerial communication from feminist perspectives. Thousand Oaks, Calif u.a.: Sage Publications.

Childs, Sarah/ Krook, Mona Lena (2008): Theorizing Women's Political Representation: Debates und Innovations in Empirical Research In: Femina Politica. 17 (2), S.20-30.

Christen, Günther (1975): Bundeskonferenz der Arbeitsgemeinschaft sozialdemokratischer Frauen In: Marxistische Blätter. 13 (4), S.106-107.

Clemens, Bärbel (1989): Der "männliche" Blick auf die Frauenbewegung In: Forschungsjournal Neue Soziale Bewegungen. 1 (3), S.249-258.

Clemens, Bärbel (Hg.) (1996): Frauen machen Politik. Parlamentarierinnen in Niedersachsen. Hannover: Fackelträger.

Cockburn, Cynthia (1988): Die Herrschaftsmaschine. Berlin/Hamburg: Argument Verlag.

Connell, Robert W. (2006): Der gemachte Mann. Konstruktion und Krise von Männlichkeiten. 3. Auflage. Wiesbaden: VS Verlag für Sozialwissenschaften.

Cornelißen, Waltraud (2005): Gender Datenreport. 1. Datenreport zur Gleichstellung von Frauen und Männern in der Bundesrepublik Deutschland. 2. Fassung. erstellt durch das Deutsche Jugendinstitut e.V. in Zusammenarbeit mit dem Statistischen Bundesamt. Im Internet unter: http://www.bmfsfj.de/doku/Publikationen/_ genderreport/o1-Redaktion/PDF-Anlagen/gesamtdokument,property\%3Dpdf,bereich\%3Dgenderreport, sprache\%3Dde,rwb\%3Dtrue.pdf, [Zugriff: 02.02.2012].

Crouch, Colin / Gramm, Nikolaus (2008): Postdemokratie. Bonn: Bundeszentrale für Politische Bildung.

Cyba, Eva (1995): Grenzen der Theorie sozialer Schließung? Die Erklärung von Ungleichheiten zwischen den Geschlechtern. In: Wetterer, Angelika, Die soziale Konstruktion von Geschlecht in Professionalisierungsprozessen. (S.5170). Frankfurt a. Main: Campus.

Cyba, Eva (200o): Geschlecht und soziale Ungleichheit. Opladen: Leska+Budrich.

Cyba, Eva (2004): Patriarchat: Wandel und Aktualität. In: Becker, Ruth / Kortendiek, Beate (Hg.), a.a.O., S.15-19.

Dackweiler, Regina (1995): Ausgegrenzt und eingemeindet: Die neue Frauenbewegung im Blick der Sozialwissenschaften. Münster: Westfälisches Dampfboot.

Dackweiler, Regina-Maria (2004a): Die Frauenbewegung als Neue Soziale Bewegung? Kritische Anmerkungen aus geschlechterreflektierter Sicht. In: Hardmeier, Sibylle (Hg.), Staat, Politik und Geschlecht. Genderforschung in der Politikwissenschaft. universelle: Beiträge zur Gleichstellung. Bd. 6 (S.89-102). Zürich: o.V. Universität Zürich. 
Dackweiler, Regina-Maria (2004b): Wohlfahrtsstaat: Institutionelle Regulierung und Transformation der Geschlechterverhältnisse. In: Becker, Ruth / Kortendiek, Beate (Hg.), a.a.O., S.450-46o.

Dackweiler, Regina-Maria (2005): Die Konstruktion von Geschlechter-Wirklichkeit durch den Wohlfahrtsstaat. In: Henninger, Annette / Ostendorf, Helga, Die politische Steuerung des Geschlechterregimes. Beiträge zur Theorie politischer Institutionen. (S.75-92). Wiesbaden: VS Verlag für Sozialwissenschaften.

Dackweiler, Regina-Maria (2007): Elite, Exzellenz, Exklusion? In: dies., Willkommen im Club? (S.9-25). Münster: Westfälisches Dampfboot.

Dackweiler, Regina-Maria (2010): Wandel bewirken: die Neue Frauenbewegung. In: Dackweiler, Regina-Maria / Schäfer, Reinhild, Wohlfahrtsstaatlichkeit und Geschlechterverhältnisse aus feministischer Perspektive. (S.20-48). Münster: Westfälisches Dampfboot.

Däubler-Gmelin, Herta (1977): Frauenarbeitslosigkeit oder Reserve zurück an den Herd! Reinbek bei Hamburg: Rowohlt.

Däubler-Gmelin, Herta (1984): Der neue Trend - ein Weg in die falsche Richtung. In: Huber, Antje (Hg.), a.a.O., S.195-209.

Däubler-Gmelin, Herta (1985a): Haben Frauenförderpläne und verbindliche Frauenförderrichtlinien eine Chance? In: Däubler-Gmelin, Herta / Pfarr, Heide / Weg, Marianne, Mehr als nur gleicher Lohn!: Handbuch zur berufliche Förderung von Frauen. (S.162-169). Hamburg: VSA-Verlag.

Däubler-Gmelin, Herta (1985b): Politische Schlußfolgerungen. In: Däubler-Gmelin, Herta / Müller, Marianne, Wir sind auch noch da! Ältere Frauen zwischen Resignation und Selbstbewußtsein. (S.148-163). Bonn: Verlag Neue Gesellschaft.

Däubler-Gmelin, Herta (1997): Kooperation statt Standortdiskussion - Zivilgesellschaftliche Aktionen gegen die Wettbewerbsgesellschaft. In: Möhring-Hesse, Matthias / Emunds, Bernhard / Schroeder, Wolfgang, Wohlstand trotz alledem. Alternativen zur Standortpolitik. (S.165-180). München: Droemersche Verlagsanstalt Th. Knaur Nachf.

Däubler-Gmelin, Herta (2003): Biomedizin und die Grenzen der Gesetzgebung. In: Tolmein, Oliver / Schweidler, Walter, Was den Menschen zum Menschen macht: Eine Gesprächsreihe zur Bioethikdiskussion. (S.83-98). Münster u.a.: LIT.

Däubler-Gmelin, Herta / Faerber-Husemann, Renate (1987): § 218 : der tägliche Kampf um die Reform. Bonn: Verlag Neue Gesellschaft.

Decker, Frank (2007): Handbuch der deutschen Parteien. Bonn: Bundeszentrale für politische Bildung.

Della Costa, Mariarosa (1973): Die Frauen und der Umsturz der Gesellschaft. In: dies. / James, Selma, Die Macht der Frauen und der Umsturz der Gesellschaft. Berlin: Merve-Verlag. 
Derichs-Kunstmann, Karin (1990): Gewerkschaftsfrauen in den 8oer-Jahren. Vom Ende der Bescheidenheit? In: Beiträge, Informationen, Kommentare. Forschungsinstitut für Arbeiterbildung, Recklinghausen (Hg.) (9), S.145 - 182.

Derichs-Kunstmann, Karin (1993): Frauen in der Männergewerkschaft - Zur Geschichte der Gewerkschaften in der Nachkriegszeit unter dem Gesichtspunkt des Geschlechterverhältnisses. In: Deutscher Gewerkschaftsbund (Hg.), "Da haben wir uns alle schrecklich geirrt...": Die Geschichte der gewerkschaftlichen Frauenarbeit im Deutschen Gewerkschaftsbund von 1945 bis 196o. (S.63129). Pfaffenweiler: Centaurus

Dertinger, Antje (1978): „Von Hexen und anderen Frauen“. In: Sozialdemokrat Magazin. 2, S.15-17.

Dertinger, Antje (1980): Herta Gotthelf (1902-1963): Als die Frauen ihre Chance verpaßten...: Das Wirken der SPD-Frauensekretärin für einen demokratischen Wiederaufbau. In: dies., Die bessere Hälfte kämpft um ihr Recht: der Anspruch der Frauen auf Erwerb und andere Selbstverständlichkeiten. (S.203226).Köln: Bund-Verlag,

Detmers, Ulrike (2003): Geschäftserfolg durch Geschlechterdemokratie. Frau und Beruf ; 3. Münster u.a.: LIT Verlag.

Detterbeck, Klaus (2002): Der Wandel politischer Parteien in Westeuropa : eine vergleichende Untersuchung von Organisationsstrukturen, politischer Rolle und Wettbewerbsverhalten von Großparteien in Dänemark, Deutschland, Großbritannien und der Schweiz, 1960 - 1999. Opladen: Leske+Budrich.

Deutscher Bundestag (1989): Bericht der Bundesregierung an den Deutschen Bundestag über die Gleichstellungsstellen in Bund, Ländern und Gemeinden. Bonn: Drucksache 11/4893 vom 28.06.89.

DIE GRÜNEN im Bundestag, AK Frauenpolitik / Sozialwissenschaftliche Forschung und Fraxis für Frauen e.V., Köln (Hg.) (1986): Frauen gegen Gentechnik und Reproduktionstechnik. Dokumentation zum Kongreß vom 9. - 21.4. 1985 in Bonn. Köln: Kölner Volksblatt Verlagsgesellschaft.

Diezinger, Angelika (2004): Alltägliche Lebensführung: Die Eigenlogik alltäglichen Handelns. In: Becker, Ruth / Kortendiek, Beate (Hg.), a.a.O., S.204-208).

Doderer, Yvonne / Kortendiek, Beate (2004): Frauenprojekte: Handlungs- und Entwicklungsräume feministischer Frauenbewegungen. In: Becker, Ruth / Kortendiek, Beate (Hg.), a.a.O., S.684-691.

Doering, Dörte (1981): Frauen und Parteipolitik. In: Gassen, Gisela, a.a.O., S.4553 .

Doormann, Lottemi (1980): Wartet nicht auf bess're Zeiten : Frauenpolitik aus Bonn und Alternativen der Frauenbewegung. Köln: Pahl-Rugenstein.

Dowe, Dieter / Klotzbach, Kurt (Hg.) (1990): Programmatische Dokumente der deutschen Sozialdemokratie. 3. überarb. und aktual. Aufl. Bonn: J.H.W. Dietz Nachf.

Dowe, Dieter / Schneider, Michael (Hg.) (2007): Anke Fuchs. Ein politisches Leben in Bildern. In Zusammenarbeit Friedhelm Boll (Interviews mit Anke 
Fuchs und Bildtexte) und Christoph Stamm (Bildtexte). Bonn: FriedrichEbert-Stiftung.

Duden, Barbara (1993): Die Frau ohne Unterleib: zu Judith Butlers Entkörperung In: Feministische Studien. 11 (2), S.24-33.

Duden, Barbara (2004): Frauen-"Körper": Erfahrung und Diskurs (1970-2004). In: Becker, Ruth / Kortendiek, Beate (Hg.), a.a.O., S.504-518.

E.R. (1978): Mut zur Macht In: Unsere kleine Zeitung von und für Lesben. 3 (6), S.29-31.

Ebbinghausen, Rolf (1969): Die Krise der Parteiendemokratie und die Parteiensoziologie. Eine Studie über Moisei Ostrogorski, Robert Michels und die neuere Entwicklung der Parteienforschung. Soziologische Abhandlungen Heft 11. Berlin: Dunker\&Humblot.

Edding, Cornelia (200o): Agentin des Wandels: der Kampf um Veränderung im Unternehmen. München: Gerling Akademie Verlag.

Eder, Klaus (1994): Die Institutionalisierung kollektiven Handelns. Eine neue theoretische Problematik in der Bewegungsforschung? In: Forschungsjournal Neue Soziale Bewegungen. 7 (2), S.40-52.

Edinger, Michael / Holfert, Claudia (2005): Frauen im Parlament: Eroberung einer Männerbastion? Politischer Werdegang, Verbleibchancen und Aufstiegsperspektiven von Parlamentarierinnen im vereinten Deutschland In: Gesellschaft. Wirtschaft. Politik - GWP. 54 (1), S.29-40.

Ehmsen, Stefanie (2008): Der Marsch der Frauenbewegung durch die Institutionen. Münster: Westfälisches Dampfboot.

Eilers, Elfriede (1980): Internationales Jahr der Frau. Aussprache über die Regierungserklärung zum Internationalen Jahr der Frau 1975. 7. Legislaturperiode, 146. Sitzung, 30. Januar 1975. In: Wehner, Herbert (Hg.), Frau Abgeordnete, die haben das Wort! Bundestagsreden sozialdemokratischer Parlamentarierinnen - 1949 bis 1979. (S.170-178). Bonn: Verlag Neue Gesellschaft.

Elias, Norbert (1986): Wandlungen der Machtbalance zwischen den Geschlechtern In: Kölner Zeitschrift für Soziologie und Sozialpsychologie. 38 (38), S.425449 .

Emma-Redaktion (1978): Frauen kämpfen um ihre Menschenwürde In: Emma. 2 (8). Im Internet unter: http://www.emma.de/artikel/frauen-kaempfen-umihre-menschenwuerde-264269, [Zugriff: 02.02.2009].

Emma-Redaktion (1983): Nicht gerade die feine Art... In: Emma. 6 (1), S.5-7.

Endruweit, Günter (2004): Organisationssoziologie. 2. Aufl. Stuttgart: Lucius\&Lucius Verlagsgesellschaft.

Engler, Steffani (2004): Habitus, Feld und sozialer Raum: zur Nutzung der Konzepte Pierre Bourdieus in der Frauen- und Geschlechterforschung. In: Becker, Ruth / Kortendiek, Beate (Hg.), a.a.O., S.222-233). 
Engler, Steffani (2005): Pierre Bourdieus Beitrag zum Verstehen symbolischer Herrschaft. In: Hardes, Ciljia / Kahlert, Heike /Schindler, Delia (Hg.), Forschungsfeld Politik. Geschlechtskategoriale Einführung in die Sozialwissenschaften. (S.127-146). Wiesbaden: VS Verlag für Sozialwissenschaften.

Eppler, Erhard (1988): Glotz, Zwerenz und die SPD In: DER SPIEGEL. 42 (6), S.5253.

Eppler, Erhard (1993): Politik statt Verwaltung. In: Unseld, Siegfried, Politik ohne Projekt? Nachdenken über Deutschland. (S.123 - 132). Frankfurt a. Main: edition suhrkamp.

Eppler, Erhard (2001): Komplettes Stückwerk: Erfahrungen aus fünfzig Jahren Politik. Überarb. und aktual. Taschenbuchausgabe. Frankfurt a. Main: Suhrkamp.

Esser, Hartmut (1990): "Habits", "Frames" und "Rational Choice". Die Reichweite von Theorien der rationalen Wahl (am Beispiel der Erklärung des Befragtenverhaltens. In: Zeitschrift für Soziologie. 19 (4), S.231-247.

Esser, Hartmut (2000): Soziologie. 3. Aufl. Frankfurt a. Main / New York: Campus.

Faulenbach, Bernd (2004): Die Siebzigerjahre - ein sozialdemokratisches Jahrzehnt? In: Friedrich-Ebert-Stiftung in Verbindung mit dem Institut für Sozialgeschichte e.V. Braunschweig-Bonn (Hg.), Archiv für Sozialgeschichte. Bd. 44 (S.1-37). Bonn: J.H.W. Dietz Nachf.

Faulenbach, Bernd (2011): Das sozialdemokratische Jahrzehnt. Von der Reformeuphorie zur Neuen Unübersichtlichkeit. Die SPD 1969-1982. München: J.H.W. Dietz Nachf.

Faulenbach, Bernd (2012): Geschichte der SPD. Von den Anfängen bis zur Gegenwart. München: J.H.W. Dietz Nachf.

Faulenbach, Bernd / Adler, Gunther (Hg.) (2008): Das sozialdemokratische Projekt im Wandel. Zur Frage der Identität der SPD. Essen: Klartext.

Feldkamp, Michael F. (2011): Datenhandbuch zur Geschichte des Deutschen Bundestages. Im Internet unter: https://www.bundestag.de/datenhandbuch, [Zugriff: 12.03.2013].

Feministisches Institut der Heinrich-Böll-Stiftung (Hg.) (2004): Die großen UNKonferenzen der goer-Jahre. Eine frauenpolitische Bilanz. Dokumentation einer Ringvorlesung im Sommer 2000. 2. leicht veränderte Auflage Berlin: Schriftenreihe des Feministischen Instituts der Heinrich Böll Stiftung, Nr. 2.

Fichter, Tilman / Lönnendonker, Siegward (1977): Macht und Ohnmacht der Studenten. Kleine Geschichte des SDS. Berlin: Rotbuch.

Fischer, Birgit (1989): Frauen im Revier: Strukturwandel und Frauenpolitik. In: Kost, Klaus / Schartau, Harald (Hg.), Wir im Revier. Schritte in die andere Zukunft an Rhein und Ruhr. (S.71-81). Marburg: SP-Verlag.

Fischer-Rosenthal, Wolfram / Rosenthal, Gabriele (1997): Narrationsanalyse biographischer Selbstpräsentationen. In: Hitzler, Ronald / Honer, Anne (Hg.), Sozialwissenschaftliche Hermeneutik: Eine Einführung. (S.133-164). Opladen: Leske+Budrich. 
Flick, Uwe (2006): Qualitative Sozialforschung : eine Einführung. 4. Aufl., vollst. überarb. und erw. Neuausg. Reinbek bei Hamburg: Rowohlt. Kap. 14-18

Foucault, Michel (1978): Dispositive der Macht : über Sexualität, Wissenschaft und Wahrheit. Berlin: Merve-Verlag.

FR o.V. (1988): „Seeheimer“" grollen Frauen. Rechte in der SPD machen gegen die Quotenregelung mobil In: Frankfurter Rundschau. 33 (13. Juni). Privatarchiv Ingrid Stange

Franz, Corinna / Gnad, Oliver (Bearb.) (2005): CDU und CSU. Mitgliedschaft und Sozialstruktur 1945-1990. In: Recker, Marie-Luise / Tenfelde, Klaus (Hg.), Handbücher zur Geschichte des Parlamentarismus und der politischen Parteien. Düsseldorf: Droste.

Fraser, Nancy (1989): Widerspenstige Praktiken. Macht, Diskurs, Geschlecht, Gender studies. Frankfurt a. Main: Suhrkamp. S. 249-283

Fraser, Nancy (2005): Frauen, denkt ökonomisch! In: die tageszeitung. 07.04.2005. Im Internet unter: http://www.taz.de/1/archiv/archiv/ ?dig=2005/04/o7/ao157, [Zugriff: 03.07.2010].

Fraser, Nancy (2009): Feminism, Capitalism and the Cunning of History In: New Left Review. 56 (März/April). Im Internet unter: http://www.newschool.edu/uploadedFiles/Faculty/NSSR/Fraser_NLR.pdf [Zugriff: 30.06.2010].

French, Marilyn (1985): Jenseits der Macht. Frauen, Männer und Moral. Reinbek bei Hamburg: Rowohlt. Kap.VI

Frevert, Ute (1986): Frauen-Geschichte. Zwischen Bürgerlicher Verbesserung und Neuer Weiblichkeit. Frankfurt a. Main: Suhrkamp.

Frevert, Ute (1988): Bewegung und Disziplin in der Frauengeschichte. Ein Forschungsbericht In: Geschichte und Gesellschaft. 14 (2), S.240-262.

Freyberg, Jutta von / Fülberth, Georg / Harrer, Jürgen / Hebel-Kunze, Bärbel / Hofschen, Heinz-Gerd / Ott, Erich / Stuby, Gerhard (1989): Geschichte der deutschen Sozialdemokratie. Köln: Pahl-Rugenstein. Kap. X. und XI.

Friedrich-Ebert-Stiftung (2008): Politik braucht Frauen. Mit der Quote am Ziel? Im Internet unter: http://www.fes.de/forumpug/inhalt/documents/ DokuPolitikbrauchtFrauen26508_ooo.pdf, [Zugriff: 20.09.2012].

Fuchs, Anke (1972): Die SPD und die Emanzipation der Frau. In: Bundesvorstand der Jungsozialisten (Hg.), JUSO. Zeitschrift der Jungsozialisten in der SPD. (S.8-9). Bonn.

Fuchs, Gesine (2006): Politische Partizipation von Frauen in Deutschland. In: Hoecker, Beate (Hg.), Politische Partizipation zwischen Konvention und Protest. Eine studienorientierte Einführung. (S.235-26o). Opladen: Barbara Budrich.

Fuchs, Katrin (1986): Wir müssen mehr verändern als nur den Frauenanteil. In: Jansen, Mechthild (Hg.), Halbe-Halbe. Der Streit um die Quotierung. (S.3136). Berlin: Leske+Budrich. 
Funken, Christiane (2004): Chancen und Risiken von (in)formellen Organisationsstrukturen. In: Pasero, Ursula / Priddat, Birger P. (Hg.), a.a.O., S.13-44.

Gabriel, Oscar W. / Niedermayer, Oskar (2001): Parteimitgliedschaften: Entwicklung und Sozialstruktur. In: dies. / Stöss, Richard (Hg.), a.a.O., S.274-296.

Gabriel, Oscar.W / Niedermayer, Oskar / Stöss, Richard (Hg.) (2001): Parteiendemokratie in Deutschland. 2. aktual. Aufl. Bonn: Bundeszentrale für Politische Bildung.

Galster, Ingrid (2004): Französischer Feminismus: Zum Verhältnis von Egalität und Differenz. In: Becker, Ruth/ Kortendiek, Beate (Hg.), a.a.O., S.42-48.

Gansel, Norbert (1971): Und die Reform der Ortsvereinsarbeit? In: Die Neue Gesellschaft. 18 (8), S.730-733.

Gassen, Gisela (1981): Wohin geht die Frauenbewegung? : 22 Protokolle. Frankfurt a. Main: S. Fischer.

Gassen, Gisela (1999): "Morgen beginne ich ein neues Leben" - Mein Weg in die Frauenbewegung. Berlin: Trafo-Verl. Weist.

Gebhardt, Miriam (2012): Alice im Niemandsland : Wie die deutsche Frauenbewegung die Frauen verlor. München: DVA.

Geissler, Birgit / Maier, Friederike / Pfau-Effinger, Birgit (Hrsg.) (1998): FrauenArbeitsMarkt. Berlin: Edition Sigma.

Geißler, Rainer (1996): Klassen und Schichten im Schmelztiegel? Kontroversen um Begriffe, Theorien und Modelle. In: ders., Die Sozialstruktur Deutschlands: zur gesellschaftlichen Entwicklung mit einer Zwischenbilanz zur Vereinigung. 2. neubearbeit. u. erweit. Aufl. (S.69-89). Bonn: Westdeutscher Verlag.

Geraedts, Regine / Kley, Frieda / Köbsell, Swantje / Timm, Angela / Tjarks, Marianne (1989): Eingriffe. Leben als Störfaktor. Beiträge zur 7. Bremer Frauenwoche zur Gen- und Reproduktionstechnologie 13.-17.3.1989. Bremen: Bremer Frauenwoche "Frauen lernen gemeinsam e.V.".

Gerhard, Ute (1989): Den Sozialstaat neu denken? Voraussetzungen und Preis des Sozialstaatskompromisses. In: Juso-Hochschulgruppen (Hg.), Arbeitshefte zur sozialistischen Theorie und Praxis. Bundesweite Zeitschrift der JusoHochschulgruppen. 13 (S.14-32 ). Bonn: SP-Verlag Norbert Schüren.

Gerhard, Ute (1991): Unerhört. Die Geschichte der deutschen Frauenbewegung. 2. Aufl. Reinbek bei Hamburg: Rowohlt.

Gerhard, Ute (1994): Die staatlich institutionalisierte "Lösung" der Frauenfrage: zur Geschichte der Geschlechterverhältnisse in der DDR. In: Kaelble, Hartmut / Kocka, Jürgen / Zwahr, Helmut, Sozialgeschichte der DDR (S.383 - 403). Stuttgart: Klett-Cotta.

Gerhard, Ute (1999): Atempause : Feminismus als demokratisches Projekt. Frankfurt a. Main: S. Fischer.

Gerhard, Ute (2006): Nachfolge in der Frauenbewegung. Generationen und sozialer Wandel In: Forschungsjournal Neue Soziale Bewegungen. 19 (1), S.24 - 37. 
Gerhard, Ute (2007): Feminismus heute? In: Feministische Studien. 25 (1), S.97104.

Gerhard, Ute (2008): Frauenbewegung. In: Roth, Roland / Rucht, Dieter (Hg.), a.a.O., S.187-217.

Gerlach, Irene (2004): Familienpolitik. Lehrbuch. Wiesbaden: VS Verl. für Sozialwissenschaften.

Gerste, Margrit (1978): Klagen allein helfen nicht In: Die Zeit. Nr. 38 (15. September). Im Internet unter: www.zeit.de/1978/38/klagen-allein-helfen-nicht.pdf, [Zugriff: 02.02.2011].

Gessenharter, Wolfgang (1998): Rückruf zur, selbstbewußten Nation'. Analyse eines neurechten Frames aus bewegungstheoretischer Sicht. In: Hellmann, KaiUwe / Koopmans, Ruud (Hg.), a.a.O., S.166-180.

Geyer, Martin (2008): 1974-1982 Bundesrepublik Deutschland. Neue Herausforderungen, wachsende Unsicherheiten. Geschichte der Sozialpolitik in Deutschland seit 1945. Band 6. Berlin/Koblenz: Nomis Verlag. Kapitel "Das Ende der sozialliberalen Koalition", S.102-109.

Giddens, Anthony (2006): Sociology. 5. Aufl. Cambridge/Malden: Polity Press.

Gildemeister, Regine / Wetterer, Angelika (1995): Wie Geschlechter gemacht werden. Die soziale Konstruktion der Zweigeschlechtlichkeit und ihre Reifizierung in der Frauenforschung. In: Knapp, Gudrun-Axeli / Wetterer, Angelika (Hg.), a.a.O. S.201 - 254.

Gilligan, Carol (1982): Die andere Stimme. Lebenskonflikte und Moral der Frau. München/Zürich: Piper.

Gille-Linne, Karin (2011): Verdeckte Strategien: Herta Gotthelf, Elisabeth Selbert und die Frauenarbeit der SPD 1945-1949. Bonn: J.H.W. Dietz Nachf.

Glaser, Barney G. / Strauss, Anselm L. (2005): Grounded theory : Strategien qualitativer Forschung. 2., korr. Aufl. Bern: Huber.

Gläser, Jochen / Laudel, Grit (2004): Experteninterviews und qualitative Inhaltsanalyse als Instrumente rekonstruierender Untersuchungen. Wiesbaden: VS Verlag für Sozialwissenschaften.

Glotz, Peter (1982): Die Beweglichkeit des Tankers. Die Sozialdemokratie zwischen Staat und neuen sozialen Bewegungen. München: Bertelsmann.

Glotz, Peter (1987): Die Malaise der Linken In: DER SPIEGEL. 41 (51), S.128-145.

Glotz, Peter (2005): Von Heimat zu Heimat : Erinnerungen eines Grenzgängers. 2. Aufl. Berlin: Econ.

Goch, Stefan (2007): 'Wir in Nordrhein-Westfalen', Die SPD in den 1970er und 8oer-Jahren. In: Mittag, Jürgen / Tenfelde, Klaus, 'Versöhnen statt spalten'Johannes Rau: Sozialdemokratie, Landespolitik und Zeitgeschichte. (S.97122). Oberhausen: assoverlag.

Göhler, Gerhard (1988): Soziale Institutionen - politische Institutionen. Das Problem der Institutionentheorie in der neueren deutschen Politikwissenschaft. 
In: Luthardt, Wolfgang / Claußen, Bernhard, Politik und Repräsentation: Beiträge zur Theorie und zum Wandel politischer und sozialer Institutionen. (S.12-28). Marburg: Schüren.

Göhler, Gerhard / Kühn, Rainer (1999): Institutionenökonomie, Neo-Institutionalismus und die Theorie politischer Institutionen. In: Edeling, Thomas / Jann, Werner / Wagner, Dieter, Institutionenökonomie und neuer Institutionalismus: Überlegungen zur Organisationstheorie. (S.17-42). Opladen: Leske+Budrich.

Gorholt, Martin (2009): Die SPD als Mitgliederpartei. In: Jun, Uwe / Niedermayer, Oskar / Wiesendahl, Elmar (Hg.), Zukunft der Mitgliederpartei. (S.257-26o). Opladen \& Farmington Hills: Barbara Budrich.

Gorholt, Martin / Voigt, Karsten D. / Winkler, Ruth (Hg.) (1990): "Wir sind die SPD der achtziger-Jahre" : 20 Jahre Linkswende der Jusos. Marburg: SP-Verlag.

Görtemaker, Manfred (2004): Kleine Geschichte der Bundesrepublik Deutschland. Bonn: Bundeszentrale für politische Bildung.

Gotthelf, Herta (1948): Die Frauenfrage als Männerfrage: zum Erfordernis, das Geschlechterdilemma zu überwinden In: Sozialdemokratischer Pressedienst. 3 (07.05) S.4-5. Im Internet unter: http://library.fes.de/spdpd/ 1948/480507.pdf, [Zugriff: 05.03.2010].

Götte, Rose (1991): Frauengeschichten aus dem Parlament. Neustadt/Wstr.: Verl. Pfälzische Post.

Gottschall, Karin (1998): Doing Gender While Doing Work? Erkenntnispotentiale konstruktivistischer Perspektiven für eine Analyse des Zusammenhangs von Arbeitsmarkt, Beruf und Geschlecht. In: Geissler, Birgit / Maier, Friederike / Pfau-Effinger, Birgit (Hg.), FrauenArbeitsMarkt. Berlin: edition sigma.

Granenberg, Nina (1983): Viele reden nicht, sie gucken nur In: Die Zeit. Nr. 25 (17. Juni). Im Internet unter: http://www.zeit.de/1983/25/viele-reden-nicht-siegucken-nur, [Zugriff: 03.04.2012].

Grebing, Helga (1987): Die Sozialdemokratische Partei Deutschlands: Auf dem Weg zu einem neuen linken Bündnis? In: Haungs, Peter / Jesse, Eckhard (Hg.), Parteien in der Krise? In- und ausländische Perspektiven. (S.99-103). Köln: Wissenschaft und Politik.

Grebing, Helga (2001): Inge Wettig-Danielmeier. Eine Bilanz nach mehr als vierzig Jahren Politik als Beruf. In: dies. / Junker, Karin (Hg.), a.a.O., S.15-35.

Grebing, Helga (2007): Geschichte der deutschen Arbeiterbewegung : von der Revolution 1848 bis ins 21. Jahrhundert. Berlin: Vorwärts-Buch, Kap. VIII. Sozialliberal-emanzipatorische Aufbrüche und die Traditionen der Arbeiterbewegung: 1966 - 1990, S.174-196.

Grebing, Helga (2008): Willy Brandt: Der andere Deutsche. Paderborn: Wilhelm Fink.

Grebing, Helga / Junker, Karin (Hg.) (20o1): Frau. Macht. Zukunft: Festschrift für Inge Wettig-Danielmeier. Marburg: Schüren. 
Greven, Michael Th. (1988): Autonomie oder Institution? - Institutionelle Folgen der Frauenbewegung In: Forschungsjournal Neue Soziale Bewegungen. 1 (4), S.51-60.

Grötemaker, Manfred (2004): Kleine Geschichte der Bundesrepublik Deutschland. Bonn: Bundeszentrale für politische Bildung.

Grünupp, Andreas / Templ, Karl-Ulrich / Trentini, Ute (1991): Perspektiven für die SPD in den 9oer-Jahren. In: Juso-Hochschulgruppen (Hg.), Arbeitshefte zur sozialistischen Theorie und Praxis. Bundesweite Zeitschrift der Juso-Hochschulgruppen. 90 (S.22-33). Bonn: SP-Verlag Norbert Schüren.

Gunzenhäuser, Randi (1995): Gibt es eine Position außerhalb des Diskurses? Zu Michel Foucault und Donna Haraway. In: Haas, Erika (Hg.), "Verwirrung der Geschlechter." Dekonstruktion und Feminismus. (S.73-94). München/Wien: Profil Verlag.

Haarhoff, Heike (2007): Die Gefürchtete In: Die Tageszeitung. 28 (16. April ), S.5. Haase, Raimund / Georg, Krücken (2005): Neo-Institutionalismus. 2. vollst. überarb. Aufl.. Bielefeld: transcript.

Habermas, Jürgen (1981): Theorie des kommunikativen Handels. Frankfurt a. Main: Suhrkamp.

Habermas, Jürgen (1985): Die Krise des Wohlfahrtsstaates und die Erschöpfung utopischer Energien. In: ders., Die Neue Unübersichtlichkeit. (S.141-162). Frankfurt a. Main: edition suhrkamp.

Hagemann, Karen / Michel, Sonya / Budde, Gunilla / International Conference on Civil Society and Gender Justice: Historical and Comparative Perspectives (2008): Civil society and gender justice : historical and comparative perspectives ; [International Conference on "Civil Society and Gender Justice: Historical and Comparative Perspectives ... July 2004 at the Social Science Research Center Berlin (WZB)]. European civil society. New York u.a.: Berghahn Books.

Hagemann-White, Carol (1987): Können Frauen die Politik verändern? In: Aus Politik und Zeitgeschichte, Beilage zur Wochenzeitung "Das Parlament". Ausg. (9-10), S.29-37.

Hagemann-White, Carol (1992): Strategien gegen Gewalt im Geschlechterverhältnis. In: Lenz, Ilse (2008), a.a.O. S.475-482.

Haibach, Marita / Immenkötter, Mechthild / Rühmkopf, Eva u.a. (1986): Frauen sind nicht zweite Klasse. Frauenpolitik für Gleichstellung. Hamburg: VSA.

Halford, Susan / Leonard, Pauline (2001): Gender, Power and Organisations : an Introduction. Basingstoke u.a.: Palgrave.

Haller, Dieter (2001): Die Vielfalt des Geschlechtlichen: Chancen und Konsequenzen für die Theoriebildung in der Anthropology of Gender. In: Schlehe, Judith (Hg.), Interkulturelle Geschlechterforschung. Identitäten - Imaginationen Repräsentationen. (S.86-108). Frankurt a. Main: Campus Verlag.

Handschell, Christian ( Bearb.) (2002): Abgeordnete in Bund und Ländern. Mitgliedschaft und Sozialstruktur 1946-199o. . In: Recker, Marie-Luise / Tenfelde, 
Klaus (Hg.), Handbuch zur Statistik der Parlamente und Parteien in den westlichen Besatzungszonen und in der Bundesrepublik Deutschland. Düsseldorf: Droste.

Hänsch, Klaus (2002): Anmerkungen zur Strategiefähigkeit in der Politik. In: Nullmeier, Frank / Saretzki, Thomas (Hg.), Jenseits des Regierungsalltags. Strategiefähigkeit politischer Parteien. (S.179-185). Frankfurt a. Main: Campus.

Hansen, Jan (2013): Zwischen Staat und Straße. Der Nachrüstungsstreit in der deutschen Sozialdemokratie (1979-1983). In: Woyke, Meik (Hg.), Wandel der Politischen: Die Bundesrepublik Deutschland während der 1980er-Jahre. (S.521-557). Bonn: J.H.W. Dietz Nachf.

Hantzsch, Holger (1983): Zur Frauenpolitik der SPD der BRD in den 7oer-Jahren. In: Forschungsgemeinschaft "Geschichte des Kampfes der Arbeitsklasse um die Befreiung der Frau" an der Sektion Geschichte der Pädagogischen Hochschule "Clara Zetkin" (Hg.), Mitteilungsblatt der Forschungsgemeinschaft "Geschichte des Kampfes der Arbeitsklasse um die Befreiung der Frau" Heft 3 (S.43-6o). Leipzig: Pädagogische Hochschule Leipzig.

Harding, Sandra (2004): Wissenschafts- und Technologieforschung: Multikulturelle und postkoloniale Geschlechteraspekte. In: Becker, Ruth / Kortendiek, Beate (Hg.), a.a.O., S.267-276.

Hark, Sabine / Kerner, Ina (2007): Der neue Spartenfeminismus In: Feministische Studien. 25 (1), S.92-95.

Härtel-Hermann, Heide / Knake-Werner, Heidi (1984): "Links und frei sind wir Frauen in der SPD noch lange nicht" In: Marxistische Blätter. 22 (5), S.36-40.

Haug, Frigga (1996): Paradoxien feministischer Realpolitik. Zum Kampf um die Frauenquote. In: dies., Frauen-Politiken. (S.25-45). Hamburg: Argument.

Haug, Frigga (2004): Sozialistischer Feminismus: eine Verbindung im Streit. In: Becker, Ruth / Kortendiek, Beate (Hg.), a.a.O., S.49-55.

Haug, Frigga (2009): Feministische Initiative zurückgewinnen - eine Diskussion mit Nancy Fraser In: Das Argument. 51 (3), S.393-408.

Haunss, Wolfgang (2001): Was in aller Welt ist "kollektive Identität"? Bemerkungen und Vorschläge zu Identität und kollektivem Handeln In: Gewerkschaftliche Monatshefte. 52 (5), S.258-267.

Hausen, Karin (1976): Die Polarisierung der "Geschlechtercharaktere". Eine Spiegelung der Dissoziation von Erwerbs- und Familienleben. In: Conze, Werner, Sozialgeschichte der Familie in der Neuzeit Europas. (S.363-393). Stuttgart: Klett-Cotta.

Heimann, Klaus / Altrogge, Hans-Peter / Stemplewski, Jochen (1975): Arbeitsgemeinschaften benötigen politischen Spielraum In: Die Neue Gesellschaft. 22 (9), S.714-720.

Heimann, Siegfried (1984): Die Sozialdemokratische Partei Deutschlands. In: Stöss, Richard (Hg.), Parteienhandbuch. Bd.2 (S.2025-2216). Opladen: Westdeutscher Verlag. 
Heimann, Siegfried (1991): Zwischen Aufbruchstimmung und Resignation. Die SPD in den 8oer-Jahren. In: Süss, Werner (Hg.), Die Bundesrepublik in den achtziger-Jahren: Innenpolitik, politische Kultur, Außenpolitik. (S.35-52). Opladen: Leske+Budrich.

Heimann, Siegfried (1993): Die Sozialdemokratie: Forschungsstand und offene Fragen. In: Niedermayer, Oskar / Stöss, Richard (Hg.), Stand und Perspektiven der Parteienforschung in Deutschland. (S.147-186). Wiesbaden: VS Verlag für Sozialwissenschaften.

Heinrich, Gudrun (2008): Die NPD als Bewegungspartei. In: Forschungsjournal Neue Soziale Bewegungen. 21 (4), S.29-38.

Heintel, Peter / Krainz, Ewald (1988): Projektmanagement - eine Antwort auf die Hierarchiekrise? Wiesbaden: Gabler. Kap.II.

Heintz, Bettina (2001): Geschlecht als (Un-)Ordnungsprinzip, Entwicklungen und Perspektiven einer Geschlechtersoziologie In: Kölner Zeitschrift für Soziologie und Sozialpsychologie. 53 (Sonderheft 41), S.9-29.

Heintz, Bettina / Nadai, Eva (1998): Geschlecht und Kontext. De-Institutionalisierungsprozesse und geschlechtliche Differenzierung In: Zeitschrift für Soziologie. 27 (2), S.75-93.

Helfferich, Cornelia (2005): Die Qualität qualitativer Daten. Manual für die Durchführung qualitativer Interviews. 2.Auflage. Wiesbaden: VS Verlag für Sozialwissenschaften / Springer Fachmedien Wiesbaden GmbH.

Hellmann, Kai-Uwe (1998a): Paradigmen der Bewegungsforschung : Forschungsund Erklärungsansätze - ein Überblick. In: ders. / Koopmans, Ruud (Hg.), a.a.O., S.9-30.

Hellmann, Kai-Uwe (1998b): Systemtheorie und Bewegungsforschung In: Rechtshistorisches Journal. 17 (VIII), S.493-510.

Hellmann, Kai-Uwe / Koopmans, Ruud (1998): Paradigmen der Bewegungsforschung : Entstehung und Entwicklung von Neuen Sozialen Bewegungen und Rechtsextremismus. Opladen u.a.: Westdt. Verlag.

Hellwig, Renate (1975): Frauen verändern die Politik. Eine gesellschaftspolitische Streitschrift. Bonn: Verlag Bonn aktuell.

Hellwig, Renate (1981): Wer rettet die Familie? In: Die Zeit. Nr. 30 (17. Juli), Im Internet unter: http://pdf.zeit.de/1981/30/wer-rettet-die-familie.pdf, [Zugriff: 02.03.2013].

Hempel-Soos, Karin (1980): Die AsF zwischen SPD und Frauenbewegung In: Die Neue Gesellschaft. 27 (2), S.111-114.

Hempel-Soos, Karin (1982): Der herbe Charme der Ladykiller. Die Bonner Frauenfeinde sind in allen Parteien zu Hause In: Die Zeit. Nr. 17 (23. April), Im Internet unter: http://www.zeit.de/1982/17/der-herbe-charme-der-ladykiller/ komplettansicht, [Zugriff: 14.03.2011].

Hempel-Soos, Karin (1983): Die AsF wird zehn Jahre alt. Zwischen "Übervaterpartei" und Frauenbewegung In: Vorwärts 108 (24), S.8. 
Henjes, Birgit (1994): Auf die Dauer ohne Power? Zum Selbstverständnis kommunaler Frauenbeauftragter. In: Biester, Elke / Holland-Cunz, Barbara / MaleckLewy, Eva / Ruf, Anja / Sauer, Birgit (Hg.), Gleichstellungspolitik - Totem und Tabus. Eine feministische Revision. (S.54-61). Frankfurt a. Main: Campus.

Henninger, Annette (2005): Selbstgebaute Barrieren - Netzwerkschließungen als Hindernis bei der Umsetzung von Frauenpolitik. In: dies. / Ostendorf, Helga (Hg.), Die politische Steuerung des Geschlechterregimes. Beiträge zur Theorie politischer Institutionen. (S.139-159). Wiesbaden: VS Verlag für Sozialwissenschaften.

Hervé, Florence / Doormann, Lottemi (1987): Geschichte der deutschen Frauenbewegung. 3. überarb. und erw. Aufl. Köln: Pahl-Rugenstein.

Hirsch, Joachim (1980): Der Sicherheitsstaat. Das "Modell Deutschland", seine Krise und die neuen sozialen Bewegungen Frankfurt a. Main: Europäische Verlagsanstalt.

Historische Kommission beim SPD-Parteivorstand / Arbeitsgemeinschaft sozialdemokratischer Frauen (1998): Vom Frauenwahlrecht zur Quotierung. Frauenbewegung und Sozialdemokratie Dokumentation des Workshops der historischen Kommission und der Arbeitsgemeinschaft sozialdemokratischer Frauen am 12./13. Dezember 1997 in Bonn. Bonn: Union-Druckerei und Verlagsanstalt.

Hoecker, Beate (1985): Frauen in den Bremer Parteien. Eine Darstellung ihres Sozial-, Einstellungs- und Partizipationsprofils. Kaack, Heino/ Roth, Reinhold (Hg.). Forschungsgruppe Parteiendemokratie Bremen: Hochschule Bremen, Fachbereich Wirtschaft.

Hoecker, Beate (1987a): Frauen in der Politik : eine soziologische Studie. Opladen: .Leske+Budrich.

Hoecker, Beate (1987b): Politik: noch immer kein Beruf für Frauen? In: Aus Politik und Zeitgeschichte, Beilage zur Wochenzeitung "Das Parlament". Ausg. (910), S.3-14.

Hoecker, Beate (1994): Parlamentarierinnen im Deutschen Bundestag 1949 bis 1990. Ein Postskriptum zur Abgeordnetensoziologie In: Zeitschrift für Parlamentsfragen. 25 (4), S. 556-581.

Hoecker, Beate (1995): Politische Partizipation von Frauen. Kontinuität und Wandel des Geschlechterverhältnisses in der Politik. Ein einführendes Studienbuch. Opladen: Leske+Budrich.

Hoecker, Beate (1998): Frauen, Männer und die Politik. Bonn: Dietz Nachf.

Hoecker, Beate (2008): Frauen in der Politik: späte Erfolge, aber nicht am Ziel In: Aus Politik und Zeitgeschichte, Beilage zur Wochenzeitung "Das Parlament". Ausg. (24-25), S.10-18.

Hoecker, Beate / Scheele, Alexandra (2008): Feminisierung der Politik? Neue Entwicklungen und alte Muster der Repräsentation - Einleitung In: Femina Politica. 17 (2), S.9-19. 
Hofbauer, Johanna (2004): Distinktion - Bewegung an betrieblichen Geschlechtergrenzen. In: Pasero, Ursula / Priddat, Birger P. (Hg.), a.a.O., S.45-64.

Hoff, Magdalena (1984): Der kleine Unterschied beträgt 26,8 Prozent In: Die Neue Gesellschaft. 31 (4), S.300-304.

Hoffmann-Nowotny, Hans-Joachim (1988): Weibliche Erwerbstätigkeit und Kinderzahl. In: Gerhard, Ute / Schütze, Yvonne (Hg.), Frauensituation. Veränderungen in den letzten zwanzig Jahren. (S.219-250). Frankfurt a. Main: Suhrkamp.

Hohenstein, Rainer (1982): Leserbrief in: Frankfurter Rundschau 37 (30.12.) in: Privatarchiv Schmarsow

Holland-Cunz, Barbara (1994): Öffentlichkeit und Intimität - demokratietheoretische Überlegungen. In: Biester, Elke / dies. / Sauer, Birgit (Hg.), a.a.O., S.227246.

Holland-Cunz, Barbara (1998): Feministische Demokratietheorie : Thesen zu einem Projekt. Opladen: Leske+Budrich.

Holland-Cunz, Barbara (1999): Sieben Thesen zu einer feministischen Theorie der Demokratie. In: Abels, Gabriele / Sifft, Stefanie (Hg.), Demokratie als Projekt: Feministische Kritik an der Universalisierung einer Herrschaftsform. (S.213230). Frankfurt a. M./New York: Campus.

Holland-Cunz, Barbara (2003): Die alte neue Frauenfrage. Frankfurt a. Main: edition suhrkamp, S.133-255.

Holtkamp, Lars / Schnittke, Sonja (2008): Erklärungsmodelle für die Unterrepräsentation von Frauen. Eine Analyse am Beispiel der Kommunalparlamente von Baden-Württemberg und Nordrhein-Westfalen In: Femina Politica. 17 (2), S. $53-64$.

Honnen, Ulrike (1988): Vom Frauenwahlrecht zur Quotierung : 125 Jahre Kampf um Gleichberechtigung in der SPD. Münster u.a.: Waxmann.

Hopf, Christel (1978): Die Pseudo-Exploration - Überlegungen zur Technik qualitativer Interviews In: Zeitschrift für Soziologie. 7 (2), S.97-115.

Hopf, Christel (1996): Hypothesenprüfung und qualitative Sozialforschung. In: Strobl, Rainer / Böttger, Andreas (Hg.), Wahre Geschichten? (S.9-21). BadenBaden: Nomos Verlagsgesellschaft.

Hornung, Ursula (1993): Tarifliche und betriebliche Vereinbarungen zur Frauenförderung: Ein Weg zur beruflichen Gleichstellung der Geschlechter? In: Aulenbacher, Brigitte / Goldmann, Monika (Hg.), Transformationen im Geschlechterverhältnis. Beiträge zur industriellen und gesellschaftlichen Entwicklung. (S.138-161). Frankfurt a. M./New York: Campus

Huber, Antje (1984): Verdient die Nachtigall Lob, wenn sie singt? Stuttgart/Herford: Seewald.

IAB / Institut für Arbeitsmarkt- und Berufsforschung (2009): Gleich und doch nicht gleich: Frauenbeschäftigung in deutschen Betrieben. Auswertung des IAB-Betriebspanels 2008. Nürnberg: o.V. 
Imhof, Kurt (2006): Politik im "neuen" Strukturwandel der Öffentlichkeit. fög discussion papers Universität Zürich. Im Internet unter: http://www.foeg.uzh.ch/staging/userfiles/file/Deutsch/fög\%2odiscussion\%2opapers/GL-2006-oo10_Politik_und_Medien.pdf, [Zugriff: 10.04.2011]. Institut für Sozialforschung (Frankfurt Main) / Pöhl, Katharina (1995): Geschlechterverhältnisse und Politik. Frankfurt a. Main: Suhrkamp.

Ismayr, Wolfgang (2001): Parteien in Bundestag und Bundesregierung. In: Gabriel, Oscar.W / Niedermayer, Oskar / Stöss, Richard (Hg.), a.a.O., S.36o-384.

Jäger, Margarete (2004): Diskursanalyse: Ein Verfahren zur kritischen Rekonstruktion von Machtbeziehungen. In: Becker, Ruth / Kortendiek, Beate (Hg.), a.a.O., S.336-341.

Jansen, Anni (1980): Der Kommerz-Feminismus von "Emma" In: parlamentarisch-politischer pressedienst. 105 (10.09), S.1-3.

Jansen, Mechthild (1986): Der Einfluß der Frauenbewegung auf die politische Kultur der Bundesrepublik In: Blätter für deutsche und internationale Politik. 31 (3), S.289-305.

Jansen, Mechthild (1986): Halbe-Halbe. Der Streit um die Quotierung. Berlin: elefanten press.

Jansen, Mechthild (1994): Nicht mehr Totem, nicht neues Tabu: Gleichstellung weiterdenken. In: Biester, Elke / Holland-Cunz, Barbara / Maleck-Lewy, Eva / Ruf, Anja / Sauer, Birgit (Hg.), a.a.O., S.141-157.

Janssen-Jurreit, Marielouise (1976): Sexismus: über die Abtreibung der Frauenfrage. München u.a.: Hanser.

Janssen-Jurreit, Marielouise (1979): Frauenprogramm - Gegen Diskriminierung: Gesetzgebung - Aktionspläne - Selbsthilfe. Ein Handbuch. Reinbek b. Hamburg: Rowohlt.

Janssen-Jurreit, Marielouise (1990): Von Papa Staat zu Mama Staat. Über das Verhältnis von Utopie und Neurose. In: Schaeffer-Hegel, Barbara (Hg.), a.a.O.. (S.223-239) Pfaffenweiler: Centaurus.

Japs, Gode (1985): SPD-Frauen verlangen 40 Prozent der Mandate "Unsere Geduld ist vorbei" AsF: Bundeskonferenz: Selbstbewußt dem Partei-Patriarchat den Kampf angesagt In: Vorwärts. 113 (12.Oktober), S.

Jun, Uwe (2009): Politische Parteien als Gegenstand der Politischen Soziologie. In: Kaina, Viktoria / Römmele, Andrea (Hg.), Politische Soziologie. Ein Studienbuch. (S.235-265). Wiesbaden: VS Verlag für Sozialwissenschaften.

Jüngling, Christiane (1992): Geschlechterpolitik in Organisationen. In: Krell, Gertraude / Osterloh, Margit (Hg.), Personalpolitik aus der Sicht von Frauen Frauen aus der Sicht der Personalpolitik. Was kann Personalforschung von der Frauenforschung lernen? (S.173-205). München und Mehring: Rainer Hampp. Junker, Karin / Frauenreferat beim SPD-Parteivorstand (Hg.) (1992): Für Inge Wettig-Danielmeier. Bonn: o.V.

Junker, Karin (1992): Von einer, die auszog, die Gleichstellung zu erkämpfen. In: dies. / Frauenreferat beim SPD-Parteivorstand (Hg.), a.a.O., S.6o-64. 
Junker, Karin (1993): Fünf Jahre nach dem Quotenbeschluß. In: Vorstand der Sozialdemokratischen Partei Deutschlands - Frauenreferat (Hg.), Hürdenlauf an die Macht. Die SPD-Frauen fünf Jahre nach der Quote. (S.1-3). Bonn: o. Verlag.

Jureit, Ulrike (1998): Konstruktion und Sinn: methodische Überlegungen zu biographischen Sinnkonstruktionen. Oldenburger Universitätsreden; 103. Oldenburg: BIS.

Jürgens, Kerstin (2001): Durch Tarifvertrag zum Geschlechterkontrakt? In: HansBöckler-Stiftung (Hg.), Neue Zeiten - neue Gewerkschaften. Auf der Suche nach einer neuen Zeitpolitik. (S.159-178). Berlin: edition sigma.

Juso-Bundeskongress (1973): Zur gesellschaftspolitischen Situation der Frau. Bundeskongreß der Jungsozialisten in der SPD 9. bis 11. März. Bonn-Bad Godesberg. In: Juso (Hg.) 1977, a.a.O., S.6-17.

Juso, Bundesvorstand der (1975a): Frauenarbeit in der SPD. In: Juso (Hg.) (1977), a.a.O., S.73-75.

Juso, Bundesvorstand der (1977): Frauenarbeit. Materialsammlung. Juso-Argumente Problem 25. Bonn. Bundesvorstand der Jungsozialisten (Hg.). In: Neuer Vorwärts-Verlag.

Juso-Hochschulgruppen (Hg.) (1989): Wieviel Feminismus braucht die SPD? Frauen und neues SPD-Grundsatzprogramm. In: dies. (Hg.), Arbeitshefte zur sozialistischen Theorie und Praxis. Bundesweite Zeitschrift der Juso-Hochschulgruppen. 13 Bonn: SP-Verlag Norbert Schüren.

Kahlert, Heike (2004): Differenz, Genealogie, Affidamento: Das italienische 'pensiero della differenza sessuale' in der internationalen Rezeption. In: Becker, Ruth / Kortendiek, Beate (Hg.), a.a.O., S.91-98.

Kahlert, Heike (2005): "Das Private ist politisch" Die Entgrenzung des Politischen im Kontext von Anthony Giddens' Strukturierungstheorie. In: Hardes, Ciljia / Kahlert, Heike / Schindler, Delia (Hg.), Forschungsfeld Politik. Geschlechtskategoriale Einführung in die Sozialwissenschaften. (S.147-173). Wiesbaden: VS Verlag für Sozialwissenschaften.

Kahlert, Heike (2006): Geschlecht als Struktur- und Prozesskategorie. Eine ReLektüre von Giddens' Strukturierungstheorie. In: Aulenbacher, Brigitte / Bereswill, Mechthild / Löw, Martina L / Meuser, Michael / Mordt, Gabriele / Schäfer, Reinhild / Scholz, Sylka (Hg.), FrauenMännerGeschlechterforschung. State of the Art. (S.206-216). Münster: Westfälisches Dampfboot.

Kanter, Rosabeth Moss (1977): Some Effects of Proportions on Group Life: Skewed Sex Ratios and Responses to Token Women In: The American Journal of Sociology. 82 (5), S.965-99o. Im Internet unter: http://www.nhh.no/ Files/Filer/adm/personal/Likestilling/MossKanter.pdf, [Zugriff: 02.02.2008].

Katz, Richard S. (2005): The Internal Life of Parties. In: Luther, Kurt Richard / Müller-Rommel, Ferdinand (Hg.), Political Parties in the New Europe. Political and Analytical Challenges. Part III Parties as Purposive Organizations (S.78-118). Oxford: Oxford University Press. 
Katz, Richard S. / Mair, Peter (1993): The Evolution of Party Organizations in Europe: The Three Faces of Party Organization. In: Crotty, William J. (Ed.), Parties in an Age of Change. Special Issue of The The American Review of Politics 14 (S.593-617).

Kavai, André (2002): Wie neoliberal ist die SPD? Sozialdemokratische Programmdiskussion im Wandel. Stuttgart: ibidem.

Keller, Reiner (2007): Diskursforschung: eine Einführung für SozialwissenschaftlerInnen. 3. aktual. Aufl.. Wiesbaden: VS Verlag für Sozialwissenschaften.

Kiera, Hans-Georg (1979): Wohin treibt die SPD? In: Die Neue Gesellschaft. 26 (8), S.678-68o.

Kieser, Alfred / Ebers, Mark (2006): Organisationstheorien. 6. erw. Aufl. Stuttgart: Kohlhammer.

Kieser, Alfred / Walgenbach, Peter (2003): Organisation. 4. überarb. u. erw. Aufl. Stuttgart: Kohlhammer.

Kinzig, Silke (2007): Auf dem Weg zur Macht? Zur Unterrepräsentation von Frauen im deutschen und U.S.-amerikanischen Regierungssystem. Wiesbaden: VS Verlag für Sozialwissenschaften.

Kirchheimer, Otto (1966): The Transformation of the Western European Party Systems. In: La Palombar, Joseph / Weiner, Myron (Hg.), Political Parties and Political Development. (S.177-200). Princeton, NJ: Pinceton University Press.

Kirsch-Auwärter, Edith (2008): Aktuelle Hochschulreformansätze und Qualitätsmerkmale institutioneller Gleichstellungspolitik - Erfahrungen aus Niedersachsen In: Esch, Marion / Herrmann, Joachim (Hg.), Qualität durch Chancengleichheit: Gleichstellung als strategischer Faktor im Qualitätsmanagement technischer Universitäten. Bundesministerium für Bildung und Forschung (S.105-134). Bielefeld: W. Bertelsmann.

Klandermans, Bert (1998): Ausländerfeindliche Bewegungen und Parteien im Vier-Länder-Vergleich. Ressourcenmobilisierung, Kosten/Nutzen-Relat-ionen, Organisationen und soziale Netzwerke. In: Hellmann, Kai-Uwe / Koopmans, Ruud (Hg.), a.a.O., S.181-197.

Klar, Ika (1981): Arbeitsgemeinschaft Sozialdemokratischer Frauen (ASF). In: Gassen, Gisela (Hg.), a.a.O., S.124-133.

Klein, Ansgar (2001): Ein Abschied in Raten von der Bewegungsforschung. Anmerkungen zur Neuformatierung der Forschungsarbeit im WZB In: Forschungsjournal Neue Soziale Bewegungen. 14 (1), S.117-119.

Klein, Ansgar (2003a): Bewegungsforschung: Quo vadis? Ein Überblick zu Entstehung, Ausprägung und Forschungsstand In: Vorgänge. 42 (4), S.12-21.

Klein, Ansgar (2003b): Diskurspolitischer Interventionismus In: Forschungsjournal Neue Soziale Bewegungen. 16 (2), S.24-28.

Klein, Michael (2005): Der Protestantismus und die Sozialdemokratische Partei Deutschlands (SPD). In: ders., Westdeutscher Protestantismus und politische Parteien. Anti-Parteien-Mentalität und parteipolitisches Engagement von 1945 bis 1963. (S.323-357). Tübingen: Mohr Siebeck. 
Klein, Markus (2006): Partizipation in politischen Parteien. In: Deutsche Vereinigung für Politische Wissenschaft (Hg.), Politische Vierteljahresschrift. 47 (S.35-61). Wiesbaden: VS Verlag für Sozialwissenschaften.

Kleinau, Elke (1985): Zum Einfluß bürgerlicher Weiblichkeitsideologie auf die sozialdemokratische Frauenemanzipationstheorie In: Geschichtsdidaktik. Probleme-Projekte-Perspektiven. 10 (2), S.203-207.

Klemm, Jana / Glasze, Georg (2005): Methodische Probleme Foucault-inspirierter Diskursanalysen in den Sozialwissenschaften. In: Forum qualitative Sozialforschung, Tagungsbericht."Praxis-Workshop Diskursanalyse", 17.-18. Juni 2004 Vol. 6, No. 2 Art.24 Im Internet unter: http://www.qualitative-research.net/fqs-texte/2-05/05-2-24-d.pdf, [Zugriff: 25.11.2007].

Kliment, Tibor (1998): Durch Dramatisierung zum Protest? In: Hellmann, KaiUwe / Koopmans, Ruud (Hg.), a.a.O., S.69-89.

Klotzbach, Kurt (1989): Die moderne SPD. Entwicklungslinien und Hauptprobleme von 1945 bis zur Gegenwart. In: Dowe, Dieter / ders. (Hg.), Kämpfe-Krisen-Kompromisse. Kritische Beiträge zum 125jährigen Jubiläum der SPD. (S.103-121). Bonn: J.H.W. Dietz Nachf.

Klotzbach, Kurt (1996): Der Weg zur Staatspartei : Programmatik, praktische Politik und Organisation der deutschen Sozialdemokratie 1945 - 1965. Nachdr. d. Ausg. v. 1982. Die deutsche Sozialdemokratie nach 1945; 1. Bonn: J.H.W. Dietz Nachf.

Knake-Werner, Heidi / Kiesbauer, Sonja (1995): Gleichberechtigung, Gleichstellung, Emanzipation - ein Streit um Worte oder was? In: Maleck-Lewy, Eva / Penrose, Virginia (Hg.), a.a.O., S.101-114.

Knapp, Gudrun-Axeli (1992): Neue Entwicklungen in der feministischen Machtdiskussion. In: Biester, Elke / Geißel, Brigitte / Lang, Sabine / Sauer, Birgit / Schäfter, Petra / Young, Brigitte (Hg.), Staat aus feministischer Sicht. (S.19-36). Berlin Freie Universität: o. Verlag.

Knapp, Gudrun-Axeli (1995): Macht und Geschlecht, Neuere Entwicklungen in der Macht- und Herrschaftsdiskussion. In: Erika Haas (Hg.), "Verwirrung der Geschlechter" - Dekonstruktion und Feminismus. 2. Aufl. (S.287 - 325). Freiburg i. Br.: Kore.

Knapp, Gudrun-Axeli (1997): Gleichheit, Differenz, Dekonstruktion: Vom Nutzen theoretischer Ansätze der Frauen- und Geschlechterforschung für die Praxis. In: Lenz, Ilse (2008), a.a.O., S.423-428.

Knapp, Gudrun-Axeli (2001): Grundlagenkritik und stille Post. Zur Debatte um einen Bedeutungsverlust der Kategorie "Geschlecht" In: Kölner Zeitschrift für Soziologie und Sozialpsychologie. 53 (Sonderheft 41), S.53-74.

Knapp, Gudrun-Axeli / Wetterer, Angelika (1995): Traditionen Brüche: Entwicklungen feministischer Theorie. 2. Auflage. Freiburg i. Br.: Kore.

Koch, Susanne (1994): Junge Frauen in der Volkspartei SPD. In: Hildebrandt, Regine / Winkler, Ruth (Hg.), Die Hälfte der Zukunft. Lebenswelten junger Frauen. (S.191-216). Köln: Bund Verlag. 
Kolb, Felix (2006): Die politischen Auswirkungen und Erfolge sozialer Bewegungen In: Forschungsjournal Neue Soziale Bewegungen. 19 (1), S.12-23.

Konieczka, Vera (1983): Feminismus und Sozialismus. In: Bundesvorstand der Jungsozialisten (Hg.), sozialistische tribüne. Zeitschrift für sozialistische Theorie. (S.91-93). Bonn: o. Verl.

Konieczka, Vera (1986): "Den Frauen die Hälfte der Welt, den Männern die Hälfte der Familie" In: Juso Magazin. o.J. (6), S.25.

Kontos, Silvia (1979): Die Partei kämpft wie ein Mann : Frauenpolitik der KPD in der Weimarer Republik. Stroemfeld: Roter Stern.

Kontos, Silvia (1986): Modernisierung der Subsumtionspolitik. Die Frauenbewegung in den Theorien neuer sozialer Bewegungen In: Feministische Studien. 4 (2), S.34-49.

Kontos, Silvia (1990): Zum Verhältnis von Autonomie und Partizipation in der Politik der neuen Frauenbewegung. In: Schaeffer-Hegel, Barbara (Hg.), a.a.O., S.50-63.

Kontos, Silvia (1994): Jenseits patriarchaler Alternativen: Grenzen der Gleichstellungspolitik. In: Biester, Elke / Holland-Cunz, Barbara / Maleck-Lewy, Eva / Ruf, Anja / Sauer, Birgit (Hg.), Gleichstellungspolitik - Totem und Tabus. Eine feministische Revision. (S.36-53). Frankfurt a. Main: Campus.

Kontos, Silvia (1998): Was machen wir, wenn Männer die Männerfrage nicht hören wollen? Die Grünen, die Feministinnen und die Geschlechterdemokratie / Eine Anfrage von Silvia Kontos In: Frankfurter Rundschau. 53 (27. Juni), S.7.

Kontos, Silvia (2004): Grüne Frauen- und Geschlechterpolitik in Regierung und Partei. Stand und Perspektiven. Beitrag zum 16. Green Ladies' Lunch am 30.4. 2004 Im Internet unter: http://www.glow-boell.de/media/de/txt_rubrik_2/Kontos.pdf, [Zugriff: 02.10.2007].

Koopmans, Ruud (1995): Bewegung oder Erstarrung? Bestandsaufnahme der deutschen Bewegungsforschung in den letzten zehn Jahren In: Forschungsjournal Neue Soziale Bewegungen. 8 (1), S.90-96.

Koopmans, Ruud (1998): Konkurrierende Paradigmen oder friedlich ko-existierende Komplemente? Eine Bilanz der Theorien sozialer Bewegungen. In: Hellmann, Kai-Uwe / ders. (Hg.), a.a.O., S.215-231.

Kopel, Mechthild (1993): Für das Recht der Frauen auf Arbeit. Ein Kampf gegen Windmühlenflügel in den Jahren 1945 - 196o. In: Deutscher Gewerkschaftsbund (Hg.) (1993), „Da haben wir uns alle schrecklich geirrt..... Die Die Geschichte der gewerkschaftlichen Frauenarbeit im Deutschen Gewerkschaftsbund von 1945 bis 1960. (S.7-61). Pfaffenweiler: Centaurus.

Kortendiek, Beate (2004): Familie: Mutterschaft und Vaterschaft zwischen Traditionalisierung und Modernisierung. In: Becker, Ruth / dies. (Hg.), a.a.O., S.384-394.

Kosser, Ursula (2012): Hammelsprünge. Sex und Macht in der deutschen Politik. Köln: Dumont. 
Kramer, Nicole (2013): Neue soziale Bewegungen, Sozialwissenschaften und die Erweiterung des Sozialstaats. Familien- und Altenpolitik in den 1970er und 198oer-Jahren. In: Woyke, Meik (Hg.), Wandel des Politischen. die Bundesrepublik während der 1980er-Jahre. (S.215-234). Bonn: J.H.W. Dietz Nachf.

Krannich, Margret / Blickhäuser, Angelika / Hessische Gesellschaft für Demokratie und Ökologie (1999): Geschlechterdemokratie in Organisationen : Dokumentation einer Fachtagung vom 10. und 11. Juni 1999 in Frankfurt am Main. Frankfurt a. Main: o.V.

Kraushaar, Wolfgang (2005): Protest gegen die Wiederbewaffnung. In: FriedensForum. 8(6), S. 22-24.

Krautkrämer-Wagner, Uta (1989): Die Verstaatlichung der Frauenfrage. Gleichstellungsinstitutionen der Bundesländer - Möglichkeiten und Grenzen staatlicher Frauenpolitik. Theorie und Praxis der Frauenforschung. Hannover: Kleine.

Krebs, Thomas (1996): Parteiorganisation und Wahlkampfführung. Wiesbaden: Deutscher Universitätsverlag.

Kreisky, Eva (1995): Der Stoff, aus dem die Staaten sind. Zur männerbündischen Fundierung politischer Ordnung. In: Becker-Schmidt, Regina / Knapp, Gudrun-Axeli (Hg.), Das Geschlechterverhältnis als Gegenstand der Sozialwissenschaften. (S.85-124). Frankfurt a. Main: Campus.

Krell, Gertraude (1992): Wie wünschenswert ist eine nach Geschlecht differenzierende Personalpolitik? - Ein Diskussionsbeitrag. In: dies. / Osterloh, Margit (Hg.), Personalpolitik aus der Sicht von Frauen - Frauen aus der Sicht der Personalpolitik. Was kann Personalforschung von der Frauenforschung lernen? (S.49-6o). München und Mehring: Rainer Hampp.

Krell, Gertraude (2004): Chancengleichheit durch Personalpolitik : Gleichstellung von Frauen und Männern in Unternehmen und Verwaltungen; rechtliche Regelungen - Problemanalysen - Lösungen. 4. vollst. überarb. und erw. Aufl. Wiesbaden: Gabler.

Krockow, Christian Graf von / Lösche, Peter (1986): Parteien in der Krise : das Parteiensystem in der Bundesrepublik und der Aufstand des Bürgerwillens. München: Beck.

Krouwel, André (2006): Party Models. In: Katz, Richard S. / Crotty, William J. (Ed.), Handbook of Party Politics. (S.249-269). London: Sage Publication Inc. Kruse, Jan (2004): Explikation der Forschungsmethode. In: ders., Arbeit und Ambivalenz: die Professionalisierung sozialer und informatisierter Arbeit. (S.145164). Bielefeld: Transcript.

Kruse, Jan (2007): Einführung in die qualitative Sozialforschung. Reader zum Sommer-Seminar 2007 an der Ruhr Universität Bochum.

Kuhlmann, Ellen / Kutzner, Edelgard / Müller, Ursula / Riegraf, Birgit / Wilz, Sylvia M. (2002): Organisationen und Profession als Produktionsstätten der Geschlechter(a)symmetrie. In: Schäfer, Eva / Fritzsche, Bettina / Nagode, Claudia (Hg.), Geschlechterverhältnisse im sozialen Wandel. Interdisziplinäre 
Analysen zu Geschlecht und Modernisierung. (S.221-249). Opladen: Leske+Budrich.

Kuhn, Annette (1987): 'Wer die menschliche Gesellschaft will, muß die männliche überwinden' Gedanken zum Irseer Entwurf aus feministischer Sicht In: Die Neue Gesellschaft. 34 (7), S.611-616.

Künnecke, Ira (1998): Zwischen Parteiraison und feministischem Selbstverständnis. Die Arbeitsgemeinschaft Sozialdemokratischer Frauen (ASF) nach Einführung der 'Quote'. Magisterarbeit im Rahmen der Magisterprüfung der Philosophischen Fakultät der Universität Köln.

Kunz, Eva / Melior, Susanne (2003): Gleichberechtigt oder gleichgestellt? Warum Anschlüsse keine reine Männersache sind. In: SPD-Landesverband Brandenburg (Hg.), Perspektive 21. Brandenburgische Hefte für Wissenschaft \& Politik. Hft.18 (S.37-46). Potsdam: o. Verlag.

Küpper, Jost (1977): Die SPD und der Orientierungsrahmen '85. Theorie und Praxis der deutschen Sozialdemokratie. Bonn-Bad Godesberg: Verl. Neue Ges.

Kurz-Scherf, Ingrid / Dzewas, Imke / Lieb, Anja / Reusch, Maire (Hg.) (2006): Reader. Feministische

Politik und Wissenschaft: Positionen, Anregungen, Perspektiven. Königstein/Ts: Ulrike Helmer.

Kürschner, Isabelle (2009): Frauen in den Parteien In: Aus Politik und Zeitgeschichte, Beilage zur Wochenzeitung "Das Parlament". Ausg. (50), S.16-21.

Kürschners Volkshandbuch Deutscher Bundestag. 11. Wahlperiode 1987 (Stand: 15. September 1987): Sonderdruck für den Deutschen Bundestag Referat Öffentlichkeitsarbeit + Beilage. Darmstadt: NDV.

L.B. (1982): Ein sicherer Platz für Frau Matthäus. Der Rang auf der SPD-Landesliste steht noch nicht fest In: Frankfurter Allgemeine Zeitung. 33 (13.12.1982).

Lafontaine, Oskar (1988): Die Frauenfrage als Männerfrage: zum Erfordernis, das Geschlechterdilemma zu überwinden In: Sozialdemokratischer Pressedienst. 43 (61/29.03.), S.1-2.

Lambsdorff, Otto Graf (1982): Konzept für eine Politik zur Überwindung der Wachstumsschwäche und zur Bekämpfung der Arbeitslosigkeit In: Neue Bonner Depesche. 9 (9. September).

Lang, Regina (1989): Frauenquoten. Der einen Freud, des anderen Leid. Bonn: J.H.W. Dietz Nachf.

Lang, Sabine (1997): Geschlechterordnung in der Demokratie: Über die Maskulinität politischer Öffentlichkeit. In: Schneider-Wilkes, Rainer (Hg.), Demokratie in Gefahr? Zum Zustand der deutschen Republik. (S.245-267). Münster: Westfälisches Dampfboot.

Lang, Sabine (2004): Politik - Öffentlichkeit - Privatheit. In: Rosenberger, Sieglinde K. / Sauer, Birgit (Hg.), Politikwissenschaft und Geschlecht. Konzepte Verknüpfungen - Perspektiven. (S.65-81). Wien: UTB. 
Leggewie, Claus (1998): Neo-Kapitalismus und Neue Rechte. Sozialstrukturelle Voraussetzungen radikaler rechter Bewegungen. In: Hellmann, Kai-Uwe / Koopmans, Ruud (Hg.), a.a.O., S.133-148.

Lehnert, Detlef (1983): Sozialdemokratie zwischen Protestbewegung und Regierungspartei 1848 bis 1983. Neue Historische Bibliothek. Frankfurt a. Main: Suhrkamp, Einleitung, Kap.5.

Lenz, Ilse (1990): Geschlechtssymmetrische Gesellschaften. In: dies. / Luig, Ute (Hg.), Frauenmacht ohne Herrschaft. 2. Aufl. (S.26-87). Frankurt a. Main: S. Fischer.

Lenz, Ilse (1995): Geschlecht, Herrschaft und internationale Ungleichheit. In: Becker-Schmidt, Regina / Knapp, Gudrun-Axeli (Hg.), Das Geschlechterverhältnis als Gegenstand der Sozialwissenschaften. (S.19-46). Frankfurt a. Main: Campus.

Lenz, Ilse (200o): Globalisierung, Geschlecht, Gestaltung? In: dies. / Nickel, Hildegard Maria / Riegraf, Birgit (Hg.), Geschlecht, Arbeit, Zukunft. (S.16 - 47). Münster: Westfälisches Dampfboot.

Lenz, Ilse (2001a): Bewegungen und Veränderungen. Frauenforschung und Neue Frauenbewegung in Deutschland. In: Hornung, Ursula / Gümen, Sedef / Weilandt, Sabine (Hg.), Zwischen Emanzipationsvision und Gesellschaftskritik. (Re)konstruktionen der Geschlechterordnung. (S.188 - 219). Opladen: Westfälisches Dampfboot.

Lenz, Ilse (2001b): Von den Geschichten zur Geschichte. Ein Literaturbericht über Forschung zur Neuen Frauenbewegung In: Zeitschrift für Frauenforschung \& Geschlechterstudien. 19 (1+2), S.188-200.

Lenz, Ilse (2002a): Neue Frauenbewegung, Feminismus und Geschlechterforschung. In: Schäfer, Eva / Fritzsche, Bettina / Nagode, Claudia (Hg.), Geschlechterverhältnisse im sozialen Wandel. Interdisziplinäre Analysen zur Geschlecht und Modernisierung. (S.35-66). Opladen: Leske+Budrich.

Lenz, Ilse (2002b): Wie verändern sich die Neuen Frauenbewegungen? Ein Ansatz zur Transformation sozialer Bewegungen In: Zeitschrift für Frauenforschung \& Geschlechterstudien. 20 (4), S.65-82.

Lenz, Ilse (2004a): Frauenbewegungen: Zu den Anliegen und Verlaufsformen von Frauenbewegungen als sozialen Bewegungen. In: Becker, Ruth / Kortendiek, Beate (Hg.), a.a.O., S.665-675.

Lenz, Ilse (2004b): Aufbruch ins Reich der Sinne nach dem Überdruss im Käfig der Anforderungen? Der Wandel der Thematisierungen von Sexualität und Körpern in der Entwicklung der Neuen Frauenbewegung in Deutschland. In: Lenz, Ilse / Mense, Lisa / Ullrich Charlotte (Hg.), Reflexive Körper? Zur Modernisierung von Sexualität und Reproduktion. (S.17-50). Opladen: Leske+Budrich.

Lenz, Ilse (2008): Die neue Frauenbewegung in Deutschland : Abschied vom kleinen Unterschied; eine Quellensammlung. Wiesbaden: VS Verlag für Sozialwissenschaften. 
Lenz, Ilse (2010): Differenzen der Humanität - die Perspektive der Geschlechterforschung. Alle Menschen werden Schwestern? Differenzen als Herausforderung an den Humanismus. In: Rüsen, Jörn (Hg.), Perspektiven der Humanität - Menschsein im Diskurs der Disziplinen. (S.373-407). Bielefeld: transcript.

Lenz, Ilse (2014): Geschlechter in Bewegung? In: Rendtorff, Barbara / Riegraf, Birgit / Mahs, Claudia (Hg.), 4o Jahre Feministische Debatten. Resümee und Ausblick. (S.12-30). Weinheim und Basel: Beltz Juventa.

Lenz, Ilse / Mae, Michiko / Klose, Karin (200o): Frauenbewegung weltweit: Einleitung. In: Dies (Hg.), Frauenbewegung weltweit. Aufbrüche, Kontinuitäten, Veränderungen. (S.7-20). Opladen: Leske+Budrich.

Lenz, Ilse / Mense, Lisa / Ullrich, Charlotte (2004): Reflexive Körper? Zur Modernisierung von Sexualität und Reproduktion: eine Einleitung. In: dies. (Hg.), Reflexive Körper? Zur Modernisierung von Sexualität und Reproduktion. (S.17-15). Opladen: Leske+Budrich.

Lenz, Ilse / Schneider, Brigitte (2004): Neue Frauenbewegungen und soziale Bewegungsforschung In: Mitteilungsblatt des Instituts für soziale Bewegung. 8 (31), S.133-155.

Lenz, Ilse / Szypulski, Anja / Molsich, Beate (1996): Frauenbewegungen international. Eine Arbeitsbibliographie. Reihe Geschlecht und Gesellschaft Bd. 3. Opladen: Leske+Budrich.

Lepsius, Renate (1963): Das Dilemma der Frau: ihr 'Wesen' In: Die Neue Gesellschaft. 10 (1), S.24-40.

Lepsius, Renate (1987): Frauenpolitik als Beruf : Gespräche mit SPD-Parlamentarierinnen. Hamburg: Hoffmann und Campe.

Lettow, Susanne (2005): Zone der Unbestimmtheit. Biopolitik und Geschlechterverhältnisse bei Foucault, Agamben und Hardt/Negri. In: dies. / Manz, Ulrike / Sarkowsky, Katja (Hg.), Öffentlichkeiten und Geschlechterverhältnisse. Erfahrungen, Politiken, Subjekte. (S.225-242). Königstein i.Taunus: Ulrike Helmer.

Lettow, Susanne / Sarkowsky, Katja (2005): Einleitung: Öffentlichkeiten und Geschlechterverhältnisse. Erfahrungen, Politiken, Subjekte. In: dies. / Manz, Ulrike (Hg.), Öffentlichkeiten und Geschlechterverhältnisse. Erfahrungen, Politiken, Subjekte. (S.9-19). Königstein i.Taunus: Ulrike Helmer.

Libreria delle donne di Milano (1989): Wie weibliche Freiheit entsteht. Eine neue politische Praxis. Berlin: Orlanda Frauenverlag.

Liebig, Brigitte (2014): Zum 'Cultural Turn' in der feministischen Organisationsforschung. Geschlecht im Licht theoretischer Perspektiven der Organisationskulturforschung. In: Funder, Marion (Hg.), Gender Cage - revisited. Handbuch zur Organisations- und Geschlechterforschung. (S.271-293). Baden-Baden: Nomos.

Linnhoff, Ursula (1972): Systemüberwindung ohne Frauenemanzipation? Zur Einschätzung der neuen Frauenbewegung In: Juso Magazin. o.J. (Hft. 5/6), S.28-29. 
Lipinski, Richard (1928): Die Sozialdemokratie von ihren Anfängen bis zur Gegenwart. Eine gedrängte Darstellung. Berlin: J.H.W. Dietz Nachf.

Lölhöffel, Helmut (1975): Die SPD-Damen entzweit der "pseudomarxisitische Kram". Hader nach der sozialdemokratischen Frauenkonferenz In: Süddeutsche Zeitung. 30 (7. Juni).

Lorber, Judith (2004): Man muss bei Gender ansetzen, um Gender zu demontieren: Feministische Theorie und Degendering In: Zeitschrift für Frauenforschung \& Geschlechterstudien. 22 (2+3), S.9-24.

Lorey, Isabell (1995): Immer Ärger mit dem Subjekt. In: (Hg.), Erika Haas, "Verwirrung der Geschlechter." Dekonstruktion und Feminismus. (S.19-34). München, Wien: Profil.

Lösche, Peter (1991): Lose verkoppelte Anarchie, nicht Oligarchie. In: Juso-Hochschulgruppen (Hg.), Arbeitshefte zur sozialistischen Theorie und Praxis. Bundesweite Zeitschrift der Juso-Hochschulgruppen (S.42-44). Bonn: SP-Verlag Norbert Schüren.

Lösche, Peter (1993): Kleine Geschichte der deutschen Parteien. Stuttgart u.a.: Kohlhammer.

Lösche, Peter (2009): Ende der Volksparteien. Essay In: Aus Politik und Zeitgeschichte, Beilage zur Wochenzeitung "Das Parlament". Ausg. (51), S.6-12.

Lösche, Peter / Walter, Franz (1992): Die SPD: Klassenpartei - Volkspartei - Quotenpartei: zur Entwicklung der Sozialdemokratie von Weimar bis zur deutschen Vereinigung. Darmstadt: Wissenschaftliche Buchgesellschaft.

Lucius-Hoene, Gabriele / Deppermann, Arnulf (2002): Rekonstruktion narrativer Identität: ein Arbeitsbuch zur Analyse narrativer Interviews. Lehrtexte Soziologie. Opladen: Leske+Budrich.

Luthardt, Wolfgang / Claußen, Bernhard (1988): Politik und Repräsentation. Beiträge zur Theorie und zum Wandel politischer und sozialer Institutionen. Schriftenreihe der Hochschulinitiative Demokratischer Sozialismus; 20. Marburg: SP-Verl. Schüren.

Mackert, Jürgen (2004): Die Theorie sozialer Schließung : Tradition, Analysen, Perspektiven. Wiesbaden: VS Verlag für Sozialwissenschaften.

Maibaum, Werner (1998) (Hg.): Geschichte der Deutschlandpolitik. Deutsche ZeitBilder. Bonn: Bundeszentrale für politische Bildung.

Maleck-Lewy, Eva / Penrose, Virginia (Hg.) (1995): Gefährtinnen der Macht. Politische Partizipation von Frauen im vereinigten Deutschland - eine Zwischenbilanz. Berlin: edition sigma.

Mamozai, Martha (1982): Herrenmenschen. Frauen im deutschen Kolonialismus. Reinbeck bei Hamburg: Rowohlt.

Mamozai, Martha (1996): Schwarze Frau. Weiße Herrin. Frauenleben in den deutschen Kolonien. Reinbeck bei Hamburg: Rowohlt.

Marquardt, Regine (1999): Das Ja zur Politik. Frauen im Deutschen Bundestag (1949-1961): ausgewählte Biographien. Opladen: Leske+Budrich. 
Marschall, Stefan / Strünck, Christoph (2010): Von der Reformpartei zur Partei der Reformen? Die SPD auf der Suche nach ihrer Zukunft. In: Gehne, David / Spier, Tim (Hg.), Krise oder Wandel der Parteiendemokratie? Festschrift für Ulrich von Alemann. (S.132-149). Wiesbaden: VS Verlag für Sozialwissenschaften.

Martens, Will / Ortmann, Günther (2006): Organisationen in Luhmanns Systemtheorie. In: Kieser, Alfred / Ebers, Mark (Hg.), a.a.O., S.427- 461.

Martiny, Anke (1980): Als Frau in der SPD. In: Schwarzer, Alice (Hg.), a.a.O. (S.36). Köln: Emma Frauenverlag.

Martiny, Anke (1984): Schwestern, zur Sonne, zur Freiheit! In: Die Neue Gesellschaft. 31 (2), S.162-167.

Martiny, Anke (1986): Wer nicht kämpft, hat schon verloren. Frauen und der Mut zur Macht. Reinbek b. Hamburg: Rowohlt.

Martiny, Anke (1991): Kühle Gefühle zur Lage der Nation. Reinbek bei Hamburg: Rowohlt.

Maruani, Margaret (2010): Transformationen der Geschlechterbeziehung - Neue Unsicherheiten. In: Soeffner, Hans-Georg (Hg.), Unsichere Zeiten. Herausforderungen gesellschaftlicher Transformationen. Verhandlungen des 34. Kongresses der Deutschen Gesellschaft für Soziologie in Jena 2008 (S.625-638). Wiesbaden: VS Verlag für Sozialwissenschaften.

Marx Ferree, Myra / McClurg Mueller, Carol (2008): Feminism and the Women's Movement: A Global Perspective. In: Snow, David A. / Soule, Sarah A. / Kriesi, Hanspeter (Ed.), The Blackwell Companion to Social Movements. (S.5766o8). Malden u.a.: Blackwell.

Matthiesen, Klaus (1980): Die Sozialdemokratie - Heimstatt für die "Grünen"? In: Die Neue Gesellschaft. 27 (3), S.276-281.

Mayring, Philipp (2003): Qualitative Inhaltsanalyse : Grundlagen und Techniken. 8. Aufl.,. Weinheim/Basel: Beltz.

Meier, Christoph / Nazarkiewicz, Kirsten (1997): 'Organisationskultur' als Alltagspraxis - eine ethnomethodologische Forschungsperspektive. In: Bentner, Ariane / Beck, Christian (Hg.), Organisationskultur erforschen und verändern. Ein Methodenrepertoire zur qualitativen Analyse und praktischen Beratung. (S.65-90). Frankfurt a. M./New York: Campus.

Meifort, Barbara (1979): Ausbildungsplätze nach Geschlecht. Über die Diskriminierung von Mädchen in der Berufsausbildung. In: Janssen-Jurreit, Marielouise (Hg.), Frauenprogramm - Gegen Diskriminierung. Gesetzgebung - Aktionspläne - Selbsthilfe. Ein Handbuch. (S.56-68). Hamburg: Rowohlt.

Meinerts, Eva (1972): Keine falsche Bescheidenheit. Neue Formen der Frauenarbeit. In: Bundesvorstand der Jungsozialisten (Hg.), JUSO. Zeitschrift der Jungsozialisten in der SPD. o.J. (S.6-7). Bonn: Bundesvorstand.

Meng, Richard (1985): Die sozialdemokratische Wende. Aussenbild und innerer Prozeß der SPD 1981-1984. Gießen: Focus. 
Menge, Marlies (1973): Die Chance, eine Frau zu sein In: Die Zeit. Nr.16 (1o. März), S.59.

Menke, Bettine (1995): Dekonstruktion der Geschlechteropposition - das Denken der Geschlechterdifferenz. Derrida. In: Haas, Erika (Hg.), "Verwirrung der Geschlechter." Dekonstruktion und Feminismus. (S.35-71). München. Wien: Profil.

Metz-Göckel, Sigrid (1989): Die Spaltung überwinden. Ist die gesellschaftliche Gleichheit von Mann und Frau eine angemessene Antwort auf die Emanzipationsforderungen der Frauen? In: Juso-Hochschulgruppen (Hg.), Arbeitshefte zur sozialistischen Theorie und Praxis. Bundesweite Zeitschrift der JusoHochschulgruppen. H 81 Bonn: SP-Verlag Norbert Schüren.

Metz-Göckel, Sigrid (1992): Frauen-Macht-Koedukation oder: Was haben 'die Quote' und die Koedukation gemeinsam? In: Frauenreferat beim SPD-Parteivorstand (Hg.), a.a.O., S.6o-64.

Metzler, Gabriele (2001): 'Wir schaffen das moderne Deutschland'. Sozialer Wandel in den sechziger-Jahren zwischen Gesellschaftspolitik und Emanzipation. In: Recker, Marie-Luise / Jellonnek, Burkhard / Rauls, Bernd (Hg.), Bilanz: 50 Jahre Bundesrepublik Deutschland. (S.279-294). St. Ingbert: Röhrig Universitätsverlag.

Meuser, Michael (2006): Geschlecht und Männlichkeit: soziologische Theorie und kulturelle Deutungsmuster. 2. überarb. und aktual. Aufl. Wiesbaden: VS Verlag für Sozialwissenschaften.

Meuser, Michael / Nagel, Ulrike (1991): ExpertInneninterviews - vielfach erprobt, wenig bedacht. In: Garz, Detlef / Kraimer, Klaus (Hg.), Qualitativ-empirische Sozialforschung. (S.441-471). Opladen: Westdeutscher Verlag.

Meuser, Michael / Nagel, Ulrike (2004): ExpertInneninterview: Zur Rekonstruktion spezialisierten Sonderwissens. In: Becker, Ruth / Kortendiek, Beate (Hg.), a.a.O., S.326-329.

Meuser, Michael / Nagel, Ulrike (2005a): Vom Nutzen der Expertise. ExpertInneninterviews in der Sozialberichterstattung. In: Bogner, Alexander / Littig, Beate / Menz, Wolfgang (Hg.), a.a.O., S.257-270.

Meuser, Michael / Nagel, Ulrike (2005b): ExpertInneninterviews - vielfach erprobt, wenig bedacht. Ein Beitrag zur qualitativen Methodendiskussion. In: Bogner, Alexander / Littig, Beate / Menz, Wolfgang (Hg.), a.a.O., S.71-93.

Meyer, Birgit (1988): Frauenpolitik und Frauenmacht. Über die Notwendigkeit der Veränderung unserer politischen Kultur In: Die Neue Gesellschaft. 25 (2), S.163-167.

Meyer, Birgit (1991): Frauenbewegung und politische Kultur in den 8oer-Jahren. In: Süß, Werner (Hg.), Die Bundesrepublik in den achtziger-Jahren. Innenpolitik, politische Kultur, Außenpolitik. (S.219-234). Opladen: Leske+Budrich.

Meyer, Birgit (1991): Von der Balance des Erträglichen. Frauenbewegung und politische Kultur in den achtziger-Jahren. In: Koch-Klenske, Eva, Die Töchter der 
Emanzen. Kommunikationsstrukturen in der Frauenbewegung. (S.34-52). München: Verlag Frauenoffensive.

Meyer, Birgit (1992): Die "unpolitische" Frau. Politische Partizipation von Frauen oder: Haben Frauen ein anderes Verständnis von Politik? In: Aus Politik und Zeitgeschichte, Beilage zur Wochenzeitung "Das Parlament". Ausg. (25/26), S.3-17.

Meyer, Margret (1975): SPD-Frauenkonferenz. Ein Kongreß für den Papierkorb. Die Frauen haben immer noch kein Programm für ihre Arbeit in der Partei In: Vorwärts. 100 (29. Mai).

Meyer, Thomas (1998): Die Transformation der Sozialdemokratie: eine Partei auf dem Weg ins 21. Jahrhundert. Bonn: J.H.W. Dietz Nachf.

Meyer, Thomas (2002): Wann Ungleichheit gerecht sein kann In: Berliner Republik 3 (4), Im Internet unter: http://www.b-republik.de/archiv/wann-ungleichheit-gerecht-sein-kann, [ Zugriff: 12.10.2008].

Meyer-Schoppa, Heike (2004): Zwischen "Nebenwiderspruch" und "revolutionärem Entwurf" : emanzipatorische Potenziale sozialdemokratischer Frauenpolitik 1945 - 1949. Herbolzheim: Centaurus.

Michal, Wolfgang (1988): Die SPD - staatstreu und jugendfrei : wie altmodisch ist die Sozialdemokratie? Reinbek bei Hamburg: Rowohlt.

Michels, Robert / Pfetsch, Frank R. (1989): Zur Soziologie des Parteiwesens in der modernen Demokratie : Untersuchungen über die oligarchischen Tendenzen des Gruppenlebens. 4. Aufl. Stuttgart: Kröner.

Miebach, Bernhard (2012): Organisationstheoretische Modelle. In: ders., Organisationstheorie: Problemstellung - Modelle - Entwicklung. 2. überarb. u. erweit. Aufl. (S.17-194). Wiesbaden: VS Verlag für Sozialwissenschaften.

Mies, Maria (1983): Subsistenzproduktion, Hausfrauisierung, Kolonialisierung. In: beiträge zur feministischen theorie und praxis. 6 (9-10), S.115-124.

Miller, Susanne (1978): Frauenfrage und Sexismus in der deutschen Sozialdemokratie. In: Horn, Hannelore / Schwan, Alexander / Weingartner, Thomas (Hg.), Sozialismus in Theorie und Praxis. Festschrift für Richard Löwenthal. (S.542-571). Berlin/New York: Walter de Gruyter.

Miller, Susanne (1980): Frauenfrage und sozialdemokratische Arbeiterbewegung In: Die Neue Gesellschaft. 27 (2), S.104-107.

Miller, Susanne / Potthoff, Heinrich (2002): Kleine Geschichte der SPD: 1848 2002. 8. aktual. und erweit. Aufl. Bonn: J.H.W. Dietz Nachf.

Millett, Kate (1985): Sexus und Herrschaft. Die Tyrannei des Mannes in unserer Gesellschaft. Reinbek bei Hamburg: Rowohlt.

Mintzel, Alf (1984): Die Volkspartei: Typus und Wirklichkeit; ein Lehrbuch. Opladen: Westdeutscher Verlag.

Mitscherlich, Alexander / Kalow, Gert (1972): Über Treue und Familie : zwei Gespräche. München: Piper. 
Momper, Walter (1989): Bündnispartner für die linke Mitte. In: Gerster, Florian / Stobbe, Dietrich (Hg.), Die linke Mitte heute. (S.27-34). Bonn: J.H.W. Dietz Nachf.

Müller, Ursula (1993): Sexualität, Organisation und Kontrolle. In: Aulenbacher, Brigitte / Goldmann, Monika (Hg.), Transformationen im Geschlechterverhältnis. (S.97-114). Frankfurt a. M./New York: Campus.

Müller, Ursula (1998): Asymmetrische Geschlechterkultur in Organisationen und Frauenförderung als Prozess - mit Beispielen aus Betrieben und der Universität. In: Zeitschrift für Personalforschung. 12 (2), S.123-142.

Müller, Ursula (1999): Zwischen Licht und Grauzone: Frauen in Führungspositionen In: Arbeit. 8 (2), S.137-161.

Müller-Jentsch, Walther (2002): Organisationales Handeln zwischen institutioneller Normierung und strategischem Kalkül. Kommentar zu Peter Walgenbachs 'Neoinstitutionalistische Organisationstheorie - State of the Art und Entwicklungslinien'. In: Schreyögg, P. Conrad (Hg.), Theorien des Managements. Managementforschung 12 (S.203-209). Wiesbaden: Springer Gabler.

Müller-Jentsch, Walther / Ittermann, Peter (200o): Industrielle Beziehungen. Daten, Zeitreihen, Trends 1950-1999. Frankfurt a. M./New York: Campus.

Murphy, Raymond (2004): Die Struktur sozialer Schließung: Zur Kritik und Weiterentwicklung der Theorien von Weber, Collins und Parkin. In: Mackert, Jürgen (Hg.), Die Theorie sozialer Schließung. Tradition, Analysen, Perspektiven. (S.87-109). Wiesbaden: VS Verlag für Sozialwissenschaften.

Müttermanifest (1987): Müttermanifest. Leben mit Kindern - Mütter werden laut (o.V.). In: Lenz, Ilse (2008), a.a.O., S.623-629.

Nachtwey, Oliver (2009): Marktsozialdemokratie: die Transformation von SPD und Labour Party. Göttinger Studien zur Parteienforschung. Wiesbaden: VS Verlag für Sozialwissenschaften.

Naßmacher, Karl-Heinz (1989): Parteien im Abstieg: Wiederbegründung und Niedergang der Bauern- und Bürgerparteien in Niedersachsen. Opladen: Westdeutscher Verlag.

Naßmacher, Karl-Heinz / Naßmacher, Hiltrud (1995): Parteienfinanzierung: ein Gesetz entsteht In: Einblicke. Forschungsmagazin der Carl von Ossietzky Universität Oldenburg. 1 (22/ Oktober), im Internet unter: http://www.presse.uni-oldenburg.de/25091.html, [Zugriff: 20.03. 2009].

Nave-Herz, Rosemarie (1997): Die Geschichte der Frauenbewegung in Deutschland. 5. überarb. u. erg. Ausg. Bonn: Bundeszentrale für politische Bildung

Neidhardt, Friedhelm (1985): Einige Ideen zu einer allgemeinen Theorie sozialer Bewegungen. In: Hradil, Stefan (Hg.), Sozialstruktur im Umbruch: Karl Martin Bolte zum 6o. Geburtstag. (S.193-204). Leverkusen/ Opladen: Leske und Budrich.

Neidhardt, Friedhelm / Rucht, Dieter (1993): Auf dem Weg in die "Bewegungsgesellschaft"? Über die Stabilisierbarkeit sozialer Bewegungen In: Soziale Welt. 44 (3), S.305-326. 
Neidhardt, Friedhelm / Rucht, Dieter (1999): Protestgeschichte der Bundesrepublik Deutschland 1950-1994. Ereignisse, Themen, Akteure. In: Kaase, Max / Schmid, Günther (Hg.), WZB-Jahrbuch 1999: Eine lernende Demokratie. (S.129-164). Berlin: Sigma.

Nentwich, Julia C. (2004): Die Gleichzeitigkeit von Differenz und Gleichheit: neue Wege für die Gleichstellungsarbeit. Facetten. Königstein/Taunus: Helmer.

Nentwich, Julia C. (2006): Gleichheit, Differenz, Diversity oder Dekonstruktion? Verschiedene Geschlechter-Theorien und ihre Konsequenzen für die Gleichstellungsarbeit In: Rote Revue. 84 (1), S.2-6.

Neuberger, Oswald (1997): Individualisierung und Organisierung. Die wechselseitige Erzeugung von Individuum und Organisation durch Verfahren. In: Ortmann, Günther / Sydow, Jörg / Türk, Klaus (Hg.), Theorien der Organisation. Die Rückkehr der Gesellschaft. (S.487-522). Opladen: Springer Fachmedien Wiesbaden.

Neumann, Ulrike / Stähr, Sybylle (1977): Berlin: Bericht des Arbeitskreises Emanzipation der Jungsozialisten. In: (Hg.), Bundesvorstand der Jungsozialisten, a.a.O., S.76- 79 .

Nickel, Hildegard Maria (2008): Transformation von Arbeit - Persistenz von betrieblichen Geschlechterverhältnissen? In: Zeitschrift für Frauenforschung \& Geschlechterstudien. 26 (3+4), S.72-87.

Niclauß, Karlheinz (2002): Das Parteiensystem der Bundesrepublik Deutschland: eine Einführung. 2. überarb. u. aktual. Aufl. Paderborn: Kap. 3

Niebuhr, Frank (2009): Mitgliederwerbung als Herausforderung und Chance - erfolgreiche Maßnahmen der CDU. In: Jun, Uwe / Niedermayer, Oskar / Wiesendahl, Elmar (Hg.), Zukunft der Mitgliederpartei. (S.251-256). Opladen\& Farmington Hills: Barbara Budrich.

Niedermayer, Oskar (1993): Innerparteiliche Demokratie. In: ders. /Stöss, Richard (Hg.), Stand und Perspektiven der Parteienforschung in Deutschland. (S.230250). Wiesbaden: Westdeutscher Verlag.

Niedermayer, Oskar / Stöss, Richard / Haas, Melanie (2006): Die Parteiensysteme Westeuropas. Wiesbaden: VS Verlag für Sozialwissenschaften.

Niethammer, Lutz (1980): Einführung. In: ders. / Trapp, Werner (Hg.), Lebenserfahrung und kollektives Gedächtnis. Die Praxis der "Oral History". Frankfurt a. Main: Syndikat.

Niggemann, Heinz / Baader, Ottilie (1981): Frauenemanzipation und Sozialdemokratie. Frankfurt a. Main: S. Fischer.

Nohl, Arnd-Michael (2006): Interview und dokumentarische Methode: Anleitungen für die Forschungspraxis. Wiesbaden: VS Verlag für Sozialwissenschaften.

Nohr, Barbara (2002): Diversity, Total-E-Quality und Gedöhns. In: dies. / Silke, Veth (Hg.), Gender Mainstreaming - kritische Reflexion einer neuen Strategie. (S.48-55). Berlin: COURAGE.

Nolan, Molly (1977): Proletarischer Anti-Feminismus. Dargestellt am Beispiel der SPD-Ortsgruppe Düsseldorf, 1890-1914. In: Gruppe Berliner Dozentinnen, 
Frauen und Wissenschaft (Hg.), Beiträge zur Berliner Sommeruniversität für Frauen. Juli 1976. (S.356-377). Berlin: COURAGE.

Notz, Gisela (2003): Frauen in der Mannschaft: Sozialdemokratinnen im Parlamentarischen Rat und im Deutschen Bundestag 1948/49 bis 1957; mit 26 Biographien. Bonn: J.H.W. Dietz Nachf.

Notz, Gisela (2004): Die autonomen Frauenbewegungen der Siebzigerjahre. In: Friedrich-Ebert-Stiftung in Verbindung mit dem Institut für Sozialgeschichte e.V. Braunschweig-Bonn (Hg.), Archiv für Sozialgeschichte Bd. 44. (S.123-148). Bonn: Verlag für Literatur und Zeitgeschehen.

Notz, Gisela (2006): Warum flog die Tomate?: Die autonomen Frauenbewegungen der Siebzigerjahre ; Entstehungsgeschichte - Organisationsformen - politische Konzepte. Materialien der AG SPAK. Neu-Ulm: AG SPAK.

Notz, Gisela (2007a): Als die Frauenbewegung noch Courage hatte: die "Berliner Frauenzeitung Courage" und die autonomen Frauenbewegungen der 1097oer und 1980er-Jahre. Dokumentation einer Veranstaltung am 17. Juni 2006 in der Friedrich-Ebert-Stiftung, Berlin, im Internet unter: http://libra-ry.fes.de/courage/courage-einl.html, [Zugriff: 02.04.2010].

Notz, Gisela (2007b): Mehr als bunte Tupfen im Bonner Männerclub. Sozialdemokratinnen im Deutschen Bundestag 1957 - 1969. Bonn: J.H.W. Dietz Nachf.

Notz, Gisela (2011): Feminismus. Köln: Papyrossa.

Notz, Gisela / Wickert, Christl (2008): SPD- Frauen im Reichstag (1919-1933) und im Bundestag (1949-1972). In: Ferner, Elke (Hg.), 9o Jahre Frauenwahlrecht. Eine Dokumentation. (S.41-69). Berlin: Vorwärts Verlag.

Nullmeier, Frank / Saretzki, Thomas (Hg.) (2002): Jenseits des Regierungsalltags.Strategiefähigkeit politischer Parteien. Frankfurt a. M. / New York: Campus.

Oertzen, Peter von / Ehmke, Horst / Ehrenberg, Herbert (Hg.) (1976): Orientierungsrahmen ' 85 . Text und Diskussion. Theorie und Praxis der deutschen Sozialdemokratie. Bonn-Bad Godesberg: Verlag Neue Gesellschaft.

Oertzen, Peter von / Möbbeck, Susi (1991): Vorwärts, rückwärts, seitwärts ... : das Lesebuch zur SPD-Organisationsreform. Köln: SPW-Verlag.

Oppen, Maria / Simon, Dagmar (2004): Verharrender Wandel : Institutionen und Geschlechterverhältnisse. Berlin: Edition Sigma.

Orth, Barbara (2003): Soziologische Forschung: Stand und Perspektiven; ein Handbuch. Opladen: Leske+Budrich.

Ortmann, Günther / Sydow, Jörg / Türk, Klaus (1997): Organisation, Strukturation, Gesellschaft. In: dies (Hg.), Theorien der Organisation. Die Rückkehr der Gesellschaft. (S.15-34). Opladen: Westdeutscher Verlag.

Ortmann, Günther / Sydow, Jörg / Windeler, Arnold (1997): Organisation als reflexive Strukturation. In: dies (Hg.), a.a.O. (S.315-354). Opladen: Westdeutscher Verlag.

Osterloh, Margit / Grand, Simon (1997): Die Theorie der Strukturation als Metatheorie der Organisation? In: Ortmann, Günther / Sydow, Jörg / Türk, Klaus 
(Hg.), Theorien der Organisation. Die Rückkehr der Gesellschaft. (S.355-359). Opladen: Westdeutscher Verlag.

Osterroth, Franz /Schuster, Dieter (1978): Chronik der deutschen Sozialdemokratie. Band III: Nach dem Zweiten Weltkrieg. Berlin/Bonn: J.H.W. Dietz Nachf.

Osterroth, Franz /Schuster, Dieter (2005): Chronik der deutschen Sozialdemokratie. Daten - Fakten - Hintergründe. Bd. 2- 5. Bonn: J.H.W. Dietz Nachf.

Papcke, Sven (1987): Erneuerung der SPD? Zur Diskussion des Irseer Programmentwurfs In: Gewerkschaftliche Monatshefte. 38 (6), S.372-383.

Parkin, Frank (2004): Strategien sozialer Schließung und Klassenbildung. In: Mackert, Jürgen (Hg.), Die Theorie sozialer Schließung. Tradition, Analysen, Perspektiven. (S.27-43). Wiesbaden: VS Verlag für Sozialwissenschaften.

Parteiengesetz (2004): Gesetz über die politischen Parteien. In der Fassung der Bekanntmachung vom 31. Januar 1994 (BGBl. I S. 149), zuletzt geändert durch Art. 2 des Gesetzes vom 22. Dezember 2004 (BGBl. I S. 3673). Bundesrepublik Deutschland, Bundeswahlleiter (Hg.). In: www.bundes-wahlleiter.de/bundestagswahl2005/angezeigts/parteieng.pdf, [Zugriff: 20.07. 2007].

Parteivorstand der SPD (1979): Orientierungsrahmen '85. 3.2. Die Vertrauensarbeit der Partei In: Die neue Gesellschaft. 26. (8), S.695-697.

Pasero, Ursula / Priddat, Birger P. (2004): Organisationen und Netzwerke: der Fall Gender. Wiesbaden: VS Verlag für Sozialwissenschaften.

Pateman, Carol (1988): The Sexual Contract. (S.19-38) Stanford: Stanford University Press.

Pausch, Wolfgang (1985): Die Entwicklung der sozialdemokratischen Frauenorganisationen: Anspruch und Wirklichkeit innerparteilicher Gleichberechtigungsstrategien in der Sozialdemokratischen Partei Deutschlands, aufgezeigt am Beispiel der Arbeitsgemeinschaft sozialdemokratischer Frauen. Frankfurt a. Main: Dissertation an der Wolfgang-Goethe-Universität.

Pausch-Gruber, Ursula (1978): Es mangelt an Solidarität. Entwicklung und Ziele der Arbeitsgemeinschaft sozialdemokratischer Frauen. In: Brandt, Willy (Hg.), Frauen heute. (S.73-87). Reinbek bei Hamburg: Rowohlt.

Pausch-Gruber, Ursula (1986): Die Quotendiskussion in der Arbeitsgemeinschaft sozialdemokratischer Frauen. In: Jansen, Mechthild (Hg.), Halbe-Halbe. Der Streit um die Quotierung. (S.84-91). Berlin: Elefanten Press.

Pêcheux, Michel (1983): Über die Rolle des Gedächtnisses als interdiskursives Material. Ein Forschungsprojekt im Rahmen der Diskursanalyse und Archivlektüre. In: Geier, Manfred / Woetzel, Harold (Hg.), Das Subjekt des Diskurses. Beiträge zur sprachlichen Bildung von Subjektivität und Intersubjektiviät. Sonderband AS 98 (S.50-58). Berlin: Argument.

Penrose, Virginia (1996): Zwischen Machtkritik und Machtgewinn : feministische Konzepte und politische Realität. Frankfurt a. M./New York: Campus 
Peters, B. Guy (1993): Alternative Modelle des Policy-Prozesses: Die Sicht "von unten" und die Sicht "von oben". In: Deutsche Vereinigung für Politische Wissenschaft (Hg.), Politische Vierteljahresschrift. 24 (S.289-303). Wiesbaden: VS Verlag für Sozialwissenschaften.

Pfadenhauer, Michaela (2005): Das Experteninterview - ein Gespräch zwischen Experte und Quasi-Experte. In: Bogner, Alexander / Littig, Beate / Menz, Wolfgang (Hg.), a.a.O., S.113- 130.

Pinl, Claudia (1979): Ursachen der ungleichen Bezahlung von Männern und Frauen und bisherige Strategien zu ihrer Überwindung. In: Janssen-Jurreit, Marielouise (Hg.), a.a.O., S.85-95.

Pinl, Claudia (1990): Die armen Männer - Abwehrkämpfe gegen "Quotistinnen" In: Das Argument. 32 (3), S.355-363.

Pinl, Claudia / Weg, Marianne (1989): Autonomie oder Institution? - Institutionelle Folgen der Frauenbewegung In: Forschungsjournal Neue Soziale Bewegungen. 2 (3/4), S.35-46.

Plato, Alexander von (2000): Zeitzeugen und die historische Zunft. Erinnerungen, kommunikative Tradierung und kollektives Gedächtnis in der qualitativen Geschichtswissenschaft - ein Problemaufriss In: BIOS - Zeitschrift für Biographieforschung, Oral History und Lebensverlaufsanalysen. 13 (1), S.5-29.

Plessner, Monika (1961): Zur Ideologie der Hausfrau In: Die Neue Gesellschaft. 8 (4), S.295-301.

Plessner, Monika (1965): Bildungswesen und Mädchenbildung In: Die Neue Gesellschaft. 12 (2), S.649-655.

Poguntke, Thomas (1994): Basisdemokratie and Political Realities: The German Green Party. In: Lawson, Kay (Hg.), How Political Parties Work: Perspectives from Within. (S.3-22). Westport/Conneticut/London: Praeger Publishers.

Poguntke, Thomas (2000): Parteiorganisation im Wandel: gesellschaftliche Verankerung und organisatorische Anpassung im europäischen Vergleich. Wiesbaden: Westdeutscher Verlag.

Poguntke, Thomas (2001): Parteiorganisationen in der Bundesrepublik Deutschland: Einheit in der Vielfalt? In: Gabriel, Oscar W. / Niedermayer, Oskar / Stöss, Richard (Hg.), a.a.O., S.253-273.

Poguntke, Thomas (2003): International vergleichende Parteienforschung. In: Berg-Schlosser, Dirk / Müller-Rommel, Ferdinand (Hg.), Vergleichende Politikwissenschaft. (S.189-206). Opladen: Leske+Budrich.

Poguntke, Thomas (2005a): Parteien ohne (An)bindung. Verkümmern die organisatorischen Wurzeln der Parteien? In: Schmid, Josef / Zolleis, Udo (Hg.), Zwischen Anarchie und Strategie. Der Erfolg von Parteiorganisationen. (S.4362). Wiesbaden: VS Verlag für Sozialwissenschaften.

Poguntke, Thomas (2005b): Politische Parteien. In: Gabriel, Oskar W. / Holtmann, Everhard (Hg.), Handbuch Politisches System der Bundesrepublik Deutschland. 3. völlig überarb. u. erweit. Aufl. (S.623 - 651). München/Wien: R. Oldenburg Verlag. 
Pomata, Gianna (1983): Die Geschichte der Frauen zwischen Anthropologie und Biologie In: Feministische Studien. 2 (2), S.113-127.

Posche, Ulrike (2004): Weibliche Übernahme: wie Frauen in Deutschland sich die Macht nehmen. Frankfurt a. M./New York: Campus.

Preisendörfer, Peter (2011): Organisationssoziologie. Wiesbaden: VS Verlag für Sozialwissenschaften. Kap.9: "Organisationen und Gesellschaft I: Effekte von Organisationen auf der individuellen und der kollektiven Ebene", S.154-168

Pross, Helge (1972): Zeugnis guten Willens - der neue Frauenbericht der Bundesregierung In: Gewerkschaftliche Monatshefte. 23 (11), S.708-715.

Przyborski, Aglaja / Wohlrab-Sahr, Monika (2008): Qualitative Sozialforschung: ein Arbeitsbuch. München: Oldenbourg.

Pühl, Katharina (2004): Neoliberale Paradoxien? Geschlechtsspezifische Veränderungen durch sozialpolitische Regulierungen als Herausforderung feministischer Theorie In: Zeitschrift für Frauenforschung \& Geschlechterstudien. 22 (2+3), S.40-50.

Radbruch, Gustav (1992): Strafrechtsreform. Band 9. Heidelberg: C.F.Müller.

Randzio-Plath, Christa (1979): Ist die SPD frauenfeindlich? Eine Mehrheit - behandelt wie eine Minderheit In: Sozialdemokratischer Pressedienst. 34 (165/ 29.08.), S.4-5.

Randzio-Plath, Christa (1980): Laßt uns endlich mitregieren!: Wege von Frauen in die Politik. Freiburg im Breisgau u.a.: Herder.

Randzio-Plath, Christa (1987): Frauenmacht - Ausweg aus der Krise. Köln: Bund Verlag.

Randzio-Plath, Christa (1988a): Frauen stellen die Machtfrage. Zur Notwendigkeit internationaler Frauensolidarität In: Die Neue Gesellschaft. 35 (1), S.16-19.

Randzio-Plath, Christa (1988b): Frauen wollen eigene Wege gehen In: Vorwärts. 113 (2), S.19.

Raschke, Joachim (1974): Innerparteiliche Opposition: die Linke in der Berliner SPD. Hamburg: Hoffmann und Campe.

Raschke, Joachim (1987): Soziale Bewegungen. Ein historisch-systematischer Grundriß. Frankfurt a. M./New York: Campus, Kap. 3,4,5,16,17.

Raschke, Joachim (1993): Die Grünen: wie sie wurden, was sie sind. Köln: Büchergilde Gutenberg, S.416-434.

Raschke, Joachim (2003): Bewegung, Reform, Protest - Blockaden und Veränderungen. Vortrag zum Festakt 15 Jahre Forschungsjournal NSB In: Forschungsjournal Neue Soziale Bewegungen. 16 (2), S.14-23.

Raschke, Joachim / Tils, Ralf (2007): Politische Strategie. Eine Grundlegung. Wiesbaden: VS Verlag für Sozialwissenschaften.

Recher, Hildegard / Schwarzer, Alice / Strobl, Ingrid (1980): Wahlboykott? Haben Frauen noch die Wahl? Eine Streitschrift zu den Wahlen '8o! Emma. Sonderband 1 (2) Köln: Emma Frauenverlag. 
Reichart-Dreyer, Ingrid (1997): Warum Programme? Entstehung und Wirkungen von Parteiprogrammen. In: Schneider-Wilkes, Rainer Hg.), Demokratie in Gefahr? Zum Zustand der deutschen Republik. (S.172-192). Münster: Westfälisches Dampfboot.

Reichart-Dreyer, Ingrid (2007): Von der Basis an die Spitze: Frauenaufstieg in den Parteien der BRD. In: Dackweiler, Regina-Maria (Hg.), Willkommen im Club. (S.169-186). Münster: Westfälisches Dampfboot.

Reichel, Ilse / Haase-Schur, Ilse (1979): Sozialdemokratische Familienpolitik In: Die Neue Gesellschaft. 26 (1), S.184-186.

Reinhardt, Max (2011): Aufstieg und Krise der SPD. Flügel und Repräsentanten einer pluralistischen Volkspartei. Baden-Baden: Nomos.

Rendtorff, Barbara (1986): Frauenbüros dürfen niemals Selbstzweck sein. Anmerkungen zu institutionalisierter Frauenpolitik aus autonomer Sicht. In: Haibach, Marita / Immenkötter, Mechthild / Rühmkopf, Eva (Hg.), Frauen sind nicht zweite Klasse. Frauenpolitik für Gleichstellung. (S.175-180). Hamburg: VSA.

Renger, Annemarie (1981): Fasziniert von Politik: Beiträge zur Zeit. Mit einem Vorwort von Helmut Schmidt. Stuttgart: Seewald.

Renger, Annemarie (1988): Nach der Alibifrau die Quotenfrau? In: Sozialdemokratischer Pressedienst. 43 (115/21.06.), S.1-2.

Renger, Annemarie (1993): Ein politisches Leben. Erinnerungen. Stuttgart: Deutsche Verlags-Anstalt, S.234-248.

Richter, Regina (2006): Frauen in politischen Machtpositionen. Dissertation. Im Internet unter: http://ediss.sub.uni-hamburg.de/volltexte/2007/3175/pdf /Diss_FrauenMacht.pdf, [Zugriff: 20.02.2014].

Riedel-Martiny, Anke (1975): Genosse Hinderlich und die Frauen - Die Situation weiblicher Mitglieder in der SPD In: Die Neue Gesellschaft. 22 (9), S.731-739.

Riedmüller, Barbara (1988): Das Neue an der Frauenbewegung. Versuch einer Wirkungsanalyse der neuen Frauenbewegung. In: Gerhard, Ute / Schütze, Yvonne (Hg.), Frauensituation. Veränderungen in den letzten zwanzig Jahren. (S.1541). Frankfurt a. Main: Suhrkamp.

Riegraf, Birgit (1996): Geschlecht und Mikropolitik : das Beispiel betrieblicher Gleichstellung. Opladen: Leske+Budrich.

Riegraf, Birgit (1997): Gleichstellungsmaßnahmen in Unternehmen: Ein umkämpftes Terrain In: Zeitschrift für Frauenforschung. 15 (1/2), S.54-68.

Ries, Ulrike (1974): Für die Frauen Fehlanzeige? Noch keinen Schritt vorangekommen. In: Bundesvorstand der Jungsozialisten (Hg.), a.a.O., S.69-72.

Ries-Augustin, Ulrike (o.J. [1983]): Es begann illegal...Über die Entstehungsgeschichte der Bundesfrauenkommission der Jusos. In: Bundesvorstand der Jungsozialisten (Hg.), sozialistische tribüne. Zeitschrift für sozialistische Theorie. Nr. 3/4, S.155-16o.

Ristau, Malte (1994): Junge Frauen in der Volkspartei SPD. Schriftenreihe Jugendpolitik Band VII. hg. SPD-Parteivorstand. Bonn: o. Verlag. 
Ristau, Malte / Scholing, Michael / Wien, Johannes (Hg.) (1992): Tanker im Nebel: zur Organisation und Programmatik der SPD. Marburg: Schüren.

Ritter, Gerhard A. / Niehuss, Merith (1987): Wahlen in der Bundesrepublik Deutschland: Bundestags- und Landtagswahlen 1946 - 1987. Statistische Arbeitsbücher zur neueren deutschen Geschichte. München: C.H. Beck.

Rommelspacher, Birgit (2006): Interdependenzen - Geschlecht, Klasse und Ethnizität. Beitrag zum virtuellen Seminar "Interdependenzen - Geschlecht, Ethnizität und Klasse". Im Internet unter: http://www2.gender.hu-berlin.de/geschlecht-ethnizitaet-klasse/www.geschlecht-ethnizitaet-klasse.de/index5aeo.html?set_language $=$ de\&cccpage $=$ referat\&set_z_refe-rentinnen $=6$, [Zugriff: 01.03.2008].

Rosenbauer, Sieglinde K. / Sauer, Birgit (2004): Politikwissenschaft und Geschlecht. Konzepte - Verknüpfungen - Perspektiven. Wien: UTB.

Rosenthal, Gabriele (1995): Erlebte und erzählte Lebensgeschichte : Gestalt und Struktur biographischer Selbstbeschreibungen. Frankfurt a. M./New York: Campus.

Roth, Roland (1988): In und gegen Institutionen. In: Luthardt, Wolfgang / Claußen, Bernhard (Hg.), Politik und Repräsentation: Beiträge zur Theorie und zum Wandel politischer und sozialer Institutionen. (S.184 - 203). Marburg: SP.-Verlag Schüren.

Roth, Roland (1994): Demokratie von unten. Neue soziale Bewegungen auf dem Wege zur politischen Institution. Köln: Bund-Verlag.

Roth, Roland (1998): 'Patch-Work'. Kollektive Identitäten neuer sozialer Bewegungen. In: Hellmann, Kai-Uwe / Koopmans, Ruud (Hg.), a.a.O., S.51-68.

Roth, Roland / Rucht, Dieter (Hg.) (2008): Die sozialen Bewegungen in Deutschland seit 1945: ein Handbuch. Frankfurt a. Main/New York: Campus.

Roth, Reinhold / Wiesendahl, Elmar (1985): Strukturbesonderheiten politischer Parteien. Zur politischen Soziologie der Organisationswirklichkeit von Parteien. In: Kaack, Heino / Roth, Reinhold (Hg.), Forschungsgruppe Parteiendemokratie: Analyse und Berichte Nr. 13. Bremen: Hochschule Bremen, Fachbereich Wirtschaft.

Rubart, Frauke (1988): Partizipation von Frauen in neuen sozialen Bewegungen In: Aus Politik und Zeitgeschichte, Beilage zur Wochenzeitung Das Parlament. Ausg. (B 42), S.30-42.

Rucht, Dieter (1987): Von der Bewegung zur Institution? Organisationsstrukturen der Ökologiebewegung. In: der./ Roth, Roland(Hg.), Neue soziale Bewegungen in der Bundesrepublik Deutschland. (S.238-26o). Bonn: Bundeszentrale für politische Bildung.

Rucht, Dieter (1994): Modernisierung und neue soziale Bewegungen. Deutschland, Frankreich und USA im Vergleich. Frankfurt a. Main: Campus.

Rucht, Dieter (1995): Kollektive Identität. Konzeptionelle Überlegungen zu einem Desiderat der Bewegungsforschung In: Forschungsjournal Neue Soziale Bewegungen. 8 (1), S.9-22. 
Rucht, Dieter (1997): Soziale Bewegungen als demokratische Produktivkraft. In: Klein, Ansgar /Schmalz-Bruns, Rainer, Politische Beteiligung und Bürgerengagement in Deutschland - Möglichkeiten und Grenzen. (S.382-403). Bonn: Bundeszentrale für politische Bildung.

Rucht, Dieter (1998): Komplexe Phänomene - komplexe Erklärungen. Die politischen Gelegenheitsstrukturen der neuen sozialen Bewegungen in der Bundesrepublik. In: Hellmann, Kai-Uwe / Koopmans, Ruud (Hg.), a.a.O., S.109-127.

Rucht, Dieter / Blattert, Barbara / Rink, Dieter (1997): Soziale Bewegungen auf dem Weg zur Institutionalisierung: zum Strukturwandel "alternativer" Gruppen in beiden Teilen Deutschlands. Frankfurt a. M./New York: Campus, Kap.1.

Rucht, Dieter / Koopmans, Ruud (1996): Rechtsextremismus als soziale Bewegung. In: Deutsche Vereinigung für Politische Wissenschaft (Hg.), Politische Vierteljahresschrift. Sonderheft 27, S.265-287.

Rudolph, Clarissa (1994): Die Institutionalisierung von Frauenpolitik im Parteienstaat. In: Biester, Elke / Holland-Cunz, Barbara / Maleck-Lewy, Eva / Ruf, Anja / , Birgit (Hg.), Gleichstellungspolitik - Totem und Tabu. Eine feministische Revision. (S.62-81). Frankfurt a. Main: Campus.

Rudolph, Clarissa / Schirmer, Uta (2004): Gestalten oder verwalten?: Kommunale Frauenpolitik zwischen Verrechtlichung, Modernisierung und Frauenbewegung. Wiesbaden: VS Verlag für Sozialwissenschaften.

Rudzio, Wolfgang (1987): Das politische System der Bundesrepublik Deutschland: Eine Einführung. Wiesbaden: Springer VS, Kap.6 "Binnensoziologie der Parteien", S.146-164.

Ruhl, Klaus-Jörg (1992): Hierarchie oder Anarchie? Der Streit um die Familienrechtsreform in den fünfziger-Jahren In: Aus Politik und Zeitgeschichte, Beilage zur Wochenzeitung "Das Parlament". Ausg. (B 45), S.31-42.

Rühmkopf, Eva / Vogt, Ute (2002): "Wir sind die Besseren". Starke Frauen und Politik. Stuttgart/München: Deutsche Verlags-Anstalt.

Rule, Wilma (1994): Women's Underrepresentation and Electoral Systems In: American Political Science Association. 27 (4), S.689-692.

Ruppert, Uta (1998): Lokal bewegen - global verhandeln: internationale Politik und Geschlecht. Frankfurt a. M./New York: Campus.

Russell, Alys (1978): Sozialdemokratie und Frauenfrage in Deutschland. In: Russell, Bertrand (Hg.), Die deutsche Sozialdemokratie. (S.197-211). erschienen 1965, hrsg. und übers. von Achim v. Borries. Mit einem Anhang "Sozialdemokratie und Frauenfrage" von Alys Russel. Bonn-Bad Godesberg: J.H.W. Dietz Nachf.

Sauer, Birgit (1994a): Totem und Tabus. Zur Neubestimmung von Gleichstellungspolitik. Eine Einführung. In: Biester, Elke / Holland-Cunz, Barbara / MaleckLewy, Eva / Ruf, Anja / dies. (Hg.), Gleichstellungspolitik-Totem und Tabus. Eine feministische Revision. (S.7-35). Frankfurt a. M./New York: Campus. 
Sauer, Birgit (1994b): Was heißt und zu welchem Zwecke partizipieren wir? Kritische Anmerkungen zur Partizipationsforschung. In: Biester, Elke / HollandCunz, Barbara / dies. (Hg.), a.a.O., S.99-130.

Sauer, Birgit (1997): Gleichstellung und Institution. Paradoxien von Frauenpolitik in der Bundesrepublik Deutschland. In: Schneider-Wilkes, Rainer (Hg.), Demokratie in Gefahr? Zum Zustand der deutschen Republik. (S.268-293). Münster: Westfälisches Dampfboot.

Sauer, Birgit (1999): Demokratisierung mit oder gegen den Staat? Sieben Thesen zu einer feministischen Revision staatstheoretischer Ansätze. In: Abels, Gabriele / Sifft, Stefanie (Hg.), Demokratie als Projekt: Feministische Kritik an der Universalisierung einer Herrschaftsform. (S.79-103). Opladen: Campus.

Sauer, Birgit (2001a): Öffentlichkeit und Privatheit revisited. Grenzneuziehungen im Neoliberalismus und die Konsequenzen für die Geschlechterpolitik In: Kurswechsel: Zeitschrift für gesellschafts-, wirtschafts- und umweltpolitische Alternativen. 16 (4), S.5-11.

Sauer, Birgit (2001b): "Die Asche des Souveräns. Staat und Demokratie in der Geschlechterdebatte". Frankfurt a. M./New York: Campus, Kap.4 "Der Staat hat ein Geschlecht. Feministische Theoretisierungen des Staates".

Sauer, Birgit / Wöhl, Stefanie (2011): Demokratie und Geschlecht. In: FriedrichEbert-Stiftung Politische Akademie (Hg.), Demokratie in Deutschland 2011 ein Report der Friedrich-Ebert-Stiftung. (S.14-15). Berlin: o. Verlag.

Schaeffer-Hegel, Barbara (1990) (Hg.): Vater Staat und seine Frauen. Erster Band: Beiträge zur politischen Theorie. Pfaffenweiler: Centaurus.

Schaeffer-Hegel, Barbara / Kopp-Degethoff, Heidi (1990) (Hg.): Vater Staat und seine Frauen. Zweiter Band: Studien zur politischen Kultur. Pfaffenweiler: Centaurus.

Schäfer, Eva (1989): Zur frauenpolitischen Erneuerung der SPD. In: Akademie für Gesellschaftswissenschaften beim ZK der SED (Hg.), Sozialdemokratie heute. Beiträge zur Analyse de Programmdiskussion in der SPD. (S.82-93). Berlin: Selbstverlag.

Schäfer, Reinhild (2001): Demokratisierung der Geschlechterverhältnisse: die politischen Strategien der neuen Frauenbewegung gegen Gewalt. Bielefeld: Kleine.

Scharping, Rudolf / Wollner, Friedhelm (1973): Demokratischer Sozialismus und Langzeitprogramm : Diskussionsbeiträge zum Orientierungsrahmen ' 85 der SPD. Reinbek bei Hamburg: Rowohlt.

Schaser, Angelika (2009): Zur Einführung des Frauenwahlrechts vor 90 Jahren am 12. November 1918 In: Feministische Studien. Zeitschrift für interdisziplinäre Frauen- und Geschlechterforschung. 27 (1), S.97-110.

Scheer, Hermann (1979): Parteien contra Bürger? Die Zukunft der Parteiendemokratie. München/Zürich: Piper, Kap. 6.6 „Parteienorganisation und innerparteiliche Demokratie“. 
Schenk, Herrad (1990): Die feministische Herausforderung. 150 Jahre Frauenbewegung in Deutschland. 5. Aufl. München: C.H. Beck.

Scherer, Andreas Georg (2006): Kritik der Organisation oder Organisation der Kritik? - Wissenschaftstheoretische Bemerkungen zum kritischen Umgang mit Organisationstheorien. In: Kieser, Alfred / Ebers, Mark (Hg.), a.a.O., S.1961.

Schildt, Axel (2010): Innere Entwicklung der Bundesrepublik bis 1989. Bundeszentrale für politische Bildung (Hg.). Im Internet unter: http://www.bpb.de/ publikationen/o1120435875986503329341441939833, 7,o,Innere_Entwicklung_der_Bundesrepublik_bis_1989.html\#art7, [Zugriff: 23.10. 2010].

Schindler, Peter (1999): Datenhandbuch zur Geschichte des Deutschen Bundestages 1949 bis 1999. Band I. Baden-Baden: Nomos.

Schmarsow, Christine (1980): Leitbilder-Leidbilder. Die Perpetuierung des traditionellen Frauenleitbildes In: Die Neue Gesellschaft. 27 (2), S.115-118.

Schmarsow, Christine (1981): Gegen die Arbeiterquote. Ein Kurieren an Symptomen hebt die Ursachen der Unterrepräsentation nicht auf. In: Sozialdemokratischer Pressedienst. 36 (246/28.12.), S.5-7.

Schmarsow, Christine (1982): Unsere Wut, liebe Genossinnen, wird anhalten. Christine Schmarsow, stellvertretende Bundesvorsitzende der AsF, protestiert gegen die Bundeskandidatur von Ingrid Matthäus-Meier auf der SPD-Liste In: Frankfurter Rundschau. 37 (o1.12.).

Schmarsow, Christine / Wettig-Danielmeier, Inge (1982): Werkstattgespräch zur Arbeitszeitverkürzung. ASF diskutierte mit Gewerkschafterinnen und Wissenschaftlern In: Sozialdemokratischer Pressedienst. 37 (208 / 02.11.), S.6-7.

Schmarsow, Christine (1984): Der Kampf der Frauen für Frieden, Freiheit und Gerechtigkeit In: Sozialdemokratischer Pressedienst. 39 (46 / o6. 03.), S.1-3.

Schmarsow, Christine (1986): Die Gleichstellung von Frauen ist eine Demokratiefrage. Thesen zum "Frauennetzwerk der Zukunft" In: Sozialdemokratischer Pressedienst. 41 (63/ 03. 04.), S.1-3.

Schmid, Josef (1995): Expertenbefragung und Informationsgespräch in der Parteienforschung: Wie föderalistisch ist die CDU? In: Alemann, Ulrich von (Hg.), Politikwissenschaftliche Methoden. Grundriß für Studium und Forschung. (S.293-326). Opladen: Westdeutscher Verlag.

Schmid, Josef / Zolleis, Udo (2005): Zwischen Anarchie und Strategie: der Erfolg von Parteiorganisationen. Wiesbaden: VS Verlag für Sozialwissenschaften.

Schmidt, Manfred G. (2007): Das politische System Deutschlands : Institutionen, Willensbildung und Politikfelder. Bonn: Bundeszentrale für Politische Bildung, Kap. 1.2 "SPD", S.90-92.

Schmidt, Renate (1984): Frau macht Politik - Mann verhungert zu Hause. In: Huber, Antje (Hg.), a.a.O., S.154-171.

Schmidt, Renate (1993): Mut zur Menschlichkeit. München: Ed. Ferenczy bei Bruckmann. 
Schmuck, Michael G. (1980): SPD, Parteiensystem und Protestbewegungen In: Die neue Gesellschaft. 27 (3), S.285-294.

Schnelle, Eva Marie / Hopkins, Richard (2011): Die Beteiligungsrechte der Gleichstellungsbeauftragten nach dem Bundesgleichstellungsgesetz: zugleich Anmerkung zum Urteil des Bundesverwaltungsgerichts vom 8. April 2010, $6 \mathrm{C}$ 3/o9 In: Die öffentliche Verwaltung (DÖV). 64 (4), S.150-157.

Schöfthaler, Ele (1978): Mißtrauen und guter Wille: Parteifrauen und Feministinnen in Bonn In: Courage: Berliner Frauenzeitung. 3 (6), S.18-19.

Schöler-Macher, Bärbel (1992): Auf den Spuren einer möglichen Fremdheit von Frauen in der Politik. In: Wetterer, Angelika (Hg.), a.a.O., S.257-276.

Schöler-Macher, Bärbel (1994): Die Fremdheit der Politik. Erfahrungen von Frauen in Parteien und Parlamenten. Weinheim: Deutscher Studien Verlag.

Scholz, Anja (2004): Oberbürgermeisterinnen in Deutschland. Zum Erfolg weiblicher Führungspersönlichkeiten. Wiesbaden: Deutscher Universitätsverlag.

Schöne, Helmar (2010): Alltag im Parlament. Parlamentskultur in Theorie und Empirie. Baden-Baden: Nomos Verlagsgesellschaft.

Schreiber, Robert (1996): Frauenverbände und Frauenvereinigungen in der Bundesrepublik Deutschland. Institut für Frau und Gesellschaft gGmbH Hannover. Stuttgart/Berlin/Köln: Kohlhammer W.

Schröter, Susanne (2002): Über Grenzverläufe zwischen den Geschlechtern. Frankfurt a. Main: S. Fischer.

Schuettemeyer, Susanne S (1998): Fraktionen im deutschen Bundestag 1949-1997: Empirische Befunde und theoretische Folgerungen. Opladen/Wiesbaden: Westdeutscher Verlag, Kap. 1.7, 2.3, 2.6

Schulte-Zurhausen, Manfred (2010): Organisation. 5. überarb. u. aktual. Aufl. München: Vahlen.

Schultz, Dagmar (1992): Akkulturationsprozesse und die Entwicklung kultureller Zwischenwelten. In: Wetterer, Angelika (Hg.), a.a.O., S.225-244.

Schulz, Kristina (2002): Der lange Atem der Provokation: die Frauenbewegung in der Bundesrepublik und in Frankreich 1968 - 1976. Frankfurt a. M./New York: Campus.

Schulz-Schaeffer, Ingo (2009): Handlungszuschreibung und Situationsdefinition In: Kölner Zeitschrift für Soziologie und Sozialpsychologie. 61 (2), S.159-182.

Schumacher, Hans (1980): Grüne Herausforderung für die SPD. Das Grundsatzprogramm der Ökologen In: Die neue Gesellschaft. 27 (3), S.282-284.

Schunter-Kleemann, Susanne (2001): Gender Mainstreaming - Neoliberale Horizonte eines neuen Gleichstellungs-Konzepts In: Kurswechsel: Zeitschrift für gesellschafts-, wirtschafts- und umweltpolitische Alternativen. 16 (3), S.15-25.

Schunter-Kleemann, Susanne (2002): Gender Mainstreaming, Workfare und "Dritte Wege " des Neoliberalismus. In: Barbara Nohr / Silke, Veth (Hg.), Gender Mainstreaming - kritische Reflexion einer neuen Strategie. (S.125-140). Berlin: 
Schunter-Kleemann, Susanne (2006): Workshop: Perspektiven eines geschlechtergerechten Sozialstaates. In: Bundesarbeitsgemeinschaft kommunaler Frauenbüros und Gleichstellungsstellen (Hg.), Dokumentation. (S.59 - 68). Berlin: o. Verlag.

Schütze, Fritz (1983): Biographieforschung und narratives Interview In: Neue Praxis, Kritische Zeitschrift für Sozialarbeit und Sozialpädagogik. 13 (3), S.283293.

Schütze, Fritz (1987): Das narrative Interview in Interaktionsfeldstudien I. Hagen: o.V.

Schütze, Yvonne (1988): Mütterliche Erwerbstätigkeit und wissenschaftliche Forschung. In: Gerhard, Ute / Schütze, Yvonne (Hg.), Frauensituation. Veränderungen in den letzten zwanzig Jahren. (S.114-137). Frankfurt a. M./New York: Suhrkamp.

Schwarzer, Alice (1975): Der "kleine Unterschied" und seine großen Folgen. Frauen über sich. Beginn einer Befreiung. Frankfurt a. Main: S. Fischer.

Schwarzer, Alice (1981): 10 Jahre Frauenbewegung. So fing es an! . Köln: EmmaFrauenverlags $\mathrm{GmbH}$.

Scott, W. Richard (2006): Reflexionen über ein halbes Jahrhundert Organisationssoziologie. In: Senge, Konstanze / Hellmann, Kai-Uwe (Hg.), Einführung in den Neo-Institutionalismus. (S.201-222). Wiesbaden VS Verlag für Sozialwissenschaften.

Seifert, Ruth (1995): Entwicklungslinien und Probleme der feministischen Theoriebildung. Warum an der Rationalität kein Weg vorbeiführt. In: Knapp, Gudrun-Axeli / Wetterer, Angelika, a.a.O., S.255-285.

Seitz, Norbert (2010): Intellektuellenpartei a.D.. Die geistige Krise der SPD In: Blätter für deutsche und internationale Politik. 54 (8), S.95-104.

Sellach, Brigitte / Enders-Dragässer, Uta / Baer, Susanne / Kuhl, Mara / Kreß, Brigitta (2003): Wissensnetz Gender Mainstreaming für die Bundesverwaltung. Gesellschaft für Sozialwissenschaftliche Frauenforschung e.V. Frankfurt a. Main, Berlin. Im Internet unter: www.dr-mara-kuhl.de/fileadmin/user_upload/Wissensnetz.pdf, [Zugriff: 12. 02. 2015].

Shiva, Vandana (1989): Das Geschlecht des Lebens. Frauen, Ökologie und Dritte Welt. Berlin: Rotbuch.

Sichtermann, Barbara (1993): Weiblichkeit : zur Politik des Privaten. Berlin: Wagenbach.

Sichtermann, Barbara (2009): Kurze Geschichte der Frauenemanzipation. Berlin: Verl.-Haus Jacoby \& Stuart.

Simonis, Heide (\{2003\} 2004): Unter Männern. Mein Leben in der Politik. München: DTV.

Soiland, Tove (2009): ,Gender': Kontingente theoretische Grundlagen und ihre politischen Implikationen In: gender...politik...online (Dezember) Im Intenet 
unter: https:// http://www.fu-berlin.de/sites/gpo/pol_theorie/ Zeitgenoessische_ansaetze/Kontingente_theoretische_Grundlagen/soiland.pdf, [Zugriff: 20.03.2014].

Soiland, Tove (2011): Queer, flexibel, erfolgreich. Haben dekonstruktive Ansätze den Feminismus entwaffnet? In: Analyse \& Kritik 41 (558) Im Internet unter: https://www.akweb.de/ak_s/ak558/27.htm, [Zugriff: 20.03.2014].

Soiland, Tove (2013). Kontingenz als Ideologie unserer Zeit In: Feministische Studien (1), S. 170-176.

Sonntag, Cornelie (1989): Quotierung und Politik-Inhalt: Was verändern die Frauen? In: Gerster, Florian / Stobbe, Dietrich (Hg.), Die linke Mitte heute. (S.35-46). Bonn: J.H.W. Dietz Nachf.

Sozialdemokrat-Magazin (1985): Langsam aber sicher an die Spitze. Innerparteiliche Frauenförderung kommt

voran. In: Sozialdemokrat-Magazin. 10, S.8-9.

Spangler, Eve / Gordon, Marsha A. / Pipkin, Ronald M. (1978): Token Women: An Empirical Test of Kanter's Hypothesis In: The American Journal of Sociology. 84 (1), S.160-170.

SPIEGEL, o.V. (1969): So einfach: Aufklärung/Sexualkundeatlas In: DER SPIEGEL. 24 (40), S.107-108.

SPIEGEL, o.V. (1970): SPD-Frauen: Loch im Strumpf In: DER SPIEGEL. 24 (45), S.116-118.

SPIEGEL, o.V. (1972a): Hier stehe ich, der Wähler helfe mir In: DER SPIEGEL. 26 (47), S.25-38.

SPIEGEL, o.V. (1972b): Egal, was die machen. In DER SPIEGEL 35 (47), S.47-48

SPIEGEL, o.V. (1976): Reise nach Jerusalem In: DER SPIEGEL. 26 (26), S.38-41. Im Internet unter: http://www.spiegel.de/spiegel/print/d-41213225.html, [Zugriff: 22.02.2011].

SPIEGEL, o.V. (1981): Peitsche im Genick. In: DER SPIEGEL. 35 (52), S.81-82.

SPIEGEL, o.V. (1981b): „Das wird die Landschaft erleuchten. In: DER SPIEGEL. 39 (52), S.19-21.

SPIEGEL, o.V. (1985): Schwestern, zur Sonne. Aufbruch der "Enkelinnen": Die SPD soll Schluß machen mit der Unterrepräsentation der Frauen in Partei und Parlamenten In: DER SPIEGEL. 39 (32), S.21-22.

SPIEGEL, o.V. (1987): Leicht gesagt. Führende SPD-Politkerinnen sind ungeduldig. Sie drängen auf einen 40-Prozent-Anteil für Frauen an Ämtern und Mandaten. In: DER SPIEGEL. 41 (35), S.22-23.

SPIEGEL, o.V. (1988a): Über Bord In: DER SPIEGEL. 42 (36), S.22-23.

SPIEGEL, o.V. (1988b): Abtreibung - grob geklotzt. Im bayrischen Memmingen praktiziert die Justiz rigoros Gesinnungsstrafrecht. Nach einer Serie von Abtreibungsverfahren gegen 380 Frauen steht in dieser Woche ein Arzt vor Gericht. In: DER SPIEGEL. 42 (36), S.54-59. 
Standfest, Erich (1979): Alterssicherung der Frau - Reform der Hinterbliebenenversorgung. In: Deutsche Gesellschaft für Soziologie (DGS) (Hg.), Konferenzbeitrag: Soziologische Analysen: Referate aus den Veranstaltungen der Sektionen der Deutschen Gesellschaft für Soziologie und der ad-hoc-Gruppen beim 19. Deutschen Soziologentag (Berlin, 17.-20. April 1979), im Internet unter: http://nbn-resolving.de/urn:nbn:de:o168-ssoar-135530, [Zugriff: 10.01.2014].

Statistisches Bundesamt Wiesbaden (1972): Die Frau in Familie und Beruf: 1970. Stuttgart u.a.: Kohlhammer.

Stegmann, Heinz / Kraft, Hermine (1986): Chancen und Risiken von Mädchen mit einer betrieblichen Berufsausbildung für einen „Männerberuf". In: Mitteilungen aus der Arbeitsmarkt- und Berufsforschung. 19 (3), Sonderdruck. Im Internet unter: http://doku.iab.de/mittab/1986/1986_3_mittab_ stegmann_kraft.pdf, [Zugriff: 12.07.2013].

Steffen, Monika (1984): Was ist Feminismus? In: Die Neue Gesellschaft. 31 (12), S.1176-1183.

Steinert, Heinz (2004): Schließung und Ausschließung. Eine Typologie der Schließungen und ihre Folgen. In: Mackert, Jürgen (Hg.), a.a.O., S.193-212.

Steininger, Rudolf (1984): Soziologische Theorie der politischen Parteien. Campus Forschung. Frankfurt a. M./New York: Campus.

Stephan, Com (1987): Besser gleich einen Mann. In: Die Zeit 41 (03.04.). Im Internet unter: http://www.zeit.de/1987/15/besser-gleich-einen-mann, [Zugriff: 12.05.2013].

Stiegler, Barbara (2000): Wie Gender in den Mainstream kommt. Konzepte, Argumente und Praxisbeispiele zur EU-Strategie des Gender Mainstreaming. Bonn: Friedrich-Ebert-Stiftung, Abt. Arbeit und Sozialpolitik.

Stiegler, Barbara (2003): Gender Mainstreaming Postmoderner Schmusekurs oder geschlechterpolitische Chance? Argumente zur Diskussion. In: Wirtschaftsund sozialpolitisches Forschungs- und Beratungszentrum der FriedrichEbert-Stiftung, Abteilung Arbeit und Sozialpolitik (Hg.), Expertisen zur Frauenforschung. (S.1-23), im Internet unter: http://library.fes.de/pdf-files/asfo/o2255.pdf, [Zugriff: 23.20.2011].

Stoehr, Irene / Pawlowski, Rita (2001): Die unfertige Demokratie 50 Jahre "Informationen für die Frau". Deutscher Frauenrat, im Internet unter: http://www.frauenrat.de/fileadmin/user_upload/frauenrat/infomaterial/ 50_Jahre_Informationen_fuer_die_Frau_web.pdf, [Zugriff: 02.08.2010].

Stöss, Richard (1987): Parteien und soziale Bewegungen. Begriffliche Angrenzung - Volksparteien - Neue soziale Bewegungen - DIE GRÜNEN. In: Roth, Roland / Rucht, Dieter (Hg.), Neue soziale Bewegungen in der Bundesrepublik Deutschland. (S.277-302). Bonn: Bundeszentrale für politische Bildung.

Strasser, Johano (1974): Einige Anmerkungen zum Demokratiebegriff der Sozialdemokratie In: Die Neue Gesellschaft. 21 (4), S.547-551. 
taz (1986): Die Zukunft ist weiblich...und Bruder Joannes ist immer dabei. Großkampftag der ASF in Wiesbaden anläßlich des 75. Internationalen Frauentages / Bruder Johannes auf Tournee In: Die Tageszeitung. 7 (10.März). Berlin: taz Verlag.

Thiessen, Barbara (2004): Feminismus: Differenzen und Kontroversen. In: Becker, Ruth / Kortendiek, Beate (Hg.), a.a.O., S.35-41.

Thönnessen, Werner (1976): Frauenemanzipation. Politik und Literatur der deutschen Sozialdemokratie zur Frauenbewegung 1863-1933. 2.unver. Auflage. Frankfurt a. Main: Europäische Verlagsanstalt.

Thörmer, Heinz (1996): "Wenn Frauen aktiv sind, sind sie's meistens länger als Männer ". Elfriede Eilers-Lebensbilder. Bonn: Schüren.

Thörmer, Heinz / Einemann, Edgar (2007): Aufstieg und Krise der Generation Schröder. Einblicke aus vier Jahrzehnten. Marburg: Schüren.

Thürmer-Rohr, Christina (1997): Die unheilbare Pluralität der Welt - von Patriarchatskritik zur Totalitarismusforschung. Colloquium vom 05.06.1997, im Internet unter: http://web.fu-berlin.de/postmoderne-psych/berichte2/ thuermer_rohr.htm, [Zugriff: 06.03.2009].

Thürmer-Rohr, Christina (2001): Geschlechterdemokratie. In: (Hg.), HeinrichBöll-Stiftung (Hg.), Geschlechterdemokratie. Vielfalt der Visionen - Visionen der Vielfalt. (S.21-33). Berlin: o. Verlag.

Thürmer-Rohr, Christina (2004): Mittäterschaft von Frauen: Die Komplizenschaft mit der Unterdrückung. In: Becker, Ruth / Kortendiek, Beate (Hg.), a.a.O., S.85-90.

Trumann, Andrea (2004): Von feministischer Staatskritik zu Gender Mainstreaming In: alaska. 245 (10.August), im Internet unter: http://www.linksnet.de/artikel.php?id=1285, [Zugriff: 20.10.2012].

Türk, Klaus (1989): Neuere Entwicklungen in der Organisationsforschung: ein Trend Report. Stuttgart: Thieme.

Türk, Klaus (1997): Organisation als Institution der kapitalistischen Gesellschaftsformation. In: Ortmann, Günther / Sydow, Jörg / Türk, Klaus (Hg.), Theorien der Organisation. Die Rückkehr der Gesellschaft. (S.124-180). Opladen: Westdeutscher Verlag.

Ullrich, Otto (1979): Weltniveau: in der Sackgasse des Industriesystems. Rotbuch. Berlin: Rotbuch

van Deth, Jan W. (2003): Vergleichende politische Partizipationsforschung. In: Berg-Schlosser, Dirk / Müller-Rommel, Ferdinand (Hg.), Vergleichende Politikwissenschaft. (S.167-187). Stuttgart: UTB.

Vogelheim, Elisabeth (1979): Der Emanzipationsbegriff im Grundgesetz. Zur Entwicklung des Gleichberechtigungsgrundsatzes In: Die neue Gesellschaft. 26 (5), S.466-468.

Waclaw, Christine (2003): Die gesellschaftliche Ächtung von Gewalt und ihre Bedeutung für den Opferschutz. In: Berliner Forum Gewaltprävention (BFG) (Hg.), im Internet unter: http://www.berlin.de/imperia/md/ content/lb- 
lkbgg/bfg/nummer12/16_waclaw.pdf?start\&ts=1239199170\&file=16_waclaw.pdf, [Zugriff: 18.08.2010].

Walgenbach, Peter (2006): Die Strukturationstheorie. In: Kieser, Alfred / Ebers, Mark (Hg.), a.a.O., S.403-426.

Walter, Franz (2002): Die SPD: vom Proletariat zur Neuen Mitte. Berlin: Fest.

Walter, Franz (2007): Ergraut und erfolgreich In: die tageszeitung. 29 (24./25.März), S.11.

Walter, Franz (2008): Chance als Scheitern In: die tageszeitung. 10 (31.Mai/ 1.Juni), S.13.

Walter, Franz (2009): Im Herbst der Volksparteien?: eine kleine Geschichte von Aufstieg und Rückgang politischer Massenintegration. Bielefeld: Transcript.

Walter, Franz (2010a): Vorwärts oder abwärts? Zur Transformation der Sozialdemokratie. Berlin: Suhrkamp.

Walter, Franz (2010b): Irrwege des Parteienstaats? In: ders., Vom Milieu zum Parteienstaat. Lebensfragen, Leitfiguren und Politik im historischen Wandel. (S.223-239). Wiesbaden: VS Verlag für Sozialwissenschaften.

Walter-Rogg, Melanie (2004): Parteien, Parteieliten und Mitglieder in einer Großstadt. Wiesbaden: VS Verlag für Sozialwissenschaften.

Wanger, Susanne (2008): Jahresarbeitszeit. Das Teilzeitphänomen in: IAB-Forum, Nr.2, S. 28-33, im Internet unter: http://doku.iab.de/forum/ 2008/Forum22008_Wanger.pdf, [Zugriff: 12.08.2009].

Weber, Max (1992): Politik als Beruf. Stuttgart: Reclam.

Weber, Max (2006): Wirtschaft und Gesellschaft. Paderborn: Voltmedia. Kap. VI „Bürokratie“, S.1046-1092.

Weigmann-Hellmich, Monika (1986): Juso-Landeskonferenz NRW: Quotierung beschlossen, aber nicht eingehalten. In: Juso Magazin. o.J. (März ), S.8.

Weinbach, Heike (2004): Wieviel Geschlecht braucht Emanzipation? Aspekte der aktuellen (Nicht-)Umsetzung von Gender Mainstreaming. In: ISOTOPIA. Graz: o.V.

Weis, Petra (1995): Hürdenlauf an die Macht? Politische Partizipation von Frauen in der SPD und die Quote. In: Maleck-Lewy, Eva / Penrose, Virginia (Hg.), a.a.O., S.65-82.

Welzel, Christian (1997): Repräsentation alleine reicht nicht mehr. Sachabstimmungen in einer Theorie der interaktiven Demokratie. In: Schneider-Wilkes, Rainer (Hg.), Demokratie in Gefahr? Zum Zustand der deutschen Republik. (S.54-79). Münster: Westfälisches Dampfboot.

Welzer, Harald (200o): Das Interview als Artefakt. Zur Kritik der Zeitzeugenforschung In: BIOS - Zeitschrift für Biographieforschung, Oral History und Lebensverlaufsanalysen. 13 (1), S.51-63.

Werlhof, Claudia von (1978): Der blinde Fleck in der politischen Ökonomie In: beiträge zur feministischen theorie und praxis. 1 (1), S.18-32. 
Westle, Bettina (200o): Politische Partizipation: Mobilisierung als Faktor geschlechtsspezifischer Ungleichheit. In: Niedermayer, Oskar (Hg.), Demokratie und Partizipation. (S.136-159). Wiesbaden: Westdeutscher Verlag.

Wetterer, Angelika (1994): Rhetorische Präsenz - faktische Marginalität. Zur Situation von WissenschaftlerInnen in Zeiten der Frauenförderung In: Zeitschrift für Frauenforschung \& Geschlechterstudien. 12 (1+2), S.93-109.

Wetterer, Angelika (1995): Dekonstruktion und Alltagshandeln. Die (möglichen) Grenzen der Vergeschlechtlichung von Berufsarbeit. In: Haas, Erika (Hg.), "Verwirrung der Geschlechter." Dekonstruktion und Feminismus. (S.123-155). München/Wien: Profil Verlag.

Wetterer, Angelika (2013): Das erfolgreiche Scheitern feministischer Kritik. Rhetorische Modernisierung, symbolische Gewalt und die Reproduktion männlicher Herrschaft. In: Appelt, Erna / Aulenbacher, Brigitte / Wetterer, Angelika (Hg.), Gesellschaft. Feministische Krisendiagnosen. (S.246-266). Münster: Westfälisches Dampfboot.

Wetterer, Angelika / Saupe, Angelika (2004): "Feminist politics" oder "Gender Mainstreaming": Über getrennte Diskurse und separierende Begriffe In: Zeitschrift für Frauenforschung \& Geschlechterstudien. 22 (2+3), S.3-8.

Wetterer, Angelika (Hg.) (1992): Profession und Geschlecht. Über die Marginalität von Frauen in hochqualifizierten Berufen. Frankfurt a. M. / New York: Campus

Wettig-Danielmeier, Inge (1972): Erfolgreiche Frauenarbeit? In: Bundesvorstand der Jungsozialisten (Hg.), JUSO. Zeitschrift der Jungsozialisten in der SPD. (S.12-13). Bonn: Bundesvorstand.

Wettig-Danielmeier, Inge (1981): Soll die AsF an die Kette? Mahnendes Wort gegen organisationspolitische Mätzchen In: Sozialdemokratischer Pressedienst. 36 (126/08.07.), S.5.

Wettig-Danielmeier, Inge (1983): Zehn Jahre AsF. Auf der Jubiläumsveranstaltung wird der Frauen-Widerstand gegen die Wende organisiert In: Sozialdemokratischer Pressedienst. 38 (107/08.06.), S.5.

Wettig-Danielmeier, Inge (1984a): 10 Jahre Arbeitsgemeinschaft sozialdemokratischer Frauen - Kontinuität sozialistischer Frauenarbeit In: Die Neue Gesellschaft. 31 (2), S.168-174.

Wettig-Danielmeier, Inge (1984b): Wären wir mehr, so wären wir stärker! Über den Einfluß von Frauen in der SPD. In: Huber, Antje, a.a.O., S.25-37.

Wettig-Danielmeier, Inge (1985c): Mitteilung für die Presse. In: Sozialdemokratischer Pressedienst. 35(474/19.09.)

Wettig-Danielmeier, Inge (1986): Gesellschaftliche Gleichheit von Mann und Frau. Nachdruck aus: Die Neue Gesellschaft/Frankfurter 2(2), S.6-9. In: SPDParteivorstand (1989), a.a.O., S.6-7.

Wettig-Danielmeier, Inge (1987a): Der schwere Weg zur Gleichstellung. Zur Quotendiskussion in der SPD. In: Sozialdemokratischer Pressedienst. 42 (202/22.10.), S.1. 
Wettig-Danielmeier, Inge (1987b): Die Quotendebatte in der SPD - Vorrangiges Ziel bleibt die gesellschaftliche Gleichheit von Mann und Frau. In: Sozialdemokratischer Pressedienst. 42 (245/23.12.), S.4-5.

Wettig-Danielmeier, Inge (1990): Wie lebt die SPD mit der Quote? In: Das Argument. 32 (3), S.389-393.

Wettig-Danielmeier, Inge (1992): Die Quote. Eine "Erfolgsstory" auf dem Prüfstand. In: Leif, Thomas / Legrand, Hans-Josef / Klein, Ansgar (Hg.), Die politische Klasse in Deutschland. Eliten auf dem Prüfstand. (S.423-428). Bonn/Berlin: Bouvier Verlag.

Wettig-Danielmeier, Inge (1995): Frauensachen: über die Gleichstellung der Frauen: Aufsätze, Reden, Materialien. Marburg: Schüren.

Wettig-Danielmeier, Inge (1997b): Greift die Quote? Köln: Stadtwege-Verlag.

Wettig-Danielmeier, Inge (1998): „Wer die menschliche Gesellschaft will, muß die männliche überwinden“- Bilanz sozialdemokratischer Gleichstellungspolitik. In: Historische Kommission beim SPD-Parteivorstand (Hg.), Vom Frauenwahlrecht zur Quotierung. Frauenbewegung und Sozialdemokratie. Dokumentation des Workshops der Historischen Kommission und der Arbeitsgemeinschaft Sozialdemokratischer Frauen am 12./13. Dezember 1977 in Bonn. Bonn: O.V.

Wettig-Danielmeier, Inge / Oerder, Katharina (2011): Feminismus - und morgen? : Gleichstellung jetzt. Berlin: Vorwärts.

Wichterich, Christa (2004): Zur Transnationalisierung von Frauenpolitik in der globalisierten UN-Arena. Strategische Verschwisterung und Suche nach Mitmacht in den 9oer-Jahren. In: (Hg.), Feministisches Institut der HeinrichBöll-Stiftung, Die großen UN-Konferenzen. Eine frauenpolitische Bilanz. Dokumentation einer Ringvorlesung im Sommer 200o. 2. leicht veränd. Aufl. (S.11-28). Berlin: Heinrich-Böll-Stiftung.

Wiesendahl, Elmar (1992): Volksparteien im Abstieg. Nachruf auf eine zwiespältige Erfolgsgeschichte In: Aus Politik und Zeitgeschichte, Beilage zur Wochenzeitung "Das Parlament". Ausg. (B 34-35), S.3-14.

Wiesendahl, Elmar (1997): Noch Zukunft für die Mitgliederparteien? Erstarrung und Revitalisierung innerparteilicher Partizipation. In: Klein, Ansgar / Schmalz-Bruns, Rainer (Hg.), Politische Beteiligung und Bürgerengagement in Deutschland. Möglichkeiten und Grenzen. (S.349-381). Baden-Baden: Nomos Verlagsgesellschaft.

Wiesendahl, Elmar (1998): Parteien in Perspektive : theoretische Ansichten der Organisationswirklichkeit politischer Parteien. Opladen u.a.: Westdt. Verl.

Wiesendahl, Elmar (2002): Die Strategie(un)fähigkeit politischer Parteien. In: Nullmeier, Frank / Saretzki, Thomas (Hg.), Jenseits des Regierungsalltags. Strategiefähigkeit politischer Parteien. (S.187-206). Frankfurt a. Main/New York: Campus. 
Wiesendahl, Elmar (2004): Parteien und die Politik der Zumutungen In: Aus Politik und Zeitgeschichte, Beilage zur Wochenzeitung "Das Parlament". Ausg. (B 40), S.19-24.

Wiesendahl, Elmar (2006): Parteien: Entstehung und Entwicklung von Parteien: Parteiendemokratie in Modell und Wirklichkeit: Mitglieder und Finanzen der Parteien: Wandlungen in der deutschen Parteienlandschaft. Frankfurt a. Main: S. Fischer.

Wiesendahl, Elmar (2010): Zwei Dekaden Party Change Forschung. Eine kritische Bilanz. In: Gehne, David / Spier, Tim (Hg.), Krise oder Wandel der Parteiendemokratie? Festschrift für Ulrich von Alemann. (S.92-118). Wiesbaden: VS Verlag für Sozialwissenschaften.

Wilz, Sylvia Marlene (2002): Organisation und Geschlecht: strukturelle Bindungen und kontingente Kopplungen. Geschlecht und Gesellschaft. Opladen: Leske+Budrich.

Wilz, Sylvia M. (2004a): Relevanz, Kontext und Kontigenz: Zur neuen Unübersichtlichkeit in der

Gendered Organization. In: Pasero, Ursula / Priddat, Birger P. (Hg.), a.a.O., S.227258.

Wilz, Sylvia M. (2004b): Organisation: Die Debatte um ,Gendered Organizations“. In: Becker, Ruth / Kortendiek, Beate (Hg.), a.a.O., S.443-449.

Wilz, Sylvia M. (2004c): Für und wider einen weiten Begriff von Schließung. eine Typologie der Schließung und ihre Folgen. In: Mackert, Jürgen (Hg.), a.a.O., S.213-231.

Wilz, Sylvia M. (2004d): Geschlechterdifferenzierung von und in Organisationen. Beitrag zur Veranstaltung "Organisierte soziale und kulturelle Differenzen" der Arbeitsgruppe Organisationssoziologie in der DGS. 32. Soziologiekongress, im Internet unter: http://www.fernuni-hagen.de/imperia/ md/content/soziologie/lgwilz/gdiff_org_o4_pdf.pdf, [Zugriff: 02.02. 2010].

Wilz, Sylvia M. (2013): Geschlechterdifferenzierung von und in Organisationen. In: Müller, Ursula / Riegraf, Birgit / diess. (Hg.), Geschlecht und Organisation. Wiesbaden: Springer VS. S.150-160.

Wolf, Michael (Hg.) (2007): Frauen und Männer in Organisationen und Leitungsfunktionen: unbewußte Prozesse und die Dynamik von Macht und Geschlecht. 2. Aufl. Frankfurt a. Main: Brandes \& Apsel.

Wolfrum, Edgar (2007): Die geglückte Demokratie: Geschichte der Bundesrepublik Deutschland von ihren Anfängen bis zur Gegenwart. Bundeszentrale für politische Bildung. Bonn: Klett Cotta, S.321-433

Yoder, Janice D. (1991): Rethinking Tokenism: Looking Beyond Numbers In: Gender and Society. 5 (2), S.178-192.

Young, Brigitte (1991): Der Staat - eine "Männerdomäne?" Überlegungen zur feministischen Staatsanalyse. In: Biester, Elke / Geißel, Brigitte / Lang, Sabine / Sauer, Birgit / Schäfter, Petra / dies. (Hg.), Staat aus feministischer Sicht. Dokumentation des workshops der ad-hoc-Gruppe "Politik und Geschlecht" in 
der Deutschen Vereinigung für Politische Wissenschaft (DVPW) anlässlich des 18. Wissenschaftlichen Kongresses der DVPW, Oktober 1991 (S.7-18). Berlin: Freie Universität: o.V.

Zick, Andreas / Wagner, Ulrich (1995): Soziale Identität und Gruppenverhalten, Sozialpschologische

Beiträge zur analse sozialer Bewegungen. In: Forschungsjournal Neue Soziale Bewegungen. 8 (1), S.56-67.

Zwingel, Susanne (2005): How do international women's rights norms become effective in domestic contexts? An analysis of the Convention on the Elimination of all Forms of Discrimination against Women (CEDAW). Im Internet unter: http://www-brs.ub.ruhr-uni-bochum.de/netahtml/HSS/Diss/Zwingel Susanne/diss.pdf, [Zugriff: 03.03.2014].

\subsubsection{Onlinedatenbanken und Onlineverzeichnisse}

Bundesstiftung Mutter und Kind. Schutz des ungeborenen Lebens Im Internet unter: www.bundesstiftung-mutter-und-kind.de/ziel-und-zweck.html, [Zugriff: 05.06.2011].

Courage (Jahrgänge 1976-1984): Alle Ausgaben online: Im Internet unter: Im Internet unter: Im Internet unter: http://library.fes.de/courage/, [Zugriff: 20.10.2012].

Geschichte des Ministeriums Bundesministerium für Familie, Senioren, Frauen und Jugend (Hg.) Im Internet unter: www.bmfsfj.de/BMFSFJ/ Ministerium/geschichte.html, [Zugriff: 04.08.2010].

Ergebnisse der Bundestagswahlen 1949 bis 2009 (2011). Der Bundeswahlleiter (Hg.) Im Internet unter: http://www.bundeswahlleiter.de/de/ bundestagswahlen/fruehere_bundestagswahlen/, [Zugriff: 10.10. 2011].

Datenhandbuch zur Geschichte des Deutschen Bundestages Deutscher Bundestag (Hg.) Im Internet unter: https://www.bundestag.de/datenhandbuch, [Zugriff: 20.02. 2014].

Chronik der Neuen Frauenbewegung FrauenMediaTurm (Hg.), Köln. Im Internet unter: Im Internet unter: http://www.frauenmediaturm.de/themenportraets/chronik-der-neuen-frauenbewegung/, [Zugriff: 12.03. 2008].

Statistik Geschlechter 16. Wahlperiode Landtag NRW Statistiken/Statistik_Geschlechter_16WP.jsp. Im Internet unter: http://www.land-tag.nrw.de/ portal/WWW/GB_II/II.2/Archiv/mdldat, [Zugriff: 06.10.2012].

Geschichte des Bundesministeriums für Familie, Senioren, Frauen und Jugend. Im Internet unter: http://www.bmfsfj.de/BMFSFJ/Ministerium/ geschichte.html, [Zugriff: 03.01.2011]. 


\subsection{Interviewte ExpertInnen der SPD}

Ilse Brusis

Inge Wettig-Danielmeier

Herta Däubler-Gmelin

Elfriede Eilers

Birgit Fischer

Angelika Himmert,

Antje Huber

Christa Randzio-Plath

Christine Schmarsow

Renate Schmidt

Renate Schmitt-Peters

Dr. Sigrid Skarpelis-Sperk

Inge Stange

Dr. Haidi Streletz

Dr. Hans-Jochen Vogel

Marianne Wallach 


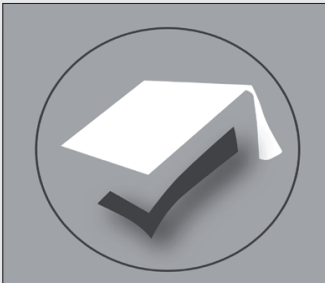

\section{budrich training}

\section{budrich training -}

\section{Schlüsselkompetenzen}

für Ihren Erfolg in der

Wissenschaft

Gelungene Wissenschaftskommunikation ist der Schlüssel zur Wissenschaftskarriere. Wer am wissenschaftlichen Diskurs nicht teilnimmt, ist nicht sichtbar. Wer nicht sichtbar ist, hat es schwer, sich in der Wissenschaft zu etablieren.

Unsere Expertise liegt im Bereich Wissenschaftskommunikation: Als Lektorinnen, Berater und Verlagsmenschen begleiten wir die Wissenschaft seit Jahrzehnten mit Schwerpunkten im Bereich Schreiben und Publizieren. Unsere Erfahrung haben wir systematisch aufbereitet und teilen sie in Vorträgen, Workshops und Coachings.

Erfahren Sie mehr über

$\square$ unsere Angebote zum wissenschaftlichen Schreiben, $\square$ unsere Angebote zum wissenschaftlichen Publizieren, $\square$ unsere Coaching-Angebote 


\section{Susanne Eyssen Der Aufbruch der Frauen in der SPD}

Die Entwicklung der Frauenarbeitsgemeinschaft (ASF) während der 1970er und 1980er Jahre

Die SPD vollzog in den $1970 e r$ und 1980 er Jahren einen beachtlichen frauenpolitischen Wandel: Sie richtete ihre Frauen- und Familienpolitik neu aus, übernahm feministische Ziele in das Grundsatzprogramm und führte eine Geschlechterquote ein, um den Anteil der weiblichen Parteimitglieder in den Parteifunktionen und in den politischen Ämtern zu erhöhen. Die Studie erzählt die Geschichte dieses Umbruchs mithilfe von ZeitzeugInnen-Interviews und einer umfangreichen Sichtung der Parteidokumente.

Die Autorin: Dr. Susanne Eyssen, Projektentwicklerin für Maßnahmen der betrieblichen und beruflichen Gleichstellung

ISBN 978-3-86388-794-0

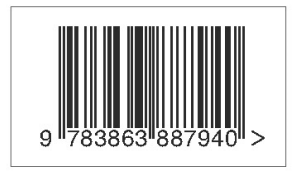

